\title{
Selected Radionuclides Important to Low-Level Radioactive Waste Management
}

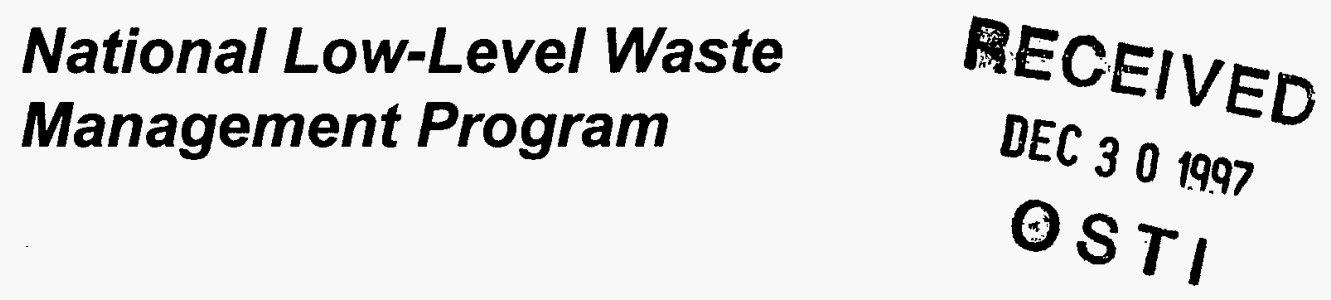

November 1996 


\section{DISCLAIMER}

This report was prepared as an account of work sponsored by an agency of the United States Government. Neither the United States Government nor any agency thereof, nor any of their employees, makes any warranty, express or implied, or assumes any legal liability or responsibility for the accuracy, completeness, or usefulness of any information, apparatus, product, or process disclosed, or represents that its use would not infringe privately owned rights. Reference herein to any specific commercial product, process, or service by trade name, trademark, manufacturer, or otherwise does not necessarily constitute or imply its endorsement, recommendation, or favoring by the United States Government or any agency thereof. The views and opinions of authors expressed herein do not necessarily state or reflect those of the United States Government or any agency thereof. 


\section{Selected Radionuclides Important to Low-Level Radioactive Waste Management}

Published November 1996

\section{Idaho National Engineering Laboratory \\ National Low-Level Waste Management Program \\ Lockheed Martin Idaho Technologies Company \\ Idaho Falls, Idaho 83415}

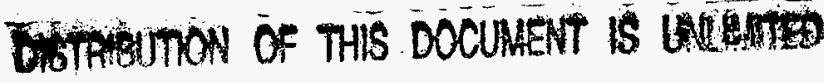
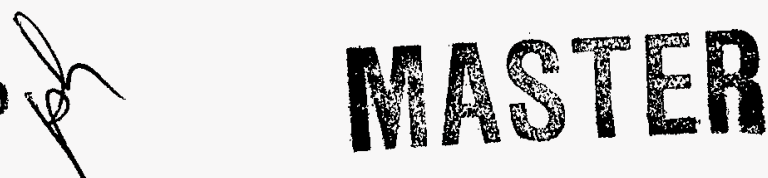

Prepared for the

U.S. Department of Energy

Assistant Secretary for Environmental Management

Under DOE Idaho Operations Office

Contract DE-AC07-94ID13223 


\begin{abstract}
The purpose of this document is to provide information to state representatives and developers of low-level radioactive waste (LLW) management facilities about the radiological, chemical, and physical characteristics of selected radionuclides and their behavior in the environment. Extensive surveys of available literature provided information for this report.

Certain radionuclides may contribute significantly to the dose estimated during a radiological performance assessment analysis of an LLW disposal facility. Among these are the radionuclides listed in Title 10 of the Code of Federal Regulations Part 61.55, Tables 1 and 2 (including alpha-emitting transuranics with half-lives greater than 5 years). This report discusses these radionuclides and other radionuclides that may be significant during a radiological performance assessment analysis of an LLW disposal facility.

This report not only includes essential information on each radionuclide, but also incorporates waste and disposal information on the radionuclide, and behavior of the radionuclide in the environment and in the human body.

Radionuclides addressed in this document include technetium-99, carbon-14, iodine-129, tritium, cesium-137, strontium-90, nickel-59, plutonium-241, nickel-63, niobium-94, cobalt-60, curium-242, americium-241, uranium-238, and neptunium-237.
\end{abstract}




\section{EXECUTIVE SUMMARY}

The purpose of this report is to provide information to state representatives and developers of lowlevel radioactive waste (LLW) management facilities about the radiological, chemical, and physical characteristics of selected radionuclides and their behavior in the disposal facility environment. The radionuclides discussed are those most likely to contribute significantly to the radiation exposures estimated from a performance assessment of a proposed LLW disposal facility.

This report not only includes essential information on each radionuclide, but also incorporates waste and disposal information on the radionuclide, and behavior of the radionuclide in the environment and in the human body.

The U.S. Nuclear Regulatory Commission (NRC) or an Agreement State licenses disposal facilities that comply with the performance objectives in Subpart C of 10 CFR 61 or equivalent Agreement State regulations. Performance assessment analyses are required in the disposal facility licensing process to predict the extent that radionuclides might be released from an LLW disposal facility and the resulting exposures to individuals. These radiation exposures can result from

- Exposure to direct gamma rays from the wastes

- Use of surface and ground water that has filtrated through the waste

- Degradation of engineered barriers and waste containers

- Atmospheric transport of radionuclides from disposal units.

The NRC analyzed 36 LLW types in its draft and final environmental impact statements (EIS) on 10 CFR 61. Each waste type was characterized according to its physical, chemical, and radiological properties and was projected to be generated from 1980 to the year 2000 . The NRC also identified 23 of the most important radionuclides in these waste types for waste classification. Tables 1 and 2 of 10 CFR Part 61.55 (Subpart D) list the final set of radionuclides and concentration limits that are used to classify the waste as Class A, B, C, or greater-than-Class-C (GTCC). (Class A has the lowest radionuclide concentration and the least potential for contamination, and GTCC has the highest concentration and highest potential for contamination.) Thus, these concentration limits are used to determine handling, storage, and disposal requirements at an LLW disposal site.

The NRC considered two groups of nuclides when it developed the waste classification tables in 10 CFR 61.55. First, they considered long-lived radionuclides that may present a health hazard to an individual who inadvertently contacts the waste (an inadvertent intruder). This hazard is greatest after institutional controls are no longer in effect. Table 1 lists these radionuclides. The magnitude of the hazard from these long-lived radionuclides is limited by the concentration at the time of disposal.

Second, the NRC considered relatively short-lived radionuclides whose hazard will be negligible after institutional controls and improved waste forms are no longer effective. Table 2 lists these radionuclides. However, these radionuclides may exhibit characteristics that pose a threat to disposal 
site workers during operations and to the public after site closure. Examples of these radionuclides include cobalt-60 (direct gamma ray exposure) and tritium (extremely mobile in the environment).

The radionuclides listed in Tables 1 and 2 are individually examined in this report, with americium241 and neptunium-237 falling under the Table 1 category of "alpha-emitting transuranics with half-lives longer than 5 years." The rationale behind choosing this set of radionuclides is twofold:

- The NRC determined that the radionuclides listed in Tables 1 and 2 of 10 CFR 61.55 are a potential health hazard to the public during the operation of an LLW disposal facility and after its closure. This determination was based on factors such as a radionuclide's half-life, mobility, volatility, maximum energy, radiation type (i.e., alpha, beta, gamma, or neutron), etc.

- These radionuclides are responsible for most of the radioactivity found at an LLW disposal facility.

Table 1. LLW classification table-long-lived radionuclides.

\begin{tabular}{|c|c|c|}
\hline \multirow[b]{2}{*}{ Radionuclides } & \multicolumn{2}{|c|}{$\begin{array}{c}\text { Concentration limits } \\
\left(\mu \mathrm{Ci} / \mathrm{cm}^{3}\right)\end{array}$} \\
\hline & Class A & Class C \\
\hline Carbon-14 $\left({ }^{14} \mathrm{C}\right)$ & 0.8 & 8 \\
\hline${ }^{14} \mathrm{C}$ in activated metal & 8 & 80 \\
\hline Nickel-59 $\left({ }^{59} \mathrm{Ni}\right)$ in activated metal & 22 & 220 \\
\hline Niobium-94 $\left({ }^{94} \mathrm{Nb}\right)$ in activated metal & 0.02 & 0.2 \\
\hline Technetium-99 $\left({ }^{99} \mathrm{Tc}\right)$ & 0.3 & 3 \\
\hline \multirow[t]{2}{*}{ Iodine-129 $\left({ }^{129} \mathrm{I}\right)$} & 0.008 & 0.08 \\
\hline & \multicolumn{2}{|c|}{$\begin{array}{c}\text { Concentration limits } \\
(\mathrm{nCi} / \mathrm{g})\end{array}$} \\
\hline Alpha-emitting transuranics with half-life longer than 5 years & 10 & 100 \\
\hline Plutonium-241 ( $\left.{ }^{241} \mathrm{Pu}\right)$ & 350 & 3,500 \\
\hline Curium-242 $\left({ }^{242} \mathrm{Cm}\right)$ & 2,000 & 20,000 \\
\hline
\end{tabular}


Table 2. LLW classification table-short-lived radionuclides.

\begin{tabular}{|c|c|c|c|}
\hline \multirow[b]{2}{*}{ Radionuclides } & \multicolumn{3}{|c|}{$\begin{array}{l}\text { Concentration limits } \\
\left(\mu \mathrm{Ci} / \mathrm{cm}^{3}\right)\end{array}$} \\
\hline & Class A & Class B & Class C \\
\hline Total of all radionuclides with half-life shorter than 5 years & 700 & $一^{a}$ & $-^{\mathrm{a}}$ \\
\hline Tritium $\left({ }^{3} \mathrm{H}\right)$ & 40 & -a & $-^{\mathrm{a}}$ \\
\hline Cobalt-60 $\left({ }^{60} \mathrm{Co}\right)$ & 700 & $-{ }^{a}$ & $-{ }^{a}$ \\
\hline Nickel-63 $\left({ }^{63} \mathrm{Ni}\right)$ & 3.5 & 70 & 700 \\
\hline${ }^{63} \mathrm{Ni}$ in activated metal & 35 & 700 & 7,000 \\
\hline Strontium-90 $\left({ }^{90} \mathrm{Sr}\right)$ & 0.04 & 150 & 7,000 \\
\hline Cesium-137 $\left({ }^{137} \mathrm{Cs}\right)$ & 1 & 44 & 4,600 \\
\hline \multicolumn{4}{|c|}{$\begin{array}{l}\text { a. No Class B and Class C limits exist for these radionuclides. Other practical considerations will limit these } \\
\text { radionuclides, such as external radiation dose for transportation or internal heat generation. The concentrations } \\
\text { of these radionuclides will be Class B unless other radionuclides determine independently that the classification } \\
\text { is higher. }\end{array}$} \\
\hline
\end{tabular}

Other radionuclides not listed in Tables 1 and 2 may contribute significantly to the dose estimated during a radiological performance assessment analysis of a LLW disposal facility. Some of these radionuclides have been addressed in this report. The following paragraphs summarize each radionuclide addressed in this report.

\section{Technetium-99}

Technetium-99 $\left({ }^{99} \mathrm{Tc}\right)$ is produced by the fission of uranium and plutonium and is not a naturally occurring radionuclide. Reactor wastes such as evaporator bottoms, filters, and sludges may contain ${ }^{99} \mathrm{Tc}$. Small amounts of ${ }^{99} \mathrm{Tc}$ can also be present in LLW generated at medical laboratories and academic institutions. Although ${ }^{99} \mathrm{Tc}$ is a fission product, it is also an activation product, just as Nickel-59 and Nickel-63 are activation products of stainless steel. Although this source of ${ }^{99} \mathrm{Tc}$ is not readily releasable to the environment, it may outweigh the amount that is present in medical sources. The predominant form of ${ }^{99} \mathrm{Tc}$ at an LLW disposal facility is the pertechnetate ion. Because pertechnetate is highly mobile in groundwater and because ${ }^{99} \mathrm{Tc}$ has a long half-life of 213,000 years, its disposal presents a potential long-term hazard to the public. However, the pertechnetate ion can be reduced to less-soluble forms of technetium that are not mobile in environmental media. The NRC, in its draft EIS on 10 CFR 61, identified ${ }^{99} \mathrm{Tc}$ as one of four radionuclides (along with tritium, ${ }^{14} \mathrm{C}$, and ${ }^{129} \mathrm{I}$ ) that will require site-specific considerations to ensure that performance objectives for long-term environmental protection are met. Because ${ }^{99} \mathrm{Tc}$ is a beta emitter with a maximum energy of 0.293 million electron volts $(\mathrm{MeV})$, it poses a greater internal than external hazard to humans. The main route that ${ }^{99} \mathrm{Tc}$ enters the human body is ingestion. 


\section{Carbon-14}

Presently, the principal means of producing carbon-14 $\left({ }^{14} \mathrm{C}\right)$ is by neutron activation of stable nitrogen-14 and stable oxygen-17, in a nuclear reactor. The fission process of the reactor supplies the large source of neutrons necessary to induce the neutron activation. Before the advent of manmade disruptions of the ${ }^{14} \mathrm{C}$ atmospheric concentration (burning of fossil fuels and atmospheric testing of nuclear weapons), this nuclide was produced by cosmic rays impinging on the atmosphere. LLW that contains ${ }^{14} \mathrm{C}$ include activated metals from reactors, sealed sources, and animal carcasses from research laboratories. The half-life of ${ }^{14} \mathrm{C}$ is 5,730 years. It is quite mobile in groundwater systems. Another concern is that ${ }^{14} \mathrm{C}$ is very volatile. The NRC, in its draft EIS on $10 \mathrm{CFR} 61$, identified ${ }^{14} \mathrm{C}$ as one of four radionuclides (along with tritium, ${ }^{99} \mathrm{Tc}$, and ${ }^{129} \mathrm{I}$ ) that will require site-specific considerations to ensure that performance objectives for long-term environmental protection are met. Because ${ }^{14} \mathrm{C}$ is a beta emitter with a maximum energy of $0.156 \mathrm{MeV}$, it poses a greater internal than external hazard to humans. The main route that ${ }^{14} \mathrm{C}$ enters the human body is by either inhalation or ingestion.

\section{lodine-129}

Iodine-129 $\left.{ }^{129} \mathrm{I}\right)$ is produced by uranium fission primarily in nuclear power reactors, and is not a naturally occurring radionuclide. ${ }^{129} \mathrm{I}$ is a long-lived radionuclide (half-life of $16,000,000$ years) present in LLW generated at nuclear power plants. LLW that contains ${ }^{129} \mathrm{I}$ includes ion-exchange resins, concentrated liquids, filter sludge, cartridge filters, and trash. Disposing of ${ }^{129} \mathrm{I}$-contaminated waste at LLW disposal facilities is a concern because ${ }^{129} \mathrm{I}$ is highly mobile in groundwater. The NRC, in its draft EIS on 10 CFR 61, identified ${ }^{129}$ I as one of four radionuclides (along with tritium, ${ }^{14} \mathrm{C}$, and ${ }^{99} \mathrm{Tc}$ ) that will require site-specific considerations to ensure that performance objectives for long-term environmental protection are met. Because ${ }^{129} \mathrm{I}$ is primarily a beta emitter with a maximum energy of $0.150 \mathrm{MeV}$, it poses a greater internal than external hazard to humans. The main route that ${ }^{129} \mathrm{I}$ enters the human body is ingestion. Whether inhaled or ingested, most of the radioiodine will dissolve in the body fluids. When dissolved, iodine travels and concentrates in the thyroid. The low-energy beta particle may irradiate the thyroid to the point of inducing cancerous thyroid nodules.

\section{Tritium}

Tritium $\left({ }^{3} \mathrm{H}\right)$ is a radioactive isotope of hydrogen. It is naturally produced in very small quantities in the atmosphere. Because of its very small naturally occurring concentration, tritium exists, for all practical purposes, as a manmade isotope. Tritium is primarily used in industrial thickness gauges, luminous paints, nonpowered (self-luminous) light sources, fusion research, thermonuclear weapons, and as a radioactive tracer in chemistry and biological experiments. Tritium has a half-life of 12.3 years and decays to ${ }^{3} \mathrm{He}$ with the emission of a beta particle and no gamma ray. Tritium produces a very-lowenergy beta particle (maximum energy of $0.019 \mathrm{MeV}$ ) and is usually considered one of the least hazardous radionuclides. However, since it can replace normal hydrogen in chemical compounds essential for life, tritium poses a hazard that can be very mobile within the physical and biological environment. Many waste types disposed of in an LLW disposal facility contain tritium. These waste types include reactor evaporator bottoms and institutional and academic research laboratory trash. Tritium is very mobile in groundwater and surface water systems. The NRC, in its draft EIS on 
$10 \mathrm{CFR} 61$, identified tritium as one of four radionuclides (along with ${ }^{14} \mathrm{C},{ }^{99} \mathrm{Tc}$, and ${ }^{129} \mathrm{I}$ ) that will require site-specific considerations to ensure that performance objectives for long-term environmental protection are met.

\section{Cesium-137}

Cesium-137 $\left({ }^{137} \mathrm{Cs}\right)$ is produced by the fission of uranium and is not a naturally occurring radionuclide. The largest source of ${ }^{137} \mathrm{Cs}$ and potential waste material is from nuclear reactor operations. It has a half-life of 30.17 years and it emits one to two high-energy beta particles. Approximately $85 \%$ of all ${ }^{137} \mathrm{Cs}$ decays result in the emission of a $0.662 \mathrm{MeV}$ gamma ray. The gamma-ray of ${ }^{137 \mathrm{~m}} \mathrm{Ba}$, which is in secular equilibrium with ${ }^{137} \mathrm{Cs}$, has been used to sterilize medical supplies, milk cartons, and irradiate food. Industrial applications of ${ }^{137} \mathrm{Cs}$ include the production of plastic shrink tubing (irradiated plastic has the tendency to shrink after being heated), radiography to inspect metal castings and welds for flaws and material defects (e.g., cracks in steel pipes), radioactive measurement gauges for liquid or solid thicknesses (e.g., gauging of automobile sheet steel), treatment of sewage sludge to kill bacteria and viruses, and radiotherapy to kill cancerous tissue. The quantity of ${ }^{137} \mathrm{Cs}$ waste material generated in medical, academic, or commercial facilities is small compared with the quantity of ${ }^{137} \mathrm{Cs}$ waste produced as a result of nuclear reactor facilities. Ion-exchange resins used to purify coolant water in a nuclear power plant frequently contain large amounts of ${ }^{137} \mathrm{Cs}$. The common chemical compounds of ${ }^{137} \mathrm{Cs}$ are water soluble and will readily move with groundwater unless preferentially retained in the soils, particularly by clay soils. Absorption of cesium by humans takes place primarily through the digestive tract. Cesium and potassium have similar chemical properties because both are alkali metals. Potassium serves a very important function in the body as an electrolyte, and one of the effects of cesium is its potential effect on the potassium levels in the body in addition to its potential radiation effects on the various body tissues.

\section{Strontium-90}

Strontium-90 $\left({ }^{90} \mathrm{Sr}\right)$ is not a naturally occurring radionuclide. The main source of ${ }^{90} \mathrm{Sr}$ is from fission product recovery. ${ }^{90} \mathrm{Sr}$ has a half-life of 29.1 years and only emits a high-energy beta particle following decay. Almost no gamma-ray particles are released from the ${ }^{90} \mathrm{Sr}$ decay sequence ${ }^{90} \mathrm{Sr}$ emits a beta particle with a maximum energy of $0.546 \mathrm{MeV} .{ }^{90} \mathrm{Sr}$ decays to yttrium-90 $\left({ }^{90} \mathrm{Y}\right)$, which has a $64-$ hour half-life. ${ }^{90} \mathrm{Y}$ emits a beta particle with a maximum energy of $2.28 \mathrm{MeV}$. Due to the high beta particle energies of ${ }^{90} \mathrm{Sr}$ or its daughter nuclide ${ }^{90} \mathrm{Y},{ }^{90} \mathrm{Sr}$ has been used in industrial applications to measure thicknesses of paper, plastic, rubber, and metal foils. It also has some medical applications such as treatment for some eye and skin diseases. Due to its low gamma-ray activity, it is not normally used as an irradiation source. The largest source of strontium, and the largest potential source of waste material, is the inventory of ${ }^{90} \mathrm{Sr}$ stored in commercial spent nuclear fuel. Most of the LLW generated at nuclear power plants will contain some ${ }^{90} \mathrm{Sr}$; however, other radionuclides (e.g., ${ }^{137} \mathrm{Cs}$ ) are usually more prevalent and generally determine the waste characterization. Wastes that contain ${ }^{90} \mathrm{Sr}$ include both wet and dry wastes such as spent ion-exchange resins, filter sludge, filter cartridges, evaporator bottoms, compactible and non-compactible trash, and irradiated components. A smaller fraction of wastes containing ${ }^{90} \mathrm{Sr}$ are generated from industrial, institutional, and medical applications. Strontium is very soluble and is transported readily with precipitation and groundwater deep into soils. As such, it can be 
taken up by plants through the roots, which is the principal means by which strontium gets into the food chain. Once ${ }^{90} \mathrm{Sr}$ is ingested, it concentrates in bone tissue. Since these areas are near blood-producing bone marrow, one of the principal health problems with ${ }^{90} \mathrm{Sr}$ contamination is reduction in the blood platelet production. Other hazards include the possibility of bone cancer.

\section{Nickel-59}

Nickel-59 $\left({ }^{59} \mathrm{Ni}\right)$ is not a naturally occurring radionuclide. ${ }^{59} \mathrm{Ni}$ is produced in the structural steels of nuclear reactor vessels and internal components from neutron activation of ${ }^{58} \mathrm{Ni}$, a naturally occurring and stable isotope of nickel. Nickel is resistant to attack by water or air, and therefore, is often used as a protective coating for other metals or as an alloy to create a corrosion-resistant metal such as stainless steel. Limited amounts of ${ }^{59} \mathrm{Ni}$ can enter the environment through operational wastes from a nuclear reactor (i.e., corrosion of stainless steel surfaces and circulation of coolant). ${ }^{59} \mathrm{Ni}$ decays by electron capture and has a half-life of 76,000 years. Radiation hazards of ${ }^{59} \mathrm{Ni}$ include the emission of $\mathrm{x}$-rays. These $\mathrm{x}$-rays have energies up to $1.06 \mathrm{MeV}$. The major concern with ${ }^{59} \mathrm{Ni}$ is in limiting the exposure to people who are decommissioning and dismantling reactors, primarily for reactors in service for more than 30 years. At that point, the ${ }^{59} \mathrm{Ni}$ activity will exceed that from the other major activation products: Iron-59 and ${ }^{60} \mathrm{Co}$. ${ }^{59} \mathrm{Ni}$ is not commonly used for medical or industrial purposes. Nickel tends to be easily absorbed by soils. However, the ability of soils to absorb nickel out of groundwater varies widely, depending on soil $\mathrm{pH}$ and soil type.

\section{Plutonium-241}

Plutonium-241 $\left({ }^{241} \mathrm{Pu}\right)$, an actinide or a transuranic, is not a naturally occurring radionuclide. It is produced within nuclear reactors via the neutron absorption in plutonium- 240 or through multiple absorptions and decays of other transuranic isotopes. ${ }^{241} \mathrm{Pu}$ has a half-life of approximately 14.4 years and decays primarily by beta particle emission to americium-241; however, a very small fraction decays to uranium-237. When it decays, it releases mostly beta particles with a maximum energy of

$0.021 \mathrm{MeV}$. The released radiation is less penetrating than that of most radionuclides, and in particular is comparable with that of tritium. ${ }^{241} \mathrm{Pu}$ concentrates in bone tissue once it enters the human body. ${ }^{241} \mathrm{Pu}$ is classified in the very high radiological hazard group, primarily because of its main daughter product, americium-241 (an alpha-emitter with emission of $5.49 \mathrm{MeV}$ particles), and the few gamma rays emitted by its secondary daughter product, uranium-237. Generally, plutonium waste ends up as transuranic or high-level waste; however, small amounts of plutonium (including ${ }^{241} \mathrm{Pu}$ ) can exist in LLW, mostly in decontamination resins and filters. Few medical or industrial uses of ${ }^{241} \mathrm{Pu}$ are known for this isotope. Most medical and industrial uses of plutonium center around plutonium-238 for cardiac pacemakers and radioisotopic thermoelectric generators, and plutonium-238, 239, and 240 used in biological studies.

\section{Nickel-63}

Nickel-63 $\left({ }^{63} \mathrm{Ni}\right)$ is not a naturally occurring radionuclide. ${ }^{63} \mathrm{Ni}$, like ${ }^{59} \mathrm{Ni}$, is produced in the structural steels of nuclear reactor vessels and internal components from neutron activation of ${ }^{62} \mathrm{Ni}$, a naturally occurring and stable isotope of nickel. Nickel is resistant to attack by water or air, and therefore, is often used as a protective coating for other metals or as an alloy to create a corrosion- 
resistant metal such as stainless steel. These reactor components are the primary LLW material containing ${ }^{63} \mathrm{Ni}$. Limited amounts of ${ }^{63} \mathrm{Ni}$ can enter the environment through operational wastes from a nuclear reactor (e.g., corrosion of stainless steel surfaces and circulation of coolant). ${ }^{63} \mathrm{Ni}$ has a half-life of 100 years and decays by emitting a beta particle with a maximum energy of $0.0659 \mathrm{MeV}$. When it decays, it emits no x-rays or gamma rays. The major concern with ${ }^{63} \mathrm{Ni}$ is in limiting its inhalation by people who are decommissioning and dismantling reactors, primarily for reactors in service for more than 30 years. At that point, the ${ }^{63} \mathrm{Ni}$ activity will become an important activation product during decommissioning activities. The ability of soil to adsorb ${ }^{63} \mathrm{Ni}$ out of groundwater varies depending on the soil type and water $\mathrm{pH}$. In general, when ${ }^{63} \mathrm{Ni}$ comes into contact with the soil and groundwater, most of it will become fixed in the soil and will not migrate appreciably from the original site. When mammals ingest this nuclide, most of it is excreted within 24 hours.

\section{Niobium-94}

Niobium-94 $\left({ }^{94} \mathrm{Nb}\right)$, an actinide, is produced from the neutron activation of ${ }^{93} \mathrm{Nb}$, the only stable isotope of niobium. ${ }^{94} \mathrm{Nb}$ is not a naturally occurring nuclide. ${ }^{94} \mathrm{Nb}$, like ${ }^{59} \mathrm{Ni}$ and ${ }^{63} \mathrm{Ni}$, is found in metallic reactor parts. ${ }^{94} \mathrm{Nb}$ has a half-life of 20,000 years and decays by both a beta particle (maximum energy of $0.470 \mathrm{MeV}$ ) and two gamma rays with energies of $0.703 \mathrm{MeV}$ and $0.871 \mathrm{MeV}$. The major concern with ${ }^{94} \mathrm{Nb}$ is in limiting the exposure that people receive who decommission and dismantle reactors, primarily reactors that have been in service for more than 30 years. If decommissioning is delayed for a long time after reactor shutdown, this nuclide would provide the dominant, long-term source of gamma radiation from these components. This nuclide can become LLW waste through corrosion of stainless steel and Inconel surfaces in nuclear power plants with subsequent discharge with the primary coolant. ${ }^{94} \mathrm{Nb}$ is commercially available and has been used as an external source of gamma rays for laboratory use. Few medical uses for this nuclide have been identified. In general, niobium is easily adsorbed by soils and is not easily leached into the groundwater (it will not migrate appreciably from the original site). When mammals ingest this nuclide, most is excreted within a few days. The part that remains is generally uniformly distributed in the body.

\section{Cobalt-60}

Cobalt-60 $\left({ }^{60} \mathrm{Co}\right)$ is produced in the structural steels and other alloys of nuclear reactor vessels and internal components from neutron activation of ${ }^{59} \mathrm{Co}$, the only stable isotope of cobalt. ${ }^{60} \mathrm{Co}$ is not a naturally occurring radionuclide. ${ }^{60} \mathrm{Co}$ has a half-life of 5.272 years; therefore, it decays to minimal activity levels within 50 years of generation. However, since it emits two highly energetic gamma rays of $1.17 \mathrm{MeV}$ and $1.33 \mathrm{MeV},{ }^{60} \mathrm{Co}$ poses an external exposure hazard. Because of its high-energy gamma radiation, ${ }^{60} \mathrm{Co}$ has been used extensively as a radiation source for both commercial and medical uses. Some uses include the transportation industry, which uses this nuclide to measure the thickness of automobile sheet steel. The metals industry uses ${ }^{60} \mathrm{Co}$ as a radiography source to detect flaws in welded joints and casting. The chemical and medical industries use the nuclide as a catalyst in flow studies, drug-metabolism studies, and sterilization of medical supplies. This nuclide is one of the principal irradiation sources for treatment of cancer in humans. Reactor components serve as the primary LLW material containing ${ }^{60} \mathrm{Co}$. In general, cobalt is easily adsorbed by soils and is not easily leached into the 
groundwater. The main concern surrounding ${ }^{60} \mathrm{Co}$ is in limiting the exposure received by persons handling sources or associated with the decommissioning and dismantling of reactors.

\section{Curium-242}

Multiple neutron absorption of nuclear fuel constituents such as uranium-238 and plutonium-239 produces curium-242 $\left({ }^{242} \mathrm{Cm}\right)$. Small amounts of ${ }^{242} \mathrm{Cm}$ can enter the primary coolant of nuclear reactors and be removed by filters and/or cleanup resins. ${ }^{242} \mathrm{Cm}$ is important in LLW disposal primarily because of the radiological daughters produced through the ${ }^{242} \mathrm{Cm}$ decay scheme. Although ${ }^{242} \mathrm{Cm}$ decays with a relatively short half-life (163 days), its radiological daughters, such as plutonium-238 with a half-life of 86 years, can persist for much longer in radioactive waste. ${ }^{242} \mathrm{Cm}$ emits highly energetic alpha particles of $6.11 \mathrm{MeV}$ and $6.07 \mathrm{MeV}$. The daughter of ${ }^{242} \mathrm{Cm}$, plutonium-238, emits alpha particles with energies of $5.5 \mathrm{MeV}$. There are some applications of ${ }^{242} \mathrm{Cm}$. For example, this nuclide has been used as the power source for an isotopic power reactor. There are few medical uses for this nuclide. In general, curium is easily adsorbed by soils and is not easily leached into the groundwater. The principal radiological hazard associated with this nuclide is due to its high energy alpha particles. The principal risk is due to inhalation of this nuclide. ${ }^{242} \mathrm{Cm}$ can decay and concentrate in bone tissue once it enters the human body.

\section{Americium-241}

Plutonium-241, produced by neutron absorption of uranium-238 and plutonium-239, decays to americium-241 $\left({ }^{241} \mathrm{Am}\right) .{ }^{241} \mathrm{Am}$ has a half-life of 432 years and emits an alpha particle with an energy of $5.49 \mathrm{MeV}$. The decay process also produces gamma-rays and $\mathrm{x}$-rays. The most intense gamma-ray energy is $0.060 \mathrm{MeV}$. ${ }^{241} \mathrm{Am}$ enters the environment from the activities related with reactor operations and decommissioning, atomic weapons production, and when sealed sources containing ${ }^{241} \mathrm{Am}$ are manufactured, used, and disposed. One major application of ${ }^{241} \mathrm{Am}$ as a radioactive sealed source is in smoke detectors (uses the radiation from ${ }^{241} \mathrm{Am}$ to detect the presence of smoke or heat sources). The regulatory limits for ${ }^{241} \mathrm{Am}$ disposal and personnel exposure are very restrictive. Relatively small concentrations of ${ }^{241} \mathrm{Am}$ can become a major contributor to the calculated doses to individuals in performance assessment calculations or an accidental release involving this radionuclide. This is primarily due to the long half-life and high energies of the alpha particles emitted during the decay process. ${ }^{241} \mathrm{Am}$ is not very mobile in soils and only small quantities can be expected to migrate within the soil to the biosphere. As stated, ${ }^{241} \mathrm{Am}$ is primarily an alpha emitter. It is most dangerous to animals and humans when it is taken into the body via inhalation or ingestion where it can interact with living tissue.

\section{Uranium-238}

Uranium-238 $\left({ }^{238} \mathrm{U}\right)$ is a naturally occurring radioactive nuclide with a half-life of $4.47 \times 10^{9}$ years. ${ }^{238} \mathrm{U}$ is the most abundant isotope of uranium, comprising $>90 \%$ of all naturally occurring uranium. Another isotope of this element, ${ }^{235} \mathrm{U}$, is used widely in energy and weapons production, and ${ }^{238} \mathrm{U}$ is a byproduct of the ${ }^{235} \mathrm{U}$ enrichment process. Therefore, this nuclide is equated with the term "depleted uranium." As such, this nuclide has widespread industrial and military usage, including radioactive 
shielding, counterweights, and nonnuclear weapons. Moderately high-energy alpha particles, low-energy gamma rays, and low-energy beta particles are emitted when this nuclide decays. Because of the long half-life of ${ }^{238} \mathrm{U}$, it is not, itself, a major factor in the ability of an LLW disposal facility to meet performance objectives. The presence of the nuclide, however, can be relatively significant in assessing the long-term performance of such a site due to the quantity, radiotoxicity, and mobility of its daughter products, which include isotopes of radium and radon. The principal radiological hazard associated with this nuclide is due to its relatively high energy alpha particles. Direct exposure from ${ }^{238} \mathrm{U}$ is negligible. The principal risk is due to either inhalation or ingestion.

\section{Neptunium-237}

Neptunium-237 $\left({ }^{237} \mathrm{~Np}\right)$ is principally produced in nuclear reactor fuel rods from the bombardment of ${ }^{238} \mathrm{U}$ with neutrons. Some naturally occurring ${ }^{237} \mathrm{~Np}$ is produced when natural uranium ore is bombarded with neutrons generated as a result of spontaneous fission. ${ }^{237} \mathrm{~Np}$ has a half-life of $2.14 \times 10^{6}$ years and primarily emits an alpha particle with an energy of $4.78 \mathrm{MeV}$. Low-energy gamma rays (maximum energy of $145 \mathrm{keV}$ ) and low-energy electrons are also emitted when this nuclide decays. Because of the long half-life (and consequent low specific activity) of ${ }^{237} \mathrm{~Np}$, it is not itself a major factor in the ability of an LLW disposal facility to meet performance objectives. The presence of the nuclide, however, can be relatively significant in assessing the long-term performance of such a site due to the quantity, radiotoxicity, and mobility of its daughter products, which include isotopes of radium and radon. Because an obvious source of this nuclide is in the spent fuel of nuclear power plants, some contamination of the reactor coolant system is possible. After irradiation, the fission and activation products can be transported with the coolant to other parts, filters, etc. of the reactor. Through operational wastes and decommissioning, small amounts of these radioactive nuclides, including ${ }^{237} \mathrm{~Np}$, will be shipped to LLW site for disposal. This nuclide has very few commercial applications. Neptunium is very soluble and tends to remain in the groundwater rather than being adsorbed by the soil. The principal radiological hazard associated with this nuclide is internal due to its relatively high-energy alpha particles. The principal risk is due to either inhalation or ingestion. 


\section{ACKNOWLEDGEMENTS}

A document of this size and content is the result of work by many people. Primary credit goes to the authors of the text: J. P. Adams, M. L. Carboneau, R. S. Garcia, C. S. Olsen, R. G. Patterson, M. J. Rudin, C. Stanton, and M. R. Winberg. They wrote the original texts when they were published as separate reports in the National Low-Level Waste Management Program Radionuclide Report Series. Credit also goes to Bill Allred of the National Low-Level Waste Management Program, and Ed May, technical editor, who oversaw the consolidation of these reports into this document, ensured that the presentation was consistent among the chapters, and that all information was up-to-date. 


\section{CONTENTS}

ABSTRACT $\ldots \ldots \ldots \ldots \ldots \ldots \ldots \ldots \ldots \ldots \ldots \ldots \ldots \ldots \ldots \ldots \ldots \ldots \ldots \ldots \ldots \ldots \ldots$

EXECUTIVE SUMMARY $\ldots \ldots \ldots \ldots \ldots \ldots \ldots \ldots \ldots \ldots \ldots \ldots \ldots \ldots \ldots \ldots \ldots$

ACKNOWLEDGEMENTS $\ldots \ldots \ldots \ldots \ldots \ldots \ldots \ldots \ldots \ldots \ldots \ldots \ldots \ldots \ldots \ldots \ldots$

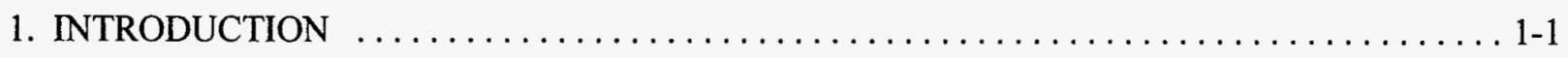

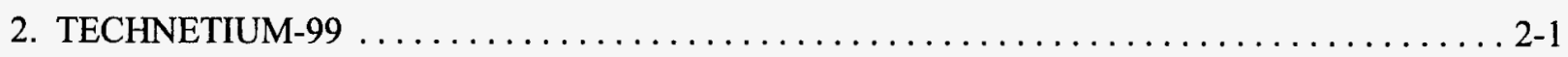

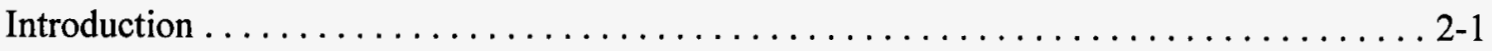

Radiological Characteristics ................................

Chemical and Physical Characteristics ............................ $2-2$

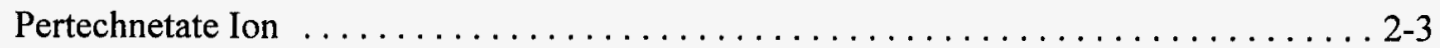

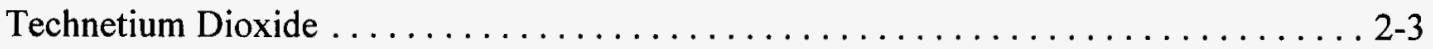

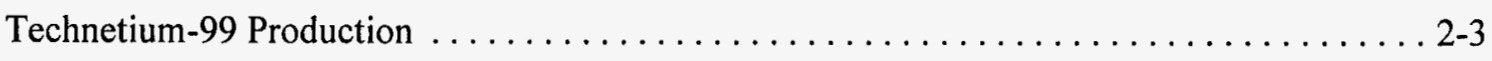

Waste and Disposal Data on Technetium-99 ... . . . . . . . . . . . . . 2-6

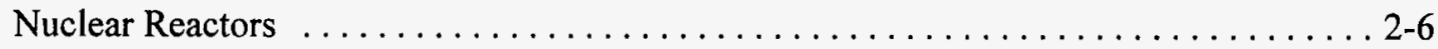

Technetium-99 Inventory in Nuclear Fuel Cycle Wastes $\ldots \ldots \ldots \ldots \ldots \ldots \ldots \ldots .7 . \ldots .7$

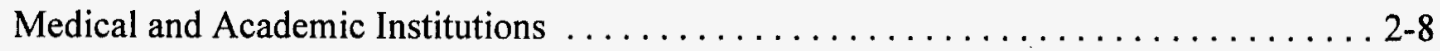

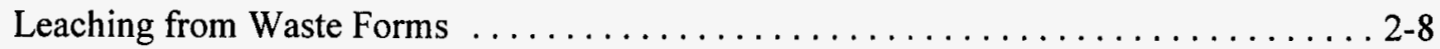

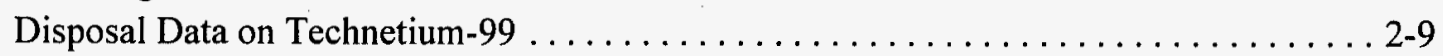

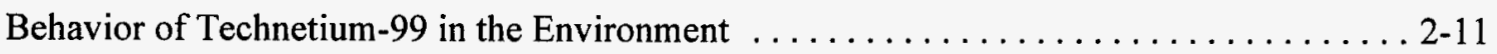

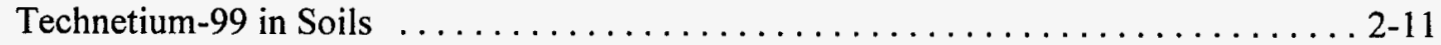

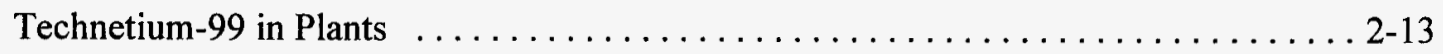

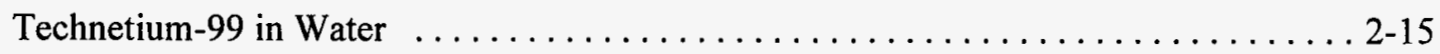

Technetium-99 in Air . . . . . . . . . . . . . . . . . .

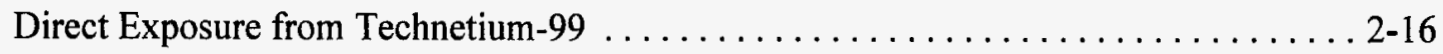

Behavior of Technetium-99 in the Human Body and in Animals . . . . . . . . . . 2-16

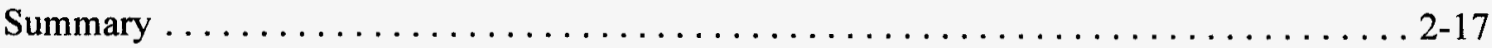

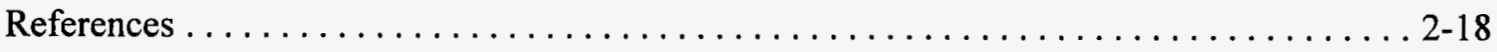

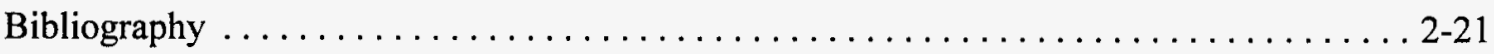

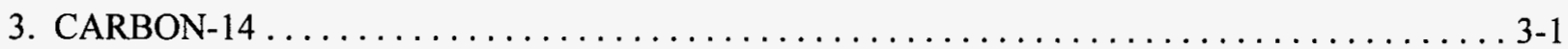

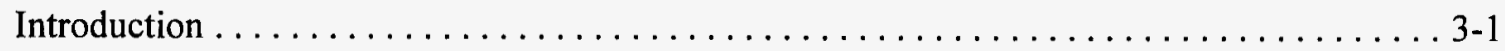

Radiological Characteristics . . . . . . . . . . . . . . . . . . . . . . . .

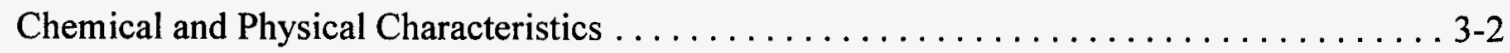

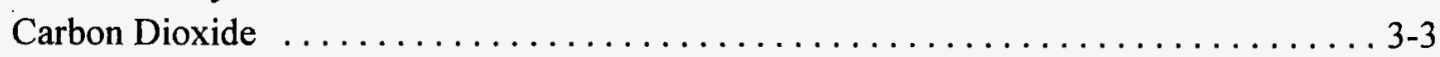

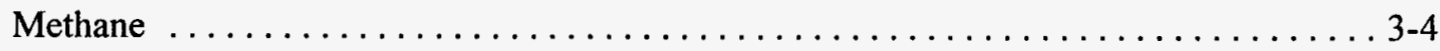

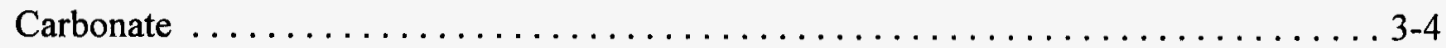

Bicarbonate . . . . . . . . . . . . . . . . . . . . . . . . . . . .

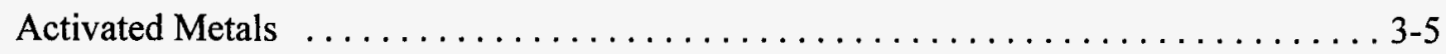

Carbon-14 Production in Nuclear Reactors . . . . . . . . . . . . . . . . . . 3-5

Waste and Disposal Data on Carbon-14 ....................... 3-6 


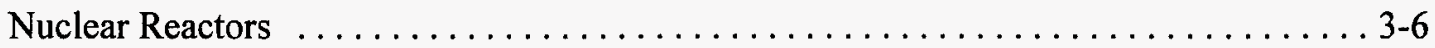

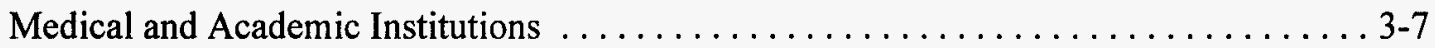

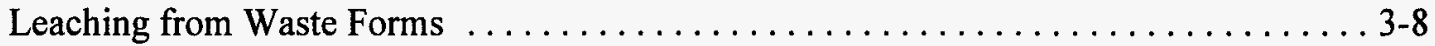

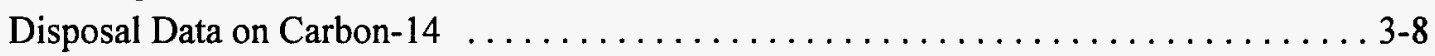

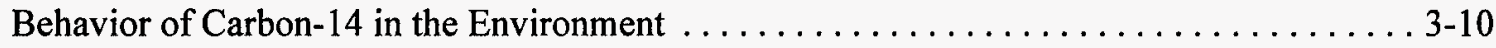

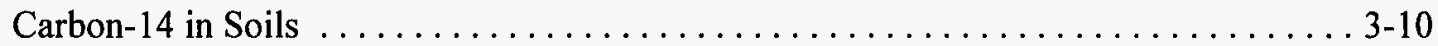

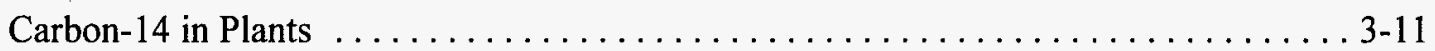

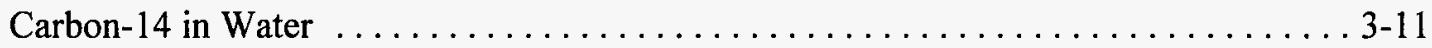

Carbon-14 in Air . . . . . . . . . . . . . . . . . . . . . . . . . . . . . .

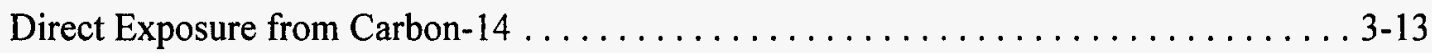

Behavior of Carbon-14 in the Human Body . . . . . . . . . . . . . . . . . . .

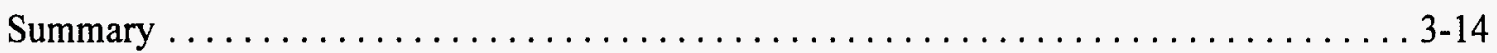

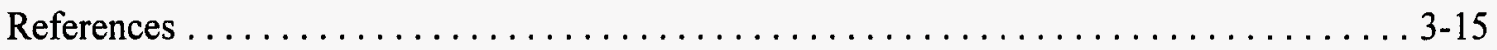

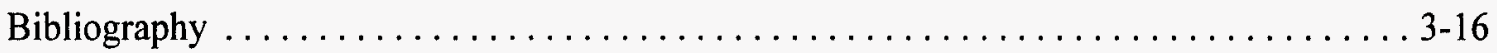

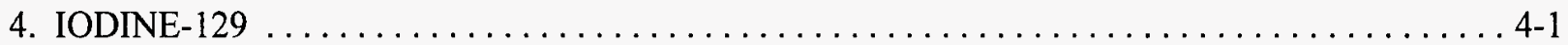

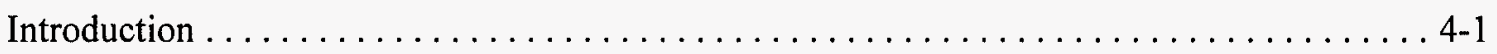

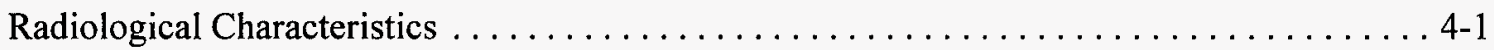

Chemical and Physical Characteristics . . . . . . . . . . . . . . . . . . . . 4-2

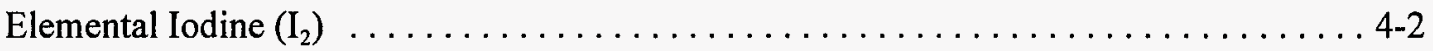

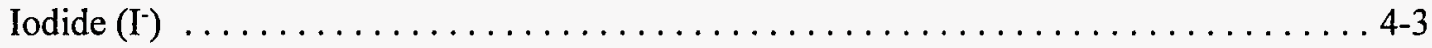

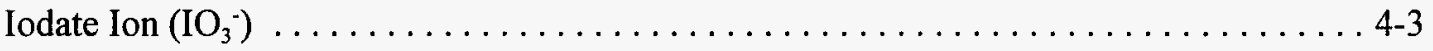

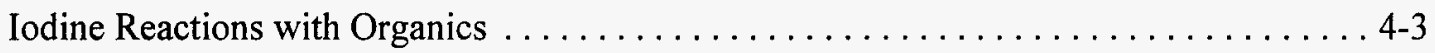

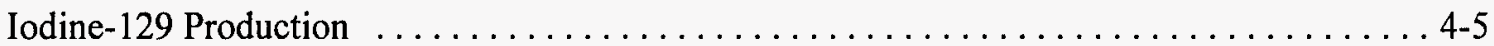

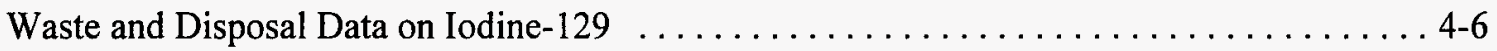

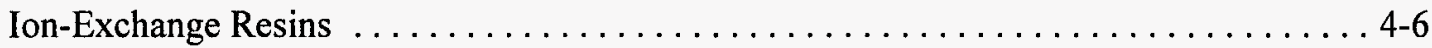

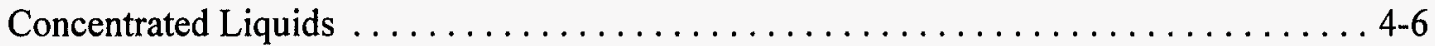

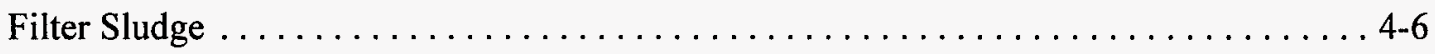

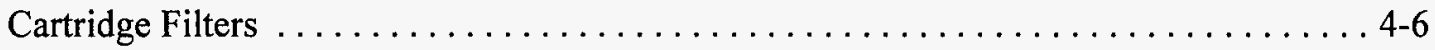

Trash .......................................... 4

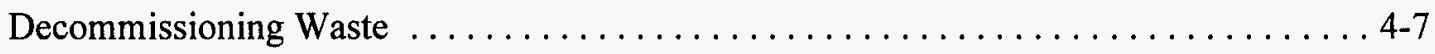

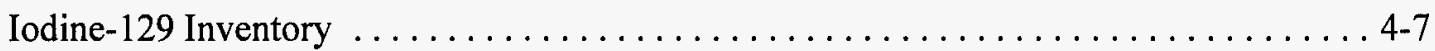

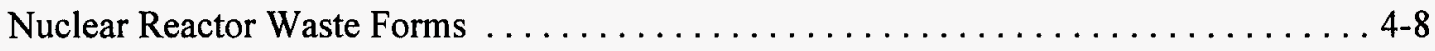

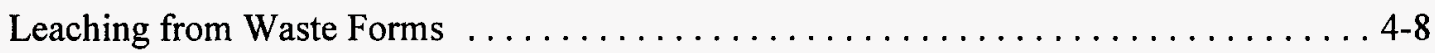

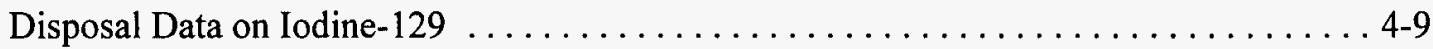

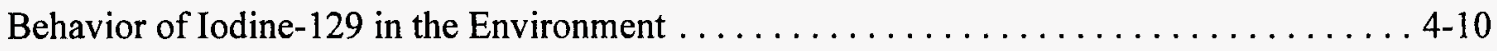

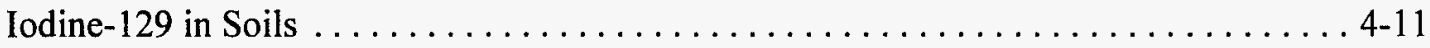

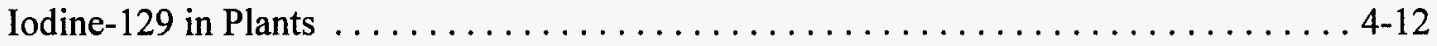

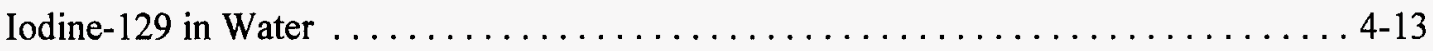

Iodine-129 in Air . . . . . . . . . . . . . . . . . . . . . . . .

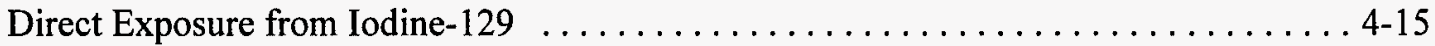

Behavior of Iodine-129 in the Human Body and in Animals . . . . . . . . . . . 4-15

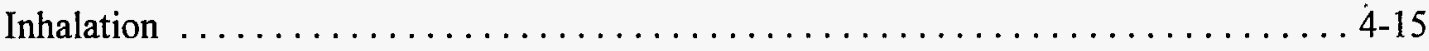

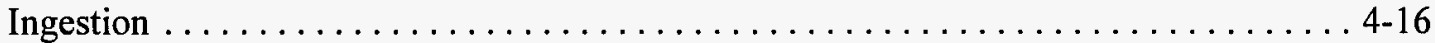

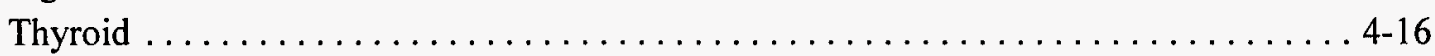


Summary $\ldots \ldots \ldots \ldots \ldots \ldots \ldots \ldots \ldots \ldots \ldots \ldots \ldots \ldots \ldots \ldots \ldots \ldots \ldots \ldots \ldots \ldots \ldots \ldots \ldots, 17$

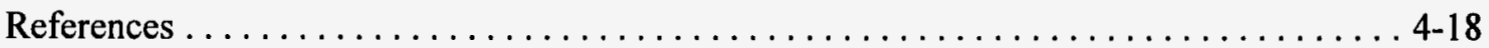

Bibliography $\ldots \ldots \ldots \ldots \ldots \ldots \ldots \ldots \ldots \ldots \ldots \ldots \ldots \ldots \ldots \ldots \ldots, 4,20$

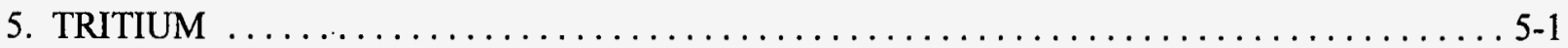

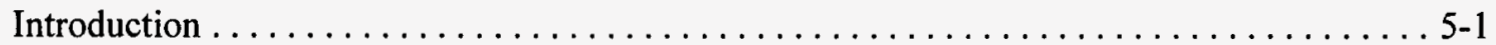

Radiological Characteristics . . . . . . . . . . . . . . . . . . . . . . .

Chemical and Physical Characteristics . . . . . . . . . . . . . . . . . . . . . 5-5

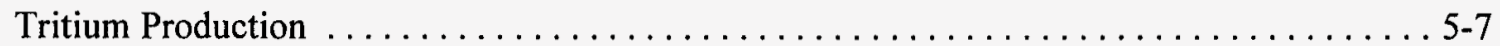

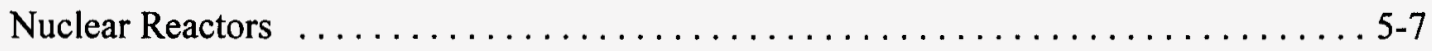

Tritium Production for Thermonuclear Weapons $\ldots \ldots \ldots \ldots \ldots \ldots \ldots \ldots \ldots \ldots \ldots$

Accelerators and Fusion Reactor Programs . . . . . . . . . . . . . . . . . .

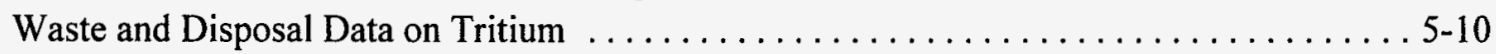

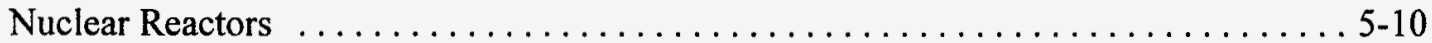

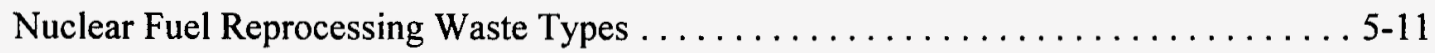

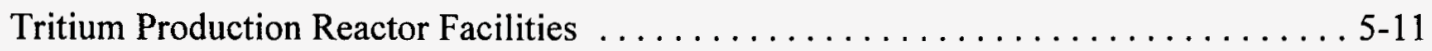

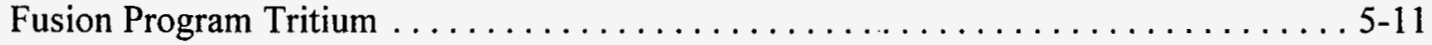

Medical, Academic Institutions, and Commercial Tritium Facilities . . . . . . . 5-12

Disposal Data on Tritium ............................. 5-13

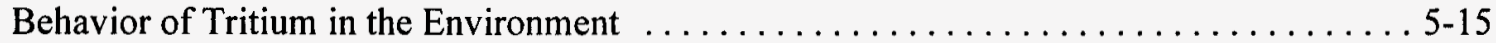

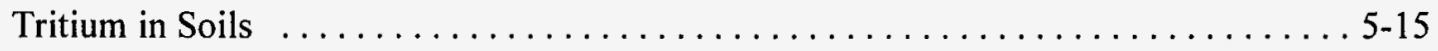

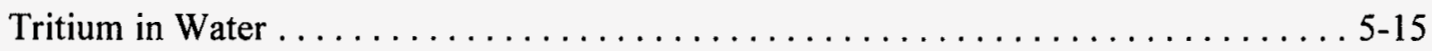

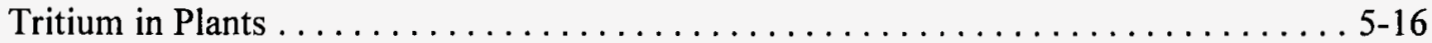

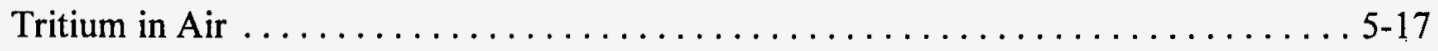

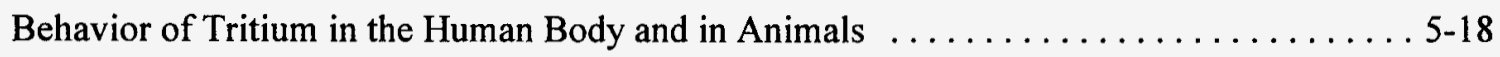

Metabolism of Tritium .............................. 5-18

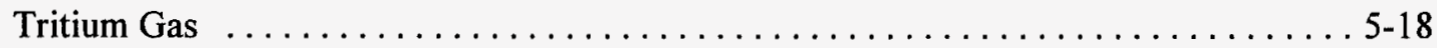

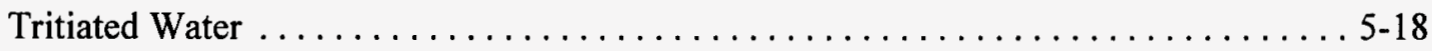

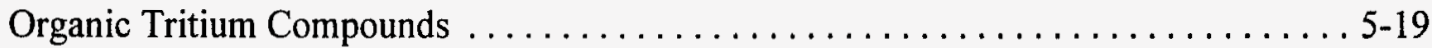

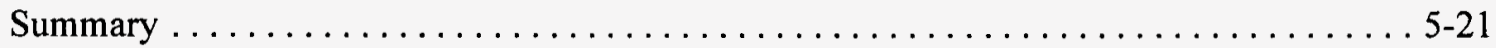

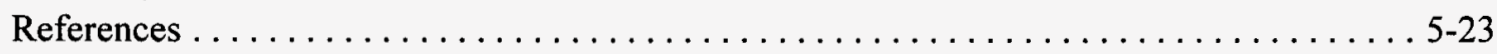

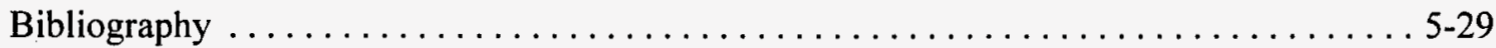

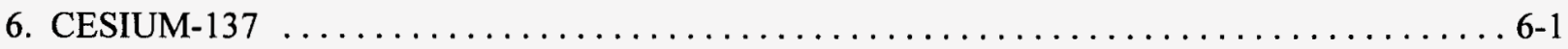

Introduction $\ldots \ldots \ldots \ldots \ldots \ldots \ldots \ldots \ldots \ldots \ldots \ldots \ldots \ldots \ldots \ldots, \ldots \ldots \ldots, 1$

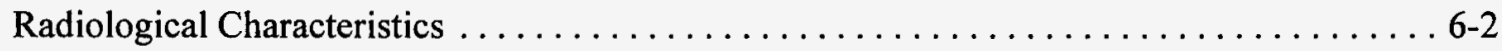

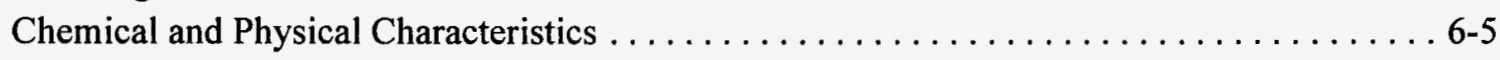

Cesium-137 Production in Nuclear Reactors $\ldots \ldots \ldots \ldots \ldots \ldots \ldots \ldots \ldots \ldots . \ldots \ldots . \ldots \ldots$

Waste and Disposal Data on Cesium-137 . . . . . . . . . . . . . . . . . . 6-9

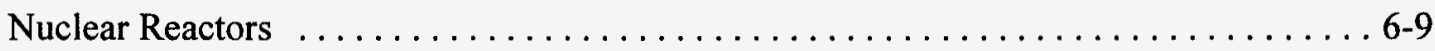

Medical, Academic Institutions, and Commercial Cesium-137 Waste . . . . . . . . 6-10

Disposal Data on Cesium-137 ............................ 6-10

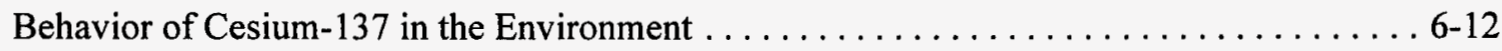

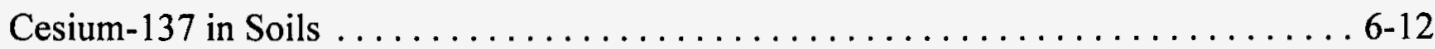

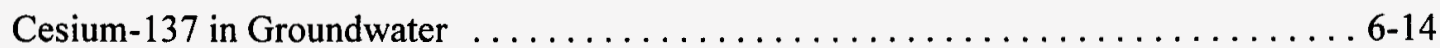


Cesium-137 in Plants $\ldots \ldots \ldots \ldots \ldots \ldots \ldots \ldots \ldots \ldots \ldots \ldots \ldots \ldots \ldots \ldots, 14$

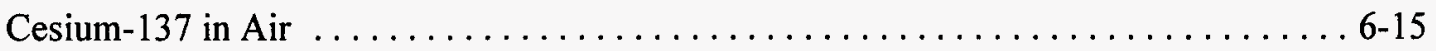

Behavior of Cesium- 137 in the Human Body and in Animals . . . . . . . . . . . . . . 6-16

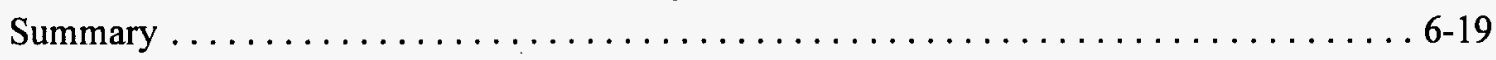

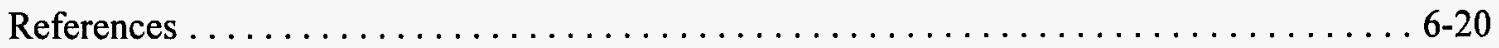

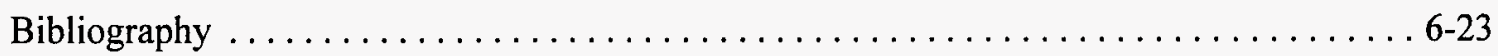

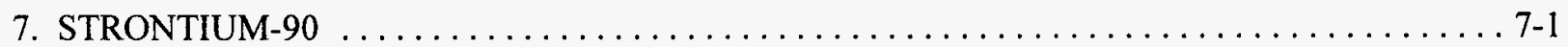

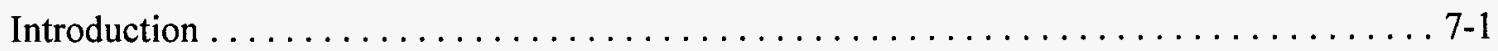

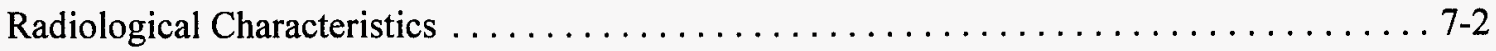

Chemical and Physical Characteristics .............................. $7-4$

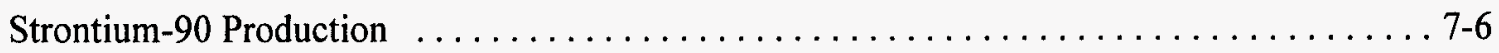

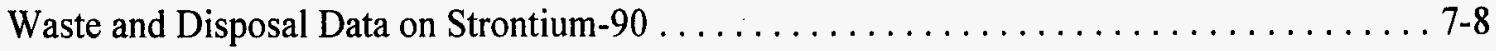

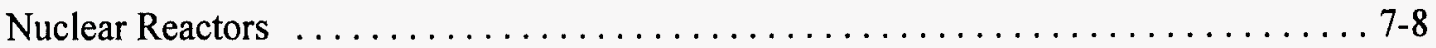

Medical, Academic Institutions, and Commercial Strontium-90 Waste $\ldots \ldots \ldots \ldots .7-10$

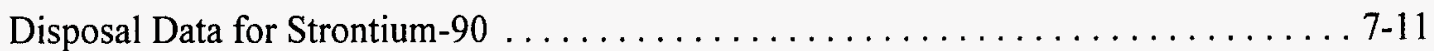

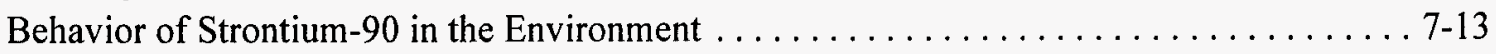

Strontium-90 in Soils ...................................... $7-13$

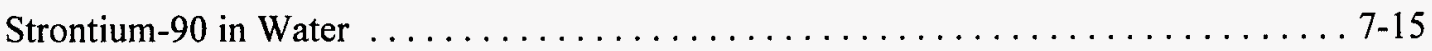

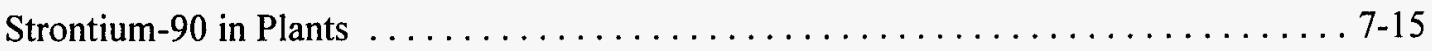

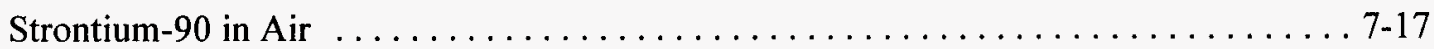

Behavior of Strontium- 90 in the Human Body and in Animals . . . . . . . . . . . . . 7-18

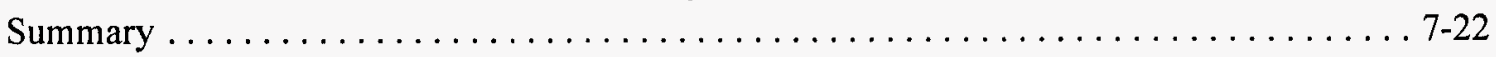

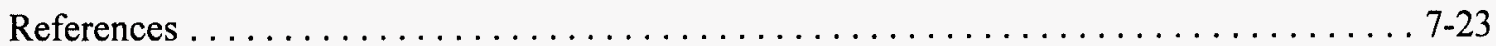

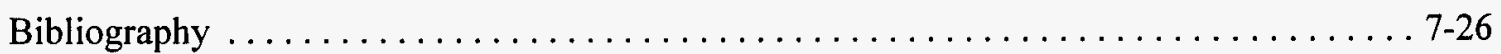

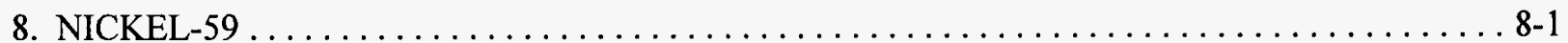

Introduction $\ldots \ldots \ldots \ldots \ldots \ldots \ldots \ldots \ldots \ldots \ldots \ldots \ldots \ldots \ldots \ldots \ldots \ldots \ldots, 1$

Radiological Characteristics .................................. $8-1$

Chemical and Physical Characteristics .............................. 8-4

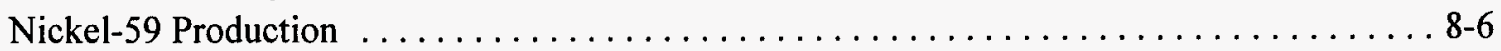

Waste and Disposal Data on Nickel-59 $\ldots \ldots \ldots \ldots \ldots \ldots \ldots \ldots \ldots \ldots \ldots \ldots . . \ldots \ldots$

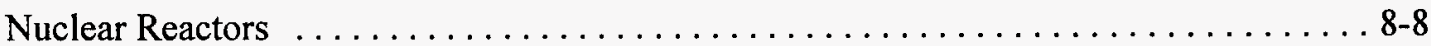

Medical, Academic Institutions, and Commercial Nickel-59 Waste . . . . . . . . . 8 8-9

Disposal Data on Nickel-59 ............................... 8-9

Behavior of Nickel-59 in the Environment $\ldots \ldots \ldots \ldots \ldots \ldots \ldots \ldots \ldots \ldots \ldots, 11$

Nickel-59 in Soils . . . . . . . . . . . . . . . . . . . . .

Nickel-59 in Water . . . . . . . . . . . . . . . . . . . .

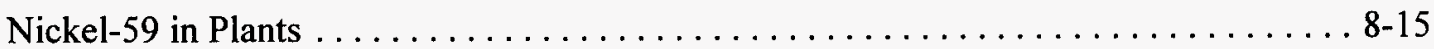

Nickel-59 in Air . . . . . . . . . . . . .

Behavior of Nickel-59 in the Human Body and in Animals $\ldots \ldots \ldots \ldots \ldots \ldots \ldots \ldots . . \ldots .16$

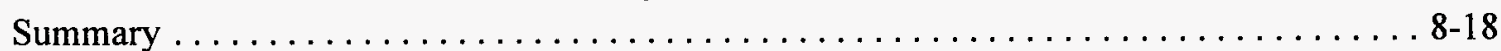

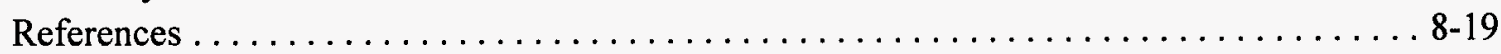

Bibliography $\ldots \ldots \ldots \ldots \ldots \ldots \ldots \ldots \ldots \ldots \ldots \ldots \ldots \ldots \ldots \ldots \ldots \ldots \ldots \ldots \ldots \ldots \ldots \ldots, 22$ 


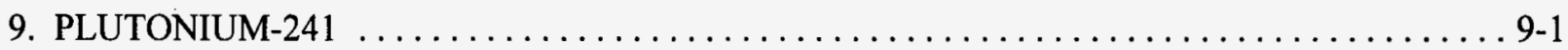

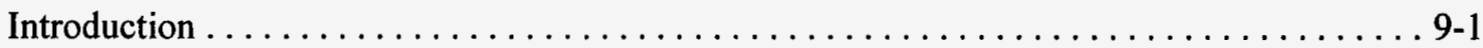

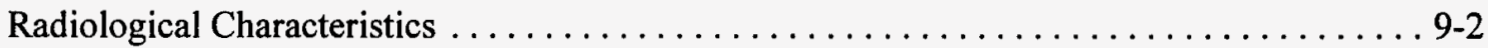

Chemical and Physical Characteristics . . . . . . . . . . . . . . . . . . . . .

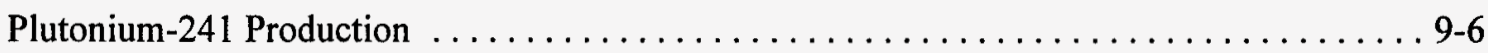

Waste and Disposal Data on Plutonium-241 $\ldots \ldots \ldots \ldots \ldots \ldots \ldots \ldots \ldots \ldots \ldots$

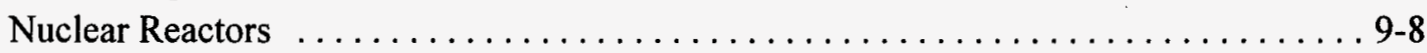

Medical, Academic Institution, and Industrial Plutonium-241 Waste . . . . . . . . 9 9-9

Disposal Data on Plutonium-241 ...................... 9-10

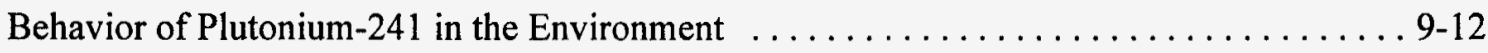

Plutonium-241 in Soils . . . . . . . . . . . . .

Plutonium-241 in Water . . . . . . . . . . . . . . . . . . . . .

Plutonium-241 in Plants . . . . . . . . . . . . . . . . . . . . . . . . .

Plutonium-241 in Air . . . . . . . . . . . . . . . . . . . . .

Behavior of Plutonium-241 in the Human Body and in Animals . . . . . . . . . . 9-15

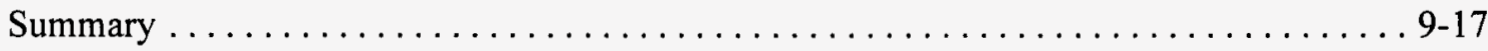

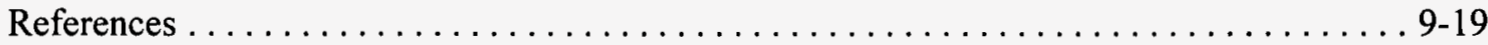

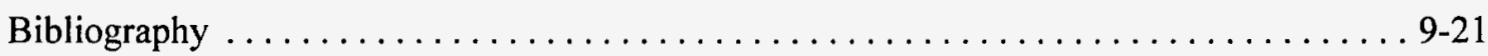

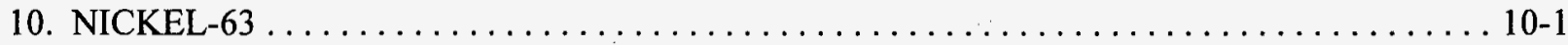

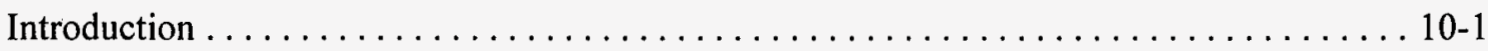

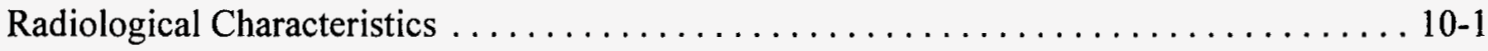

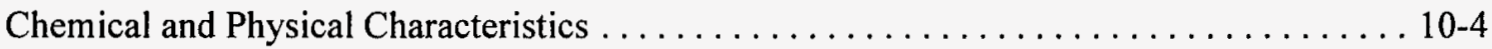

Nickel-63 Production . . . . . . . . . . . . . . . . . . . . . . . . . 10-6

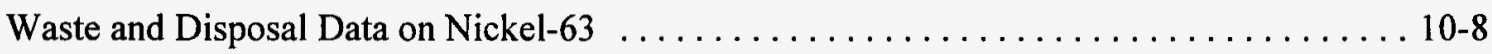

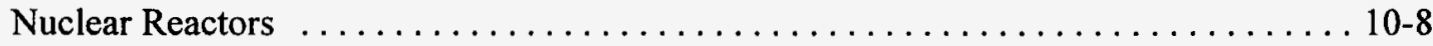

Medical, Academic Institutions, and Commercial Nickel-63 Waste $\ldots \ldots \ldots \ldots \ldots$. . . . .

Disposal Data on Nickel-63 ......................... 10-10

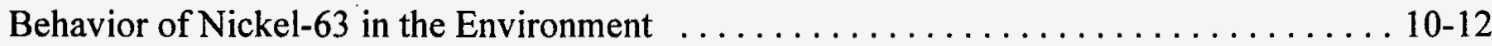

Nickel-63 in Soils . . . . . . . . . . . . . . . . . .

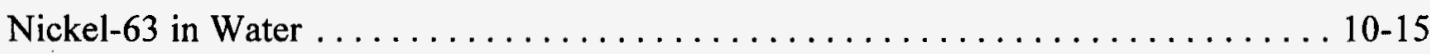

Nickel-63 in Plants . . . . . . . . . . . . . . . . . . . . . . . . . . . .

Nickel-63 in Air . . . . . . . . . . . . . . . . . . . . . . . . . . . . .

Behavior of Nickel-63 in the Human Body and in Animals . . . . . . . . . . 10-17

Human Body . . . . . . . . . . . . . . . . . . . . . . . . . . . . 10-17

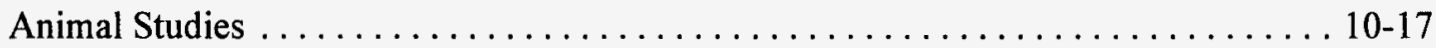

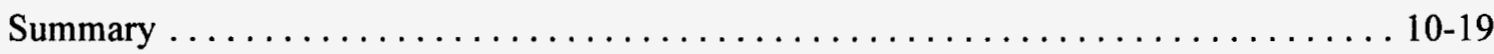

References . . . . . . . . . . . . . . . . . . . . . . . . . . . . . . . . . 10-21

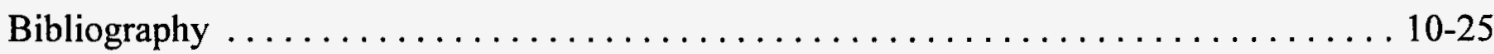

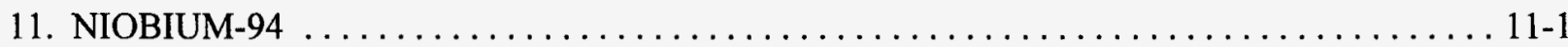

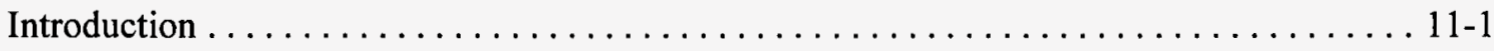

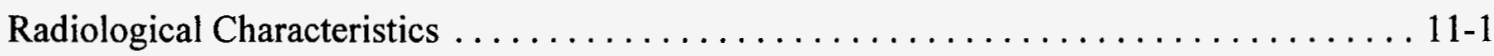

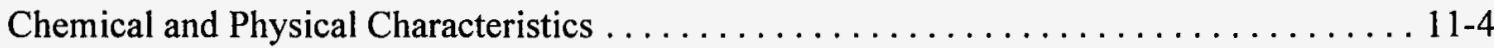

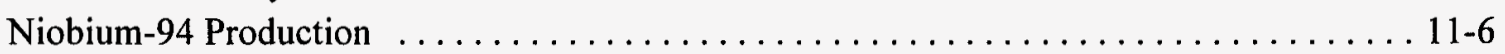




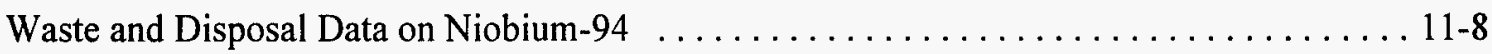

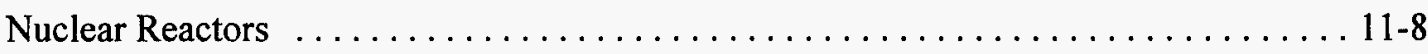

Medical, Academic Institutions, and Commercial Niobium-94 Waste . . . . . . . 11-10

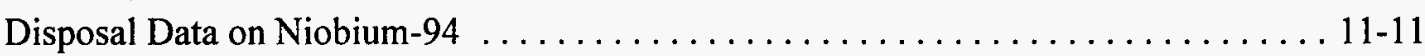

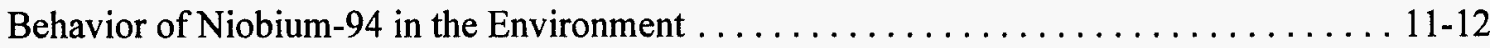

Niobium-94 in Soils . . . . . . . . . . . . . . . . . . . . . . . . . .

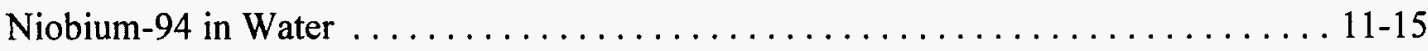

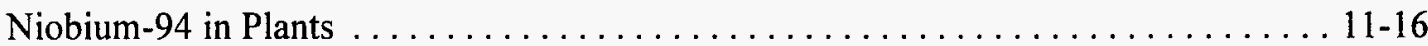

Niobium-94 in Air . . . . . . . . . . . . . . . . . . . . . . . . . . 11-17

Behavior of Niobium-94 in the Human Body and in Animals . . . . . . . . . . . 11-18

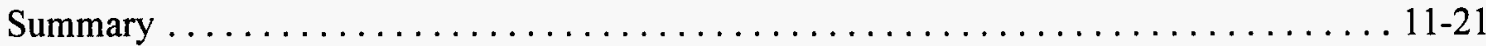

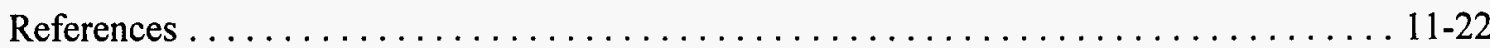

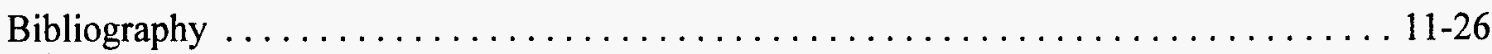

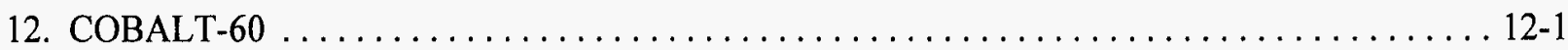

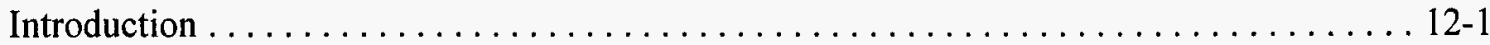

Radiological Characteristics . . . . . . . . . . . . . . . . . . . . . . . . 12-1

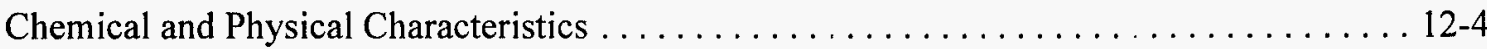

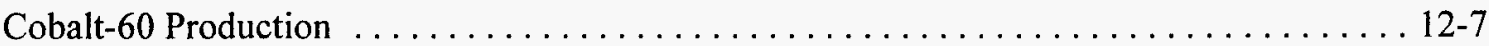

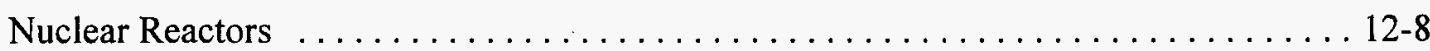

Medical, Academic Institutions, and Commercial Cobalt-60 Waste . . . . . . . . 12-10

Disposal Data on Cobalt-60 . . . . . . . . . . . . . . . . . . . . . 12-11

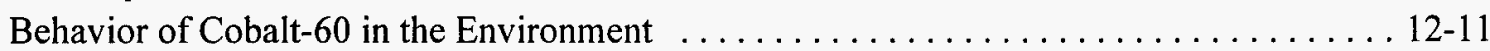

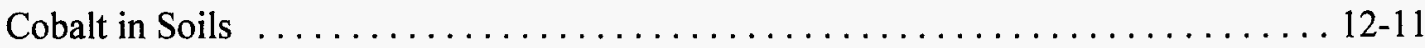

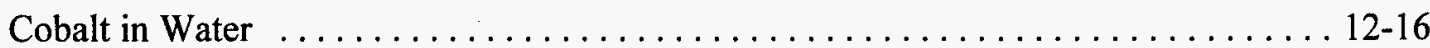

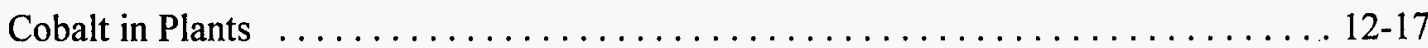

Cobalt in Air . . . . . . . . . . . . . . . . . . . . . . . . . . . . . . 12-19

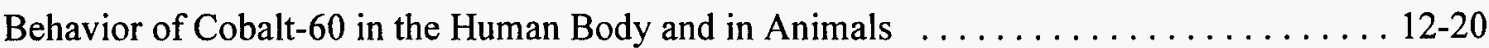

Behavior of Cobalt -60 in Animals . . . . . . . . . . . . . . . . . . . . . . $2-20$

Behavior of Cobalt-60 in Humans . . . . . . . . . . . . . . . . . . . . . . . 12-21

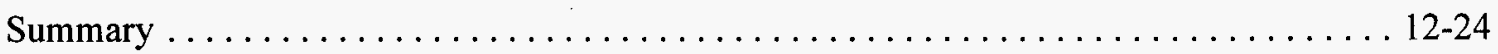

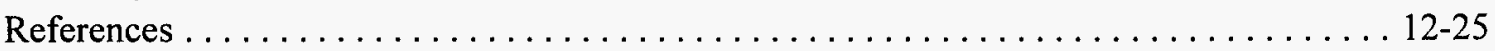

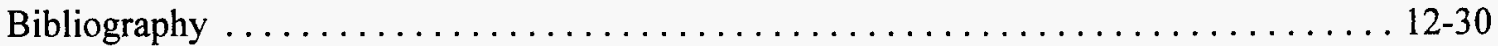

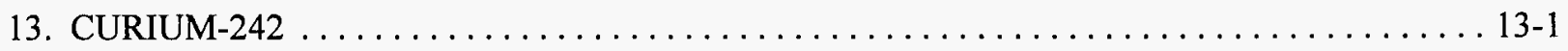

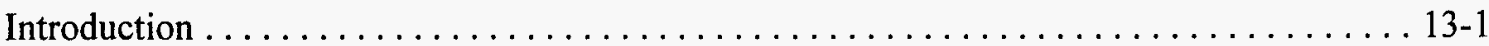

Radiological Characteristics . . . . . . . . . . . . . . . . . . . . . . . 13-2

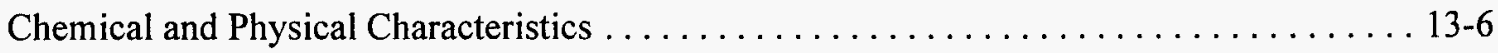

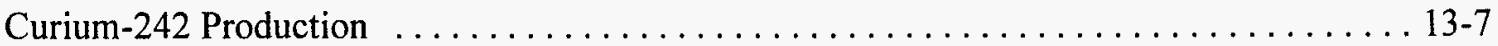

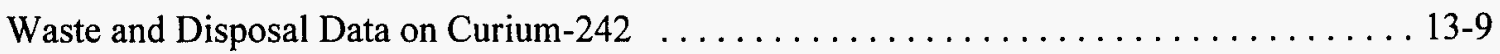

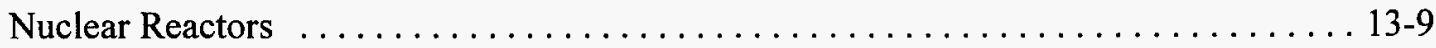

Medical, Academic Institutions, and Commercial Curium-242 Waste . . . . . . . 13-10

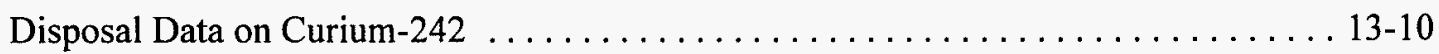

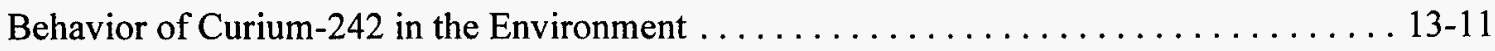

Curium-242 in Soils . . . . . . . . . . . . . . . . . . . . . . 


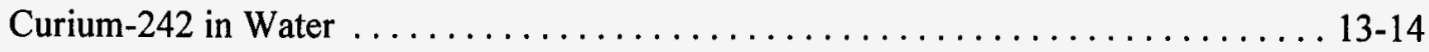

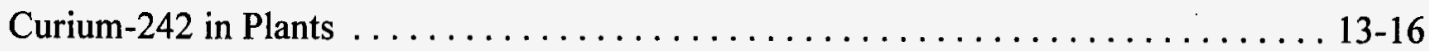

Curium-242 in Air . . . . . . . . . . . . . . . . . . . . . . . . . $13-18$

Behavior of Curium-242 in the Human Body and in Animals . . . . . . . . . . 13-19

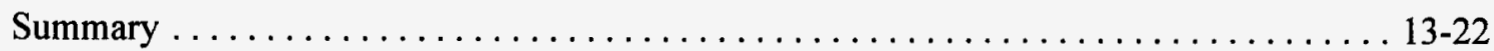

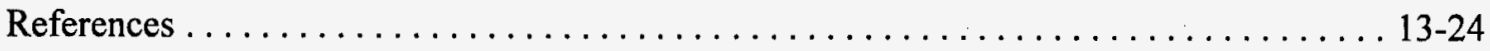

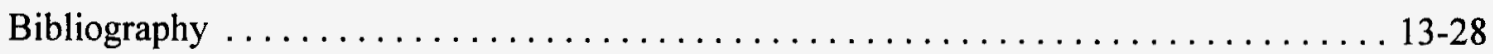

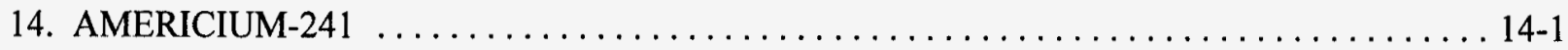

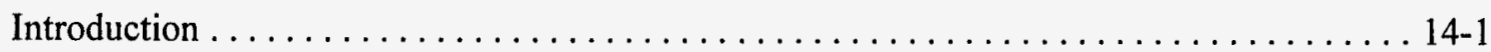

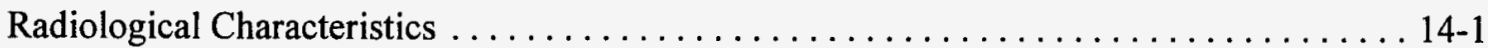

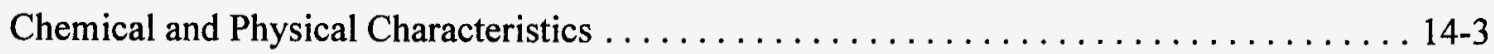

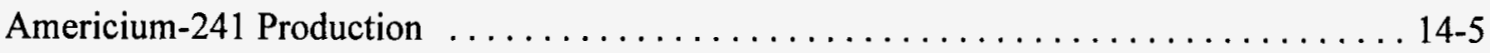

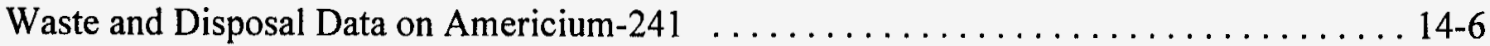

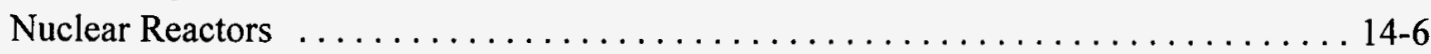

Government Waste . . . . . . . . . . . . . . . . . . . . . . . 14-7

Medical, Academic Institutions, and Commercial Americium-241 Waste . . . . . . . . 14-7

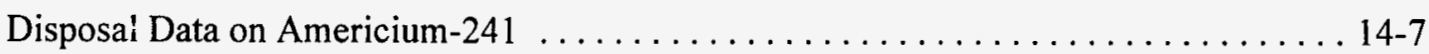

Behavior of Americium-241 in the Environment . . . . . . . . . . . . . . . .

Americium-241 in Soils . . . . . . . . . . . . . . . . . . . . . . . .

Americium-241 in Water . . . . . . . . . . . . . . . . . . . . . . . . 14-11

Americium-241 in Air . . . . . . . . . . . . . . . . . . . . . . . . . 14-13

Behavior of Americium-241 in the Human Body and in Animals . . . . . . . . . . . . 14-13

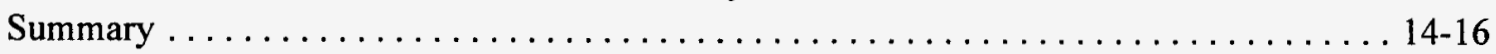

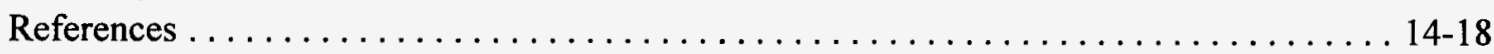

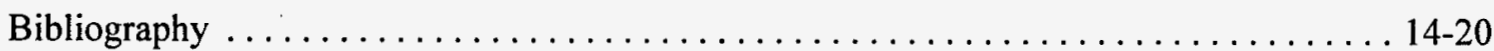

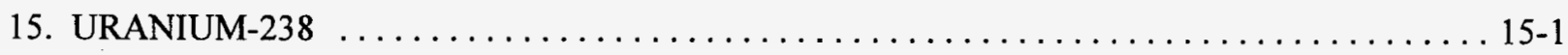

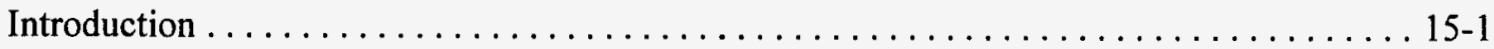

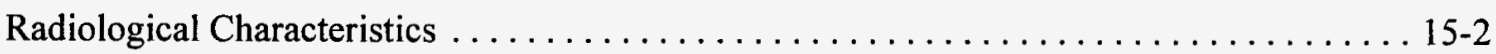

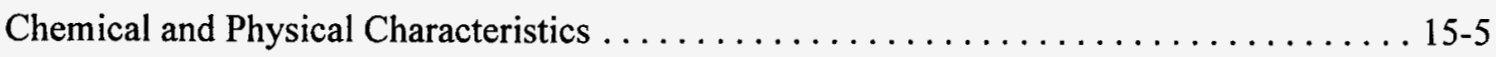

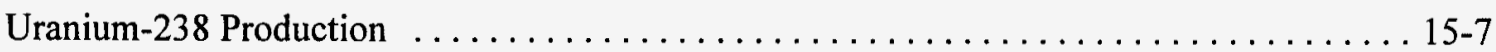

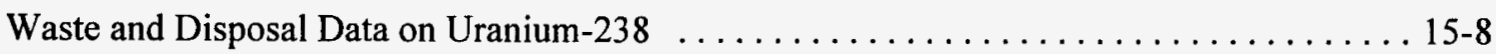

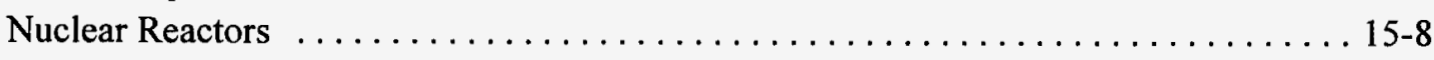

Medical, Academic Institutions, and Commercial Uranium-238 Waste . . . . . . . . 15-8

Disposal Data on Uranium-238 ... . . . . . . . . . . . . . . . . . . 15-9

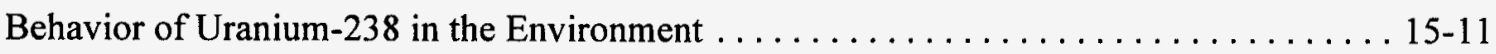

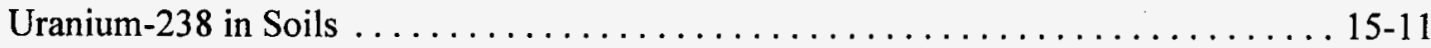

Uranium-238 in Water . . . . . . . . . . . . . . . . . . . . . . . . .

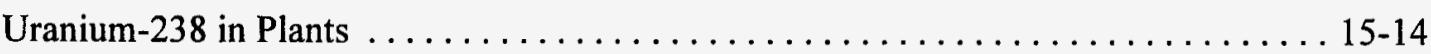

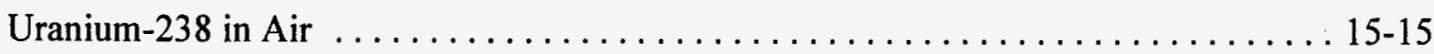

Behavior of Uranium-238 in the Human Body and in Animals . . . . . . . . . . . 15-16

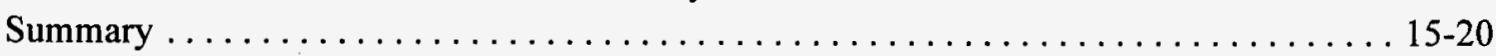

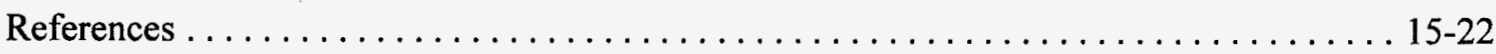

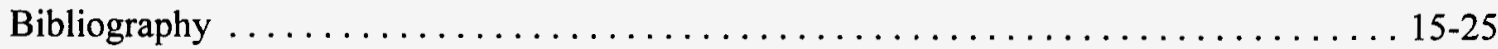




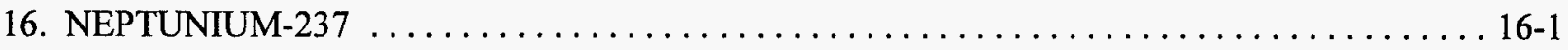

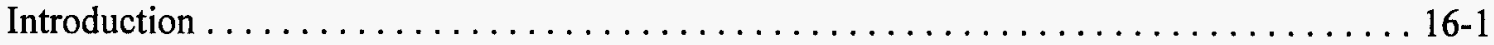

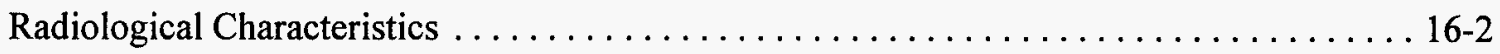

Chemical and Physical Characteristics . . . . . . . . . . . . . . . . .

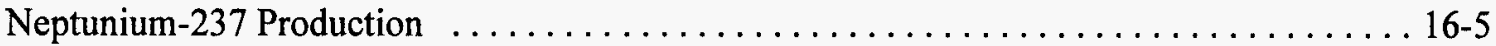

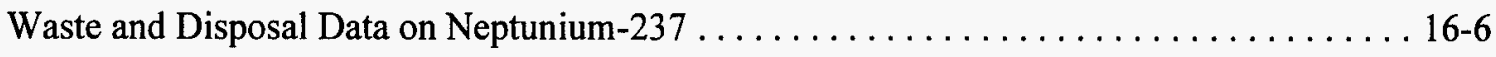

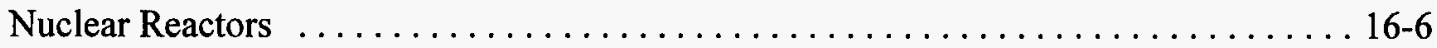

Medical, Academic Institutions, and Commercial Neptunium-237 Waste . . . . . . 16-6

Disposal Data on Neptunium-237 . . . . . . . . . . . . . . . . . 16-7

Behavior of Neptunium-237 in the Environment . . . . . . . . . . . . . . . 16-9

Neptunium-237 in Soils . . . . . . . . . . . . . . . . . . . . . . . . .

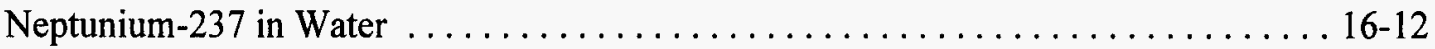

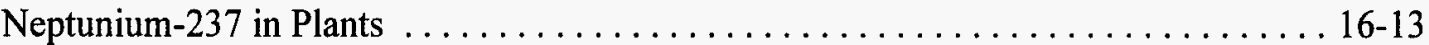

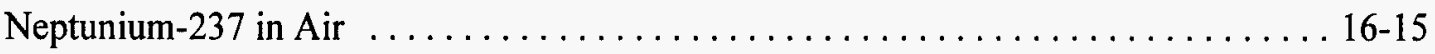

Behavior of Neptunium-237 in the Human Body and in Animals . . . . . . . . . . 16-15

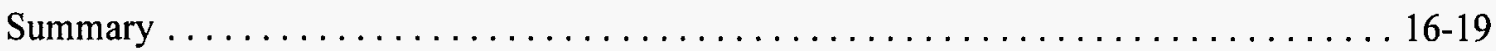

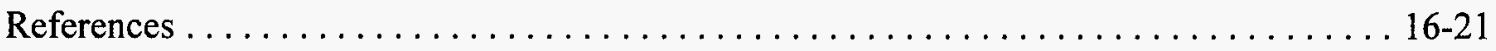

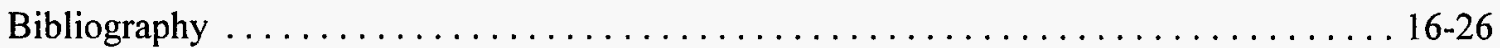

Figures

2-1. Fission-product distributions from thermal-neutron fission of ${ }^{233} \mathrm{U}$ and ${ }^{239} \mathrm{Pu} \ldots \ldots \ldots \ldots 2-5$

2-2. ${ }^{99} \mathrm{Tc}$ activity deposited at Richland, Beatty, and Barnwell sites by year (log scale) . . . . . . . 2-9

2-3. ${ }^{99} \mathrm{Tc}$ activity deposited at Richland, Beatty, and Barnwell sites by source (log scale) . . . . . 2-10

2-4. ${ }^{99} \mathrm{Tc}$ activity deposited at Richland and Beatty sites by waste type (log scale) $\ldots \ldots \ldots \ldots 2-11$

3-1. ${ }^{14} \mathrm{C}$ activity deposited at Richland, Beatty, and Barnwell sites by year (log scale) . . . . . . 3-9

3-2. ${ }^{14} \mathrm{C}$ activity deposited at the Richland, Beatty, and Barnwell sites by source (log scale) . . . . . 3-9

3-3. ${ }^{14} \mathrm{C}$ activity deposited at the Richland and Beatty sites by waste type (log scale) $\ldots \ldots \ldots .10$

4-1. Speciation of iodine in water as function of $\mathrm{pH}$ and redox potential $\ldots \ldots \ldots \ldots \ldots \ldots$

4-2. Fission-product distributions from thermal-neutron fission of ${ }^{233} \mathrm{U}$ and ${ }^{239} \mathrm{Pu} \ldots \ldots \ldots \ldots \ldots$

4-3. ${ }^{129}$ I activity deposited at the Richland, Beatty, and Barnwell sites by year (log scale) . . . . . . . 4-9

4-4. ${ }^{129}$ I activity deposited at the Richland, Beatty, and Barnwell sites by source (log scale) . . . . 4-10

4-5. ${ }^{129}$ I activity deposited at the Richland and Beatty sites by waste type (log scale) $\ldots \ldots \ldots$. . 10

5-1. Fission product yield curve for thermal fission of ${ }^{235} \mathrm{U} \ldots \ldots \ldots \ldots \ldots \ldots \ldots \ldots \ldots$

5-2. Tritium activity deposited at the Richland, Beatty, and Barnwell sites by year (log scale) . . 5-13

5-3. Tritium activity deposited at the Richland, Beatty, and Barnwell sites by source (log scale) . 5-14

5-4. Tritium activity deposited at the Richland and Beatty sites by waste type (log scale) . . . . 5-14

6-1. Fission product yield curve for thermal fission of ${ }^{235} \mathrm{U} \ldots \ldots \ldots \ldots \ldots \ldots \ldots \ldots \ldots$

6-2. $\quad{ }^{137}$ Cs activity deposited at the Richland, Beatty, and Barnwell sites by year (log scale) . . . 6-10

6-3. $\quad{ }^{137} \mathrm{Cs}$ activity deposited at the Richland, Beatty, and Barnwell sites by source (log scale) . . 6-11 
6-4. $\quad{ }^{137}$ Cs activity deposited at the Richland and Beatty sites by waste type (log scale) . . . . 6-12

6-5. Variation of biological half-life with mass $\ldots \ldots \ldots \ldots \ldots \ldots \ldots \ldots \ldots \ldots \ldots \ldots$

7-1. Fission product yield curve for thermal fission of ${ }^{235} \mathrm{U}$, showing ${ }^{90} \mathrm{Sr}$ cumulative yield . . . 7-7

7-2. $\quad{ }^{90} \mathrm{Sr}$ activity deposited at the Richland, Beatty, and Barnwell sites by year (log scale) . . . . 7-11

7-3. $\quad{ }^{90} \mathrm{Sr}$ activity deposited at the Richland, Beatty, and Barnwell sites by source (log scale) . . . 7-12

7-4. $\quad{ }^{90} \mathrm{Sr}$ activity deposited at the Richland and Beatty sites by waste type (log scale) $\ldots \ldots \ldots 7-13$

8-1. Fission product yield curve for thermal fission of ${ }^{235} \mathrm{U} \ldots \ldots \ldots \ldots \ldots \ldots \ldots \ldots \ldots$ 8-7

8-2. Buildup of some important activation products in a PWR as a function

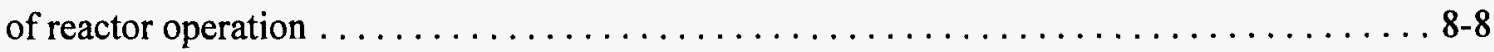

8-3. $\quad{ }^{59} \mathrm{Ni}$ activity deposited at the Richland, Beatty, and Barnwell sites by year (log scale) . . . 8 8-9

8-4. $\quad{ }^{59} \mathrm{Ni}$ activity deposited at the Richland, Beatty, and Barnwell sites by source (log scale) . . . 8-10

8-5. $\quad{ }^{59} \mathrm{Ni}$ activity deposited at the Richland and Beatty sites by waste type (log scale) $\ldots \ldots \ldots 8-11$

9-1. Fission product yield curve for thermal fission of ${ }^{235} \mathrm{U}$ and ${ }^{241} \mathrm{Pu} \ldots \ldots \ldots \ldots \ldots \ldots \ldots$

9-2. $\quad{ }^{241} \mathrm{Pu}$ activity deposited at the Richland, Beatty, and Barnwell sites by year (log scale) . . . . 9-11

9-3. $\quad{ }^{241} \mathrm{Pu}$ activity deposited at the Richland, Beatty, and Barnwell sites by source (log scale) . . 9-11

9-4. $\quad{ }^{241} \mathrm{Pu}$ activity deposited at the Richland and Beatty sites by waste type (log scale) . . . . . 9-12

10-1. Fission product yield curve for thermal fission of ${ }^{235} \mathrm{U} \ldots \ldots \ldots \ldots \ldots \ldots \ldots \ldots \ldots$

10-2. Buildup of some important activation products in a PWR as a function of

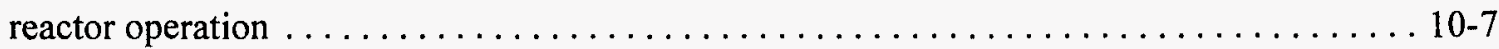

10-3. ${ }^{63} \mathrm{Ni}$ activity deposited at the Richland, Beatty, and Barnwell sites by year (log scale) . . . 10-10

10-4. $\quad{ }^{63} \mathrm{Ni}$ activity deposited at the Richland, Beatty, and Barnwell sites by source (log scale) . . 10-11

10-5. ${ }^{63} \mathrm{Ni}$ activity deposited at the Richland and Beatty sites by waste type (log scale) . . . . 10-11

11-1. Fission product yield curve for thermal fission of ${ }^{235} \mathrm{U} \ldots \ldots \ldots \ldots \ldots \ldots \ldots \ldots \ldots \ldots$

11-2. Buildup of some important activation products in a PWR as a function of

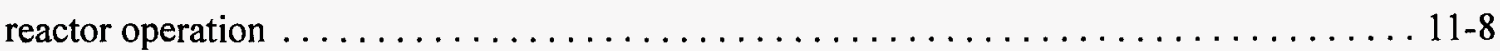

11-3. ${ }^{94} \mathrm{Nb}$ activity deposited at the Richland, Beatty, and Barnwell sites by year (log scale) . . . 11-11

11-4. ${ }^{94} \mathrm{Nb}$ activity deposited at the Richland, Beatty, and Barnwell sites by source (log scale) . . 11-12

$11-5 .{ }^{94} \mathrm{Nb}$ activity deposited at the Richland and Beatty sites by waste type (log scale) $\ldots \ldots \ldots 11-12$

12-1. Fission product yield curve for thermal fission of ${ }^{235} \mathrm{U} \ldots \ldots \ldots \ldots \ldots \ldots \ldots \ldots \ldots$

12-2. Buildup of some important activation products in a PWR as a function of reactor operation

12-3. ${ }^{60} \mathrm{Co}$ activity deposited at the Richland, Beatty, and Barnwell sites by year (log scale) . . . 12-12

12-4. $\quad{ }^{60} \mathrm{Co}$ activity deposited at the Richland, Beatty, and Barnwell sites by source (log scale) . . 12-12

12-5. ${ }^{60} \mathrm{Co}$ activity deposited at the Richland and Beatty sites by waste type (log scale) . . . . 12-13

13-1. $\quad{ }^{242} \mathrm{Cm}$ activity deposited at the Richland, Barnwell and Beatty sites by year (log scale) . . 13-10

13-2. $\quad{ }^{242} \mathrm{Cm}$ activity deposited at the Richland, Beatty, and Barnwell sites by source (log scale) . 13-11

13-3. $\quad{ }^{242} \mathrm{Cm}$ activity deposited at the Richland and Beatty sites by waste type (log scale) . . . . 13-12 


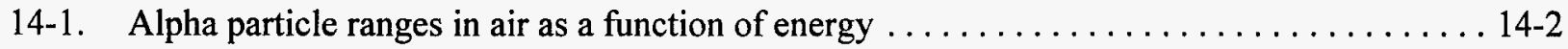

14-2. Diagram for the primary decay sequence for ${ }^{241} \mathrm{Am} \ldots \ldots \ldots \ldots \ldots \ldots \ldots \ldots \ldots \ldots \ldots$

14-3. In-growth of ${ }^{241} \mathrm{Am}$ activity from $1 \mathrm{~g}$ of ${ }^{241} \mathrm{Pu}$ over a 50 -year period $\ldots \ldots \ldots \ldots \ldots \ldots$ 14-6

14-4. $\quad{ }^{241} \mathrm{Am}$ activity deposited at the Richland, Beatty, and Barnwell sites by year (log scale) . . . 14-8

14-5. $\quad{ }^{241}$ Am activity deposited at the Richland, Beatty, and Barnwell sites by source (log scale) . . 14-8

14-6. ${ }^{241}$ Am activity deposited at the Richland and Beatty sites by waste type (log scale) . . . . . . 14-9

15-1. ${ }^{238} \mathrm{U}$ activity deposited at the Richland, Beatty, and Barnwell sites by year (log scale) . . 15-10

15-2. $\quad{ }^{238} \mathrm{U}$ activity deposited at the Richland, Beatty, and Barnwell sites by source (log scale) . . 15-10

15-3. ${ }^{238} \mathrm{U}$ activity deposited at the Richland and Beatty sites by waste type (log scale) . . . . . 15-11

16-1. $\quad{ }^{237} \mathrm{~Np}$ activity deposited at the Richland, Beatty, and Barnwell sites by year (log scale) . . 16-7

16-2. $\quad{ }^{237} \mathrm{~Np}$ activity deposited at the Richland, Beatty, and Barnwell sites by source (log scale) . . 16-8

16-3. $\quad{ }^{237} \mathrm{~Np}$ activity deposited at the Richland and Beatty sites by waste type (log scale) . . . . . 16-9

\section{Tables}

1-1. LLW classification table-long-lived radionuclides $\ldots \ldots \ldots \ldots \ldots \ldots \ldots \ldots \ldots \ldots$

1-2. LLW classification table - short-lived radionuclides $\ldots \ldots \ldots \ldots \ldots \ldots \ldots \ldots \ldots \ldots \ldots$

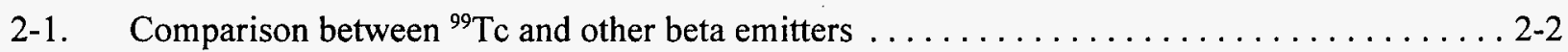

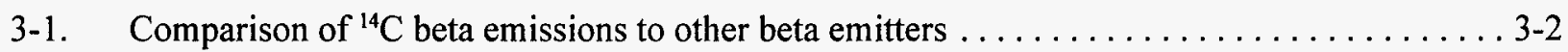

4-1. Comparison of ${ }^{129} \mathrm{I}$ beta emissions with emissions from other radionuclides $\ldots \ldots \ldots \ldots 4-2$

5-1. Comparison of the calculated stopping distance for an average energy beta particle

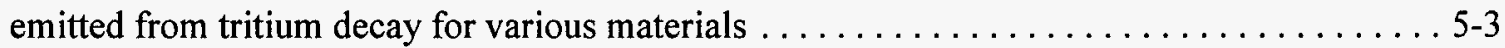

5-2. Comparison of the radiotoxicity of several important radionuclides $\ldots \ldots \ldots \ldots \ldots \ldots$ 5-4

5-3. Average and maximum kinetic energies of beta particles released during decay of several

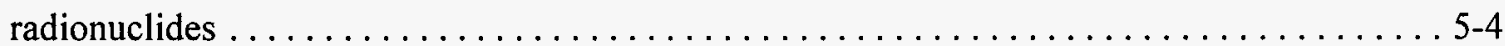

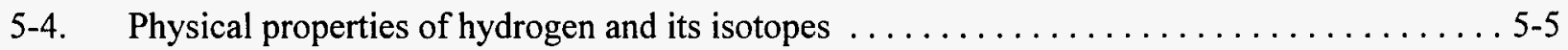

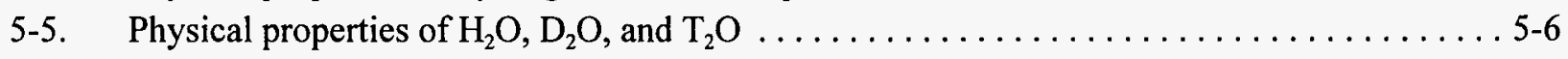

5-6. Estimated release rates of tritium to the reactor coolant for a 1,000-MWe $\mathrm{PWR}^{\mathrm{a}}$ and a BWR . 5-9

5-7. Biological half-life of tritium in body water after administration of tritium in the form

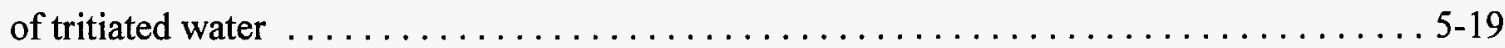

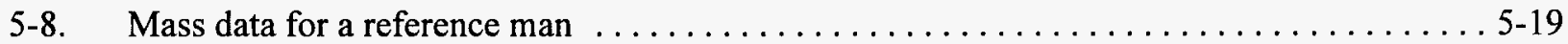

5-9. Annual limits on intake (ALI) and derived air concentrations (DAC) for tritium . . . . . . 5-21

6-1. Comparison of the calculated maximum ranges for $511-\mathrm{keV}$ and $1,176-\mathrm{keV}$ energy beta particles emitted from ${ }^{137} \mathrm{Cs}$ decay for various materials $\ldots \ldots \ldots \ldots \ldots \ldots \ldots .3$

6-2. Comparison of the radiotoxicity of several important radionuclides $\ldots \ldots \ldots \ldots \ldots \ldots \ldots 6-3$

6-3. Average and maximum kinetic energies of beta particles released during decay of several

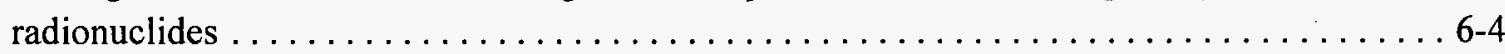


6-4. Minimum thickness required to decrease the initial $662-\mathrm{keV}$ gamma ray intensity from

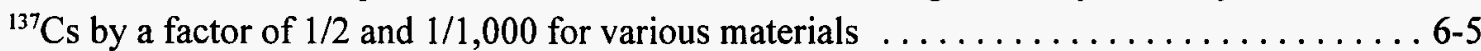

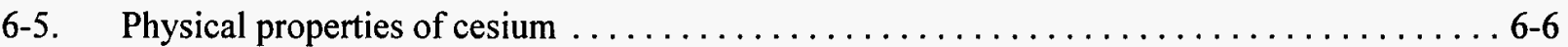

6-6. Cesium and total radioactive fission product activities calculated as a function of decay time following a 3-year irradiation in a 3,050-MW thermal power LWR producing a total fuel

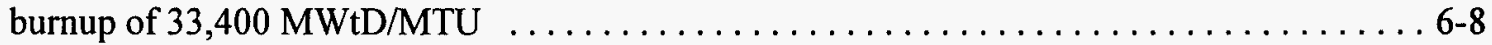

6-7. Maximum permissible body burdens and maximum permissible concentrations . . . . . 6-18

6-8. Annual limits on intake (ALI) and the derived air concentrations (DAC) for ${ }^{137} \mathrm{Cs} \ldots \ldots .6$ 6-18

7-1. Comparison of the calculated maximum ranges for $546-\mathrm{keV}$ and $2,284-\mathrm{keV}$ energy beta particles emitted from ${ }^{90} \mathrm{Sr}$ and strontium daughter $\left({ }^{90} \mathrm{Y}\right)$ decay for various materials $\ldots \ldots$ 7-3

7-2. Comparison of the radiotoxicity of several important radionuclides $\ldots \ldots \ldots \ldots \ldots \ldots \ldots 7-3$

7-3. Average and maximum kinetic energies of beta particles released during decay of several

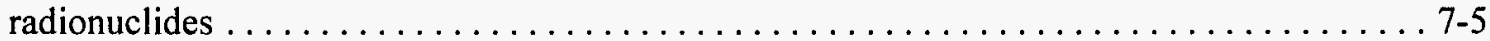

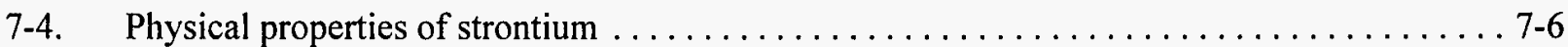

7-5. Strontium and total radioactive fission product activities calculated as a function of decay time following a 3-year irradiation in a 3,050-MW thermal power LWR producing a total fuel burnup of $33,400 \mathrm{MWtD} / \mathrm{MTU} \ldots \ldots \ldots \ldots \ldots \ldots \ldots \ldots \ldots$

7-6. Maximum permissible body burdens and maximum permissible concentrations (for a

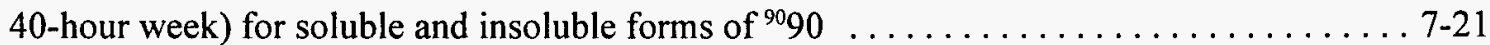

7-7. Annual limits on intake (ALI), the derived air concentrations (DAC), and the maximum

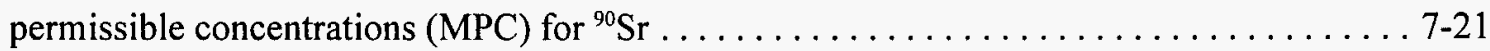

8-1. Comparison of the estimated maximum ranges for a 4.1-keV average energy Auger electron emitted from ${ }^{59} \mathrm{Ni}$ decay for various materials $\ldots \ldots \ldots \ldots \ldots \ldots \ldots \ldots \ldots \ldots \ldots$

8-2. Comparison of the radiotoxicity of several important radionuclides $\ldots \ldots \ldots \ldots \ldots \ldots \ldots$ 8-4

8-3. Average and maximum kinetic energies of beta particles and negative (atomic) electrons released during the decay of several important radionuclides $\ldots \ldots \ldots \ldots \ldots \ldots \ldots \ldots-5$

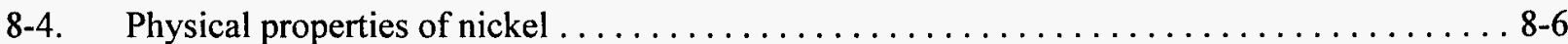

8-5. Maximum permissible body burdens and maximum permissible concentrations . . . . . . 8-17

8-6. Annual limits on intake (ALI) and the derived air concentrations (DAC) for ${ }^{59} \mathrm{Ni} \ldots \ldots .8-17$

9-1. Comparison of the estimated maximum ranges for a 21-keV maximum energy beta particle

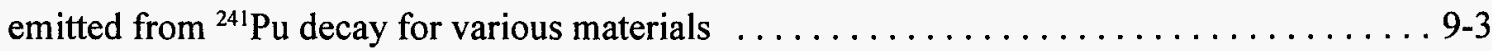

9-2. Comparison of the radiotoxicity of several important radionuclides including ${ }^{241} \mathrm{Pu} \ldots \ldots \ldots 9-3$

9-3. Average and maximum kinetic energies of beta particles and negative (atomic) electrons released during the decay of several important radionuclides $\ldots \ldots \ldots \ldots \ldots \ldots \ldots .4$

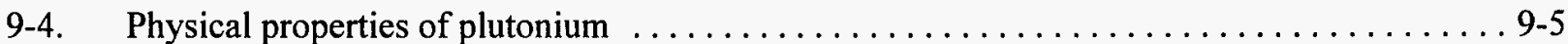

9-5. Plutonium-241, total plutonium, total actinide, and total fission product inventories calculated as a function of decay time following a 3-year irradiation in a 3,200-MW thermal power LWR producing a total fuel burnup of 33,400 MWD/MTU . . . . . . . . 9-7

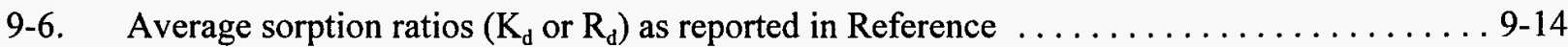

9-7. Annual limits on intake (ALI) and the derived air concentrations (DAC) for ${ }^{241} \mathrm{Pu}$ for ingestion and inhalation 
10-1. Comparison of the estimated maximum ranges for a $17-\mathrm{keV}$ average energy beta particle emitted

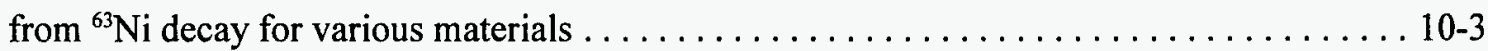

10-2. Comparison of the radiotoxicity of several important radionuclides $\ldots \ldots \ldots \ldots \ldots \ldots$ 10-3

10-3. Average and maximum kinetic energies of beta particles and Auger electrons released

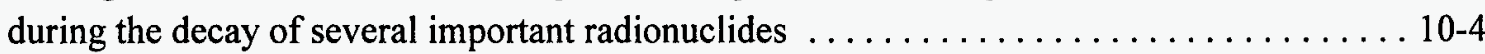

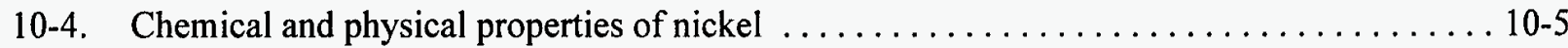

10-5. Annual limits on intake (ALI) and the derived air concentrations (DAC) for ${ }^{63} \mathrm{Ni} \ldots \ldots$. $10-19$

11-1. Comparison of the estimated maximum ranges for a 156-keV average energy beta particle

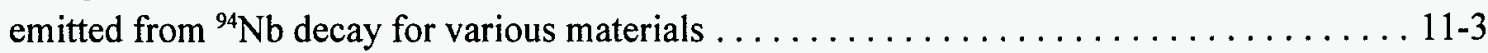

11-2. Half-value layers for the 870-keV gamma ray emitted from the decay of a ${ }^{94} \mathrm{Nb}$ nucleus $\ldots 11-3$

11-3. Comparison of the radiotoxicity of several important radionuclides $\ldots \ldots \ldots \ldots \ldots \ldots \ldots 11-4$

11-4. Average and maximum kinetic energies of beta particles and negative (atomic) electrons

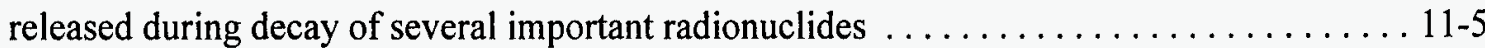

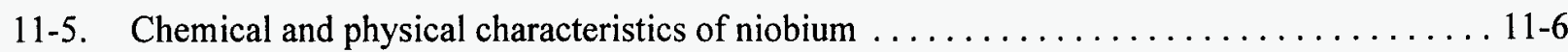

11-6. Annual limits on intake (ALI) and the derived air concentrations (DAC) for ${ }^{94} \mathrm{Nb} \ldots \ldots \ldots 11-20$

12-1. Comparison of the estimated maximum ranges for a 94-keV average energy beta particle emitted

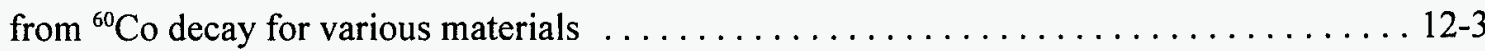

12-2. Half-value layers for the $1,330-\mathrm{keV}$ gamma ray emitted from the decay of a ${ }^{60} \mathrm{Co}$ nucleus $\ldots 12-3$

12-3. Comparison of the radiotoxicity of several important radionuclides . . . . . . . . . . 12-4

12-4. Average and maximum kinetic energies of beta particles and negative (atomic) electrons released

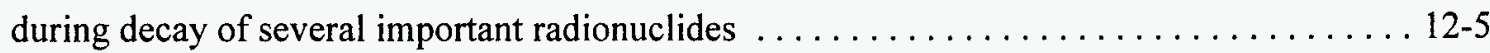

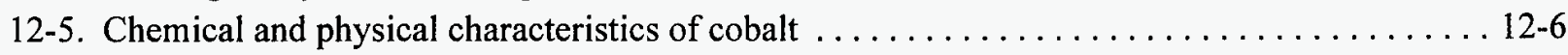

12-6. Annual limits on intake and the derived air concentrations for ${ }^{60} \mathrm{Co} \ldots \ldots \ldots \ldots \ldots \ldots$ 12-23

13-1. Comparison of the estimated maximum ranges for a 39-keV average energy beta particle emitted

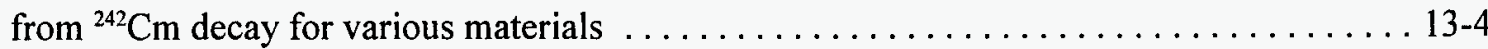

13-2. Half-value layers for the 890-keV gamma ray emitted from the decay of a ${ }^{242} \mathrm{Cm}$ nucleus $\ldots . .13-5$

13-3. Comparison of the radiotoxicity of several important radionuclides $\ldots \ldots \ldots \ldots \ldots \ldots$

13-4. Average and maximum kinetic energies of beta particles and atomic electrons released during

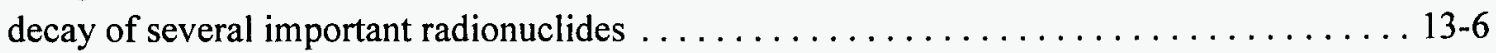

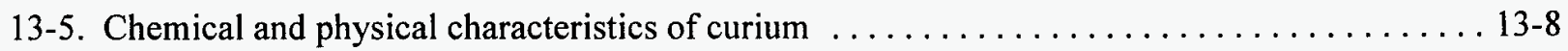

13-6. Annual limits on intake and the derived air concentrations for ${ }^{242} \mathrm{Cm} \ldots \ldots \ldots \ldots \ldots \ldots$ 13-22

14-1. Thickness of lead required to reduce useful beam to $5 \% \ldots \ldots \ldots \ldots \ldots \ldots \ldots \ldots \ldots \ldots$

14-2. Comparison of the radiotoxicity of several important radionuclides. . . . . . . . . . 14-4

14-3. Physical properties of americium and its compounds $\ldots \ldots \ldots \ldots \ldots \ldots \ldots \ldots \ldots \ldots \ldots$

14-4. ${ }^{241} \mathrm{Am}$ in bush beans for 96 hours to three different concentrations of ${ }^{241} \mathrm{Am}$ in solution culturel 4-11 14-5. ${ }^{241} \mathrm{Am}$ in roots, stems, and leaves of plants grown in contaminated soil in a glasshouse . . . 14-12

14-6. Committed dose equivalents per unit uptake via ingestion and inhalation . . . . . . . 14-14

14-7. Annual limits on intake and derived air concentrations for ${ }^{241} \mathrm{Am} \ldots \ldots \ldots \ldots \ldots \ldots \ldots$

15-1. Half-value layers for the $110-\mathrm{keV}$ gamma ray emitted from the decay of a ${ }^{238} \mathrm{U}$ nucleus $\ldots \ldots 15-4$ 15-2. Comparison of the radiotoxicity of several important radionuclides $\ldots \ldots \ldots \ldots \ldots \ldots \ldots$ 
15-3. Average and maximum kinetic energies of electrons released during decay of several important radionuclides ................................................ 15-5

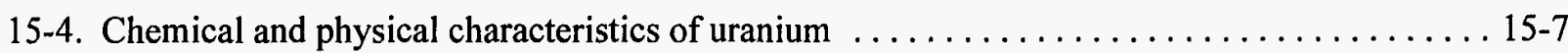

15-5. Annual limits on intake (ALI) and the derived air concentrations (DAC) for ${ }^{238} \mathrm{U} \ldots \ldots \ldots 15-20$

16-1. Comparison of the radiotoxicity of several important radionuclides ................ 16-4

16-2. Average and maximum kinetic energies of electrons released during decay of several important

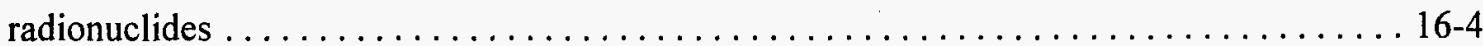

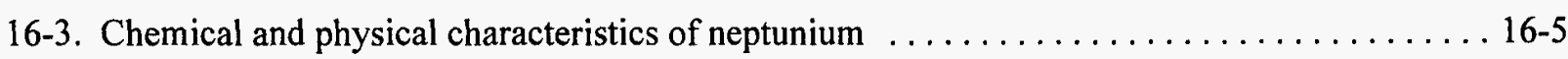

16-4. Annual limits of intake (ALI) and the derived air concentrations (DAC) for ${ }^{237} \mathrm{~Np} \ldots \ldots \ldots$ 16-19 


\section{Selected Radionuclides Important to Low-Level Radioactive Waste Management}

\section{INTRODUCTION}

This document discusses a set of radionuclides that would most likely contribute to the radiation exposures estimated from a performance assessment of a proposed low-level radioactive waste (LLW) disposal facility. This report not only includes essential information on each radionuclide, but also incorporates waste and disposal information on the radionuclides, and behavior of the radionuclide in the environment and in the human body.

The U.S. Nuclear Regulatory Commission (NRC) or an Agreement State grants a license to disposal facilities that comply with performance objectives set forth in Subpart C of 10 CFR 61 or equivalent Agreement State regulations. ${ }^{1}$ Performance assessment analyses are required in the disposal facility licensing process because they predict the extent that radionuclides will be released from an LLW disposal facility and the resulting exposure to individuals. A performance assessment uses computer codes to estimate the effects of radiation exposures on humans resulting from LLW disposal operations. These radiation exposures can result from

- Exposure to direct gamma rays from the wastes

- Use of surface and ground water that has filtrated through the waste

- Degradation of engineered barriers and waste containers

- Atmospheric transport of radionuclides from disposal units.

There are several radionuclides contained in various waste forms that the NRC identified as "key" or "sensitive" regarding performance assessment. ${ }^{2}$ That is, these radionuclides offer the greatest contribution to the exposure estimated during a performance assessment analysis and therefore require site-specific considerations to ensure that performance objectives for long-term environmental protection are met. Sensitive radionuclides identified by the NRC are technetium-99, carbon-14, iodine-129, and tritium. ${ }^{2,3}$ Chapters 2 through 5 of this report address these four radionuclides, and twelve additional chapters discuss other significant radionuclides.

A radionuclide considered sensitive at one LLW disposal facility may not be considered sensitive at another facility. The behavior of a radionuclide at a particular LLW disposal site depends primarily on the radiological, chemical, and physical characteristics of the waste, and the inventory of the radionuclide. The behavior of a radionuclide also depends on the geology, hydrology, and climate at the disposal site. The individual radionuclide chapters indicate characteristics and potential difficulties in dealing with particular radionuclides. However, since radionuclide behavior and appropriate handling, storage, or disposal will vary depending on particular site or waste forms, the chapters do not attempt to 
discuss the extent of the difficulties or appropriate solutions. Each disposal site facility design should consider and address the specific waste content and behavior under that site's particular circumstances.

Other radionuclides present in the inventory of an LLW disposal facility are generally not considered sensitive, but must still be accounted for during performance assessment efforts. Although these radionuclides do not usually contribute significantly to the final estimated exposure (as determined through performance assessment), the inventory of these radionuclides at an LLW disposal site may be so large that their behavior in the disposal environment must be assessed. Examples of radionuclides in this category are cesium-137 $\left({ }^{137} \mathrm{Cs}\right)$, nickel-59 $\left({ }^{59} \mathrm{Ni}\right)$, and nickel-63 $\left({ }^{63} \mathrm{Ni}\right)$.

The NRC considered $36 \mathrm{LLW}$ types for analysis in its draft and final environmental impact statements (EISs) on 10 CFR 61.,45 Each waste type was characterized according to its physical, chemical, and radiological properties and was projected to be routinely generated from 1980 to the year 2000. The NRC also identified what they considered to be the 23 most important radionuclides in these waste types for waste classification purposes. The final EIS lists 12 individual radionuclides plus alphaemitting transuranics with half-lives greater than 5 years. Tables 1-1 and 1-2 (below) list the final set of radionuclides and concentration limits for classifying LLW as determined by 10 CFR Part 61.55 (Subpart D). The concentration limits define the waste as Class A, B, C, or greater-than-Class-C (GTCC), with Class $\mathrm{A}$ having the lowest radionuclide concentration and presenting the least hazard to humans, and GTCC having the highest concentration and highest hazard to humans. Thus, these concentration limits determine handling, storage, and disposal requirements for an LLW disposal site.

When the NRC was developing concentration limits for waste classification of radionuclides listed in 10 CFR 61.55, they considered two groups of nuclides. First, they considered long-lived radionuclides that may present a potential health hazard to an individual who inadvertently contacts the waste (inadvertent intruder) after controls such as the 100-year institutional control period are no longer in effect. These radionuclides are listed in Table 1-1. The magnitude of hazard from these long-lived radionuclides is limited by the concentration at the time of disposal.

Second, the NRC considered relatively short-lived radionuclides whose hazard will be negligible after institutional controls and improved waste forms are no longer effective. Table 1-2 lists these radionuclides. However, these radionuclides may exhibit characteristics that pose a threat to disposal site workers during operations and to the public after site closure. Examples of these radionuclides include cobalt-60 (direct gamma ray exposure) and tritium (extremely mobile in the environment).

The radionuclides listed in Tables 1-1 and 1-2 are examined in this report, with Am-241 and neptunium-237 falling under the Table 1 category of "alpha-emitting transuranics with half-lives longer than 5 years." The rationale behind choosing this set of radionuclides is twofold:

- The NRC has determined that the radionuclides listed in Tables 1 and 2 of 10 CFR 61.55 are a potential health hazard during the operation of an LLW disposal facility and after its closure. This was based on factors such as a radionuclide's half-life, mobility, volatility, maximum energy, radiation type (i.e., alpha, beta, gamma, or neutron), etc.

- These radionuclides contribute most of the radioactivity found at an LLW disposal facility. 
Table 1-1. LLW classification table-long-lived radionuclides.

\begin{tabular}{|c|c|c|}
\hline \multirow[b]{2}{*}{ Radionuclides } & \multicolumn{2}{|c|}{$\begin{array}{l}\text { Concentration limits } \\
\left(\mu \mathrm{Ci} / \mathrm{cm}^{3}\right)\end{array}$} \\
\hline & Class A & Class C \\
\hline Carbon- $14\left({ }^{14} \mathrm{C}\right)$ & 0.8 & 8 \\
\hline${ }^{14} \mathrm{C}$ in activated metal & 8 & 80 \\
\hline Nickel-59 $\left({ }^{59} \mathrm{Ni}\right)$ in activated metal & 22 & 220 \\
\hline Niobium-94 $\left({ }^{94} \mathrm{Ni}\right)$ in activated metal & 0.02 & 0.2 \\
\hline Technetium-99 $\left({ }^{99} \mathrm{Tc}\right)$ & 0.3 & 3 \\
\hline \multirow[t]{2}{*}{ Iodine- $129\left({ }^{129} \mathrm{I}\right)$} & 0.008 & 0.08 \\
\hline & \multicolumn{2}{|c|}{$\begin{array}{c}\text { Concentration limits } \\
(\mathrm{nCi} / \mathrm{g})\end{array}$} \\
\hline Alpha-emitting transuranics with half-life longer than 5 years & 10 & 100 \\
\hline Plutonium-241 $\left({ }^{241} \mathrm{Pu}\right)$ & 350 & 3,500 \\
\hline Curium-242 $\left({ }^{242} \mathrm{Cm}\right)$ & 2,000 & 20,000 \\
\hline
\end{tabular}

Table 1-2. LLW classification table-short-lived radionuclides.

\begin{tabular}{|c|c|c|c|}
\hline \multirow[b]{2}{*}{ Radionuclides } & \multicolumn{3}{|c|}{$\begin{array}{c}\text { Concentration limits } \\
\left(\mu \mathrm{Ci} / \mathrm{cm}^{3}\right)\end{array}$} \\
\hline & Class A & Class B & Class C \\
\hline Total of all radionuclides with half-life shorter than 5 years & 700 & $一^{\mathrm{a}}$ & $一^{a}$ \\
\hline Tritium $\left({ }^{3} \mathrm{H}\right)$ & 40 & $-^{\mathrm{a}}$ & $一^{\mathrm{a}}$ \\
\hline Cobalt-60 $\left({ }^{60} \mathrm{Co}\right)$ & 700 & $-^{a}$ & $-^{\mathrm{a}}$ \\
\hline Nickel-63 $\left({ }^{63} \mathrm{Ni}\right)$ & 3.5 & 70 & 700 \\
\hline${ }^{63} \mathrm{Ni}$ in activated metal & 35 & 700 & 7,000 \\
\hline Strontium-90 $\left({ }^{90} \mathrm{Sr}\right)$ & 0.04 & 150 & 7,000 \\
\hline Cesium-137 $\left({ }^{137} \mathrm{Cs}\right)$ & 1 & 44 & 4,600 \\
\hline \multicolumn{4}{|c|}{$\begin{array}{l}\text { a. No Class B and Class C limits exist for these radionuclides. Other practical considerations will limit these } \\
\text { radionuclides, such as external radiation dose for transportation or internal heat generation. The concentrations } \\
\text { of these radionuclides will be Class B unless other radionuclides determine independently that the classification } \\
\text { is higher. }\end{array}$} \\
\hline
\end{tabular}


This report addresses the nuclides in Tables 1-1 and 1-2 as well as additional nuclides that may be significant during a radiological performance assessment of an LLW disposal facility. Radionuclides addressed in this report include technetium-99, carbon-14, iodine-129, tritium, cesium-137, strontium90, nickel-59, plutonium-241, nickel-63, niobium-94, cobalt-60, curium-242, americium-241, uranium238, and neptunium-237. Each radionuclide will be addressed in its own chapter, which contains the following sections:

- Radiological characteristics

- Chemical and physical characteristics

- $\quad$ Production of radionuclide

- Waste and disposal data on radionuclide

- Behavior of radionuclide in the environment

- Behavior of radionuclide in the human body and in animals

- Summary.

Upon request, additional radionuclides may be evaluated and included in a future revision of this report, 


\section{References}

1. Code of Federal Regulations, 10 CFR 61, "Licensing Requirements for Land Disposal of Radioactive Wastes," Office of the Federal Register, January 1, 1989.

2. Rogers and Associates Engineering Corporation, Conceptual Design Report, Alternative Concepts for Low-Level Radioactive Waste Disposal, DOE/LLW-60T, June 1987.

3. U.S. Environmental Protection Agency, Office of Radiation Programs, Low-Level and NARM Radioactive Wastes, Draft Environmental Impact Statement for Proposed Rulemaking, Volume 1, EPA-520/1-87-012-1, June 1988.

4. U.S. Nuclear Regulatory Commission, Office of Nuclear Material Safety and Safeguards, Draft Environmental Impact Statement on 10 CFR Part 61, "Licensing Requirements for Land Disposal of Radioactive Waste," Summary, Volume 1, NUREG-0782, September 1981.

5. U.S. Nuclear Regulatory Commission, Office of Nuclear Material Safety and Safeguards, Final Environmental Impact Statement on 10 CFR Part 61, "Licensing Requirements for Land Disposal of Radioactive Waste, "Summary and Main Report, Volume 1, NUREG-0945, November 1982. 


\section{TECHNETIUM-99}

\section{Introduction}

This chapter discusses the basic radiological, chemical, and physical characteristics of technetium$99\left({ }^{99} \mathrm{Tc}\right)$ and examines how these characteristics affect the behavior of ${ }^{99} \mathrm{Tc}$ in various environmental media, such as soils, water, plants, the atmosphere, and the human body. Also included are methods of ${ }^{99} \mathrm{Tc}$ production and waste and disposal data on ${ }^{99} \mathrm{Tc}$.

${ }^{99} \mathrm{Tc}$ is a long-lived radionuclide present in low-level radioactive waste (LLW) generated at nuclear power plants, medical laboratories, and academic institutions. Disposing of ${ }^{99} \mathrm{Tc}$-contaminated waste at LLW disposal facilities is a concern because ${ }^{99} \mathrm{Tc}$ can be highly mobile in groundwater. The U.S.

Nuclear Regulatory Commission (NRC), in its draft EIS on 10 CFR 61, Licensing Requirements for Land Disposal of Radioactive Waste, ${ }^{1}$ identified ${ }^{99} \mathrm{Tc}$ as one of four radionuclides (along with tritium, carbon14 , and iodine-129) that will require site-specific considerations to ensure that performance objectives for long-term environmental protection are met.

A radionuclide considered sensitive at one LLW disposal facility may not be considered sensitive at another facility. The behavior of a radionuclide at a particular LLW waste disposal site will depend primarily upon the radiological, chemical, and physical characteristics of the waste, and the inventory of the radionuclide. The behavior of a radionuclide also depends upon the geology, hydrology, and climate at the disposal site. This chapter reports characteristics and potential difficulties in dealing with ${ }^{99} \mathrm{Tc}$. However, since ${ }^{99} \mathrm{Tc}$ behavior and appropriate handling, storage, or disposal will vary depending on particular sites or waste form, this chapter does not attempt to discuss the extent of a difficulty or appropriate solutions. Each disposal site facility design should consider and address the specific waste content and behavior under that site's particular circumstances.

\section{Radiological Characteristics}

${ }^{99} \mathrm{Tc}$ is a long-lived radionuclide with a half-life of 213,000 years. When it undergoes radioactive decay, its nucleus emits a single beta particle $\left(\beta^{-}\right)$that ranges in energy from zero to a maximum of 0.293 million electron volts $(\mathrm{MeV})$. The decay of ${ }^{99} \mathrm{Tc}$ forms stable ruthenium-99 $\left({ }^{99} \mathrm{Ru}\right)$ :

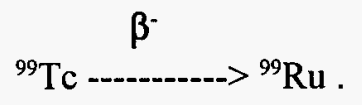

\section{$2.1 \times 10^{5} \mathrm{y}$}

The parent of ${ }^{99} \mathrm{Tc}$ is technetium-99m $\left({ }^{99 \mathrm{~m}} \mathrm{Tc}\right)$. The ${ }^{99 \mathrm{~m}} \mathrm{Tc}$ nucleus is at a higher energy state than the ${ }^{99} \mathrm{Tc}$ nucleus. The highly unstable ${ }^{99 \mathrm{~m}} \mathrm{Tc}$ nucleus releases some of this excess energy by emitting a $0.140 \mathrm{MeV}$ gamma ray $(\gamma)$ to form the more stable, but still radioactive, ${ }^{99} \mathrm{Tc}$ :

$$
{ }^{99 \mathrm{~m}} \mathrm{Tc} \stackrel{\gamma}{6.0 \mathrm{~h}}
$$


Technetium-99m is formed when molybdenum- $99\left({ }^{99} \mathrm{Mo}\right)$, produced during the fission of uranium isotopes in nuclear reactors, undergoes beta particle decay. Therefore, ${ }^{99} \mathrm{Tc}$ is also a direct descendant of ${ }^{99} \mathrm{Mo:}$

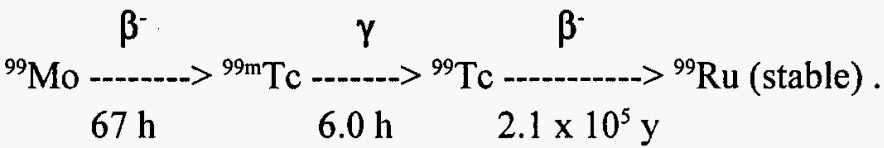

Twenty-two isotopes and nine isomers of technetium exist, with mass numbers ranging from 90 to $111 .^{2}$ There are no stable isotopes of technetium. The isomer associated with ${ }^{99} \mathrm{Tc}$ is ${ }^{99 \mathrm{~m}} \mathrm{Tc}$.

The $0.293 \mathrm{MeV}$ beta particle emitted by the ${ }^{99} \mathrm{Tc}$ nucleus is fairly energetic. Table 2-1 compares the energy of the ${ }^{99} \mathrm{Tc}$ beta particle to the emissions of other beta emitters.

\section{Chemical and Physical Characteristics}

Technetium, with the atomic number of 43, was the first element to be produced artificially (1939). It is prepared by the reduction of ammonium pertechnetate with hydrogen. Technetium is a silvery-gray metal of high density and is a remarkable corrosion inhibitor for steel. Technetium has a melting point of $2,445.2 \mathrm{~K}$ and a boiling point of $4,840 \mathrm{~K}$. As stated, twenty-two isotopes and nine isomers of technetium exist, with mass numbers ranging from 90 to 111 . There are no stable isotopes of technetium. The isomer associated with ${ }^{99} \mathrm{Tc}$ is ${ }^{99 \mathrm{~m}} \mathrm{Tc}$. ${ }^{99 \mathrm{~m}} \mathrm{Tc}$ is the most widely used radioactive isotope for diagnostic studies in nuclear medicine.

Oxidation-reduction reactions dominate the chemistry of ${ }^{99} \mathrm{Tc}$. Its electron structure makes it possible for technetium to exist in eight oxidation states ranging in charges from +7 to -1 . The two most common oxidation states are +7 (pertechnetate ion, $\mathrm{TcO}_{4}^{-}$) and +4 (technetium dioxide, $\mathrm{TcO}_{2}$ ). The pertechnetate ion is the dominant chemical form of technetium in the environment. The chemistry of these two oxidation states is discussed below.

Table 2-1. Comparison between ${ }^{99} \mathrm{Tc}$ and other beta emitters.

\begin{tabular}{ll}
\hline Radionuclide & Maximum Energy $(\mathrm{MeV})$ \\
\hline Tritium $\left({ }^{3} \mathrm{H}\right)$ & 0.019 \\
Iodine-129 $\left({ }^{129} \mathrm{I}\right)$ & 0.150 \\
Carbon-14 $\left({ }^{14} \mathrm{C}\right)$ & 0.156 \\
Technetium-99 $\left({ }^{99} \mathrm{Tc}\right)$ & 0.293 \\
Chlorine-36 $\left({ }^{36} \mathrm{Cl}\right)$ & 0.709 \\
Iodine-131 $\left({ }^{131} \mathrm{I}\right)$ & 0.806 \\
Potassium-40 $\left({ }^{40} \mathrm{~K}\right)$ & 1.330 \\
Phosphorous-32 $\left({ }^{32} \mathrm{P}\right)$ & 1.710 \\
\hline
\end{tabular}




\section{Pertechnetate lon}

The pertechnetate ion $\left(\mathrm{TcO}_{4}^{-}\right)$is the most oxidized form of technetium (+7). It is a colorless material that is extremely soluble in water and is stable over a wide range of $\mathrm{pH}$ redox potential values. The redox potential is a measure of the likelihood of a chemical species undergoing a reduction or oxidation reaction. As the redox potential decreases, technetium dioxide $\left(\mathrm{TcO}_{2}\right)$ becomes the predominant stable species. ${ }^{3}$

The pertechnetate ion may combine with cations to form stable alkali salts that are also very soluble in water. However, pertechnetate does not form complexes with chelating agents, nor does it coprecipitate with particles unless it is first reduced to a less stable form of technetium such as technetium heptoxide $\left(\mathrm{Tc}_{2} \mathrm{O}_{7}\right)$ or technetium dioxide.

The reduction of pertechnetate to technetium heptoxide, and ultimately to the insoluble technetium dioxide species, is not easily achieved and often requires strong reduction conditions before it can proceed. Several agents capable of reducing pertechnetate include tin $\left(\mathrm{Sn}^{2+}\right)$, ferrous iron $\left(\mathrm{Fe}^{2+}\right)$, concentrated hydrochloric acid $(\mathrm{HCl})$, and hydrogen sulfide $\left(\mathrm{H}_{2} \mathrm{~S}\right)$. The reduction of the soluble pertechnetate ion to the inscluble technetium dioxide becomes quite important during attempts to immobilize technetium in the environment.

\section{Technetium Dioxide}

Technetium, in the oxidation state of +4 , exists as technetium dioxide at $\mathrm{pH}<3$. Technetium dioxide is fairly stable and can exist in both the unhydrated $\left(\mathrm{TcO}_{2}\right)$ and hydrated $\left(\mathrm{TcO}_{2} \mathrm{H}_{2} \mathrm{O}\right)$ state. Both species are highly insoluble in water.

The reoxidation of technetium heptoxide and technetium dioxide to pertechnetate is also difficult and requires oxidizing agents such as nitric acid, permanganate, chlorine, or air. The oxidation rate of technetium dioxide in air is very slow. Because of the difficulty of oxidizing and reducing technetium, it is not uncommon to observe the presence of the pertechnetate ion in $\mathrm{pH}$ and redox conditions that predict the presence of technetium dioxide.

\section{Technetium-99 Production}

Uranium and plutonium undergoing thermal fission in nuclear reactors produce most of the ${ }^{99} \mathrm{Tc}$ found at commercially operated LLW disposal facilities. The cumulative fission yield of radionuclides with an atomic mass of 99 is about $6 \% .{ }^{99} \mathrm{Tc}$ has the longest half-life of any other isotope of mass 99 ; therefore, it is a relatively abundant species in the nuclear fuel cycle. ${ }^{99} \mathrm{Tc}$ is also an activation product that is found in nearly every inconel and 300-series stainless steel that has been irradiated in a reactor.

The following mechanisms contribute to the production of ${ }^{99} \mathrm{Tc}$ :

1. Technetium-99m $\left({ }^{99 \mathrm{~m}} \mathrm{Tc}\right)$ is commonly produced by neutron bombardment of molybdenum-99 $\left({ }^{99} \mathrm{Mo}\right)$. This reaction produces ${ }^{99} \mathrm{Mo}$, which decays to ${ }^{99 \mathrm{~m}} \mathrm{Tc}$. With a half-life of 6 hours, ${ }^{99 \mathrm{~m}} \mathrm{Tc}$ will decay to ${ }^{99} \mathrm{Tc}$. 
2. ${ }^{99} \mathrm{Tc}$ is produced from the decay of a primary fission product, zirconium $-99\left({ }^{99} \mathrm{Zr}\right)$, by the following reaction:

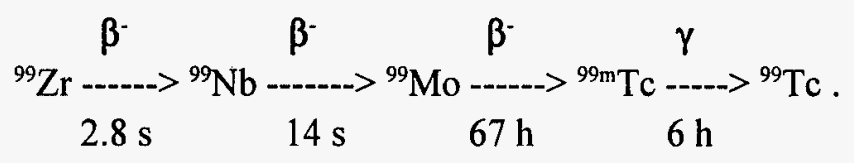

Figure 2-1 shows that ${ }^{99} \mathrm{Zr}$ has a fairly high fission yield of approximately $6 \%$ due to the thermal fission of both uranium-233 ${ }^{233} \mathrm{U}$ ) (also applicable to ${ }^{235} \mathrm{U}$ ) and plutonium-239 $\left({ }^{239} \mathrm{Pu}\right){ }^{4}$ Since ${ }^{99} \mathrm{Tc}$ has a cumulative fission yield of approximately $6 \%$, this suggests that the majority of ${ }^{99} \mathrm{Tc}$ produced in a reactor is a result of ${ }^{99} \mathrm{Zr}$ decay.

3. The neutron activation of a primary fission product of ${ }^{233} \mathrm{U}$, stable molybdenum-98 $\left({ }^{98} \mathrm{Mo}\right)$, produces small quantities of ${ }^{99} \mathrm{Tc}$.

It can be expressed by the equation

$$
\lambda N=\phi \sigma n\left(1-e^{-\lambda t}\right)
$$

where:

$$
\begin{aligned}
& \lambda N=\text { activity of transformed radioactive element } \\
& \phi=\text { neutron flux bombarding stable element, neutrons per } \mathrm{cm}^{2} \text { per sec } \\
& \sigma=\text { activation cross section of stable element, } \mathrm{cm}^{2} \\
& \left(1-\mathrm{e}^{-\lambda t}\right)=\text { decay of newly formed radionuclide } \\
& \mathrm{n}=\text { number of neutrons. }
\end{aligned}
$$

There is a certain probability that the nucleus of a stable element exposed to a neutron flux will capture a neutron. The probability is expressed as the effective "area" or cross section of the nucleus. The unit for activation cross section is the barn. One barn is equal to $10^{-24} \mathrm{~cm}^{2}$.

The nucleus of the stable ${ }^{98} \mathrm{Mo}$ atom captures a neutron $\left({ }_{0}^{1} n\right)$ and a highly unstable compound nucleus forms. The ${ }^{98} \mathrm{Mo}$ compound nucleus $\left(\left[{ }^{98} \mathrm{Mo}\right]\right)$ instantaneously releases some of its excess energy by emitting a gamma ray $(\gamma)$ to form ${ }^{99} \mathrm{Mo}$. This reaction is often referred to as a radiative capture, or $(\mathrm{n}, \gamma)$ reaction, and can be expressed as

${ }^{98} \mathrm{Mo}(\mathrm{n}, \gamma){ }^{99} \mathrm{Mo}$.

Eventually ${ }^{99} \mathrm{Tc}$ is formed:

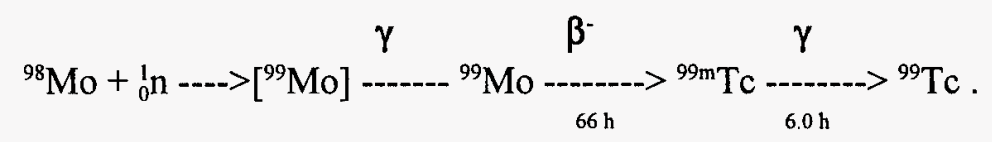




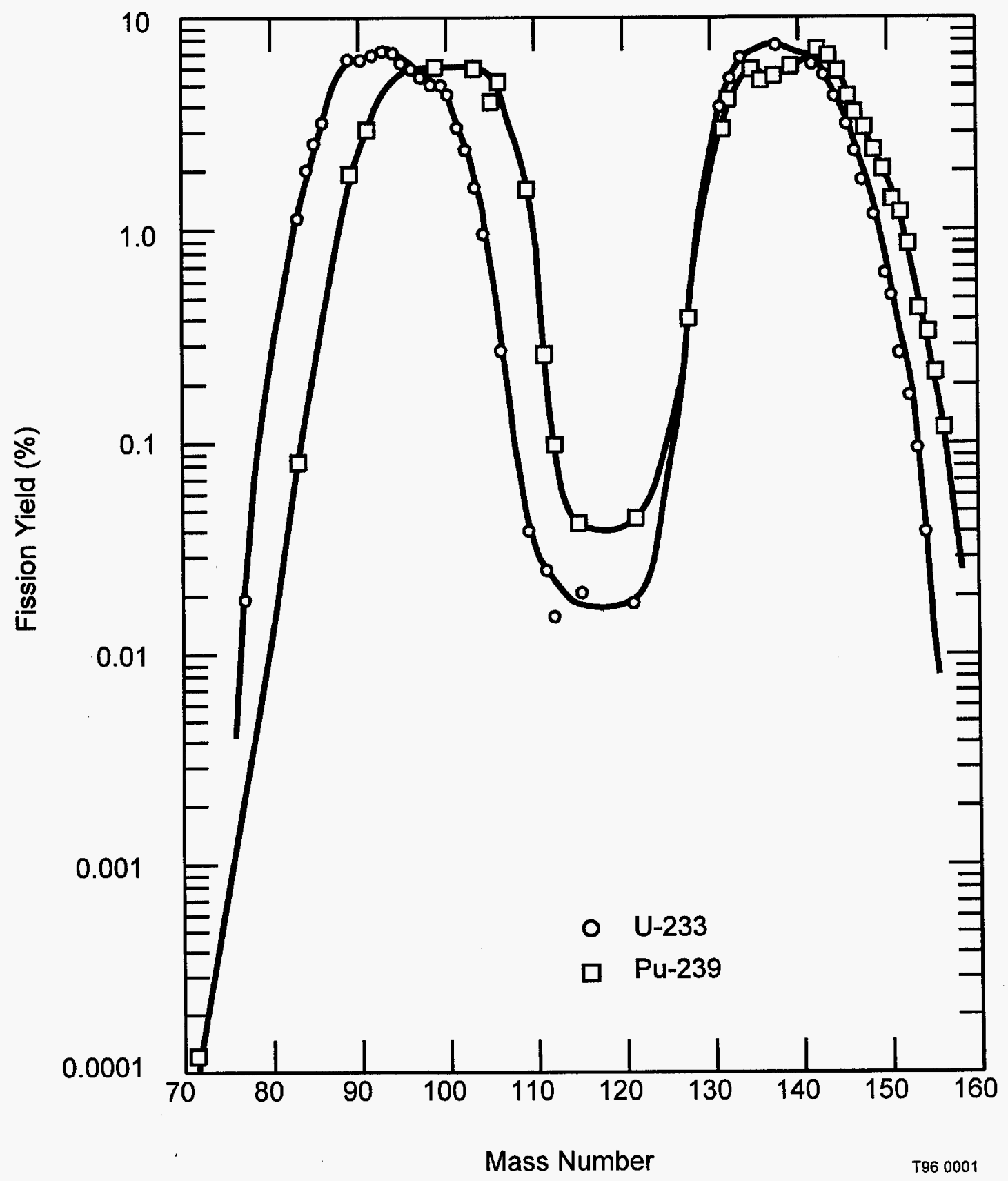

Figure 2-1. Fission-product distributions from thermal-neutron fission of ${ }^{233} \mathrm{U}$ and ${ }^{239} \mathrm{Pu}$. 


\section{Waste and Disposal Data on Technetium-99}

This section discusses the types of activities that generate ${ }^{99} \mathrm{Tc} L L W$, waste types and forms that contain ${ }^{99} \mathrm{Tc}$, and disposal data on ${ }^{99} \mathrm{Tc}$.

\section{Nuclear Reactors}

Since ${ }^{99} \mathrm{Tc}$ is a fission product and is continuously produced in a reactor core, it may be found in a variety of nuclear power plant wastes. The predominant chemical form of ${ }^{99} \mathrm{Tc}$ found in reactor wastes is the pertechnetate ion $\left({ }^{99} \mathrm{TcO}_{4}^{-}\right)$. The following waste types are common to light-water nuclear reactors (boiling-water and pressurized-water reactors) and would most likely contain the pertechnetate ion.

Ion-Exchange Resins. Used in light-water reactors, ion-exchange resins remove dissolved ions, including radioactive ions, from liquids. Since the chemical form of ${ }^{99} \mathrm{Tc}$ generated at reactors is predominantly the pertechnetate anion, anion exchange resins would remove any free pertechnetate.

Ion-exchange resins are usually packed into cylindrical columns and the liquid containing the unwanted ions passes through the column. The pertechnetate ion chemically displaces ions on the anion resin and becomes chemically or physically bound to the resin. When the sites that can bind the ions to the resin are expended, the resin is transferred to a shipping container (liner), and excess water is removed.

Concentrated Liquids. Evaporation of a variety of liquid wastes at a reactor produces concentrated liquids or evaporator bottoms. They have up to a $25 \%$ suspended and dissolved solids content. Liquid wastes that may be evaporated at a reactor include liquids from decontamination work, floor drains, and laboratory drains.

Filter Sludge. This waste type consists of both the filter material (precoat filter) and the thin layer of dissolved and suspended radioactive solids retained by the filter. Typical filter material may include high-purity cellulose or a mixture of powdered anion and cation exchange resins to improve the ability of the filter to trap contaminants. The pertechnetate ion can be trapped by these filters and become incorporated in the filter sludge.

Cartridge Filters. Cartridge filters trap suspended solids carried in various reactor liquids; however, they do not have the superior ion-exchange capacity found in precoat filters. The filters are constructed of woven cotton and nylon or matted paper supported by a stainless steel brace. Many nuclear plants use cartridge filters in combination with precoat filters, evaporators, and ion-exchange columns to remove suspended solids and dissolved radioactive ions from liquids used in the operation of a reactor.

Trash. The trash and dry active waste (DAW) generated during light-water reactor operations are diverse in content and can contain everything from paper towels and latex gloves to reactor hardware. Trash and DAW are classified as compactible or noncompactible. In general, compactible DAW consists mainly of combustible material like paper products; noncompactible DAW contains metallic components such as pipes and failed equipment. 
Decommissioning Waste. Decommissioning will produce large volumes of LLW in the form of contaminated concrete and metal vessels and piping. This waste will contain the same radionuclides found in noncompactible dry active waste generated during plant operations. Therefore, the ${ }^{99} \mathrm{Tc}$ species will also be contained in these wastes.

\section{Technetium-99 Inventory in Nuclear Fuel Cycle Wastes}

It is difficult to accurately determine the inventory (expressed in curies) of ${ }^{99} \mathrm{Tc}$ in nuclear fuel cycle wastes for two reasons. First, ${ }^{99} \mathrm{Tc}$ is not as abundant as other fission products common to these wastes. Second, ${ }^{99} \mathrm{Tc}$ emits a beta particle with a maximum energy of only $0.293 \mathrm{MeV}$, and the radiations of ${ }^{99} \mathrm{Tc}$ are masked by more energetic emissions from other radionuclides. Consequently, a precise inventory of ${ }^{99} \mathrm{Tc}$ in nuclear reactor waste types can usually be attained only by analyzing individual waste samples. This approach is impractical from an economic, manpower, and radiation control (as low as reasonably achievable) standpoint. Therefore, estimates of ${ }^{99} \mathrm{Tc}$ inventory are used for completing manifest shipping forms.

Since the inventory of ${ }^{99} \mathrm{Tc}$ in nuclear reactor waste is relatively small compared to other fission products, power plant personnel have often used the lower limit of detection (LLD) of ${ }^{99} \mathrm{Tc}$ as a conservative estimate of its inventory. The LLD of a radionuclide is dependent upon several factors, including the energy of the radionuclide's emissions and the efficiency of the counting system.

Scaling factors have been used to estimate the inventory of radionuclides like ${ }^{99} \mathrm{Tc}$ since $1982 .{ }^{5} \mathrm{The}$ scaling factor methodology involves determining an inventory ratio of easy-to-detect fission products, such as cesium-137 $\left({ }^{137} \mathrm{Cs}\right)$, to difficult-to-detect species such as ${ }^{99} \mathrm{Tc}$. Once the ratio or scaling factor is established for a pair of radionuclides, it can be used in the future to determine the activity of the difficult-to-detect radionuclides.

The development of scaling factors indicated that using LLDs grossly overestimated the inventory of fission products like technetium-99 in waste. Therefore, the ${ }^{99} \mathrm{Tc}$ waste inventory values used in preliminary performance assessments of LLW facilities resulted in projecting greater final doses to the public than should be realistically expected from ${ }^{99} \mathrm{Tc}$. The Electric Power Research Institute (EPRI) is validating a computer code developed by Vance and Associates, Inc. that predicts how much ${ }^{99} \mathrm{Tc}$ is generated during fission processes and how much is distributed to each waste type. Analyses and measurements made by Vance and Associates indicate that the actual amounts of these isotopes in LLW are smaller than the amounts based on the LLD by several orders of magnitude. EPRI is performing ${ }^{99} \mathrm{Tc}$ measurements on ion-exchange columns placed on reactor coolant sample lines. The measurement data will be compared against Vance and Associates' model prediction values (see Reference 5).

Several nuclear power plant waste types that may contain ${ }^{99} \mathrm{Tc}$ are usually mixed with concrete to create a solid waste form. All liquid wastes including evaporator bottoms must be solidified before disposal. It is not necessary to solidify dry filters, though some plants do so to reduce radiation exposure. The practice of solidifying dewatered ion-exchange resins is not widespread in the United States. However, the development of more stringent disposal requirements at new LLW disposal facilities may make it more common. 
The large volume of trash generated at nuclear utilities may be reduced by compaction or incineration. Compaction changes only the density of the waste, not its chemical properties. Incineration produces contaminated ash, which is often solidified with cement.

\section{Medical and Academic Institutions}

Molybdenum/Technetium Generators. Molybdenum/technetium generators commonly found at medical laboratories and academic institutions generate additional ${ }^{99} \mathrm{Tc}$ waste. Nuclear reactors produce the molybdenum used in the generator. Types of LLW resulting from the use of molybdenum/technetium generators include ${ }^{99} \mathrm{Tc}$-contaminated generators, liquids, and trash. The amount of ${ }^{99} \mathrm{Tc}$ generated from these practices is small compared to that generated from nuclear power operations.

Biological Waste. Biological waste from universities and medical institutions may also contain trace amounts of ${ }^{99} \mathrm{Tc}$. These wastes consist of animal carcasses and tissues, vegetation, and culture media. Normally, when ${ }^{99} \mathrm{Tc}$ is used for experiments and diagnostic studies at medical and academic institutions, it is known exactly how much ${ }^{99} \mathrm{Tc}$ was used and in what form it was used. Therefore, investigators can estimate the curie content of ${ }^{99} \mathrm{Tc}$ in their volume of LLW quite accurately. The activity of ${ }^{99} \mathrm{Tc}$ in these wastes is in the microcurie or millicurie range.

Liquid wastes and molybdenum/technetium producers containing ${ }^{99} \mathrm{Tc}$ are normally placed in absorbing media such as vermiculite, silica, and clays in preparation for disposal. These absorbing materials may eventually be combined with solidification media. Biological wastes are often incinerated to prevent their decomposition at the disposal facility.

\section{Leaching from Waste Forms}

Radionuclide release from waste forms is accelerated if the waste form comes into contact with water. Leaching occurs when water removes radionuclides from a waste form. The magnitude of leaching can be determined by a leach test. A leach test involves exposing a waste form containing radionuclides to a solution (leachate) for extended periods of time and measuring the amount of radioactive material that releases or "leaches" into the leachate solution.

The mechanism of ${ }^{99} \mathrm{Tc}$ leaching from unsolidified waste forms is thought to be a simple rinsing of the highly soluble pertechnetate ion from the waste. However, the leaching behavior of the pertechnetate ion in solidified cement waste forms appears to be quite different. In a study performed by Brodda, ${ }^{6}$ liquid waste from nuclear reactors containing cesium-137 $\left({ }^{137} \mathrm{Cs}\right)$, strontium- $90\left({ }^{90} \mathrm{Sr}\right)$, chlorine- $36\left({ }^{36} \mathrm{Cl}\right)$, and ${ }^{99} \mathrm{Tc}$ were solidified in Portland concrete and were leached for 250 days. Results indicated that ${ }^{99} \mathrm{Tc}$ on the surface of the cement waste form is easily removed by the leachate. However, the ${ }^{99} \mathrm{Tc}$ located within the concrete matrix is effectively fixed. The chemical form of the fixed technetium- 99 was not yet known and its mechanism for fixation in the cement matrix is subject to further investigation.

There is a parameter that quantifies the sorption of a radionuclide on a waste form, called the waste form distribution coefficient or $K_{d}$. A waste form $K_{d}$ is usually expressed in $\mathrm{mL} / \mathrm{mg}$ and can be defined as follows: 


$$
K_{d}=\frac{\text { Concentration of radionuclide in waste form }(\mathrm{mg} / \mathrm{mg})}{\text { Concentration of radionuclide in solution }(\mathrm{mg} / \mathrm{mL})}
$$

The Environmental Protection Agency's (EPA) draft EIS for proposed rules for low-level and naturally occurring and accelerator-produced radioactive materials (NARM) radioactive wastes, Volume $1,{ }^{7}$ lists waste form $K_{d}$ values for ${ }^{99} \mathrm{Tc}$ in a variety of waste forms at three types of LLW environmental settings: a humid site that has permeable soil, an arid site that has permeable soil, and a humid site that has impermeable soil.

It is inappropriate to apply one waste form $\mathrm{K}_{\mathrm{d}}$ value for ${ }^{99} \mathrm{Tc}$ to all waste forms disposed of at a LLW facility that may contain the ${ }^{99} \mathrm{Tc}$ species. The spectrum of waste types and waste forms is too diverse. ${ }^{99} \mathrm{Tc}$ does not behave the same in all waste forms because of its chemical characteristics.

\section{Disposal Data on Technetium-99}

Technetium-99 has been deposited in three LLW sites in Richland, Washington; Barnwell, South Carolina; and Beatty, Nevada over a period of several years. Data for this nuclide have been obtained from the Manifest Information Management System Database. ${ }^{1}$ Figure 2-2 shows the total annual ${ }^{99} \mathrm{Tc}$

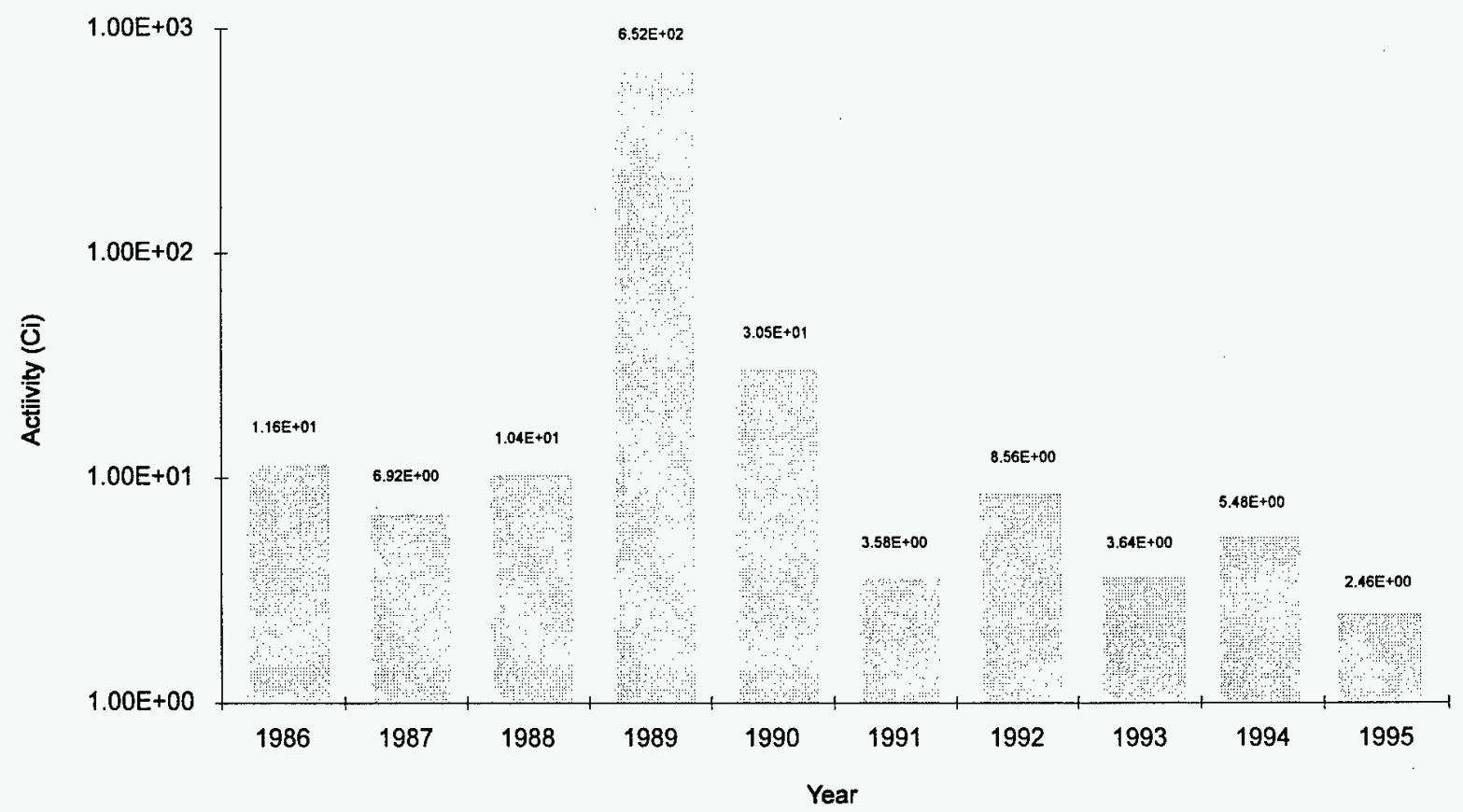

Figure 2-2. ${ }^{99} \mathrm{Tc}$ activity deposited at Richland, Beatty, and Barnwell sites by year (log scale).

a. Information provided through the DOE waste management system maintained by the National Low-Level Waste Management Program, Idaho National Engineering Laboratory (INEL). 
activity deposited in the three sites for each year between 1986 and 1995. The database confirms that nearly $90 \%$ of this nuclide's total activity, deposited in disposal facilities, came from commercial power reactors (utilities). More than $95 \%$ of the total activity was deposited in 1986, 1987, 1989, and 1990. Only a small fraction of the total activity was deposited in the other six years. The difference between the ${ }^{99} \mathrm{Tc}$ activity deposited in disposal facilities in 1989 and the activity deposited in other years may be due to several reasons, including cyclic maintenance of nuclear power reactors, cleanup and decommissioning activities, or a change in the use of scaling factors in estimating ${ }^{99} \mathrm{Tc}$ activity.

Figure 2-3 shows the activity of ${ }^{99} \mathrm{Tc}$ deposited in these three sites as a function of waste source. The overwhelming majority of the activity was generated by utilities, $720 \mathrm{Ci}$ or $98 \%$ of the total. An additional $1.5 \%$ was generated by industrial sources and only minor activities were generated by the other sources. The definition of disposal categories given in Figure 2-3 is as follows: academic sources associated with university laboratories; government - sources associated with the government, such as military hospitals; industry - sources associated with manufacturing, other than utilities; medical - sources associated with hospitals and medical laboratories, excluding pharmaceutical manufacturing; utility - sources generated by nuclear utilities and stored onsite or at a disposal facility. Waste treatment facilities are included in the utility category.

Figure 2-4 shows the activity of ${ }^{99} \mathrm{Tc}$ deposited in the Richland and Beatty sites as a function of waste type. The waste disposal manifests for the Barnwell site did not break down the waste by type, which is unfortunate since most of this nuclide ( $84 \%)$ is stored at this site. As shown in this figure, the distribution for this nuclide is relatively uniform across the various waste types. The waste types illustrated in Figure 2-4 are from nuclear reactors, academic institutions, and medical facilities.

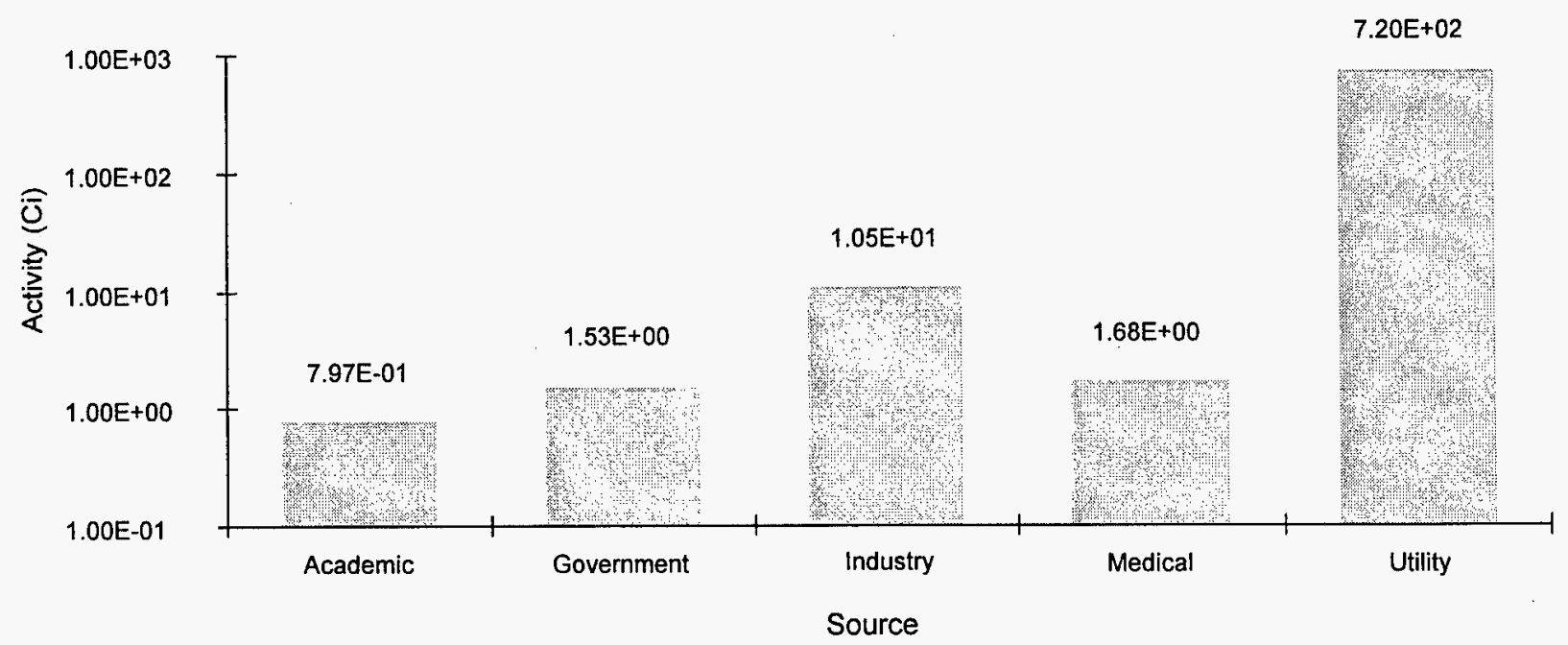

Figure 2-3. ${ }^{99} \mathrm{Tc}$ activity deposited at Richland, Beatty, and Barnwell sites by source (log scale). 


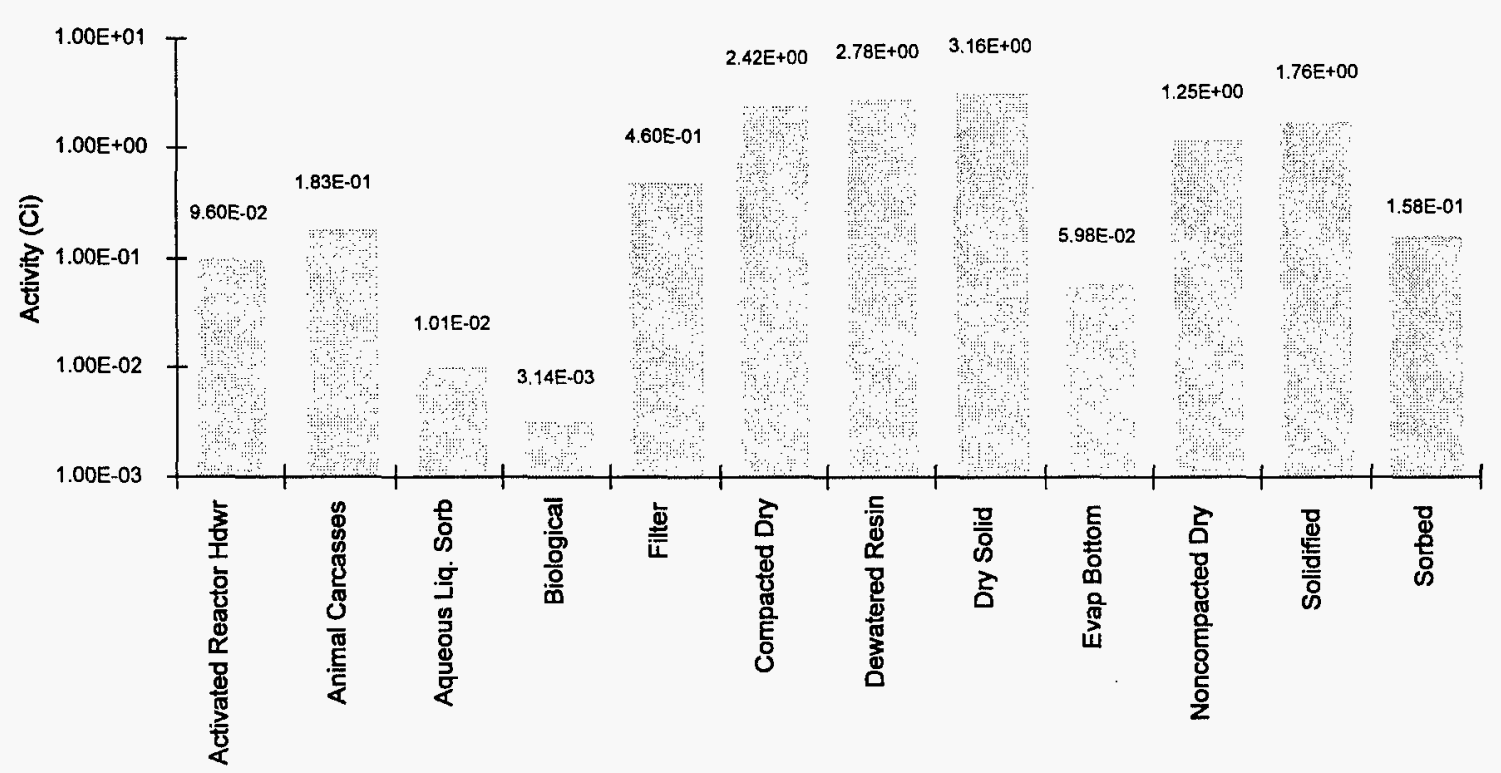

Figure 2-4. ${ }^{99} \mathrm{Tc}$ activity deposited at Richland and Beatty sites by waste type (log scale).

\section{Behavior of Technetium-99 in the Environment}

This section discusses the behavior of ${ }^{99} \mathrm{Tc}$ in various components of a LLW disposal environment-soils, plants, water, and the atmosphere. An understanding of this information is crucial during attempts to model the performance of a potential LLW disposal facility.

The main routes for ${ }^{99} \mathrm{Tc}$ entry into the environment are from nuclear weapons testing fallout, nuclear power plant emissions, nuclear fuel reprocessing plant emissions, and, potentially, releases from radioactive waste disposal facilities. The pertechnetate ion is the predominant form of ${ }^{99} \mathrm{Tc}$ released from a radioactive waste disposal site. This is a concern, because the soluble pertechnetate ion is known to be quite mobile in the environment. For example, during radionuclide migration studies at the Savannah River Site shallow-land disposal facility, the pertechnetate ion has been shown to migrate at greater than $88 \%$ of groundwater velocity. ${ }^{8}$ This value is significant if the groundwater velocity is high.

\section{Technetium-99 in Soils}

The behavior of the ${ }^{99} \mathrm{Tc}$ species in soils is governed by the potential of oxidation-reduction chemical (redox) reactions of the soil. If sufficient reducing conditions exist, the pertechnetate ion will be reduced to insoluble oxidation states of technetium such as ${ }^{99} \mathrm{TcO}_{2} 2 \mathrm{H}_{2} \mathrm{O},{ }^{99} \mathrm{Tc}_{2} \mathrm{~S}_{7}$, and ${ }^{99} \mathrm{TcS}_{2}$. These reduced ${ }^{99} \mathrm{Tc}$ species are readily sorbed by soil constituents or form complexes with organic matter and become fixed in the soil. Reduced forms of technetium are not likely to reoxidize under normal conditions. If sufficient oxidation conditions exist in the soil, the pertechnetate ion will not react with soil constituents or form complexes and will be available for transport.

Soils high in organic matter are particularly effective in reducing the pertechnetate ion to insoluble forms of technetium. ${ }^{9}$ Reducing conditions are created by the presence of large amounts of soil bacteria and positively charged organic compounds common to these types of soils. Some soil bacteria have the ability to reduce technetium by incorporating it in their metabolic processes. The reduced technetium reacts with carboxyl, amine, hydroxyl, and sulfide groups often found in soils high in organic matter and 
insoluble technetium complexes are formed, resulting in substantial reductions in its migration potential.

The presence of reducing agents in the soil such as ferrous iron $\left(\mathrm{Fe}^{2+}\right)$, solid iron $(\mathrm{Fe})$, or lead $(\mathrm{Pb})$ can also lead to the reduction of the pertechnetate ion (see Reference 3 ). This would suggest that soils high in iron content, such as clays, would be effective in immobilizing pertechnetate.

The technetium complexing/sorption process can be influenced by fluctuations in the water content of the soil. When oxygen is present in the soil, an equilibrium exists between the reduced form (technetium-organic complexes) and the oxidized form $\left(\mathrm{TcO}_{4}{ }^{-}\right)$of technetium. Additional technetium is released from the organic complexes as the soil dries (more oxygen) and there is an increase in pertechnetate ion concentration. Alternatively, as the soil saturates with water (less oxygen), the reducing potential of the soil increases and there is an increased concentration of the technetium-organic complexes.

The effect of chelating agents such as ethylene diamine tetra-acetic acid (EDTA) and diethylene triamine penta-acetic acid (DTPA) on the sorption/desorption of ${ }^{99} \mathrm{Tc}$ on soils has been studied. Chelating agents are organic molecules capable of forming multiple bonds with metals in solution. Resılts indicate that EDTA and DTPA have the ability to desorb reduced forms of technetium from soil and create a potential pathway for mobilizing reduced ${ }^{99} \mathrm{Tc}^{10}$

The soil distribution coefficient, $K_{d}$, is defined as the amount of the radionuclide sorbed on the soil divided by the amount of the radionuclide remaining in the fluid phase:

$$
\mathrm{K}_{\mathrm{d}}=\frac{\text { Concentration of radionuclide sorbed on soil }(\mathrm{mg} / \mathrm{mg})}{\mathrm{C}}
$$

$\mathrm{K}_{\mathrm{d}}$ values for various radionuclides and soil and mineral types are available in the literature (see Bibliography). A single soil $\mathrm{K}_{\mathrm{d}}$ is an arbitrary value and is not reliable for all soil types, redox conditions, and moisture levels. Site-specific soil $\mathrm{K}_{\mathrm{d}}$ values would give site developers a more realistic estimate of site performance. Generally a range of $\mathrm{K}_{d}$ values is used during the characterization of a LLW disposal facility, since there is so much variability associated with a soil $\mathrm{K}_{\mathrm{d}}$.

A study was made of the various environmental tendencies of ${ }^{99} \mathrm{Tc}$ by personnel at the Savannah River Site. ${ }^{11}$ This study concludes that in reducing conditions, where the oxidation-reduction potential is below the pertechnetate solubility, ${ }^{99} \mathrm{Tc}$ is held up in the soil, that is, it does not migrate significantly with the groundwater. However, in oxidizing conditions, and in the absence of organic material, technetium tends to move with the groundwater.

The behavior of ${ }^{99} \mathrm{Tc}$ in bedrock is influenced by the same factors as ${ }^{99} \mathrm{Tc}$ in soils. The pertechnetate ion can be transported through granitic rock by diffusion through micropores and microcracks. In a study performed by Allard et al., ${ }^{12}$ the $\mathrm{K}_{\mathrm{d}}$ of pertechnetate in granite was studied under several conditions. The results of that study indicate that granite has negligible sorption for pertechnetate in aerated and de-aerated conditions. However, when $\mathrm{Fe}^{2+}$ (a reducing agent) is added, the 
data suggests that the pertechnetate ion is reduced to less soluble forms of technetium and that it is sorbed more readily by the granite. $\mathrm{K}_{\mathrm{d}}$ values for a variety of bedrock materials are listed in the literature (see Bibliography).

Researchers at the Battelle Memorial Institute, Pacific Northwest Laboratories measured $\mathrm{K}_{\mathrm{d}}$ values for ${ }^{99} \mathrm{Tc}$ on subsoil samples from both Washington and South Carolina. ${ }^{13}$ This study showed that independent of soil $\mathrm{NaHCO}_{3}$ concentration, the sorption of ${ }^{99} \mathrm{Tc}$ was essentially zero.

The soil concentrations of ${ }^{99} \mathrm{Tc}$ were measured in the vicinity of the Hanford, Washington, DOE site. ${ }^{14}$ This was done as part of the site characterization study for this laboratory. The average ${ }^{99} \mathrm{Tc}$ concentration was $0.99 \mathrm{pCi} / \mathrm{gm}$.

The presence of organics in the soil can have a significant effect on the migration of radioactive nuclides in the soil. A study of this effect for ${ }^{99} \mathrm{Tc}$ was made by researchers at the Batelle North-West Laboratory. ${ }^{15,16}$ Specifically, the effect of sodium citrate and EDTA on the mobility was measured. In general, it was found that the addition of either of these two organic compounds did not affect the sorbtion of ${ }^{99} \mathrm{Tc}$ in the soils. However, when technetium, complexed with either EDTA or DTPA, was introduced into soil, only a slight amount of the nuclide was sorbed by the soil.

\section{Technetium-99 in Plants}

The uptake of ${ }^{99} \mathrm{Tc}$ in plants is influenced by the chemical form of ${ }^{99} \mathrm{Tc}$, concentration of ${ }^{99} \mathrm{Tc}$ in the soil, and plant type. The majority of ${ }^{99} \mathrm{Tc}$ found in plant tissues is in the form of the pertechnetate ion. ${ }^{17}$ This suggests that the root systems of plants growing in oxidized soils, where the pertechnetate ion predominates, would be more likely to uptake technetium than plants growing in soils under reducing conditions. Uptake of insoluble technetium organic complexes or lower oxidation states of technetium (most commonly found in a soil under reducing conditions) is possible, but the rate is approximately two orders of magnitude less than that of pertechnetate. ${ }^{18}$

Reference 18 states that plants can either take up ${ }^{99} \mathrm{Tc}$ from the soil, via their roots, or can absorb this nuclide when it is deposited on their outer membranes. Field studies report a plant to soil concentration ratio ranging from $9-22 \mathrm{~g}(\mathrm{Tc}) / \mathrm{g}($ soil), which values are an order of magnitude less than laboratory findings.

Certain molecules on the outer root membrane can temporarily bond to the pertechnetate ion and aid in its transfer into the root system. Once inside the plant, pertechnetate rapidly relocates to the xylem, commonly known as the water tube of the plant. Because pertechnetate is highly soluble in water, it diffuses quickly through the plant's transport system. The greatest concentration of the pertechnetate ion occurs in the older tissues of the plant.

The uptake of pertechnetate is directly proportional to the concentration of the species in the soil. However, moderate soil concentrations of technetium (far in excess of those possible at a LLW disposal site) may become toxic to plants. The pertechnetate ion acts as a nutrient analog to permanganate, molybdate, sulfate, selenite, and phosphate. Leaves of a plant that has taken up technetium often exhibit 
a very dark green color and begin a twisted and stunted growth habit. This leads to the complete disorganization of the plant's vascular tissues and results in an inability to translocate water, salts, and metabolites, and the plant dies.

The concentration ratio (CR) is a parameter used to quantify the amount of radionuclide uptake from soils to plants and is defined as

$\mathrm{CR}=\frac{\text { pCi/g plant }}{-\mathrm{pCi}_{\mathrm{g} \text { soil }}}$

Field values of the CR for ${ }^{99} \mathrm{Tc}$ are often an order of magnitude lower than calculated laboratory values of the $\mathrm{CR}$. In the field environment, the plant uptake of ${ }^{99} \mathrm{Tc}$ in the form of pertechnetate can be large. However, the source of ${ }^{99} \mathrm{Tc}$ in the natural soil is eventually depleted. In laboratory investigations, the source of ${ }^{99} \mathrm{Tc}$ is constantly replenished; consequently, the plants continue to take up any available ${ }^{99} \mathrm{Tc}$. CR values vary for a variety of plant and soil combinations from 30 to 1,200 , depending on the influences discussed above. CR values for a variety of plants can be found in Rogers and Rickard (see Reference 9).

At the Savannah River Site, it is planned to dispose of liquid LLW by incorporating the waste into a solid, concrete-based waste form called "saltstone" and burying it in clay-capped subterranean vaults. A set of experiments was conducted to measure the potential for vegetative uptake of various nuclides from the saltstone during storage. ${ }^{19}$ Of all of the various nuclides studied, ${ }^{99} \mathrm{Tc}$ showed the greatest potential for plant uptake, via the root structure. The uptake of this nuclide appeared to be related to release of the ${ }^{99} \mathrm{Tc}$ from the saltstone into the soil water since the concentrations in each were similar.

${ }^{99} \mathrm{Tc}$ has been measured in various marine plants, such as seaweed, in the waters near Japan. Since various seaweeds are used in Japan as food, researchers from the National Institute of Radiological Sciences in Japan have studied the uptake of this nuclide in marine vegetation. ${ }^{20}$ The concentration of this nuclide in one seaweed was $276 \mathrm{mBq} / \mathrm{kg}$ of plant mass, though it was not detected at all in another species.

A French study was conducted to measure the uptake rates of ${ }^{99} \mathrm{Tc}$ by rye grass from contaminated soils and to calculate the transfer factors from soil to plants. ${ }^{21}$ The study showed that the initial uptake by the plants was relatively rapid, resulting in nuclide concentrations in the plant of between 2.5 to 25 $\mathrm{kBq} / \mathrm{kg}$ after 4 weeks. The uptake rate decreased exponentially as the exposure time increased. The transfer factors (concentration of the nuclide in dry plant tissues divided by the concentration in the dry soil) ranged from a few tens to several hundred.

The absorption of ${ }^{99} \mathrm{Tc}$ by tumbleweed and cheatgrass was measured in a study conducted by the Pacific Northwest Laboratory. ${ }^{22}$ The concentration ratio varied from 80 to 390, depending on the length of time of exposure and the specific soil type.

Reference 22 also included the average sagebrush concentration of ${ }^{99} \mathrm{Tc}$ in the area surrounding the Hanford, Washington, DOE site. The average value was $1.99 \mathrm{pCi} / \mathrm{g}$, or approximately twice the average concentration in the soil. 
Since ${ }^{99} \mathrm{Tc}$ contamination is widespread, due to atmospheric weapons testing, a study was made of the transfer to man via the lichen - reindeer - man food chain in Lappland. ${ }^{23}$ This study was specific to the time frame from 1956 to 1981 . Even though relatively high concentrations of this nuclide were measured in the carpets of lichen in this region, the residence time in reindeer (of the order of 5 days) was so short the nuclide did not propagate up the food chain to man.

\section{Technetium-99 in Water}

The high solubility of pertechnetate allows it to move quite rapidly in groundwater systems. The migration rate of pertechnetate is expected to be very close to the velocity of groundwater unless it is reduced to a less soluble form. A study performed by Salter et al..$^{24}$ compared the travel time of the pertechnetate ion in groundwater to that of reduced states of ${ }^{99} \mathrm{Tc}$. The study was performed in two groundwater scenarios, Case I and Case II. Case I was nondisruptive transport of the ${ }^{99} \mathrm{Tc}$ species through 10 kilometers of basalt. The basalt had a porosity of $0.05 \%$ and a density of $2.7 \mathrm{~g} / \mathrm{cm}^{3}$. The water velocity of the groundwater in Case I was $0.06 \mathrm{~m} / \mathrm{yr}$. Case II was transport of the ${ }^{99} \mathrm{Tc}$ species through $10 \mathrm{~km}$ of a confined aquifer of basalt (aquifer confined by an upper and lower layer of basalt). The basalt had a porosity of $0.1 \%$ and a density of $2.6 \mathrm{~g} / \mathrm{cm}^{3}$. The water velocity of the groundwater in Case II was $3.2 \mathrm{~m} / \mathrm{yr}$. The results of the study were as follows:

Travel times to accessible environment - $10 \mathrm{~km}$ (in years):

$\begin{array}{ll}\frac{\text { Case I }}{\text { Tc Oxidized }} & \text { Tc Reduced } \\ 1.6 \times 10^{5} & 2.5 \times 10^{5}\end{array}$

Groundwater $1.6 \times 10^{5}$

$\begin{array}{ll}\text { Case II } & \\ \text { Tc Oxidized } & \text { Tc Reduced } \\ 3.2 \times 10^{3} & 5.8 \times 10^{3}\end{array}$

Groundwater

$3.2 \times 10^{3}$

In both cases, the travel time of the reduced states of technetium- 99 is greater than that of ${ }^{99} \mathrm{TcO}_{4}{ }^{-}$. The results of the study also indicate the travel time of ${ }^{99} \mathrm{TcO}_{4}{ }^{-}$is the same as the travel time of the groundwater.

The presence of ${ }^{99} \mathrm{Tc}$ in the Rhone river was measured by French scientists. ${ }^{25}$ This study was conducted to determine the pollution of the Rhone river due to the presence of the Marcoule nuclear fuel reprocessing plant. The concentration increases from $0.016 \mathrm{mBq} / \mathrm{l}$ upstream of the plant to $0.4 \mathrm{mBq} / \mathrm{l}$ at a location $14 \mathrm{~km}$ downstream of the plant.

\section{Technetium-99 in Air}

The pertechnetate ion is not volatile; its escape from a LLW disposal facility into the atmosphere is not a concern. Even if the water that contained the pertechnetate ion evaporated, the ${ }^{99} \mathrm{Tc}$ would be left behind in a solid ionic form. Three volatile forms of technetium do exist $\left(\mathrm{HTcO}_{4}, \mathrm{Tc}_{2} \mathrm{O}_{7}\right.$, and $\left.\mathrm{Tc}_{2} \mathrm{~S}_{7}\right)$. If sufficient acidic conditions are present in the disposal environment, these volatile species can form and escape into the atmosphere. However, they will eventually react with water vapor and particulate matter and deposit on the ground. These volatile forms of ${ }^{99} \mathrm{Tc}$ are highly insoluble in water; therefore, their mobility, once deposited, is very low. Reoxidation of the volatile compounds is also difficult. Any 
oxidation that does occur will result in the formation of the pertechnetate ion, which is not volatile. The pertechnetate ion is mobile in the environment, but since it is not volatile, there should not be any aerial deposition of this oxidized form. Therefore, atmospheric releases of ${ }^{99} \mathrm{Tc}$ from LLW disposal facilities can be safely assumed to be negligible.

Scientists from the Universidad de Sevilla, in Spain, have studied the atmospheric behavior of various radioactive nuclides over the last two or three decades. ${ }^{26}$ Based on these studies, they determined that the atmospheric residence time for this nuclide is $1.62 \pm 0.21$ years, similar to that for other fission products. In another study, scientists from the same institute measured atmospheric concentrations of this nuclide over a 3-year period, 1965-1967. ${ }^{27}$ The activity peaked in early fall and ranged, typically, from 0.1 to $3 \mathrm{mGq} / 1,000 \mathrm{~m}^{3}$ of air. A possible reason for this yearly cycle was given - namely that the high evaporation of water during the hot summer days can lift considerable amounts of ${ }^{99} \mathrm{Tc}$-laden dust into the atmosphere, where it is swept down with the autumn rains. Other factors may also affect the atmospheric concentrations of this nuclide but this is believed to be the dominant one.

While only limited data exist on the dispersion of this nuclide due to atmospheric weapons testing, one study estimated that this source contributed to a soil concentration of $0.17 \mathrm{pCi} / \mathrm{kg}$ soil, world-wide. ${ }^{28}$ Concentrations in rainwater have been measured to be from $1.8 \times 10^{-3}$ to $3.6 \times 10^{-2} \mathrm{pCi} / 1$.

\section{Direct Exposure from Technetium-99}

Radiation doses resulting from the direct exposure of ${ }^{99} \mathrm{Tc}$ to waste generators, transportation workers, waste treatment workers, and LLW disposal facility employees is negligible. The beta particle emitted by ${ }^{99} \mathrm{Tc}$ is fairly weak in energy and is not able to penetrate any type of containment (steel drums, solidification media) typically used in its disposal.

\section{Behavior of Technetium-99 in the Human Body and in Animals}

The main route of entry of ${ }^{99} \mathrm{Tc}$ into the human body is by ingestion. Once in the body, ${ }^{99} \mathrm{Tc}$ localizes in the thyroid gland and the gastrointestinal tract. Within 10 hours, it redistributes to the stomach and organs with excretory functions, such as the kidneys and salivary glands. The time required for the body to eliminate one-half of an administered dosage of ${ }^{99} \mathrm{Tc}$ by regular processes of excretion (biological half-life) is approximately 60 hours (see Reference 17). Little ${ }^{99} \mathrm{Tc}$ is assimilated by the muscle or brain. Hair, however, retains ${ }^{99} \mathrm{Tc}$ for long periods of time after a dose has been administered and can be a good indicator of ${ }^{99} \mathrm{Tc}$ contamination. ${ }^{99} \mathrm{Tc}$ ingested in the form of a pertechnetate localized initially in the thyroid gland and GI tract and redistributes quickly to the stomach and organs with excretory functions. Ingestion of $1 \mathrm{Ci}$ of ${ }^{99} \mathrm{Tc}$ will result in a fatal cancer with a risk of $0.08-0.3$ per person-year. The most probable form of cancer is of the stomach and intestine.

Belgium researchers studied the toxicity of ${ }^{99} \mathrm{Tc}$ in rats. ${ }^{29}$ Included in the study was measurement of the effect of iodine sufficiency/deficiency on the toxicity. The study concluded that the principal organ of concern was the thyroid and that both the chemical and radiological toxicity of ${ }^{99} \mathrm{Tc}$ to rats were relatively small. These conclusions were independent on the sufficiency/deficiency of iodine in the diet. 
A study was made of the residence time of ${ }^{99} \mathrm{Tc}$ in various parts of the human body by researchers in Spain. ${ }^{30}$ Four different regions in the body were analyzed and the mean residence times for this nuclide in these regions were $10^{-5}, 10^{-4}, 10^{-4}$, and $10^{-3}$ years for the thyroid, stomach wall, liver, and pulmonary region, respectively.

Researchers from the same institute deduced the intake by inhalation and calculated resultant doses to the population due to atmosphere-born ${ }^{99} \mathrm{Tc}^{31}$ This study concluded that during the time from 1965 to 1967 , the average exposure was of the order of a few $\mathrm{mBq}$, with resultant doses in the range of $>1 \mathrm{nSv}$.

There is a concern that lactating mothers might pass radionuclides to their babies through nursing. Because of this concern, Swedish researchers measured the carryover of ${ }^{99} \mathrm{Tc}$ in breast milk of nursing mothers. ${ }^{32}$ While there were some large variations, depending on the amounts of free pertechnetate in the preparations and whether the mothers had been breast feeding their children for several months prior to the study or had just started, in general less than $2 \%$ of the administered technetium was ingested by the children.

The annual limit on intake (ALI) for ${ }^{99} \mathrm{Tc}$ is $5.4 \mathrm{mCi}$ or $318 \mathrm{mg}$. An ALI is defined as the annual intake that would lead to a 50 -year dose commitment to the human body not exceeding $5 \mathrm{rem}$, and an annual dose equivalent to any single organ or tissue not exceeding 50 millirem.

\section{Summary}

The behavior of ${ }^{99} \mathrm{Tc}$ in various environmental media such as soils, plants, water, and air is governed by its chemical form. The predominant form of ${ }^{99} \mathrm{Tc}$ at an LLW disposal facility is the pertechnetate ion. Because pertechnetate is highly mobile in groundwater and because ${ }^{99} \mathrm{Tc}$ has a long half-life, its disposal presents a potential hazard to the general public over the long term. However, the pertechnetate ion can be reduced to less soluble forms of technetium that are not mobile in environmental media. An understanding of the chemical conditions at the disposal environment is critical in predicting the behavior of ${ }^{99} \mathrm{Tc}$.

Reactor wastes such as evaporator bottoms, filters, and sludges may contain ${ }^{99} \mathrm{Tc}$. Minimal amounts of ${ }^{99} \mathrm{Tc}$ can also be present in LLW generated at medical laboratories and academic institutions.

The NRC, in its draft EIS on 10 CFR 61 , identified ${ }^{99} \mathrm{Tc}$ as one of four radionuclides (tritium, carbon-14, ${ }^{99} \mathrm{Tc}$, and iodine-129) that will require site-specific considerations to ensure the performance objectives for long-term environmental protection are met. Because ${ }^{99} \mathrm{Tc}$ is a beta emitter with a maximum energy or $0.293 \mathrm{MeV}$, it poses a greater internal than external hazard to humans. The main route that ${ }^{99} \mathrm{Tc}$ enters the human body is ingestion. 


\section{References}

1. U.S. Nuclear Regulatory Commission, Licensing Requirements for Land Disposal of Radioactive Waste, NUREG-0782-V1, September 1981.

2. F. William Walker, Josef R. Parrington, and Frank Feiner, Chart of the Nuclides, United States Department of Energy, Fourteenth Edition, Revised April 1988.

3. B. Torstenfelt et al., Technetium in the Geologic Environment-A Literature Survey, Prav 4.28, July 1981.

4. Seymour Katcoff, "Fission-Product Yields from U, Th, and Pu," Nucleonics, Vol. 16, No. 4, April 1958, pp. 78-85.

5. Electric Power Research Institute, Updated Scaling Factors in Low-Level Radwaste, EPRI NP5077, March 1987.

6. Bert G. Brodda and Xu Mingxia, "Leaching of Chlorine, Cesium, Strontium, and Technetium from Cement-Fixed Intermediate-Level Liquid Waste," Scientific Basis for Nuclear Waste Management XII, Vol. 127, 1989, pp. 481-487.

7. U.S. Environmental Protection Agency, Low-Level and NARM Radioactive Wastes Draft Environmental Impact Statement for Proposed Rules, Vol. 1, Background Information Document, EPA-520/1-87-012-1, June 1988.

8. J. A. Stone, Radionuclide Migration Studies at the Savannah Plant LLW Burial Ground, A Humid SLB Site, ORNL/NFW-82/18, October 1982, pp. 469-476.

9. L. E. Rogers and W. H. Rickard, Ecology of the 200 Area Plateau Waste Management Environs: A Status Report, PNL-2253, October 1977.

10. J. A. Franz et al., Behavior of Reduced Technetium and Technetium Organic Complexes in Hanford Soil, PNL-4178, February 1982.

11. M. D. S. Turcotte, Environmental Behovior of Technetium-99, DP-1644, December 1982.

12. B. Allard and B. Torstenfelt, On the Solubility of Technetium in Geochemical Systems, SKBF-KBSTR-83-60, May 5, 1983.

13. R. C. Routson, G. Jansen, and A. V. Robinson, " ${ }^{241} \mathrm{Am},{ }^{237} \mathrm{~Np}$, and ${ }^{99} \mathrm{Tc}$ Sorption on Two United States Subsoils from Differing Weathering Intensity Areas," Health Physics, Vol. 33, 1977, pp. 311-317.

14. D. S. Landeen, Comparison of Radionuclide Levels in Soil, Sagebrush, Plant Litter, Cryptogams, and Small Mammals, WHC-EP-0771, September 1994.

15. L. Y. Martin and J. A. Franz, "Effect of Organic Ligands on the Soil Behavior of Technetium-99," Transactions of the American Nuclear Society, Vol. 35, 1980, p. 53. 
16. J. A. Franz, L. Y. Martin, and D. J. Wiggins, Behavior of Reduced ${ }^{99} T c$ and ${ }^{99}$ Tc Organic Complexes on Hanford Soil, PNL-4178, February 1982.

17. Marie-Daniele S. Turcotte, Environmental Behavior of Technetium-99, DP-1644, December 1982.

18. J. E. Till, F. O. Hoffman, and D. E. Dunning, "A New Look at Releases to the Atmosphere," Health Physics, Vol. 36, January, pp. 21-30.

19. C. E. Murphy, Jr., and T. L. Johnson, "Vegetative Uptake of Technetium-99 from Buried, Solidified, Low-Level Radioactive Waste," Journal of Environmental Quality, Vol. 22, 1993, pp. 793-799.

20. S. Hirano, M. Matsuba, and H. Kamada, "The Determination of ${ }^{99} \mathrm{Tc}$ in Marine Algae," Radioisotopes, Vol. 38, 1989, pp. 186-189.

21. G. Echevarria, et al., Availability of ${ }^{99} T c$ to Rye Grass Grown on Agricultural Soils, IAEA-SM$334 / 30,1995$.

22. R. C. Routson and D. A. Cataldo, "Accumulation of ${ }^{99} \mathrm{Tc}$ by Tumbleweed and Cheatgrass Grown on Arid Soils," Healih Physics, Vol. 34, 1978, pp. 685-690.

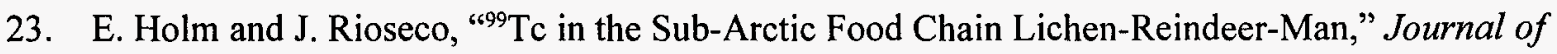
Environmental Radioactivity, Vol. 5, 1987, pp. 343-357.

24. K. Anderson, Nuclide Solubilities and Distribution Coefficients for Use in Probabilistic Modeling, SKI-87132, Stockholm, January 15, 1988.

25. G. Barci-Funel, et al., "Technetium-99 in the Rhone River Water," Journal of Radioanalytical and Nuclear Chemistry Letters, Vol. 153, 1991, pp. 431-438.

26. M. Garcia-Leon, G. Majon, and C. I. Sanchez-Angulo, ${ }^{~}{ }^{99} \mathrm{Tc} /{ }^{137} \mathrm{Cs}$ Activity Ratios in Rainwater Samples Collected in the South of Spain," Journal of Environmental Radioactivity, Vol. 20, No. 1, 1993, pp. 49-61.

27. M. Garcia-Leon, C. Piazza, and G. Madurga, " ${ }^{\circ 99}$ Tc in Surface Air Samples During the Years 1965 1967," International Journal of Applied Radiation \& Isotopes, Vol. 35, 1984, pp. 961-963.

28. J. E. Till, F. O. Hoffman, and D. E. Dunning, Jr., "A New Look at ${ }^{99}$ Tc Releases to the Atmosphere," Health Physics, Vol. 36, 1979, pp. 21-30.

29. G. B. Gerber, et al., "Toxicity of ${ }^{99}$ Tc: Can it Represent a Risk to Man?" Health Physics, Vol. 57, 1989, pp. 345-350.

30. E. Garcia-Montano, M. Garcia-Leon, and L. Hallstadius, "A New Approach to the Dosimetry of ${ }^{99} \mathrm{Tc}$ in the Human Body after Inhalation or Ingestion," Radiation Protection Dosimetry, Vol. 32, 1990, pp. 253-257.

31. M. Garcia-Leon and G. Madurga, "Radiological Impact of Fallout ${ }^{99} \mathrm{Tc}$ in Seville, 1965 - 1967," International Journal of Applied Radiation \& Isotopes, Vol. 36, 1985, pp. 129-131. 
32. S. Mattsson, et al., "Excretion of Radionuclides in Human Breast Milk Following Administration of ${ }^{125}$ I-Fibrinogen, ${ }^{99} \mathrm{Tc}^{\mathrm{m}}$-MAA and ${ }^{51} \mathrm{Cr}$-EDTA," ORAU Radiopharmaceutical Dosimetry Symposium, FDA-81-8166, 1981, pp. 102-110. 


\section{Bibliography}

Allard, B., H. Kipatsi, and B. Torstenfelt, "Technetium: Reduction and Sorption in Granitic Bedrock," Radiochemical and Radioanalytical Letters, Vol. 37, (4-5) 1979, pp. 223-230.

Anderson, K., and B. Allard, Sorption of Radionuclides on Geologic Media, SKBF-KBS-TR-83-07, January $31,1983$.

Battelle Memorial Institution, Radionuclide Migration/Retardation: Research and Development Technology Status Report, ONWI-321, 1982.

Browne, E., R. B. Firestone, and J. Wiley, Table of Radioactive Isotopes, 1986.

Desmet, G., and C. Myttenaere, Technetium in the Environment, Elsevier Applied Science Publishers, 1984.

Gast R. G., et al., Behavior of Technetium-99 in Soils and Plants, COO-2447-6, December 31, 1978.

Henrot J., et al., Behavior of Technetium in Soil: Sorption-Desorption Processes, ORNL/TM-10721, January 1989.

MacLean S. C., et al., Measurement of Sorption Ratios for Selected Radionuclides on Various Geologic Media, UCID-17928, September 1978.

Rai, D., and M. J. Mason, Batch $K_{d}$ Measurements of Nuclides to Estimate Migration Potential at the Proposed Waste Isolation Pilot Plant in New Mexico, PNL-2448, October 7, 1977.

Sheppard, Marsha I., et al., Soil Nuclide Distribution Coefficients and Their Statistical Distributions, AECL-8364, December 1984.

Strickert, R., A. M. Friedman, and S. Fried, "The Sorption of Technetium and Iodine Radioisotopes by Various Minerals," Transactions of the American Nuclear Society 1978 Annual Meeting, San Diego, California, June 18-22, 1978, Vol. 28, ISSN:0003-018X, pp. 365-366.

Torstenfelt, B., et al., "Diffusion Measurements in Compacted Bentonite," Scientific Basis for Nuclear Waste Management, 1982, pp. 295-302. 


\section{CARBON-14}

\section{Introduction}

This chapter discusses the basic radiological, chemical, and physical characteristics of carbon-14 $\left({ }^{14} \mathrm{C}\right)$, and examines how these characteristics affect the behavior of ${ }^{14} \mathrm{C}$ in various environmental media such as soils, water, plants, the atmosphere, and the human body. Also included are methods of ${ }^{14} \mathrm{C}$ production and waste and disposal data on ${ }^{14} \mathrm{C}$.

${ }^{14} \mathrm{C}$ is a long-lived radionuclide present in LLW generated at nuclear power plants, medical laboratories, and academic institutions. Disposing of ${ }^{14} \mathrm{C}$-contaminated waste at LLW disposal facilities is a concern because ${ }^{14} \mathrm{C}$ is highly mobile in the environment. The $\mathrm{NRC}$, in its draft EIS on $10 \mathrm{CFR}$ 61, "Licensing Requirements for Land Disposal of Radioactive Waste," 1 identified ${ }^{14} \mathrm{C}$ as one of four radionuclides (along with tritium, technetium-99, and iodine-129) that require site-specific considerations to ensure that performance objectives for long-term environmental protection are met.

A radionuclide considered sensitive at one LLW disposal facility may not be considered sensitive at another facility. The behavior of a radionuclide at a particular LLW disposal site depends primarily upon the radiological, chemical, and physical characteristics of the waste, and the inventory of the radionuclide. The behavior of a radionuclide also depends upon the geology, hydrology, and climate at the disposal site. This chapter indicates characteristics and potential difficulties in dealing with ${ }^{14} \mathrm{C}$. However, since ${ }^{14} \mathrm{C}$ behavior and appropriate handling, storage, or disposal vary depending on particular sites or waste form, this chapter does not attempt to discuss the extent of a difficulty or appropriate solutions. Each disposal site facility design should address the specific waste content and behavior under that site's particular circumstances.

\section{Radiological Characteristics}

${ }^{14} \mathrm{C}$ is a long-lived radionuclide with a half-life of 5,730 years. When ${ }^{14} \mathrm{C}$ undergoes radioactive decay, the nucleus emits a single beta particle $\left(\beta^{-}\right)$with an energy of 0.156 million electron volts $(\mathrm{MeV})$.

The $0.156 \mathrm{MeV}$ beta particle emitted by the ${ }^{14} \mathrm{C}$ nucleus is fairly low in energy. Table 3-1 compares the energy of the ${ }^{14} \mathrm{C}$ beta particle to the emissions of other beta emitters. 
Table 3-1. Comparison of ${ }^{14} \mathrm{C}$ beta emissions to other beta emitters.

\begin{tabular}{ll}
\hline Radionuclide & Maximum Energy $(\mathrm{MeV})$ \\
\hline Tritium $\left({ }^{3} \mathrm{H}\right)$ & 0.019 \\
Iodine-129 $\left({ }^{129} \mathrm{I}\right)$ & 0.150 \\
Carbon $\left({ }^{14} \mathrm{C}\right)$ & $\mathbf{0 . 1 5 6}$ \\
Technetium-99 $\left({ }^{99} \mathrm{Tc}\right)$ & 0.293 \\
Chlorine-36 $\left({ }^{36} \mathrm{Cl}\right)$ & 0.709 \\
Iodine-131 $\left({ }^{13} \mathrm{I}\right)$ & 0.806 \\
Potassium-40 $\left({ }^{40} \mathrm{~K}\right)$ & 1.330 \\
Phosphorous-32 $\left({ }^{32} \mathrm{P}\right)$ & 1.710 \\
\hline
\end{tabular}

The decay of ${ }^{14} \mathrm{C}$ results in stable nitrogen-14 $\left({ }^{14} \mathrm{~N}\right)$ :

${ }^{14} \mathrm{C}-\frac{\beta^{-}}{-{ }_{5730 y}}{ }^{14} \mathrm{~N}$.

No radionuclides decay to form ${ }^{14} \mathrm{C}$; therefore, it has no parent. Eight isotopes of carbon exist with mass numbers ranging from 9 to $16 .{ }^{2}$ Only two stable carbon isotopes exist: ${ }^{12} \mathrm{C}$ and ${ }^{13} \mathrm{C}$.

\section{Chemical and Physical Characteristics}

The chemistry of carbon is quite complex and involves both oxidation-reduction (redox) and nonredox reactions. The carbon atom has four available bonding sites, and its oxidation state can range from -4 to +4 . Carbon- $12\left({ }^{12} \mathrm{C}\right)$ accounts for almost $98.9 \%$ of the carbon on the Earth. Carbon- $13\left({ }^{13} \mathrm{C}\right)$ accounts for most of the remaining $1.1 \%$, while other isotopes collectively make up less than $0.1 \%$ of the total amount of carbon on the Earth. ${ }^{3}$

Carbon forms organic molecules because of its unique ability to form long chains with itself. These molecules are the basic constituents of all life forms on Earth and almost always contain hydrogen. Carbon also forms organic anions (negatively charged ions) such as oxalate $\left(\mathrm{C}_{2} \mathrm{O}_{4}^{-2}\right)$ and acetate $\left(\mathrm{CH}_{3} \mathrm{CO}_{2}{ }^{-}\right)$. Also, some inorganic chemical forms, such as the carbonate $\left(\mathrm{CO}_{3}{ }^{-}\right)$and bicarbonate $\left(\mathrm{HCO}_{3}^{-}\right)$ions, contain carbon.

${ }^{14} \mathrm{C}$ behaves as normal carbon in the environment, although its reaction time is slightly slower because of its higher molecular weight. ${ }^{3}$ The structure of essential organic compounds incorporates ${ }^{14} \mathrm{C}$. 
Nitrogen-14, which results from the decay of ${ }^{14} \mathrm{C}$, has only three bonding sites. This change in the number of potential bonds can disrupt the structure of the molecule and bring about serious consequences. For example, the enzymes in the human body can perform their respective functions because of their ability to bind to specific molecules. When the molecular structure is upset, that binding ability can be lost. The enzyme can become useless, leaving its function unaccomplished, or it may even act as another enzyme and perform the wrong function at the wrong time.

The predominant forms of ${ }^{14} \mathrm{C}$ available for transport at an LLW disposal site are carbon dioxide $\left({ }^{14} \mathrm{CO}_{2}\right)$, methane $\left({ }^{14} \mathrm{CH}_{4}\right)$, carbonate ion $\left({ }^{14} \mathrm{CO}_{3}{ }^{-2}\right)$, bicarbonate ion $\left(\mathrm{H}^{14} \mathrm{CO}_{3}{ }^{-}\right)$, and elemental carbon in activated metals. ${ }^{4}$

\section{Carbon Dioxide}

Carbon dioxide, which exists only as a gas at normal atmospheric pressures and temperatures, makes up about $99 \%$ of the atmospheric carbon. Inorganic gases such as carbon monoxide, and low molecular weight organic compounds such as methane $\left(\mathrm{CH}_{4}\right)$ and formaldehyde $\left(\mathrm{CH}_{2} \mathrm{O}\right)$, make up the remaining $1 \%$.

Microbial decomposition of ${ }^{14} \mathrm{C}$-contaminated organic waste (for example, paper and animal carcasses) creates most of the carbon dioxide at an LLW disposal site in a process called methanogenesis. Methanogenesis results in the formation of both carbon dioxide and methane. Methane production increases in areas lacking oxygen and is inhibited in areas where oxygen is present. Methanogenesis can also result in the production of low molecular weight carboxylic acids. Examples of these acids are formic acid $\left(\mathrm{CH}_{2} \mathrm{O}\right)$ and acetic acid $\left(\mathrm{CH}_{3} \mathrm{CHO}\right){ }^{5}$

When carbon dioxide dissolves in water, it forms a weak, unstable acid called carbonic acid $\left(\mathrm{H}_{2} \mathrm{CO}_{3}\right)$; carbonic acid readily breaks apart to form hydrogen $\left(\mathrm{H}^{+}\right)$and bicarbonate $\left(\mathrm{HCO}_{3}{ }^{-}\right)$ions:

$$
\mathrm{CO}_{2}+\mathrm{H}_{2} \mathrm{O}<====>\mathrm{H}_{2} \mathrm{CO}_{3}<====\mathrm{H}^{+}+\mathrm{HCO}_{3}^{-} \text {. }
$$

Carbon dioxide can react with calcium hydroxide $\left[\mathrm{Ca}(\mathrm{OH})_{2}\right]$, a common constituent of cement. The end product of this reaction is calcium carbonate $\left(\mathrm{CaCO}_{3}\right)$ :

$$
\mathrm{CO}_{2}+\mathrm{Ca}(\mathrm{OH})_{2}-\cdots-->\mathrm{H}_{2} \mathrm{O}+\mathrm{CaCO}_{3}
$$

Carbon dioxide accelerates the corrosion of steel drums. The rate of corrosion depends on the concentration of iron in the steel of the drum, the pressure exerted by carbon dioxide in a sealed drum, the $\mathrm{pH}$ of the waste, and the moisture content inside the drum. As the $\mathrm{pH}$ of the waste inside a steel drum decreases and becomes more acidic, the rate of corrosion increases. The mechanism of waste drum corrosion from carbon dioxide can be represented by the following equation:

$$
\mathrm{CO}_{2}+\mathrm{Fe}+\mathrm{H}_{2} \mathrm{O}----->\mathrm{FeCO}_{3}+\mathrm{H}_{2} \text {. }
$$

A film of iron carbonate $\left(\mathrm{FeCO}_{3}\right)$ tends to collect on the surface of the interior of the waste drum. The film can build up as a barrier to slow the reaction as additional reactive iron is covered. If the pressure of carbon dioxide is too low to cause the formation of iron carbonate and some oxygen is 
available, the film could consist of iron oxide $(\mathrm{FeO})$ or rust rather than iron carbonate. ${ }^{6}$ More information on the extent of this phenomenon and how it can be ameliorated can be found in Reference 6.

\section{Methane}

Methane $\left(\mathrm{CH}_{4}\right)$ is the simplest of the organic compounds. Although it is fairly inert, it is highly volatile and can escape from an LLW disposal unit through small cracks or diffusion. ${ }^{6}$ If it then mixes with oxygen, it can be explosive when exposed to a source of ignition. Therefore, suitable provisions should be made in the LLW site to safely address this possibility if much methane generation is anticipated. After long periods of exposure to oxygen, methane is likely to be oxidized to carbon dioxide:

$$
\mathrm{CH}_{4}+\mathrm{O}_{2}-\cdots--->\mathrm{CO}_{2}+\mathrm{H}_{2} \mathrm{O} \text {. }
$$

\section{Carbonate}

About $75 \%$ of the ${ }^{14} \mathrm{C}$ from the nuclear fuel cycle is in the form of carbonates, predominantly calcium carbonate. ${ }^{4}$ Calcium is used to bind the carbonate at a nuclear power plant before its disposal for several reasons: (a) calcium carbonate $\left(\mathrm{CaCO}_{3}\right)$ is a stable compound, (b) calcium carbonate is not very soluble, (c) calcium carbonate is naturally abundant, and therefore, the calcium carbonate at the disposal site will be diluted, and (d) calcium carbonate is a product of the carbon dioxide scrubbing procedure.

Four technologies are commonly employed in the capturing process: caustic/alkaline earth hydroxide scrubbers, molecular sieve adsorption, fluorocarbon absorption, and barium hydroxide hydrate adsorption. All four of these processes involve passing carbon dioxide through a calcium or barium hydroxide slurry to form bicarbonate.

Carbonates dissolve in water to form the calcium ion $\left(\mathrm{Ca}^{+2}\right)$ and the bicarbonate ion.,

$$
\mathrm{H}^{+}+\mathrm{HCO}_{3}^{-}+\mathrm{CaCO}_{3}=====\mathrm{Ca}^{+2}+2 \mathrm{HCO}_{3}^{-} \text {. }
$$

Carbonate is a moderately strong base and can react with an acid to form the bicarbonate ion $\left(\mathrm{HCO}_{3}{ }^{-}\right)$:

$$
\mathrm{CO}_{3}^{-2}+\mathrm{H}^{+}-\ldots-.>\mathrm{HCO}_{3}^{-}
$$

\section{Bicarbonate}

Both the carbonic acid dissolution and the carbonate equilibrium equations involve the bicarbonate ion. The bicarbonate ion will be at a higher concentration than the carbonate ion at $\mathrm{pH}$ values typically found in the LLW disposal environment. If the $\mathrm{pH}$ increases to above 9.0, the predominant form would be the carbonate ion. ${ }^{4}$

Bicarbonate can act as a source of carbon for microbial activity, but a source of oxygen is required by most microbes to produce carbon dioxide or methane. ${ }^{5}$ 
Bicarbonate is a weak base and can act as a buffer in the LLW environment. Its buffering capacity allows it to neutralize strong acids produced by microbial activity. This reaction with acid $\left(\mathrm{H}^{+}\right)$results in the formation of a weak acid, carbonic acid $\left(\mathrm{H}_{2} \mathrm{CO}_{3}\right)$ :

$$
\mathrm{HCO}_{3}{ }^{-}+\mathrm{H}^{+}<====\mathrm{H}_{2} \mathrm{CO}_{3} \text {. }
$$

As shown earlier, the carbonic acid can dissociate to release $\mathrm{CO}_{2}$.

\section{Activated Metals}

${ }^{14} \mathrm{C}$, in the form of activated metals, is expected to remain as residual material at the LLW disposal site. Most of the metal is likely to be stainless steel, whose corrosion products are reportedly essentially insoluble in either freshwater or seawater. Carbon exists in the metal as elemental carbon, and would thus be unavailable for microbial activity. ${ }^{4}$

\section{Carbon-14 Production in Nuclear Reactors}

Before the advent of manmade disruptions of the ${ }^{14} \mathrm{C}$ atmospheric concentration (burning of fossil fuels and atmospheric testing of nuclear weapons), this nuclide was produced by cosmic rays impinging on the atmosphere. Presently, the principal means of producing ${ }^{14} \mathrm{C}$ in a nuclear power reactor is by the neutron activation of stable nitrogen-14 $\left({ }^{14} \mathrm{~N}\right)$. Neutron activation of stable oxygen-17 $\left({ }^{17} \mathrm{O}\right)$ produces the remainder of ${ }^{14} \mathrm{C}$.

Oxide fuels, coolant water, and structural materials contain nitrogen-14 and oxygen-17. The fission processes of the reactor supply the large source of neutrons necessary to induce the neutron activation of ${ }^{14} \mathrm{~N}$ and ${ }^{17} \mathrm{O}$.

The nucleus of the stable nitrogen- 14 atom captures a neutron $\left({ }^{1} n\right)$ and a highly unstable compound nucleus is formed. The nitrogen- 14 compound nucleus releases some of its excess energy by emitting a proton $\left({ }^{1} \mathrm{p}\right.$ ) with an energy of $0.600 \mathrm{MeV}$ to form ${ }^{14} \mathrm{C}$ :

$$
{ }^{14} \mathrm{~N}+{ }^{1} \mathrm{n}-\cdots----->{ }^{14} \mathrm{C}+{ }^{1} \mathrm{p} \text {. }
$$

This reaction is often referred to as a $(n, p)$ reaction. The reaction can also be written as

$$
{ }^{14} \mathrm{~N}(\mathrm{n}, \mathrm{p}){ }^{14} \mathrm{C}
$$

The nucleus of the stable oxygen- 17 atom can also capture a neutron $\left({ }^{1} n\right)$ resulting in the formation of a highly unstable compound nucleus. The ${ }^{17} \mathrm{O}$ compound nucleus releases some of its excess energy by emitting an alpha particle $\left({ }^{4} \alpha\right)$ :

$$
{ }^{17} \mathrm{O}+{ }^{1} \mathrm{n}-\cdots---->>{ }^{14} \mathrm{C}+{ }^{4} \alpha \text {. }
$$

This reaction is often referred to as a $(n, \alpha)$ reaction. The reaction can also be written as

$$
{ }^{17} \mathrm{O}(\mathrm{n}, \alpha){ }^{14} \mathrm{C} \text {. }
$$




\section{Waste and Disposal Data on Carbon-14}

This section discusses the types of activities that generate ${ }^{14} \mathrm{C} L L W$, waste types and forms that contain ${ }^{14} \mathrm{C}$, and disposal data on ${ }^{14} \mathrm{C}$ LLW.

\section{Nuclear Reactors}

Neutron activation of nitrogen-14 $\left({ }^{14} \mathrm{~N}\right)$, an impurity found in nonfuel reactor components, produces ${ }^{14} \mathrm{C}$. The activated metals waste type contains a substantial amount of ${ }^{14} \mathrm{C}$. Additional ${ }^{14} \mathrm{C}$ produced in the coolant may add to the contamination of other waste types. These waste types include ion-exchange resins, concentrated liquids, filter sludge, cartridge filters, and trash.

Activated Metals. Nonfuel reactor parts generated as waste during normal operations can contain ${ }^{14} \mathrm{C}$ because of neutron activation. Some of these parts include fuel channels, control rods, control rod channels, shim rods, in-core instrumentation, and flux wires. In addition, disposal of internal reactor parts containing ${ }^{14} \mathrm{C}$ occurs during decommissioning. Examples of internal reactor parts are the core shroud, core barrel, thermal shield, upper and lower grid plates, and lower support columns. These matsrials contain ${ }^{14} \mathrm{C}$ atoms dispersed throughout the metal.

Ion-Exchange Resins. Light Water Reactors (pressurized water reactors and boiling water reactors) use ion-exchange resins to remove unwanted dissolved ions, including radioactive ions, from liquids. Since the chemical form of ${ }^{14} \mathrm{C}$ generated in the reactor coolant is the carbonate ion, anion-exchange resins are used to remove free carbonate.

Ion-exchange resins are usually packed into cylindrical columns and the liquid containing the radioactive ions is passed through the columns. The carbonate ion chemically displaces ions on the resins and becomes chemically bound to the resin. When the sites that can bind the ions on the resin are expended, the resin is transferred to a shipping container (liner) and excess water is removed.

Concentrated Liquids. The evaporation of a variety of liquid wastes at a reactor produces concentrated liquid wastes, also called "evaporator bottoms." They contain up to $25 \%$ suspended and dissolved solids. Liquid wastes that may be evaporated at a reactor include liquids from laundry operations, floor drains, decontamination work, and laboratory drains.

Filter Sludge. This waste type consists of both the filter material (precoat filter) and the thin layer of dissolved radioactive solids retained by the filter. Typical filter material include high purity cellulose or a mixture of powdered anion and cation exchange resins. These resins improve the ability of the filter to trap radioactive contaminants.

Cartridge Filters. Cartridge filters trap suspended radioactive solids in various reactor liquids; however, they do not have the superior ion-exchange capacity found in precoat filters. The filters are constructed of woven cotton and nylon or matted paper supported by a stainless steel brace. Many nuclear power plants use cartridge filters in combination with precoat filters, evaporators, and ionexchange columns to remove suspended radioactive solids and dissolved radioactive ions from liquids used in the operation of a reactor. 
Trash. Trash and dry active waste (DAW) generated during LWR operations are diverse in content and can contain everything ranging from paper towels and latex gloves to irradiated reactor hardware. Trash and DAW can be classified as compactible or noncompactible. In general, compactible trash consists of combustible material like paper and rubber products. Noncompactible trash contains noncombustible metallic parts such as pipes and failed equipment.

Several nuclear power plant waste types, such as liquid waste and evaporator bottoms, may contain ${ }^{14} \mathrm{C}$. These wastes are combined with cement or other solidifying media before disposal. It is not necessary to solidify wastes, such as dry filters, although some plants do so to reduce radiation exposure. The practice of solidifying dewatered ion-exchange resins is not widespread in the U.S. However, the development of more stringent disposal requirements at new LLW disposal facilities may make it more common.

Compaction or incineration reduces large volumes of trash generated at nuclear utilities. Compaction changes only the density of the waste, not its chemical properties. Incineration produces contaminated ash, which is often solidified with cement.

Activated metal containing ${ }^{14} \mathrm{C}$ is a common reactor waste form. In this form, ${ }^{14} \mathrm{C}$ is unavailable to biological activity and will not release for transport because it exists in the metal as elemental carbon. ${ }^{4}$ Nonfuel reactor components such as control rods, instrumentation for the core, neutron-absorbing curtains, and flow channels are usually cut in small pieces to reduce the packaging volume of the waste. They are then suspended in cement and sealed. Activated metals have been shown to corrode at a rate of only $1 \mathrm{~mm} / \mathrm{yr}$ after solidification. ${ }^{4}$ These ${ }^{14} \mathrm{C}$-containing corrosion products are not soluble in water.

\section{Medical and Academic Institutions}

${ }^{14} \mathrm{C}$ appears in a wide variety of compounds used in hospitals, medical schools, universities, research, industries, classroom projects, and nuclear medicine procedures. LLW resulting from these procedures include liquid scintillation vials, absorbed aqueous and organic liquids, calibration standards, biological wastes, and trash. Trash consists of items such as paper products, laboratory glassware, and rubber gloves.

The amount of ${ }^{14} \mathrm{C}$ contained in this type of waste is small compared to other types of waste. However, the volume of this waste can be quite large. Efforts are often taken to reduce the volume of this waste type prior to disposal through incineration or compaction.

Preparation for disposal usually includes placing liquid wastes into an absorbing media such as vermiculite, silica, and clays. These absorbing materials may eventually be combined with solidification media. Biological wastes are normally incinerated in preparation for disposal, resulting in a decrease in volume. The remains are solidified. Sealed sources can be encapsulated in cement before being placed in a waste disposal container. 


\section{Leaching from Waste Forms}

Leaching from waste forms is accelerated if the waste is in contact with water. A leach test determines the magnitude of leaching. A leach test involves exposing a waste form containing radionuclides to a solution (leachate) for extended periods of time and measuring the amount of radioactive material that releases or "leaches" into the leachate solution.

A parameter that quantifies the sorption of a radionuclide on a waste form is called the waste form distribution coefficient, $\mathrm{K}_{\mathrm{d}}$. A waste form $\mathrm{K}_{\mathrm{d}}$ is expressed in $\mathrm{mL} / \mathrm{mg}$ and is defined as follows:

$$
\mathrm{K}_{\mathrm{d}}=\frac{\text { Concentration of radionuclide in waste form }(\mathrm{mg} / \mathrm{mg})}{\mathrm{y}}
$$

The Environmental Protection Agency's (EPA) draft environmental impact statement on proposed rules for low-level and NARM (naturally occurring or accelerator-produced radioactive materials) radioactive wastes, Volume $1,{ }^{8}$ lists waste form $\mathrm{K}_{\mathrm{d}}$ values for ${ }^{14} \mathrm{C}$ in a variety of waste forms at three types of LLW environmental settings: a humid site that has a permeable soil, an arid site with permeable soil, and a humid site having soil that has a low permeability.

\section{Disposal Data on Carbon-14}

${ }^{14} \mathrm{C}$ has been deposited in three LLW sites in Richland, Washington; Barnwell, South Carolina; and Beatty, Nevada over a period of several years. Data have been obtained on the activity, sources, and waste types for this nuclide from the Manifest Information Management System Database. ${ }^{a}$ Figure 3-1 shows the total annual ${ }^{14} \mathrm{C}$ activity deposited in the three sites for each year between 1986 and 1995 . Significant amounts of this nuclide have been deposited in each of the years listed-more than $100 \mathrm{Ci}$ per year with the exception of 1995 , when $98 \mathrm{Ci}$ were deposited. However, nearly two-thirds of the total were deposited between 1989 and 1992.

Figure 3-2 shows the activity of ${ }^{14} \mathrm{C}$ deposited in these three sites as a function of waste source. Two sources, industry and utilities, account for more than $97 \%$ of the total deposited. The other three sources split the remaining $3 \%$ approximately equally. The definition of disposal categories given in Figure 3-2 is as follows: academic - sources associated with university laboratories; government sources associated with the government, such as military hospitals; industry - sources associated with manufacturing, other than utilities; medical - sources associated with hospitals and medical laboratories, excluding pharmaceutical manufacturing; utility - sources generated by nuclear utilities and stored onsite or sent to one of the three disposal sites. Waste treatment facilities are included in the utility category.

a. Information provided through the DOE waste management system maintained by the National Low-Level Waste Management Program, Idaho National Engineering Laboratory (INEL). 


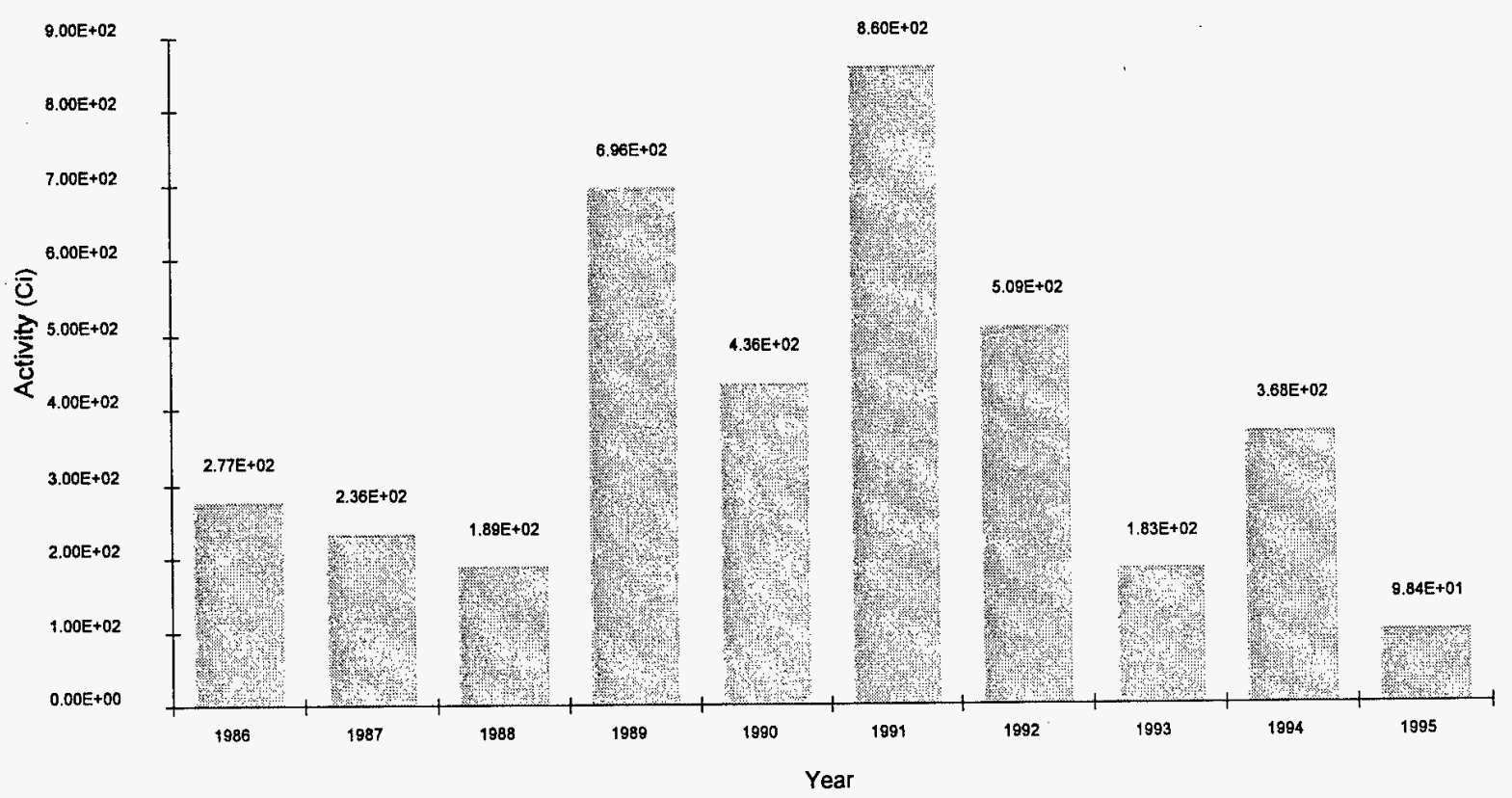

Figure 3-1. ${ }^{14} \mathrm{C}$ activity deposited at Richland, Beatty, and Barnwell sites by year (log scale).

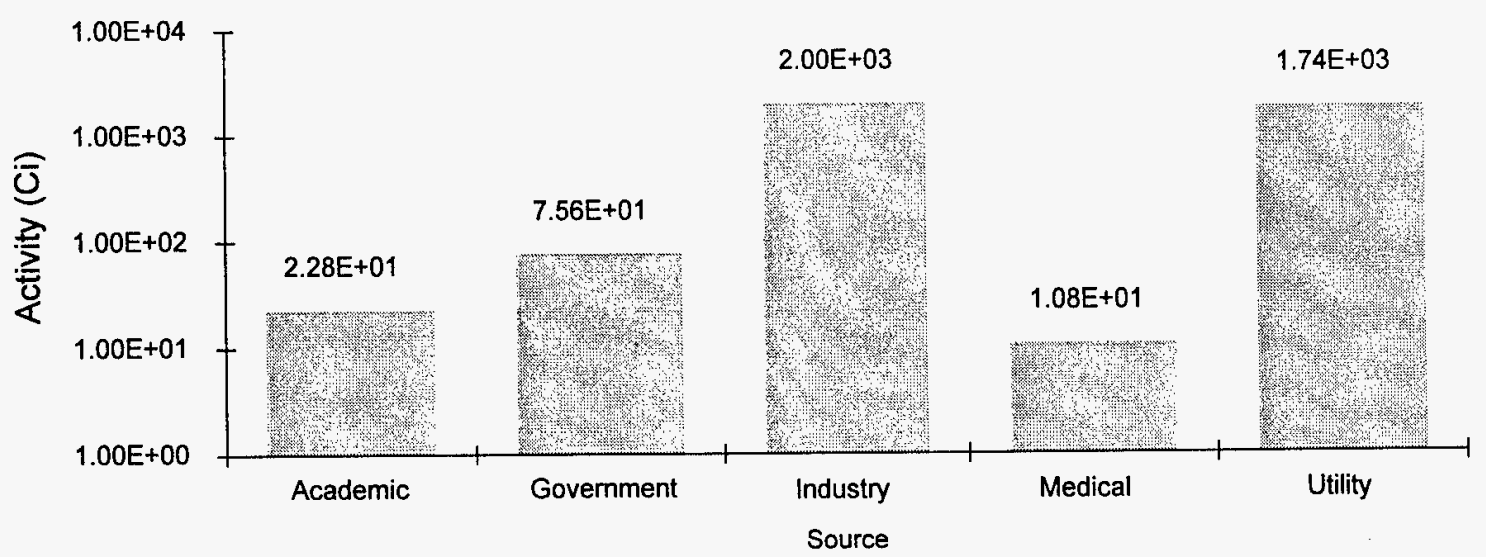

Figure 3-2. ${ }^{14} \mathrm{C}$ activity deposited at the Richland, Beatty, and Barnwell sites by source (log scale).

Figure 3-3 shows the activity of ${ }^{14} \mathrm{C}$ deposited in the Richland and Beatty sites as a function of waste type. The waste disposal manifests for the Barnwell site did not break down the waste by type, which is unfortunate since most of this nuclide (57\%) is stored at this site. Of the waste types listed in the data base, dry solid waste accounts for nearly $60 \%$ of the total storage. Only two other waste types list more than $100 \mathrm{Ci}$, compacted dry waste and solidified waste. The remaining waste is approximately uniformly distributed among the other nine types. The waste types illustrated in Figure 3-3 are from nuclear reactors, academic institutions, and medical facilities. 


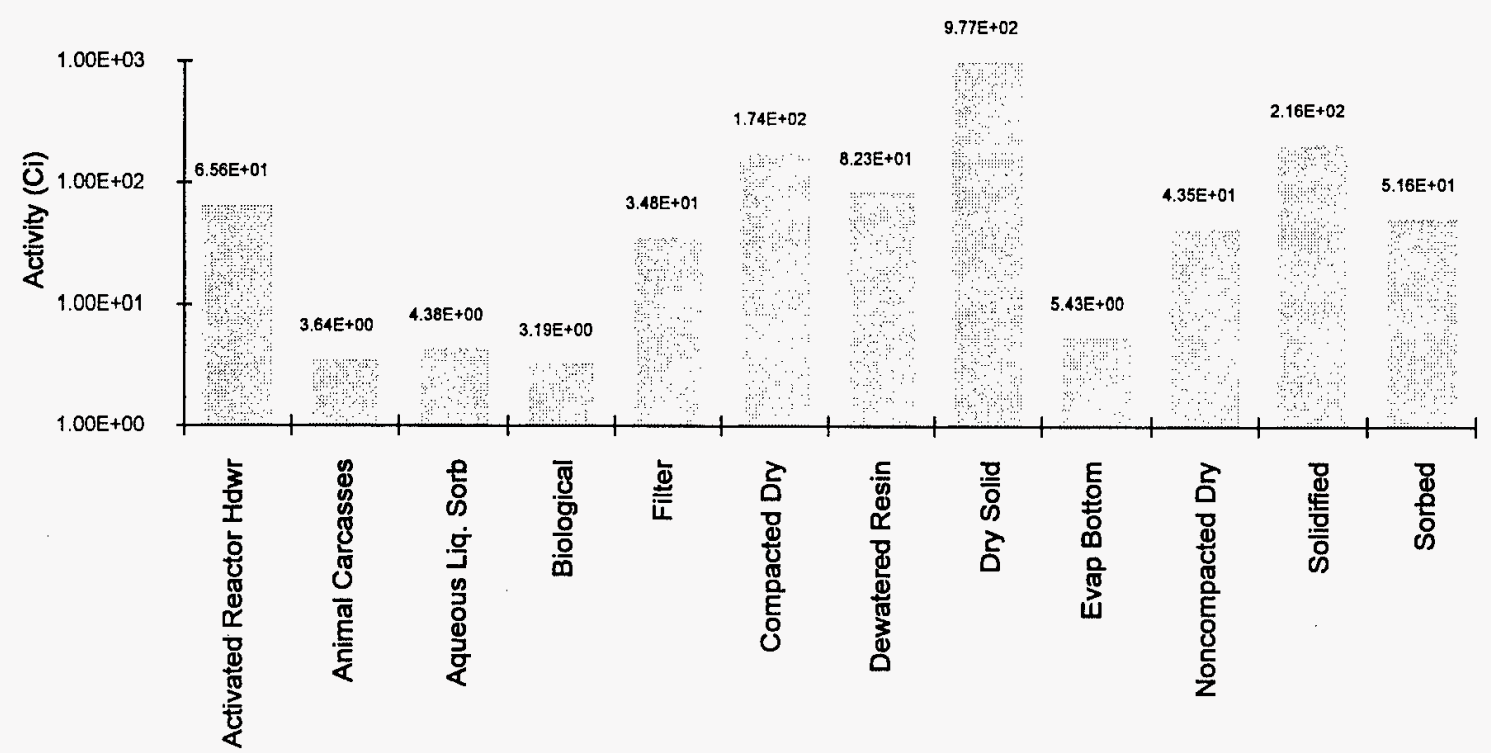

Figure $3-3 .{ }^{14} \mathrm{C}$ activity deposited at the Richland and Beatty sites by waste type (log scale).

\section{Behavior of Carbon-14 in the Environment}

This section discusses the behavior of ${ }^{14} \mathrm{C}$ in various media of the LLW disposal environment soils, plants, water, and the atmosphere. An understanding of this information is crucial during attempts to model the performance of a potential LLW disposal facility.

The main routes for ${ }^{14} \mathrm{C}$ entry into the environment are from natural activation of atmospheric ${ }^{14} \mathrm{~N}$ by cosmic ray interactions, fallout from nuclear weapons testing, nuclear power plant emissions, and, potentially, releases from radioactive waste disposal facilities. Carbon dioxide $\left({ }^{14} \mathrm{CO}_{2}\right)$ and bicarbonate $\left(\mathrm{H}^{14} \mathrm{CO}_{3}{ }^{-}\right)$would be the predominant forms of ${ }^{14} \mathrm{C}$ released from a radioactive waste disposal facility. This is of concern because of the wide dispersement of carbon dioxide, its incorporation by plants, and the high solubility of the bicarbonate ion.

\section{Carbon-14 in Soils}

The absorption or adsorption (sorption) of carbonate/bicarbonate in soils is low. This is due in part to the inability of most soils to act as good anion exchangers ${ }^{9}$ and the high solubility of bicarbonate. The inability of soils to act as anion exchangers is due to the net negative charge on the surface of most soil materials and rock. Some clays, however, do have coatings of aluminum or iron that carry a positive charge. This allows for a limited sorption on these specific media. Another possible mechanism is specific adsorption, which leads to positively charged sites and an attraction and sorption of negatively charged ions with a low $\mathrm{pH}$. 
For most safety analyses, the soil distribution coefficient $\left(\mathrm{K}_{d}\right)$ is conservatively assumed to be zero. The soil distribution coefficient is defined as the concentration of radionuclide sorbed on the soil divided by the concentration of radionuclide remaining in the fluid phase:

$$
\mathrm{K}_{\mathrm{d}}=\frac{\text { Concentration of radionuclide sorbed on soil }(\mathrm{mg} / \mathrm{mg})}{\text { Concentration of radionuclide in solution }(\mathrm{mg} / \mathrm{mL})}
$$

A study was commissioned by EPRI and performed by scientists at AECL to measure $\mathrm{K}_{d}$ values for ${ }^{14} \mathrm{C}$ two different soils and two different carbon chemical forms. ${ }^{9}$ For the carbonate form, the $\mathrm{K}_{\mathrm{d}}$ values were 6 and $1.2 \mathrm{~mL} / \mathrm{g}$ for the high acidic and low acidic, high-carbonate soils, respectively. For an organic PCB form, the values were 49 and $22 \mathrm{~mL} / \mathrm{g}$, indicating much more holdup in the soil for the organic-based chemical form.

\section{Carbon-14 in Plants}

The incorporation of ${ }^{14} \mathrm{C}$ into the structure of plants is primarily through the uptake of carbon dioxide during the photosynthetic process. A very small amount of ${ }^{14} \mathrm{C}$ may enter the plant through the root system from groundwater or soil. Since every process occurring within plants involves carbon, it is difficult to follow its metabolic pathway. Little has been reported on the effects of radiocarbon on plants.

Carbon dioxide is taken into plants through small pore openings on their leaves called stomata. Since air fills most of the cellular spaces in plants, the carbon dioxide can move through the entire plant until it reaches the wall of a cell. The cell metabolizes the carbon dioxide to manufacture other compounds, such as glucose or other sugars, lipids, amino acids, and nucleotides.

The plants' systems incorporate ${ }^{14} \mathrm{C}$ in the same manner as nonradioactive carbon. A potential exists for the modification of essential organic compounds by the decay of the ${ }^{14} \mathrm{C}$ to ${ }^{14} \mathrm{~N}$. The results could be small mutations or other variations in normal plant functions.

Reference 9 summarizes an investigation into the concentration ratios for ${ }^{14} \mathrm{C}$ in both carbonate and organic-PCB chemical forms and in high acidic and low acidic/high carbonate soils. This ratio for the carbonate form was 0.7 and 1.3 (dry weight basis) for the high acidic and low acidic soils, respectively. For the organic-PCB form, the values were 0.014 and 0.088 , respectively.

\section{Carbon-14 in Water}

The main forms of ${ }^{14} \mathrm{C}$ of concern for groundwater transport are bicarbonate and carbonate. Bicarbonate is produced during the dissolution of calcium carbonate into water with a $\mathrm{pH}$ of 6.5 to 9 , or in the dissolving of carbon dioxide. These two categories encompass essentially all of the ${ }^{14} \mathrm{C}$ activity in the waste disposal site available for groundwater transport.

Many groundwater reservoirs are already near saturation with regard to carbonate and bicarbonate because of the high natural abundance of calcium carbonate. This results in the dilution and diminished 
solubility of the carbonate ion. The contamination under these saturated conditions results largely from ion exchange, that is, $\mathrm{Ca}^{14} \mathrm{CO}_{3}$ dissolving as $\mathrm{Ca}^{12} \mathrm{CO}_{3}$ is precipitated out.

Groundwater sources should not be contaminated by metals activated by ${ }^{14} \mathrm{C}$. The ${ }^{14} \mathrm{C}$ found in activated metals is expected to remain in the disposal site because (a) ${ }^{14} \mathrm{C}$ atoms are dispersed throughout the metal matrix, (b) most of the metals are corrosion resistant, (c) the corrosion products are, in general, insoluble in either freshwater or seawater, (d) the carbon is in elemental form, and thus unavailable for microbial activity. ${ }^{4}$

Reference 10 summarizes a study that characterized the release of ${ }^{14} \mathrm{C}$ from three different PWRs. This study concluded that less than $5 \%$ of the total release was in the form of liquid and solid waste more than $95 \%$ was gaseous release. This is consistent with a study performed by the Bhabha Atomic Research Centre in Bombay, India, wherein the liquid effluent release of ${ }^{14} \mathrm{C}$ from the Rajasthan Atomic Power Station pressurized heavy-water reactors is estimated to be of the order of $0.2 \%$ of the gaseous release. ${ }^{10}$

Measurements were made of the ${ }^{14} \mathrm{C}$ concentration in samples from three reactors. ${ }^{11}$ The water concentrations ranged from 0.01 to $2.4 \mathrm{~d} / \mathrm{s} / \mathrm{mL}$.

\section{Carbon-14 in Air}

Carbon released from an LLW disposal facility is in the form of carbon dioxide or methane. After long periods of exposure to air, methane oxidizes to carbon dioxide. Upon entry into the atmosphere, ${ }^{14} \mathrm{CO}_{2}$ is diluted by the naturally abundant ${ }^{12} \mathrm{CO}_{2}$. The major area of concern is in the immediate vicinity of the ${ }^{14} \mathrm{CO}_{2}$ release, before the ${ }^{14} \mathrm{C}$ dilutes. The higher concentration increases the chances of incorporation into biologically important molecules.

Before the advent of man-made disruptions of the ${ }^{14} \mathrm{C}$ atmospheric concentration, this nuclide was produced by cosmic rays impinging on the atmosphere, resulting in a steady-state concentration. ${ }^{12}$ Since the middle of the $19^{\text {th }}$ century, two distinctly different man-originated disruptions of this concentration have occurred. First, the burning of fossil fuel released large quantities of ${ }^{14} \mathrm{C}$-free carbon (in the form of $\mathrm{CO}_{2}$ ), which diluted the concentration of this nuclide in the atmosphere. Second, atmospheric testing of nuclear weapons resulted in large quantities of ${ }^{14} \mathrm{C}$ being released into the atmosphere, artificially increasing the concentration of this nuclide. The first phenomenon resulted in a $3 \%$ decrease in the naturally occurring concentration of ${ }^{14} \mathrm{C}$. The second phenomenon resulted in a doubling of the ${ }^{14} \mathrm{C}$ concentration.

In addition to atmospheric weapons testing, which was discontinued several decades ago, ${ }^{14} \mathrm{C}$ can also be released into the atmosphere because of nuclear power plant operation. A study was made of the venting of this nuclide from the R. E. Ginna PWR in New York during full power operations in $1980 .{ }^{13}$ Based on air samples from the vent, it was estimated that as much as $14 \mathrm{Ci} / \mathrm{GW}(\mathrm{c}) /$ year could be released. A later study showed that $12 \mathrm{Ci} / \mathrm{GW}(\mathrm{e}) /$ year was released from this plant during this year. ${ }^{9}$ This study also concluded that 9.6 and $12.4 \mathrm{Ci} / \mathrm{GW}(\mathrm{e}) /$ year were released from the Indian Point Unit 3 and J. A. Fitzpatrick PWRs, respectively, during the same time. 


\section{Direct Exposure from Carbon-14}

Radiation doses resulting from the direct exposure of ${ }^{14} \mathrm{C}$ is negligible. The beta particle emitted by ${ }^{14} \mathrm{C}$ is fairly weak and is not able to penetrate any containment (steel drums, solidification media) typically used in its disposal.

\section{Behavior of Carbon-14 in the Human Body}

Radiocarbons behave as normal carbon when entering the body. They can be retained as proteins, fats, carbohydrates, and other materials. ${ }^{3}$ The most likely pathways of uptake for humans are inhalation or ingestion. The allowable limit on uptake (ALI) for humans is $270 \mu \mathrm{Ci}$ for inhalation or ingestion. $\mathrm{ALI}$, the annual intake of a year committed effective dose equivalent attributable to intake during that year, is $\leq 50$ rem for limiting stochastic effects. Another measure of intake is the derived air concentration (DAC) or the concentration of a radionuclide aerosol allowed if breathed by a reference man for a working year of 2000 hours that would result in one $\mathrm{ALI}$ by inhalation. For ${ }^{14} \mathrm{C}$ it is $1.6 \times 10^{-7}$ $\mu \mathrm{Ci} / \mathrm{cm}^{3}$ (Reference 3).

Inhaled ${ }^{14} \mathrm{CO}_{2}$ enters the bloodstream by passing through the alveolar membranes of the lungs and reaching an equilibrium with the $\mathrm{CO}_{2}$ already in the bloodstream. The inhaled or ingested carbon can enter the citric acid (Krebs) cycle by natural biochemical reactions. The citric acid cycle is the system of biochemical reactions by which the human body obtains energy from ingested food. After entering the cycle, the ${ }^{14} \mathrm{C}$ may, through a complex series of reactions and molecular rearrangements, enter virtually all of the organic components of the body, albeit in very dilute amounts, ${ }^{3}$ and seems to accumulate in bone or fat tissues more than in others. However, most tissues affected by ${ }^{14} \mathrm{C}$ inhalation or ingestion have a fairly high turnover rate. The biological half-life of ${ }^{14} \mathrm{C}$ in the whole body is about ten days.

The digestive tract absorbs ingested carbon. The normal human body expels roughly the same amount of carbon as it takes in through ingestion. It is uncertain how much of the carbon that is expelled is from the sample ingested and how much is from previously ingested material.

Reference 12 summarizes a study of ${ }^{14} \mathrm{C}$ absorbed in humans-specifically, the ratio of ${ }^{13} \mathrm{C}$ to ${ }^{14} \mathrm{C}$ in blood protein. A comparison of this ratio in humans in the 1950s and 1960s to that expected to have existed prior to atmospheric nuclear weapons testing revealed that this testing caused a decrease by a factor of 60 in the ratio. Reference 15 summarizes a study that showed that bomb-generated ${ }^{14} \mathrm{C}$ resulted in a $50 \%$ increase in the ${ }^{14} \mathrm{C}$ concentration in human hair and blood.

Reference 16 summarizes a study about the effects of bomb-generated ${ }^{14} \mathrm{C}$ on humans. This study showed that the bomb-related ${ }^{14} \mathrm{C}$ dose to the bone-lining cells and soft-tissue/bone marrow results in a 25 and $50 \%$ increase in concentration, respectively. 


\section{Summary}

Before the advent of manmade disruptions of the ${ }^{14} \mathrm{C}$ atmospheric concentration, this nuclide was produced by cosmic rays impinging on the atmosphere, resulting in a steady-state concentration. Presently, the principal means of producing ${ }^{14} \mathrm{C}$ is in a nuclear reactor by neutron activation of stable nitrogen-14 and stable oxygen-17. The fission process of the reactor supply the large source of neutrons necessary to induce the neutron activation.

Low-level radioactive wastes that contain ${ }^{14} \mathrm{C}$ include activated metals from reactors, sealed sources, and animal carcasses from research laboratories.

The half-life of ${ }^{14} \mathrm{C}$ is 5,730 years. It is quite mobile in groundwater systems. Another concern is that ${ }^{14} \mathrm{C}$ is very volatile in air and is absorbed by plants in the form of carbon dioxide $\left({ }^{14} \mathrm{CO}_{2}\right) \cdot{ }^{14} \mathrm{C}$ is easily transported in water in the form of carbonate or bicarbonate.

${ }^{14} \mathrm{C}$ is a beta emitter with a maximum energy of $0.156 \mathrm{MeV}$. Direct radiation (outside of the body) from ${ }^{14} \mathrm{C}$ is negligible. The real danger is internal. Inhaled or ingested, ${ }^{14} \mathrm{C}$ can affect many of the biochemical reactions in the human body. Although ${ }^{14} \mathrm{C}$ is expelled from the body in a short time, it is known to accumulate in bone tissue. 


\section{References}

1. Nuclear Regulatory Commission, Draft Environmental Impact Statement on 10 CFR Part 61, "Licensing Requirements for Land Disposal of Radioactive Waste," NUREG-0782, Vol. 1, September 1981.

2. William Walker et al., Chart of the Nuclides, U.S. Department of Energy, 14th Ed., revised April 1988.

3. National Council for Radiation Protection, Carbon-14 in the Environment, NCRP Report No. 81, 1985 .

4. James M. Gruhlke, James Neiheisel, and Lewis Battist, Estimates of the Quantities, Form, and Transport of Carbon-14 in LLW, EPA 520/1-86-019, September 1986.

5. V. J. Sharpe, Microbial Effects--Radioactive Waste Disposal Summary Report, OH-85-271-K, October 1985.

6. Robert R. Landolt, The Diffusion of ${ }^{1+} \mathrm{CO}_{2}$ through Engineered Barrier Media, Purdue University.

7. Clifford A. Hampel (ed.), "Carbon," The Encyclopedia of the Chemical Elements, New York: Reinhold Book Corporation, 1968, pp. 106-119.

8. U.S. Environmental Protection Agency, Low-Level and NARM Radioactive Wastes Draft Environmental Impact Statement for Proposed Rules, Vol. 1, Background Information Document, EPA-520/1-87-012-1, June 1988.

9. M. I. Sheppard, et al., Soil-to-Plant Transfer of Carbon-14 for Environmental Assessment of Radioactive Waste Repositories, EPRI NP-6946, August 1990.

10. C. Kunz, "Carbon-14 Discharge at Three Light-Water Reactors," Health Physics, Vol. 49, No. 1, July 1985 , pp. 25-35.

11. L. Joshi, B. Ramamirtham, and S. D. Soman, "Measurement of ${ }^{14} \mathrm{C}$ Emission Rates from a Pressurized Heavy Water Reactor," Health Physics, Vol. 52, 1987, pp. 787.

12. G. K. Knowles, "Carbon-14 in Reactor Plant Water," Conference on Analytical Chemistry in Energy Technology, Gatlinburg, Tenn, October 9, 1979, pp. 10.

13. D. D. Harkness and A. Walton, "Carbon-14 in the Biosphere and Humans," Nature, Vol. 223, 1969, pp. 1216.

14. C. O. Kunz, "Continuous Stack Sampling for ${ }^{14} \mathrm{C}$ at the R. E. Ginna Pressurized Water Reactor," Transactions of the American Nuclear Society, Vol. 38, 1981, pp. 100-101.

15. R. Nydal, K. Lovseth, and O. Syrstad, "Bomb ${ }^{14} \mathrm{C}$ in the Human Population," Nature, Vol. 232, 1971, pp. 418.

16. M. J. Stenhouse and M. S. Baxter, "Bomb ${ }^{14} \mathrm{C}$ and Human Radiation Burden," Nature, Vol. 267, No. 5614, 30 June 1977, pp. 825-827. 


\section{Bibliography}

Anderson, K., Nuclide Solubilities and Distribution Coefficients for Use in Probabilistic Modeling, SKI-87132, January 1988.

Anderson, M. R., and J. F. Pankow, "A Case Study of a Chemical Spill: Polychlorinated Biphenyls (PCBs) 3, PCB Sorption and Retardation in Soil Underlying the Site," Water Resources, Vol. 22, 1986, pp. 1051-1057.

Arteca, R. N., and B. W. Poovaiah, "Absorption of ${ }^{14} \mathrm{CO}_{2}$ by Potato Roots and Its Subsequent Translocation," Journal of American Society of Horticultural Science, Vol. 107, 1982, pp. 398-401.

Bacci, E., and C. Gaggi, "Polychlorinated Biphenyls in Plant Foliage: Translocation or Volatilization from Contaminated Soils?" Bulletin of Environmental Contamination Toxicology, Vol. 35, 1985, pp. 673-681.

Berlin, Robert E., and Catherine C. Stanton, Radioactive Waste Management, New York: John Wiley \& Sons, Inc., 1989.

Browne, E., R. B. Firestone, and J. Wiley, Table of Radioactive Isotopes, 1986.

Bush, B., L. A. Shane, L. R. Wilson, E. L. Barnard, and D. Barnes, "Uptake of Polychlorobiphenyl Congeners by Purple Loosestrife (Lythrum Salicaria) on the Banks of the Hudson River," Environmental Contamination Toxicology, Vol. 15, 1986, pp. 285-290.

Chiou, C. T., P. E. Porter, and D. W. Schmeddling, "Partition Equilibria of Nonionic Organic Compounds Between Soil Organic Matter and Water," Environmental Science Technology, Vol. 17, 1983, pp. 227-231.

Chou, S. F. J., and R. A. Griffin, "Solubility and Soil Mobility of Polychlorinated Biphenyls," PCBs and the Environment, editor J. S. Waid, Boca Raton, Florida: CRC Press Inc., 1986, pp. 101-120.

Coughtrey, P. J., D. J. Nancarrow, and D. Jackson, "The Assessment of Terrestrial Pathways of Radionuclides to Man: Experimental Studies on C-14 and H-3 Transfers in Soils and Plants," Associated Nuclear Services Report No. 555-1, 1985.

CRC Handbook of Chemistry and Physics, 66th Ed., Boca Raton, Florida: CRC Press, 1985.

Denmead, O. T., "Temperate Cereals," Vegetation in the Atmosphere, J. L. Monteith (ed.), Volume 2, pp. 1-31, Academic Press, London, 1976.

Electric Power Research Institute, Soil-to-Plant Transfer of Carbon-14 for Environmental Assessment of Radioactive Waste Repositories, EPRI NP-6946, August 1990.

Electric Power Research Institute, Proceedings: 1987 EPRI PCB Seminar, Electric Power Research Institute Project 2028, EPRI EA/EL-5612, Palo Alto, California, 1988. 
Fries, G. F., and G. S. Marrow, "Clorobiphenyl Movement from Soil to Soybean Plants," Journal of Agricultural Food Chemistry, Vol. 29, 1981, pp. 757-759.

Gracheva, L. M., and V. G. Korolev, Dr. V. S. Kothekar (ed.), Dr. (Mrs.) V. Kothekar (trans.), Genetic Effects of the Decay of Radionuclides in Cells, English version: New Delhi, India: Amerind Publishing Co. Pvt. Ltd., 1980, pp. 39-46. Russian (original): Moscow, Russia: Atomizdat Publishers, 1977.

Hawker, D. W., and D. W. Connell, "Octanol-Water Partition Coefficients of Polychlorinated Biphenyl Congeners," Environmental Science Technology, Vol. 22, 1988, pp. 382-387.

Higuchi, T., K. Yoda, and K. Tensho, "Further Evidence for Gaseous $\mathrm{CO}_{2}$ Transport in Relation to Root Uptake of $\mathrm{CO}_{2}$ in Rice Plant," Soil Science Plant Nutrition, Vol. 30, 1984, pp. 125-136.

Karickhoff, S. W., D. S. Brown, and T. A. Scott, "Sorption of Hydrophobic Pollutants on Natural Sediments," Water Resources, Vol. 13, 1979, pp. 241-248.

Keeley, J. E., C. B. Osmond, and J. A. Raven, "Stylites, a Vascular Land Plant Without Stomata Absorbs $\mathrm{CO}_{2}$ Via Its Roots," Nature, Vol. 310, 1984, pp. 694-695.

Keeton, William T., James L. Gould, and Carol Grant Gould, Biological Science, New York: W. W. Norton and Co., 1986, pp. 274-280.

Klepper, B., D. G. Watson, and J. F. Cline, "Iodine-129 Concentration Factors for Food Products," Pacific Northwest Laboratory Annual Report for 1975 to the USERDA Division of Biomedical and Environmental Research, Part 2 Ecological Sciences, BNWL-2000 PT2:179, 1976.

Lee, M. C., R. A. Griffin, M. L. Miller, and E. S. K. Chian, "Adsorption of Water-Soluble Polychlorinated Biphenyl Aroclor 1242 and Used Capacitor Fluid by Soil Materials and Coal Chars," Journal of Environmental Science Health, A14, 1979, pp. 415-442.

Lindsay, W. L. ,Chemical Equilibria in Soils, New York: John Wiley and Sons, 1979.

Meyer-Spasche, H. and H. W. Scharpenseel, "Background ${ }^{14} \mathrm{C}$ Concentration in Soils and Its Transfer to Man," Pflanzenernaehr. Bodenkd., Vol. 143, 1980, pp. 537-545.

McKay, H. A. C., "Background Considerations in the Immobilization of Volatile Radionuclides, in Management of Gaseous Wastes from Nuclear Facilities," Proceedings of an International Symposium on Management of Gaseous Wastes from Nuclear Facilities, February 18-22, 1980, Vienna, Austria.

Moore, T. R., and R. Knowles, "The Influence of Water Table Levels on Methane and Carbon Dioxide Emissions from Peatland Soils," Journal of Soil Science, Vol. 69, 1989, pp. 33-38. 
Moza, P., I. Weisgerber, and W. Klein, "Fate of 2,2'-dichlorobiphenyl- ${ }^{14} \mathrm{C}$ in Carrots, Sugar Beets and Soil Under Outdoor Conditions," Journal of Agricultural Food Chemistry., Vol. 24, 1976, pp. 881-885.

National Council for Radiation Protection, Tritium and Other Radionuclide Labeled Organic Compounds Incorporated in Genetic Material, NCRP Report No. 63, 1979.

New York State Department of Environmental Conservation, Draft Environmental Impact Statement for Promulgation of 6 NYCRR Part 382: Regulations for LLW Disposal Facilities, New York State Department of Environmental Conservation, Division of Regulatory Affairs, Bureau of Energy and Radiation, July 1987.

Ng, Y. C., C. A. Burton, S. E. Thompson, R. K. Tandy, H. K. Kretner, and M. W. Pratt, "Prediction of the Maximum Dosage to Man from the Fallout of Nuclear Devices-IV," Handbook for Estimating the Maximum Internal Dose from Radionuclides Released to the Biosphere, Lawrence Radiation Laboratory, University of California, Livermore, California, Report UCRL-50163, 1968.

Oztunali, O. I., and G. W. Roles, Update of Part 61, Impacts Analysis Methodology, NUREG/CR-4370, 1986.

Pelkonen, P., E. M. Vapaavuori, and H. Vuorinen, " $\mathrm{HCO}_{3}$ Uptake Through the Roots in Willow and Sunflower and Effect of $\mathrm{HCO}_{3}$ Uptake on the Productivity of Willow Cuttings," Proceedings of the International Conference on Energy from Biomass, Elsevier Applied Sciences Publications, London, 1985, pp. 417-421.

Pine, Stanley H. ,Organic Chemistry, New York: McGraw-Hill, 1987.

Raven, J. A., L. L. Handley, J. J. MacFarlane, S. McInroy, L. McKenzie, J. H. Richards, and G. Samuelsson, "The Role of $\mathrm{CO}_{2}$ Uptake by Roots and CAM in Acquisition of Inorganic $\mathrm{C}$ by Plants of the Isoetid Life-Form: A Review, with New Data on Eriocaulon Decangulare L.," New Phytologist, Vol. 108, 1988, pp. 125-148.

Schäfer, W., "Plant Growth After Application of $\mathrm{CO}_{2} / \mathrm{HCO}_{3}$ to the Root System," Journal of Agronomy Crop Science, Vol. 160, 1988, pp. 228-234.

Shane, L. A., and B. Bush, "Accumulation of Polychlorobiphenyl Congeners and P,p'-DDE at Environmental Concentrations by Corn and Beans," Ecotoxicology and Environmental Safety, Vol. 17, 1989, pp. 38-46.

Sheppard, S. C., and W. G. Evenden, "Comparison of Partition Coefficients for ${ }^{54} \mathrm{Mn}$ and Soil Extractable Mn, Including Relationship to Plant Uptake," Canadian Journal of Soil Science, 1989, (in press).

Sheppard, S. C., and W. G. Evenden, "Characteristics of Plant Concentration Ratios Assessed in a 64Site Field Survey of 23 Elements," Journal of Environmental Radioactivity, 1989, (in press). 
Sheppard, S. C., and W. G. Evenden, "Mobility and Uptake by Plants of Elements Placed Near a Shallow Water Table Interface," Journal of Environmental Quality, Vol. 14, 1985, pp. 554-560.

Sheppard, M. I., D. H. Thibault, and J. H. Mitchell, "Element Leaching and Capillary Rise in Sandy Soil Cores: Experimental Results," Journal of Environmental Quality, Vol. 16, 1987, pp. 273-284.

Sheppard, M. I., D. I. Beals, D. H. Thibault, and P. O'Connor, Soil Nuclide Distribution Coefficients and Their Statistical Distributions, Atomic Energy of Canada Limited Report, AECL-8364, 1984.

Sheppard, M. I., S. C. Sheppard, and D. H. Thibault, "Uptake by Plants and Migration of Uranium and Chromium in Field Lysimeters," Journal of Environmental Quality, Vol. 13, 1984, pp. 357-361.

Sheppard, M. I., The Soil Model for Concept Assessment of Canada's Nuclear Fuel Waste Management Program, Atomic Energy of Canada Limited Report, AECL-9577, 1990.

Simpson, Linda, and L. L. Bennett, Jr., "Biological Effects of Carbon-14 Incorporated into Nucleic Acids of Mouse Embryos," Radiation Research, 17, 1962, pp. 145-157.

Sternberg, L. da, "A Model to Estimate Carbon Dioxide Recycling in Forests Using ${ }^{13} \mathrm{C} /{ }^{12} \mathrm{C}$ Ratios and Concentrations of Ambient Carbon Dioxide," Agricultural Meteorology, Vol. 48, 1989, pp. 163-173.

Stolwijk, J. A. J., and K. V. Thimann, "On the Uptake of Carbon Dioxide and Bicarbonate by Roots, and Its Influence on Growth," Plant Physiology, Vol. 32, 1957, pp. 513-520.

Taylor, P. ,Solubility and Stability of Inorganic Carbonates, AECL-9073, 1987.

Taylor N. K., (ed.), Organics in Radwaste, AERE-R-13079, 1988.

Tucker, E. S., W. J. Litschgi, and W. M. Mees, "Migration of Polychlorinated Biphenyls in Soil Induced by Percolating Water," Bulletin of Environmental Contamination Toxicology, Vol. 13, 1975, pp. 86-93.

Videm, Dugstad and Ketil, Evaluation of Hydrogen Production from $\mathrm{CO}_{2}$ Corrosion of Steel Drums in SFR, Part 2, SKI-86058, June 1987.

Wada, H., T. Yokoyama, and Y. Takai, "Movement of $\mathrm{CO}_{2}$ from the Rhizosphere of Rice to the Top and Its Discharge Into the Atmosphere," Journal of Science of Soil and Manure, Vol. 54, 1983, pp. 217-222.

Wershaw, R. L., "A New Model for Humic Materials and Their Interactions with Hydrophobic Organic Chemicals in Soil-Water or Sediment-Water Systems," Journal of Contamination Hydrology, Vol. 1, 1986, pp. 29-45.

Wirth, E., "The Applicability of the ${ }^{14} \mathrm{C}-$ Specific Activity Model," Health Physics, Vol. 43, 1982, pp. 919-922. 
Worobey, B. L., "Fate of 3,3', 4,4'-tetrachloroazobenzene in Soybean Plants Grown in Treated Soils," Chemosphere, Vol. 13, 1984, pp. 1103-1111. 


\section{IODINE-129}

\section{Introduction}

This chapter discusses the basic radiological, chemical, and physical characteristics of iodine-129 $\left({ }^{129} \mathrm{I}\right)$, and examines how these characteristics affect the behavior of ${ }^{129} \mathrm{I}$ in various environmental media such as soils, water, plants, the atmosphere, and the human body. Also included are methods of ${ }^{129} \mathrm{I}$ production and waste and disposal data on ${ }^{129} \mathrm{I}$.

Iodine-129 is a long-lived radionuclide present in low-level radioactive waste (LLW) generated at nuclear power plants. Disposing of ${ }^{129} \mathrm{I}$-contaminated waste at LLW disposal facilities is a concern to site developers and regulators because ${ }^{129} \mathrm{I}$ is highly mobile in groundwater. The U.S. NRC in its Draft EIS on 10 CFR Part 61, "Licensing Requirements for Land Disposal of Radioactive Waste,"1 identified ${ }^{129} \mathrm{I}$ as one of four radionuclides (along with tritium, ${ }^{14} \mathrm{C}$, and ${ }^{99} \mathrm{Tc}$ ) that will require site-specific considerations to ensure that performance objectives for long-term environmental protection are met.

A radionuclide considered sensitive at one LLW disposal facility may not be considered sensitive at another facility. The behavior of a radionuclide at a particular LLW disposal site will depend primarily upon the radiological, chemical, and physical characteristics of the waste, and the inventory of the radionuclide. The behavior of a radionuclide also depends upon the geology, hydrology, and climate at the disposal site. This chapter describes characteristics and potential difficulties in dealing with ${ }^{129} \mathrm{I}$. However, since ${ }^{129} \mathrm{I}$ behavior and appropriate handling, storage, or disposal will vary depending on particular sites or waste form, this chapter does not attempt to discuss the extent of a difficulty or appropriate solutions. Each disposal site facility design should consider and address the specific waste content and behavior under that site's particular circumstances.

\section{Radiological Characteristics}

${ }^{129} \mathrm{I}$ is a long-lived radionuclide with a half-life of 16 million years. When it undergoes radioactive decay, the nucleus of ${ }^{129} \mathrm{I}$ emits a beta particle with an energy ranging from zero to a maximum value of 0.150 million electron volts $(\mathrm{MeV})$. In addition, ${ }^{129} \mathrm{I}$ emits two internal conversion electrons with energies of 0.005 and $0.034 \mathrm{MeV}$. The decay of ${ }^{129} \mathrm{I}$ results in the formation of stable xenon- $129\left({ }^{129} \mathrm{Xe}\right)$ :

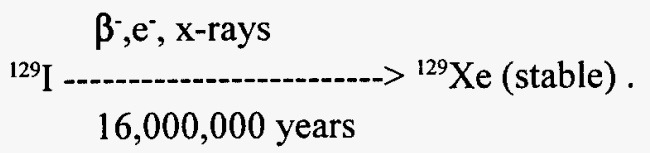

The parent of ${ }^{129} \mathrm{I}$ is tellurium-129 $\left({ }^{129} \mathrm{Te}\right)$. The nucleus of ${ }^{129} \mathrm{Te}$ emits a single beta particle with a maximum energy of $1.45 \mathrm{MeV} .{ }^{129} \mathrm{Te}$ can also emit internal conversion electrons with energies of 0.022 and $0.026 \mathrm{MeV}$, and iodine $x$-rays with energies of $0.027,0.275,0.455,0.081$, and $1.080 \mathrm{MeV}$. The half-life of ${ }^{129} \mathrm{Te}$ is 68.7 minutes. 


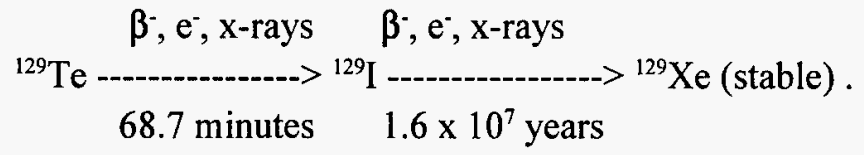

Twenty-three isotopes of iodine exist with mass numbers ranging from 117 to 139 . The only stable species of iodine is ${ }^{127} \mathrm{I}^{2}$

The $0.150 \mathrm{MeV}$ beta particle that the nucleus of ${ }^{129} \mathrm{I}$ emits is fairly weak in energy compared to the emissions of other common beta emitters, as shown in Table 4-1:

Table 4-1. Comparison of ${ }^{129} \mathrm{I}$ beta emissions with emissions from other radionuclides.

\begin{tabular}{ll}
\hline Radionuclide & Maximum Energy $(\mathrm{MeV})$ \\
\hline Tritium $\left({ }^{3} \mathrm{H}\right)$ & 0.019 \\
Iodine-129 $\left({ }^{129} \mathrm{I}\right)$ & $\mathbf{0 . 1 5 0}$ \\
Carbon-14 $\left({ }^{14} \mathrm{C}\right)$ & 0.156 \\
Technetium-99 $\left({ }^{99} \mathrm{Tc}\right)$ & 0.293 \\
Chlorine-36 $\left({ }^{36} \mathrm{Cl}\right)$ & 0.709 \\
Iodine-131 $\left({ }^{131} \mathrm{I}\right)$ & 0.806 \\
Potassium-40 $\left({ }^{40} \mathrm{~K}\right)$ & 1.330 \\
Phosphorous-32 $\left({ }^{32} \mathrm{P}\right)$ & 1.710 \\
\hline
\end{tabular}

\section{Chemical and Physical Characteristics}

The iodine atom has a large radius that makes reactions with other elements and compounds readily reversible. Its electron structure makes it possible for iodine to exist in oxidation states ranging from -1 to +7 . The three most common oxidation states are 0 (elemental iodine, $\mathrm{I}_{2}$ ), -1 (iodide ion, $\mathrm{I}^{-}$), and +5 (iodate ion, $\mathrm{IO}_{3}^{-}$). Discussions of these three oxidation states of ${ }^{129} \mathrm{I}$ follow.

\section{Elemental lodine $\left(I_{2}\right)$}

Iodine, like other members of the halogen family (e.g., fluorine, bromine, chlorine), is chemically active in its elemental state. In addition to having a larger ion radius than common halogens, iodine also has a much lower electronegativity (2.5). Electronegativity is the tendency of an atom to attract electrons of other atoms in a molecule to itself. The change in electronegativity between bromine and iodine is much greater than between any of the other halogens. This accounts for the relatively high degree of instability and reactivity of iodide compounds compared to corresponding bromide and chloride compounds. 
Elemental iodine forms compounds with all of the other elements except the noble gases, sulfur, and selenium. It can react directly with carbon, nitrogen, or oxygen, but only at high temperatures. Iodine reacts with metals, except for copper and silver, to form volatile iodides. ${ }^{3}$

\section{lodide (I)}

The hydrolysis of elemental iodine forms the iodide ion and hypoiodous acid (HIO) (Reference 3):

$$
\mathrm{I}_{2}+\mathrm{H}_{2} \mathrm{O}<======\Rightarrow \mathrm{HOO}+\mathrm{H}^{+}+\mathrm{I}^{-} .
$$

Hydrolysis is a type of reaction characterized by water breaking apart a molecule. In the process, water itself is broken apart to form $\mathrm{OH}^{-}$and $\mathrm{H}^{+}$. These ions can join with the products of the reaction. Elemental iodine is not hydrolyzed to the extent of the other halogens, and, therefore, this reaction is reversible. In low $\mathrm{pH}$ conditions, most of the iodine present is elemental iodine; at $\mathrm{pH}$ of 8 or greater, the iodide ion predominates.

The hypoiodous acid formed in the above reaction can dissociate into the hypoiodite ( $\left.\mathrm{IO}^{-}\right)$ion. This occurs because the large size of iodine is not conducive to stable compounds:

$$
\mathrm{HIO}<=====\mathrm{H}^{+}+\mathrm{IO}^{-} \text {. }
$$

High concentrations of elemental iodine and iodide facilitate tri-iodide formation $\left(\mathrm{I}_{3}{ }^{-}\right)$:

$$
\mathrm{I}_{2}+\mathrm{I}^{\cdot}-\cdots>\mathrm{I}_{3}^{-}
$$

The tri-iodide ion formed above can form polyhalide salts. Polyhalide salts are ionic compounds composed of more than one halogen. This can be two or more of the same or different halogens in a myriad of combinations. Large cations like cesium combine best with tri-iodide to form a stable polyhalide salt, cesium tri-iodide $\left(\mathrm{CsI}_{3}\right)$ :

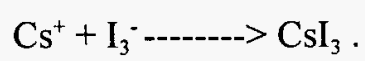

\section{lodate Ion $\left(\mathrm{IO}_{3}{ }^{-}\right)$}

The iodate ion is the most common form of iodine in highly basic solutions; at low $\mathrm{pH}$ the acid form $\left(\mathrm{HIO}_{3}\right)$ predominates.

\section{lodine Reactions with Organics}

Iodine reacts with organic compounds in the same manner as the other halogens. There is a weak carbon-iodine bond; therefore, the energy released during these reactions is small and many reactions are readily reversible. ${ }^{3}$ For example, propanol $\left(\mathrm{CH}_{3}\left(\mathrm{CH}_{2}\right)_{2} \mathrm{OH}\right)$ reacts with hydroiodic acid $(\mathrm{HI})$ to produce iodopropane $\left(\mathrm{CH}_{3}\left(\mathrm{CH}_{2}\right)_{2} \mathrm{I}\right)$ and water.

$$
\mathrm{CH}_{3}\left(\mathrm{CH}_{2}\right)_{2} \mathrm{OH}+\mathrm{HI}<===>\mathrm{CH}_{3}\left(\mathrm{CH}_{2}\right)_{2} \mathrm{I}+\mathrm{H}_{2} \mathrm{O} \text {. }
$$


Elemental iodine, iodide, and the iodate ion can react with organic compounds. The iodide free radical reacts with methane to form iodomethane $\left(\mathrm{CH}_{3} \mathrm{I}\right)$. Methane is common at an LLW facility because of the decomposition of organic materials. This is a free radical reaction, but most typical iodide reactions with organics take place with iodine in the -1 valence state and two available electrons. The formation of the free radical takes a long time. It also needs a catalyst, such as heat, but once the first one has been formed the reaction is self-propagating.

$$
\mathrm{I}_{2}-\cdots>\mathrm{I}^{-}+\mathrm{CH}_{4}-\cdots-\cdots>\mathrm{CH} 3 \mathrm{I}+\mathrm{I}^{-}
$$

Iodomethane $\left(\mathrm{CH}_{3} \mathrm{I}\right)$ reacts with sulfur or metals under certain environmental conditions and releases tin, lead, and mercury from the soil or rocks into the water. ${ }^{4,5}$ Iodine can also react with organics containing double bonds, breaking these bonds and attaching to the newly opened site. It reacts with humic acids in soils by adding directly to a benzene ring structure.

The stability diagram in Figure 4-1 depicts the predominance of $\mathrm{I}_{2}, \mathrm{I}^{\circ}$, and $\mathrm{IO}_{3}{ }^{\circ}$ over a wide range of oxidation reduction potential and $\mathrm{pH}$ conditions. Oxidation, reduction, potential, or the redox potential, is a parameter that measures the likelihood of a chemical species to undergo an oxidation or reduction reaction. As the redox potential increases at lower $\mathrm{pH}(2-8)$, iodate and then periodate $\left(\mathrm{IO}_{4}^{-}\right)$are formed. At low redox potential, iodide is the only form despite changes in $\mathrm{pH}$. High $\mathrm{pH}$ and high redox potential lead to $\mathrm{IO}_{5}{ }^{3-}$ formation. ${ }^{6}$

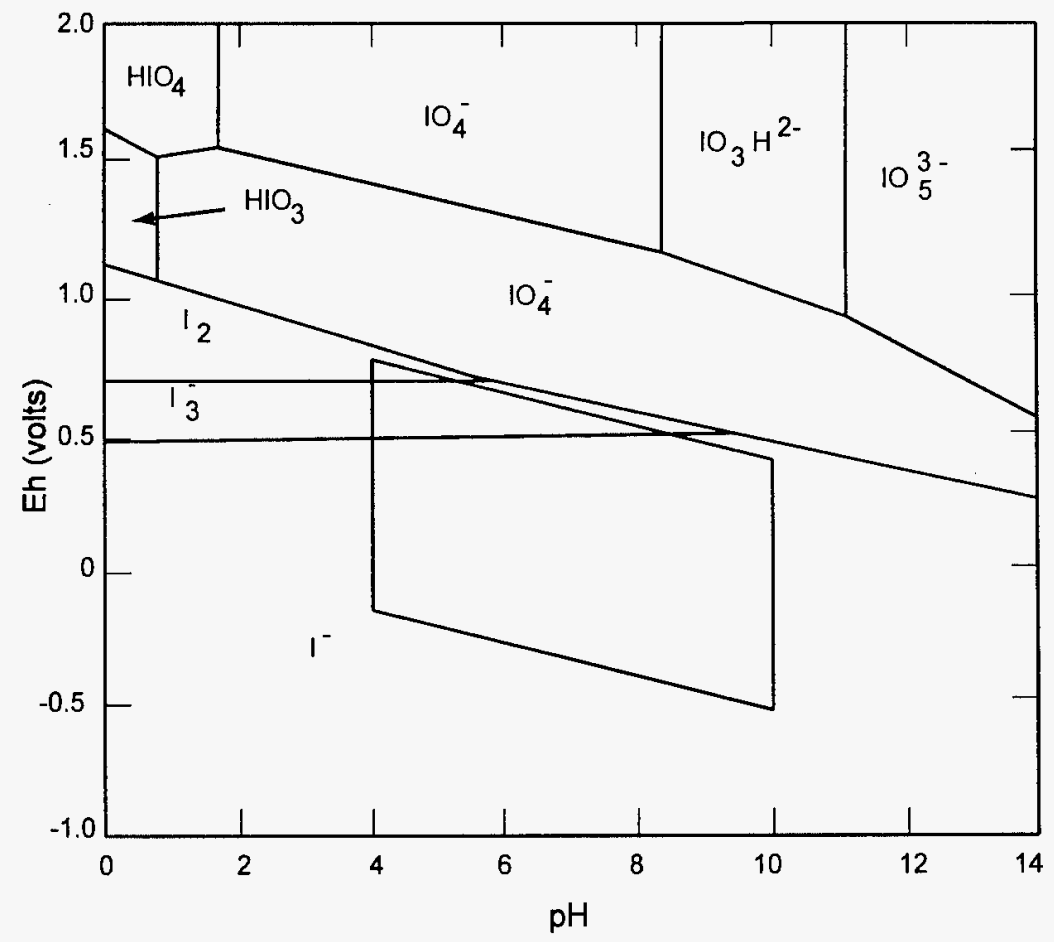

Figure 4-1. Speciation of iodine in water as function of $\mathrm{pH}$ and redox potential. 


\section{lodine-129 Production}

${ }^{129} \mathrm{I}$ is not a naturally occurring radionuclide. Thermal fission of uranium and plutonium in nuclear reactors produces ${ }^{129} \mathrm{I}$. The cumulative fission yield of ${ }^{129} \mathrm{I}$ is about $1 \%$ of all fission products.

The following mechanism contributes to the cumulative fission yield of ${ }^{129} \mathrm{I}$ during the fission of uranium-233 $\left({ }^{233} \mathrm{U}\right)$, uranium-235 $\left({ }^{235} \mathrm{U}\right)$, and plutonium-239 $\left({ }^{239} \mathrm{Pu}\right)$ contained in the nuclear fuel. The decay of antimony-129 $\left({ }^{129} \mathrm{Sb}\right)$ produces ${ }^{129} \mathrm{I}$ by the following decays:

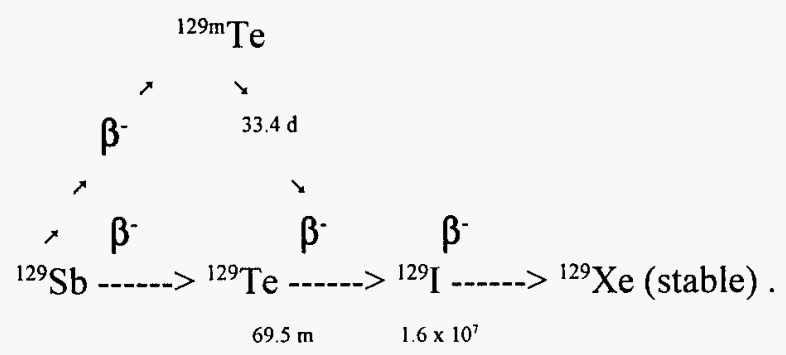

Figure 4-2 indicates that antimony-129 $\left({ }^{129} \mathrm{Sb}\right)$, with a mass number of 129 , has a cumulative fission yield of approximately $1.0 \%$ due to the thermal fission of both ${ }^{233} \mathrm{U}$ and ${ }^{239} \mathrm{Pu}$. Since ${ }^{129} \mathrm{I}$ also has a cumulative fission yield of approximately $1.0 \%$; this indicates that all of the ${ }^{129} \mathrm{I}$ produced in a reactor is a result of ${ }^{129} \mathrm{Sb}$ decay.

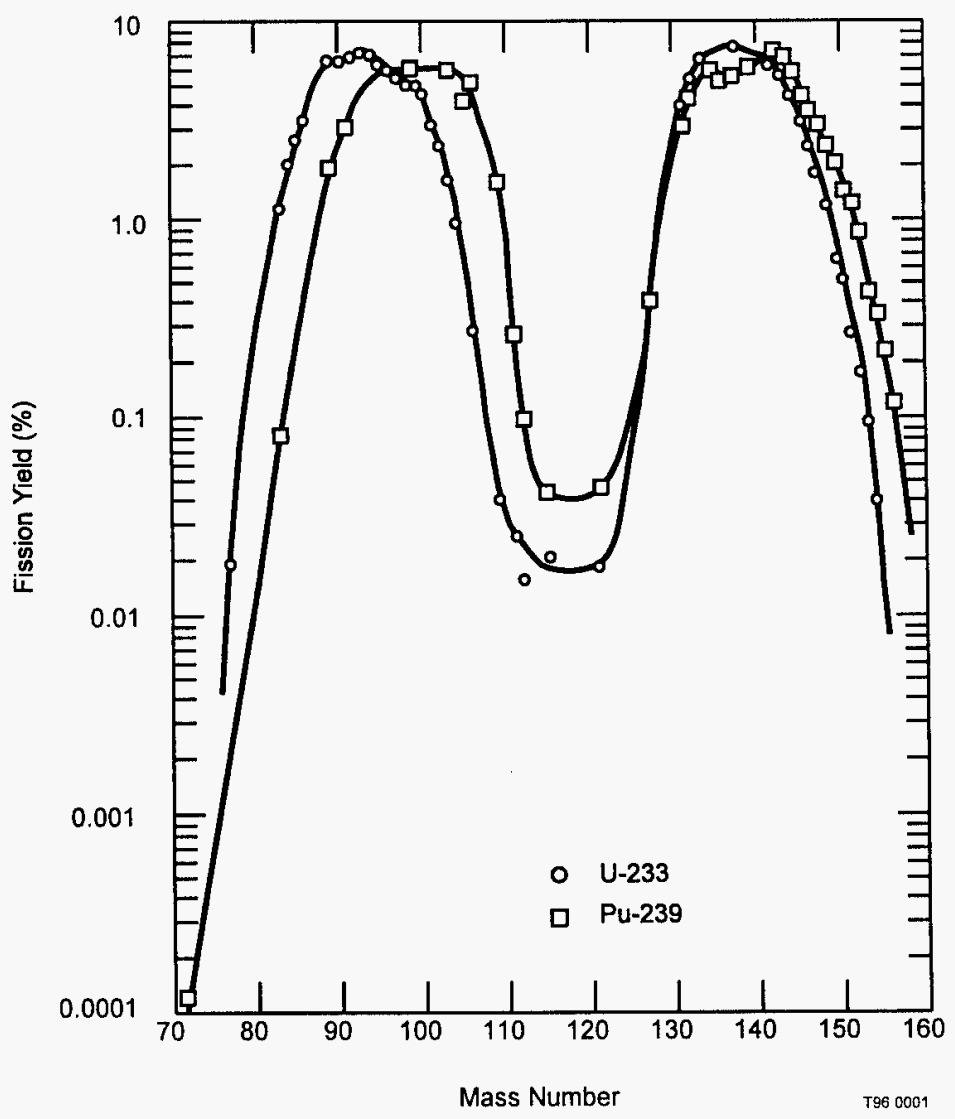

Figure 4-2. Fission-product distributions from thermal-neutron fission of ${ }^{233} \mathrm{U}$ and ${ }^{239} \mathrm{Pu}$. 


\section{Waste and Disposal Data on lodine-129}

This section discusses the types of activities that generate ${ }^{129} \mathrm{I} \mathrm{LLW}$, waste types and forms that contain ${ }^{129} \mathrm{I}$, and disposal data on ${ }^{129} \mathrm{I}$.

A variety of nuclear power plant waste types contain ${ }^{129} \mathrm{I}$, a fission product continuously produced in a reactor core. The predominant chemical forms of ${ }^{129} \mathrm{I}$ found in reactor waste types are the iodate and iodide ions and elemental iodine. The following waste types are common to light water nuclear reactors (boiling water and pressurized water reactors) and would most likely contain iodate and iodide ions and iodine.

\section{lon-Exchange Resins}

LWRs use ion-exchange resins to remove dissolved ions, including radioactive ions, from liquids. Since the chemical form of ${ }^{129} \mathrm{I}$ generated at reactors is predominantly anionic, the anion exchange resins are used to remove free ${ }^{129} \mathrm{I}$. However, anion resins are not the best method for removing iodine from liquids because of iodine's highly soluble nature. Most iodine is generally removed in an activated carbon filter that precedes the ion-exchange columns. These activated carbon filters are then dewatered and/or solidified into a waste form ready for disposal.

Ion-exchange resins are usually packed into cylindrical columns and the liquid containing the unwanted ions passes through the columns. The $\mathrm{I}^{-}$and $\mathrm{IO}_{3}{ }^{-}$ions chemically displace the ions on the anion resin and become chemically or physically bound to the resin. When the sites that can bind the ions on the resin are expended, the resin is transferred to a shipping container (liner). Any excess water is then removed.

\section{Concentrated Liquids}

The evaporation of a variety of liquid wastes at a reactor produces concentrated liquid wastes, otherwise known as "evaporator bottoms." They contain up to $25 \%$ suspended and dissolved solids. Liquids wastes that may be evaporated at a reactor include liquids from laundry operations, floor drains, decontamination work, and laboratory drains.

\section{Filter Sludge}

This waste type consists of both the filter material (precoat filter) and the thin layer of dissolved and suspended radioactive solids retained by the filter. Typical filter material can include high purity cellulose, or a mixture of powdered anion and cation exchange resins to improve the ability of the filter to trap contaminants. The iodate and iodide ions can be trapped by these filters and become incorporated in the filter sludge.

\section{Cartridge Filters}

Cartridge filters trap suspended solids in various reactor liquids; however, they do not have the superior ion-exchange capacity found in precoat filters. The filters are constructed of woven cotton and nylon, or matted paper supported by a stainless steel brace. Many nuclear plants use cartridge filters in 
combination with precoat filters, evaporators, and ion-exchange columns to remove suspended solids and dissolved radioactive ions from liquids used in the operation of a reactor.

\section{Trash}

Trash and dry active waste (DAW) generated during light-water reactor operations can contain everything ranging from paper towels and latex gloves to reactor hardware. Trash and DAW can be classified as compactible or noncompactible. In general, compactible DAW consists mainly of combustible material like paper products and noncompactible DAW contains metallic components such as pipes and failed equipment.

\section{Decommissioning Waste}

Decommissioning will produce large volumes of LLW in the form of contaminated concrete and metal vessels and piping. This waste will contain the same radionuclides found in noncompactible dry active waste generated during plant operations. Therefore, the ${ }^{129} \mathrm{I}$ species will also be contained in these waste types.

\section{lodine-129 Inventory}

It is difficult to accurately determine the inventory (expressed in curies) of ${ }^{129} \mathrm{I}$ in nuclear fuel cycle waste for two reasons. First, ${ }^{129} \mathrm{I}$ is not as abundant as other fission products common to these waste types. Second, ${ }^{129}$ I emits a beta particle with a maximum energy of only $0.150 \mathrm{MeV}$ and the radiations of

${ }^{129} I$ are masked by more energetic emissions from other radionuclides. Consequently, a precise inventory of ${ }^{129} \mathrm{I}$ in nuclear reactor waste can usually only be attained by analyzing individual waste samples. This approach is impractical from an economic, manpower, and radiation control (as low as reasonably achievable) standpoint; therefore, estimates of ${ }^{129} I$ inventory are used for completing shipping manifest forms.

Since the inventory of ${ }^{129} \mathrm{I}$ in nuclear reactor waste types is relatively small compared to other fission products, power plant personnel have often used the lower limit of detection (LLD) of ${ }^{129} \mathrm{I}$ as a conservative estimate of its inventory. The LLD of a radionuclide is dependent upon several factors, including the energy of the radionuclide's emissions and the efficiency of the counting system.

Scaling factors are used to estimate the inventory of radionuclides like ${ }^{129} \mathrm{I}^{7}$ The scaling factor methodology involves determining an inventory ratio of easy-to-detect fission products, such as ${ }^{137} \mathrm{Cs}$, to difficult-to-detect species, such as ${ }^{129} \mathrm{I}$. Once the ratio or scaling factor is established for a pair of radionuclides, it can be used in the future to determine the activity of difficult-to-detect radionuclides in nuclear power waste.

The development of scaling factors indicated that using LLDs grossly overestimated the inventory of fission products like ${ }^{129} \mathrm{I}$ in waste. Therefore, the ${ }^{129} \mathrm{I}$ waste inventory values used in preliminary performance assessments of LLW facilities resulted in projecting greater final doses to the public than should reasonably be expected from ${ }^{129}$ I. The Electrical Power Research Institute (EPRI) is validating a computer code developed by Vance and Associates, Inc., that predicts how much ${ }^{129} \mathrm{I}$ is generated during fission processes and how much is distributed to each waste type. Analyses and measurements made by 
Vance and Associates to date indicate that the actual amounts of these isotopes in LLW are smaller than the amounts based on the LLD by several orders of magnitude. EPRI is performing ${ }^{129}$ I measurements on ion-exchange columns placed on reactor coolant sample lines. The measurement data will be compared against Vance and Associates' model prediction values. ${ }^{7}$

Class B and C LLW is treated to obtain waste forms that will be structurally stable at an LLW disposal facility in the long term. In addition, waste forms should provide safeguards against the potential release of radionuclides into the environment. The following gives examples of LLW forms in which ${ }^{129}$ I may be found.

\section{Nuclear Reactor Waste Forms}

Several nuclear power plant waste types that contain ${ }^{129} \mathrm{I}$ are usually solidified into a cementitious waste form. All liquid wastes including evaporator bottoms must be solidified before disposal. It is not necessary to solidify dry filters, though some plants do to reduce dose rates. The practice of solidifying dewatered ion-exchange resins is not widespread in the United States. However, the development of additional disposal requirements at new LLW disposal facilities may make it more common.

The large volume of trash generated at nuclear utilities may be reduced by compaction or incineration. Compaction changes only the density of the waste, not its chemical properties. Incineration produces contaminated ash that is often solidified with cement.

\section{Leaching from Waste Forms}

Leaching from waste forms is greatly enhanced if the waste form comes into contact with water. The magnitude of leaching can be determined by a leach test. A leach test involves exposing a waste form containing radionuclides to a solution (leachate) for extended periods of time and measuring the amount of radioactive material that releases or "leaches" into the leachate solution.

There is a parameter that quantifies the sorption of a radionuclide on a waste form called the waste form distribution coefficient, $\mathrm{K}_{\mathrm{d}}$. A waste form $\mathrm{K}_{\mathrm{d}}$ is usually expressed in $\mathrm{mL} / \mathrm{mg}$ and can be defined as follows:

$$
\mathrm{K}_{\mathrm{d}}=\frac{\text { Concentration of radionuclide in waste form }(\mathrm{mg} / \mathrm{mg})}{\text { Concentration of radionuclide in solution }(\mathrm{mg} / \mathrm{mL})}
$$

The Environmental Protection Agency's (EPA) draft EIS for proposed rules for LLW and NARM (naturally occurring or accelerator-produced radioactive materials) radioactive wastes, Volume 1, lists waste form $\mathrm{K}_{d}$ values for ${ }^{129} \mathrm{I}$ in a variety of waste forms at three types of LLW environmental settings: a humid site that has a permeable soil, an arid site with permeable soil, and a humid site with impermeable soil. $^{8}$

It may be inappropriate to apply one waste form $K_{d}$ value for ${ }^{129} I$ to all waste forms disposed of at an LLW facility that may contain the ${ }^{129} \mathrm{I}$ species. The spectrum of waste types and waste forms is too diverse. ${ }^{129} \mathrm{I}$ does not behave the same in all waste forms because of its chemical characteristics. 


\section{Disposal Data on lodine-129}

${ }^{129} \mathrm{I}$ has been deposited in three LLW sites in Richland, Washington; Barnwell, South Carolina; and Beatty, Nevada over a period of several years. Data have been obtained on the activity, sources, and waste types related to the deposition for this nuclide in these sites from the Manifest Information Management System Data Base. ${ }^{\mathrm{a}}$ Figure 4-3 shows the total annual ${ }^{129}$ I activity deposited in the three sites for each year between 1986 and 1995. There have not been significant deposits of this, less than 2 Ci per year during this time.

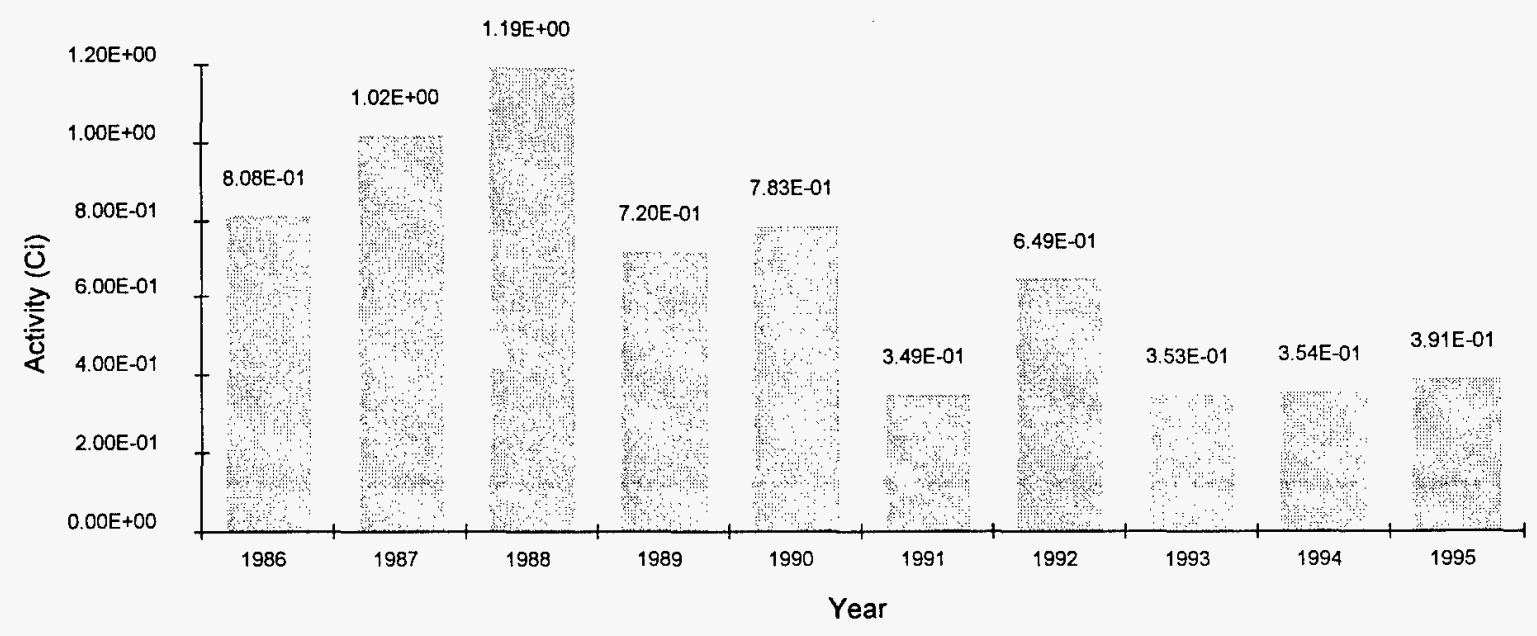

Figure 4-3. ${ }^{129} \mathrm{I}$ activity deposited at the Richland, Beatty, and Barnwell sites by year (log scale).

Figure 4-4 shows the activity of ${ }^{\mathrm{I} 29} \mathrm{I}$ deposited in these three sites as a function of waste source. Two sources, industry and utilities, account for more than $99 \%$ of the total deposited. The other three sources split the remaining $1 \%$ approximately equally. The definition of disposal categories given in Figure 4-4 is as follows: academic - sources associated with university laboratories; government sources associated with the government, such as military hospitals; industry - sources associated with manufacturing, other than utilities; medical - sources associated with hospitals and medical laboratories, excluding pharmaceutical manufacturing; utility - sources generated by nuclear utilities and stored onsite or sent to one of the three disposal sites. Waste treatment facilities are included in the utility category.

Figure 4-5 shows the activity of ${ }^{129} \mathrm{I}$ deposited in the Richland and Beatty sites as a function of waste type. The waste disposal manifests for the Barnwell site did not break down the waste by type, which is unfortunate since most of this nuclide (93\%) is stored at this site. The waste types illustrated in Figure 4-5 are from nuclear reactors, academic institutions, and medical facilities.

a. Information provided through the DOE waste management system maintained by the National Low-Level Waste Management Program, Idaho National Engineering Laboratory (INEL). 


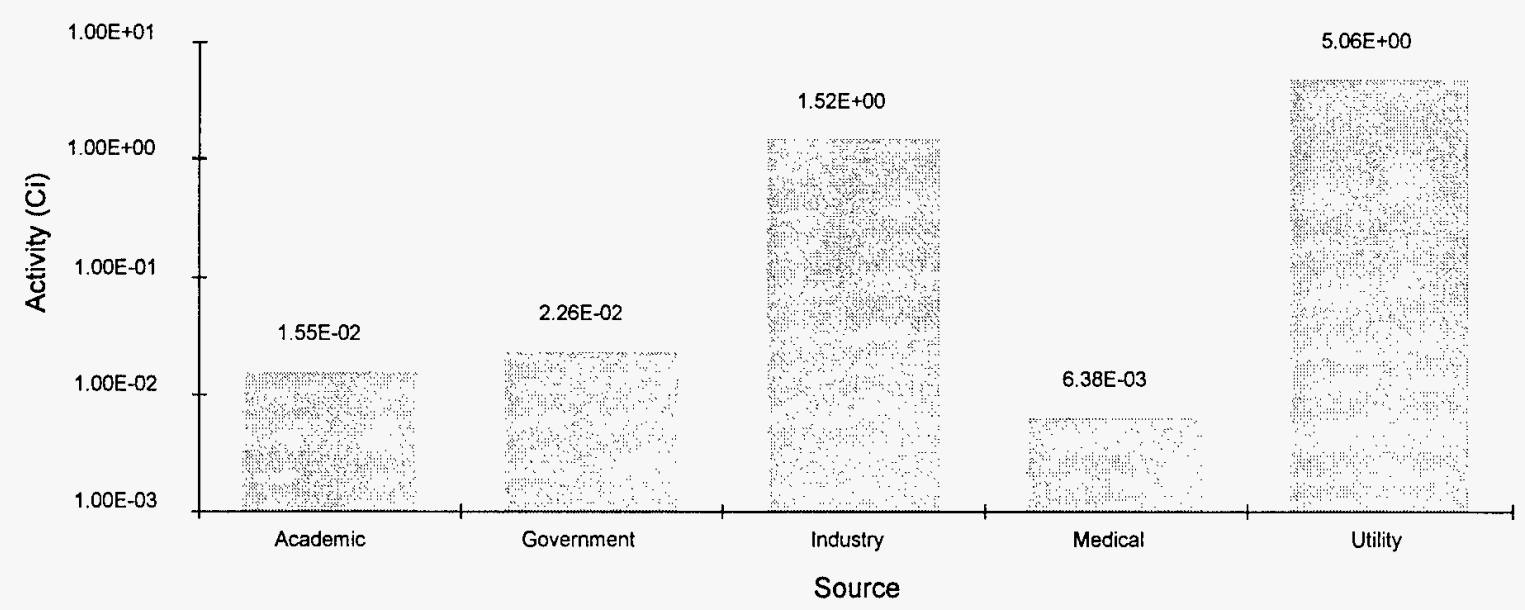

Figure 4-4. ${ }^{129}$ I activity deposited at the Richland, Beatty, and Barnwell sites by source (log scale).

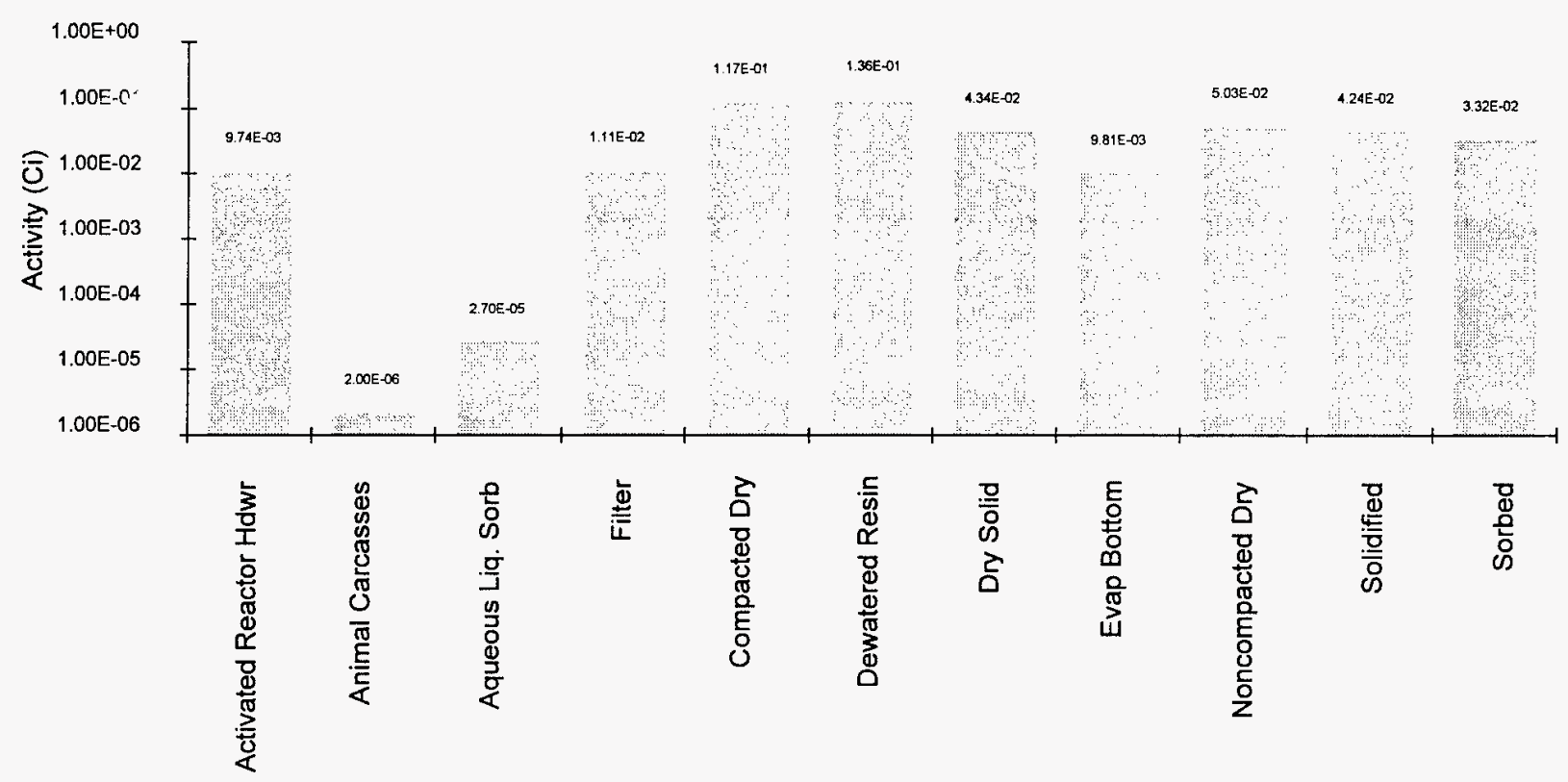

Waste Type

Figure 4-5. ${ }^{129} \mathrm{I}$ activity deposited at the Richland and Beatty sites by waste type (log scale).

\section{Behavior of lodine-129 in the Environment}

This section discusses the behavior of ${ }^{129} \mathrm{I}$ in various components of an LLW disposal environment-soils, plants, water, and the atmosphere. An understanding of this information is crucial for attempting to model the performance of a potential LLW disposal facility.

The main routes for ${ }^{129} \mathrm{I}$ entry into the environment are from nuclear weapon test fallout, nuclear power plant emissions, nuclear fuel reprocessing plant emissions, and, potentially, releases from radioactive waste disposal facilities. Elemental iodine and iodide $(\mathrm{I})$, and iodate $\left(\mathrm{IO}_{3}^{-}\right)$ions would be the predominant forms of ${ }^{129} \mathrm{I}$ released from a radioactive waste disposal facility. 


\section{lodine-129 in Soils}

In soils, iodine is present mainly as iodide. However, as the soil turns more arid and alkaline the concentration of iodate increases and then predominates. Because of this, the forms most pertinent to an LLW arid site are the iodide and iodate ions.

Organic fixation of iodide and iodate in soil appears to retard the migration of ${ }^{129} \mathrm{I}$. There is a relationship between high $\mathrm{K}_{d}$ of ${ }^{129} \mathrm{I}$ and carbon and nitrogen content of soils. ${ }^{9}$ The soil distribution coefficient, $\mathrm{K}_{\mathrm{d}}$, is defined as the amount of the radionuclide sorbed on the soil divided by the amount of the radionuclide remaining in the fluid phase.

$$
\mathrm{K}_{\mathrm{d}}=\frac{\text { Concentration of radionuclide sorbed on soil }(\mathrm{mg} / \mathrm{mg})}{\mathrm{Concentration} \text { of radionuclide in solution }(\mathrm{mg} / \mathrm{mL})}
$$

In topsoil, $99.9 \%$ of added iodide will bond to the solid organic material. This usually occurs with the aid of microbes. The microbes oxidize ${ }^{129} \mathrm{I}$, and it is incorporated into organic compounds, most likely proteins. In a study by Bors and Martens, microbial fixation is supported by $\mathrm{K}_{\mathrm{d}}$ of two to three orders of magnitude lower in sterilized soil. ${ }^{6,10}$

The lower soil levels containing clays have some ability to sorb the anions iodide and iodate because of aluminum and iron coatings on the clay particles. ${ }^{6,11}$ Not all clays have this ability; because of a lack of extensive sorption and organic compounds, ${ }^{129} \mathrm{I}$ is quite mobile in the lower soil levels.

The mechanism of ${ }^{129} I$ adsorption is related to mineral structure of the surrounding rock, not to the dissolved or colloidal material present; it occurs directly on the mineral surface. One possible sorption mechanism is chemical reduction of ions to more easily immobilized forms. Another is the formation of insoluble compounds by incorporation into a crystal lattice of an insoluble matrix. However, the large size of the iodide ion does not allow it to replace smaller common ions such as fluoride and hydroxide in rocks. Some crystal lattice incorporation was suggested by the large absorption of ${ }^{129} \mathrm{I}$ in minerals and chemicals containing metals that form low solubility compounds $(\mathrm{Cu}, \mathrm{Pb}, \mathrm{Ag})$ and have a high anion exchange capacity. ${ }^{9,12}$ Silver (Ag) absorbed $99 \%$. The oxidation state of the metal and ${ }^{129} \mathrm{I}$ have no effect on the sorption. $\mathrm{Cu}_{2} \mathrm{~S}$ (copper in the +1 state) and $\mathrm{CuS}$ (copper in the +2 state) both sorbed $99 \%$ of iodide and iodate.

Specific adsorption, another possible mechanism, is the formation of chemical bonds between chemical groups exposed on the surface of the metal and species in solution and is generally an irreversible sorption process. ${ }^{6}$ Protonation (the addition of a proton or $\mathrm{H}^{+}$) of the metal-OH groups on the surface leads to a positively charged site and an attraction and sorption of anions.

At lower $\mathrm{pH}$ levels, the protonation process takes place easily, and the bonding to an anion occurs more readily. A wide variety of anions are more easily sorbed by this process than iodide, and sorption is slight by this method. 
The duration and distance of ${ }^{129} \mathrm{I}$ transport depends on porosity, permeability, and tortuosity of rocks and the nature of the retardation process. In almost all cases, it is still significantly mobile in soils. Once released from a disposal facility, physical and chemical properties of ${ }^{129}$ I facilitate its transport.

In a limestone test, $62 \%$ of the added iodine came through the sample while only $4 \%$ filtered through chalcopyrite. However, with the iodate ion in chalcopyrite, $72 \%$ washed through; in bornite, $47 \%$. Silicate rocks, tuff, and basalt sorbed $<10 \%$ of the iodate. Minerals containing $\mathrm{Cu}, \mathrm{Pb}$, and $\mathrm{FeS}$ (bornite, galena, and chalcopyrite) adsorb strongly up to and exceeding $99 \%$ of the iodate.

The $\mathrm{K}_{\mathrm{d}}$ values for iodide and methyl iodide ranged from 0.8 to 52.6 and from 0.1 to 3.1 , respectively. Iodide, an anion, was generally sorbed to a greater extent than methyl iodide, which is nonionic." These $\mathrm{K}_{\mathrm{d}}$ are lower than those performed with organic materials or microbial action.

However, iodide $\mathrm{Kd}$ values, which are generally much higher, were correlated only with silt content. Methyl iodide retention by soils was positively correlated to clay, organic carbon, and cation exchange capacity and negatively correlated to $\mathrm{pH} . "$ "These observations are consistent with the high surface area of clay and organic matter and the tendency of organic matter to serve in bonding by Van der Waals forces, including hydrogen bonding, of nonionic organic compounds.

The positive correlation of methyl iodide retention with cation exchange capacity and the negative correlation with $\mathrm{pH}$ likely occur for reasons similar to those of pertechnetate. The increase in positive charge and surface positive charge density with decreased $\mathrm{pH}$ can be expected to increase the potential for sorption by hydrogen bonding and charge-induced interactions.

$\mathrm{K}_{\mathrm{d}}$ values for various radionuclides and soil and mineral types are available in the literature (see Bibliography). Site-specific soil $\mathrm{K}_{\mathrm{d}}$ values would provide LLW disposal site developers with a more realistic estimation of site performance. Generally, a range of $K_{d}$ values are used during the characterization of an LLW disposal facility, since there is so much variability associated with a soil $\mathrm{K}_{\mathrm{d}}$.

Mobility characteristics are impacted to the least extent by geochemical variations around those assumed for disposal sites. Because the iodide ion is so mobile, it is considered to move at the same velocity as groundwater. Volatile halogenated hydrocarbons are rapidly transported in the ground and many are quite resistant to chemical or biological transformation under conditions typical for the subsurface.

${ }^{129}$ I concentrations were measured in soil samples taken in the vicinity of the Karlsruhe, Germany, Reprocessing plant. ${ }^{13}$ Only very small concentrations were measured, of the order of $10^{-6} \mathrm{~Bq} / \mathrm{g}$, though a few soil samples had concentrations of the order of $10^{-5} \mathrm{~Bq} / \mathrm{g}$.

\section{lodine-129 in Plants}

${ }^{129}$ I exists in different forms in the soil, depending upon the soil processes controlling equilibrium solubility. These different chemical forms may cause potential differences during foliar and root absorption, and may account for dissimilarities in composition, eventual leaching, and soil solubility. 
For example, reducing the $\mathrm{pH}$ from 7 to 4 increases the uptake of iodine by a factor of four. This is a broad statement, but each site's conditions will be different and the implications of the uptake will vary.

Uptake of gaseous ${ }^{129} \mathrm{I}$ in plants is highly dependent on the rate of diffusion when it contacts the leaf. It may be further limited by the absorptive capacity of the leaf, dependent on metabolic state and particularly whether the stomata are open or closed. In direct foliar uptake from the air, $10-15 \%$ of the iodine is retained after 50 days. One-fourth of aerial deposition is retained on the plant and not absorbed. ${ }^{14}$

${ }^{129} \mathrm{I}$ hardly reacts with leaves and is slowly available biologically. Forms of iodine that are water soluble and exchangeable have a low uptake, such as the free iodide ion. Those bound with humic and fulvic acids have a high uptake. ${ }^{15}$

The iodine level in the plant and soil are directly correlated in the early stages of plant development. Later, the concentration is higher in the aerial regions of the plant because of foliar uptake. Starchy food products are lower in iodine concentration than leafy shoots, showing that mobility of iodine in phloem is restricted. Concentration factors for ${ }^{129} \mathrm{I}$ vary from species to species. The concentration factor is the ratio of the nuclide in the organism to the concentration of the nuclide in its source of that nuclide. Selected others may be found that are pertinent to the location of specific types of sites. $^{16}$

Only iodides and small iodinated organic molecules can enter plants through metabolism. These can be incorporated into the plant by the saturation of double bonds in a carbon chain. It may also react with mercapto proteins by bonding to the exposed sulfur on the amino acid. Little translocation occurs. ${ }^{17}$

Transfer to a plant is dependent on its stage of development. The seed absorbs ${ }^{129} \mathrm{I}$ to the fourth day of exposure. After that, ${ }^{129} \mathrm{I}$ absorption is by the root and directly correlates to root development. Direct foliar uptake occurs from the two-leaf stage. ${ }^{14}$

Reference 13 also contains data from the measurement of ${ }^{129} \mathrm{I}$ in plant samples taken in the vicinity of the Karlsruhe, Germany, nuclear fuel reprocessing plant. With only a few exceptions, plant concentrations of this nuclide were smaller than those of the surrounding soil. These exceptions include concentrations measured in rye chaff and barley chaff and straw, which exceeded soil sample concentrations by as much as a factor of 3 . Animal product nuclide sample concentrations were generally lower than either the soil or plant concentrations.

\section{lodine-129 in Water}

Four main forms of iodine are found in groundwater: iodide, iodate, periodate, and elemental iodine. ${ }^{14}$ Oxidation reactions take place in groundwater. The following equation shows oxidation by iodate (slightly acidic):

$5 \mathrm{I}^{-}+\mathrm{IO}_{3}^{-}+6 \mathrm{H}^{+}----->3 \mathrm{I}_{2}+3 \mathrm{H}_{2} \mathrm{O}$ 
then oxidation of iodine occurs by addition of the periodate ion:

$\mathrm{IO}_{4}^{-}+2 \mathrm{I}^{-}+\mathrm{H}_{2} \mathrm{O}----->\mathrm{IO}_{3}^{-}+\mathrm{I}_{2}+2 \mathrm{OH}^{-}$

and possibly:

$\mathrm{OH}^{-}+\mathrm{I}_{2}-\cdots-\cdots>\mathrm{I}^{-}+\mathrm{IOH}$

$3 \mathrm{IOH}------>2 \mathrm{HI}+\mathrm{HIO}_{3}$.

The iodates formed can react again according to the first equation to form free iodine, which can be released into the atmosphere as vapor.

Because of iodide's low solubility in soils and rock, researchers assume it travels at the velocity of groundwater. ${ }^{17}$ But transport of iodides in water is restricted by discontinuities in the rock and their effective porosities. Because of this, radioiodine is used as a classic tracer for water movement. A shallow, unconfined (water table) aquifer is affected more than a deeper confined table. ${ }^{18}$

Groundwater velocity has a direct effect on sorption. The sorption rate can increase dramatically and quickly in some media, but in most, the rate of establishing an equilibrium between sorbed and aqueous is very slow. Particle size and amount of sorbent do not change the $\mathrm{K}_{\mathrm{d}}$.

Since one of the means by which this nuclide can reach the groundwater is through liquid discharges from a fuel reprocessing facility, scientists in Germany have examined the means of minimizing this discharge. ${ }^{19}$ In the two decades between 1971 and 1990, the WAK reprocessing plant processed more than 200 tons of uranium from oxide fuel. The cleanup system retained approximately $98.2 \%$ of the total inventory of ${ }^{129} \mathrm{I}$ that was in the fuel. Their analysis indicated that if the then-current technology had been fully utilized, only $0.3 \%$ of the total iodine in the fuel would have been released, or $1 / 6$ th of that which was released.

Scientists at the Bhabha Atomic Research Center in Bombay, India, collected water samples in the vicinity of the their reprocessing plant. ${ }^{20}$ Samples were taken of rainwater and seawater. The concentrations were of the order of $1-2 \mathrm{mBq} / \mathrm{L}$ for all of the samples.

\section{lodine-129 in Air}

Once in the natural air currents, the volatile forms of iodine $\left(\mathrm{I}_{2}\right.$ and $\left.\mathrm{CH}_{3} \mathrm{I}\right)$ formed at an LLW site could have an estimated residence time of about 0.06 years. ${ }^{9}$ Although ${ }^{129} \mathrm{I}$ disperses into the atmosphere, it quickly deposits on the ground because of its large size and density. Airborne iodine affects not only the soil concentration, but also the root and foliar uptake of plants. Any deposited volatile iodine will remain mainly in the soil for a very long time and may react with the soil by three main reactions:

$\mathrm{I}_{2}+\mathrm{I}^{-} \cdots-\cdots \mathrm{I}_{3}^{-}$

$\mathrm{I}_{2}+\mathrm{R} \equiv \mathrm{C}-\mathrm{R}-\ldots . . .-\mathrm{P}-\mathrm{R}_{2}-\mathrm{R}$

$\mathrm{CH}_{3} \mathrm{I}+\mathrm{R}-\mathrm{OH}------>>\mathrm{R}-\mathrm{O}-\mathrm{CH}_{3}+\mathrm{NaI}$ or $\mathrm{HI}$ or $\mathrm{R}-\mathrm{O}-\mathrm{Na}$. 
$\mathrm{R}$ stands for any alkyl group. The two reactants containing this $\mathrm{R}$ group can be found in the soil, as they are decomposition products of organic matter. Through these reactions, the soil is able to retain gaseous iodine and the volatile organic iodines. Two main forms exist in the soil: iodides or polyiodides, and organic compounds containing iodine.

Measurements were taken of the ambient air concentrations of ${ }^{129} \mathrm{I}$ in and near the Hanford Site from 1984 to $1992 .^{21}$ Air samples were collected from three locations, onsite, at the downwind perimeter of the site, and at a distant location. The average air concentrations for these three locations ranged from 1.8 to $30,0.08$ to 2.2 , and 0.005 to $0.09 \mu \mathrm{Bq} / \mathrm{m}^{3}$ for the onsite, perimeter, and distant locations, respectively. These concentrations were from five to nine orders of magnitude lower than the $1992 \mathrm{DOE}$ Derived Concentration Guide. The estimated potential dose for the hypothetical maximally exposed individual ranged from 0.2 to $2.2 \mu \mathrm{Sv} / \mathrm{y}$.

The total gas and aerosol fractions of ${ }^{129} \mathrm{I}$ in air samples in Lithuania were measured by scientists from the Lithuanian Academy of Sciences. ${ }^{22}$ Before the Chernobyl accident, the air concentrations were of the order of $2 \mathrm{nBq} / \mathrm{m}^{3}$, with the gas phase accounting for $65-75 \%$ of the total activity. Despite the proximity of Lithuania to Chernobyl, the air concentrations of the nuclide did not exceed normal concentrations by more than one order of magnitude.

Reference 20 also includes the results of ${ }^{129} \mathrm{I}$ concentrations in air samples taken near the Bhabha Atomic Research Center reprocessing plant. These samples contained a range of 0.054 to $0.295 \mu \mathrm{Bq} / \mathrm{m}^{3}$ of this nuclide. These concentrations result in negligible doses to the public.

\section{Direct Exposure from lodine-129}

Radiation doses resulting from the direct exposure of ${ }^{129} \mathrm{I}$ to workers at nuclear power plants, transportation workers, waste treatment workers, and LLW disposal facility employees are negligible. The beta particle emitted by ${ }^{129} \mathrm{I}$ is fairly weak in energy, and is not able to penetrate any type of containment (steel drums, solidification media) typically used in its disposal.

\section{Behavior of lodine-129 in the Human Body and in Animals}

Iodine has a biological half-life of 100 days for the thyroid and general body, 14 days for bone, and 7 days for kidney, spleen, and reproductive organs in humans. Biological half-life is the time required for the body to excrete or otherwise expel one-half of the nuclide. ${ }^{11}$ It can enter the human body by either ingestion or inhalation. Volatile forms of iodine such as elemental iodine and iodomethane are an inhalation concern. Nonvolatile forms such as heavier organic compounds, iodates, iodide and others enter through the ingestion pathway.

\section{Inhalation}

The allowable level of intake (ALI) by inhalation is 8.1 microcuries. ${ }^{23}$ Absorption of radioiodine and its volatile compounds from alveolar air to the blood is extremely rapid. ${ }^{24}$ Once it has entered the bloodstream, ${ }^{129} \mathrm{I}$ makes its way to the thyroid gland. Most iodine compounds are soluble in body fluids; however, a few are not. If the compound is insoluble or sparingly soluble such as iodoform $\left(\mathrm{CHI}_{3}\right)$, the 
lungs receive the total radiation dose from this pathway. The soluble compounds spend very little time in the bloodstream; therefore, radiation to the circulatory system and the tissues in proximity is small. The mechanism of entrance into the blood stream from either alveolar blood or the blood in the small intestine is probably the same as that of oxygen bonding to heme groups in the blood. The chance of any damage to cells in the human body depends on the amount of ${ }^{129} \mathrm{I}$ inhaled. The more ${ }^{129} \mathrm{I}$ inhaled, the greater the chances of biological effects taking place.

\section{Ingestion}

The allowable level of annual intake by oral administration is 5.4 microcuries. ${ }^{23}$ Essentially all compounds of radioiodine in the environment are completely soluble in body fluids. ${ }^{24}$ If the compound is insoluble, the gastrointestinal tract would be the only area receiving a radiation dose from ${ }^{129} \mathrm{I}$. If it is soluble, it quickly enters the bloodstream and travels to the thyroid. The mechanism is probably one of sorption or diffusion in the small intestine. Another possible mechanism is the incorporation into proteins digested and entering the bloodstream with them. The most important pathway affecting humans is the air-vegetable-cow-milk pathway, especially for children and infants. ${ }^{25}$ Again, as with inhalation, the chance of any effects taking place increases as the amount of ingestion increases. Reference 13 includes the results of an analysis of the human exposure due to ingestion of plant and animal products in the vicinity of a fuel reprocessing plant. The estimated exposure was of the order of $10^{-7} \mathrm{~Sv} / \mathrm{y}$, compared to the international standard of $10^{-4} \mathrm{~Sv} / \mathrm{y}$.

\section{Thyroid}

Iodine acts on the thyroid in five different ways. These interactions include the following: (a) substrate, (b) suppression of release of organic iodine from gland, (c) inhibition of organic iodine formation, (d) saturation of iodine transport system, and (e) formation of organic compounds inhibits further uptake of iodine. ${ }^{24}$

Accumulation in the thyroid is largely within the first twelve hours of exposure. Of the total amount taken in, $10 \%$ to $40 \%$ is retained. There is a physical limit to the amount of iodine that can be held in the thyroid. Iodine uptake and incorporation is inversely related to the iodine supply in the diet. A high intake of inorganic iodine may block uptake of more. But it is less efficient in blocking uptake of organic compounds of iodine. ${ }^{11}$

The beta particle emitted by ${ }^{129} \mathrm{I}$ is of such low penetrating power that it does not significantly irradiate any other organ. Most nodules that are radiation-induced can be readily and successfully treated. ${ }^{26}$ Children have a much higher sensitivity, two to three times, for developing nodules. No effect has been found between irradiation and cancer rates in rats. This may be due to the long period of time for tumors to occur. In most cases, it takes 10 to 20 years for benign and malignant tumors to occur. ${ }^{25}$

Once in the thyroid, ${ }^{129} \mathrm{I}$ is metabolized into organic compounds where it could reside long enough for considerable local irradiation. ${ }^{24}{ }^{129} \mathrm{I}$ can react with tyrosine, an amino acid that leads melanin (a skin pigment) to create an $\mathrm{SI}_{3}$ group. $\mathrm{S}$ is the exposed sulfur on the amino acid. This is done without substantially changing the conformation of the amino acid and in this way can be incorporated into proteins. ${ }^{6}$ 
Since one of the principal exposure pathways for humans involves ingestion of contaminated animal parts, studies have been conducted into the concentrations of this nuclide in various animals. Samples were taken of various local animals in the vicinity of the Nevada Test Site. ${ }^{27}$ The results of this study indicate that there are slightly elevated concentrations of this nuclide in the thyroids of cattle that graze near the test site, typically of the order of $0.001 \mathrm{pCi} / \mathrm{g}$. Researchers from the University of Tennessee measured ${ }^{129} \mathrm{I}$ concentrations in the thyroids of deer in the vicinity of the Savannah River Site and Oak Ridge National Laboratory and in sheep from the vicinity of Birmingham, UK. ${ }^{28}$ Concentrations as high as $100 \mathrm{~Bq} / \mathrm{g}$ were measured near the Savannah River Site but were much lower, of the order of $10 \mathrm{~Bq} / \mathrm{g}$ near Oak Ridge and Birmingham. A similar, though more widespread, study was made using animal samples from the vicinity of several nuclear production sites, including the Hanford Reservation, West Valley, NY, and the Idaho National Engineering Laboratory. ${ }^{29}$ Of all the samples, the maximum concentration was $20-65 \mathrm{pCi} / \mathrm{g}$, though most of the measured concentrations were less than $1 \mathrm{pCi} / \mathrm{g}$.

\section{Summary}

${ }^{129} \mathrm{I}$ has a long half-life ( 16 million years). Disposing of ${ }^{129} \mathrm{I}$-contaminated waste at LLW disposal facilities is a concern because ${ }^{129} \mathrm{I}$ is highly mobile in the environment. Airborne iodine is deposited on the ground quickly because of its large size and density. Once in the soil, ${ }^{129} \mathrm{I}$ can migrate to the groundwater or be absorbed by plants, thus potentially entering the food chain.

The NRC, in its draft EIS on 10 CFR 61, identified ${ }^{129} \mathrm{I}$ as one of four radionuclides (along with tritium, carbon-14, and technetium-99) that will require site-specific considerations to be sure that performance objectives for long-term environmental protection are met.

If ${ }^{129} \mathrm{I}$ is ingested, then most of the radioiodine will dissolve in the body fluids. The soluble iodine travels and concentrates in the thyroid until a physical limit is met. ${ }^{129} \mathrm{I}$ emits a low energy beta particle that may irradiate the thyroid to the point of inducing cancerous thyroid nodules. Most nodules that are radiation-induced can be readily and successfully treated. Any insoluble compounds of iodine would pass through the gastrointestinal tract. 


\section{References}

1. U.S. Nuclear Regulatory Commission, Draft Environmental Impact on 10 CFR 61, "Licensing Requirements for Land Disposal of Radioactive Waste," NUREG-0782-V1, September 1981.

2. F. William Walker et al., Chart of the Nuclides, Department of Energy, Fourteenth Edition, Revised April 1988.

3. Clifford A. Hampel, The Encyclopedia of the Chemical Elements, Reinhold Book Corporation, pp. 292-299.

4. R. P. Schwarzenbach, W. Giger, C. Schaffner, O. Wanner, "Groundwater Contamination by Volatile Halogenated Alkanes: Abiotic Formation of Volatile Sulfur Compounds Under Anaerobic Conditions," Environmental Science and Technology, Vol. 19, No. 4, April 1985, pp. 322-327.

5. J. S. Thayer, G. J. Olson, F. E. Brinckman, "Iodomethane as a Potential Metal Mobilizing Agent in Nature," Environmental Science and Technology, Vol. 28, No. 9, 1984, pp. 726-729.

6. J. V. Christiansen and Lars Carlsen, Iodine in the Environment Revisited. An Evaluation of the Chemical and Physico Chemical Processes Possibly Controlling the Migration Behavior of Iodine in the Terrestrial Environment, Riso-M-2791, Roskilde, Denmark, May 1989.

7. Electric Power Research Institute, Updated Scaling Factors in Low-Level Radwaste, EPRI NP5077, March 1987.

8. U.S. Environmental Protection Agency, Low-Level and NARM Radioactive Wastes Draft Environmental Impact Statement for Proposed Rules, Vol. 1, Background Information Document, EPA-520/1-87-012-1, June 1988.

9. Y. Liu et al., Migration Chemistry and Behavior of Iodine Relevant to Geological Disposal of Radioactive Wastes: A Literature Review with a Compilation of Sorption Data, PSI-16, Villigen, Switzerland, September 1988.

10. J. Bors, R. Martens, Studies on the Role of Soil Biomass in the Sorption of Radioiodine.

11. W. H. Rickard and others; Radionuclides in the Environment, BNWL-1950 pt. 2; pp. 37-41, 192-203.

12. R. Strickert, A. M. Friedman, S. Fried, "The Sorption of Technetium and Iodine Radioisotopes by Various Minerals," Nuclear Technology, Vol. 49, July 1980, pp. 253-266.

13. E. Robens and D. C. Aumann, "Iodine-129 in the Environment of a Nuclear Fuel Reprocessing Plant: I. ${ }^{129} \mathrm{I}$ and ${ }^{127} \mathrm{I}$ Contents of Soils, Food Crops, and Animal Products," Journal of Environmental Radioactivity, Vol. 7, No. 2, 1988, pp. 159-175.

14. A. Saas and A. Grauby, "An Approach to Investigations of the Behaviour of Iodine-129 in the Atmosphere-Soil-Plant System," Health Physics, Vol. 31, No. 1, July 1976, pp. 21-26. 
15. J. K. Soldat, "Radiation Doses From Iodine-129 in the Environment," Health Physics, Vol. 30, No. 1, January 1976, pp. 61-70.

16. T. R. Garland, D. A. Cataldo, K. M. McFadden, R. G. Schreckhise, and R. E. Wildung, "Comparative Behavior of ${ }^{99} \mathrm{Tc},{ }^{129} \mathrm{I},{ }^{127} \mathrm{I}$, and ${ }^{137} \mathrm{Cs}$ in the Environment Adjacent to a Fuels Reprocessing Facility," Health Physics, Vol. 44, No. 6, June 1983, pp. 658-662.

17. Ernest A. Bondietti, The Influence of Geochemical Variables on Long-Lived Radionuclide Migration and Risk Assessment, NUREG/CP-0022, March 9, 1981.

18. R. H. Gray, Overview of a Comprehensive Environmental Monitoring and Surveillance Program: The Role of Fish and Wildlife, PNL-SA-15922, May 1988.

19. F. J. Herrmann, et al., "Minimizing of Iodine-129 Release at the Karlsruhe Reprocessing Plant WAK," 22nd DOE/NRC Nuclear Air Cleaning and Treatment Conference, August 24-27, 1992, NUREG/CP-0130, Vol. 1, pp. 75-90.

20. G. R. Doshi, S. N. Joshi, and K. C. Pillai, "Determination of ${ }^{129} \mathrm{I}$ in Water and Air Samples near a Reprocessing Plant by Neutron Activation Analysis," Water, Air, and Soil Pollution, Vol. 73, No. 1/4, February 1994, pp. 121-129.

21. G. W. Patton and A. T. Cooper, "Measurement of ${ }^{129} \mathrm{I}$ in Ambient Air at the Hanford Site," 40th Annual Meeting of the Health Physics Society, July 1995.

22. T. Nedveckaite and W. Filistowicz, "Determination of Gaseous and Particulate ${ }^{129} \mathrm{I}$ in Atmospheric Air by Neutron Activation Analysis," Journal of Radioanalytical and Nuclear Chemistry, Vol. 174, No. 1, 1993, pp. 43-47.

23. Merril Eisenbud, Environmental Radioactivity from Natural, Industrial, and Military Sources, Harcourt Brace Jovanovich: New York University Medical Center, 1987, pp. 413-414.

24. National Council on Radiation Protection and Measurements, NCRP Report No. 55; "Protection of the Thyroid Gland in the Event of Releases of Radioiodine," August 1, 1977.

25. A. Hepburn, P. Roger, J. Mockel, and J. E. Dumont, Irradiation and Thyroid Disease, E10-C-36081 B.

26. R. Bergman, U. Berstrom, S. Evans, and A. B. Atomenergi, "Environmental Transport and LongTerm Dose: A Preliminary Study of Iodine 129," Iodine-129 Proceedings of an NEA Specialist Meeting, Paris, 1977, pp. 43-50.

27. D. D. Smith, ${ }^{129}$ I in Animal Thyroids from Nevada and Other Western States, EPA-600/3-77-067, June 1977.

28. L. Van Middlesworth, " ${ }^{129}$ I and ${ }^{137}$ Cs Fission Products in Thyroids of Animals, $1984-1991$," Health Physics, Vol. 64, No. 1, January 1993, pp. 52-58.

29. R. V. Ballad, et al., "Iodine-129 in Thyroids of Grazing Animals," Health Physics, Vol. 30, No. 4, April 1976, pp. 345-350. 


\section{Bibliography}

Andersson K., et al., Sorption of Radionuclide on Geologic Media: A Literature Survey, SKBF-KBS-TR83-07, Stockholm, January 1983.

Andersson, Karin, Nuclide Solubilities and Distribution Coefficients for Use in Probabilistic Modeling, SKI-87132, Stockholm, Sweden, January 15, 1988.

Browne, E., R. B. Firestone, and J. Wiley, Table of Radioactive Isotopes, 1986.

Friedman, A. M., et al., Chemical Properties of Pu, Am, Np, I and Tc and their Influence on Migration, Conf 770512--17, May 23, 1977.

Gracheva, L. M., and V. G. Korolev, Genetic Effects of the Decay of Radionuclides in Cells, Moscow: Atomizdat Publishers, 1977, pp. 107-112.

Jaquish, R. E., and K. R. Price, Iodine-129: Environmental Monitoring and Population Dose in the Hanford Environs, PNL-SA-16066, Las Vegas, NV, October 17-21, 1988.

Johnson, Kathryn, "Geochemical Models of Mobility of Components from Low-Level Waste Disposal Sites," Waste Management 1985; Tucson, Arizona, March 24-28, 1985.

Kelly, G. N., "Thyroid Irradiation-Biological Effects; I-129," Proceedings of an NEA Specialist Meeting, Paris, 1977.

Kleinberg, Jacob, and G. A. Cowan, The Radiochemistry of Fluorine, Chlorine, Bromine and Iodine, National Academy of Sciences, National Research Council, January 1960.

Leddicotte et al., Management of Low-Level Radioactive Waste, Vol. 2, Pergamon Press, 1979.

Raid, D., and M. J. Mason, Batch Kd Measurements of Nuclides to Estimate Migration Potential at the Proposed Waste Isolation Pilot Plant in New Mexico, PNL-2248, Battelle, October 7, 1977.

Sheppard M. I., et al., Soil Nuclides Distribution Coefficients and Their Statistical Distributions, AECL8364, Pinawa, Manitoba, December 1984.

Wildung R. E., et al., Pertechnetate, Iodide and Methyl Iodide Retention by Surface Soils, BNWL-1950pt 2, 1974. 


\section{TRITIUM}

\section{Introduction}

This chapter outlines the basic radiological, chemical, and physical characteristics of tritium $\left({ }^{3} \mathrm{H}\right)$ and examines how these characteristics affect the behavior of tritium in various environmental media, such as soils, water, plants, the atmosphere, and the human body. Also included are methods of tritium production and waste and disposal data.

Tritium is a short-lived radionuclide present in low-level radioactive waste (LLW) generated at nuclear power plants. Disposing of tritium-contaminated waste at LLW disposal facilities is a concern to site developers and regulators because it is highly mobile in groundwater. The NRC in its Draft EIS on 10 CFR Part 61, "Licensing Requirements for Land Disposal of Radioactive Waste,"1 identified tritium as one of four radionuclides (along with ${ }^{14} \mathrm{C},{ }^{99} \mathrm{Tc}$, and ${ }^{129} \mathrm{I}$ ) that will require site-specific considerations to ensure that performance objectives for long-term environmental protection are met.

A radionuclide considered sensitive at one LLW disposal facility may not be considered sensitive at another facility. The behavior of a radionuclide at a particular LLW waste disposal site will depend primarily upon the radiological, chemical, and physical characteristics of the waste, and the inventory of the radionuclide. The behavior of a radionuclide also depends upon the geology, hydrology, and climate at the disposal site. This chapter describes characteristics and potential difficulties in dealing with tritium. However, since tritium behavior and appropriate handling, storage, or disposal will vary depending on particular sites or waste form, this chapter does not attempt to discuss the extent of a difficulty or appropriate solutions. Each disposal site facility design should consider and address the specific waste content and behavior under that site's particular circumstances.

Although most of the information presented in this chapter was obtained from U.S. sources, tritium technology and research, as well as environmental, health, and safety data concerning tritium production, storage, and utilization, are available from Japanese, Canadian, and European programs. ${ }^{2,3,4}$ The principal U.S. facilities involved in the production, research, storage, shipping, analyzing, processing, and recovery of tritium are (a) the tritium production reactors and Replacement Tritium Facility located at the Savannah River Site, (b) the Mound Facility, (c) the Tritium Systems Test Assembly, the Tritium Salt Facility, and the High Pressure Tritium Laboratory located at Los Alamos National Laboratory, (d) the Tritium Facility at Lawrence Livermore National Laboratory, (e) the Tritium Research Laboratory at Sandia National Laboratories, and (f) the several tritium facilities in operation at the Los Alamos National Laboratory for nuclear weapons component evaluation, development, and research programs. ${ }^{5,6}$ Many other facilities utilizing tritium include universities involved in fusion research (e.g., the Princeton Plasma Physics Laboratory), as well as commercial facilities manufacturing tritium products.

All hydrogen atoms contain one proton $(\mathrm{Z}=1)$ and either 0 , 1 , or 2 neutrons (e.g., $\mathrm{N}=0,1$, or 2 ) within the atom's nucleus. Furthermore, all electrically neutral hydrogen atoms contain 1 electron outside the nucleus. The total mass number $(\mathrm{A}=\mathrm{Z}+\mathrm{N})$ for the three possible hydrogen isotopes is either 1,2 , or 3 . The most abundant and lightest isotope of hydrogen has a mass number of one and is 
represented as either ${ }^{1} \mathrm{H}$ or simply $\mathrm{H}$. Approximately $99.985 \%$ of all naturally occurring isotopes of hydrogen (present on Earth) consists of the light hydrogen $\left({ }^{1} \mathrm{H}\right)$ isotope. The next heaviest isotope of hydrogen, called deuterium, has a mass number of two and is represented by the chemical symbols ${ }^{2} \mathrm{H}$ or D. Deuterium occurs in nature with a natural abundance of about $0.015 \%$. Deuterium is also referred to as heavy hydrogen. Together, ${ }^{1} \mathrm{H}$ and ${ }^{2} \mathrm{H}$ are both nonradioactive and comprise nearly $100 \%$ of all naturally occurring forms of hydrogen. The heaviest isotope of hydrogen, called tritium, has a mass number of three. Tritium is radioactive and is represented by either of the two chemical notations ${ }^{3} \mathrm{H}$ or T. The tritium nucleus, called a triton, contains one proton and two neutrons. Hydrogen- $4\left({ }^{4} \mathrm{H}\right)$ exists as only a transient isotope that decays to tritium and a neutron.

Tritium is naturally produced in very small quantities by the interaction of cosmic rays (i.e., high energy extraterrestrial particles) with atoms and molecules of the upper atmosphere. ${ }^{7}$ Tritium is thought to be produced by neutron-proton ( $n-p)$ reactions involving cosmic-ray produced neutrons and ${ }^{14} \mathrm{~N}$ in the atmosphere according to the reaction ${ }^{8}{ }^{14} \mathrm{~N}+{ }^{1} \mathrm{n}-->\left({ }^{15} \mathrm{~N}\right)->{ }^{12} \mathrm{C}+{ }^{3} \mathrm{H}$. Naturally-occurring sources of tritium exist in the atmosphere at concentrations of about $0.05 \times 10^{-12} \mathrm{Ci} / \mathrm{m}^{3}\left(1 \mathrm{Ci}=3.7 \times 10^{10}\right.$ disintegrations per second); or equivalently, $\sim 7$ disintegrations-per-hour $/ \mathrm{m}^{3}$, or $\sim 1{ }^{3} \mathrm{H}$ atom $/ \mathrm{cm}^{3}$ of air. ${ }^{7}$ Since tritium is constantly being created in the atmosphere, it should be widely distributed over the earth. However, due in part to its relatively short half-life (12.3 years), it naturally exists in extremely small concentrations. Measurements of tritium in Norwegian surface waters before 1951 have indicated tritium concentrations of one tritium atom per $10^{18}$ atoms of ordinary hydrogen $\left({ }^{1} \mathrm{H}\right) .{ }^{8}$ Before atmospheric testing of thermonuclear devices, the constant source of natural tritium production in the atmosphere from cosmic rays was balanced with radioactive decay, and an equilibrium inventory of a few kilograms of tritium existed for the entire Earth (estimates of $\sim 70 \times 10^{6} \mathrm{Ci}$ or $7300 \mathrm{~g}$ have been reported). ${ }^{9}$ In fact, before 1954 , rainwater contained only 1 to 10 tritium atoms per $10^{18}$ atoms of hydrogen, or equivalently 67,000 to 670,000 tritium atoms $/ \mathrm{cm}^{3}$ of water. ${ }^{10}$ At these concentrations, tritium is considered one of the rarest naturally occurring species.

The tritium concentrations mentioned above can be compared with data in the 1987 Environmental Protection Agency (EPA) federal radiation protection guidance report ${ }^{11}$ data that limit tritium exposure to less than $20 \times 10^{-6} \mathrm{Ci} / \mathrm{m}^{3}\left(4.2 \times 10^{8}\right.$ tritium atoms $\left./ \mathrm{cm}^{3}\right)$ of air and define a maximum annual limit on tritium intake to $0.08 \mathrm{Ci}\left(1.7 \times 10^{18}\right.$ atoms or $\left.8.3 \times 10^{-6} \mathrm{~g}\right)$. Based on the above information, a person would have to drink 80 liters ( 1 liter $=1,000 \mathrm{~cm}^{3}$ ) of seawater at a tritium concentration of 10 atoms per $10^{18} \mathrm{H}$ atoms each second for an entire year to reach the EPA annual intake limit.

Since the beginning of the atomic age, large quantities of tritium have entered the environment from man-made sources, mainly atmospheric testing of thermonuclear weapons (e.g., hydrogen bombs). However, increasing amounts of tritium are being released as the result of the normal operation of nuclear power reactors and fuel reprocessing operations. Future fusion power reactors will contain large sources of tritium. The atmospheric testing of thermonuclear devices in the late $1950 \mathrm{~s}$ and mid-1960s injected into the stratosphere about $500 \mathrm{~kg}$ of tritium in the form of water. ${ }^{10}$ This new source of tritium increased the tritium content of rainwater to values as high as 500 tritium atoms per $10^{18}$ light hydrogen atoms. ${ }^{10}$ The tritium concentration in the upper regions of the world's oceans ( 0 to $1 \mathrm{~km}$ in depth) varies from 0.2 to $\sim 10$ tritium atoms per $10^{18}$ light hydrogen atoms. This is the equivalent of 13,400 to $\sim 670,000{ }^{3} \mathrm{H}$ atoms $/ \mathrm{cm}^{3}$ of water, with the average tritium concentration in water deeper than $1 \mathrm{~km}$ usually less than 0.2 tritium atoms per $10^{18}$ light hydrogen. ${ }^{12}$ 
Due to its very small naturally occurring concentrations, tritium exists, for all practical purposes, as a man-made isotope. Today, the presence of tritium in the environment is generally an indication of human actions. Tritium is primarily used in industrial thickness gauges, luminous paints, non-powered (self-luminous) light sources, fusion research, thermonuclear weapons, and as a radioactive tracer in chemistry and biological experiments.

\section{Radiological Characteristics}

Tritium has a 12.32 year half-life $\left(\mathrm{T}_{1 / 2}\right)$ or equivalently $\mathrm{T}_{1 / 2}=4,500$ days. ${ }^{13}$ When it undergoes radioactive decay, it emits a low energy beta particle ( $\beta$ [i.e., a negative electron]) with a maximum energy ${ }^{13}$ of $18.6 \mathrm{keV}$ (thousand electron volt) or equivalently $0.0186 \mathrm{MeV}$ (million electron volt). The average beta energy is only $5.68 \mathrm{keV} \cdot{ }^{10,14,15}$ In fact, tritium is the lowest-energy beta emitter known. ${ }^{15}$ The electron emitted from the tritium nucleus has only about one-fourth of the energy of an electron in a typical color TV picture tube. ${ }^{16}$ Tritium decay is also unusual in that no gamma ray emission accompanies the decay of the nucleus. ${ }^{13,14}$ The beta particles (of average energy) emitted from tritium decay are stopped by $\sim 7 \mathrm{~mm}$ of air, $0.01 \mathrm{~mm}$ of paper, a few thousandths of a millimeter of liquids or solids, ${ }^{10}$ and about $0.001 \mathrm{~mm}$ of tissue. ${ }^{17}$ Table 5-1 shows the calculated stopping distance required to absorb $99 \%$ of the beta particle energy for various substances. Although the beta particles emitted from tritium decay are stopped by very thin materials, the tritium atom itself can diffuse through relatively thick materials (e.g., stainless steel cladding). For biological purposes, tritium is classified as a low radiotoxicity material. Table 5-2 compares the radiotoxicity of several important radionuclides.

Table 5-1. Comparison of the calculated stopping distance for an average energy beta particle emitted from tritium decay for various materials.

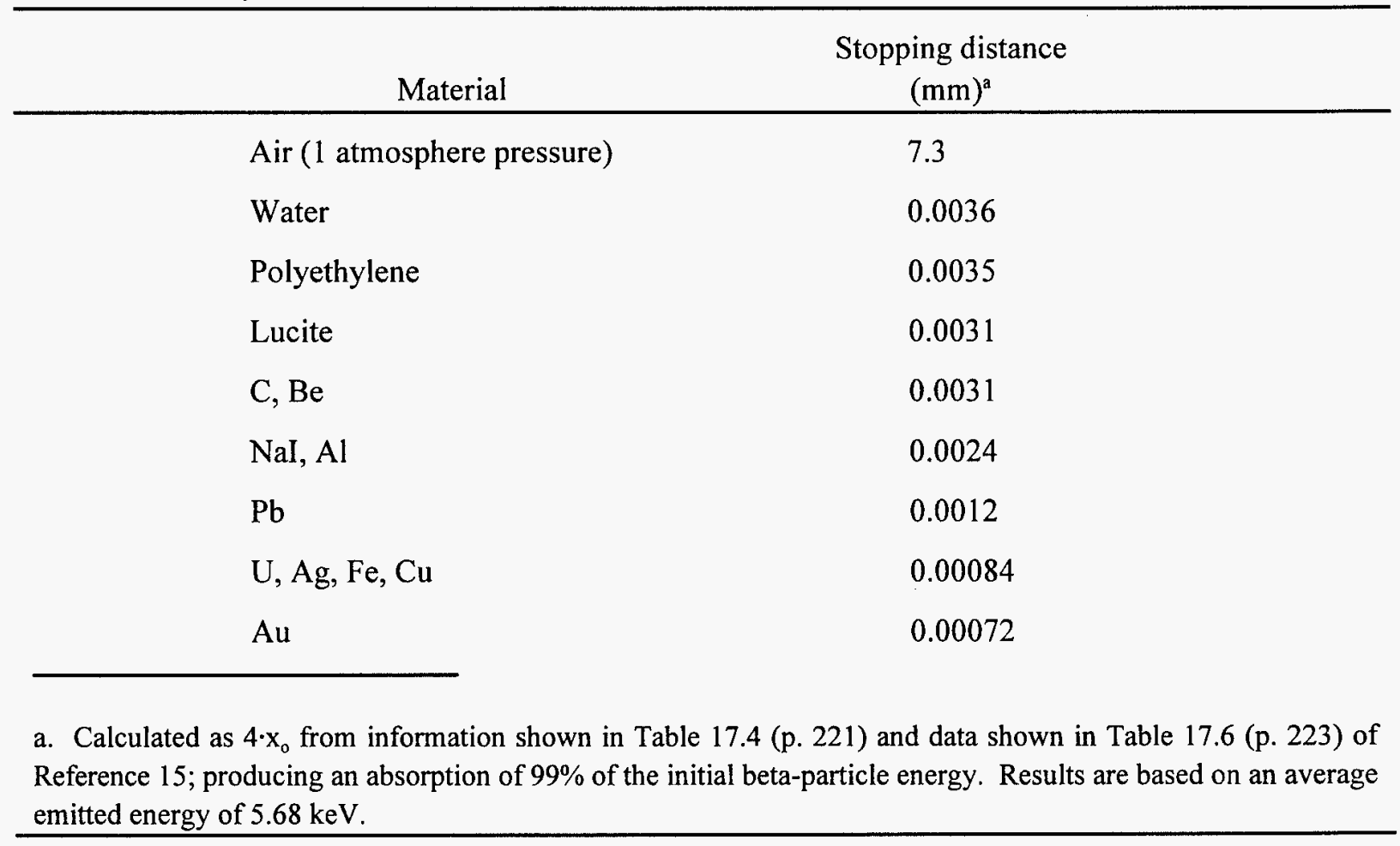


Table 5-2. Comparison of the radiotoxicity of several important radionuclides (obtained from Appendix 2 of Reference 18).

\begin{tabular}{lll}
\hline \multicolumn{2}{c}{ Radiotoxicity } & \multicolumn{1}{c}{ Species } \\
\hline Very high & Group 1 & ${ }^{241} \mathrm{Pu},{ }^{242} \mathrm{Cm},{ }^{241} \mathrm{Am},{ }^{237} \mathrm{~Np}$ \\
High & Group 2 & ${ }^{60} \mathrm{Co},{ }^{90} \mathrm{Sr},{ }^{94} \mathrm{Nb}$ \\
Moderate & Group 3 & ${ }^{14} \mathrm{C},{ }^{63} \mathrm{Ni},{ }^{137} \mathrm{Cs}$ \\
Low & Group 4 & ${ }^{3} \mathrm{H},{ }^{59} \mathrm{Ni},{ }^{99 \mathrm{~m}} \mathrm{Tc},{ }^{99} \mathrm{Tc},{ }^{129} \mathrm{I}$ \\
\hline
\end{tabular}

The decay scheme for tritium (showing the emission of an antineutrino particle) is represented by the reaction:

${ }^{3} \mathrm{H}-\cdots-\cdots>{ }^{3} \mathrm{He}+\beta^{-}+\hat{\mathrm{v}}$.

\section{$12.3 \mathrm{y}$}

For this equation, ${ }^{3} \mathrm{H}$ represents the tritium nucleus, ${ }^{3} \mathrm{He}$ represents helium- 3 (a rare but stable isotope of helium), $\beta$ - depicts a negative electron, and $\hat{v}$ is an antineutrino particle that is also emitted with beta decay. Since the released $\beta$ - particle is usually emitted with an energy less than the maximum theoretical (e.g., $18.6 \mathrm{keV}$ for tritium decay), the antineutrino particle carries off the energy difference between $18.6 \mathrm{keV}$ and that of the released $\beta$ particle. Consequently, $\beta$ particles are emitted with a continuous energy spectrum ranging from 0 to $18.6 \mathrm{keV}$. Since neutrinos (and antineutrinos) very rarely interact with matter, they are not radiologically important. Therefore, the antineutrino particle is usually eliminated in the decay equation. Hence, Equation (5-1) is usually written as ${ }^{3} \mathrm{H}-->{ }^{3} \mathrm{He}+\beta$.

The $0.0186 \mathrm{MeV}$ beta particle emitted by the ${ }^{3} \mathrm{H}$ nucleus is very weak. Table $5-3$ illustrates how the maximum and average beta emission energies of tritium compare to the emissions of other beta emitters. Although tritium produces only a weak energy beta particle, it does pose a potential biological hazard because of its chemical similarity to hydrogen $\left({ }^{1} \mathrm{H}\right)$.

Table 5-3. Average and maximum kinetic energies of beta particles released during decay of several radionuclides (compiled from data in References 13, 14, 15, 19, and 20).

\begin{tabular}{lcc}
\hline & \multicolumn{2}{c}{$\beta$ particle energy } \\
\cline { 2 - 3 } \multicolumn{1}{c}{ Radionuclide } & $\begin{array}{c}\text { Average energy } \\
(\mathrm{MeV})\end{array}$ & $\begin{array}{c}\text { Maximum energy } \\
(\mathrm{MeV})\end{array}$ \\
\hline Tritium $\left({ }^{3} \mathrm{H}\right)$ & 0.00568 & 0.019 \\
Iodine-129 $\left({ }^{129} \mathrm{I}\right)$ & 0.040 & 0.150 \\
Carbon-14 $\left({ }^{14} \mathrm{C}\right)$ & 0.049 & 0.156 \\
Technetium-99 $\left({ }^{99} \mathrm{Tc}\right)$ & 0.085 & 0.293 \\
Iodine-131 $\left({ }^{131} \mathrm{I}\right)$ & 0.180 & $0.806^{\mathrm{a}}$ \\
Cesium-137 $\left({ }^{137} \mathrm{Cs}\right)$ & 0.195 & 1.167 \\
Potassium-40 $\left({ }^{40} \mathrm{~K}\right)$ & 0.541 & 1.330 \\
Phosphorous-32 $\left({ }^{32} \mathrm{P}\right)$ & 0.694 & 1.710 \\
\hline & & \\
a. Note that $90.4 \%$ of the particle intensity occurs at $0.606 \mathrm{MeV}$ and that only $0.6 \%$ occurs at $0.806 \mathrm{MeV}$. & \\
\hline
\end{tabular}




\section{Chemical and Physical Characteristics}

Chemically, tritium behaves like ordinary hydrogen. However, due to its higher mass, many of its reactions take place more slowly than those of hydrogen, ${ }^{10}$ and the strength of the chemical bonds are affected by the nuclear mass. Table 5-4 compares some of the important physical properties of molecular hydrogen ${ }^{1} \mathrm{H}_{2}$ and its isotopes ${ }^{2} \mathrm{H}_{2}$ and ${ }^{3} \mathrm{H}_{2}$.

The oxidation states of hydrogen and its isotopes are +1 and -1 . Because of the much larger percentage differences in the hydrogen isotopic masses, these isotopes show a greater variation in their physical and chemical properties than do the isotopes of other elements. Hydrogen occupies a special niche in the periodic table. It displays some similarities to both the alkali metals as the +1 oxidation state and to the halogens as the -1 oxidation state. Also, hydrogen forms more compounds than any of the other elements including carbon. ${ }^{21}$

A hydrogen molecule is formed by the sharing of electrons from each atom producing a covalent bond. The hydrogen mass affects the molecular bond strength and increases with the isotopic mass of the hydrogen atom. ${ }^{22}$ Similarly, the energy level of the isotopes in the solid and liquid state increase with increasing mass, as show $\mathrm{n}$ by the increase in the melting point, boiling point, heat of fusion, and heat of vaporization (Table 5-4). Also shown in Table 5-4 are the energies required to form a hydrogen cation and the hydride anion by the donation and receiving of an electron. The critical constants for the transition from a vapor to a gas are listed in Table 5-4 for each of these isotopes.

Table 5-4. Physical properties of hydrogen and its isotopes.

\begin{tabular}{|c|c|c|c|}
\hline Property & $\begin{array}{c}\text { Hydrogen } \\
{ }^{1} \mathrm{H}_{2}\end{array}$ & $\begin{array}{c}\text { Deuterium } \\
{ }^{2} \mathrm{H}_{2}\end{array}$ & $\begin{array}{c}\text { Tritium } \\
{ }^{3} \mathrm{H}_{2} \\
\end{array}$ \\
\hline Melting point (degrees Kelvin) ${ }^{\mathbf{a}}$ & 13.95 & 18.73 & 25.04 \\
\hline Boiling point (degrees Kelvin) ${ }^{a}$ & 20.39 & 23.67 & 50.2 \\
\hline Heat of fusion (cal/mole) & 28.0 & 47.0 & - \\
\hline Entropy of melting (cal $/{ }^{\circ} \mathrm{C}$-mole) & 2.0 & 2.5 & - \\
\hline Heat of vaporization (cal/mole) & 216. & 293. & 333. \\
\hline Entropy of vaporization $\left(\mathrm{cal} /{ }^{\circ} \mathrm{C}\right.$-mole) & 10.6 & - & - \\
\hline Critical temperature (degrees Kelvin) ${ }^{a}$ & 33.19 & 38.35 & 40.6 \\
\hline Critical pressure (atmospheres) & 12.98 & 16.432 & 18.1 \\
\hline Critical volume $\left(\mathrm{cm}^{3} / \mathrm{mole}\right)$ & 66.95 & 60.3 & 57.1 \\
\hline \multicolumn{4}{|l|}{ Heat of Formation $(\mathrm{kcal} / \mathrm{mole})$} \\
\hline $1 / 2 \mathrm{H}_{2} \rightarrow \mathrm{H}$ & 52.089 & 52.982 & 53.4 \\
\hline $1 / 2 \mathrm{H}_{2} \rightarrow \mathrm{e}^{-}+\mathrm{H}^{+}$ & 367.088 & 368.066 & 365.4 \\
\hline $1 / 2 \mathrm{H}_{2}+\mathrm{e}^{-} \rightarrow \mathrm{H}^{-}$ & 34.054 & 34.943 & 一 \\
\hline
\end{tabular}


Besides tritium being found in free water along with water containing normal hydrogen, tritium may exist in minerals that contain water of hydration such as mica (e.g., $\mathrm{K}_{2} \mathrm{O} \cdot 3 \mathrm{Al}_{2} \mathrm{O}_{3} \cdot 6 \mathrm{SiO}_{2} \cdot 2 \mathrm{H}_{2} \mathrm{O}-$ potassium aluminosilicate). In fact, tritium atoms can substitute for light hydrogen atoms in any hydrated form of water.

Very few compounds of pure tritium have been prepared and studied. Such compounds would undergo decomposition following decay. Tritium oxide (e.g., tritiated water) has been prepared by oxidizing tritium gas with hot copper oxide or by passing an electric spark through a mixture of tritium and oxygen. The distribution of tritiated water in ground and surface waters is controlled by the operation of the hydrological cycle. Several properties of the oxides of the three isotopes of hydrogen are listed in Table 5-5.

A large number of compounds containing hydrogen or tritium bonded to fluorine, oxygen, or nitrogen appears to be associated in the liquid and solid states; this means that the forces holding the separate molecules together appear to be abnormally strong. The boiling points of water $\left(\mathrm{H}_{2} \mathrm{O}\right)$, ammonia $\left(\mathrm{NH}_{3}\right)$, and hydrogen fluoride (HF), for example, are higher than that predicted from an extrapolation of the boiling points of similar compounds with sulfur, phosphorous, and chlorine. This strong association is attributed to hydrogen bonding, which is essentially the attraction of the positively charged hydrogen atoms on one molecule to the negatively charged oxygen atoms on another molecule. This strong bonding elevates the melting points and the boiling points. ${ }^{23}$ Hydrogen bonding gives deoxyribonucleic acid (DNA) its unique properties and gives water the unusual property of expanding upon freezing, resulting in a density of ice less than the liquid.

Hydrocarbons are another important class of compounds that may include tritium atoms substituted for normal hydrogen atoms bonded to carbon atoms. In many hydrocarbons, the carbon-carbon bonds usually dictate the properties of the compound. One factor affecting the bonding between tritium and hydrocarbons is the presence of other elements bonded to carbon: for instance, oxygen and nitrogen. ${ }^{24}$ These other atoms, in addition to the different types of carbon bonding, affect the chances of tritium substitution for light hydrogen. Nitrogen plays an important role in some important hydrocarbons. In particular, nitrogen affects the formation of amino acids, the basic building blocks of life, and the formation of DNA. The importance of tritium incorporation in amino acids, or DNA, is that eventually the tritium atom will decay. Once this happens, the molecules that had incorporated it would be changed.

Table 5-5. Physical properties of $\mathrm{H}_{2} \mathrm{O}, \mathrm{D}_{2} \mathrm{O}$, and $\mathrm{T}_{2} \mathrm{O}$.

\begin{tabular}{llcc}
\hline \multicolumn{1}{c}{ Property } & $\mathrm{H}_{2} \mathrm{O}$ & ${ }^{2} \mathrm{H}_{2} \mathrm{O}$ & ${ }^{3} \mathrm{H}_{2} \mathrm{O}$ \\
\hline Density at $25^{\circ} \mathrm{C}\left(\mathrm{g} / \mathrm{cm}^{3}\right)$ & 0.99707 & 1.10451 & - \\
Maximum density $\left(\mathrm{g} / \mathrm{cm}^{3}\right)$ & 1.00000 & 1.10589 & 1.21502 \\
Temperature of maximum density & 3.98 & 11.21 & 13.4 \\
Melting point $\left({ }^{\circ} \mathrm{C}\right)$ & 0.00 & 3.81 & 4.49 \\
Boiling point $\left({ }^{\circ} \mathrm{C}\right)$ & 100.0 & 101.41 & - \\
\hline
\end{tabular}




\section{Tritium Production}

Tritium was first produced in 1934 by bombarding deuterium $\left({ }^{2} \mathrm{H}\right)$ with high-energy deuterons according to the equation:

${ }^{2} \mathrm{H}+{ }^{2} \mathrm{H}-\cdots---->{ }^{3} \mathrm{H}+{ }^{1} \mathrm{H}$.

In alternate notation:

$\mathrm{D}+\mathrm{D}$

Equation (5-2b) is also referred to as the D-D fuel cycle in fusion research. The reaction identified in Equation (5-2b) has only a 50\% chance of occurring, with the altemate reaction being D + D -$>{ }^{3} \mathrm{He}+\mathrm{n}$. All of these reactions require energy to initiate; however, they liberate more energy than they consume.

Today, the primary means of producing commercial quantities of tritium is in nuclear reactors utilizing thermal neutrons (n) and lithium ( $\mathrm{Li}$ ) target materials according to the reaction:

${ }^{6} \mathrm{Li}+\mathbf{n}-\cdots-\ldots-.->{ }^{3} \mathrm{H}+{ }^{4} \mathrm{He}$.

Lithium metal is composed of the two stable isotopes ${ }^{6} \mathrm{Li}$ and ${ }^{7} \mathrm{Li} .{ }^{6} \mathrm{Li}$ is the rarer of the two isotopes, with an isotopic abundance of $7.5 \%$. Since large-scale tritium production requires a nuclear reactor, $\mathrm{Li}$ target materials, and a postirradiation processing facility, tritium is very expensive. The commercial price of tritium for $1989-1990$ was about $\$ 28,000$ per gram (e.g., $\$ 2.90$ per Ci). ${ }^{25,26}$

\section{Nuclear Reactors}

Although tritium can be produced in a nuclear (fission) reactor utilizing lithium target materials via Equation (5-3), small quantities of tritium are naturally generated in the fuel and coolant of a nuclear reactor. For instance, tritium is produced as a result of the fission process itself and as activation of boron contained in the coolant of pressurized water reactors (PWRs), but tritium is absent from boiling water reactors (BWRs). Figure 5-1 shows the detail fission product yield distribution for thermal neutron fission of ${ }^{235} \mathrm{U}$. This information was obtained from the fission yield data from the ORIGEN2 $2^{27,28}$ computer code. The curve shown in Figure 5-1 between mass numbers 70 and 160 is typical of other published binary fission yield distributions, and the fission yield data for fission of ${ }^{233} \mathrm{U}$ and ${ }^{239} \mathrm{Pu}$ is also very similar. However, the interesting part of Figure 5-1 is that portion of the yield curve for mass number 3 (e.g., the left-most point of this figure). Based on Figure 5-1, the fission yield for ${ }^{3} \mathrm{H}$ for thermal fission of ${ }^{235} \mathrm{U}$ is about $0.01 \%$. Consequently, tritium atoms are produced as a result of ${ }^{235} \mathrm{U}$ fission at the rate of about one atom per 10,000 fissions. ${ }^{29,30}$ The fission yield of tritium from ${ }^{239} \mathrm{Pu}$ is about $0.02 \%$. The fission process produces tritium atoms because in about 1 event in 400 , the ${ }^{235} \mathrm{U}$ atom splits into three main parts (e.g., two large fragments and a light element fragment called ternary fission) instead of only two main parts (e.g., binary fission), plus the release of 2 or 3 neutrons. ${ }^{31}$ Most of the time, an alpha particle is released as the light element. However, in a few cases a tritium atom is produced. For a 3,000-megawatt thermal (MWt) reactor, either PWRs or BWRs, the annual production rate of tritium via direct fission is about $2.0 \pm 0.5 \mathrm{~g},{ }^{32}$ with an equilibrium core inventory of $\sim 3.0$ to $4.0 \mathrm{~g}$. 
In comparison, a 3,000-MWt heavy-water reactor would produce about $62 \mathrm{~g}(600 \mathrm{kCi})$ of tritium per year. ${ }^{9}$ Tritium is also produced in high-temperature gas-cooled reactors by ternary fission and activation of ${ }^{3} \mathrm{He}$ present in small amounts in the helium coolant.

The other primary source of tritium for PWRs is the activation of boron contained within the coolant, which is used as a chemical reactivity shim. Significant quantities of tritium can also be generated from activation of boron used in control rods. However, most of this material is trapped inside the rods. The particular nuclear reaction that produces tritium from boron is:

${ }^{10} \mathrm{~B}+\mathrm{n}-\ldots . .->{ }^{3} \mathrm{H}+{ }^{4} \mathrm{He}+{ }^{4} \mathrm{He}$.

In addition, small amounts of tritium can also be produced through the activation of boron or lithium impurities, ${ }^{32}$ and through deuterium reactions involving the ${ }^{2} \mathrm{H}$ atoms naturally present in the reactor coolant. Table 5-6 shows the estimated tritium inventories for the reactor coolant of typical PWRs and BWRs.

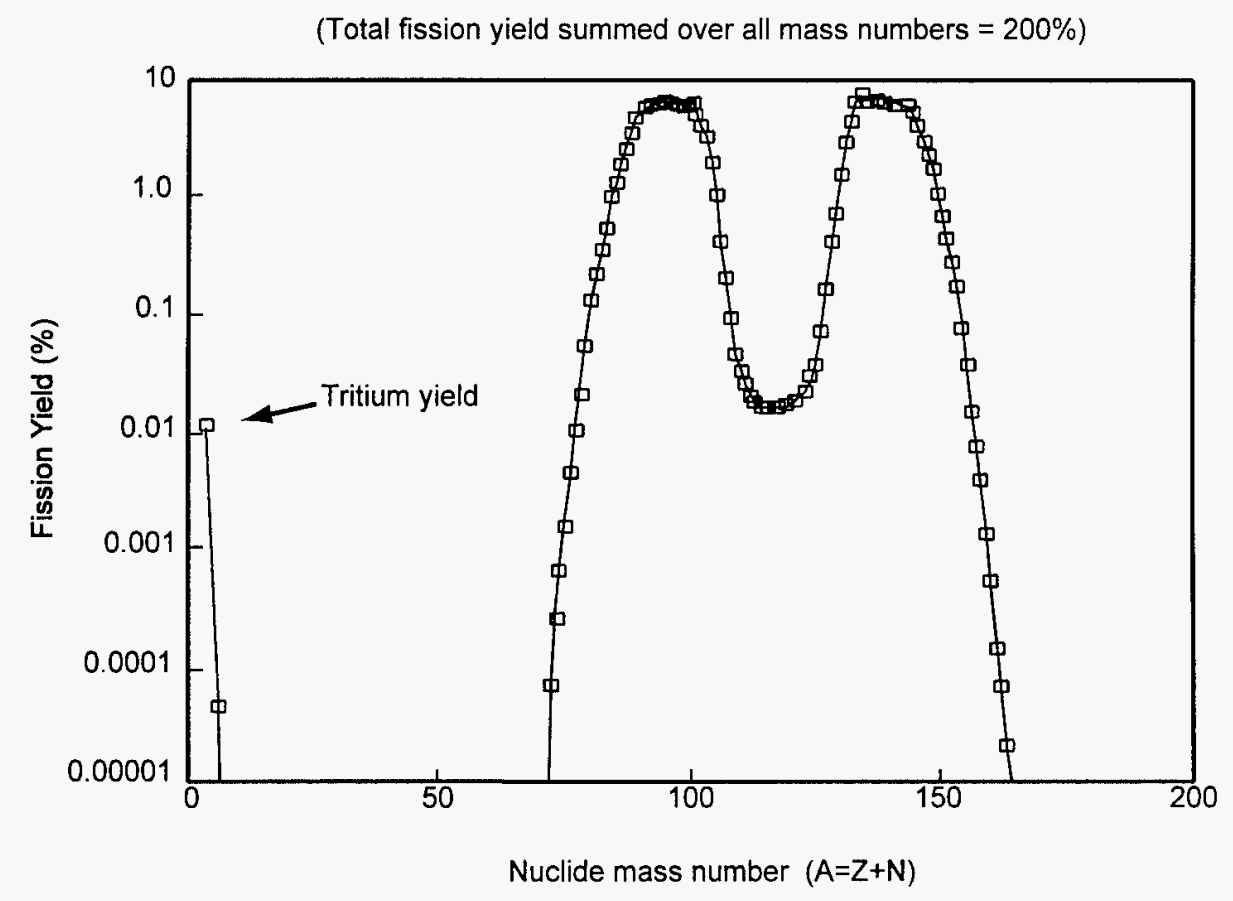

Figure 5-1. Fission product yield curve for thermal fission of ${ }^{235} \mathrm{U}$. 
Table 5-6. Estimated release rates of tritium to the reactor coolant for a 1,000-MWe ${ }^{\mathrm{a}} \mathrm{PWR}$ and a BWR, based on Reference 31.

\begin{tabular}{|c|c|c|}
\hline Tritium Source & $\begin{array}{c}\text { PWR } \\
\text { (mg of }{ }^{3} \mathrm{H} / \text { year) } \\
\end{array}$ & $\begin{array}{c}\text { BWR } \\
\text { (mg of }{ }^{3} \mathrm{H} / \text { year) } \\
\end{array}$ \\
\hline Ternary fission ${ }^{\mathrm{b}}$ & 4.1 & 4.1 \\
\hline Boron activation & 58. & - \\
\hline Lithium reactions & 1.8 & - \\
\hline Deuterium reactions & 1.0 & 1.0 \\
\hline Total & 64.9 & 5.1 \\
\hline \multicolumn{3}{|c|}{$\begin{array}{l}\text { a. A typical PWR or BWR produces about } 1,000 \mathrm{MW}(1,000 \text { million watts) of electricity from } 3,000 \mathrm{MW} \text { of } \\
\text { thermal heat (denoted as } 3,000 \mathrm{MWt} \text { ). }\end{array}$} \\
\hline \multicolumn{3}{|c|}{$\begin{array}{l}\text { b. With zircaloy-clad fuel rods only } \sim 0.1 \% \text { of the tritium inventory is released to the coolant. The tritium } \\
\text { diffusion rate increases by a factor of } 10 \text { if stainless steel cladding is used instead of zircaloy. For this entry, a } \\
\text { peak tritium inventory of } 4.0 \mathrm{~g}(4,000 \mathrm{mg}) \text { was assumed for the entire reactor core. }\end{array}$} \\
\hline
\end{tabular}

\section{Tritium Production for Thermonuclear Weapons}

Most information concerning tritium production for thermonuclear weapons is classified. Therefore, accurate information regarding the production and inventory requirements of tritium for weapons programs is unknown. It is reasonable to assume, however, that most of the tritium that exists today has been produced for thermonuclear weapons and the stockpile inventory associated with the manufacturing and maintenance of these weapons. Today, the primary source of tritium in the environment results from past atmospheric testing of thermonuclear weapons. For instance, about $300 \mathrm{~kg}(2,800 \mathrm{MCi})$ of tritium, or about 40 times the natural background tritium activity, was released to the environment from fusion explosives prior to $1963 .^{9}$ Annual releases of the order of $21 \mathrm{~g}(200,000 \mathrm{Ci})$ have typically occurred at the Savannah River Site reactors that produce tritium for the Department of Energy (DOE) weapons program. ${ }^{33}$ One estimate ${ }^{25}$ of the U.S. tritium production and stockpile inventory suggests an annual production rate of $\sim 11 \mathrm{~kg}$ and a stockpile inventory of at least $70 \mathrm{~kg}$; however, these results are speculative. Environmental impact studies performed for the DOE have assumed an inventory of $7.3 \mathrm{~kg}(70 \mathrm{MCi})$ present in one Savannah River production reactor as a tritium source term. ${ }^{34}$ This tritium is contained within the fuel, $\mathrm{Li}-\mathrm{Al}$ targets, control components, and the heavy water moderator, with less than $520 \mathrm{~g}(5 \mathrm{MCi})$ estimated for the moderator.

\section{Accelerators and Fusion Reactor Programs}

Tritium was first produced with a charged-particle accelerator in 1934 by impacting accelerated deuterium nuclei $\left({ }^{2} \mathrm{H}\right)$ onto a deuterium target. Today, the result of this experiment demonstrates that nuclear fusion can be achieved with deuterium atoms [via Equation (5-2b)]. Present research uses both deuterium and tritium as potential fusion fuels. As a result of laboratory experiments, small quantities of tritium have been produced and consumed in accelerator programs, with the vast majority of tritium 
production relying on fission reactors. Currently, only small quantities of tritium are stored and used at laboratories performing fusion research (e.g., the Princeton Plasma Physics Laboratory), usually less than $10 \mathrm{~g}$ of tritium, with most research facilities having less than $0.104 \mathrm{~g}(1,000 \mathrm{Ci})$. However, some facilities ${ }^{35}$ report tritium inventories of as much as $53 \mathrm{~g}$.

Present experimental fusion programs are small compared with hypothetical commercial scale fusion reactors. Large commercial thermonuclear reactors have been designed based on experimental tokamak reactors. Facilities as large as 4,660 and 5,305 MWt have been proposed. ${ }^{36}$ In these facilities, the deuterium-tritium fuel cycle is used and tritium is bred from lithium (coolant-blanket) material surrounding the fusion chamber. The tritium inventories for these hypothetical fusion power reactors are large compared with fission reactors. For example, the tritium inventory for a 4,660 MWt commercial fusion reactor (University of Wisconsin design) ${ }^{36}$ would be about $13,500 \mathrm{~g}$. Compare this with the $4 \mathrm{~g}$ maximum inventory of tritium for a typical 3,000 MWt fission reactor. The estimated tritium releases to the environment from a large fusion power reactor are of the order of $10 \mathrm{Ci}$ of tritium/day $(\sim 1.0 \mathrm{mg} /$ day $) .{ }^{36}$ The overall tritium hazard does become pronounced when dealing with these large inventories. However, containment rather than disposal of the tritium in a commercial fusion reactor becomes the primary objective. On an energy basis, it has been estimated that the production demands of tritium could be 100,000 times greater than that from a commercial light-water reactor (LWR) to fuel a single large fusion reactor. A large commercial fusion plant could theoretically burn 100 to $1000 \mathrm{~g} / \mathrm{day}$ ( $10^{6}$ to $10^{7} \mathrm{Ci} / \mathrm{day}$ ), or approximately 1,100 to 11,000 liters of tritium gas (at standard temperature and pressure conditions). This amount of tritium represents a significant fraction of the current world stockpile. ${ }^{37}$ Although a commercial fusion reactor would simultaneously burn and generate tritium, it would not be $100 \%$ efficient in producing as much tritium as it consumed. Makeup supplies would have to be purchased from fission reactor sources. Therefore, fission reactors would still be needed to supply some of the tritium requirements of the first generation fusion power plants.

\section{Waste and Disposal Data on Tritium}

This section discusses the types of activities that generate tritium LLW, waste types and forms that contain tritium, and disposal data on tritium.

\section{Nuclear Reactors}

At least $98 \%$ of the tritium produced in a LWR is trapped within the fuel rods, with less than $2 \%$ of the tritium inventory for a commercial LWR present in the primary coolant system. Most tritium leaks result from the primary coolant pumps and from water removed during normal refueling operations, which is discharged to the waste disposal systems. Tritium is also discharged with these waste waters and is eventually released to the environment as tritiated water. Currently, no economical technology exists for separating the tritiated water from light water; however, several research programs are dedicated to tritium separation technology. Because of tritium's small radiological hazard and the difficulty of separating it from reactor water, tritium removal at the reactor site is not currently practical. However, public opinion and the increasing production and inventory of tritium wastes at LWRs may force the storage and/or treatment of tritiated waters, instead of the current process of dilution and release into environment. Tritium normally composes at least $50 \%$ of the total amount of radioactive material 
discharged as liquid waste from a nuclear reactor; and the amount of tritium discharged in gaseous form is only $\sim 1 \%$ of the total tritium discharge. ${ }^{36}$ About $99 \%$ of the released tritium is in the liquid form of tritiated water, although some tritiated water vapor may also exist.

\section{Nuclear Fuel Reprocessing Waste Types}

The largest source of tritium waste and potential release to the environment, associated with commercial reactor operations, results from the reprocessing of fuel. Nearly all of the tritium produced in a light-water reactor is contained within the fuel rods and will end up at a fuel reprocessing plant if and when the reactor fuel is reprocessed. The projected release rate of tritium from a fuel reprocessing plant with no tritium control systems is estimated to be 88 Curies per Metric Ton Uranium (Ci/MTU). ${ }^{36}$ Several tritium control processes of various degrees of technical and economic feasibility are chemical exchange, distillation, electrolysis, radiolysis, diffusion and centrifugation, solvent extraction, adsorption and chromatography, molecular excitation, and voloxidation. Voloxidation is an interesting tritium control procedure that can be performed during fuel reprocessing. After the nuclear fuel rods are opened, the fuel is heated to $\sim 650^{\circ} \mathrm{C}$ in an air/oxygen atmosphere. During the oxidation process, the volume of the oxide fuel increases by about $30 \%$, thereby breaking up the $\mathrm{UO}_{2}$ fuel pellets and releasing many of the volatile fission products, including tritium. The tritium that is released from the $\mathrm{UO}_{2}$ fuel then reacts with the free oxygen to form tritiated water vapor, which is eventually condensed and separated from the other gaseous fission products. The tritiated water that is collected would be relatively free of ordinary water and would occupy a volume smaller than the tritiated water wastes generated by alternative tritium control procedures. With the voloxidation process, tritium decontamination factors of 100 are possible. ${ }^{36}$

\section{Tritium Production Reactor Facilities}

Aside from the detonation of thermonuclear weapons in the atmosphere (primarily before 1963), the largest tritium releases to the environment have been associated with the production of tritium at the Savannah River Site reactors for the thermonuclear weapons program. Typical releases of the order of $21 \mathrm{~g}(200,000 \mathrm{Ci})$ per year have been documented for the Savannah River reactor complex. ${ }^{33,37}$ The chemical composition of the Savannah River Site released tritium has varied from nearly $100 \%$ tritium gas to $100 \%$ tritiated water. ${ }^{37}$ Although detailed information concerning the Savannah River tritium production reactors is not available, the primary tritium wastes associated with these facilities are probably tritiated heavy water and tritium associated with lithium and lithium-aluminate as a lithium. The most likely chemical form of tritium is as a lithium-hydride, or more precisely, a mixture of lithium- 6 deuteride and lithium- 6 tritide, which comprises the fusible trigger. When a thermonuclear weapon is retired, it is ultimately dismantled and the existing tritium in the weapon is recycled. The primary tritium waste forms from the recycling process are likely to consist of tritium gas and lithium-tritide, with other gaseous and liquid tritium waste forms generated from the recycling effort.

\section{Fusion Program Tritium}

The amount of tritium wastes released to the environment from research fusion programs is small in comparison to that currently generated and released from LWRs. Eventually, however, if commercial scale fusion power plants are constructed, they will contain inventories of several kilograms of 
tritium for each reactor, a significant fraction of the current world stockpile. In comparison with LWRs, the estimated normal tritium release rates from a fusion power plant would be one or two orders of magnitude higher, even if the fractional tritium leakage rates are smaller than current LWRs. For example, the estimated average fractional tritium release rate of two postulated commercial fusion power plants is $\sim 1.5 \times 10^{-7}$; and the tritium leak rate for a BWR is $\sim 100 \times 10^{-7}$ per day. However, the BWR releases are from 50 to $100 \mathrm{Ci}$ of tritium per year, while the commercial fusion power plant is expected to release $\sim 4,500 \mathrm{Ci} /$ year. If the fusion power plant actually had a fractional release rate equal to the $\mathrm{BWR}$ rate, it would routinely release $300,000 \mathrm{Ci} /$ year, more than the average accidental tritium releases from the Savannah River Site production reactors. The primary waste forms of tritium from fusion reactor research programs, and probably from a full scale fusion power reactor, would be tritiated water (as a vapor), and tritium gas. ${ }^{36}$

\section{Medical, Academic Institutions, and Commercial Tritium Facilities}

Accelerator targets are used to produce radionuclides by direct bombardment with charged particles or by indirect reactions of the target fragments with other materials. Accelerator targets are also used to study the properties of subatomic particles. The spent targets from institutional sources are commonly made of titanium metals and foils, and can contain absorbed tritium. The quantity of tritium wastes from accelerator facilities is fairly small in comparison to commercial and reactor generated tritium wastes.

Tritium is commonly used in biochemical and biomedical research, industrial applications (radioluminous paint, scintillation vials, etc.), and many manufactured items (radioluminous products watches, compasses, instrument dials, markers, nonpowered exit signs for commercial buildings, public telephone dials, light switch markers, miniature light sources, electronic tubes, cold-cathode tubes, glow lamps, gas chromatographs, etc.). The primary use of tritium in biochemistry research is as a chemical tag. For example, ${ }^{3} \mathrm{H}$-labeled thymidine has been used as a biochemical marker for DNA research, ${ }^{38}$ determiner of cell kinetics and life span, and tracer in steroids (e.g., ${ }^{3} \mathrm{H}$-testosterone) ${ }^{39}$ Tritiated water has also been useful in determining human body water content and blood plasma volume. ${ }^{40}$

The radionuclide most used in the production of luminescent paints and emergency lighting is tritium. Tritium powered exit signs are available from 10 to 20 year lifetimes. The initial quantity of tritium contained in these signs is estimated to range from 10 to $25 \mathrm{Ci}$. Luminescent paints are used in watches, self-lighted instruments (dials, compasses, etc.), and in emergency and safety sign applications (e.g., direction and exit signs). Also, tritium can either be used as a tritiated pigment fixed to a base material and then covered by varnishes, plastics, or other materials, or sealed in a gas tight vial for emergency exit signs. Depending upon the manufactured product, several different tritium waste forms can exist. Assessment of tritium release from consumer products is much more difficult to determine than for nuclear power plants. This is partly due to the uncertain form, means, and time of disposal of these products. For example, discharge of tritium to the environment from a consumer product is possible at every stage during the entire lifetime of that product (e.g., production, distribution, use, repair, and disposal). 


\section{Disposal Data on Tritium}

Tritium has been deposited in three LLW sites in Richland, Washington; Barnwell, South Carolina; and Beatty, Nevada over a period of several years. Data have been obtained on the activity, sources, and waste types for this nuclide from the Manifest Information Management System Database. ${ }^{a}$ Figure 5-2 shows the total annual tritium activity deposited in the three sites for each year between 1986 and 1995 . Over half of the total activity for this nuclide was deposited during four years, 1989-1992. Tritium was deposited approximately uniformly during the other years.

Figure 5-3 shows the activity of tritium deposited in these three sites as a function of waste source. Government and industrial sources account for more than $96 \%$ of the total deposited in these three sites. An additional 3.5\% came from utilities and the rest from the other sources. The definition of disposal categories given in Figure 5 -3 is as follows: academic - sources associated with university laboratories; government - sources associated with the government, such as military hospitals; industry - sources associated with manufacturing, other than utilities; medical - sources associated with hospitals and medical laboratories, excluding pharmaceutical manufacturing; utility - sources generated by nuclear utilities and stored onsite or sent to one of the three disposal sites. Waste treatment facilities are included in the utility category.

Figure 5-4 shows the activity of tritium deposited in the Richland and Beatty sites as a function of waste type. The waste disposal manifests for the Barnwell site did not break down the waste by type, which is unfortunate since more than half of this nuclide has been stored at this site. As shown in this figure, more than three-fourths of this nuclide was in the form of dry solids. The waste types illustrated in Figure 5-4 are from nuclear reactors, academic institutions, and medical facilities.

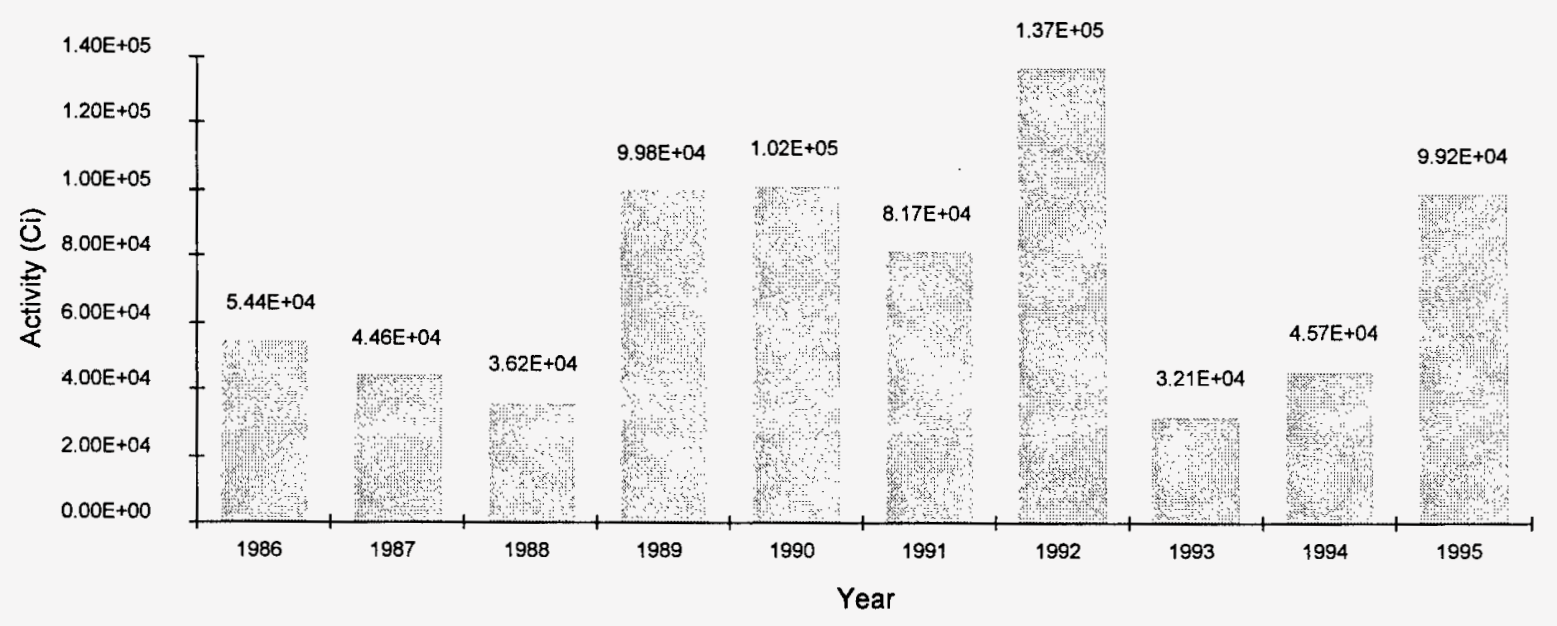

Figure 5-2. Tritium activity deposited at the Richland, Beatty, and Barnwell sites by year (log scale).

a. Information provided through the DOE waste management system maintained by the National Low-Level Waste Management Program, Idaho National Engineering Laboratory (INEL). 


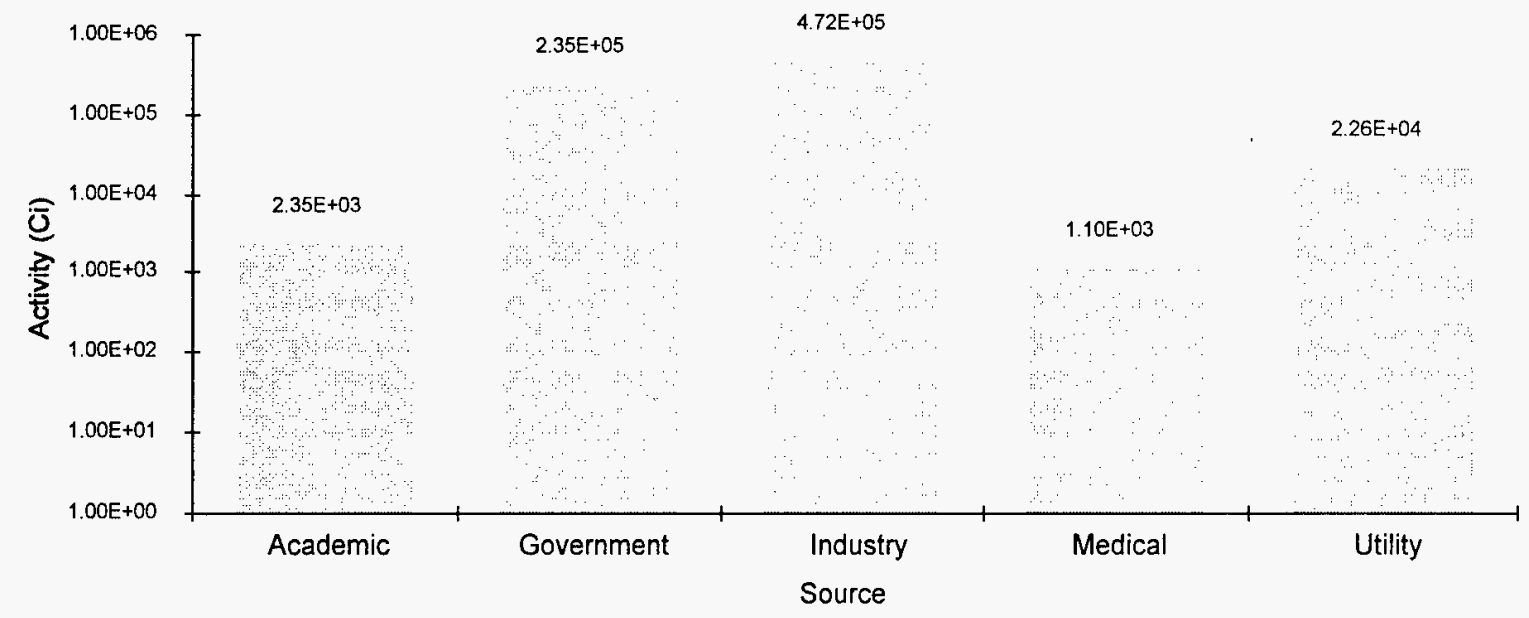

Figure 5-3. Tritium activity deposited at the Richland, Beatty, and Barnwell sites by source (log scale).

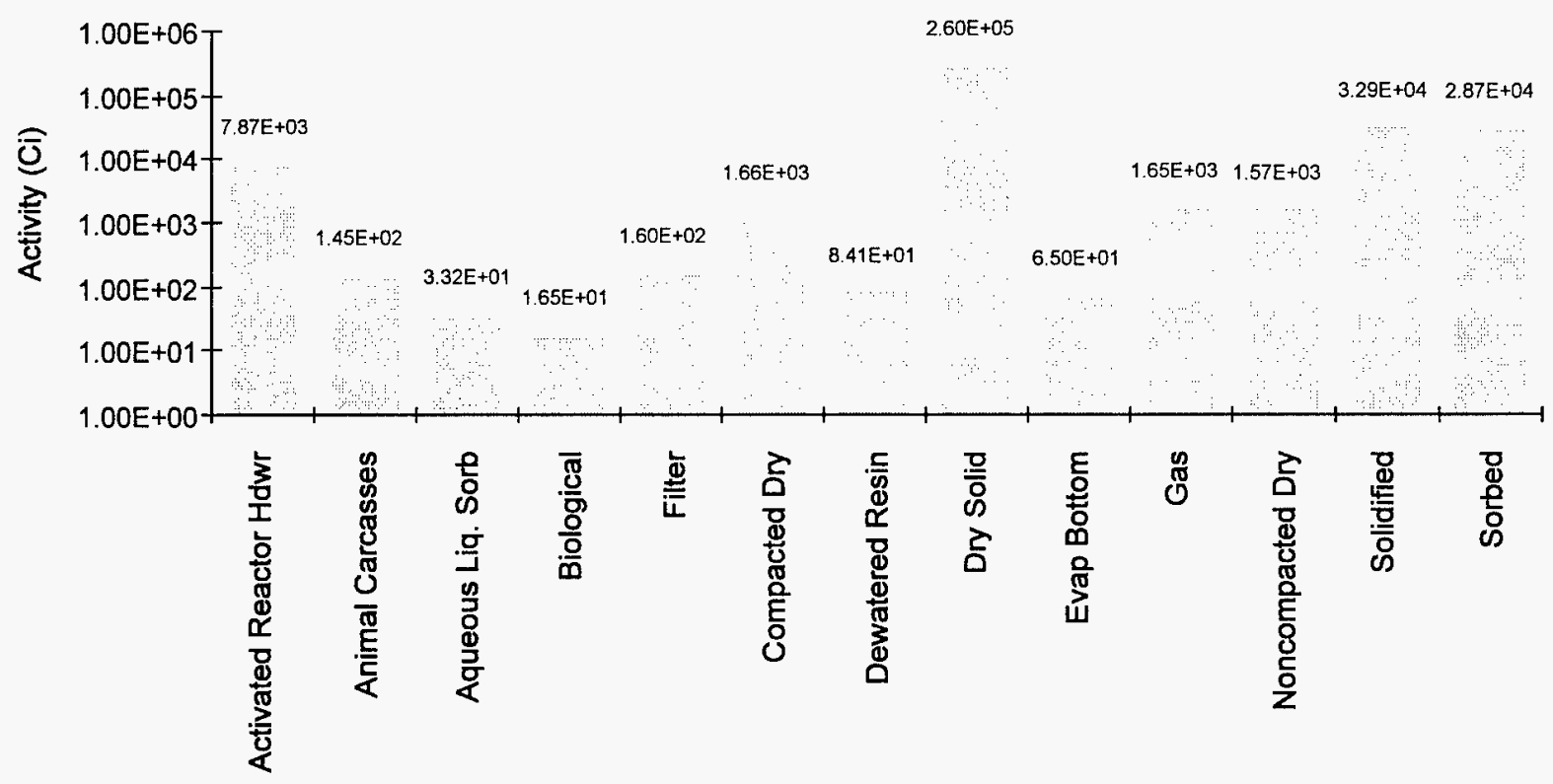

Waste Type

Figure 5-4. Tritium activity deposited at the Richland and Beatty sites by waste type (log scale). 


\section{Behavior of Tritium in the Environment}

Tritium behavior in soils, water, vegetation, and air is expected to be similar to hydrogen where it exists as an ion, gas or liquid (tritiated water). Except for the slight differences in vapor pressure, tritiated water behaves like ordinary water. ${ }^{41}$ Tritium can associate itself with soil organic components containing hydrogen, with some soil minerals as mobile water, water of hydration, or as part of hydroxyl groups. ${ }^{11,42}$

\section{Tritium in Soils}

Tritium ultimately exists in the soil as a tritiated water molecule. Theoretically, tritium ions are capable of exchanging for ordinary hydrogen ions and other ions in the soil. However, tritium is usually in an aqueous solution before contacting soils, so that the most common mechanism of tritium incorporation is due to isotopic exchange of hydroxyl water molecules. Tritium distribution has not been quantified to a large extent. An electrodialysis technique has been reported to speed up tritium hydroxyl exchange in clays. ${ }^{43}$ Tritium hydroxyl exchange was reported to be proportional to the cation exchange capacity of the clays. Most field studies have indicated that tritium distribution coefficients were very low because tritium migration velocities were essentially the same as those of the accompanying ground water. $^{44,45}$

Because soil water and ground water systems are similar, it would be expected that tritium oxide would move through these systems at essentially the same rate as water. However, the tritium migration rate ultimately depends upon the type of soil (e.g., clay versus sand) and whether the tritium can be "fixed" in the soil. Several retention mechanisms of tritium on clays are possible. For example, (a) exchange of tritium ions for hydrogen ions, (b) tritiated water molecules exchanged for hydroxyl water or water of crystallization, (c) exchange of tritium ions for nonhydrogen cations, and (d) replacement of aluminum in lattice sites by tritium. Comparing chloride ions and tritium breakthrough curves (i.e., the time for tritium to migrate a specific distance) for various soil types, the tritium breakthrough curve lags behind that for chloride ions in soils containing clays and silt. ${ }^{46}$ This behavior is caused by the tritiated water molecule entering the clays and replacing nontritiated water adsorbed on clay surfaces or interlayers.

Field studies performed near Argonne Illinois have shown that tritium movement through soil is affected by isolated compartments of immobile water in the soil. ${ }^{47,48}$ However, all of the field studies have shown that tritium movement is synonymous with water movement.

\section{Tritium in Water}

Tritium migration has been studied in the field at the Pacific Northwest Laboratory, at the Argonne National Laboratory, and in Puerto Rico.

Based on the rate and direction of groundwater flow, the movement of tritium in the ground at the Hanford Purex Plant would require 6 or 7 years to reach the Columbia River, which is located approximately 17 miles from the Purex Plant. ${ }^{49,50}$ The half-life of tritium allowed $\sim 70 \%$ of the initial tritium discharged to the soil to reach the river. The tritium content of Columbia River water was expected to be less than 1.5 times the current tritium background activity. This was due to tritium 
dispersion during travel and the large dilution represented by the Columbia River $(80,000$ to $200,000 \mathrm{ft}^{3} / \mathrm{sec}$ ). In another review of the hydrology and geology of the Hanford area, it was reported that tritium moved at essentially the same rate as the groundwater. ${ }^{45}$

In summary, tritium substitutes readily for ordinary hydrogen in water, and thus becomes part of the hydrological cycle. Migration of tritium through the groundwater takes place at the same velocity as the groundwater through sandy soils.

\section{Tritium in Plants}

The effect of tritium on plants is summarized in Reference 51. Some of the most important aspects of this information is presented below.

Tritium can be readily oxidized to produce tritiated water by soil microorganisms..$^{52,53,54}$ The oxidation process is carried out by the same soil organisms that were important in the natural cycling of hydrogen between organic material, gaseous hydrogen, and water.

It has also been shown that tritium gas can be oxidized to form tritiated water in the leaves of green plants. ${ }^{55}$ Additional work corroborated the oxidation of tritium gas in higher plants, but indicated the rate of uptake was smaller than the exchange of tritiated water vapor with the atmosphere. ${ }^{56,57}$ Nevertheless, the process responsible for tritium uptake by plants is not fully understood, and it is quite possible that a number of processes might be involved. A certain amount of physical absorption of gaseous hydrogen by the waxed leaf surface can take place and chemical transformation, mediated by plant metabolic processes, would also be expected to be important.

The biological uptake of gaseous materials by plants can be limited by the physical processes of diffusion and solubility, or by the rate of metabolism of the plant. Because the molecular diffusivity of tritium in air is high and the solubility of hydrogen in water is low, ${ }^{58}$ solubility in the plant cell limits transport to the active metabolic sites in the plant to a greater degree than diffusion from the atmosphere into the leaf.

The limiting chemical step to molecular hydrogen oxidation is the breaking of the hydrogen bond between the atoms making up the hydrogen molecule. Green plants possess compounds with redox potential large enough to break the molecular hydrogen bond, but enzyme systems to catalyze this reaction have not been identified. ${ }^{59}$ However, hydrogen uptake by primitive plants, such as algae and moss, is well documented. ${ }^{60,61}$

In plants, tritium can be associated with the plant water or with other plant materials that are often described as the organic fraction of the plant. The organic fraction is composed of a large number of compounds, some of which are not really organic (i.e., contain carbon). For the purpose of determining the transport characteristics of tritium in plants, the organic tritium is usually classified into that fraction that is readily mobile or exchangeable with water and not easily extracted from the organic matrix. The less removable tritium, often called organically bound tritium, is associated with tritium atoms that are bonded to carbon atoms in the molecules of organic compounds. ${ }^{62}$ Tritium atom exchange is usually 
associated with atoms in hydroxyl or other groups that are freely exchanged with the surrounding water. Because the rate of exchange is dependent on both the chemical form of the groups and their accessibility in the organic structure, there is a continuum of exchange rates.

In plants exposed to tritiated or deuterated water, $25-40 \%$ of the hydrogen of the organic materials comes into equilibrium with the water concentration by exchanging within a few days of exposure. ${ }^{63,64,65}$ Plant organic materials can be labeled by this means when plants oxidize tritiated hydrogen.

Further incorporation takes place by metabolic processes. The better understood of these processes is the incorporation through the photosynthesis of carbon dioxide and water. ${ }^{62.66}$ Compounds produced through this process are in equilibrium with the water activity at the time of synthesis. In addition, the increase in the incorporation of tritiated water into organically bound tritium caused by increasing light intensity is proportional to the increase in the rate of photosynthesis, which is measured by carbon dioxide $\left({ }^{14} \mathrm{CO}_{2}\right)$ uptake. ${ }^{66}$ Part of the tritium "fixed" by photosynthesis is exchangeable with ordinary hydrogen, depending upon the equilibrium condition of the water around the material.

Although small amounts of tritium can be "fixed" by physical absorption or radiochemical reactions, tritium uptake is likely to be small for any of these processes at the normal tritium concentrations found in the environment.

The uptake of tritium by plants through tritium oxidation is much lower than the uptake by hydrogen exchange with tritium gas existing in the atmosphere. Furthermore, oxidation of tritium gas by plants is much lower than that observed for soil micro-organisms. Under most circumstances tritium oxidation by plants would be expected to make a negligible contribution to the dose to man. However, the question of the relative contribution of tritiated water and organic tritium to long-term tritium releases has not been answered by any of the short term experiments done to date.

\section{Tritium in Air}

Since tritiated water is about 10,000 times more harmful than tritium gas, it is important to know the extent of tritium oxidation in the open environment in order to assess the ultimate hazard of tritium gas releases. Laboratory experiments have indicated that the oxidation rate of tritium gas is very slow, but some field experiments in the early 1970s suggested that this is not necessarily correct. Participation by scientists from six countries provided a comprehensive study of the dispersion, deposition and cycling of tritium from atmospheric releases. ${ }^{67}$

The results of other experiments indicate that conversion of tritium gas to tritiated water in the atmosphere is very slow. However, tritiated water is usually present in any tritium gas plume and appears in the soil and vegetation over which the plume passes.

Detailed tritium data for the atmosphere appears in References 68 through 70. The water content of the troposphere decreases with altitude ${ }^{69}$ Atmospheric tritium gas has a practically constant mixing ratio invariant with height. ${ }^{70,71}$ The average residence time for tritium in the atmosphere, which appears to be 4 to 10 years, ${ }^{70,71}$ is governed by chemical conversion in the atmosphere as well as microbiological processes. 


\section{Behavior of Tritium in the Human Body and in Animals}

To determine the effects of tritium on the human body, most experiments have relied on animal data. These experiments have been extrapolated to humans. In addition to meeting human data needs, animal experimentation has helped to determine the impact on animals as a source of human food.

Due to the low beta particle energy emitted by tritium, a single cell layer constitutes an efficient barrier against the beta particle. Thus, external radiation from tritium is a negligible hazard to man. ${ }^{68}$

The body weight of water in humans is approximately $43 \mathrm{~kg}$, and at a daily intake of $2.5 \mathrm{~kg}$ of water, the mean residence time of a water molecule in man is $\sim 17$ days, with the effective biological half-life of tritium in the human body of $\sim 12$ days. ${ }^{68}$ The biological half-life refers to the amount of time required to remove half of the initial material from the affected organism via a combination of radioactive decay, chemical, and biological removal processes. The biological half-lives of tritium in various species is summarized in Table 5-7.,73

\section{Metabolism of Tritium}

In order to evaluate tritium metabolism in man, the important reference mass data for humans are summarized in Table 5-8. For a number of soft tissues, water comprises about $80 \%$ of the total tissue mass.

\section{Tritium Gas}

Exposure to tritium gas in air is limited by the total dose received from tritium contained in the lungs. The exposure limit from tritium as a gas is about four orders of magnitude larger than that for tritiated water. Consequently, in many cases the practical tritium exposure limit is governed by the limit on tritiated water and not tritium gas.

\section{Tritiated Water}

Ingested tritiated water is assumed to be completely absorbed from the gastrointestinal tract. It is assumed to mix rapidly with the total body water so that, at all times following ingestion, the concentration in sweat, sputum, urine, blood, insensible perspiration, and expired water vapor is the same. $^{74}$

Exposure to an atmosphere contaminated by tritiated water results in intake of that substance both by inhalation and by absorption through the intact skin. It has been shown that exposure to an atmosphere contaminated by tritiated water at a concentration of $1.0 \mathrm{~Bq} / \mathrm{m}^{3}(1 \mathrm{~Bq}$ is defined as 1 disintegration/second, or $3.7 \times 10^{10} \mathrm{~Bq}=1 \mathrm{Ci}$ ) results in the absorption of $10^{-2} \mathrm{~Bq} / \mathrm{min}$ through the intact skin. ${ }^{75}$ For an average human breathing air at a rate of $0.02 \mathrm{~m}^{3} / \mathrm{min}$, the rate of inhaling tritiated water is $2 \times 10^{-2} \mathrm{~Bq} / \mathrm{min}$, with most of this material contained with the body fluids. ${ }^{76}$ Therefore, the total rate of absorption of tritiated water into body fluids is $3 \times 10^{-2} \mathrm{~Bq} / \mathrm{min}$ or $3.6 \times 10^{3} \mathrm{~Bq}$ in 2,000 hours. Usually, this tritiated water would be uniformly distributed among all the soft tissues of the body. Data on many humans have indicated that the retention of tritiated water is governed by a biological half-life of 10 to 12 days. 
Table 5-7. Biological half-life of tritium in body water after administration of tritium in the form of tritiated water.

\begin{tabular}{lc}
\hline \multicolumn{1}{c}{ Species } & $\begin{array}{c}\text { Biological half-life } \\
\text { (days) }\end{array}$ \\
\hline Mouse & 1.1 \\
Kangaroo rat & 13.2 \\
Goat (lactating) & 4.1 \\
Goat (nonlactating) & $\mathbf{8 . 3}$ \\
Miniature Goat (nonlactating) & 4.3 \\
Pig & 3.8 \\
Cow (lactating) & 3.1 \\
Cow (nonlactating) & 4.0 \\
Chicken & 4.6 \\
Human & $10.0-12.0$ \\
\hline
\end{tabular}

Table 5-8. Mass data for a reference man.

\begin{tabular}{lc}
\hline \multicolumn{1}{c}{ Mass content } & $\begin{array}{c}\text { Mass } \\
(\mathrm{g})\end{array}$ \\
\hline Hydrogen content of the body & 7,000 \\
Hydrogen content of soft tissue & 6,300 \\
Daily intake of hydrogen & 350 \\
Water content of the body & 42,000 \\
Daily intake of water (including water of oxidation) & 3,000 \\
\hline
\end{tabular}

\section{Organic Tritium Compounds}

When tritium-labeled organic compounds are ingested, a considerable fraction can be broken down in the gastrointestinal tract, producing tritiated water. Organic compounds of tritium may also catabolize to tritiated water after they have crossed the gastrointestinal tract. For example, in rodents, more than $90 \%$ of tritiated thymidine is broken down in the gastrointestinal tract and about $2 \%$ of the ingested substance is actually incorporated into DNA. ${ }^{77}$ The fraction of tritium incorporated into DNA after ingestion of tritiated thymidine is about one-fifth of that after the direct entry of tritiated thymidine into blood. ${ }^{78}$ The fractional absorption of other nucleic acid precursors and of most other tritiated compounds 
into the blood is not known; and, in most instances, it is probably greater than that of tritiated thymidine. Incorporation of tritium into DNA would result in the disassociation of the DNA molecule after the tritium atom decayed. However, this event in itself may not affect the overall health of the organism since DNA can sometimes be repaired; and, even if the DNA change results in the death of a single cell, multicellular organisms (e.g., man) usually have millions of dead cells to process all of the time. Only in the rare event that the DNA change results in a cancerous mutation that survives, would this have a detrimental impact on the health of the entire organism.

Many organic compounds of tritium are not very volatile under normal circumstances and the probability of their being inhaled as vapors is therefore small. In situations where they might be inhaled, it would be prudent to assume that once they enter the lungs they are absorbed into the blood stream.

Tritiated organic compounds that are metabolic precursors are usually distributed throughout the soft tissues and rarely concentrate in unique cells. A notable exception is tritiated thymidine, which, if not catabolized, is taken up only by the nuclei of those cells synthesizing DNA. In mice, about $45 \%$ of all DNA synthesizing cells in the body are located in the lining of the gastrointestinal tract, about $15 \%$ are found in the bone marrow and the rest are distributed mainly among the spleen, skin, parenchyma, and lymphatic tissues. ${ }^{79}$ These cells absorb approximately $30 \%$ of the tritiated thymidine that enters the blood, ${ }^{80}$ and the clearance rate from the blood corresponds to a half-life of less than 1 hour. Following ingestion, the efficiency of incorporation of the tritiated compound is reduced by a factor of $\sim 5 .^{78}$

Average absorbed doses received by organs and tissues in experimental animals have been estimated for a number of organic compounds labeled with tritium; these include folic acid, ${ }^{78}$ thymidine ${ }^{81}$ sex hormones, ${ }^{77}$ and corticosteroids. ${ }^{82}$ Reports on these experiments ${ }^{83}$ concluded that, under the accepted radiological protection criteria, the maximum permissible annual intakes to blood of tritiated thymidine and tritiated folic acid should be about one-third of the maximum permissible annual intake of tritiated water, however; the maximum permissible annual intakes of tritiated sex hormones and tritiated corticosteroids should be about 30 times the maximum permissible annual intake of tritiated water. Consideration of the absorbed dose to the cell nucleus, ${ }^{84}$ the estimated biological effectiveness, ${ }^{85,86}$ and the long-lived, self-renewing, and DNA-synthesizing cells ${ }^{78}$ indicates that the annual limits on intake (ALI) to blood of tritiated thymidine should be about one-fourth to one-fiftieth of the ALI to blood of tritiated water. Furthermore, the ALI by ingestion of tritiated thymidine might need to be one-tenth of that for tritiated water. ${ }^{78}$

Specific values of ALI are not recommended for organic compounds of tritium, but it is noted that they might differ considerably from those for tritiated water, and that the value for tritiated thymidine might be as much as 50 times smaller. The exact ratio depends on the specific compound and its route of entry into the body. Table 5-9 lists the annual limits on intake and the derived air concentration for tritium in water and gas forms. 
Table 5-9. Annual limits on intake (ALI) and derived air concentrations (DAC) for tritium.

\begin{tabular}{cccc}
\hline Radionuclide & Component & Ingestion & Inhalation \\
\hline${ }^{3} \mathrm{H}$ (Tritiated water) & ALI & $0.08 \mathrm{Ci}$ & $0.08 \mathrm{Ci}$ \\
& DAC & - & $20 \times 10^{-6} \mathrm{Ci} / \mathrm{m}^{3}$ \\
& ALI & - & - \\
${ }^{3} \mathrm{H}$ (Tritium gas) & DAC & - & $0.54 \mathrm{Ci} / \mathrm{m}^{3}$ \\
\hline
\end{tabular}

\section{Summary}

Tritium is a radioactive isotope of hydrogen. It has a half-life of 12.3 years and decays to ${ }^{3} \mathrm{H}$ with the emission of a beta particle and no gamma ray. Tritium produces a very low-energy beta particle and is usually considered one of the least radiologically hazardous of the radionuclides. However, since it can replace normal hydrogen in chemical compounds essential for life, tritium poses a potential hazard that can be very mobile within the biological environment. As tritiated water, tritium is perhaps 10,000 times more dangerous than tritium gas (e.g., in molecular form). A very small quantity of tritium naturally exists due to cosmic ray interactions with nitrogen. However, most of the tritium currently present in the environment is the result of human activities; primarily, thermonuclear weapons testing in the atmosphere (prior to 1963), accidental releases from tritium production reactors, and fuel reprocessing activities. Normal light-water reactors produce only a small amount of tritium each year primarily from ternary fission, but large future inventories of tritium will be consumed and generated at commercial-scale fusion power plants (if built). The primary chemical waste forms of tritium from commercial reactor activities are tritium gas and tritiated water either as a liquid or vapor. The tritium waste forms generated from the thermonuclear weapons program (e.g., the heavy water tritium production reactors), are probably lithium metal hydrides; namely, lithium-6 tritide, possible lithium-aluminum-tritium compounds, and all other commercial reactor tritium waste forms.

The migration of tritium in groundwater is influenced by the soil type. Tritium migration is not slowed in sandy soils, but in clay soils a small part of the tritium may be bound with the clay through the exchange of tritium atoms with ordinary hydrogen atoms in water molecules.

The mechanisms of tritium uptake in vegetation is not well understood, but plants have the capability to oxidize tritium to form tritiated water. Five metabolic processes, other than photosynthesis, can lead to incorporation of tritium as an organically bound compound. Many of the metabolic reactions that take place in living organisms are involved with the transfer of hydrogen. Any of these reactions can involve tritium instead of ordinary hydrogen.

The biological half-life of tritium in the human body is about 10 to 12 days. The behavior of tritium in the biosphere is dictated by its chemical properties, the bond strength of the tritium molecule compared with the hydrogen molecule and the bond strength of hydrogen in organic molecules. As a result, tritium gas is only slowly oxidized in the atmosphere, but can be oxidized in soil and by vegetation. The oxygen and nitrogen atoms in organic molecules make it much easier for tritium to replace hydrogen associated with these groups than with hydrogen attached to carbon atoms. 
The uptake of hydrogen in humans can occur through inhalation, ingestion, or absorption through the skin. The rate of inhalation is about the same as absorption through the skin. Specific values of annual limits on intake are not recommended for organic compounds of tritium, but it is noted that they might differ considerably from those for tritiated water and that the value for tritiated thymidine might be as much as 50 times smaller. The exact ratio depends on the specific compound and its route of entry into the body. 


\section{References}

1. U.S. Nuclear Regulatory Commission, Draft Environmental Impact on 10 CFR 61, "Licensing Requirements for Land Disposal of Radioactive Waste," NUREG-0782-V1, September 1981.

2. M. Okamoto, Y. Naruse, K. Okuno, "Overview of Tritium Work in Japan," Fourth Topical Meeting on Tritium Technology in Fission Fusion and Isotopic Applications, Albuquerque, New Mexico, September 29-October 4, 1991, Fusion Technology, Volume 21, Number 2, Part 2, A Journal of the American Nuclear Society, March 1992, pp. 187-196.

3. D. P. Dautovich, et al., "Overview of Tritium Work in Canada," Fourth Topical Meeting on Tritium Technology in Fission, Fusion, and Isotopic Applications, Albuquerque, New Mexico, September 29-October 4, 1991, Fusion Technology, Volume 21, Number 2, Part 2, A Journal of the American Nuclear Society, March 1992, pp. 215-225.

4. B. Hircq, "Overview of Tritium Technology Development for Fusion in Europe," Fourth Topical Meeting on Tritium Technology in Fission, Fusion, and Isotopic Applications, Albuquerque, New Mexico, September 29-October 4, 1991, Fusion Technology, Volume 21, Number 2, Part 2, A Journal of the American Nuclear Society, March 1992, pp. 206-214.

5. J. L. Anderson, "Tritium Technology Programs in the United States," Fourth Topical Meeting on Tritium Technology in Fission, Fusion, and Isotopic Applications, Albuquerque, New Mexico, September 29-October 4, 1991, Fusion Technology, Volume 21, Number 2, Part 2, A Journal of the American Nuclear Society, March 1992, pp. 226-231.

6. P. Gildea, "Operating Experience with the Sandia Tritium Facility Cleanup Systems," Second National Topical Meeting on Tritium Technology in Fission, Fusion and Isotopic Applications, Dayton, Ohio, April 30 to May 2, 1985, Fusion Technology, Volume 8, Number 2, Part 2, A Journal of the American Nuclear Society, September 1985, pp. 2505-2510.

7. R. John Garner, Transfer of Radioactive Materials from the Terrestrial Environment to Animals and Man, Boca Raton, Florida: CRC Press, 1972, p. 10 and pp. 33-34.

8. H. Semat, Introduction to Atomic and Nuclear Physics, New York: Holt, Rinehart and Winston, August 1963, p. 394.

9. J. N. Stannard, Radioactivity and Health: $A$ History, DOE/RL/01830-T59 (DE88013791), October 1988, pp. 706-841.

10. McGraw-Hill, Encyclopedia of Science and Technology, 6th Edition, New York: McGraw-Hill Book Company, 1987, Vol. 18, pp. 559-561, and Vol. 16, p. 165.

11. K. F. Eckerman, A. G. Wolbarst, A. C. B. Richardson, Limiting Values of Radionuclide Intake and Air Concentration and Dose Conversion Factors for Inhalation, Submersion, and Ingestion, Federal Guidance Report No. 11, EPA-520/1-88-020, Oak Ridge National Laboratory, September 1988. 
12. P. Kilho Park, D. R. Kester, I. W. Duedall, B. H. Ketchum, Wastes in the Ocean (Volume 3), Radioactive Wastes and the Ocean, New York: John Wiley \& Sons, 1982, pp. 24-30.

13. General Electric Company, Nuclides and Isotopes, 14th Edition, 1989.

14. C. M. Lederer, J. M. Hollander, I. Perlman, Table of Isotopes, 6th Edition, New York: John Wiley and Sons, Inc., 1967, p. 3 and p. 155.

15. P. C. Souers, Hydrogen Properties for Fusion Energy, University of California Press, 1986, Chapters 1,16 , and 17 , and p. 6 .

16. SRB Technologies, Inc., Brochure Concerning Tritium Radioisotope Use in Non-Powered EXIT Signs, Company located at P. O. Box 25267, Winston-Salem, NC, 27114, Phone: 919/659-2610.

17. J. R. Rubini and K. Matsui, "Rationale and Biochemistry of Tritiated Thymidine as a Cell Label," Radioisotopes in Medicine in Vitro Studies, U.S. Atomic Energy Commission/Division of Technical Information, CONF-671111, pp. 623.

18. R. Granier and D. Gambini, Applied Radiobiology and Radiation Protection, published by Ellis Horwood Limited, English edition published in 1990.

19. R. C. Weast (ed.), CRC Handbook of Chemistry and Physics, Boca Raton, Florida: CRC Press, 1977, 58th Edition, pp. B270-B354 (Table of Isotopes).

20. Bureau of Radiological Health, Radiological Health Handbook, Revised Edition, January 1970, U.S. Government Printing Office, pp. 92-94 (Average and Maximum Beta Energy by Radionuclide).

21. E. S. Gould, Inorganic Reactions and Structure, New York: Holt, Rinehart, and Winston, 1962, p. 24.

22. E. Teller, ed., Fusion Vol. 1 - Magnetic Confinement Part B, New York: Academic Press, 1981, p. 314.

23. F. A. Cotton and G. Wilkinson, Advanced Inorganic Chemistry - A Comprehensive Text, New York: Interscience Publishers, 1962.

24. R. T. Morrison and R. H. Goyd, Organic Chemistry, Boston: Allyn and Bacon Inc., 1962.

25. J. C. Warf, All Things Nuclear, printed by Graphics 2100, Los Angeles, CA, p. 120.

26. Isotope Sales Group, Oak Ridge National Laboratory, Oak Ridge, TN, 37830 (615/574-6984).

27. A. G. Croff, A User's Manual for the ORIGEN2 Computer Code, ORNL/TM-7175, July 1980.

28. U.S. Department of Energy, Characteristics of Spent Fuel, High-Level Waste, and Other Radioactive Wastes Which May Require Long-Term Isolation, DOE/RW-0184, Volume 2 of 6, December 1987. 
29. A. R. Foster and R. L. Wright, Jr., Basic Nuclear Engineering, 2nd Edition, Boston: Allyn and Bacon, Inc., 1973, p.70.

30. J. R. Lamarsh, Introduction to Nuclear Engineering, Addison-Wesley Publishing Company, June 1977, pp. 564-566.

31. H. Semat, Introduction to Atomic and Nuclear Physics, New York: Holt, Rinehart and Winston, August 1963, p. 425.

32. F. J. Rahn, et al., A Guide to Nuclear Power Technology, New York: John Wiley \& Sons, 1984, pp. 288-289.

33. J. L. Anderson, "Tritium Technology Programs in the United States," Fourth Topical Meeting on Tritium Technology in Fission, Fusion, and Isotopic Applications, Albuquerque, New Mexico, September 29-October 4, 1991, Fusion Technology, Volume 21, Number 2, Part 2, A Journal of the American Nuclear Society, March 1992, pp. 226-231.

34. K. R. O'Kula, R. L. Olson, D. M. Hamby, "Consequences of Tritium Release to Water Pathways from Postulated Accidents in a DOE Production Reactor (U)," Fourth Topical Meeting on Tritium Technology in Fission, Fusion, and Isotopic Applications, Albuquerque, New Mexico, September 29-October 4, 1991, Fusion Technology, Volume 21, Number 2, Part 2, A Journal of the American Nuclear Society, March 1992, pp. 659-667.

35. H. Gurol and A. E. Dabiri, "Safety Assessment of the Mars Tandem Mirror Reactor," Fusion Engineering Proceedings, 10th Symposium, Volume 2, 1983, pp. 1283-1286.

36. W. R. Gilmore (ed.), Radioactive Waste Disposal Low and High Level, published by Noyes Data Corporation, 1977, pp. 22-34, pp. 159-164, pp. 225-228, and p. 315.

37. C. E. Murphy, Jr. and G. R. Wortham, An Atmospheric Tritium Release Database for Model Comparisons (U), WSRC-TR-91-671, December 19, 1991, pp. 1-34.

38. J. R. Rubini and K. Matsui, Rationale and Biochemistry of Tritiated Thymidine as a Cell Label, Radioisotopes in Medicine in Vitro Studies, U.S. Atomic Energy Commission, Division of Technical Information, CONF-671111, pp. 621-632.

39. B. E. Pearson Murphy, "Protein Binding and its Application in the Assay of Nonantigenic Hormones: Thyroxine and Steroids," Radioisotopes in Medicine in Vitro Studies, U.S. Atomic Energy Commission/Division of Technical Information, CONF-671111, pp. 43-57.

40. E. W. Phelan, Radioisotopes in Medicine, U.S. Atomic Energy Commission, Division of Technical Information, Understanding the Atom Series, 1966, p. 29.

41. D. C. Jacobs, Impacts in Groundwater of Effluent Arising in the Nuclear Industry, NP-20456, pp. vp., Paper 16 (1974).

42. J. J. Koranda, "Preliminary Studies of the Persistence of Tritium and ${ }^{14} \mathrm{C}$ in the Pacific Proving Ground," Health Physics, Vol.11, 1965, pp. 1445-1457. 
43. D. D. Rabinowitz, C. R. Holmes, G. W. Gross, "Forced Exchange of Tritiated Water with Clays," in Tritium, Phoenix and Las Vegas: Messenger Graphics, 1973, pp. 471-485.

44. D. J. Brown and W. A. Haney, Chemical Effluent Technology Waste Disposal Investigations July-December, 1973 - The Movements of Contaminated Ground Water from the 200 Areas to the Columbia River, HW-80909, 1964.

45. D. J. Brown, Migration Characteristics of Radionuclides Through Sediments Underlying the Hanford Reservation, ISO-SA-32, 1967.

46. W. J. Kaufman and G. T. Orlob, Measuring Ground Water Movement with Radioactive and Chemical Tracers, paper presented at the Annual Meeting of the California Section of AWWA, Sacramento, 1955.

47. J. R. Kline and C. F. Jordan, "Tritium Movement in Soil of Tropical Rain Forest," Science, Vol. 160, 1968, pp. 550-551.

48. C. F. Jordan, J. R. Kline, D. S. Sasscer, "Tritium Movement in an Old-Field Ecosystem Determined Experimentally," Radionuclides in Ecosystems, 1971, CONF-710501-P1, pp. 199-203.

49. W. A. Haney, "Consequences of Activity Release," Nuclear Safety, Vol. 5, 1964, p. 399-403.

50. W. A. Haney, D. J. Brown, A. E. Reisenauer, Fission Product Tritium in Separations Wastes and in the Ground-Water, HW-74536, 1962.

51. C. E. Murphy, Jr., Controlled Environment Estimates of HT Uptake by Vegetation, DP-MS-88-183, November 8, 1988.

52. C. E. Murphy, Jr., A. L. Boni, S. F. Tucker, The Conversion of Gaseous Molecular Tritium to Tritiated Water in Biological Systems, DP-1422, E. I. du Pont de Nemours \& Co., Inc., Savannah River Laboratory, Aiken, SC, 1976, p. 15.

53. J. C. McFarlane, Tritium Accumulation in Lettuce Fumigated with Elemental Tritium, EPA-600/3-76-006, Environmental Monitoring and Support Laboratory, Las Vegas, Nevada, 1976, p. 18.

54. D. V. Bradley, Jr., R. D. Rogers, J. C. Macfarlane, Possible Use of Alcaligenes Paradoxus as a Biological Monitor, EPA-600/3-79-048, Environmental Monitoring and Support Laboratory, Las Vegas, Nevada, p. 32, 1979.

55. J. F. Cline, "Absorption and Metabolism of Tritium Oxide and Tritium Gas by Bean Plants," Plant Physiology Vol. 28, 1953, pp. 717-723.

56. C. W. Sweet and C. E. Murphy, Jr., "Tritium Deposition in Pine Trees and Soil from Atmospheric Releases of Molecular Tritium," Environmental Science Technology, Vol. 18, 1984, pp. 358-361.

57. T. G. Dunstall, G. L. Orgram, F. S. Spencer, Elemental Tritium Deposition and Conversion in the Terrestrial Environment, Canadian Fusion Fuels Technology Project, CFFTP-G-85035, 1985, p. 121. 
58. U. Schmidt, "The Solubility of Carbon Monoxide and Hydrogen in Water and Sea-Water at Partial Pressures of About 10-5 Atmospheres," Tellus, Vol. 31, 1979, pp. 68-74.

59. D. W. Krogmann, The Biochemistry of Green Plants, Englewood Cliffs, New Jersey: Prentice-Hall, Inc., 1973, p. 122.

60. B. D. Ben-Amotz, B. D. L. Erbes, M. A. Riederer-Henderson, D. G. Peavey, M. Gibbs, "H. Metabolism in Photosynthetic Organisms, 1. Dark $\mathrm{H}_{2}$ Evolution and Uptake by Algae and Mosses," Plant Physiology, Vol. 56, 1975, pp. 72-77.

61. L. W. Jones and N. I. Bishop, "Simultaneous Measurement of Oxygen Hydrogen Exchange from the Blue-Green Alga Anabaena," Plant Physiology, Vol. 57, 1976, pp. 659-665.

62. V. Moses and M. Calvin, "Photosynthesis Studies with Tritiated Water," Biochimica et Biophysica Acta:33, 1959, pp. 297-312.

63. V. J. Frilette, J. Hanle, H. Mark, "Rate of Exchange of Cellulose with Heavy Water," Journal of the American Chemical Society, Vol. 70, 1948, pp. 1107-1113.

64. J. C. Luvall and C. E. Murphy, Jr, "Evaluation of the Tritiated Water Method for Measurement of Transpiration in Young Pinus Taeda L," Forest Science, Vol. 28, No. 1, 1982, pp. 5-16.

65. T. Taniguchi, H. Harada, K. Nakato, "Determination of Water Adsorption Sites in Water by a Hydrogen-Deuterium Exchange," Nature, Vol. 272, 1978, pp. 230-231.

66. J. Guenot and Y. Belot, "Assimilation of ${ }^{3} \mathrm{H}$ in Photosynthesizing Leaves Exposed to HTO," Health Physics, Vol. 42, 1984, pp. 849-855.

67. R. M. Brown, G. L. Ogram, and F. S. Spencer, "Field Studies of HT Behavior in the Environment: 1. Dispersion and Oxidation in the Atmosphere," Fusion Technology, Vol. 14, September 1988, pp. 1165-1169.

68. R. Bergman, U. Bergstrom, S. Evans, "Environmental Transport and Long-Term Exposure for Tritium Released in the Biosphere," Proceedings of the International Symposium on the Behavior of Tritium in the Environment, San Francisco, October 16-20, 1978, IAEA Proceedings Series 498-STI/PUB, Vienna, p. 535.

69. F. Niehaus, Langzeitaspekte der Umveltbelastung durch Energieerzeugung in CO2 und H-3, KFZ-Jul-1165 (1975).

70. A. S. Mason, "Atmospheric HT and HTO: 4. Estimation of Atmospheric Hydrogen Residence Time from Interhemispheric Tritium Gas Transport," Journal of Geophysical Research., Vol. 82, No. 37, 1977, p. 5913-5916.

71. U. Schmidt, "Molecular Hydrogen in Atmosphere," Tellus, Vol. 26, No. 1-2, 1975, p. 78.

72. J. Van Den Hoek, R. Kirchmann, N. B. Juan, Transfer and Incorporation of Tritium in Mammals, IAEA-SM-232/48, p. 433. 
73. International Commission on Radiological Protection (1978), "Limits for Intakes of Radionuclides by Workers," ICRP Publication 30, Pergamon Press, Oxford.

74. E. A. Pinson and W. H. Langham, "Physiology and Toxicology of Tritium in Man," Journal of Applied Physiology, Vol.10, January 1957, pp. 108-126

75. R. V. Osborne, "Absorption of Tritiated Water Vapour by People," Health Physics, Vol. 12, 1966, pp. 1527-1537.

76. ICRP Publication 23 Report of the Task Group on Reference Man, Pergamon Press, Oxford, 1975.

77. B. E. Lambert and R. J. Clifton, "Radiation Doses Resulting from the Ingestion of Tritiated Thymidine by the Rat, Health Physics, Vol. 15, 1968, pp. 3-9.

78. L. E. Feinendegen and E. P. Cronkite, "Effects of Microdistribution of Radionuclides on Recommended Limits in Radiation Protection, A Model," Current Topics in Radiation Research, Vol. 12, No. 1, 1977, pp. 83-99.

79. W. L. Hughes, S. L. Commerford, D. Gitlin, R. C. Krueger, B. Schultze, V. Shah, and P. Reilly, "Studies on Deoxyribonucleic Acid Metabolism Cell Proliferation and Death as Measured by Incorporation and Elimination of Iododeoxyuridine,"Federation Proceedings: Federation of American Societies for Experimental Biology, Vol. 23, 1964, pp. 640-648.

80. L. E. Feinendegen, H. J. Heiniger, G. Friedrich, E. P. Cronkite, "Differences in Neutilization of Thymidine in Hemopoietic and Lymphopoietic Tissues of the Normal Mouse," Cell and Tissue Kinetics, Vol. 6, 1973, pp. 573-585.

81. B. E. Lambert and R. J. Clifton, "Radiation Doses Resulting from the Administration of Tritiated Folic Acid and Tritiated Water to the Rat," British Journal of Radiology, Vol. 40, 1967, pp. 56-61.

82. J. Vennart, "Radiotoxicology of Tritium and t4C Compounds," Health Physics, Vol. 16, 1969, pp. $429-440$.

83. M. Standeven and D. A. Clarke, "Estimation of Radiation Doses to Tissues After Administration of Tritiated Corticosteroids to the Rat," British Journal of Radiology, Vol. 40, 1967, pp. 48-55.

84. R. J. Berry, R. Oliver, A. S. Reiskin, "Reproductive Death of Mammalian Cells Due to Beta Radiation from Incorporated Thymidine Labeled with ${ }^{3} \mathrm{H}$ or ${ }^{14} \mathrm{C}$," Health Physics, Vol. 12, 1966, pp. 1461-1466.

85. B. E. Lambert, "Cytological Damage Produced in the Mouse Testes by Tritiated Thymidine, Tritiated Water and X-rays," Health Physics, Vol. 17, 1969, pp. 547-557.

86. V. P. Bond and L. E. Feinendegen, "Intranuclear ${ }^{3} \mathrm{H}$ Thymidine: Dosimetric, Radiological and Radiation Protection Aspects," Health Physics, Vol. 12, 1966, pp. 1007-1020. 


\section{Bibliography}

A Journal of the American Nuclear Society, March 1992, Fourth Topical Meeting on Tritium Technology in Fission, Fusion, and Isotopic Applications, Albuquerque, New Mexico, September 29-October 4, 1991, Fusion Technology, Volume 21, Number 2, Part 2.

A Journal of the American Nuclear Society, September 1985, Second National Topical Meeting on Tritium Technology in Fission, Fusion, and Isotopic Application, Dayton, Ohio, April 30 to May 2, 1985, Fusion Technology, Volume 8, Number 2, Part 2.

Amano, H. et al., 1987, "Evaluation of Cement Composites for Tritiated Water Fixation," ANS Fuel Cycle and Waste Management Div. Spectrum '86: Proceedings, Vol. 1, pp. 90-111.

Belot, Y. et al., 1986, "Assessment of the Environmental Impact of a Tritium Gas Release:

Resuspension of HTO from Soil Surface," CEA Centre d'Etudes de Bruyeres-le-Chatel, France. IAEA Committee on Fusion Energy Study, U.K.

Bergman, R., U. Berstrom, S. Evans, 1978, "Environmental Transport and Long-Term Exposure for Tritium Released in the Biosphere," Studsvik Energiteknik AB, Sweden. IAEA Proceedings on the Behavior of Tritium in the Environment, San Francisco, CA, pp. 535-554.

Bretthauer, E. W., A. A. Moghissi, R. G. Fatzer, 1987, "Biological Concentration of Tritium," Health Physics, Vol. 53, pp. 385-388.

Brown, R. M., 1988, "Field Studies of HT Behavior in the Environment," Fusion Technology, Vol. 14, pp. 1165-1169.

Butler, H. L. and J. H. LeRoy, 1965, "Observations of Biological Half-Life of Tritium," Health Physics, Vol. 11, pp. 283-285.

Clayton, R. N. et al., 1966, "The Origin of Saline Formation Waters. I. Isotopic Composition," Journal Geophysical Research, Vol. 71, p. 3869-3882.

Corey, J. C. and J. H. Horton, 1968, "Movement of Water Tagged with ${ }^{2} \mathrm{H},{ }^{3} \mathrm{H}$ and ${ }^{18} \mathrm{O}$ Through Acidic Kaolinitic Soil," Soil Science Society of America, Proceedings, Vol. 32, pp. 471-475.

Cronkite, E. P., J. S. Robertson, L. E. Feinendegen, 1973, "Somatic and Teratogenic Effects of Tritium," In: Tritium, eds. A. A. Moghissi and M. W. Carter, Messenger Graphics Publisher, Phoenix, Arizona, and Las Vegas, Nevada.

Devell, L. and O. Edlund, 1986, "Environmental Radiation Doses from Tritium Releases," Studsvik Energiteknik AB, Sweden, IAEA Fusion Reactor Safety Conference Vienna, pp. 317-326.

Diabate, S. and D. Honig, 1988, "Conversion of Molecular Tritium to HTO and OBT in Plants and Soils," Fusion Technology, Vol. 14, pp. 1232-1240. 
Eisenbud, M., 1987, Environmental Radioactivity, Third Edition, Academic Press, Inc., New York.

Evans, A. G., 1969, "New Dose Estimates from Chronic Tritium Exposures," Health Physics, Vol.16, pp. 57-63.

Failor, R. A., S. G. Prusin, P. C. Souers, 1988, "Initial Radiolysis Effects on the $\mathrm{T}_{2}-\mathrm{O}_{2}$ Gas Reaction," The Journal of Physical Chemistry, 92, pp. 429-433.

Feinendegen, L. E., 1978, "Biological Damage from Radioactive Nuclei Incorporated into DNA of Cells, Implications for Radiation Biology and Radiation Protection," 6th Symposium on Microdosimetry, Brussels, 22-26 May, (CEC, 1979).

Foerstel, H., K. Lepa, H. Trierweiller, 1988, "Re-emission of HTO into the Atmosphere after HT/HTO Conversion in the Soil," Fusion Technology, 14, pp. 1203-1208.

Garland, J. A., 1978, "Transfer of Tritiated Water Vapour to and from Land Surfaces," Atomic Energy Research Establishment, IAEA Proceedings on the Behavior of Tritium in the Environment, San Francisco, pp. 349-359.

Gordon, C. W., 1986, "Tritium Safety Program at JET," Commission of the European Communities, Abingdon, U.K. IAEA Fusion Reactor Safety Conference, Vienna, pp. 63-72.

Gracheva, L. M. and V. G. Korolev, 1977, Genetic Effects of the Decay of Radionuclides in Cells, Atomizdat Publishers, Moscow, Translated from Russian for the Department of Energy and the National Science Foundation by Amerind Publishing Co., Pvt. Ltd., New Delhi, TT 78-52006 DOE-TR-22 UC-48, Chapter 2.

Gruber, J. and A. A. Moghissi, 1978, "Methodology for Hazard Assessment of Environmental Tritium," IAEA Proceedings on the Behavior of Tritium in the Environment, San Francisco, pp. 555-573.

Halevy, E., 1964, "The Exchangeability of Hydroxyl Groups in Kaolinite," Geochimica et Cosmochimica Acta, Vol. 28, pp. 1139-1145.

Haney, W. A., 1963, Fission Product Tritium in Fuel Reprocessing Wastes, HW-SA-3303, 1963.

Haywood, S. M. and P. V. Shaw, 1986, "A Dynamic Model to Predict the Movement of Tritium in the Environment," Radiation Protection Dosimetry, Vol. 16, pp. 59-61.

Hedley, W. H. et al., Improvements in Efficiency, Capacity, and Reliability of Mound's Effluent Removal System, Monsanto Research Corporation (Mound Facility in Miamisburg, Ohio), MLM--3511(OP) DE88 012881, CONF-880505--31.

Higgins, G. H., 1959, "Evaluation of the Ground-Water Contamination Hazard from Underground Nuclear Explosions," Journal of Geophysical Research, Vol. 64, p. 1509-1520. 
International Atomic Energy Agency, 1981, Handling of Tritium Bearing Wastes, IAEA Technical Reports Series No 203, Vienna.

International Atomic Energy Agency, 1984, Management of Tritium at Nuclear Facilities, IAEA Technical Reports Series No. 234, Vienna.

International Atomic Energy Agency, 1987, Tritium in Some Typical Ecosystems, IAEA Technical Reports Series No. 207, Vienna.

International Commission on Radiological Protection (1983). Radionuclide Transformations Energy and Intensity of Emissions, ICRP Publication 38, Pergamon Press. Oxford.

Jalbert, R. A. and C. E. Murphy, 1988, "The Canadian Experimental HT Release of June 10, 1987, U.S. Measurements," Los Alamos National Laboratory, Department of Energy Contract W-7405-ENG-36.

Jolly, W. J., 1989, "Hydrogen"("Chemical Elements"), The New Encyclopedia Britannica, 15th Edition, Chicago.

Juan, H. B., R. Kirchmann, J. Van Den Hoek, 1978, "Transfer and Incorporation of Tritium in Mammals," IAEA Proceedings on the Behavior of Tritium in the Environment, San Francisco, pp. 433-443.

Kaplan, L., 1987, "Tritium," McGraw-Hill Encyclopedia of Science and Technology, 6th Edition, New York.

Kathren, R. L., 1984, Radioactivity in the Environment, Harwood Academic Publishers, New York.

Krasznai, J. P., 1987, "Conditioning of Tritiated Wastes from a Tritium Removal Facility," ANS Fuel Cycle and Waste Management Div. Spectrum '86: Proceedings., pp. 144-156.

Kurzeja, R. J., C. E. Murphy, R. W. Taylor, 1988, Dispersion of HT and HTO Following an Unplanned Release of Tritium to the Atmosphere, Savannah River Laboratory, U.S. Department of Energy Contract AC09-76SR00001.

McGraw-Hill, Concise Encyclopedia of Science and Technology, Second Edition, New York: McGrawHill Publishing Company, p. 1925.

Miettinen, J., 1978, "Transfer and Uptake Mechanism of Tritium in Soil," University of Helsinki. IAEA Proceedings on the Behavior of Tritium in the Environment, San Francisco, pp. 339-347.

Moghissi, A. A., M. W. Carter, E. W. Bretthauer, 1972, "Further Studies on the Long Term Evaluation of the Biological Half-Life of Tritium," Health Physics, Vol. 23, pp. 805-806.

Murphy, Jr., C. E., 1986, "Modeling Tritium Transport in the Environment," Radiation Protection Dosimetry, Vol. 16, pp. 51-58. 
Okada, S., 1988, "Japanese University Program on Tritium Radiobiology and Environmental Tritium," Kyoto University, Japan. Third Japan-US Workshop on Tritium Radiobiology and Health Physics, Japan, pp. 24-31.

Partk, P. K., D. R. Kester, I. W. Duedall, B. H. Ketchum, 1983, Wastes in the Ocean, Volume 3, New York: John Wiley \& Sons, pp. 26-30.

Rabinowitz, D. D., 1969, Forced Exchange of Tritiated Water with Natural Clay, MS Thesis, New Mexico Institute of Mining and Technology, Socorro, NM.

Rosenquist, I. T., 1963, "Studies in Position and Mobility of the H Atoms in Hydrous Micas," Clays and Clay Minerals, Monograph No. 13, New York: Macmillan \& Co., pp. 11-135.

Sanders, Jr., S. M. and W. C. Reinig, 1968, "Assessment of Tritium in Man," In: Diagnosis and Treatment of Deposited Radionuclides, Eds. H. A. Kornberg and W. D. Norwood, pp. 534-542. Excerpta Medica Foundation, Amsterdam.

Schultz, V. and F. W. Whicker, 1982, Radioecoloqy: Nuclear Energy and the Environment, Boca Raton, Florida: CRC Press, Inc.

Second Ethel (European Tritium Handling Experimental Laboratory)-TLK (Tritium Laboratory, Karlsruhe), Workshop on Tritium Technology and Safety in Thermonuclear Fusion, Proceedings, Ispra, Italy, February 6-7, 1992.

Sherry, R. J. and L. C. Miller, 1988, "Design of a Tritium Recovery System," Lawrence Livermore Laboratory, U.S. Department of Energy Contract W-7405-ENG-48.

Snyder, W. S., et al., 1968, "Urinary Excretion of Tritium Following Exposure of Man to HTO - A Two Exponential Model," Phys. Med. Biol., Vol. 13, pp. 547-559.

Stacey, Jr., W. M., 1984, FUSION An Introduction to the Physics and Technology of Magnetic Confinement Fusion, New York: John Wiley \& Sons, Inc.

Stannard, J. N., 1988, Radioactivity and Health: A History, Pacific Northwest Laboratory, U. S. Department of Energy Contract DE-AC06-76RL0 1830.

Stewart, G. L., 1967, "Fractionation of Tritium and Deuterium in Soil Water," IN: Isotope Techniques in the Hydrologic Cycle, Geophys., Monograph No. 11, 9-168.

Swanson, D. E., et al., October 1988, Preliminary Report Initial Studies of Tritium Migration at the Greater Confinement Disposal Test (GCDT) Facility; February 1987-July 1988, DOE/NV/10327-40 DE89 003838, pp. 1-25.

Teller, E., W. K. Telley, G. H. Higgens, The Constructive Uses of Nuclear Explosives, New York: McGraw-Hill. 
Wehner, G., 1978, "Discharges of Tritium to the Environment from Unrestricted Use of Consumer Products Containing this Radionuclide," Federal Ministry of the Interior, FRG. IAEA Proceedings on the Behavior of Tritium in the Environment, San Francisco, pp. 79-91.

Wieneke, R. E. et al., 1988, "Tritium Emissions Reduction Facility," Monsanto Research Corp., Miamisburg, U.S. Department of Energy Contract AC04-76DP00053.

Wylie, K. F., W. A. Bigler, G. R. Grove, 1963, "Biological Half-Life of Tritium," Health Physics, Vol. 9 , pp. $911-914$. 


\section{CESIUM-137}

\section{Introduction}

This chapter discusses the basic radiological, chemical, and physical characteristics of cesium-137 $\left({ }^{137} \mathrm{Cs}\right)$ and examines how these characteristics affect the behavior of ${ }^{137} \mathrm{Cs}$ in various environmental media, such as soils, groundwater, plants, the atmosphere, and the human body. Also included are methods of ${ }^{137} \mathrm{Cs}$ production and waste and disposal data on ${ }^{137} \mathrm{Cs}$.

This chapter also describes potential difficulties in dealing with ${ }^{137} \mathrm{Cs}$. However, ${ }^{137} \mathrm{Cs}$ behavior and appropriate handling, storage, or disposal will vary depending on the waste form and the disposal site's geology, hydrology, and climate. Therefore, this chapter does not attempt to discuss the extent of a difficulty or appropriate solutions. Each disposal site facility design should consider and address the specific waste content and behavior under that site's particular circumstances. A radionuclide considered sensitive at one low-level radioactive waste (LLW) disposal facility may not be considered sensitive at another facility.

All cesium atoms contain 55 protons $(Z=55)$ and various numbers of neutrons (typically $N=69$ to 85 neutrons) within the atom's nucleus. There exists only one stable form of cesium, namely ${ }^{133} \mathrm{Cs}$, which contains 78 neutrons and 55 protons. All other cesium isotopes, including ${ }^{137} \mathrm{Cs}$, are radioactive. The radioactive isotopes of cesium are not a normal constituent of the natural background radiation, but are present in nature because of man-made activities.

The primary source of ${ }^{137} \mathrm{Cs}$ in the environment has been radioactive fallout from nuclear weapons testing and accidental releases (e.g., the Windscale accident ${ }^{1}$ in 1957 and the Chernobyl accident in 1986); however, radioactive releases from nuclear power plants, propulsion reactors (submarines), and intentional radioactive waste disposal in the oceans all contribute to the background inventory of man-made radioactive isotopes, including ${ }^{137} \mathrm{Cs}$. For instance, the normal background activity of ${ }^{137} \mathrm{Cs}$ in seawater should be zero; however, it is known that at least $7.7 \times 10^{17}$ becquerels ( 1 becquerel, or simply 1 $\mathrm{Bq}$ is defined as 1 disintegration/second or $3.7 \times 10^{10} \mathrm{~Bq}=1$ curie $=1 \mathrm{Ci}$ ). ${ }^{2}$ Equivalently, $2.5 \times 10^{7} \mathrm{Ci}$ of ${ }^{137} \mathrm{Cs}$ have been deposited in the world's oceans up until 1979 , primarily from radioactive fallout and intentional discharges. The natural radioactivity of ocean waters is 13 or $14 \mathrm{~Bq} / \mathrm{kg}$, of which $95 \%$ comes from potassium $-40 .{ }^{1,3}$ The average ${ }^{137} \mathrm{Cs}$ concentration usually contributes less than $0.06 \%$ of the total radioactivity found in ocean water.

Measurements of the ${ }^{137} \mathrm{Cs}$ concentration in the Irish Sea between 1976 to 1977 have shown concentrations ranging from 0.1 to $100 \mathrm{~Bq} / \mathrm{kg}$, depending upon the sample location and the season, with most measurements less than $10 \mathrm{~Bq} / \mathrm{kg}$. ${ }^{1}$ In some isolated sites, the ${ }^{137} \mathrm{Cs}$ concentration does make up a large fraction of the total background activity. For the Irish Sea, it is believed that the primary source of the ${ }^{137} \mathrm{Cs}$ contamination is from discharged wastes from the Windscale facility. In all measured cases, seawater concentrations of ${ }^{137} \mathrm{Cs}$ are smaller than the maximum permissible safe disposal concentrations of ${ }^{137} \mathrm{Cs}$ in water, which ranges from 250 to $1500 \mathrm{~Bq} / \mathrm{kg}$ depending upon the exposure group and chemical form of the cesium. ${ }^{4}$ Consequently, the observed ${ }^{137} \mathrm{Cs}$ concentrations in the Irish Sea are not considered dangerous but are clear evidence of man's impact on the environment. 


\section{Radiological Characteristics}

${ }^{137} \mathrm{Cs}$ has a 30.2 year half-life $\left(\mathrm{T}_{1 / 2}\right)$, or $\mathrm{T}_{1 / 2} \sim 11,000$ days. $^{2}$ When it undergoes radioactive decay, $\sim 94 \%$ of the time the ${ }^{137} \mathrm{Cs}$ nucleus decays to barium- $137 \mathrm{~m}\left({ }^{137 \mathrm{~m}} \mathrm{Ba}\right.$, a metastable state of $\left.{ }^{137} \mathrm{Ba}\right)$ with the emission of a $514-\mathrm{keV}$ (thousand-electron volt) beta particle ( $\beta$; a negative electron emitted from the nucleus). Approximately $6 \%$ of the initial ${ }^{137} \mathrm{Cs}$ atoms decay directly to ${ }^{137} \mathrm{Ba}$ and emit a 1,176 -keV (l.176-MeV) beta particle. Of those ${ }^{137} \mathrm{Cs}$ atoms that decay to ${ }^{137 \mathrm{~m}} \mathrm{Ba}$, and therefore produce a 514-keV $(0.514-\mathrm{MeV})$ beta particle, $90 \%$ of the subsequent ${ }^{137 \mathrm{~m}} \mathrm{Ba}$ atoms produce a $662-\mathrm{keV}(0.662-\mathrm{MeV})$ gamma ray. Due to the short half-life of ${ }^{137 \mathrm{~m}} \mathrm{Ba}(\sim 153$ seconds), the $662-\mathrm{keV}$ gamma ray is commonly associated with ${ }^{137} \mathrm{Cs}$.

Table 6-1 lists the maximum ranges for $514-\mathrm{keV}$ and $1,176-\mathrm{keV}$ beta particles in various substances. The average beta particle energy produced from ${ }^{137} \mathrm{Cs}$ decay is $195 \mathrm{keV}$ and has a range of about one-quarter of the range shown for the 514-keV beta particle. Table 6-2 compares the radiotoxicity of several important radionuclides.

The three possible decay schemes for ${ }^{137} \mathrm{Cs}$ showing the various combinations of beta $\left(\beta^{-}\right)$particles, captured and re-emitted negative electrons ( $\left.\mathrm{e}^{-}\right)$, gamma ray ( $\gamma$-ray) energies, event probabilities, and isotope half-life leading to the production of stable ${ }^{137} \mathrm{Ba}$ are shown in the following three nuclear transformations:

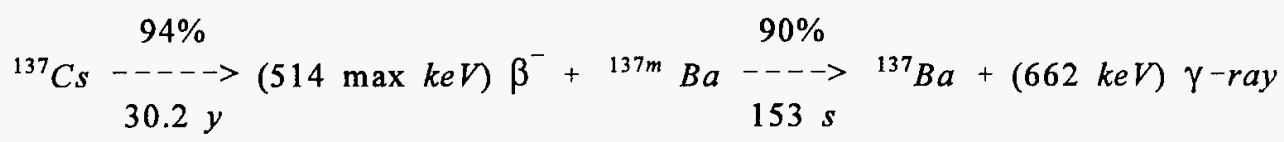

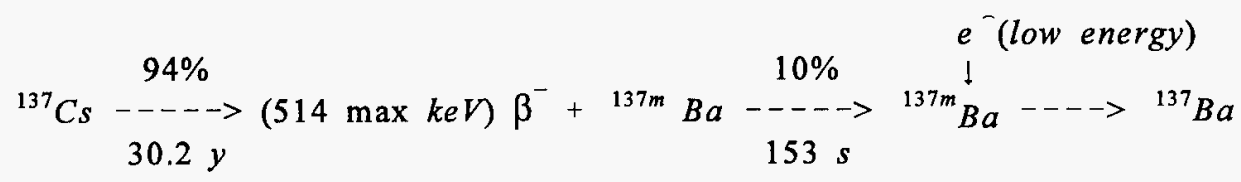

$$
\begin{aligned}
& +(\sim 640 \text { avg keV }) e^{-} \\
& { }^{137} \mathrm{Cs} \underset{30.2 y}{\stackrel{6 \%}{-} \mathrm{y}} \text { (1176 max keV) } \beta^{-}+{ }^{137} \mathrm{Ba} \text {. }
\end{aligned}
$$

The beta particle energies shown above represent maximum particle energies with a continuous energy spectrum possible with the simultaneous emission of an antineutrino particle (not shown) carrying off the energy difference. The decay event probabilities are shown as percentage numbers above the arrows, and the isotope half-lives are shown below the arrows. 
Although a major portion of the beta and gamma ray emissions occur with the decay of the ${ }^{137 \mathrm{~m}} \mathrm{Ba}$ nucleus, because of the short half-life of ${ }^{137 \mathrm{~m}} \mathrm{Ba}$, these emissions are usually associated with the parent nucleus $\left({ }^{137} \mathrm{Cs}\right)$. Based on the Equation (6-1 a) decay sequence, $84.6 \%=94 \% \times 90 \%$ of all ${ }^{137} \mathrm{Cs}$ decays result in the emission of a $662-\mathrm{keV}(0.662-\mathrm{MeV})$ gamma ray; in other words, the gamma ray from ${ }^{137} \mathrm{Cs}$ decay is produced $84.6 \%$ of the time. The other possible decay events lead to the emission of either a 514-keV maximum energy beta particle and a captured and re-emitted high energy electron (e), or a 1,176-keV maximum energy beta particle. Events that produce a beta particle also produce an antineutrino particle. Since neutrinos (and antineutrinos) almost never interact with matter, they are not radiologically important. Therefore, the antineutrino particle is usually not shown in the standard decay equations. Since the released beta particle is usually emitted with an energy less than the maximum theoretical value, the antineutrino particle carries off the energy difference. Hence, beta particles are emitted with a continuous energy spectrum that varies from the maximum theoretical value down to zero. In summary, beta particles and gamma rays are produced from ${ }^{137} \mathrm{Cs}$ decay. The primary beta particle has a maximum energy of $514 \mathrm{keV}$, and $85 \%$ of the time a $662-\mathrm{keV}$ gamma ray is produced.

Table 6-1. Comparison of the calculated maximum ranges for 514-keV and 1,176-keV energy beta particles emitted from ${ }^{137} \mathrm{Cs}$ decay for various materials.

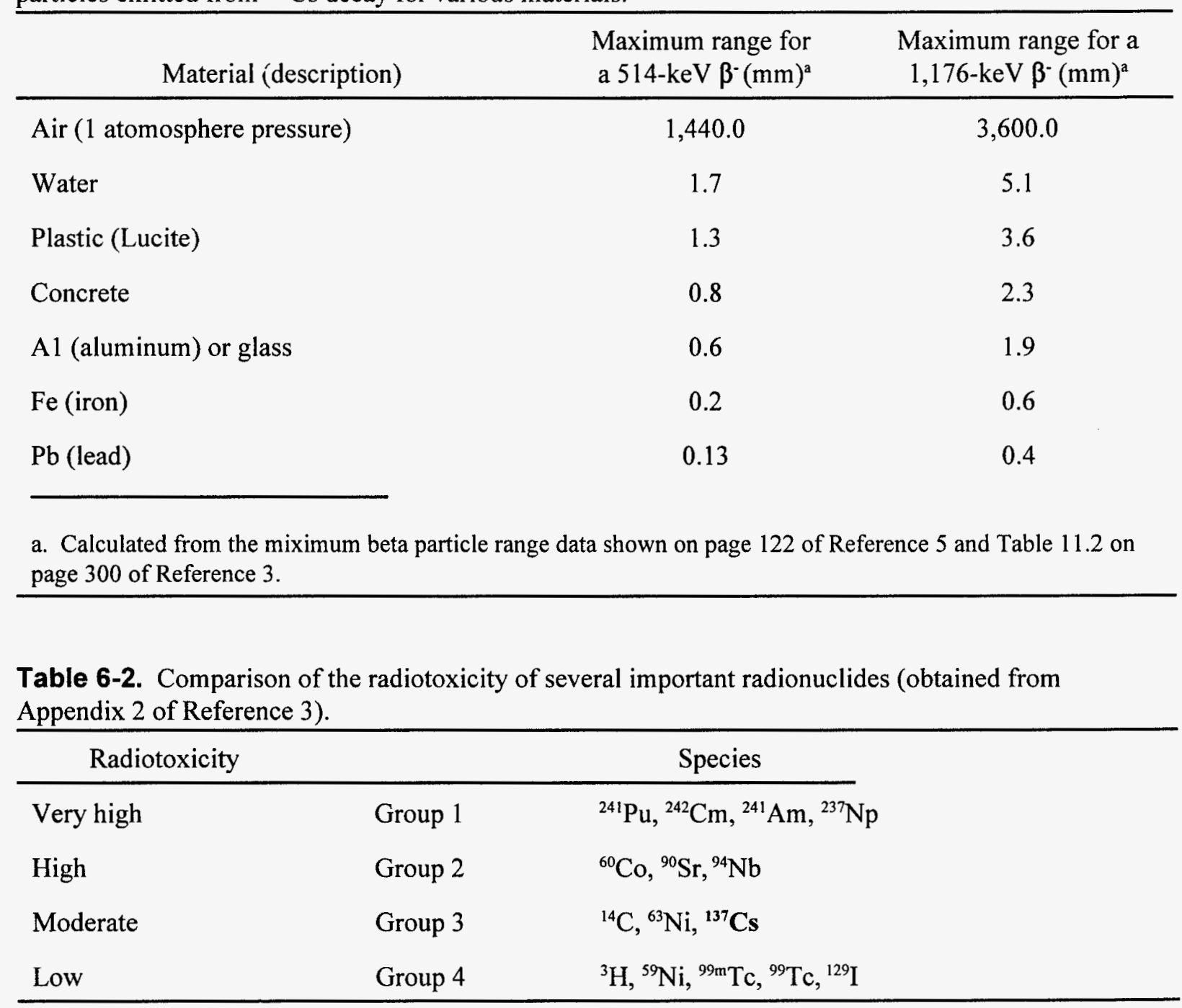


Table 6-3 illustrates how the maximum and average beta particle emission energies associated with ${ }^{137} \mathrm{Cs}$ decay compare to the emissions of other beta emitters. Since a $70-\mathrm{keV}$ beta can penetrate the 0.07 $\mathrm{mm}$ of human skin, ${ }^{5}$ the maximum and average energy beta particles associated with ${ }^{137} \mathrm{Cs}$ decay are radiologically hazardous. In fact, the highest energy beta particles $(1,170 \mathrm{kev})$ from ${ }^{137} \mathrm{Cs}$ can penetrate approximately $3 \mathrm{~mm}$ into an unprotected human body. Although the beta particles from Cs decay are hazardous, they can be adequately shielded against with less than 2 in. of water or other common materials (see Table 6-1). However, to protect against the penetrating gamma rays, thick high-density shields are required. Table 6-4 lists the thickness of materials needed to reduce the gamma ray intensity of $\mathrm{a}^{137} \mathrm{Cs}$ source of $662-\mathrm{keV}$ photons by a factor of $1 / 2$ and $1 / 1000$. The data associated with the $1 / 2$ factor (e.g., the factor of 2 attenuation) is defined as the half-value thickness; that is, for every half-value thickness of material added to a shield, the gamma ray intensity would decrease by about a factor of 2 . Since $(1 / 2)^{10}=1,024 \sim 1,000$, then 10 half-value thickness would decrease the initial source term by about a factor of 1,000 . Based on the information shown in Table 6-4, it is clear that the gamma rays emitted from ${ }^{137} \mathrm{Cs}$ (actually ${ }^{137 \mathrm{~m}} \mathrm{Ba}$ atoms) are very penetrating. For example, to reduce the initial gamma ray field from a ${ }^{137} \mathrm{Cs}$ source by a factor of 1,000 , at least $55 \mathrm{~mm}$ (2.2 in.) of lead or $560 \mathrm{~mm}$ (22 in.) of concrete are required.

Table 6-3. Average and maximum kinetic energies of beta particles released during decay of several radionuclides (compiled from data in References $2,6,7,8,9$ ).

\begin{tabular}{lcc}
\hline \multicolumn{1}{c}{ Radionuclide } & Beta particle energy \\
\cline { 2 - 3 } & $\begin{array}{c}\text { Average Energy } \\
(\mathrm{keV})\end{array}$ & $\begin{array}{c}\text { Maximum Energy } \\
(\mathrm{keV})\end{array}$ \\
\hline Tritium $\left({ }^{3} \mathrm{H}\right)$ & 5.68 & 19.0 \\
Iodine-129 $\left({ }^{129} \mathrm{I}\right)$ & 40.0 & 150.0 \\
Carbon-14 $\left({ }^{14} \mathrm{C}\right)$ & 49.0 & 156.0 \\
Technetium-99 $\left({ }^{99} \mathrm{Tc}\right)$ & 85.0 & 293.0 \\
Iodine-131 $\left({ }^{131} \mathrm{I}\right)$ & 180.0 & $806.0^{\mathrm{b}}$ \\
Cesium-137 $\left({ }^{137} \mathrm{Cs}\right)$ & 195.0 & $\mathbf{1 , 1 7 6 . 0}$ \\
Potassium-40 $\left({ }^{40} \mathrm{~K}\right)$ & 541.0 & $1,330.0$ \\
Phosphorous-32 $\left({ }^{32} \mathrm{p}\right)$ & 694.0 & $1,710.0$ \\
\hline a. $1000 \mathrm{keV}=1 \mathrm{MeV}$ (million-electron volt). & & \\
b. $90.4 \%$ of the beta particle intensity for I-131 occurs at $606 \mathrm{keV}$, and only $0.6 \%$ occurs at $806 \mathrm{keV}$.
\end{tabular}


Table 6-4. Minimum thickness required to decrease the initial $662-\mathrm{keV}$ gamma ray intensity from ${ }^{137} \mathrm{Cs}$ by a factor of $1 / 2$ and $1 / 1,000$ for various materials. ${ }^{a}$

\begin{tabular}{|c|c|c|}
\hline Material (description) & $\begin{array}{c}\text { Thickness required to } \\
\text { reduce gamma ray source } \\
\text { by an attenuation factor } \\
\text { of } 2 \text { (one half-value } \\
\text { layer })(\mathrm{mm})\end{array}$ & $\begin{array}{c}\text { Thickness required to } \\
\text { reduce gamma ray source } \\
\text { by an attenuation factor of } \\
1,000 \text { (ten half-value layers) } \\
(\mathrm{mm})\end{array}$ \\
\hline Air (1 atmosphere pressure) & $75,000.0$ & $750,000.0$ \\
\hline Water & 80.0 & 800.0 \\
\hline Concrete $\left(\right.$ density $\left.=2.4 \mathrm{~g} / \mathrm{cm}^{3}\right)$ & 56.0 & 560.0 \\
\hline C (carbon) & 40.0 & 400.0 \\
\hline $\mathrm{Fe}$ (iron) & 18.0 & 180.0 \\
\hline $\mathrm{Pb}$ (lead) & 5.5 & 55.0 \\
\hline
\end{tabular}

\section{Chemical and Physical Characteristics}

Chemically, cesium (Cs) belongs to the alkali metals group and, therefore, behaves like lithium, sodium, potassium, or rubidium, which are all in the same chemical family. In addition, the decay product of ${ }^{137} \mathrm{Cs}$, namely barium-137 $\left({ }^{137} \mathrm{Ba}\right.$ ) behaves like calcium $(\mathrm{Ca})$ or magnesium $(\mathrm{Mg})$. Cesium is very chemically reactive and easily reacts with water to form hydroxides $(\mathrm{CsOH})$ or with other elements generally present in irradiated uranium dioxide $\left(\mathrm{UO}_{2}\right)$ to form cesium-iodide (CsI) or cesium-telluride $\left(\mathrm{Cs}_{2} \mathrm{Te}\right)$. All of these compounds are highly soluble and generally move with the water released from a nuclear reactor, or follow the atmospheric water cycle following a nuclear weapons explosion and eventually fall to earth with rainwater. Because of the relatively long half-life of ${ }^{137} \mathrm{Cs}$, it generally remains in the environment and can be a long-term ground contamination hazard.

Some of the most important physical properties of cesium are shown in Table $6-5 .^{10,11,12}$ Because the binding energy of the close-packed cesium atom lattice is relatively weak, cesium metal is soft and has the lowest melting point of all the alkali metals $\left(28.5^{\circ} \mathrm{C}\right)$. Where most of the alkali metals are silvery in appearance, cesium has a golden yellow color. 
Table 6-5. Physical properties of cesium.

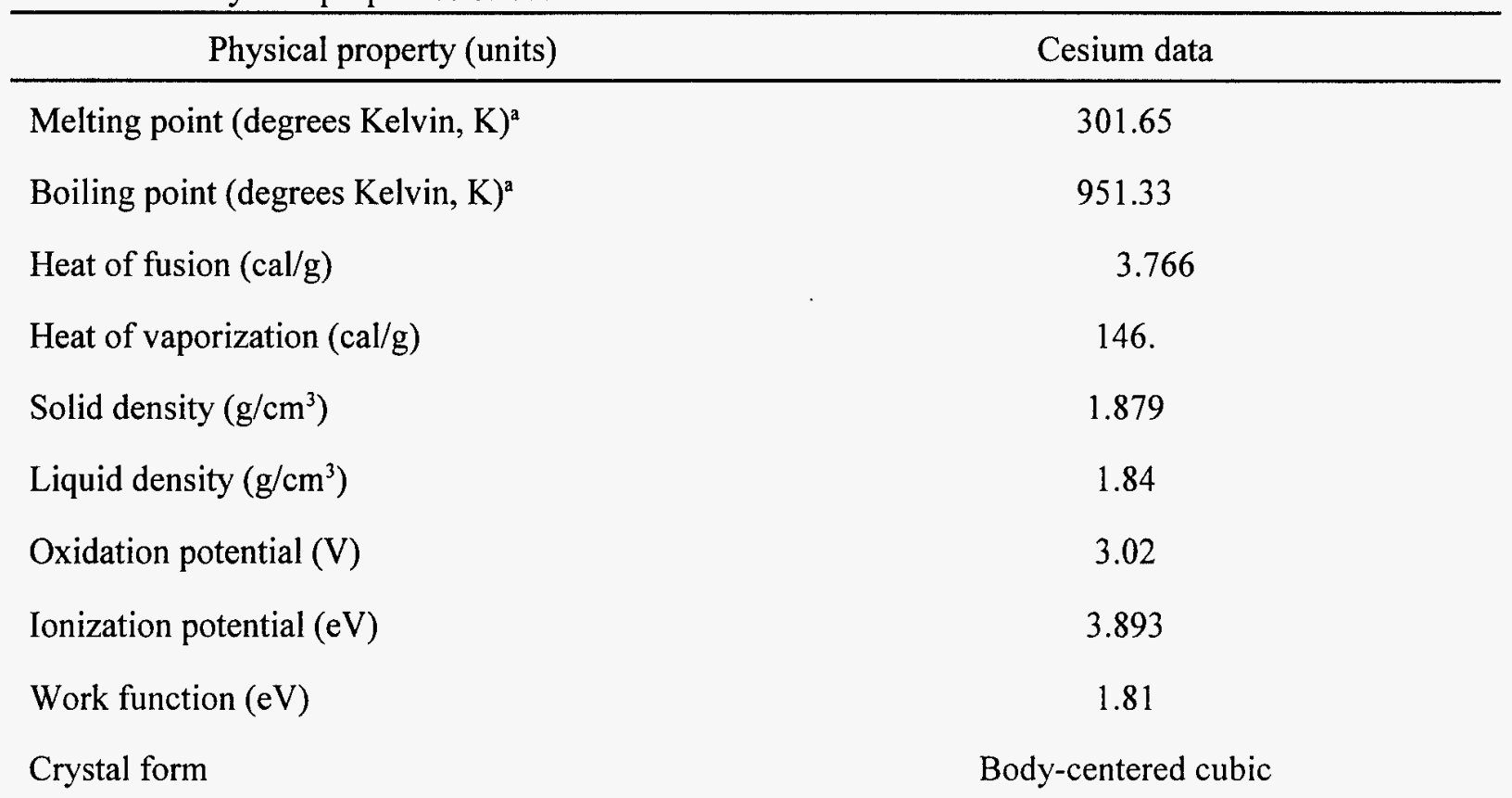

a. Note that zero degrees kelvin $(0 \mathrm{~K})$ equals $-273.15^{\circ} \mathrm{C}$ or $-459.67^{\circ} \mathrm{F}$.

The oxidation state of cesium and its isotopes is +1 and has a chemistry dependent on the positive $\mathrm{Cs}^{+}$ion. Although the chemistry of the alkali metals are predominantly ionic, some degree of covalent bonding occurs in special cases. Studies of the Group I alkali metal vapors near their boiling points show the presence of doubled (diatomic) molecules $1 \%$ of the time.

All of the alkali metals are highly electropositive and react with most other elements directly. The reactivities of the alkali metals toward air and water increase with increasing atomic mass and number; therefore, cesium reacts rapidly with air and water, even igniting hydrogen as it is generated from the decomposition of water to form cesium-hydroxide $(\mathrm{CsOH})$. Consequently, metallic cesium must be handled in an inert atmosphere.

Cesium reacts directly with most nonmetals to produce one or more binary compounds; it also forms numerous alloys and compounds with other metals such as lead and tin. On combustion, at atmospheric pressure, cesium produces cesium-peroxide $\left(\mathrm{CsO}^{2}\right)$, a compound that can also exist within uranium dioxide $\left(\mathrm{UO}^{2}\right)$, which is used as a fuel for nuclear reactors.

Due to the highly electropositive nature of the alkali metals, the various oxides, sulfides, and similar compounds are readily hydrolysed by water forming hydroxides (e.g., cesium-hydroxide). The hydroxides are white crystalline solids that are soluble in water and alcohols. They can change directly from solid to vapor states without producing a liquid. Cesium hydroxide can also exist as doubled molecules called dimers (e.g., $[\mathrm{CsOH}]^{21}$ ). Cesium-hydroxide is probably the most likely cesium compound that would be released from a nuclear reactor in the event of a severe accident. This compound is so reactive that it can chemically attack stainless steel. 


\section{Cesium-137 Production in Nuclear Reactors}

The primary means of producing ${ }^{137} \mathrm{Cs}$ is via nuclear fission, and the source of ${ }^{137} \mathrm{Cs}$ is from fission product recovery. Figure 6-1 shows the fission product yield distribution for thermal neutron fission of uranium-235 $\left({ }^{235} \mathrm{U}\right)$. This information was obtained from the fission yield data from the ORIGEN2 $2^{13,14}$ computer code. The curve shown in Figure 6-1 between mass numbers 70 and 160 is typical of other published binary fission yield distributions, and the fission yield data for fission of ${ }^{233} \mathrm{U}$ and plutonium-239 $\left({ }^{239} \mathrm{Pu}\right)$ are also very similar. The cumulative fission yield of ${ }^{137} \mathrm{CS}$ from fission of ${ }^{235} \mathrm{U}$ atoms averages about $6.2 \%$.

Since ${ }^{137} \mathrm{Cs}$ atoms have a very small thermal neutron absorption cross-section (i.e., $\sigma^{\mathrm{a}}=\mathrm{O} .11$ barns $=$ $0.11 \times 10^{-24} \mathrm{~cm}^{2}$ ) compared with most other atoms present with the nuclear fuel and fission products (including other cesium isotopes), and since ${ }^{137} \mathrm{Cs}$ has a relatively long half-life ( 30.2 years), then almost all $(>93 \%)$ of the ${ }^{137} \mathrm{Cs}$ atoms produced in a reactor are present when the nuclear fuel is extracted from the reactor. In other words, the ${ }^{137} \mathrm{Cs}$ inventory for a nuclear reactor increases linearly with fuel burnup and does not significantly decrease during the in-reactor portion of the fuel cycle.

The amounts of fission products (including the ${ }^{137} \mathrm{Cs}$ inventory) in a reactor core depend upon the power and operating history of the reactor. $\mathrm{A}^{137} \mathrm{Cs}$ inventory calculated by ORIGEN2 ${ }^{13,14}$ for a typical $100 \mathrm{MTU}$ (metric tons of uranium) reactor operated at a thermal power of $3050 \mathrm{MW}$ (million watts) for a total irradiation burnup of 33,400 MWTD/MTU (megawatt thermal days per metric ton uranium), or approximately 3 years of irradiation at full power, is 10.9 million curies (or $125 \mathrm{~kg}$ ). However, other references ${ }^{15,16}$ report reactor core inventories of ${ }^{137} \mathrm{Cs}$ at 5.1 million curies. For this chapter, the larger result (10.9 million $\mathrm{Ci})$ will be assumed.

The reactor core inventory of ${ }^{137} \mathrm{Cs}$ represents only $0.072 \%$ of the total fission product inventory generated at the end of the fuel irradiation history, or $0.125 \%$ of the initial uranium mass. However, after 100 years of decay, the remaining ${ }^{137} \mathrm{Cs}$ inventory ( 1.08 million curies) represents $31 \%$ of the total remaining fission product inventory. Table 6-6 shows the time-dependent inventories of ${ }^{137} \mathrm{Cs}$, total cesium isotopes, and total fission product for a typical light-water reactor (LWR). From Table $6-6,{ }^{137} \mathrm{Cs}$ accounts for more than $5 \%$ of the total fission product inventory after 1 year of decay, and more than $25 \%$ of the radioactive products remaining after 10 years of decay. If cesium is chemically separated from the other fission products, then several radioactive isotopes of cesium would be present with ${ }^{137} \mathrm{Cs}$. For example, about $55 \%$ of the initial cesium activity is due to ${ }^{134} \mathrm{Cs}$ and only $45 \%$ from ${ }^{137} \mathrm{Cs}$. Since ${ }^{134} \mathrm{Cs}$ has a much shorter half-life than ${ }^{137} \mathrm{Cs}$ (e.g., 2.1 years versus 30.2 years for ${ }^{137} \mathrm{Cs}$ ), then decay time will naturally decrease the inventory of the undesired cesium isotopes and increase the relative abundance of ${ }^{137} \mathrm{Cs}$.

In recent years, ${ }^{137} \mathrm{Cs}$ has been available from the Pacific Northwest National Laboratory located at the U.S. Department of Energy (DOE) facility in Hanford, Washington. The typical quantities of ${ }^{137} \mathrm{Cs}$ that have been shipped are $<10 \mathrm{Ci}$ in encapsulated stainless steel containers. Gamma source units from 30 to $12,000 \mathrm{Ci}$ have been shipped in doubly encapsulated stainless steel. The overall cost of ${ }^{137} \mathrm{Cs}$ is more dependent upon the packaging and shipping costs than the actual cost of the radioactive material. ${ }^{\text {al7 }}$ Nevertheless, the ${ }^{137} \mathrm{Cs}$ production line at Hanford has been shut down for the last couple years due to a lack of funding. The Hanford facility has a large quantity of ${ }^{137} \mathrm{Cs}$ onsite (estimated at $\sim 210$ million curies), ${ }^{18}$ separated from nuclear fuel that was processed 20 to 30 years ago. Presently, ${ }^{137} \mathrm{Cs}$ sources are

a. Personal communication with Sue Goiladay at Pacific Northwest National Laboratory, February 17, 1994, concerning ${ }^{137} \mathrm{Cs}$ price and availability. 
not available in the United States for commercial applications; however, small laboratory/research sources are available from other companies, and a supplier in France still produces commercial quantities of ${ }^{137} \mathrm{Cs}$ sources for foreign customers.

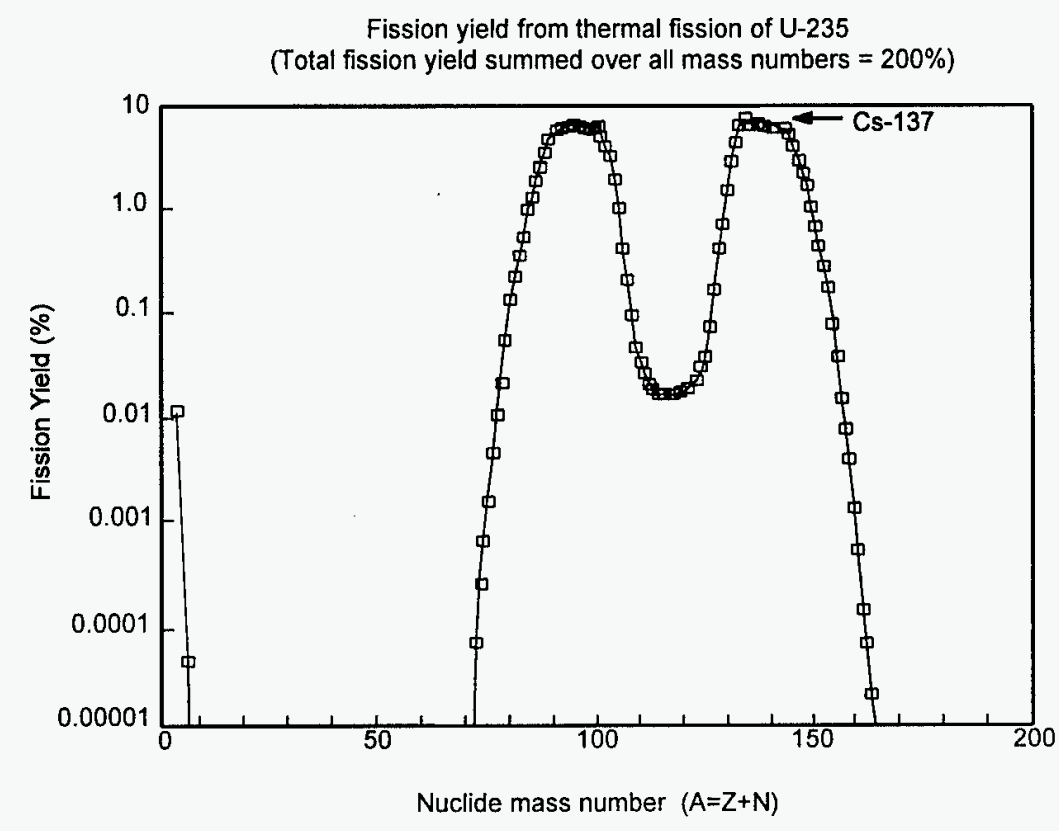

Figure 6-1. Fission product yield curve for thermal fission of ${ }^{235} \mathrm{U}$.

Table 6-6. Cesium and total radioactive fission product activities calculated as a function of decay time following a 3-year irradiation in a 3,050-MW thermal power LWR producing a total fuel burnup of $33,400 \mathrm{MWtD} / \mathrm{MTU}$. Results are based on an ORIGEN2 calculation of a pressurized water reactor (PWR).

Reactor core inventory (millions of curies)

\begin{tabular}{lrrrrrr} 
& \multirow{5}{c}{$\begin{array}{c}\text { Completion } \\
\text { of fuel }\end{array}$} & \multicolumn{5}{c}{ Decay time following reactor irradiation } \\
\cline { 3 - 7 } $\begin{array}{c}\text { Spradiation } \\
\left(\mathrm{T}_{0}\right)\end{array}$ & $\mathrm{T}_{0}+1 \mathrm{yr}$ & $\mathrm{T}_{0}+5 \mathrm{yr}$ & $\mathrm{T}_{0}+10 \mathrm{yr}$ & $\mathrm{T}_{0}+50 \mathrm{yr}$ & $\mathrm{T}_{0}+100 \mathrm{yr}$ \\
\hline${ }^{137} \mathrm{Cs}$ & 10.9 & 10.6 & 9.7 & 8.6 & 3.4 & 1.08 \\
$\begin{array}{l}\text { All Cs } \\
\text { isotopes }\end{array}$ & 686.0 & 21.7 & 12.6 & 9.2 & 3.4 & 1.08 \\
$\begin{array}{l}\text { All fission } \\
\text { products }\end{array}$ & $15,000.0$ & 200.0 & 46.4 & 31.6 & 11.3 & 3.51 \\
\hline
\end{tabular}




\section{Waste and Disposal Data on Cesium-137}

This section discusses the types of activities that generate ${ }^{137} \mathrm{Cs} L L W$, waste types and forms that contain ${ }^{137} \mathrm{Cs}$, and disposal data on ${ }^{137} \mathrm{Cs}$.

\section{Nuclear Reactors}

The quantity of ${ }^{137} \mathrm{Cs}$ generated in a nuclear reactor increases linearly with burnup; that is, double the fuel burnup and the ${ }^{137} \mathrm{Cs}$ inventory doubles. The only process that effectively decreases the ${ }^{137} \mathrm{Cs}$ inventory is radioactive decay. Since ${ }^{137} \mathrm{Cs}$ has a relatively long half-life ( 30.2 years), almost all of it generated within a reactor will be present at the end of fuel irradiation cycle.

In boiling water reactors and PWRs, the sources of liquid waste are handled by liquid waste treatment systems that also provide for the eventual purification of the reactor coolant. These liquid radioactive waste treatment systems handle the radioactive liquids generated by the plant and support operations. The estimated quantity of ${ }^{137} \mathrm{Cs}$ that is discharged to the environment due to primary-to-secondary leakages at a light water power reactor is considered to be small; for instance, $0.003 \mathrm{Ci} /$ year for the chemical control system, $0.012 \mathrm{Ci} /$ year for the waste treatment system, and 6.06 $\mathrm{Ci} /$ year for a postulated steam generator blowdown event. ${ }^{4}$ The quantity of ${ }^{137} \mathrm{Cs}$ released to the environment from an atmospheric steam dump (assuming a projected 76 liter/day primary-to-secondary leakage, $0.2 \%$ failed fuel rods, and a $3,358 \mathrm{MWt}$ reactor) is $0.0000354 \mathrm{Ci} /$ year. These results are small compared with the 5 to 11 million curies of ${ }^{137} \mathrm{Cs}$ present in the reactor fuel.

The largest source of ${ }^{137} \mathrm{Cs}$ and potential waste material is from commercial reactor operations and the large inventory of cesium stored in the irradiated fuel. Nearly all of the cesium produced in a LWR is generally contained within the $\mathrm{UO}_{2}$ fuel rods. The projected inventory of cesium produced from LWR fuel is 100,000 to $200,000 \mathrm{Ci} /$ metric ton of fuel (computed at 1 year of decay). These inventories would drop by about $20 \%$ after 10 years of decay.

Cesium is chemically reactive and exists within the uranium dioxide $\left(\mathrm{UO}_{2}\right)$ fuel as cesium-iodide (CsI) and cesium-telluride $\left(\mathrm{Cs}_{2} \mathrm{Te}\right)$ until all the iodine and tellurium are consumed - there is $\sim 10$ times more cesium than iodine and tellurium in LWR fuel-and the remaining cesium can exist as either a cesium-uranate $\left(\mathrm{Cs}_{2} \mathrm{UO}_{4}\right)$, cesium-molybdate $\left(\mathrm{Cs}_{2} \mathrm{MO}_{4}\right)$, cesium-oxide $\left(\mathrm{Cs}_{2} \mathrm{O}\right)$, or other compounds. ${ }^{11}$ Radioactive waste can originate from several sources; for example: (a) commercial nuclear fuel cycle operations (e.g., uranium mining, ${ }^{235} \mathrm{U}$ enrichment, $\mathrm{UO}_{2}$, fabrication, reactor operation, and spent fuel disposal), (b) institutions (e.g., hospitals, universities and research facilities), (c) DOE facilities (e.g., research, weapons manufacturing, testing, and decommissioning facilities), and (d) industrial uses (e.g., irradiation sources and radioisotope applications).

LLW may contain low quantities of fission products, including ${ }^{137} \mathrm{Cs}$. The primary waste forms that can contain ${ }^{137} \mathrm{Cs}$ that are produced as a result of nuclear reactor operations are contaminated scrub water, decontamination solutions, and demineralizers; contaminated clothing or gloves; contaminated tools and equipment used in radioactive areas; and pumps, valves, seals, bearings, scrap materials, and ion-exchange resins and filters.

LLW containing ${ }^{137} \mathrm{Cs}$ may exist in either liquid or solid waste forms, depending upon the original source of the contaminate material; for example: contaminated equipment, decontamination items, dry solids (e.g., plant wastes and combustible materials), solidified sludge (wastes generated from processed sludge such as evaporator bottoms, precipitated salts, etc.), and materials used to cleanup the reactor primary and secondary coolant water. 


\section{Medical, Academic Institutions, and Commercial Cesium-137 Waste}

${ }^{137} \mathrm{Cs}$ (and ${ }^{134} \mathrm{Cs}$ ) can be recovered from high-level waste streams, via several processes, for eventual separate disposal or possible industrial or medical applications. Although this has taken place in the past, no facilities are currently recovering ${ }^{137} \mathrm{Cs}$ for medical or commercial purposes.

The quantity of ${ }^{137} \mathrm{Cs}$ waste material generated in medical, academic, or commercial facilities is small compared with the quantity of ${ }^{137} \mathrm{Cs}$ waste produced as a result of nuclear reactor facilities.

The primary chemical forms of ${ }^{137} \mathrm{Cs}$ that have been used in past source capsules are either of the two cesium salts: cesium-chloride $\left({ }^{137} \mathrm{CsCl}\right)$ or cesium sulfate $\left({ }^{137} \mathrm{Cs}_{2} \mathrm{SO}_{4}\right) \cdot{ }^{19}$ Either of these salts is compacted and placed within a standard-size plug made of a high-density tungsten alloy which is then placed within a stainless steel cup. The majority of the past ${ }^{137} \mathrm{Cs}$ source units are contained within a standardized international source capsule. Standardization of the source capsule size was initially set by the U.S. and Canada in 1953, but most manufacturers throughout the world have accepted this standardized design. The standard source capsules consist of three basic parts: a cap and plug made of a tungsten alloy, and a stainless steel cup. The radioactive source is placed within the stainless steel cup and is weld-sealed. The cup is then placed within the tungsten plug and the cap is welded to the plug. The ${ }^{137} \mathrm{Cs}$ source is doubly sealed on all sides, except the face, by a high-density tungsten-alloy that attenuates the source beam. The face of the capsule through which the focused gamma ray beam passes is made of stainless steel and is about $0.5 \mathrm{~mm}$ thick. The approximate outside dimensions of the source capsule are $51 \mathrm{~mm}$ (diameter) by $47 \mathrm{~mm}$ (length). The actual source size can vary up to $30 \mathrm{~mm}$ (diameter) by $30 \mathrm{~mm}$ (length). ${ }^{19}$

${ }^{137} \mathrm{Cs}$ has also been used for interstitial (within tissues) and intracavitary curie-therapy for cancer treatment. ${ }^{3}$ In this case, ${ }^{137} \mathrm{Cs}$ is extracted from the fission products of uranium and is chemically isolated as an insoluble silica-aluminate called pollucite. The grains of pollucite are then placed in small stainless steel envelopes that are sealed. Typically these sources have dimensions of $1.78 \mathrm{~mm}$ (diameter) by $3.5 \mathrm{~mm}$ (length), with a maximum source strength of $740 \times 10^{6} \mathrm{~Bq}(0.02 \mathrm{Ci})$.

Although it is not the primary radioisotope used for industrial radiography, ${ }^{137} \mathrm{Cs}$ sources have been used in thickness gauges (e.g., gaging of automobile sheet steel) and density gauges, to produce plastic shrink tubing (irradiated plastic has the tendency to shrink after being heated), in radiography to inspect metal castings and welds for flaws and material defects (e.g., cracks in steel pipes), to treat sewage sludge to reduce the number of micro-organisms contained in it before processing into agricultural fertilizer, and for $\gamma$-sterilization of medical products, foods, and milk cartons. ${ }^{137} \mathrm{Cs}$ is also used for many other industrial, agriculture, and biological purposes (e.g., the control of harmful insect populations) ${ }^{20}$

\section{Disposal Data on Cesium-137}

${ }^{137} \mathrm{Cs}$ has been deposited in three LLW sites in Richland, Washington; Barnwell, South Carolina; and Beatty, Nevada over a period of several years. Data have been obtained on the activity, sources, and waste types for this nuclide from the Manifest Information Management System Database. ${ }^{b}$ Figure 6-2 shows the total annual ${ }^{137} \mathrm{Cs}$ activity deposited in the three sites for each year between 1986 and 1995 . This nuclide has been deposited in these three sites nearly uniformly throughout this period, with the exception of the last two years, when the rate of deposit decreased significantly from previous years.

b. Information provided through the DOE waste management system maintained by the National Low-Level Waste Management Program, Idaho National Engineering Laboratory (INEL). 


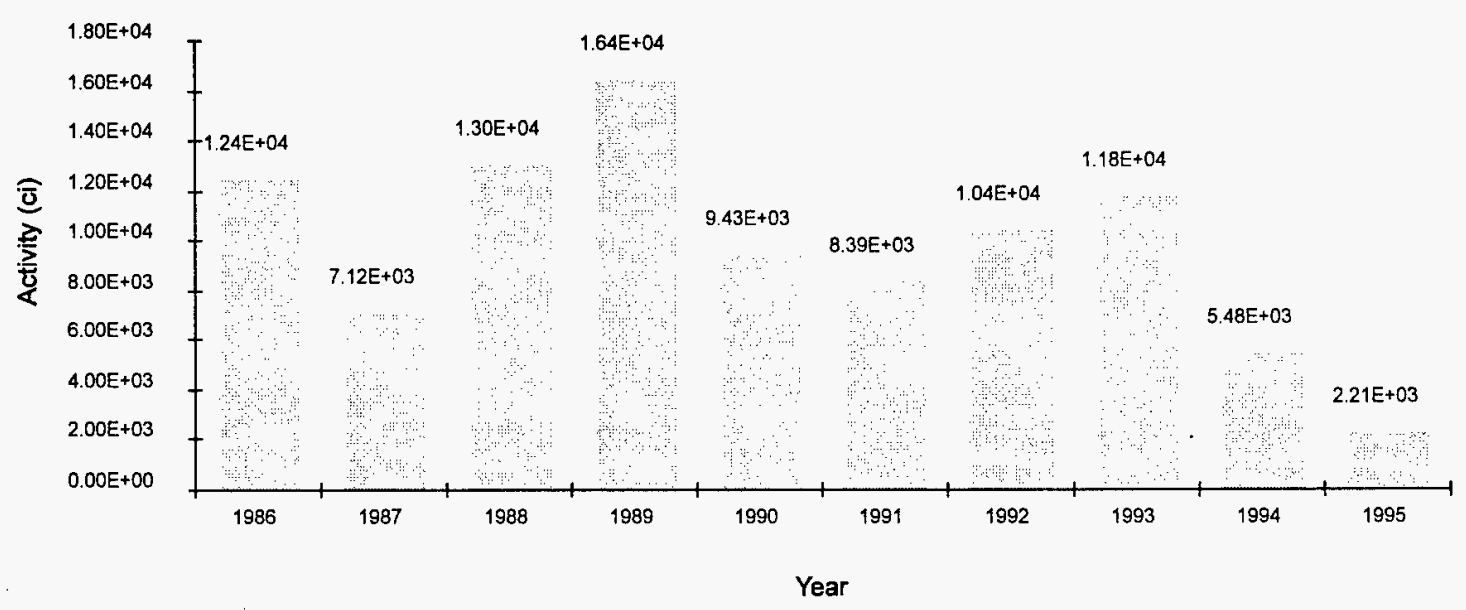

Figure 6-2. ${ }^{137} \mathrm{Cs}$ activity deposited at the Richland, Beatty, and Barnwell sites by year (log scale).

Figure 6-3 shows the activity of ${ }^{137} \mathrm{Cs}$ deposited in these three sites as a function of waste source. The overwhelming majority of the activity was generated by utilities, $77,000 \mathrm{Ci}$ or $80 \%$ of the total. An additional $19 \%$ was generated by industrial sources and only minor activities were generated by the other sources. The definition of disposal categories given in Figure 6-3 is as follows: academic - sources associated with university laboratories; government - sources associated with the government, such as military hospitals; industry - sources associated with manufacturing, other than utilities; medical sources associated with hospitals and medical laboratories, excluding pharmaceutical manufacturing; utility - sources generated by nuclear utilities and stored onsite or sent to one of the three disposal sites. Waste treatment facilities are included in the utility category.

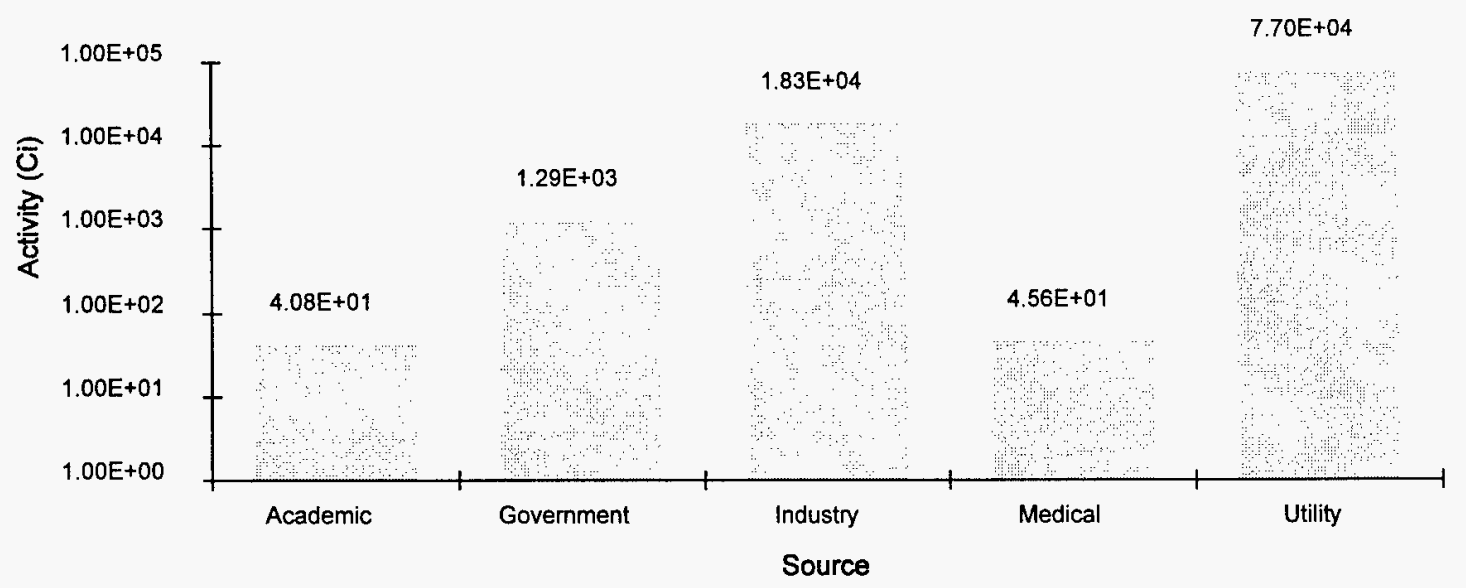

Figure $6-3 .{ }^{137} \mathrm{Cs}$ activity deposited at the Richland, Beatty, and Barnwell sites by source (log scale). 
Figure 6-4 shows the activity of ${ }^{137} \mathrm{Cs}$ deposited in the Richland and Beatty sites as a function of waste type. The waste disposal manifests for the Barnwell site did not break down the waste by type, which is unfortunate since most of this nuclide $(70 \%)$ is stored at this site. As shown in this figure, more than $90 \%$ of this nuclide was from dewatered resins and dry solids. The waste types illustrated in Figure 6-4 are from nuclear reactors, academic institutions, and medical facilities.

\section{Behavior of Cesium-137 in the Environment}

\section{Cesium-137 in Soils}

Understanding the behavior of fission products such as cesium in the soil is important in predicting the dissolution of radioactive waste in underground vaults and the subsequent transport of radionuclides through the biosphere. ${ }^{21}$ It is important to understand the interactions between radionuclides and various media along the path to the biosphere, whether disposal is in deep or shallow rock caverns or in shallow overburden facilities.

Four parameters were reported to be essential to accurately predict soil concentrations from either contaminated ground water or irrigation water. ${ }^{21}$ The four parameters, in order of decreasing importance, are (a) soil retention, (b) annual precipitation, (c) soil texture, and (d) depth to the water table. The soil retention parameter represents the solid/liquid partition coefficient and is denoted by the symbol $\mathrm{K}_{\mathrm{d}}$, where $K_{d}$ is defined as the ratio of the cesium concentration in soil to the cesium concentration in the liquid; for instance, $\mathrm{K}_{\mathrm{d}}=\mathrm{C}_{s} / \mathrm{C}_{\mathrm{l}}$. This empirical model combines all operating retention mechanisms into one value. The $K_{d}$ model assumes that the liquid and solid phases are at equilibrium and that there is a linear relationship between solute concentration in the solid $\left(\mathrm{C}_{\mathrm{s}}\right)$ and liquid $\left(\mathrm{C}_{1}\right)$ phases.

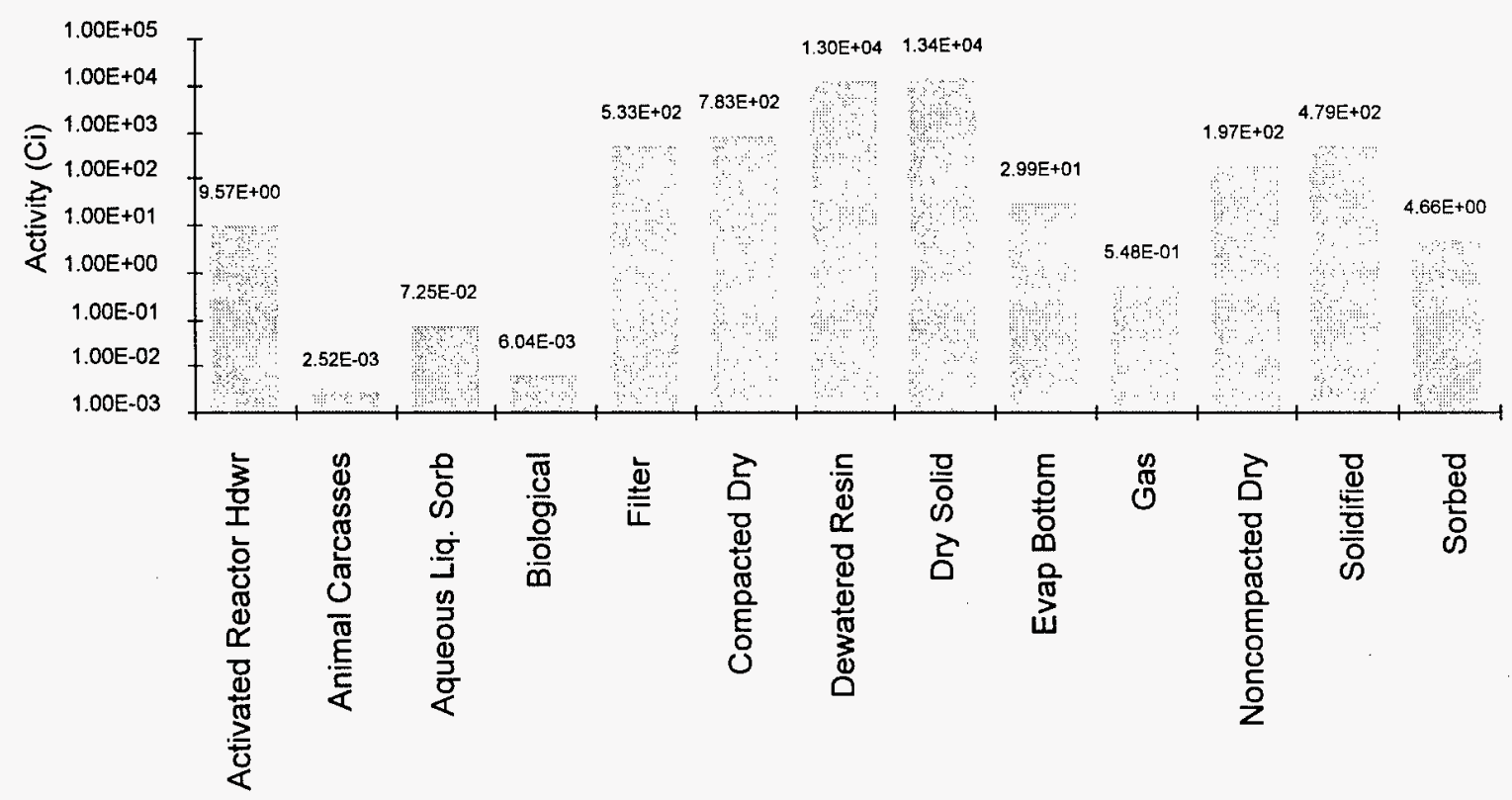

Waste Type

Figure 6-4. ${ }^{137} \mathrm{Cs}$ activity deposited at the Richland and Beatty sites by waste type (log scale). 
In order to correlate the interaction of cesium with different soil types, the mineral soils are divided into three different categories: (a) sand, (b) clay, or (c) loam (between sandy and clay textures). The soils that contain $\geq 70 \%$ sand-sized particles are classified as sandy soils, and those containing $\geq 35 \%$ clay-sized particles are classified as clay soils. Loam soils have an even distribution of sand, clay, and silt-sized particles and can consist of up to $80 \%$ silt-sized particles. Organic solids contain greater than $30 \%$ organic matter.

Certain elements such as $C s$ have the lowest $K_{d}$ values in sand solids, but show a higher $\mathrm{K}_{\mathrm{d}}$ for clay soils with no consistent trend for loam soils. The secondary silicates (e.g., clays and zeolites) remove cesium from solution much better than the primary silicates (e.g., feldspars, quartz, etc.). Soils representative of the Hanford site - the Rizvill silt loam, Burbank loamy sand, and Ephrat sandy loam-have been studied for their ion-exchange properties with cesium. Cesium, as an element, is easily absorbed by the soil and is firmly fixed to a depth of about $5 \mathrm{~cm} .{ }^{22}$ These results are also consistent with a study conducted by the Pacific Northwest Laboratory wherein the depth profiles of strontium- $90\left({ }^{90} \mathrm{Sr}\right)$ and ${ }^{137} \mathrm{Cs}$ were measured in the vicinity of the Hanford site. ${ }^{23}$ In general, ${ }^{137} \mathrm{Cs}$ seems to be more tightly fixed in these soils than ${ }^{90} \mathrm{Sr}$, based on the observation that the cesium concentration decreases more rapidly with depth than that of strontium. The presence of competing positive ions (e.g., from common table salt $-\mathrm{NaCl}$ ) has a most dramatic effect on the sorption of cesium ions that behave predominantly as positive ions. For instance, the $\mathrm{K}_{\mathrm{d}}$ value for $\mathrm{Cs}$ decreased two orders of magnitude when the concentration of $\mathrm{NaCl}$ increased by 500 times.

Trace cesium concentrations are also completely adsorbed above $\mathrm{pH}$ values of 4.0 in a Hanford calcareous soil. However, when accompanied with high concentrations of sodium chloride, less than $75 \%$ of the trace cesium is adsorbed, and adsorption was nearly independent of $\mathrm{pH}$ over a wide range. ${ }^{24}$

At $\leq 1 \%$ of the soil capacity of cesium, competing positive ion effects on cesium adsorption are slight. Trace concentrations of cesium were adsorbed to a greater degree and were more difficult to displace from the soil by competing positive ions than when the cesium was adsorbed in greater concentrations. The presence of small amounts of mineral phases in the soil with high cesium selectivities may account for this behavior.

Cesium atoms in soils mainly exist in solution as the positive ion: $\mathrm{Cs}^{+1}$. Therefore, the principal reaction mechanism of cesium adsorption on soils and rocks is expected to be positive ion exchange. In some instances, cesium shows a direct $\mathrm{K}_{\mathrm{d}}$-Plus ion-exchange capacity relationship, and in other instances no relation was found between $\mathrm{K}_{\mathrm{d}}$ and exchange capacity. At trace cesium concentrations, competing effects are minor, while at $10 \%$ or more of the exchange capacity occupied by cesium, the $\mathrm{K}_{\mathrm{d}}$ value begins to decrease. For instance, potassium is better than sodium or calcium for desorbing cesium.

In temperate climates, the fixation of cesium in clay minerals makes it difficult for cesium to be absorbed by plants from mineral soils, ${ }^{25}$ although the degree of fixation is much less in some tropical soils. There is evidence of a greater availability of cesium in peat-type soils. Another study, conducted at the Connecticut Agricultural Experiment Station, was done to measure the effects of different mineral contents in the clay on the sorption of cesium. ${ }^{26}$ Samples were taken of seven different clay-based soils and the ability of each of these to absorb cesium from water was measured. The general conclusion was that the minerals in the clays can significantly affect the ability of the soil to absorb ${ }^{137} \mathrm{Cs}$. 


\section{Cesium-137 in Groundwater}

The migration rate of cesium in the groundwater is faster at lower $\mathrm{pH}$ values but slower through clays than through sands due to large clay $\mathrm{K}_{d}$ values. ${ }^{24}$ Much of the cesium that migrates in surface waters is adsorbed on suspended solids. Organic soil materials have little effect on cesium migration through soils. Over a wide range of $\mathrm{pH}$ and concentrations in groundwater, ${ }^{137} \mathrm{Cs}$ occurs with a univalent positive ion $\left({ }^{137} \mathrm{Cs}^{+}\right)$. The migration rate of cesium is faster in groundwater at low acidity conditions, and it tends to move through rock fissures containing calcite, epidote, or chlorate in veins. Granite and basalt rocks tend to retard ${ }^{137} \mathrm{Cs}$ and limit its detection in groundwater.

For the Idaho National Engineering Laboratory (INEL), groundwater testing has been performed over several years at many well locations on the site. This testing program has detected ${ }^{137} \mathrm{Cs}$. Some data taken in wells near the Idaho Chemical Processing Plant have shown ${ }^{137} \mathrm{Cs}$ concentrations of $0.050,10^{-9}$ $\left(0-05 \mu \mathrm{Ci} / \mathrm{M}^{3}\right)$ to $1.05 \times 10^{-9} \mathrm{Ci} / \mathrm{liter}\left(1.05 \mu \mathrm{Ci} / \mathrm{m}^{3}\right){ }^{27}$

Russian studies were made on the contamination of water in the vicinity of and as a result of the nuclear accident at Chernobyl. ${ }^{28}$ This study included measurements of the concentrations of this nuclide in the Ukrainian, Byelorussian and Russian Federation rivers, the Dnieper reservoir chain, the Dnieper estuary, and the Black, Baltic, and Azov Seas. Of these, the highest levels of contamination were measured in the Pripyat and Dnieper rivers. The article reported temporal variations, depth profiles, and other information. The concentrations of ${ }^{137} \mathrm{Cs}$ in the reservoirs varied from as low as 100 to more than $3000 \mathrm{~Bq} / \mathrm{m}^{3}$. Samples were taken from the Danube River which contained ${ }^{137} \mathrm{Cs}$ concentrations ranging from very small to as high as several tens of $\mu \mathrm{Bq} / \mathrm{m}^{3}{ }^{29}$ Concentrations of this nuclide in the Bay of Bengal, resulting from this same accident, were less than $1 \mu \mathrm{Bq} / \mathrm{m}^{3} .{ }^{30}$

A study was performed by scientists at the Bhabha Atomic Research Centre in Bombay, India, to investigate the effect of various ions in seawater on the ability of the water to dissolve ${ }^{137} \mathrm{Cs}$ that had been previously sorbed onto sediments. ${ }^{31}$ Of the five principal ions, $\mathrm{Na}, \mathrm{K}, \mathrm{Ca}, \mathrm{Mg}$, and $\mathrm{Sr}$, only sodium and potassium were shown to be effective in removing cesium from the sediments.

Since leaching into groundwater is a principal mechanism for propagation of this nuclide out of LLW repositories, it is important to prevent this from occurring. A study was made at the Istanbul University into the ability of bauxite wastes (red mud) to sorb ${ }^{137} \mathrm{Cs}$ from water, to determine whether a barrier of this substance could be utilized to minimize migration of this nuclide with the groundwater. ${ }^{32}$ The study supported conclusions from previous studies that red mud would be an effective barrier for migration and reported on how various environmental parameters (e.g. pH, heat treatment, etc.) affected this capability.

\section{Cesium-137 in Plants}

The fate and biological transport of cesium in plants have been studied in an effort to predict the extent of cesium migration in the food web and its potential toxicity. ${ }^{33}$ Concentration ratios measured as a function of soil-radionuclide concentration were found to be independent of soil concentration for three orders of magnitude in the cesium concentration. This information suggests that data from these studies can be extrapolated to environmental contamination levels for modeling purposes. The relationships observed between plant age and concentration ratios indicate that data obtained from seedlings may underestimate the concentration ratio for more mature plants. Analyses of dry matter production, total shoot content, and tissue concentration of cesium indicates that plant uptake of these radionuclides continues at a linear rate over the growing season, and that the observed age-dependent changes in concentration ratios are related to production of dry matter and changes in shoot concentrations. 
Trifolium pratense, used as a fodder crop, is one of the fundamental elements of the animal and human food chain. ${ }^{21}$ The cesium concentration in this plant initially peaks when cesium is first absorbed by the roots, and then peaks a second time when the flowering begins. After the rapid initial penetration of the roots into the soil, a horizontal network of secondary roots is formed beneath the surface of the ground to supply the plant with nourishment. As the plants grow older, this network can penetrate farther down into the soil, and consequently, the absorption of the radioisotope in the surface becomes less evident.

Cesium has been found to particularly concentrate in the roots, the lower part of the foliage, and the veins of the leaves of plants. The amount of ${ }^{137} \mathrm{Cs}$ deposited on the leaves is likely to penetrate into the plant more rapidly than the amount fixed in the ground.

The fallout of radioactivity produced from the April 1986 Chernobyl accident contaminated vast areas of Sweden with ${ }^{137} \mathrm{Cs}^{33}$ Besides control surveys, studies were carried out on the transfer rate of cesium to the grassland hay crops on a number of farms. A large variation was found in the transfer of cesium. The field data made it possible to estimate the fraction of early fallout cesium, which could be regarded as retained in positions available for contamination of the growing grass. The range found was rather narrow for the experiments. Allowing for the time for growth, for the productivity of the land, and for the residence time of the contaminant, it should be possible to give fair estimates of the contamination level of grass crops in situations similar to that after the Chernobyl fallout. However, land quality and farm management need to be classified into a suitable system before the outcome can be calculated for large districts.

The soil-to-plant transfer factors for ${ }^{137} \mathrm{Cs}$ were measured for various plants and soils in a study conducted by the Austrian Research Centre, Seibersdorf. ${ }^{34}$ Samples of central European soils were collected and the ${ }^{137} \mathrm{Cs}$ concentrations (due, principally, from fallout from the Chernobyl Nuclear Plant accident) were measured. Thus, the cesium contamination of the soils was due to air deposition and the researchers did not resort to artificially injecting cesium into the soil samples. In general, fruits and tubers had lower transfer factors (that is, less relative uptake into the plant) than vegetative plant parts. In addition, it was observed that higher soil concentrations of ${ }^{137} \mathrm{Cs}$ resulted in smaller transfer factors for otherwise similar experiments.

\section{Cesium-137 in Air}

Cesium is not normally found in air unless there is a large-scale accident such as the Chernobyl accident, which did not have a containment structure around the nuclear reactor, or from nuclear bomb testing into the atmosphere, which is currently banned by most nuclear nations. Even in the Three-Mile Island accident, for which the PWR had containment, most of the cesium was released from the $\mathrm{U}_{2}$ fuel; however, it was not released into the atmosphere primarily because of the reactor containment structure. The major fission product releases were limited to controlled releases of the radioactive noble gases a year after the accident.

In the case of severe fuel damage accidents, cesium tends to be released in the form of volatile radioactive compounds (such as $\mathrm{CsI}$ and $\mathrm{CsOH}$ ).

Most of the cesium compounds such as carbonates, nitrates, and sulfates decompose at relatively low temperatures forming cesium oxide that, in the presence of water vapor, will hydrolyze and form cesium hydroxides which vaporize. Even cesium iodide can vaporize with cesium hydroxide and form aerosol particles that can move through the air. Cesium transport on aerosol particles is very complex 
behavior that depends upon thermal-hydraulic conditions and specific geometry situations. Even if the cesium becomes airborne in the form of aerosols, it tends to precipitate in cooler regions and falls to earth with rain.

\section{Behavior of Cesium-137 in the Human Body and in Animals}

Cesium is absorbed almost completely from the gastrointestinal (GI) tract and concentrates mainly in soft tissue, particularly in muscles. ${ }^{35}$ The body inventory of ${ }^{137} \mathrm{Cs}$ can be determined by either whole-body radioactivity measurements or by excretion analysis. ${ }^{35}$ The biological half-life of ${ }^{137} \mathrm{Cs}$ in humans depends upon body weight and generally varies from about 50 to 150 days for adults, with a mean value of 101 days. ${ }^{4}$ The biological half-life refers to the amount of time required to remove half of the initial material from the affected organism through a combination of radioactive decay, chemical, and biological removal processes.

Studies involving ${ }^{137} \mathrm{Cs}$ intake and excretion by humans and determining associated rate constants are of primary importance to radiation protection and human radioecology, and could prove to be even more significant in illuminating fundamental metabolic relationships and states of health and disease. ${ }^{36}$

For a human population, the biological half-life measured for men, women, and children are distinctly different, and attempts have been made to account for this observation. There has been some disagreement concerning the basis for differences between males and females. An approach to circumvent the sex and age problem was to correlate the half-lives with body mass, but some problems were encountered in using correlations based on weighted averages of the data.

In view of all the foregoing analysis and discussion, it is concluded that the biological half-life for cesium in humans can be considered as a function of age for juveniles and sex for adults, but is not necessarily (directly) dependent upon the body mass of the individual, although several mathematical relationships have attempted to correlate these two items. This conclusion in no way conflicts with the suggestion that relationship of half-life and body mass could be useful in interpreting the available data.

The half-life may be represented by the following equation with the data shown in Figure $6-5: 37$

$$
T_{1 / 2}=1.14( \pm 0.13) m+4.6( \pm 7.3)
$$

Where $\mathrm{m}$ represents the body mass in $\mathrm{kg}$ and $\mathrm{T}_{1 / 2}$ is the biological half-life in days.

The average biological half-life of ${ }^{137} \mathrm{Cs}$ for adults is 101 days; for children and infants, the half-lives are much less. It is estimated at 7 to 10 days in babies and 33 and 40 days in girls 6 and 8 years old. For humans, cesium is retained more tenaciously than potassium. ${ }^{38}$

The rate of cesium turnover may be under hormonal influence or control or may reflect the general metabolic rate. ${ }^{36}$ Experiments in animals appear to confirm earlier but inconclusive results in humans which indicated that ${ }^{137} \mathrm{Cs}$ half-times were dependent upon thyroid function. 


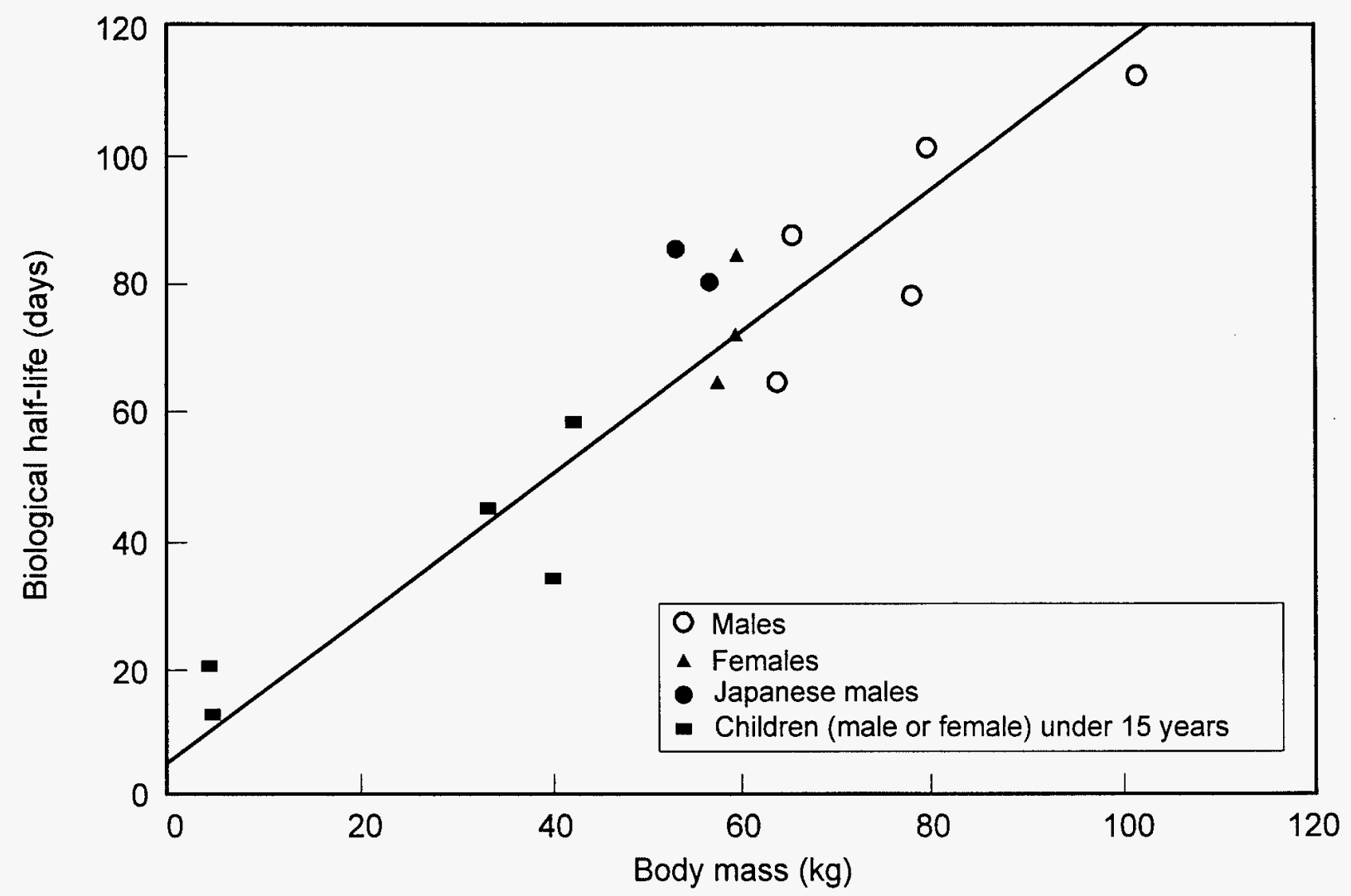

Figure 6-5. Variation of biological half-life with mass.

Potassium and cesium are both alkali metals, and potassium serves a very important function in the body as an electrolyte. ${ }^{38}$ Since cesium has similar chemical properties, one of the effects of cesium is its potential effect on the potassium levels in the body in addition to its potential radiation effects on the various body tissues.

Increasing the potassium intake only slightly decreases the cesium body content. Thus, cesium metabolism is both similar to, but independent of, potassium metabolism.

Cesium has been shown to have a pronounced physiological action on animals when administered in amounts equivalent to the potassium content in the diet of rats. ${ }^{12}$ Hyperirritability including spasms have resulted, eventually leading to death in 2 to 17 days.

One of the routes for the exposure of humans to radioactive nuclides in LLW disposal sites is uptake by plants that are eaten by animals that are, in turn, eaten by humans. A Swedish study was conducted to investigate this pathway. ${ }^{39}$ This study reported a strong correlation between plant contamination and subsequent contamination in humans. A German study was made of the concentrations of ${ }^{137} \mathrm{Cs}$ in animal livers. ${ }^{40} \mathrm{~A}$ similar study was made of the transfer factors from feed to milk and meat in beef and pork for animals grazing in the vicinity of a planned nuclear power plant in Czecholslovakia. ${ }^{41}$ Of the three, beef, pork, and milk, the highest transfer factors for ${ }^{137} \mathrm{Cs}$ were for pork meat. Even though these studies concentrated on contamination induced by fallout, the plant to animal to human information can be relevant to LLW depositories. 
Absorption of both cesium and potassium takes place through the digestive tract. Cesium and potassium enter body cells, where cesium is more tenaciously retained. Excretion from the body is urinary and fecal in varying degrees, depending on species and diet. The maximum permissible body burdens and maximum permissible concentrations in water and air are listed in Table 6-7. These concentration data are based on a 40-hour work week.

The annual limits on ${ }^{137} \mathrm{Cs}$ intake and the derived maximum air concentrations for ${ }^{137} \mathrm{Cs}$ are shown in Table 6-8.

Table 6-7. Maximum permissible body burdens and maximum permissible concentrations.

\begin{tabular}{|c|c|c|c|}
\hline Reference organ & $\begin{array}{l}\text { Maximum } \\
\text { permissible burden } \\
\text { in total body } \\
(\mu \mathrm{c})\end{array}$ & $\begin{array}{c}\text { Maximum } \\
\text { permissible } \\
\text { concentration in water } \\
\left(\mu \mathrm{c} / \mathrm{cm}^{3}\right)\end{array}$ & $\begin{array}{c}\text { Maximum } \\
\text { permissible } \\
\text { concentrations in air } \\
\left(\mu \mathrm{c} / \mathrm{cm}^{3}\right)\end{array}$ \\
\hline $\begin{array}{l}\text { Total body } \\
\text { (soluble) }\end{array}$ & 30 & $4 \times 10^{-4}$ & $6 \times 10^{-8}$ \\
\hline Liver (soluble) & 40 & $5 \times 10^{-4}$ & $8 \times 10^{-8}$ \\
\hline Spleen (soluble) & 50 & $6 \times 10^{-4}$ & $9 \times 10^{-8}$ \\
\hline Muscle (soluble) & 50 & $7 \times 10^{-4}$ & $1 \times 10^{-7}$ \\
\hline Bone (soluble) & 100 & $1 \times 10^{-3}$ & $2 \times 10^{-7}$ \\
\hline Kidney (soluble) & 100 & $1 \times 10^{-3}$ & $2 \times 10^{-7}$ \\
\hline Lung (soluble) & 300 & $5 \times 10^{-3}$ & $6 \times 10^{-7}$ \\
\hline GI (SI) (soluble) & & $2 \times 10^{-2}$ & $5 \times 10^{-6}$ \\
\hline Lung (insoluble) & & & $1 \times 10^{-8}$ \\
\hline $\begin{array}{l}\text { GI (LLI) } \\
\text { (insoluble) }\end{array}$ & & $1 \times 10^{-3}$ & $2 \times 10^{-7}$ \\
\hline
\end{tabular}

Table 6-8. Annual limits on intake (ALI) and the derived air concentrations (DAC) for ${ }^{137} \mathrm{Cs}$ (obtained from Reference 38).

\begin{tabular}{cccc} 
Radionuclide & Component & Ingestion & Inhalation \\
\hline${ }^{137} \mathrm{Cs}$ & $\mathrm{ALI}$ & $100 \mu \mathrm{Ci}$ & $200 \mu \mathrm{Ci}$ \\
& $\mathrm{DAC}$ & - & 0.06 \\
& & & $\mu \mathrm{Ci} / \mathrm{m}^{3}$ \\
\hline
\end{tabular}




\section{Summary}

${ }^{137} \mathrm{Cs}$ is not a naturally occurring radionuclide. Its half-life is 30.2 years and it emits one to two high-energy beta particles. Approximately $85 \%$ of all ${ }^{137} \mathrm{Cs}$ decays result in the emission of a $662-\mathrm{keV}$ gamma ray. Due to the gamma ray energy of ${ }^{137} \mathrm{Cs}$, it has been used to sterilize medical supplies, milk cartons, and irradiate food. Industrial applications of ${ }^{137} \mathrm{Cs}$ include the production of plastic shrink tubing (irradiated plastic has the tendency to shrink after being heated), radiography to inspect metal castings and welds for flaws and material defects (e.g., cracks in steel pipes), radioactive measurement gauges for liquid or solid thicknesses (e.g., gaging of automobile sheet steel), treatment of sewage sludge to kill bacteria and viruses, and radiotherapy to kill cancerous tissue.

Chemically, cesium behaves like the other alkali metals and has the simplest of elemental chemistries (excepting the inert gases such as helium). Cesium reacts with most other elements directly and reacts explosively with air and water. Therefore, metallic cesium must be handled in an inert atmosphere. Cesium reacts with most nonmetals to produce one or more binary compounds; it also forms numerous alloys and compounds with other metals such as lead and tin. Various oxides, sulfides, and similar compounds are readily hydrolysed by water forming cesium hydroxides. Cesium salts are generally characterized by high melting points, electrical conductivity of the melts, and high solubility in water.

The behavior of cesium in the biosphere is dictated by its chemical properties. Because of its high solubility, cesium readily moves with groundwater unless it is preferentially retained in the soils, particularly by clay soils. If cesium is not held in the soils, it can relocate through the root system of plants or through the leaves and stems from atmospheric deposition. The amount of ${ }^{137} \mathrm{Cs}$ deposited on leaves is likely to penetrate into the plant more rapidly than cesium absorbed from the ground.

Absorption of cesium by humans takes place primarily through the digestive tract. Cesium and potassium enter body cells, where cesium is bound more tightly than potassium. The biological half-life for cesium in humans depends on age, sex, and body mass. For adult humans, the biological half-life varies between 50 and 150 days with a mean value of 101 days, and for infants and children, the biological half-life ranges between 5 and 50 days. 


\section{References}

1. P. Kilho Park, D. R. Kester, I. W. Duedall, B. H. Ketchum, Wastes in the Ocean, (Volume 3) Radioactive Wastes and the Ocean, New York: John Wiley \& Sons, 1982, pp. 5, 19, 22, 27, 28, $58-60,189,191,446,447,459$.

2. General Electric Company, Nuclides and Isotopes, Fourteenth Edition, 1989.

3. R. Granier and D. Gambini, Applied Radiobiology and Radiation Protection, Ellis Horwood Limited, English edition published in 1990, pp. 194, 195, 201, Table 7.1 on p. 205, 251, 252, 253, 257, Table 10.3 on 273 , p. 285 , Table 11.2 on p. 300 , and Table 11.3 on p. 301.

4. W. R. Gilmore (ed.), Radioactive Waste Disposal, Low and High Level, Noyes Data Corporation, 1977, p. 221, Table 5.4 on p. 21, Table 1.9 on 25, and pp. 148, 219, 222, 224, 225.

5. U.S. Department of Health, Education, and Welfare, Radiological Health Handbook, Revised Edition January 1970, pp. 93, 122, 122, 148, 149, 154, 155, 163, 164, and 204.

6. C. M. Lederer, J. M. Hollander, I. Perlman, Table of Isotopes, Sixth Edition, New York: John Wiley \& Sons, Inc., 1967, p. 3 and p. 155.

7. P. C. Souers, Hydrogen Properties for Fusion Energy, University of California Press, 1986, Chapters 1, 16, and 17, and p. 6.

8. R. C. Weast (ed.), CRC Handbook of Chemistry and Physics, Boca Raton, Florida: CRC Press, 1977, 58th Edition, pp. B270-B354 (Table of Isotopes).

9. Compiled and edited by the Bureau of Radiological Health, Radiological Health Handbook, Revised Edition, January 1970, U.S. Government Printing Office, pp. 92-94 (Average and Maximum Beta Energy by Radionuclide).

10. E. S. Gould, Inorganic Reactions and Structure, New York: Holt, Rinehart, and Winston, 1962.

11. F. A. Cotton and G. Wilkinson, Advanced Inorganic Chemistry-A Comprehensive Text, New York: Wiley-Interscience, 1980.

12. C. A. Hampel ed., Encyclopedia of the Chemical Elements, New York: Reinhold Book Corporation, 1968.

13. A. G. Croff, $A$ User's Manual for the ORIGEN2 Computer Code, ORNLTM-7175, July 1980.

14. U.S. Department of Energy, Characteristics of Spent Fuel, High-Level Waste, and Other Radioactive Wastes Which May Require Long-Term Isolation, DOE/RW-0184, Volume 2 of 6 , December 1987.

15. F - J. Rahn et al., A Guide to Nuclear Power Technology, New York: John Wiley \& Sons, 1984, p. 719 (Table 17.2), p. 228.

16. J. C. Warf, All Things Nuclear, Graphics 2100, Los Angeles, p. 80. 
17. U.S. Department of Energy, Isotope Production \& Distribution, Westinghouse Hanford Company Isotope Program Office, Richland, Washington, April 1992, Section VII.

18. Sybil P. Parker (ed), McGraw-Hill Encyclopedia of Energy, 2nd Edition, New York: McGraw-Hill, 1977, Table 3 on p. 573.

19. C. F. Behrens, and E. R. King, Atomic Medicine, Williams \& Wilkins Company, 4th Edition, 1964, pp. 658 and 662 .

20. R. E. Bolz and G. L. Tuve (eds), CRC Handbook of Tables for Applied Engineering Science, Second Edition, Boca Raton, Florida: CRC Press, 1977, Table 4-19, p. 427.

21. M. I. Sheppard and D. H. Thibault, "Default Soil Solid/Liquid Partition Coefficients, $\mathrm{K}_{d} \mathrm{~s}$, for Four Major Soil Types: A Compendium," Health Physics, Vol. 59, No. 4, October 1990, pp. 471-482.

22. P. C. Bergamini, G. Paimas, F. Piantelli, and M. Rigato, "Absorption and Distribution of ${ }^{137}$ Cs by Trifolium Pratense," Health Physics, Vol. 19, October 1970, pp. 521-528.

23. K. R. Price, "The Distr.bution of Strontium-90 and Cesium-137 in Soil Profile Samples from the Hanford Site and Environs," Thirty-Fourth Annual Conference on Bioassay, Analytical and Environmental Radiochemistry, Las Vegas, Nevada, October 17-21, 1988, PNL-SA-16034.

24. D. A. Barber, "Influence of Soil Organic Matter on the Entry of Cesium-137 into Plants," Nature, Vol. 204, December 26, 1964, pp. 1326-1327.

25. R. C. Routson and D. A. Cataldo, "A Growth Chamber Study of the Effect of Soil Concentration and Plant Age on the Uptake: Uptake of Strontium and Cesium by Tumbleweed," Communications in Soil Science and Plant Analysis, Vol. 9, No. 3, 1978, pp. 215-219.

26. C. R. Frink, Fixation of Cesium 137 by Soil Clays, NYO-2955-25, September 1971.

27. R. Bobo, "A Review of the Production, Use, and Disposal of Groundwater and the Generation, Storage and Processing of Radioactive Liquid Waste at the Idaho Chemical Processing Plant, INEL," State of Idaho INEL Oversight Program, OPTR 93-03, August 1993, Table 5.

28. S. M. Vakulovsky, et al., "Cesium-137 and Strontium-90 Contamination of Water Bodies in the Areas Affected by Releases from the Chernobyl Nuclear Power Plant Accident: An Overview," Journal of Environmental Radioactivity, Vol. 23, No. 2, 1994, pp. 103-122.

29. F. J. Maringer, et al., On the Behovior of Sr-90 and Cs-137 in Water, Suspended Matter and Sediment of the River Danube, INIS-MD-13969.

30. M. N. Alam, et al., "Radioactivity of ${ }^{134} \mathrm{Cs}$, ${ }^{137} \mathrm{Cs}$, and ${ }^{40} \mathrm{~K}$ in Sea Water of the Bay of Bengal," Applied Radiation and Isotopes, Vol. 47, No. 1, 1996, pp. 33-35.

31. D. V. M. Desai, S. S. Kumar, and K. C. Pillai, "Influence of Major Cations of Sea Water on the Desorption of ${ }^{137} \mathrm{Cs}$ from Marine Sediments," Journal of Radioanalytical and Nuclear Chemistry Letters, Vol. 187, 1994, pp. 197-205.

32. R. Apak, et al., "Sorptive Removal of Cesium-137 and Strontium-90 from Water by Unconventional Sorbents, 1: Usage of Bauxite Wastes (Red Mud)," Journal of Nuclear Science 
and Technology, Vol. 32, No. 10, 1995, pp. 1008-1017.

33. A. Eriksson, "Use of Chernobyl Field Data in Modeling Cesium Transfer to Grassland Crops," S-75007, Swedish University of Agri-Sciences.

34. O. Horak, K. Muech, and M. H. Gerzabek, Cs-137 Soil to Plant Transfer Factors Derived from Pot Experiments and Field Studies, OEFZS-4515, November 1989.

35. R. D. Lloyd, "Cesium-137 Half-Times in Humans," Health Physics, Vol. 25, No. 12, 1973, pp. 605-612.

36. M. A. Cryer and K. F. Baverstock, "Biological Half-Life of ${ }^{137} \mathrm{Cs}$ in Man," Health Physics, Vol. 23, No. 9, 1972, pp. 394-395.

37. R. C. Pendleton, C. W. Mays, R. D. Lloyd, B. W. Church, "A Trophic Level Effect on ${ }^{137} \mathrm{Cs}$ Concentration," Health Physics, Vol. 11, No. 12, 1965, pp. 1503-1510.

38. K. F. Eckerman, A. G. Wolbarst, and A. C. B. Richardson, Limiting Values of Radionuclide Intake and Air Concentration and Dose Conversion Factors for Inhalation, Submersion, and Ingestion, Federal Guidance Report No. 11, EPA-520/1-88-020, Oak Ridge National Laboratory, September 1988.

39. G. K. Svensson and K. Liden, "The Transport of ${ }^{137} \mathrm{Cs}$ from Lichen to Animal and Man," Health Physics, Vol. 11, No. 12, 1965, pp. 1393-1400.

40. K. Bunzl and W. Kracke, "Fallout ${ }^{239,240} \mathrm{Pu}$ and ${ }^{137} \mathrm{Cs}$ in Animal Livers Consumed by Man," Health Physics, Vol. 46, No. 2, 1984, pp. 466-470.

41. O. Musatovova and M. Vavrova, "Transfer of ${ }^{137} \mathrm{Cs}$ and ${ }^{90} \mathrm{Sr}$ to Some Animal Products in the Site of Previewed Nuclear Power Plant Construction," Isotopenpraxis, Vol. 27, No. 7, 1991, pp. 339-341. 


\section{Bibliography}

Ames, L. L. and D. Rai, Radionuclide Interactions with Soil and Rock Media, Vol. 1, EPA 520/6-78-007-a, U.S. Environmental Protection Agency, August 1978.

Catarrh, C. M., J. M. Hollander, I. Permian, Table of Isotopes, 6th Edition, John Wiley and Sons, Inc., 1967 , pp. 75 and 285.

Garner, R. John, Transfer of Radioactive Materials from the Terrestrial Environment to Animals and Man, CRC Press, 1972, pp. 11, 13, 25, 38, 42.

Miller, C. E., "Retention and Distribution of ${ }^{137} \mathrm{Cs}$ after Accidental Inhalation," Health Physics, 10, 1964, p. 1065.

Resnik, M. C., O. R. Lunt, and A. Wallace, "Cs, K, Sr, and Ca Transport in Two Different Plant Species," Soil Science 108 (1), 1969, p. 64.

Rogers, R. D. and S. E. Williams, "Vesicular Arbuscular Mycorrhiza: Influence on Plant Uptake of Cesium and Cobalt," Soil Biology Biochemistry, 18 (4), 1986, p. 371.

Sanders, C. L., R. H. Busch, J. E. Ballou, D. D. Mahlum (eds), Radionuclide Carcinogenesis, U.S. Atomic Energy Commission Office of Information Services, 1972, pp. 13 and 262.

Sheppard, M. I., D. I. Beals, D. H. Thibault, P. O'Connor, Soil Nuclide Distribution Coefficients and Their Statistical Distributions, AECL-8364, Atomic Energy of Canada, Limited, December 1984.

Weast, R. C. (ed), CRC Handbook of Chemistry and Physics, Boca Raton, Florida: CRC Press, 1977, 58th Edition, pp. B270-B354 (Table of Isotopes). 


\section{STRONTIUM-90}

\section{Introduction}

This chapter discusses the basic radiological, chemical, and physical characteristics of strontium-90 $\left.{ }^{90} \mathrm{Sr}\right)$ and examines how these characteristics affect the behavior of ${ }^{90} \mathrm{Sr}$ in various environmental media such as soils, water, plants, the atmosphere, and the human body. Also included are methods of ${ }^{90} \mathrm{Sr}$ production and waste and disposal data on ${ }^{90} \mathrm{Sr}$.

This chapter also describes potential difficulties in dealing with ${ }^{90} \mathrm{Sr}$. However, ${ }^{90} \mathrm{Sr}$ behavior and appropriate handling, storage, or disposal will vary depending on the waste form and the disposal site's geology, hydrology, and climate. Therefore, this chapter does not attempt to discuss the extent of a difficulty or appropriate solutions. Each disposal site facility design should consider and address the specific waste content and behavior under that site's particular circumstances. A radionuclide considered sensitive at one low-level radioactive waste (LLW) disposal facility may not be considered sensitive at another facility.

All strontium atoms contain 38 protons $(Z=38)$ and various numbers of neutrons (typically between 40 and 55 neutrons) within the atom's nucleus. There exists four stable forms of strontium; namely ${ }^{84} \mathrm{Sr}$, ${ }^{86} \mathrm{Sr},{ }^{87} \mathrm{Sr}$, and ${ }^{88} \mathrm{Sr}$, with ${ }^{88} \mathrm{Sr}$ being the most abundant isotope (82.6\% of naturally occurring strontium). All other strontium isotopes, including ${ }^{90} \mathrm{Sr}$, are radioactive. The radioactive isotopes of strontium are not a normal constituent of the natural background radiation, but are present in nature because of human activities.

The primary source of ${ }^{90} \mathrm{Sr}$ in the environment has been radioactive fallout from nuclear weapons testing and accidental releases (e.g., the Windscale accident ${ }^{1}$ in 1957 and the Chernobyl accident in 1986); however, radioactive releases from nuclear power plants, propulsion reactors (submarines), and intentional radioactive waste disposal in the oceans all contribute to the background inventory of manmade radioactive isotopes, including ${ }^{90} \mathrm{Sr}$.

Since ${ }^{90} \mathrm{Sr}$ is not a normal constituent of the natural background radioactivity, it should not be present in seawater; however, it is known that at least $5.3 \times 10^{17}$ becquerels ( 1 becquerel, or simply $1 \mathrm{~Bq}$, is defined as 1 disintegration per second; 1 curie, or $1 \mathrm{Ci}$, is defined as $\left.3.7 \times 10^{10} \mathrm{~Bq}\right)^{2}$ or equivalently $1.4 \times 10^{7} \mathrm{Ci}$ of ${ }^{90} \mathrm{Sr}$ have been deposited in the world's oceans through 1979 , primarily from radioactive fallout and intentional discharges. ${ }^{1}$ The natural radioactivity contained in ocean waters is 13 or $14 \mathrm{~Bq} / \mathrm{kg}$, of which $95 \%$ comes from potassium- $40 .{ }^{1,2}$ The natural radioactivity contained in the lower levels of the atmosphere is $\sim 3.7 \mathrm{~Bq} / \mathrm{m}^{3}$, essentially due to radon gas. The average ${ }^{90} \mathrm{Sr}$ concentration usually contributes less than $0.003 \%$ of the total radioactivity found in ocean water, or 0.0004 to $0.006 \mathrm{~Bq} / \mathrm{liter}$ $\left(7.4 \times 10^{-17}\right.$ to $1.1 \times 10^{-15} \mathrm{~g} /$ liter $)$. Stable forms of strontium are also present in sea water to an average concentration of $0.008 \mathrm{~g} /$ liter of water. ${ }^{1}$ Since calcium belongs to the same chemical family as strontium, it also competes with ${ }^{90} \mathrm{Sr}$ and effectively reduces its uptake by marine organisms. Consequently, every ${ }^{90} \mathrm{Sr}$ atom in the ocean is surrounded by and diluted by stable atoms of strontium and chemically similar atoms of calcium $(0.41 \mathrm{~g} /$ liter $){ }^{1}$ 
The average seawater concentrations of ${ }^{90} \mathrm{Sr}(\sim 0.0005 \mathrm{~Bq} / \mathrm{liter})$ are much smaller than the maximum permissible concentrations of ${ }^{90} \mathrm{Sr}$ in seawater $(\sim 1,300 \mathrm{~Bq} /$ liter $)$ (Reference 1, p. 459). Therefore, the observed ${ }^{90} \mathrm{Sr}$ concentrations in ocean water are not considered dangerous but are evidence of man's impact on the environment.

${ }^{90} \mathrm{Sr}$ has been released to the earth's atmosphere from the testing of nuclear weapons. About $5 \%$ of the total radioactivity from a nuclear explosion is due to ${ }^{90} \mathrm{Sr}$ and its daughter nuclide yttrium $\left({ }^{90} \mathrm{Y}\right) .{ }^{1}$ The amount of ${ }^{90} \mathrm{Sr}$ released to the atmosphere before 1971 from radioactive debris was $5.74 \times 10^{17} \mathrm{~Bq}$, and of this material about $97 \%$ was deposited on the earth's surface, $\sim 73 \%$ in the northern hemisphere, with only $1.85 \times 10^{16} \mathrm{~Bq}$ remaining in the stratosphere. The ratio of the amount of ${ }^{90} \mathrm{Sr}$ and ${ }^{137} \mathrm{Cs}$ that exists in the air and land due to nuclear weapons testing is nearly constant at 16 atoms of ${ }^{90} \mathrm{Sr}$ to 10 atoms of ${ }^{137} \mathrm{Cs}^{2}$

\section{Radiological Characteristics}

${ }^{90} \mathrm{Sr}$ has a half-life $\left(\mathrm{T}_{1 / 2}\right)$ of about 29 years or equivalently $\mathrm{T}_{1 / 2} \approx 10,600$ days (note: the reported half-life of ${ }^{90} \mathrm{Sr}$ varies from 27.7 to 28.4 years $^{2,3,4,5}$ to 29.1 years ${ }^{2}$ ). When it undergoes radioactive decay, the ${ }^{90} \mathrm{Sr}$ nucleus decays to yttrium-90 $\left({ }^{90} \mathrm{Y}\right.$ ) with the emission of a $546-\mathrm{keV}$ (thousand electron volt) maximum energy beta particle ( $\beta$, a negative electron emitted from the nucleus), with no accompanying gamma-ray. After decaying to yttrium, the ${ }^{90} \mathrm{Y}$ nucleus usually decays $\left(\mathrm{T}_{1 / 2} \approx 64\right.$ hours) to zirconium-90 with the e mission of a $2,284-\mathrm{keV}$ maximum energy beta particle. However, in a very small number of cases $(\sim 0.02 \%)$, the ${ }^{90} \mathrm{Y}$ nucleus emits a $523-\mathrm{keV}$ maximum energy beta particle and produces a 1,750 keV gamma-ray. ${ }^{3,6,7}$

Table 7-1 lists the maximum ranges for $546-\mathrm{keV}$ and $2,284-\mathrm{keV}$ beta particles in various substances. The average beta particle energy produced from ${ }^{90} \mathrm{Sr}$ decay is $196 \mathrm{keV}^{3}$ and has a range of about one-fourth the range shown for the $546-\mathrm{keV}$ beta particle. The average beta particle energy produced from the daughter nuclide $\left({ }^{90} \mathrm{Y}\right)$ is $939 \mathrm{keV} .{ }^{2}$ The average beta particle range in human tissue is of the order of 2 to 13 millimeters. Table 7-2 compares the radiotoxicity of several important radionuclides, and shows ${ }^{90} \mathrm{Sr}$ in the "high" or group 2 radiotoxicity category.

The two possible decay schemes for ${ }^{90} \mathrm{Sr}->^{90} \mathrm{Y}$, showing the emission of beta $\left(\beta^{-}\right)$particles are illustrated in the following nuclear transformations. Also shown are the maximum particle energies, event probabilities, and isotope half-lives. The first decay scheme, Equation (1a), is the most likely sequence, occurring approximately $99.98 \%$ of the time. In only $\sim 0.02 \%$ of all ${ }^{90} \mathrm{Y}$ daughter decays, the second sequence, Equation ( $1 \mathrm{~b})$, occurs with the emission of a beta particle and a gamma-ray ( $\gamma$-ray). Consequently, in nearly all cases, the decay sequence of ${ }^{90} \mathrm{Sr}$ and its daughter nuclide ${ }^{90} \mathrm{Y}$ result in the emission of only beta particles.

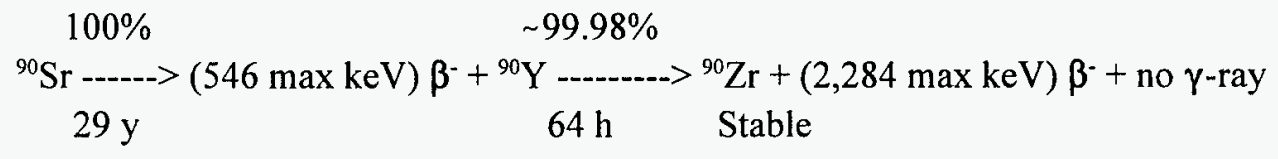




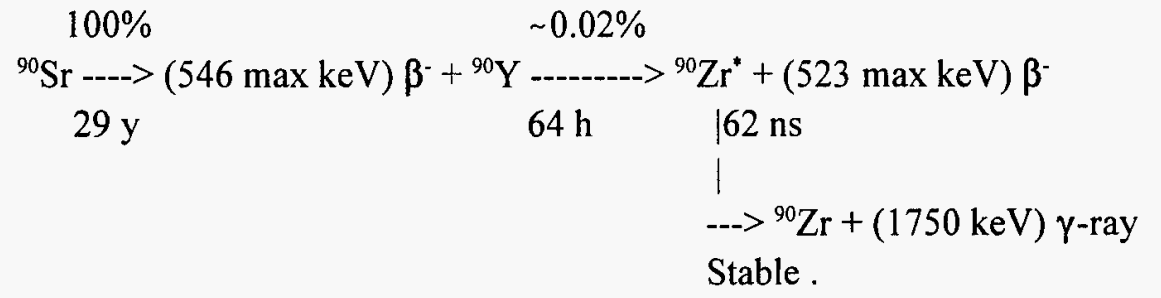

The beta particle energies shown in Equations ( $1 \mathrm{a})$ and (1b) above represent maximum particle energies with a continuous range of possible energies between zero and the maximum possible value usually occurring, with the simultaneous emission of an antineutrino particle (not shown) carrying off the energy difference. The decay event probabilities are shown as percentage numbers above the arrows and the nuclide half-lives are shown below the arrows.

Table 7-1. Comparison of the calculated maximum ranges for 546-keV and 2,284-keV energy beta particles emitted from ${ }^{90} \mathrm{Sr}$ and strontium daughter $\left({ }^{90} \mathrm{Y}\right)$ decay for various materials.

\begin{tabular}{lcc}
\hline \multicolumn{1}{c}{ Material (description) } & $\begin{array}{c}\text { Maximum range for a } \\
546-\mathrm{kev} \beta \\
(\mathrm{mm})^{\mathrm{a}}\end{array}$ & $\begin{array}{c}\text { Maximum range for a } \\
2,284-\mathrm{kev} \beta^{-} \\
(\mathrm{mm})^{\mathrm{a}}\end{array}$ \\
\hline Air (1 atmosphere pressure) & $1,500.0$ & $9,700.0$ \\
Water & 1.8 & 12.0 \\
Plastic (Lucite) & 1.4 & 9.1 \\
Concrete & 0.8 & 6.4 \\
$\mathrm{Al}$ (aluminum) or glass & 0.7 & 5.0 \\
$\mathrm{Fe}$ (iron) & 0.2 & 1.5 \\
$\mathrm{~Pb}$ (lead) & 0.14 & 1.0
\end{tabular}

a. Calculated from the maximum beta particle range data shown on p. 122 of Radiological Health Handbook (Reference 4) or p. 266 of Radioisotopes in Industry (Reference 6).

Table 7-2. Comparison of the radiotoxicity of several important radionuclides.

\begin{tabular}{lll}
\multicolumn{2}{c}{ Radiotoxicity } & \multicolumn{1}{c}{ Species } \\
\hline Very high & Group 1 & ${ }^{241} \mathrm{Pu},{ }^{242} \mathrm{Cm},{ }^{241} \mathrm{Am},{ }^{237} \mathrm{~Np}$ \\
High & Group 2 & ${ }^{60} \mathrm{Co},{ }^{90} \mathrm{Sr},{ }^{94} \mathrm{Nb}$ \\
Moderate & Group 3 & ${ }^{14} \mathrm{C},{ }^{63} \mathrm{Ni},{ }^{137} \mathrm{Cs},{ }^{90} \mathrm{Y}$ \\
Low & Group 4 & ${ }^{3} \mathrm{H},{ }^{59} \mathrm{Ni},{ }^{99 \mathrm{~m}} \mathrm{Tc},{ }^{99} \mathrm{Tc},{ }^{129} \mathrm{I}$
\end{tabular}

Source: Obtained from Appendix 2 of Applied Radiobiology and Radiation Protection (Reference 2). Similar results are shown in Radionuclide Tracers: Their Detection and Measurement. ${ }^{8}$ 
A major portion of the beta particle energy occurs with the decay of the ${ }^{90} \mathrm{Y}$ nucleus; because of the short half-life of ${ }^{90} \mathrm{Y}$, these subsequent radiations can be associated with the parent nucleus $\left({ }^{90} \mathrm{Sr}\right)$, unless

${ }^{90} \mathrm{Y}$ is chemically separated from the ${ }^{90} \mathrm{Sr}$ source material. Approximately $99.98 \%$ of all ${ }^{90} \mathrm{Y}$ decays yield a $523-\mathrm{keV}$ maximum (or $188-\mathrm{keV}$ average) energy beta with no gamma ray. Only $\sim 0.02 \%$ of decays produce a $2,284-\mathrm{keV}$ beta particle and a $1,750-\mathrm{keV}$ gamma. ${ }^{3}$ The $1750-\mathrm{keV}$ gamma-ray is considered weak due to its very low probability. This decay possibility is shown in Equation (1b). The interesting aspect of the ${ }^{90} \mathrm{Sr}$ and ${ }^{90} \mathrm{Y}$ decay chain is the nearly complete lack of any gamma-ray emission. ${ }^{90} \mathrm{Sr}$ decays produce a continuous energy spectrum of beta particles only. Note that decay events that produce a beta particle also produce an antineutrino particle. Since neutrinos (and antineutrinos) almost never interact with matter, they are not radiologically important. Therefore, the antineutrino particle is usually not shown in the standard decay equations. Since the released beta particle is usually emitted with an energy less than the maximum theoretical value, the antineutrino particle carries off the energy difference. Hence, beta particles are emitted with a continuous energy spectrum that varies from the maximum theoretical value down to zero. In summary, a beta particle - but no gamma-rays-is directly produced from ${ }^{90} \mathrm{Sr}$ decay. The primary beta particle has a maximum energy of $546 \mathrm{keV}$, and the average energy of the entire beta particle spectrum is $196 \mathrm{keV}$.

Table 7-3 illustrates how the maximum and average beta particle emission energies associated with ${ }^{90} \mathrm{Sr}$ decay compared to the emissions of other beta emitters. Since a $70-\mathrm{keV}$ beta can penetrate the $0.07 \mathrm{~mm}$ of human skin, ${ }^{4}$ the maximum and average energy beta particles associated with ${ }^{90} \mathrm{Sr}$ decay can be radiologically hazardous. In fact, the highest energy beta particles $(546 \mathrm{keV})$ from ${ }^{90} \mathrm{Sr}$ can penetrate a maximum distance of about $2 \mathrm{~mm}$ into an unprotected human body ( $50 \%$ beta attenuation in skin at $0.6 \mathrm{~mm}$ ), and the 2,284-keV maximum energy beta particles from ${ }^{90} \mathrm{Y}$ decay can penetrate a maximum distance of $\sim 13 \mathrm{~mm}$ (i.e., $\sim 1 / 2$ inch). Although the beta particles from ${ }^{90} \mathrm{Sr}$ decay can be hazardous, simple shielding techniques (e.g., a few inches of water or other common materials—see Table 7-1) can adequately protect against this radiation.

\section{Chemical and Physical Characteristics}

Based on chemical family similarities, strontium mimics calcium, which in turn is an essential element important to living organisms. Both strontium and calcium are readily absorbed by plants and animals. Strontium, being a chemical impostor of calcium, accumulates in the bone and bone marrow of animals. Another important feature of strontium is its possible association with DNA. DNA is known to chemically bond with calcium and magnesium. Since strontium is in the same chemical family as calcium and magnesium, it also can chemically link with DNA or other enzymes. If ${ }^{90} \mathrm{Sr}$ is associated with these molecules at the time that it decays, then the ejected beta particle can cause molecular damage to DNA.

Strontium belongs to the alkaline-earth metals group and, therefore, behaves like beryllium, magnesium, calcium, barium, and radium, which are all in the same chemical family. Strontium is the least abundant of the alkaline-earth metals, composing only $\sim 0.042 \%$ of the earth's crust. In addition, the decay product of ${ }^{90} \mathrm{Sr}$, namely yttrium-90 $\left({ }^{90} \mathrm{Y}\right)$, is a Group IIIB element and behaves like scandium, lanthanum, and actinium, as well as the lanthanum- and actinium-series elements. Strontium is chemically reactive; although not as reactive as the alkali metals (e.g., cesium), it reacts quickly with water to form hydroxides $\left(\mathrm{Sr}[\mathrm{OH}]_{2}\right)$. All of the strontium compounds are soluble and generally move 
Table 7-3. Average and maximum kinetic energies of beta particles released during decay of several radionuclides.

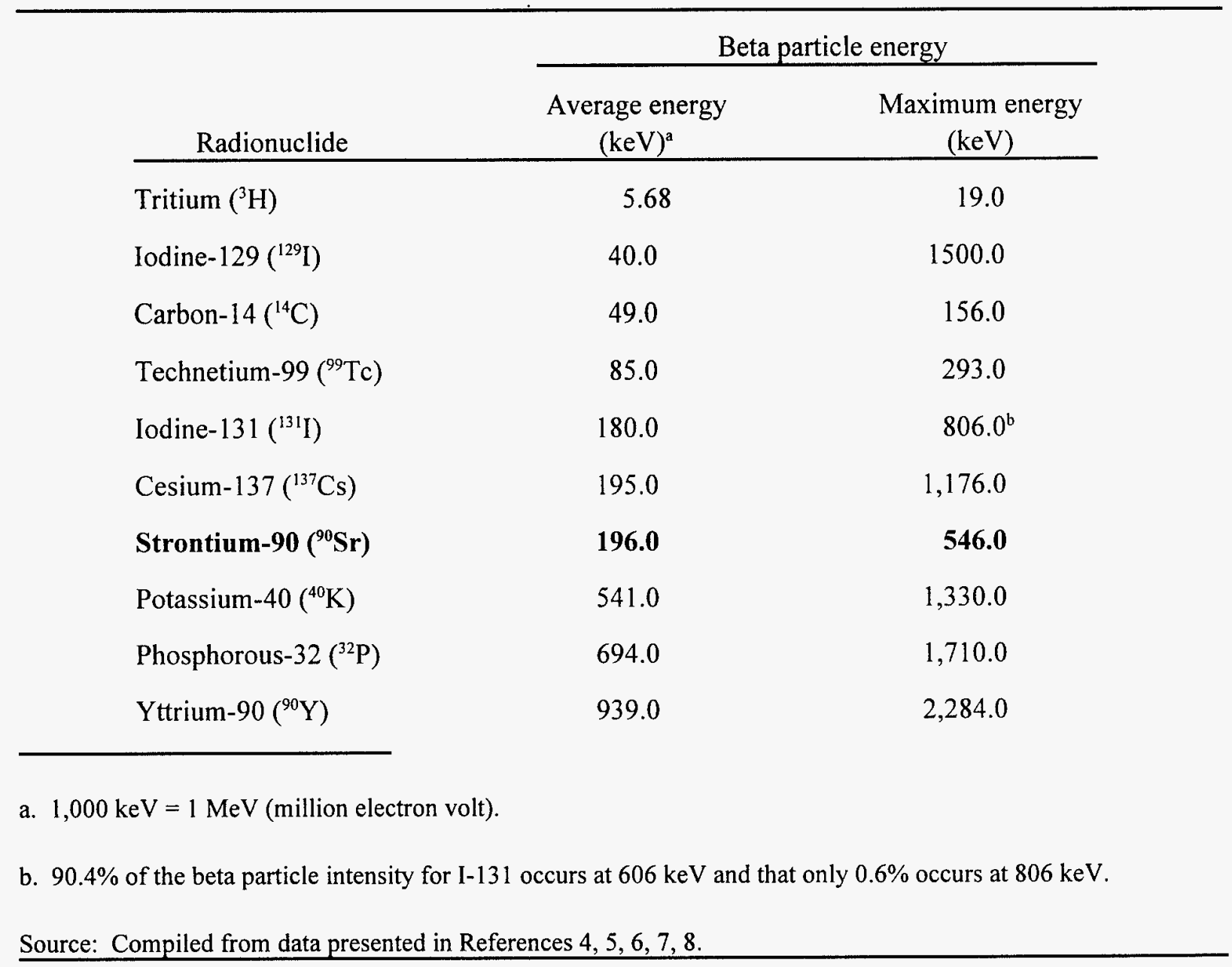

with the water released from a nuclear reactor, or follow the atmospheric water cycle following a nuclear weapons explosion, eventually falling to earth with rainwater. The hydroxide, fluoride, and sulfate compounds are less soluble than the other strontium compounds. Because of the half-life of ${ }^{90} \mathrm{Sr}$, it generally remains in the environment for a significant enough length of time to be considered a ground contamination hazard.

Some of the most important physical properties of strontium are shown in Table 7-4. Strontium is divalent (i.e., having a valence of 2 ) in all its compounds. Strontium can form complex ions but to a lesser degree than, for example, calcium -also an alkaline-earth metal. Strontium reacts vigorously with hydrogen, completely combining with it at temperatures of a few hundred degrees Celsius $\left({ }^{\circ} \mathrm{C}\right)$. 
Table 7-4. Physical properties of strontium.

\begin{tabular}{lc}
\multicolumn{1}{c}{ Physical property (units) } & Strontium data \\
\hline Melting point (degrees Kelvin, K) & 977.0 \\
Boiling point (degrees Kelvin, K) & 1911.0 \\
Heat of fusion (cal $/ \mathrm{g}$ ) & $\mathrm{b}$ \\
Heat of vaporization (cal/g) & 447.0 \\
Solid density $\left(\mathrm{g} / \mathrm{cm}^{3}\right)$ & 2.6 \\
Liquid density $\left(\mathrm{g} / \mathrm{cm}^{3}\right)$ & $\mathrm{b}$ \\
Oxidation potential $(\mathrm{V})$ & 2.89 \\
Ionization potential $(\mathrm{eV})$ & 5.69 \\
Work function $(\mathrm{eV})$ & $\mathrm{b}$ \\
Crystal form & $\alpha$ - face-centered-cubic \\
& $\beta$ - body-centered-cubic
\end{tabular}

a. Note that zero degrees kelvin $(0 \mathrm{~K})$ equals $-273.15^{\circ} \mathrm{C}$ or $-459.67^{\circ} \mathrm{F}$.

b. Data not available.

c. The transition between the $\alpha$ and $\beta$ forms takes place at $830 \mathrm{~K}$.

Source: Obtained from References $9,10,11,12,13$.

All of the alkaline-earth metals are highly electropositive and react with most other elements directly. The reactivities of the alkali metals toward air and water increase with increasing atomic mass and number, as does reactivity with hydrogen. Strontium oxide, $\mathrm{SrO}$, reacts readily with water to form the hydroxide, $\operatorname{Sr}(\mathrm{OH})_{2}$. The oxide can also absorb carbon dioxide from the air. Strontium hydroxide is soluble in water and is a strong base. The colors of the various salts of strontium are dominated by the negative ions (anions). Strontium reacts with carbon, at high temperatures, to form the carbide $\mathrm{SrC}_{2}$. Strontium also reacts with other elements, such as boron, silicon, arsenic, and sulfur, to form binary compounds-in each case the chemical bond is ionic (i.e., strontium tends to give up electrons to these other atoms, and the resulting molecule is held together by opposite charges rather than by shared electrons in covalent bonding).

\section{Strontium-90 Production}

The primary means of producing ${ }^{90} \mathrm{Sr}$ is by nuclear fission and the main source of ${ }^{90} \mathrm{Sr}$ is from fission product recovery. Figure 7-1 shows the fission product yield distribution for thermal neutron fission of ${ }^{235} \mathrm{U}$. This information was obtained from the fission yield data from the ORIGEN2 ${ }^{14,15}$ computer code. The curve shown in Figure 7-1 between mass numbers 70 and 160 is typical of other published binary fission yield distributions, and the fission yield data for fission of uranium-233 $\left({ }^{233} \mathrm{U}\right)$ and plutonium-239 $\left({ }^{239} \mathrm{Pu}\right)$ are also very similar. The cumulative fission yield of ${ }^{90} \mathrm{Sr}$ from fission of ${ }^{235} \mathrm{U}$ atoms is approximately $5.9 \%$. 


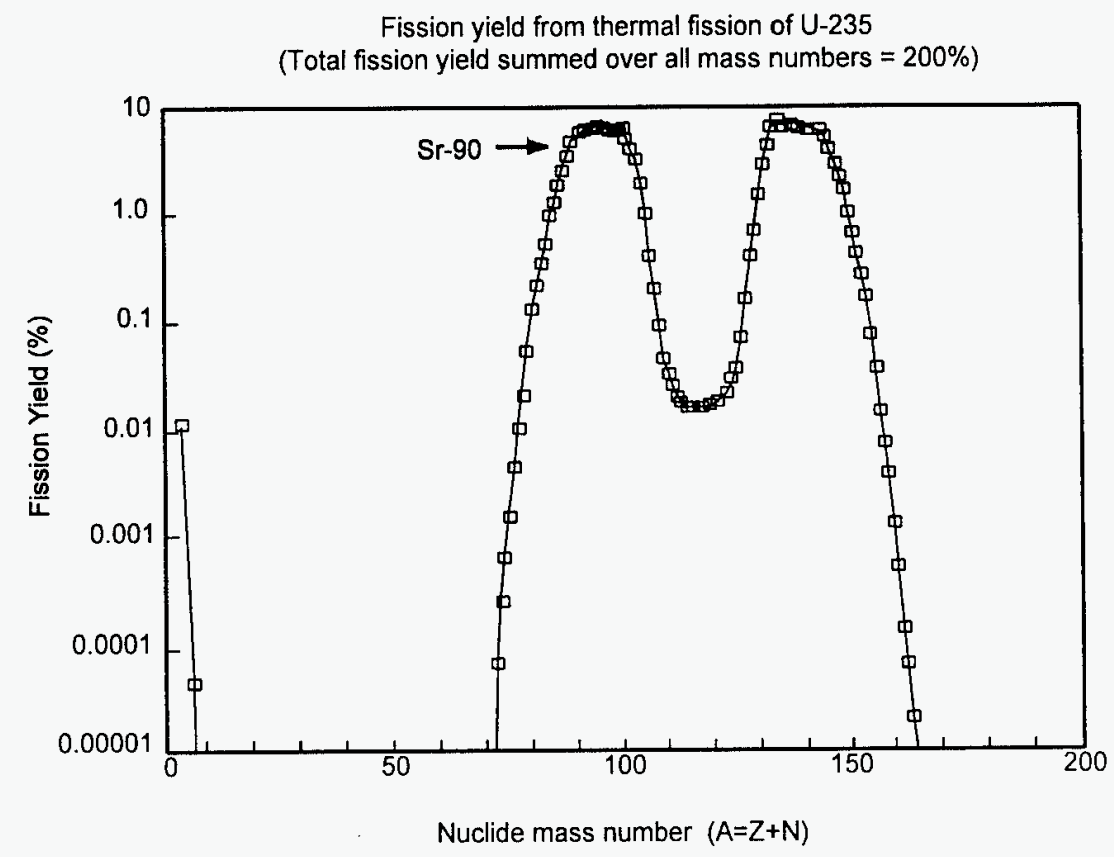

Figure 7-1. Fission product yield curve for thermal fission of ${ }^{235} \mathrm{U}$, showing ${ }^{90} \mathrm{Sr}$ cumulative yield.

Since ${ }^{90} \mathrm{Sr}$ atoms have a very small thermal neutron absorption cross-section (i.e., $\sigma_{\mathrm{a}}=0.014$ barns $=0.014 \times 10^{-24} \mathrm{~cm}^{2}$ ) compared with most other atoms present with the nuclear fuel and fission products; and since ${ }^{90} \mathrm{Sr}$ has a half-life of 29 years, then almost all of the ${ }^{90} \mathrm{Sr}$ atoms produced in a reactor are present when the nuclear fuel is extracted from the reactor. In other words, the ${ }^{90} \mathrm{Sr}$ inventory for a nuclear reactor increases linearly with fuel burnup and does not significantly decrease during the inreactor portion of the fuel cycle. The only effective means of decreasing the ${ }^{90} \mathrm{Sr}$ inventory is through radioactive decay - in other words, time.

The amounts of fission products (including the ${ }^{90} \mathrm{Sr}$ inventory) in a reactor core depends upon the power and operating history of the reactor. As calculated by ORIGEN2, the ${ }^{90} \mathrm{Sr}$ inventory for a typical $100 \mathrm{MTU}$ (metric tons of uranium) reactor operated at a thermal power of $3050 \mathrm{MW}$ (million watts) for a total irradiation burnup of 33,400 MWtD/MTU (megawatt thermal days per metric ton uranium), or approximately 3 years of irradiation at full power, is 7.5 million $\mathrm{Ci}$ (or $55 \mathrm{~kg}$ ). Other references ${ }^{16,17}$ report reactor core inventories of ${ }^{90} \mathrm{Sr}$ of 4.0 million $\mathrm{Ci}$. For this chapter, the larger result $(7.5$ million $\mathrm{Ci})$ is assumed.

The reactor core inventory of ${ }^{90} \mathrm{Sr}$ represents only $0.05 \%$ of the totạl fission product mass inventory that exists at the end of the fuel irradiation history, or $0.055 \%$ of the initial uranium mass. However, after 100 years of decay, the remaining ${ }^{90} \mathrm{Sr}$ inventory $(0.70$ million $\mathrm{Ci})$ represents $20 \%$ of the total remaining fission product inventory. Table 7-5 shows the time-dependent inventories of ${ }^{90} \mathrm{Sr}$, total strontium isotopes, and total fission product inventory for a typical light-water reactor (LWR). From Table $7-5,{ }^{90} \mathrm{Sr}$ accounts for $3.7 \%$ of the total fission product inventory after 1 year of decay, and about 
$19 \%$ of the radioactive inventory remaining after 10 years of decay. After 5 years of decay, the only radioactive isotope of strontium remaining in significant quantities is ${ }^{90} \mathrm{Sr}$.

Table 7-5. Strontium and total radioactive fission product activities calculated as a function of decay time following a 3-year irradiation in a 3,050-MW thermal power LWR, producing a total fuel burnup of 33,400 MWtD/MTU.

Reactor core inventory (millions of $\mathrm{Ci}$ )

\begin{tabular}{|c|c|c|c|c|c|c|}
\hline \multirow[b]{2}{*}{ Species } & \multirow{2}{*}{$\begin{array}{c}\text { Completion } \\
\text { of fuel } \\
\text { irradiation } \\
\mathrm{T}_{0} \\
\end{array}$} & \multicolumn{5}{|c|}{ Decay time following reactor irradiation } \\
\hline & & $\mathrm{T}_{0}+1 \mathrm{yr}$ & $\mathrm{T}_{0}+5 \mathrm{yr}$ & $\mathrm{T}_{0}+10 \mathrm{yr}$ & $\mathrm{T}_{0}+50 \mathrm{yr}$ & $\mathrm{T}_{0}+100 \mathrm{yr}$ \\
\hline${ }^{90} \mathrm{Sr}$ & 7.51 & 7.33 & 6.67 & 5.92 & 2.28 & 0.70 \\
\hline All $\mathrm{Sr}$ isotopes & 734.0 & 7.81 & 6.67 & 5.92 & 2.28 & 0.70 \\
\hline All fission products & $15,000.0$ & 200.0 & 46.4 & $31.6^{\circ}$ & 11.3 & 3.51 \\
\hline
\end{tabular}

Note: Results are based on an ORIGEN2 calculation of a 100-MTU pressurized water reactor (PWR).

${ }^{90} \mathrm{Sr}$ has been available from the Pacific Northwest Laboratory located at the U.S. Department of Energy (DOE) facility in Hanford, Washington. Hanford's inventory of nuclides, including ${ }^{90} \mathrm{Sr}$, represents one of the world's only large sources of this nuclide. Typically, ${ }^{90} \mathrm{Sr}$ is chemically combined with fluorine to produce strontium-fluoride $\left({ }^{90} \mathrm{SrF}_{2}\right)$ or with chlorine $\left(\mathrm{Cl}_{2}\right)$ to produce strontium-chloride $\left({ }^{90} \mathrm{SrCl}_{2}\right)$. This material is then encapsulated in stainless steel or placed in solution, depending upon the desired application. Encapsulated forms of ${ }^{90} \mathrm{Sr}$ can be used in medical therapy work (e.g., ${ }^{90} \mathrm{Sr}$ eye applicators) or industrial applications (such as radionuclide thickness gauges). Direct sale of stored strontium fluoride sources is possible, as well as reencapsulation into smaller capsules. Encapsulated materials can be reused for other applications. Depending upon the quantity of radioactive material existing in the capsules after use, this material might be recycled or disposed as LLW material.

\section{Waste and Disposal Data on Strontium-90}

This section discusses the types of activities that generate ${ }^{90} \mathrm{Sr} L L W$, waste types and forms that contain ${ }^{90} \mathrm{Sr}$, and disposal data on ${ }^{90} \mathrm{Sr}$.

\section{Nuclear Reactors}

The quantity of ${ }^{90} \mathrm{Sr}$ generated in a nuclear reactor increases linearly with burnup; that is, double the fuel burnup and the ${ }^{90} \mathrm{Sr}$ inventory doubles. The only process that effectively decreases the ${ }^{90} \mathrm{Sr}$ inventory is radioactive decay. Since ${ }^{90} \mathrm{Sr}$ has a half-life of 29 years, almost all ${ }^{90} \mathrm{Sr}$ generated within a reactor will be present at the end of the fuel irradiation cycle. Although produced in nuclear reactors, the primary 
source of ${ }^{90} \mathrm{Sr}$ is in the high-level radioactive aqueous waste streams generated from spent fuel processing of the nuclear fuel. The ${ }^{90} \mathrm{Sr}$ LLW quantities are small compared with the quantity of ${ }^{90} \mathrm{Sr}$ existing in spent fuel or with high-level radioactive waste material.

The largest source of strontium, and the largest potential source of waste material, is the inventory of ${ }^{90} \mathrm{Sr}$ stored in commercial spent nuclear fuel. Nearly all of the ${ }^{90} \mathrm{Sr}$ atoms produced in a LWR are contained within the $\mathrm{UO}_{2}$ fuel rods. The projected inventory of ${ }^{90} \mathrm{Sr}$ produced from LWR fuel is $73,000 \mathrm{Ci} /$ metric ton of fuel (computed at 1 year of decay). Nevertheless, the ${ }^{90} \mathrm{Sr}$ that does appear in the reactor coolant system must be removed. Based on information presented in Radioactive Waste Disposal, ${ }^{18}{ }^{90} \mathrm{Sr}$ composes about $0.00035 \%$ of the nongaseous fission product inventory of reactor coolant water, or equivalently $4.42 \times 10^{-5} \mu \mathrm{Ci} / \mathrm{cm}^{3}$ (assuming $1 \%$ failed fuel rods). In comparison, the primary coolant concentrations for ${ }^{131} \mathrm{I}$ and ${ }^{137} \mathrm{Cs}$ are, respectively, $1.6 \mu \mathrm{Ci} / \mathrm{cm}^{3}$ and $0.43 \mu \mathrm{Ci} / \mathrm{cm}^{3}$. The radionuclide concentrations of ${ }^{131} \mathrm{I}$ and ${ }^{137} \mathrm{Cs}$ in the primary coolant water of a reactor are much higher than that of ${ }^{90} \mathrm{Sr}$, and, therefore, almost all of the ${ }^{90} \mathrm{Sr}$ produced as a result of fission events is trapped inside the $\mathrm{UO}_{2}$ fuel. Only a small quantity of ${ }^{90} \mathrm{Sr}$ escapes the fuel and enters the reactor coolant system.

Radionuclides found in the primary coolant systems of boiling water reactors (BWRs) and PWRs are removed by liquid waste treatment systems. Each reactor type provides a purification system that removes fission products from the reactor coolant water. In BWRs, this system is referred to as the reactor water cleanup system. In PWRs, the coolant purification and chemical adjustment (e.g., boron concentration for neutron control) is handled by the chemical and volume control system (i.e., the reactor coolant cleanup and boron recovery subsystems. ${ }^{18}$ The liquid radioactive waste treatment systems also handle the miscellaneous radioactive liquids generated by the plant operation as well as those produced as a result of the coolant purification systems. Since the concentration of ${ }^{90} \mathrm{Sr}$ in the primary coolant system of a LWR is small compared with most other fission products (e.g., ${ }^{137} \mathrm{Cs}$ ), the water clean up system resins, filters, rags, etc., used to clean up the primary coolant water, leaks, or spills will be contaminated with many different radionuclides at concentrations higher than ${ }^{90} \mathrm{Sr}$.

The primary LLW types produced at LWRs include both wet and dry wastes, such as spent ionexchange resins, filter sludges, filter cartridges, evaporator bottoms, compactible trash, noncompactible trash, irradiated components, ashes produced from the incineration of combustible materials, contaminated detergents or solvents, organic liquids such as lubricating oils or greases, miscellaneous effluent concentrates including boron effluent concentrates, and discarded contaminated equipment or tools. Again, most of these waste types contain small amounts of ${ }^{90} \mathrm{Sr}$; in most cases, however, other radionuclides are usually present in much higher concentrations, and these other radionuclides usually determine the ultimate classification of this waste material (e.g., Class A, B, C, or greater-than-Class C).

Most of the ${ }^{90} \mathrm{Sr}$ that exists is trapped inside the spent $\mathrm{UO}_{2}$ fuel in complex chemical compounds. Eventually this material will have to be processed and stored or disposed of. Current technology suggests that possible waste forms for strontium include borosilicate glasses, concrete, or calcinated compounds (high-temperature oxidized compounds containing calcium-chemically similar to strontium).$^{18}$ Many advanced waste forms containing strontium waste include glass-ceramics, sintered glass composites (e.g., mixing calcine and glass together at high temperature and pressure) as well as other multibarrier materials. Studies have evaluated Savannah River Site high-level radioactive waste that incorporated ${ }^{90} \mathrm{Sr}$ with concrete. The results of these investigations include data on strontium leachability from Portland-type cements with concrete composites with alumina and sodium nitrate. ${ }^{18}$ 
Of the LLW generated today, approximately $64 \%$ of the volume and $70 \%$ of the activity are generated as a result of nuclear power activities or supporting fuel cycle operations. Therefore, the amount of LLW generated at institutional and industrial facilities is relatively small compared to those generated as a result of nuclear power operations. Most of the LLW produced at LWRs contain some ${ }^{90} \mathrm{Sr}$; however, other radionuclides (e.g., ${ }^{137} \mathrm{Cs}$ ) are usually more prevalent and generally determine the waste characterization. Nearly all of the ${ }^{90} \mathrm{Sr}$ produced at nuclear power reactors remains trapped with the spent fuel.

\section{Medical, Academic Institutions, and Commercial Strontium-90 Waste}

LLW not generated during a fuel cycle is often referred to as industrial or institutional wastes. Approximately $36 \%$ of the total volume of all LLW generated today, or $30 \%$ of the total activity, are produced as a result of industrial applications. Of these wastes, however, only a very small fraction is due to ${ }^{90} \mathrm{Sr}$ or ${ }^{90} \mathrm{Y}$ inventories. Most LLW results from other radionuclides (e.g., cobalt-60, cesium-137, technetium-99, or combinations of radionuclides).

${ }^{90} \mathrm{Sr}$ can be recovered from high-level radioactive waste for eventual separate disposal or used in industrial or medical applications. A large inventory of ${ }^{90} \mathrm{Sr}$ exists at the Hanford facility, which also supports a full range of radioisotope applications involving medical, research, and commercial uses.

Medical applications of ${ }^{90} \mathrm{Sr}$ have included the treatment of some diseases of the eye and a few skin diseases. ${ }^{6}$ For example, ${ }^{90} \mathrm{Sr}$ eye applicators are used for the treatment of pterygium, a superficial eye condition. ${ }^{19}$ The quantity of ${ }^{90} \mathrm{Sr}$ source material that exists in medical, academic, or commercial facilities is not known but is considered to be insignificant compared with the large quantity of ${ }^{90} \mathrm{Sr}$ that exists at nuclear reactors or military and national laboratory facilities. Due to its long radiological and biological half-lives in the body, ${ }^{90} \mathrm{Sr}$ has not been used for many diagnostic or inter-body studies. However, radioactive strontium has been used to investigate bone metabolism. ${ }^{20}$ There has also been some limited use of this isotope for beta-therapy irradiation (i.e., for irradiation therapy of the skin).

In the early days of irradiation therapy, radioisotopes had distinct advantages over electrically produced radiation in that they provided very stable beams of ionizing radiation. While nearly all of these units used either ${ }^{137} \mathrm{Cs}$ or ${ }^{60} \mathrm{Co}$ as the radioactive source, one unique unit used ${ }^{90} \mathrm{Sr}^{20}$ This unit, located in Addenbrooke's Hospital in Cambridge, England, was used primarily to irradiate the skin, due to its almost pure beta-ray spectrum. The half-life of ${ }^{90} \mathrm{Sr}$ made it an ideal source for this therapy.

Injection of ${ }^{90} \mathrm{Sr}$ for either therapy or diagnosis was not used because of its half-life ( $29 \mathrm{y}$ ) plus its affinity to be fixed in the bone tissues due to its chemical similarity with calcium. Although $95 \%$ of ingested ${ }^{90} \mathrm{Sr}$ is typically excreted from the body within a few weeks, the remaining $5 \%$ is fixed in the bones, representing a long-term source of internal radiation to the bone tissue. ${ }^{20}$

Many different chemical forms of strontium have been used in radioactive source capsules; for instance, strontium-fluoride $\left({ }^{90} \mathrm{SrF}_{2}\right)$, strontium-chloride $\left({ }^{90} \mathrm{SrCl}_{2}\right)$ in solution with hydrogen-chloride $(\mathrm{HCl})$, and strontium-nitrite $\left(\mathrm{Sr}\left[\mathrm{NO}_{3}\right]_{2}\right){ }^{21}$ All of these chemical compounds can be expected to exist as a possible waste form after the source capsules' useful life. 
${ }^{90} \mathrm{Sr}$ has been used in many commercial applications. The chemical form of ${ }^{90} \mathrm{Sr}$ varies depending upon the application. For example, strontium-titanate, a refractory substance, has been used in thermoelectric generators (e.g., navigational lights, buoys and remote light houses, arctic weather stations, and power supplies for space vehicles). Smaller thermoelectric generators sometimes use strontium-fluoride instead of strontium-titanate. ${ }^{16}$ In either case, thermocouples are connected in series to form a thermopile and the decay of ${ }^{90} \mathrm{Sr}$ produces the heat that generates the electricity. Radiation sources using $\mathrm{SrTiO}_{3}$ pellets have been used, as well as strontium-sulfate $\left(\mathrm{SrSO}_{4}\right)$ and strontium-carbonate $\left(\mathrm{SrCO}_{3}\right) .{ }^{90} \mathrm{Sr}$ has been used in medical applicators (e.g., sources sealed in steel and aluminum). It also has been used as a beta standard source (e.g., a standard source bounded within a silver disc or foil) used for calibrating liquid counters, or in a chloride solution with $\mathrm{HCl}$ for standardization of $4 \pi$ counting. All of these chemical forms of ${ }^{90} \mathrm{Sr}$ would exist as potential waste forms after the useful life of the product. In addition, ${ }^{90} \mathrm{Sr}$ sources exist on plexiglass sources, foils, compounds sealed within silver strips or plates, and as sources sealed within brass screws or steel capsules.

${ }^{90} \mathrm{Sr}$ sources are used commercially to measure density and thicknesses of many materials. Its uses have included measuring steel, copper, and aluminum sheets, as well as paper, plastic, and rubber products. ${ }^{22}$ Proper disposal or recycling of the medical and industrial sources of ${ }^{90} \mathrm{Sr}$ has to be considered an important part of the initial purchase plan.

\section{Disposal Data for Strontium-90}

${ }^{90} \mathrm{Sr}$ has been deposited in three LLW sites in Richland, Washington; Barnwell, South Carolina; and Beatty, Nevada over a period of several years. Data on the activity, sources, and waste types for this nuclide have been obtained from the Manifest Information Management System Database. ${ }^{a}$ Figure 7-2 shows the total annual ${ }^{90} \mathrm{Sr}$ activity deposited in the three sites for each year between 1986 and 1995 . Nearly $90 \%$ of the total activity for this nuclide was deposited during four years, 1988-1991. Only a small fraction of the total activity was deposited in the other years.

Figure 7-3 shows the activity of ${ }^{90} \mathrm{Sr}$ deposited in these three sites as a function of waste source. The overwhelming majority of the activity was generated by utilities, $17,100 \mathrm{Ci}$ or $85 \%$ of the total. An additional $14 \%$ was generated by industrial sources and only minor activities were generated by the other sources. The definition of disposal categories given in Figure 7-3 is as follows: academic - sources associated with university laboratories; government - sources associated with the government, such as military hospitals; industry - sources associated with manufacturing, other than utilities; medical sources associated with hospitals and medical laboratories, excluding pharmaceutical manufacturing; utility - sources generated by nuclear utilities and stored onsite or sent to one of the three disposal sites. Waste treatment facilities are included in the utility category.

a. Information provided through the DOE waste management system maintained by the National Low-Level Waste Management Program, Idaho National Engineering Laboratory (INEL). 


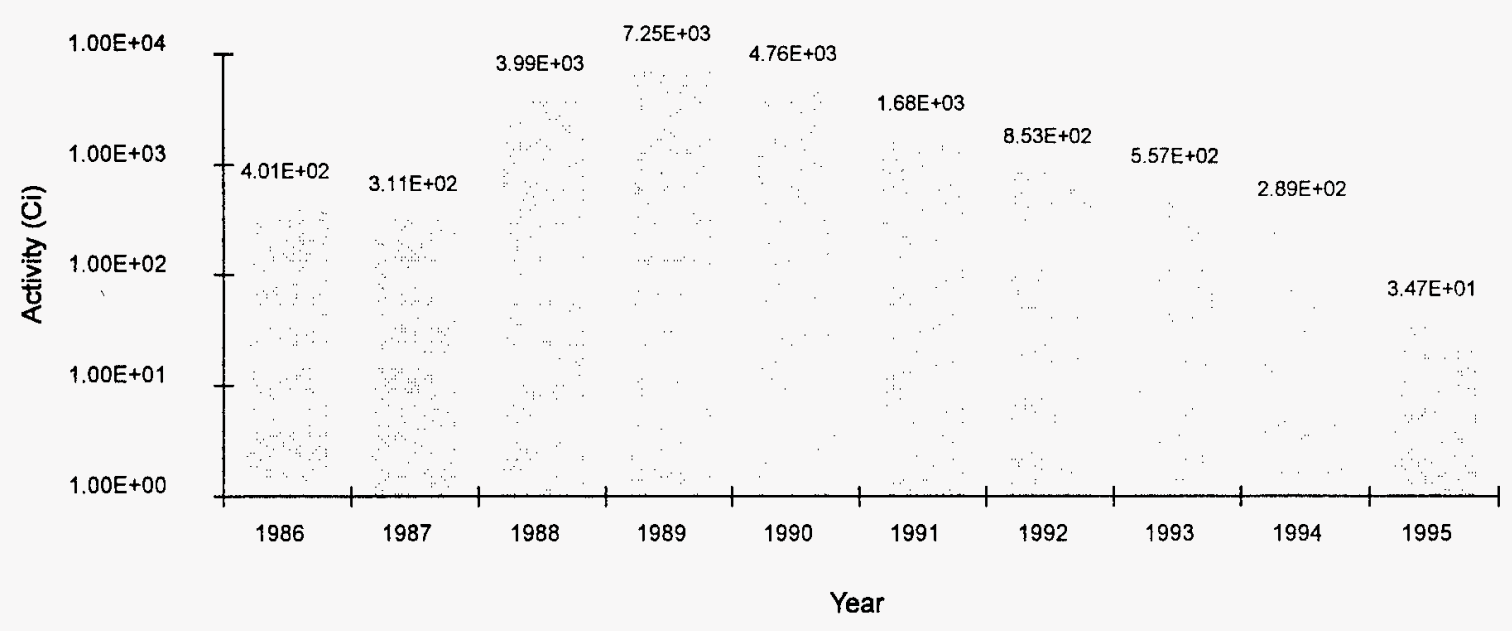

Figure 7-2. ${ }^{90} \mathrm{Sr}$ activity deposited at the Richland, Beatty, and Barnwell sites by year (log scale).

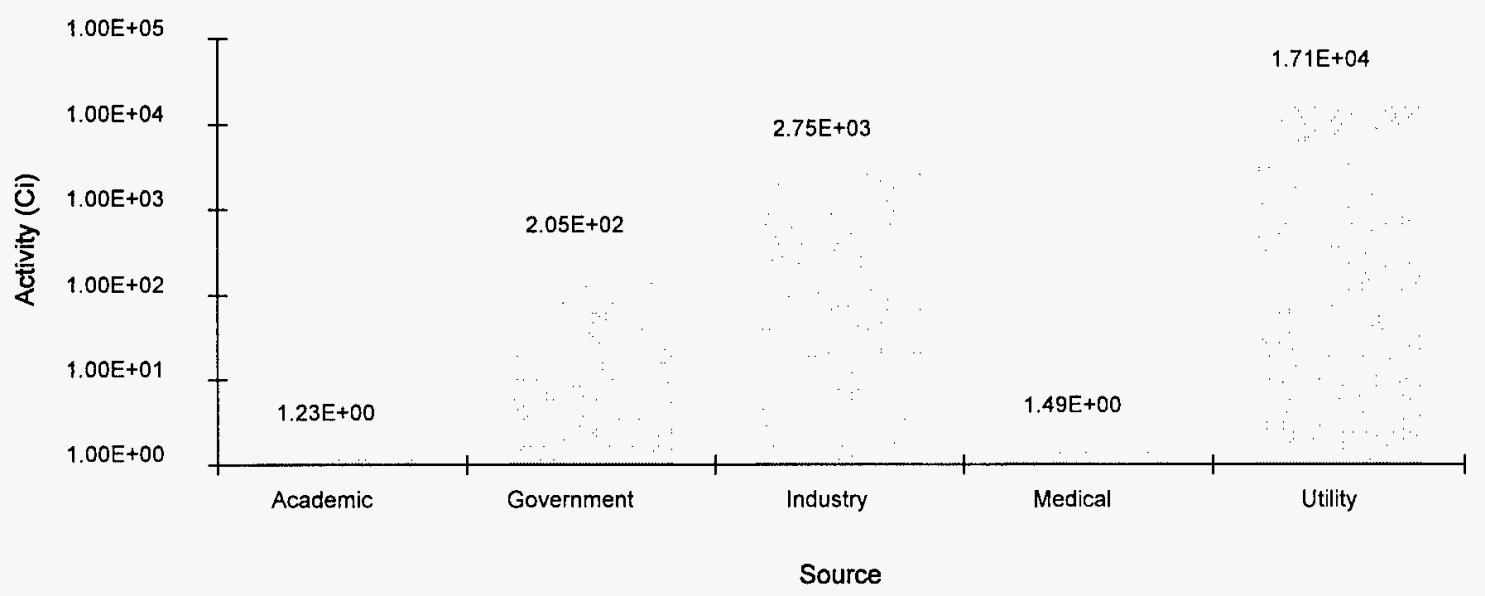

Figure 7-3. ${ }^{90} \mathrm{Sr}$ activity deposited at the Richland, Beatty, and Barnwell sites by source (log scale). 
Figure 7-4 shows the activity of ${ }^{90} \mathrm{Sr}$ deposited in the Richland and Beatty sites as a function of waste type. The waste disposal manifests for the Barnwell site did not break down the waste by type, which is unfortunate since more than half of this nuclide (55\%) is stored at this site. As shown in this figure, more than $90 \%$ of the activity was deposited in the form of dewatered resins and dry solids. The waste types illustrated in Figure 7-4 are from nuclear reactors, academic institutions, and medical facilities.

\section{Behavior of Strontium-90 in the Environment}

\section{Strontium-90 in Soils}

Understanding the behavior of fission products such as ${ }^{90} \mathrm{Sr}$ in the soil is important in predicting the dissolution of radioactive waste in underground vaults and the subsequent transport of radionuclides through the biosphere. ${ }^{23}$ It is important to understand the interactions between radionuclides and various media along the path to the biosphere, whether disposal is in deep or shallow rock caverns or in shallow overburden facilities.

Four parameters were reported to be essential to accurately predict soil concentrations from either contaminated ground water or irrigation water. ${ }^{23}$ The four parameters, in order of decreasing importance, are soil retention, annual precipitation, soil texture, and depth to the water table. The soil retention parameter represents the solid/liquid partition coefficient and is denoted by the symbol: $\mathrm{K}_{d}$. $\mathrm{K}_{\mathrm{d}}$ is defined by $\mathrm{K}_{d}=\mathrm{C}_{\mathrm{s}} / \mathrm{C}_{l}$, where $\mathrm{C}_{\mathrm{s}}$ is the strontium concentration in the soil (solid) and $\mathrm{C}_{l}$ is the strontium

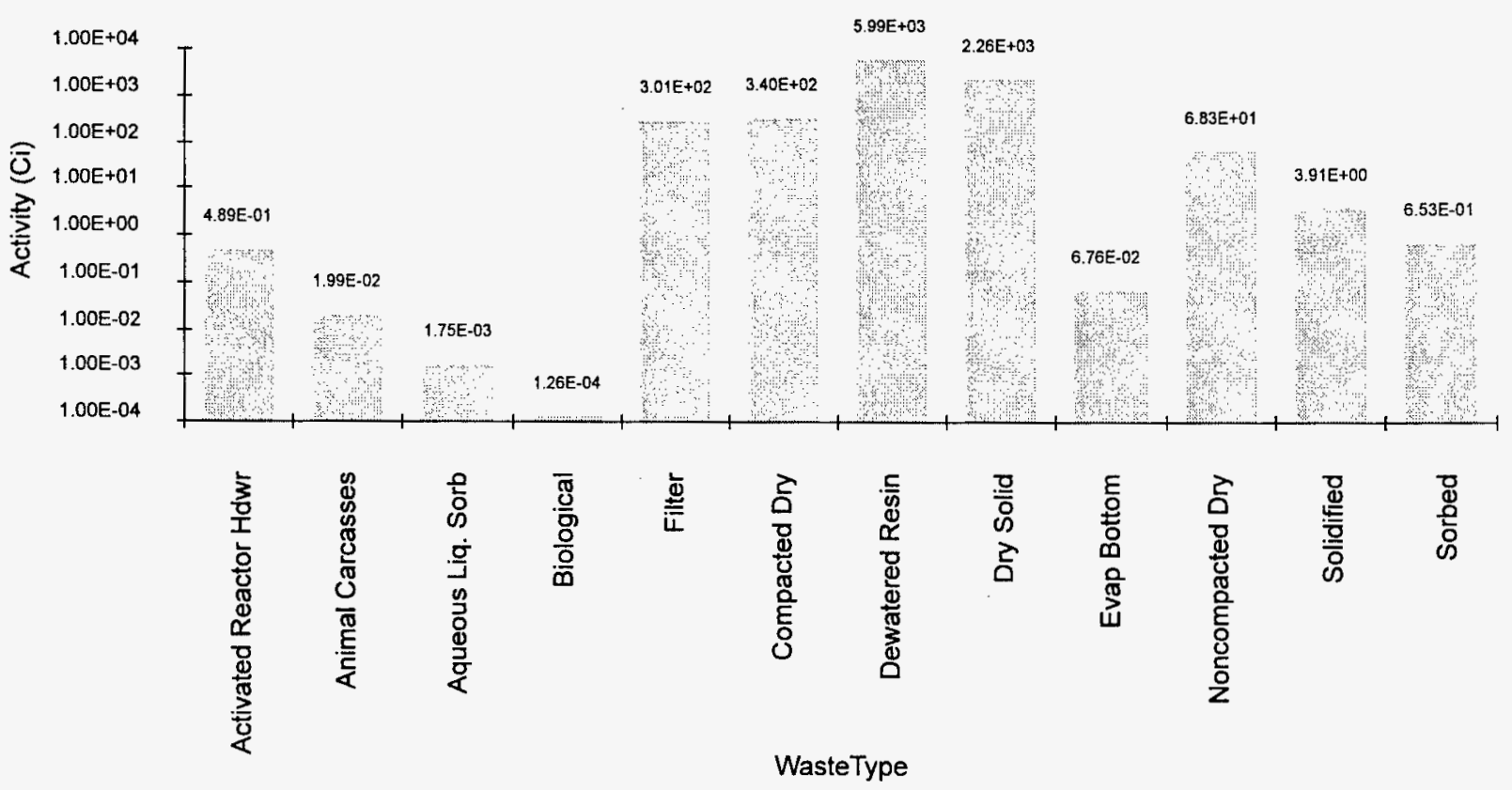

Figure 7-4. ${ }^{90} \mathrm{Sr}$ activity deposited at the Richland and Beatty sites by waste type (log scale). 
concentration in the groundwater (liquid). This empirical model combines all soil retention mechanisms into a simple linear partition relation between the soil and the surrounding groundwater. This model assumes that the $C_{s}$ and $C_{1}$ are in equilibrium with each other; that is, they are not changing with time.

Typically, $\mathrm{K}_{\mathrm{d}}$ is measured under laboratory conditions, using samples that are relatively homogenous, and where it can be ensured that equilibrium conditions are met. Applying these values to specific soils in the field can be difficult because actual soils are generally not homogeneous and there are uncertainties as to how long it takes for strontium concentrations in soil and groundwater to reach equilibrium. Therefore, one must be careful to ensure that soil samples used in the laboratory studies are as closely representative of the field as possible. However, even though the soil samples do not precisely match conditions in the field, $\mathrm{K}_{d}$ values from these laboratory studies can be used in computer models that extrapolate data from laboratory experiments and field studies. In addition, some experiments are conducted using intact field samples to validate the laboratory $K_{d}$ values and to study the effects due to soil inhomogeneity. ${ }^{24}$

Strontium retention is very sensitive to the presence of calcium in the soil. This is because these two elements are both alkaline-earth metals and exhibit very similar chemical properties. This chemical similarity can be used to advantage in certain waste stream removal systems. For example, in a soil contaminated with ${ }^{90} \mathrm{Sr}$, more of the strontium will be absorbed by the soil (and removed from the groundwater) if the soil is treated with calcium carbonate. The strontium in the groundwater is exchanged with the calcium in the carbonate to form strontium carbonate, which is then absorbed by the soil. ${ }^{25}$

In order to correlate the interaction of strontium with different soil types, the mineral soils are divided into three different categories: sand, clay, or loam (i.e., between sandy and clay textures). The soils that contain $\geq 70 \%$ sand-sized particles are classified as sandy soils, and those containing $\geq 35 \%$ clay-sized particles are classified as clay soils. Loam soils have an even distribution of sand, clay, and silt-sized particles and can consist of up to $80 \%$ silt-sized particles. In addition to the mineral soils, there is one additional soil type, organic soil. Organic soils are any of the mineral soils that contain greater than $30 \%$ organic matter.

Strontium is more easily retained by clay or organic soils, as evidenced by larger $\mathrm{K}_{\mathrm{d}}$ values for these soil types. The retention in sand or loam soils is approximately an order of magnitude less, given otherwise similar conditions. However, even the retention in the clay and organic soils is much less than for many of the other radiologically important nuclides, such as cesium and cobalt. For example, the $\mathrm{K}_{\mathrm{d}}$ for strontium in organic soils (the largest listed value for strontium in Reference 23) is a factor of 2 smaller than that for cesium in organic soils (the smallest listed value for cesium) and a factor of 6.7 smaller than that for cobalt. The values from Reference 23 are representative of saturated soil conditions. In the field, soils are typically not saturated. Strontium retention typically increases with decreased soil water content. The smaller $\mathrm{K}_{d}$ for strontium results in deeper migration of ${ }^{90} \mathrm{Sr}$ than many other radioactive species, such as ${ }^{137} \mathrm{Cs}^{26}$

Stable strontium isotopes occur naturally in many soils. In fact, on an elemental basis, the naturally occurring strontium can be much more prevalent than the trace amounts of ${ }^{90} \mathrm{Sr}$ found in typical waste types. ${ }^{27}$ Strontium typically is in a $+2\left(\mathrm{Sr}^{2+}\right)$ oxidation state and is very soluble in the groundwater, especially if acidic $\mathrm{pH}$ conditions exist. This is the dominant chemical state for the $\mathrm{pH}$ range of most 
environments. In this state, the principal reaction of strontium with soils and rocks is ion exchange, especially with calcium compounds. Reference 27 summarizes the results from several experimental studies of strontium retention in various soils (also see References 28, 29, and 30). In most of these studies, strontium retention was by ion exchange. If the groundwater has an alkaline $\mathrm{pH}$, however, strontium can form a stable carbonate $\left(\mathrm{SrCO}_{3}\right)$ that is more readily fixed with the soil.

Clay soils and tuff (fused volcanic dust) retain strontium much more readily than other types of rocks and soils, such as quartz-bearing rocks, sandstone, and mineral-type soils. ${ }^{27}$

The effect of $\mathrm{pH}$ on strontium retention in various types of shale was reported in Reference 31 . The results from this experimental study support the $\mathrm{pH}$ effect stated above, namely that retention of strontium increases with increasing $\mathrm{pH}$. This was true for all four of the shale types included in the study. Also confirmed in the study is the conclusion that strontium absorption is much lower, in general, than that of cesium. Comparison of the adsorption and desorption of strontium from these shales indicates that a small percentage of the strontium is permanently fixed in the shale and that the sorption/desorption is not totally reversible.

One additional point can be made regarding strontium retention in soils. Since strontium (including ${ }^{90} \mathrm{Sr}$ ) tends to stay in a soluble form and is not easily fixed in the soil, it tends to migrate deeper into the soil than, for example, ${ }^{137} \mathrm{Cs}$. This means the greatest concentration of ${ }^{90} \mathrm{Sr}$ tends to be at or below root level. Therefore, strontium is less susceptible to surface erosion and runoff-dominated migration. ${ }^{32}$

\section{Strontium-90 in Water}

Since strontium typically is in a soluble form and chemically bonds less with surrounding soil and rock than many other radioactive species (for example ${ }^{137} \mathrm{Cs}$ ), it tends to migrate further with the groundwater. Strontium tends to percolate deeper into the soil due to the effects of leaching by soil moisture. This has the beneficial effect of reducing the probability that strontium will become airborne due to surface erosion, but it also means that strontium can more quickly migrate into an underground water supply.

For the Idaho National Engineering Laboratory (INEL), groundwater testing has been performed over several years at many well locations on the site. Some data taken in wells near the Idaho Chemical Processing Plant have shown ${ }^{90} \mathrm{Sr}$ concentrations of 6 to $37,000 \mathrm{pCi} / \mathrm{L}\left(6 \times 10^{-3}\right.$ to $\left.37 \mathrm{pCi} / \mathrm{g}\right) .^{33}$ These concentrations can be compared to ${ }^{137} \mathrm{Cs}$ concentrations of 50 to $1,000 \mathrm{pCi} / \mathrm{L}\left(5 \times 10^{-2}\right.$ to $\left.1 \mathrm{pCi} / \mathrm{g}\right)$. The total ${ }^{90} \mathrm{Sr}$ and ${ }^{137} \mathrm{Cs}$ releases during this time were comparable. This illustrates the higher mobility of strontium into groundwater, as discussed above.

\section{Strontium-90 in Plants}

The uptake and biological transport of strontium in plants have been studied in an effort to predict the extent of strontium migration in the food chain and its potential toxicity. ${ }^{34}$ This study used soil and plant types typical of the area around Hanford, Washington, where significant amounts of ${ }^{90} \mathrm{Sr}$ have been produced and are being stored. Concentration ratios (defined as the ratio between the ${ }^{90} \mathrm{Sr}$ in the plant material and the ${ }^{90} \mathrm{Sr}$ concentration in the soil-both plant material and soil having been oven-dried to drive off all moisture) were measured as a function of soil-radionuclide concentration and were found to 
be independent of soil concentration for 5 orders of magnitude. This information suggests that data from these studies can be extrapolated to environmental contamination levels for modeling purposes.

The time-dependence of the concentration ratio was studied, in the time frame from 0 to 12 weeks after planting. It was observed that the ratio increased significantly between 8 and 12 weeks. This observation indicates that data obtained from seedlings may underestimate the concentration ratio for more mature plants. Analyses of dry matter production, total shoot content, and tissue concentration of strontium indicates that plant uptake of these radionuclides continues at a linear rate over the growing season, and that the observed age-dependent changes in concentration ratios are related to production of dry matter and changes in shoot concentrations. In other words, the uptake of strontium through the roots into the plant continues at a constant rate even though plant growth has slowed due to maturation.

In another study, "Persistence of Radionuclides in Soil, Plants, and Small Mammals in Areas Contaminated with Radioactive Fallout," the uptake and accumulation of strontium by two different plants (barley, a monocot, and bush beans, a dicot) were investigated. ${ }^{35}$ This investigation included the effects of strontium concentration in water and the presence of two cations (potassium and calcium) on strontium uptake and the distribution of strontium among the various plant parts, roots, stem, and leaves.

The results from this study indicate that the preferred location of strontium in bush beans is in the roots, as opposed to the stem and leaves. In barley, however, the distribution within the plant was much more uniform, with a slightly higher concentration in the stem. In general, the strontium concentrations in barley were much higher than in the bush bean. The total mass of strontium was a relatively strong function of the strontium concentration in the feedwater-a 2 order-of-magnitude decrease in feed water concentration resulted in a 1 order-of-magnitude decrease in strontium uptake. The effects of the two added cations were that the ratio between strontium concentration in the shoots to that in the roots was increased with increased calcium in the water. There was little consistent effect of the presence or absence of potassium in the water.

One more study is included in this reference. This study included the effect of shielding on strontium plant uptake from weapons testing fallout during the atmospheric test program. ${ }^{35}$ In this study, native grasses were grown with and without enclosures of clear plastic covers and filter-cloth sides. There was a dramatic reduction in the uptake of strontium due to the covers, ranging from 85 to $90 \%$ for three different grass species. In addition, soil samples were taken from five different locations within the fallout area and there was an order of magnitude spread in the total amount of strontium uptake among these different samples, although there were some inconsistencies between different plant types. For example, strontium uptake in alfalfa increased approximately two-fold between two sites, but the strontium uptake in a common native desert scrub, (Franseria dumosa) decreased $30 \%$ for the same two samples. Also of interest is that distance alone did not explain the differences in strontium uptake. The two sites discussed above were located approximately equidistant from the explosion location, but lay at two different directions.

The path whereby strontium contaminates plants is discussed in Transfer of Radioactive Materials from the Terrestrial Environment to Animals and Man. ${ }^{36}$ This study includes an assessment of the "weathering half-life" of various radioactive contaminants from the plant surfaces. This is a measure of the length of time for surface contamination to be reduced to half of its original magnitude. For ${ }^{90} \mathrm{Sr}$, this weathering half-life is approximately two weeks immediately after contamination. It increases to 
between 20 and 40 days thereafter. Since ${ }^{90} \mathrm{Sr}$ has a much longer radioactive half-life, the weathering half-life is dominated by removal due to washing by precipitation.

Reference 36 also included an assessment of the ability of various plants to concentrate radioactive species from the soil. These were ranked from "strongly concentrated" (concentration ratio of 10 to 1000 ) to "strongly excluded" (concentration ratio <0.01). Strontium was listed in the second-highest category, "slightly concentrated" (concentration ratio 1 to 10 ). There are some prophylactic measures that can be taken to reduce the uptake of strontium into plants. For example, for crops with shallow root systems (e.g., pasture grasses), deep plowing forces the surface contamination deep into the soil where it is not available to the roots. This procedure reduced strontium uptake by 50 to $75 \%$ in soybean, sugar beet, sudan grass, and cabbage. Adding sodium carbonate to the soil reduced the strontium uptake to less than $10 \%$ relative to an untreated and shallow-plowed field. Treating a wheat field with nominal amounts of sodium silicate and trisodium phosphate (equal to the content of exchangeable calcium in the soil) reduced strontium uptake by a factor ranging from 3 to 5 . Adding large amounts of sodium silicate reduced strontium uptake by a factor of 13 in the grain and 2.5 to 7 in the chaff.

In some parts of the world, especially in Eastern Europe, bread is a major source of ${ }^{90} \mathrm{Sr}$ ingestion to man. Some of the strontium is absorbed into the endosperm of the grain, but a significant proportion arises from those parts of the grain ear external to the endosperm from which the flour is milled. In this regard, dark breads include a higher proportion of these grain parts and, therefore, a higher ${ }^{90} \mathrm{Sr}$ contamination.

\section{Strontium-90 in Air}

Strontium is not normally found in air unless there is a large-scale accident such as Chernobyl, which did not have a containment structure around the nuclear reactor, or from hydrogen bomb testing in the atmosphere, which is currently banned by most nations. Even in the Three-Mile Island accident, for which the PWR had a containment, a large fraction of the strontium was released from the $\mathrm{UO}_{2}$ fuel; however, it was not released into the atmosphere primarily because of the reactor containment structure. The major fission product releases were limited to controlled releases of the radioactive noble gases a year after the accident.

While not a direct measurement of strontium in air, Reference 35 does contain an indirect indication. This study included an investigation of the uptake of strontium in small mammals that live in fallout areas around the Nevada Test Site, where a number of atmospheric nuclear tests were conducted. In this study, it was determined that the uptake of strontium into the animal's lungs had decreased to a nearly undetectable amount, relative to the uptake into the gastrointestinal tract, by the mid-1960s. The last atmospheric test before this study was in 1958. However, the Sudan Test Event, one of the Plowshare Test Series that tested shallow underground explosions, produced a significant atmospheric release in 1962. This study indicates that within 4 to 8 years of a major atmospheric release, the strontium in the air will be essentially eliminated as a source of contamination. This study was conducted in the fallout area of the Nevada Test Site. Atmospheric concentrations of strontium in areas further removed from an event may persist longer but would be of reduced magnitude.

The above observations are consistent with the expected chemical form of strontium at atmospheric conditions. Strontium is expected to form $\mathrm{SrO}$, which has a very low vapor pressure at atmospheric 
temperatures and should remain in a condensed form. ${ }^{37}$ When it comes into contact with water, SrO reacts to form $\mathrm{Sr}(\mathrm{OH})_{2}$ and then dissolves in the water. Thus, shortly after any dispersement in air (as, for example, during a severe core damage accident like the one that happened at Chernobyl) strontium should settle to the earth and remain there. Its high solubility infers that subsequent precipitation would transport it relatively quickly deep into the soil so that it would not be redispersed into the air by wind.

\section{Behavior of Strontium-90 in the Human Body and in Animals}

The two principal modes of entry of radioactive materials into animals or man are inhalation and ingestion. It is widely recognized that the major part of the additional radiation exposure to man from man-made sources has come from contaminated food, mainly agricultural crops and animal produce. ${ }^{36}$ For the case of strontium, a principal route into the human body is through milk from cows that graze on contaminated plants. Because of strontium's high solubility in water, the plants are principally contaminated by uptake through the roots of contaminated groundwater, rather than by direct contamination from radioactive fallout. Reference 36 also includes the results from a laboratory study concerning the transfer of ingested radioactive species into milk. For cows, approximately $0.8 \%$ of strontium ingested daily is transferred to the milk (based on $0.08 \% /$ liter and average of 10 liters of milk per day).

Based on the nature, distribution, and metabolism of fission products, ${ }^{90} \mathrm{Sr}$ appears to be the critical nuclide in consideration of the long-term effects from internally deposited radioactive sources originating from weapons testing. ${ }^{38}$ Except where otherwise specifically noted, all of the information in this section is based on this reference, Atomic Medicine, which includes a comprehensive compilation of the effects of radiation and radioactive contamination on the human body.

${ }^{90} \mathrm{Sr}$ is readily absorbed in the body, where it is firmly fixed in the skeleton because of the chemical similarity to calcium. About $20 \%$ of the ingested strontium in man is absorbed through the gastrointestinal tract. Of the total amount of strontium ingested, it is expected that $50-75 \%$ is excreted within two weeks, and approximately $95 \%$ is excreted within one year. Nearly all of the excretion is by urine, and only $\sim 10 \%$ is excreted through the intestinal tract. The remaining $5 \%$ in the body can be assumed to be fixed in the skeletal tissues.

Health Protection of Radiation Worker ${ }^{39}$ reports the results of a corroborating experiment wherein humans ingested amounts of the shorter-lived ${ }^{85} \mathrm{Sr}$ and its transport in the human body was studied. In this study, less than $20 \%$ of the ingested strontium was excreted in the urine and less than $8 \%$ was retained, in most cases, after 8 days. The strontium ingested in this study was absorbed into the body through the gastrointestinal tract. In another study, ${ }^{40}$ strontium was injected into the bloodstream and its retention was approximately $20 \%$ after 100 days.

Reference 19 includes the results of additional studies into the metabolism of strontium in the human body. In some of the studies, as much as $35 \%$ of ingested strontium was absorbed by the body (that is, not immediately excreted in feces). Approximately $20 \%$ of the whole was carried with the urine, leaving $15 \%$ that was retained in the body for more than one month. On average, however, the author indicates that $20 \%$ (rather than $35 \%$ ) is a representative figure for absorption of soluble strontium salts. Reference 40 also contains a discussion of the ability of the human body to discriminate between strontium and calcium. Although plants and many other organisms tend to incorporate these two alkaline-earth metals 
equally, mammals (including humans) have the ability to absorb calcium preferentially. In the adult human, experimental studies indicate that ratio of strontium to calcium absorbed in the body is $\sim 1 / 4$ the ratio of the ingested material. To illustrate, if a food sample contained $100 \mathrm{~g}$ of strontium and $100 \mathrm{~g}$ of calcium (a ratio of 1:1), $40 \mathrm{~g}$ of calcium would be absorbed but only $10 \mathrm{~g}$ of strontium (a ratio of 1:4). That is, the human body is much more likely to absorb the calcium from ingested food than strontium. For infants, the ability to discriminate is weaker but still substantial (the ratio of strontium to calcium absorbed in the body is $\sim 1 / 2$ that of the ingested material). Experimental studies have been conducted to investigate this phenomena, which seems to be associated only with mammals. The study results indicate that the differentiation occurs by two processes: (a) the mucosa in the intestines are able to differentiate between the two substances during the initial absorption in the intestines; and (b) the kidneys are also able to differentiate in the removal of the substances from the blood, before quasipermanent absorption in the bones, resulting in removal with urine. Both of these mechanisms are effective in adults. In infants, the mucosa in the intestine do not appear to be able to discriminate between the two substances (at least to the degree this occurs in adults) and only the discrimination in the kidneys (to preferentially void strontium that is in the blood serum) is active during the period of rapid bone growth.

There are other biological mechanisms whereby calcium is preferentially treated with respect to strontium in mammals. For example, in lactating women, some studies indicate a much higher concentration of calcium in the milk relative to strontium; however, these data are not sufficient to draw a firm conclusion and more research is indicated. In one study, examining infants one week old, the strontium in the blood actually decreased in those being breast fed while those who were on cow's milk experienced an increase in strontium. Also, the placenta in pregnant women provides an effective discrimination barrier, allowing large amounts of calcium to pass preferentially to the fetus while discriminating against strontium (a discrimination factor of approximately 2 ).

Strontium does not uniformly deposit within the skeletal tissues. In tests utilizing other radioactive strontium isotopes (e.g., ${ }^{85} \mathrm{Sr}$ ), the $\mathrm{Sr} / \mathrm{Ca}$ ratio was measured at various locations within the skeleton. It was shown that the strontium localized in active building sites in the bone, resulting in a higher radioactive dose to these "hot spots."

Most of the biological effects of ${ }^{90} \mathrm{Sr}$ in man have been inferred by extrapolation of these effects in test animals. The principal short-term biological effects include suppression of blood formation in the bone marrow and radiation injury to the bone growth centers. Longer-term effects include development of bone cancer (osteogenic sarcoma), shortened life, and, in some cases, leukemia.

The ${ }^{90} \mathrm{Sr}$ dose at which $50 \%$ of the animals in a test population died within 30 days after exposure has been measured as a function body mass for mice, rats, and dogs to be $6 \mu \mathrm{Ci} / \mathrm{g}, 2.5$ to $3.0 \mu \mathrm{Ci} / \mathrm{g}$, and $0.15 \mu \mathrm{Ci} / \mathrm{g}$, respectively. These results were not extrapolated to man, possibly due to the relatively large range $(0.2$ to $6.0 \mu \mathrm{Ci} / \mathrm{g})$. Two studies reported in Reference 38 are noted wherein the dose range for detection of bone damage were reported as 6 to $15 \mu \mathrm{Ci} / \mathrm{g}$ and 5 to $10 \mu \mathrm{Ci} / \mathrm{g}$.

Other animal studies have been carried out wherein specific bone damage assessments were made after ingestion of ${ }^{90} \mathrm{Sr}$. Life-span shortening in adult mice was observed at an injected dose as low as 44 $\mu \mathrm{Ci} / \mathrm{kg}$ of body weight. Two interesting observations came out of this particular study. First, neither the life-span shortening nor the mean time to death was a simple linear function of dose. Second, the 
accumulated dose was much less important (relative to the effects) than the initial dose rate. The second observation supports the conclusion that the body can recover from small doses.

In addition to direct bone damage, ${ }^{90} \mathrm{Sr}$ ingestion also affects the blood. Doses as low as $0.1 \mu \mathrm{Ci} / \mathrm{g}$ cause transient depression of the blood platelet level. This observation is applicable to mice, rats, and dogs and is a consequence of the fact that strontium deposits in the mineral structure of actively growing bones, adjacent to the bone marrow spaces. ${ }^{90} \mathrm{Sr}$ deposited in these locations subjects the bone marrow to beta radiation. The beta particles have a range of only a few millimeters in tissue, so one must exercise care in extrapolating these results to larger mammals, such as man, where the distance between the mineral structure and the bone marrow is larger.

As an additional note, Reference 39 includes a discussion of counter measures that can be used, in the event of a major atmospheric dispersion of ${ }^{90} \mathrm{Sr}$, to minimize the radiological hazard. These counter measures consist of medicine that can be taken to either reduce the amount of strontium that is absorbed by the body or that hasten the removal from the body.

Sodium alginate both suppresses absorption of and aids in the removal of strontium from the body. For example, in a test involving two groups of mice, adding the sodium alginate to the diet of the test group resulted in a retained strontium fraction about half that of the control group. Aluminum phosphate gel is also indicated as an effective prophylactic for absorption of strontium. In a test involving human subjects, the absorption of strontium was decreased by an average of $43 \%$ to $57 \%$ (relative to the control group) depending on whether the gel was taken $1 / 2$ or $1 \mathrm{~h}$ after ingestion. When the gel was administered before strontium ingestion, the effect was even greater; for example, $87 \%$ reduction of strontium absorption relative to the test group.

To minimize inhaled strontium absorption, administration of nonradioactive strontium and ammonium chloride has been recommended. ${ }^{39}$ Early use of this prophylactic resulted in a $55 \%$ reduction in strontium absorption relative to the control group.

The metabolism of strontium is similar to that of calcium; both are members of the same chemical family. Consequently, the ${ }^{90} \mathrm{Sr}$ that is absorbed by a human generally deposits in the bones. The effective biological half-life is defined as that time required for an organism to eliminate one-half of the initial quantity of material through chemical, biological, or physical (radioactive decay) processes. ${ }^{90} \mathrm{Sr}$ is a radionuclide with a long biological half-life. ${ }^{8}$ The effective biological half-life of ${ }^{90} \mathrm{Sr}$ in humans has been reported to be 18 years (Reference 16) (50 years for biological processes only and 29 years for radioactive decay); however, an older reference ${ }^{41}$ considered the biological half-life of ${ }^{90} \mathrm{Sr}$ in bones to be about 4,000 days ( 11 years), with an effective half-life of 2,700 days ( 7.4 years).

The maximum permissible body burdens and maximum permissible concentrations in water and air for ${ }^{90} \mathrm{Sr}$ are listed in Table 7-6. These data indicate acceptable concentrations for ${ }^{90} \mathrm{Sr}$ during the early 1970s and are presented here for general and historical information only. Furthermore, these data are based on a 40-hour work week and apply for occupational exposure only; that is, they do not apply for continuous exposure to the population at large, which would be at least a factor of 3 smaller.

Based on the information shown in Table 7-6, the maximum permissible body burden of ${ }^{90} \mathrm{Sr}$ is $20 \mu \mathrm{Ci}$. For a standard man weighing $70 \mathrm{~kg}$, the maximum permissible body burden would equate to an 
average activity concentration of $\sim 0.0003 \mu \mathrm{Ci} / \mathrm{g}$. If the maximum permissible amount of ${ }^{90} \mathrm{Sr}(2 \mu \mathrm{Ci})$ is distributed uniformly over the $5,000 \mathrm{~g}$ of skeleton bone mass for an average man, then this activity would represent an average concentration of $0.0004 \mu \mathrm{Ci} / \mathrm{g}$. Note that the maximum permissible human concentration data shown in Table 7-6 are much smaller than the $10 \mu \mathrm{Ci} / \mathrm{g}{ }^{90} \mathrm{Sr}$ concentration level known to produce some forms of leukemia and osteogenic sarcomas. ${ }^{42}$ As another example, consider the $1 \times 10^{-5} \mu \mathrm{Ci} / \mathrm{cm}^{3}$ maximum permissible concentration for ${ }^{90} \mathrm{Sr}$ in water (for total body dose) in Table 7-6. Since an average person consumes approximately $3,000 \mathrm{~g}\left(3,000 \mathrm{~cm}^{3}\right)$ of water each day, then if ${ }^{90} \mathrm{Sr}$ is consumed with this water at the $1 \times 10^{-5} \mu \mathrm{Ci} / \mathrm{cm}^{3}$ concentration level, a total amount of $11 \mu \mathrm{Ci} /$ year $\left(=3,000 \times 1 \times 10^{-5}\right)$ would be consumed. The annual limits on ${ }^{90} \mathrm{Sr}$ intake and the derived maximum air concentrations for ${ }^{90} \mathrm{Sr}$ are shown in Table 7-7.

Table 7-6. Maximum permissible body burdens and maximum permissible concentrations (for a 40hour week) for soluble and insoluble forms of ${ }^{90} \mathrm{Sr}$.

\begin{tabular}{lccc}
\hline \multicolumn{1}{c}{ Reference organ } & $\begin{array}{c}\text { Maximum } \\
\text { permissible total } \\
\text { body burden }(\mu \mathrm{Ci})\end{array}$ & $\begin{array}{c}\text { Maximum permissible } \\
\text { concentrations in water } \\
\left(\mu \mathrm{Ci} / \mathrm{cm}^{3}\right)^{\mathrm{a}}\end{array}$ & $\begin{array}{c}\text { Maximum permissible } \\
\text { concentrations in air } \\
\left(\mu \mathrm{Ci} / \mathrm{cm}^{3}\right)^{\mathrm{a}}\end{array}$ \\
\hline Total body (soluble) & 20 & $1 \times 10^{-5}$ & $9 \times 10^{-10}$ \\
Bone (soluble) & 2 & $4 \times 10^{-6}$ & $3 \times 10^{-10}$ \\
GI tract (soluble) & - & $1 \times 10^{-3}$ & $3 \times 10^{-7}$ \\
Lung (insoluble) & - & - & $5 \times 10^{-9}$ \\
GI tract & - & $1 \times 10^{-3}$ & $2 \times 10^{-7}$ \\
\hline a. For a 40-hour week. & & & \\
Source: Reference 4, p. 207. & & & \\
\hline
\end{tabular}

Table 7-7. Annual limits on intake (ALI), the derived air concentrations (DAC), and the maximum permissible concentrations (MPC) for ${ }^{90} \mathrm{Sr}$.

\begin{tabular}{lccc}
\hline Radionuclide & Component & Ingestion $^{\mathrm{a}}$ & Inhalation $^{\mathrm{a}}$ \\
\hline${ }^{90} \mathrm{Sr}$ & ALI & $30 / \mathrm{D}$ to $400 / \mathrm{Y} \mu \mathrm{Ci}$ & 4 to $20 \mu \mathrm{Ci}$ \\
& DAC & - & 0.002 to $0.008 \mu \mathrm{Ci} / \mathrm{m}^{3}$ \\
& MPC & $0.0003 / \mathrm{D}$ to $0.005 / \mathrm{Y} \mu \mathrm{Ci} / \mathrm{m}^{3}$ &
\end{tabular}

a. Values depend upon the removal time of the specific chemical form of ${ }^{90} \mathrm{Sr}$ and is classified as either D for Days, $\mathrm{W}$ for weeks, and $\mathrm{Y}$ for years.

Source: Reference 43. 


\section{Summary}

${ }^{90} \mathrm{Sr}$ is not a naturally occurring radionuclide. It has a half-life of 29 years and it only emits a highenergy beta particle following decay. Almost no gamma-ray particles are released from the ${ }^{90} \mathrm{Sr}$ decay sequence. For example, approximately $99.98 \%$ of all ${ }^{90} \mathrm{Sr}$ decays result in the emission of a $523-\mathrm{keV}$ maximum-energy beta particle and a 2,280-keV maximum-energy beta particle from ${ }^{90} \mathrm{Y}$ decay with no gamma ray. In general, a continuous spectrum of beta particle energies exist between 0 and $523 \mathrm{keV}$ and 0 and $2280 \mathrm{keV}$.

${ }^{90} \mathrm{Sr}$ exists because of man-made activities. Due to the high beta particle energies of ${ }^{90} \mathrm{Sr}$ or its daughter nuclide $\left({ }^{90} \mathrm{Y}\right),{ }^{90} \mathrm{Sr}$ has been used in industrial applications to measure thicknesses of paper, plastic, rubber, and metal foils. It also has some medical applications such as treatment for some eye and skin diseases. Due to the low gamma-ray activity of ${ }^{90} \mathrm{Sr}$, it is not normally used as an irradiation source. Radioactive strontium wastes (primarily ${ }^{90} \mathrm{Sr}$ ) pose a possible health hazard if not handled properly, and since their total inventories continue to increase with nuclear power programs, the eventual processing, use, and disposal of this material is an issue that needs to be resolved.

Chemically, strontium behaves like the other alkaline-earth metals (e.g., magnesium, calcium, and barium) and has a relatively simple chemistry. In a fuel element, strontium preferentially forms a stable oxide. When released into the atmosphere, strontium oxide has a high affinity for water and readily forms a soluble hydroxide.

The behavior of strontium in the biosphere is dictated by its chemical properties. Because of its high solubility, it is transported readily with precipitation and groundwater deep into soils. Strontium is not as susceptible to ground erosion as other radionuclides because it quickly is transported below the top surface of the ground. Therefore, it is less liable to be resuspended in the air after deposition. Compared to other radioactive species, such as ${ }^{137} \mathrm{Cs},{ }^{90} \mathrm{Sr}$ is not as readily fixed in the soils or rocks but preferentially remains in a soluble state. As such, it can be taken up by plants through the roots, which is the principal means by which strontium gets into the food chain. Absorption through the upper plant structures (leaves, stem) does not happen to an appreciable degree.

Absorption of strontium by humans takes place primarily through the gastrointestinal tract, though some contamination by inhalation is possible shortly after a major atmospheric release. Once in the body, up to $95 \%$ of ${ }^{90} \mathrm{Sr}$ is eventually excreted within a few weeks. The remaining fraction is fixed within the skeletal structures, preferentially in the areas of bone growth. Since these areas are near blood-producing bone marrow, one of the principal health problems associated with ${ }^{90} \mathrm{Sr}$ contamination is reduction in the blood platelet production in the body. Other health hazards include the possibility of bone cancer. Strontium enters the body and can replace calcium atoms within bone. The effective halflife of strontium in a human body (including both decay and biological/chemical processes) is about 18 years. 


\section{References}

1. P. Kilho Park, D. R. Kester, I. W. Duedall, B. H. Ketchum, Wastes in the Ocean, Volume 3, Radioactive Wastes and the Ocean, New York: John Wiley \& Sons, 1982, pp. xvi, 26, 28, 423, 446, 447 , and 459.

2. R. Granier and D. Gambini, Applied Radiobiology and Radiation Protection, Ellis Horwood Limited, English edition published in 1990, pp. 194, 195, Table 7.1 on p. 203, 206, 237, 273, 283, 335, Appendix 2 on pp. $346 \& 347$.

3. C. M. Lederer, J. M. Hollander, I. Perlman, Table of Isotopes, Sixth Edition, New York: John Wiley and Sons, Inc., 1967, pp. 38, 40, and 226.

4. U.S. Department of Health, Education, and Welfare, Radiological Health Handbook, Revised Edition, January 1970, pp. 92, 104, 122, 123, 204, 207, 266.

5. R. C. Weast (ed.), CRC Handbook of Chemistry and Physics, 58th Edition, Boca Raton, Florida: CRC Press, 1977, p. B-289 (Table of Isotopes), p. B-368 (Gamma Energies and Intensities of Radionuclides).

6. J. R. Bradford (ed.), Radioisotopes in Industry, Reinhold Publishing Corporation, 1953, pp. 15, 60, $88,162,264,266$.

7. General Electric Company, Nuclides and Isotopes, Fourteenth Edition, 1989, p. 28.

8. M. F. L'Annunziata, Radionuclide Tracers: Their Detection and Measurement, Academic Press, 1987, Table A.1.

9. E. S. Gould (ed.), Inorganic Reactions and Structure, New York: Holt, Rinehart, and Winston, 1962.

10. F. A. Cotton and G. Wilkinson, Advanced Inorganic Chemistry-A Comprehensive Text, New York: Interscience Publishers, Division of John Wiley \& Sons, 1962.

11. T. Lyman (ed.), Metals Handbook, 8th Edition, Vol. 8, American Society for Metals, 1973.

12. E. W. Washburn (ed.), International Critical Tables of Numerical Data, Physics, Chemistry, and Technology, McGraw-Hill Book Co., Inc., 1926.

13. McGraw-Hill Encyclopedia of Science and Technology, 6th Edition, Vol. 17, New York: McGrawHill Book Co., Inc., 1987.

14. A. G. Croff, A User's Manual for the ORIGEN2 Computer Code, ORNL/TM-7175, July 1980.

15. U.S. Department of Energy, Characteristics of Spent Fuel, High-Level Waste, and Other Radioactive Wastes Which May Require Long-Term Isolation, DOE/RW-0184, Volume 2 of 6, December 1987.

16. J. C. Warf, All Things Nuclear, Graphics 2100, Los Angeles, pp. 55, 58, 79, 80, 83, 273. 
17. F. J. Rahn et al., A Guide to Nuclear Power Technology, New York: John Wiley \& Sons, 1984, pp.119 (Table 17.2), 125, 126.

18. W. R. Gilmore (ed.), Radioactive Waste Disposal - Low and High Level, Noyes Data Corporation, 1977, p. $19,48,82,83,84,85,148,219$.

19. John F. Loutit, Irradiation of Mice and Men, Chicago: The University of Chicago Press, 1962, pp. 105-140.

20. V. S. Balabukha and G. Y. Fradkin, Accumulation of Radioactive Elements in the Body and Their Excretion, A Translation Series by the United States Atomic Energy Commission, AEC-tr-5236, 1958 , pp. 93 and 94.

21. International Directory of Radioisotopes, Second Edition, Part I, International Atomic Energy Agency, June 1962, pp. 256-62.

22. J. Kohl, R. D. Zentner, H. R. Lukens, Radioisotope Applications Engineering, D. Van Nostrand Company, Inc., 1961, pp. 464, 465.

23. M. I. Sheppard and D. H. Thibault, "Default Soil Solid/Liquid Partition Coefficients, $\mathrm{K}_{\mathrm{d}} \mathrm{s}$, for Four Major Soil Types: A Compendium," Health Physics 59 (4), October 1990, pp. 471-482.

24. R. S. Rundberg, I. R. Triay, M. A. Ott, A. J. Mitchell, "Observation of Time Dependent Dispersion in Laboratory Scale Experiments with Intact Tuff," Proceedings for Migration '89, Monterey, California, 1989.

25. J. Dragun, The Soil Chemistry of Hazardous Materials, Hazardous Materials Control Research Institute, Silver Spring, Maryland, 1988.

26. K. R. Price, "The Distribution of ${ }^{90} \mathrm{Sr}$ and ${ }^{137} \mathrm{Cs}$ in Soil Profile Samples from the Hanford Site and Environs," 34th Annual Conference on Bioassay, Analytical, and Environmental Radiochemistry, Las Vegas, October 17, 1988, 5 pp.

27. L. L. Ames and D. Rai, Radionuclide Interactions with Soil and Rock Media, Vol. 1, Environmental Protection Agency, 520/6-78-007-a, August 1978.

28. J. H. Baker, and W. A. Beetem, "Distribution Coefficients for Adsorption of Carrier-Free Cesium, Strontium, and Iodine by Sample from the Vicinity of Cape Thompson, NW Alaska," U.S.G.S. Tech Letter Chariot-1, 1961.

29. W. J. Kaufman, An Appraisal of the Distribution Coefficient for Estimating Underground Movement of Radioisotopes, HNS-1229-21, 1963.

30. P. Cohen and C. Gailledreau, Preliminary Investigations of the Adsorption of Radiostrontium in Saclay Soil - Three Component System, TID-7621, 1961.

31. R. E. Meyer and W. D. Arnold, Effects of Experimental Parameters on the Sorption of Cesium, Strontium, and Uranium from Saline Groundwaters onto Shales, ORNL TM-10933, 1988. 
32. R. E. Smith, R. M. Summer, V. A. Ferreira, Model Feasibility Study of Radioactive Pathways from Atmosphere to Surface Water, NUREG/CR-5475, 1990.

33. R. Bobo, A Review of the Production, Use, and Disposal of Groundwater and the Generation, Storage, and Processing of Radioactive Liquid Waste at the Idaho Chemical Processing Plant, INEL, OPTR 93-03, 1993.

34. R. C. Routson and D. A. Cataldo, "A Growth Chamber Study of the Effect of Soil Concentration and Plant Age on the Uptake of Sr and Cs by Tumbleweed," Communications in Soil Science and Plant Analysis, Vol. 9, No.3, 1978, pp. 215-230.

35. E. M. Romney, W. A. Rhoads, A. Wallace, R. A. Wood, "Persistence of Radionuclides in Soil, Plants, and Small Mammals in Areas Contaminated with Radioactive Fallout," Proceedings of the Third National Symposium on Radioecology, Oak Ridge, Tennessee, 1971.

36. R. J. Garner, Transfer of Radioactive Materials from the Terrestrial Environment to Animals and Man, Boca Raton, Florida: CRC Press, 1972.

37. J. M. Broughton, D. L. Hargman, P. R. Davis, Experiment Requirements for In-Pile Severe Fuel Damage Tests to Fuel Melting in the Power Burst Facility, FIN No. A6305, Draft Preliminary Report for Comment, 1984.

38. C. F. Behrens and E. R. King, Atomic Medicine, Williams and Wilkins Co., Baltimore, 1964, p. 259 (two studies noted) and 257, 285, 401, 436.

39. W. D. Norwood, Health Protection of Radiation Workers, Charles C. Thomas, Pub., 1975.

40. U.S. Nuclear Regulatory Commission Information Notice 94-17, "Strontium-90 Eye Applicators: Submission of Quality Management Plan (QMP), Calibration, and Use," March 11, 1994.

41. C. F. Behrens, and E. R. King, Atomic Medicine, Williams \& Wilkins Company, Fourth Edition, 1964 , pp. 258, 259, 285, 352, 401, 436 and 651.

42. A. C. Uption, R. E. Albert, F. J. Burns, R. E. Shore (eds.), Radiation Carcinogenesis, Elsevier, 1986, pp. 139 and 220.

43. K. F. Eckerman, A. G. Wolbarst, and A. C. B. Richardson, Limiting Values of Radionuclide Intake and Air Concentration and Dose Conversion Factors for Inhalation, Submersion, and Ingestion, Federal Guidance Report No. 11, EPA-520/1-88-020, Oak Ridge National Laboratory, September 1988. 


\section{Bibliography}

Ames, L. L., and D. Rai, Radionuclide Interactions with Soil and Rock Media, Vol. 1, Environmental Protection Agency, 520/6-78-007-a, August 1978.

Bolz, R. E., and G. L. Tuve (eds.), CRC Handbook of Tables for Applied Engineering Science, Second Edition, Boca Raton, Florida: CRC Press, 1977, Table 4-19, pp. 427 and 430.

Bradbury, M. H., and I. G. Stephen, "Diffusion and Permeability Based on Sorption Measurements in Intact Rock Samples," Materials Research Society Symposium Proceedings Vol. 50, 1985.

Carmon, B., A. Dyer, and D. Keir, "Influence of $\mathrm{pH}$ and Sodium Concentration on the Adsorption of ${ }^{137} \mathrm{Cs},{ }^{90} \mathrm{Sr}$, and ${ }^{90} \mathrm{Y}$ by Clinoptilolite and Zeolite A," Research Laboratories Annual Report 1987, IA$1440,1987$.

Garner, R. John, Transfer of Radioactive Materials from the Terrestrial Environment to Animals and Man, Boca Raton, Florida: CRC Press, 1972, pp. 11, 13, 25, 38, 42.

Haigh, D. G., and P. J. Hooker, A Sorption Study of ${ }^{85} \mathrm{Sr},{ }^{13-} \mathrm{Cs}$, and ${ }^{22-}$ Th onto Glacial Sand as Part of an Interlaboratory Exercise, DOE/RW/88/078, 1988.

Hampel, C. A. (ed.), The Encyclopedia of the Chemical Elements, New York: Reinhold Book Corporation, current edition.

Jacobsen, J. S., and C. L. Carnahah, Numerical Simulation of Cesium and Strontium Migration Through Bentonite Altered by Cation Exchange with Groundwater Components, LBL-26395, 1988.

Miller, C. E., "Retention and Distribution of ${ }^{137} \mathrm{Cs}$ after Accidental Inhalation," Health Physics, Vol.10, 1964, p. 1065.

Moody, J. B., Radionuclide Migration/Retardation: Research and Development Technology Status Report, ONWI-321, 1982.

Norwood, W. D., Health Protection of Radiation Workers, Charles C. Thomas Publisher, 1975, pp. 249 and 255 .

Resnik, M. C., O. R. Lunt, and A. Wallace, "Cs, K, Sr, and Ca Transport in Two Different Plant Species," Soil Science, Vol. 108, No. 1, 1969, p. 64.

Rogers, R. D., and S. E. Williams, "Vesicular Arbuscular Mycorrhiza: Influence on Plant Uptake of Cesium and Cobalt," Soil Biology Biochemisty, Vol. 18, No.4, 1986, p. 371.

Sanders, C. L., R. H. Busch, J. E. Ballou, and D. D. Mahlum, (eds.), Radionuclide Carcinogenesis, U.S. Atomic Energy Commission Office of Information Services, 1972, pp. 13 and 262. 
Sheppard, M. I., D. I. Beals, D. H. Thibault, and P. O'Connor, Soil Nuclide Distribution Coefficients and their Statistical Distributions, AECL-8364, Atomic Energy Commission, December 1984.

U.S. Department of Energy, Isotope Production \& Distribution, obtained from the Westinghouse Hanford Company Isotope Program Office, P.O. Box 1970, Richland, Washington, 99352, Phone: (509) 376-9898, Section VII. 


\section{NICKEL-59}

\section{Introduction}

This chapter outlines the basic radiological, chemical, and physical characteristics of nickel-59 $\left({ }^{59} \mathrm{Ni}\right)$ and examines how these characteristics affect the behavior of ${ }^{59} \mathrm{Ni}$ in various environmental media, such as soils, groundwater, plants, the atmosphere, and the human body. Also included are methods of ${ }^{59} \mathrm{Ni}$ production and waste and disposal data on ${ }^{59} \mathrm{Ni}$.

All nickel atoms contain 28 protons $(Z=28)$ and various numbers of neutrons (typically $N=28$ to 38 neutrons) within the atom's nucleus. There exists five stable isotopes of nickel, namely ${ }^{58} \mathrm{Ni},{ }^{60} \mathrm{Ni}$, ${ }^{61} \mathrm{Ni},{ }^{62} \mathrm{Ni}$, and ${ }^{64} \mathrm{Ni}$. All other nickel isotopes, including ${ }^{59} \mathrm{Ni}$, are radioactive, with ${ }^{59} \mathrm{Ni}$ having the longest half-life of all the radioactive nickel isotopes. The radioactive isotopes of nickel are not a normal constituent of the natural environment and are generated from human activities.

The primary source of ${ }^{59} \mathrm{Ni}$ in the environment has recently been low-level radioactive waste (LLW) material generated as a result of neutron activation of ${ }^{58} \mathrm{Ni}$ in the structural components of reactor vessels and produced from the dismantling activities associated with nuclear reactor decommissioning. However, small amounts of ${ }^{63} \mathrm{Ni}$ have been detected in the environment following the testing of thermonuclear weapons in the South Pacific. ${ }^{1}$ Since both ${ }^{59} \mathrm{Ni}$ and ${ }^{63} \mathrm{Ni}$ are produced as a result of neutron activation of stable nickel isotopes commonly found in stainless steels, ${ }^{59} \mathrm{Ni}$, more difficult to detect than ${ }^{63} \mathrm{Ni}$, should also have been released to the environment from thermonuclear weapons tests. ${ }^{59} \mathrm{Ni}$ is not created as a fission product, but instead is produced as a result of neutron capture in ${ }^{58} \mathrm{Ni}$, a common isotope present in stainless steels (e.g., stainless-304 contains $9 \%$ total $\mathrm{Ni}$ or $\sim 6 \%{ }^{58} \mathrm{Ni}$ ).

This chapter also describes potential difficulties in dealing with ${ }^{59} \mathrm{Ni}$. However, ${ }^{59} \mathrm{Ni}$ behavior and appropriate handling, storage, or disposal will vary depending on the waste form and the disposal site's geology, hydrology, and climate. Therefore, this chapter does not attempt to discuss the extent of a difficulty or appropriate solutions. Each disposal site facility design should consider and address the specific waste content and behavior under that site's particular circumstances. A radionuclide considered sensitive at one LLW disposal facility may not be considered sensitive at another facility.

\section{Radiological Characteristics}

${ }^{59} \mathrm{Ni}$ has a reported half-life $\left(\mathrm{T}_{1 / 2}\right)$ of between 75,000 and 76,000 years and is formed via neutron capture $(\mathrm{n}, \gamma)$ of ${ }^{58} \mathrm{Ni}\left(\right.$ e.g., ${ }^{58} \mathrm{Ni}+\mathrm{n}->{ }^{50} \mathrm{Ni}+\gamma$-ray) ${ }^{2,3,4,5}{ }^{59} \mathrm{Ni}$ undergoes radioactive decay either by electron capture (EC) $\sim 99.999985 \%$ of the time, or $\sim 0.000015 \%$ of the time via positron $\left(\beta^{+}\right)$emission. ${ }^{2}$ Since the positron emission is very small, for all practical purposes and for the purposes of this chapter, positron emission from ${ }^{59} \mathrm{Ni}$ is ignored and only decay by electron capture is considered. Nuclear decay involving electron capture can be more complicated than beta or alpha decay processes, as the next paragraph demonstrates.

The ${ }^{59} \mathrm{Ni}$ nucleus decays to the stable isotope of cobalt-59 $\left({ }^{59} \mathrm{Co}\right)$ with the emission of a discrete number of $\mathrm{x}$-ray photons from the ${ }^{59} \mathrm{Co}$ atom (e.g., $19.6 \%$ probability with a $6.930-\mathrm{keV} \mathrm{K} \mathrm{a}_{1} \mathrm{x}$-ray; $9.9 \%$ with a $6.915-\mathrm{keV} \mathrm{K}_{\alpha 2} \mathrm{x}$-ray; $3.56 \%$ with a $7.649-\mathrm{keV} \mathrm{K}_{\beta 1} \mathrm{x}$-ray; $0.33 \%$ with a $0.799-\mathrm{keV} \mathrm{x}$-ray; etc.). 
The overall average cobalt $\mathrm{x}$-ray emission energy is $2.32 \mathrm{keV}$ (thousand-electron volts) per disintegration with a peak x-ray energy of $\sim 7.7 \mathrm{keV} .^{3}$ A continuous spectrum of bremsstrahlung (x-ray) radiation is also released with an average energy of $0.30 \mathrm{keV}$ per disintegration. ${ }^{3}$ And finally, an atomic electron (called an Auger electron) can be ejected from the newly created ${ }^{59} \mathrm{Co}$ atom (average energy is $4.1 \mathrm{keV}$ per disintegration). ${ }^{3}$ An Auger electron is an atomic electron that receives enough kinetic energy to be ejected from the atom, usually from the L-shell (e.g., via x-ray absorption). This process occurs when another electron falling from the same shell to fill a lower K-shell vacancy liberates an x-ray photon that is subsequently absorbed by another electron which is then ejected from the atom. The production of Auger electrons usually competes with $\mathrm{x}$-ray (photon) emission. The energy of an Auger electron is equivalent to the energy of the $\mathrm{x}$-ray photon that was absorbed minus the electron binding energy. The energy difference between the ground states of ${ }^{59} \mathrm{Co}$ and ${ }^{59} \mathrm{Ni}$ is $1,060 \mathrm{keV}$; however, the average amount of recoverable energy released per ${ }^{59} \mathrm{Ni}$ disintegration (e.g., not including neutrino energy) is $6.72 \mathrm{keV} .{ }^{4}$ Both gamma-rays and $x$-rays consist of high energy photon radiation of short wave-lengths. The primary difference between gamma-rays and $\mathrm{x}$-rays is the origin of this radiation. Generally, gamma-rays originate from the nucleus of the atom (due to nuclear events) and $x$-rays result from the radiation emitted by accelerated electrons surrounding the nucleus. Although $x$-rays have lower energies and longer wave-lengths than gamma-rays, the essential difference between $x$-rays and gamma-rays is that $\mathrm{X}$-iays are produced outside the nucleus. Bremsstrahlung radiation is electromagnetic radiation that is similar to x-rays. It is produced by charged particles (e.g., electrons) as they decelerate in a series of collisions with other atoms. In other words, the continuous spectrum of $\mathrm{x}$-rays produced from bremsstrahlung radiation are caused by high speed electrons slowing down and losing some of their energy while passing through matter.

Although the $(\mathrm{n}, \gamma)$ capture cross-section of ${ }^{58} \mathrm{Ni}$ is small (e.g., 4.6 barns or $4.6 \times 10^{-24} \mathrm{~cm}^{2}$ ), over a long period of neutron irradiation a significant amount of ${ }^{59} \mathrm{Ni}$ will be produced and will pose special problems in the decommissioning of light-water reactors. In particular, the $\mathrm{x}$-ray and particle emissions from ${ }^{59} \mathrm{Ni}$ decay are not very energetic and generally do not pose a radiological hazard. However, under some conditions, ${ }^{59} \mathrm{Ni}$ can contribute a major fraction of the total dose received by persons involved in the dismantling of nuclear reactors (e.g., greater than the ${ }^{60} \mathrm{Co}$ dose). This situation can occur if the reactor has been operated for a very long time (e.g., $~ 30$ years). Generally, ${ }^{59} \mathrm{Ni}$ does not represent a primary concern in shielding or waste classification, but can produce a significant contributor to the radioactivity from activation isotopes and can determine the acceptability of certain reactor hardware as LLW material.

The decay sequence for ${ }^{59} \mathrm{Ni}$ showing the absorption of an atomic electron and the emission of cobalt $\mathrm{x}$-rays, atomic (or Auger) electrons, and bremsstrahlung produced x-rays are illustrated in the following nuclear transformations:

$$
\begin{aligned}
& 100 \%
\end{aligned}
$$

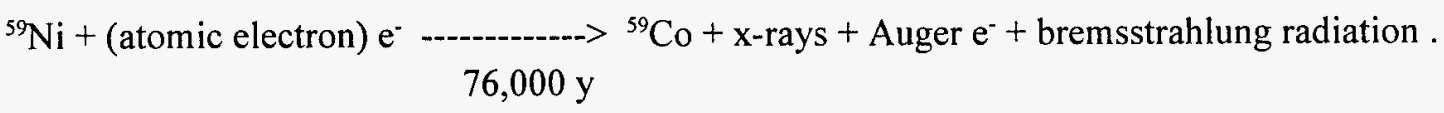

${ }^{59} \mathrm{Ni}$ is usually detected by measuring the $6.915-\mathrm{keV} \mathrm{x}$-ray photon.

In electron capture decay, usually a K-shell or L-shell orbital atomic electron (i.e., an electron close to the nucleus) is captured by the nucleus. The absorbed electron combines with a proton to form a neutron 
(n) and a neutrino (v) particle within the nucleus (e.g., $\mathrm{e}^{-+} \mathrm{p}^{+}->\mathrm{n}+\mathrm{v}$ ). The neutrino escapes the nucleus with excess energy and ${ }^{59} \mathrm{Co}$ atom is created with one less proton and one more neutron than the original ${ }^{59} \mathrm{Ni}$ atom. The overall decay process is called electron capture (EC). The capture of the orbital electron by the nucleus leaves a vacancy in the outer electron shell of the new atom and, therefore, this atom is left in an excited and positive state $\left(\right.$ e.g. $\left.{ }^{59} \mathrm{Co}^{+}\right)$. In order for the new atom to reach a normal energy state, the remaining electrons tend to cascade down into lower shells to fill the original vacancy. During this process, $\mathrm{x}$-rays are emitted as the electrons lose energy in the form of short wavelength photons. Also, atomic (or Auger) electrons are emitted due to absorption of $\mathrm{x}$-ray photons by the atomic electrons.

Table 8-1 lists the maximum ranges for a 4.1-keV (average energy) Auger electron emitted from ${ }^{59} \mathrm{Co}$ due to ${ }^{59} \mathrm{Ni}$ decay. Note that the maximum particle ranges are very small and since it requires a $70-\mathrm{keV}$ electron to penetrate the protective layer of human skin, these electrons, lacking sufficient energy, cannot penetrate the $0.07 \mathrm{~mm}$ of human skin. The Auger electrons from ${ }^{59} \mathrm{Co}$ (due to ${ }^{59} \mathrm{Ni}$ decay) are about as dangerous as the $5.7-\mathrm{keV}$ average energy beta $\left(\beta\right.$, or negative electron) particles emitted by tritium $\left({ }^{3} \mathrm{H}\right)$ decay (note Tables 8-2 and 8-3). ${ }^{6}$

The $\mathrm{x}$-rays produced from ${ }^{59} \mathrm{Ni}$ decay are more penetrating than the Auger electrons. The half-value thickness, the thickness required to reduce the original $x$-ray intensity by a factor of 2 , for the maximum energy x-rays $(\sim 7.7 \mathrm{keV})$ in water media is about $0.8 \mathrm{~mm}$. That is, for every $0.8 \mathrm{~mm}$ of water, the $\mathrm{x}$-ray intensity will drop by a factor of 2 . In order to reduce the cobalt $x$-ray intensity by a factor of 1,000 (i.e., ten half-value layers), approximately $8 \mathrm{~mm}$ or 0.3 inches of water would be required. The $\mathrm{x}$-rays from ${ }^{59} \mathrm{Ni}$ decay have wavelengths of $\geq 1.6 \AA$ (Angstroms or $10^{-10}$ meters), with an average energy $\mathrm{x}$-rays having a wavelength of $3.0 \AA$. X-rays of wave-lengths of about $3 \AA$ or larger are usually considered "soft" and the $\mathrm{x}$-rays produced from ${ }^{59} \mathrm{Ni}$ decay are primarily of this type. ${ }^{7}$

Table 8-1. Comparison of the estimated maximum ranges for a 4.1-keV average energy Auger electron emitted from ${ }^{59} \mathrm{Ni}$ decay for various materials.

\begin{tabular}{lc}
\hline Material (description) & $\begin{array}{c}\text { Estimated maximum } \\
\text { range for a } \\
4.1-\mathrm{keV} \mathrm{e}^{-}(\mathrm{mm})^{\mathrm{a}}\end{array}$ \\
\hline Air (1 atmosphere pressure) & 2.0 \\
Water & 0.0022 \\
Plastic (Lucite) & 0.0019 \\
Concrete & 0.0017 \\
Al (aluminum) or glass & 0.0015 \\
Fe (iron) & 0.0005 \\
$\mathrm{~Pb}$ (lead) & 0.0002 \\
\hline
\end{tabular}

a. Estimates are based on extrapolations of the maximum beta particle range data shown on p. 122 of Reference 6 or Figure 13.3 on p. 266 of Reference 8 as a function of energy and materials. 
Table 8-2. Comparison of the radiotoxicity of several important radionuclides (obtained from Appendix 2 of Reference 9).

\begin{tabular}{lll}
\hline \multicolumn{2}{c}{ Radiotoxicity } & \multicolumn{1}{c}{ Species } \\
\cline { 2 - 3 } Very high & Group 1 & ${ }^{241} \mathrm{Pu},{ }^{242} \mathrm{Cm},{ }^{241} \mathrm{Am},{ }^{237} \mathrm{~Np}$ \\
High & Group 2 & ${ }^{60} \mathrm{Co},{ }^{90} \mathrm{Sr},{ }^{94} \mathrm{Nb}$ \\
Moderate & Group 3 & ${ }^{14} \mathrm{C},{ }^{63} \mathrm{Ni},{ }^{137} \mathrm{Cs}$ \\
Low & Group 4 & ${ }^{3} \mathrm{H},{ }^{59} \mathrm{Ni},{ }^{99 \mathrm{~m}} \mathrm{Tc},{ }^{99} \mathrm{Tc},{ }^{129} \mathrm{I}$ \\
\hline
\end{tabular}

Table 8-2 lists the radiotoxicity of several important radionuclides. Note that both tritium $\left({ }^{3} \mathrm{H}\right)$ and ${ }^{59} \mathrm{Ni}$ are in the same low (Group 4) classification. Table 8-3 compares the average and maximum Auger electron energies associated with ${ }^{59} \mathrm{Ni}$ decay with other well-known electron (beta particle) emitters. Note that the average and maximum energy of the Auger electrons emitted from ${ }^{59} \mathrm{Ni}$ decay are lower than the beta particle (i.e., negative electron) energies emitted from tritium decay.

\section{Chemical and Physical Characteristics}

Nickel is a silver-white metal with metallic properties. It has high electrical and thermal conductivities and can be drawn, rolled, forged, and polished. It is ferromagnetic, though not so strongly as iron. The finely divided metal is reactive to air and may be pyrophoric under some conditions. ${ }^{10}$

Nickel occurs in nature primarily in combination with arsenic, antimony, and sulfur. The largest nickel deposits are garnierite, a magnesium-nickel silicate, and certain varieties of pyrrhotite, an ironsulfur compound that can contain between 3 to $5 \%$ nickel. $^{10}$ The center of the earth is believed to contain considerable quantities of iron and nickel.

Although nickel shares some chemical characteristics with its two neighboring elements in the periodic table, iron and cobalt, palladium and platinum are in the same chemical family as nickel. The most abundant oxidation state for nickel is $\mathrm{Ni}^{2+}$. Nickel may be oxidized to the +3 and +4 states, or reduced to the +1 state, in the presence of a suitable complexing agent (nickel can even form compounds as $\mathrm{Ni}^{\circ}$ ), but such reactions are seldom carried out. The melting and boiling points for nickel are 1450 and 2800 degrees Celsius $\left({ }^{\circ} \mathrm{C}\right.$ ), respectively. ${ }^{11}$ The oxidation potential of nickel (to remove the two $4 \mathrm{~s}$ electrons from an atom) is $0.25 \mathrm{eV}$. The metal dissolves readily in dilute mineral acids but does not dissolve in concentrated nitric acid (similar to iron) because it is rendered passive by this reagent. Nickel is quite resistant to attack by air or water at ordinary temperatures (when compact) and is often electroplated as a protective coating. Table 8-4 summarizes some of the more important chemical properties of nickel. 
Table 8-3. Average and maximum kinetic energies of beta particles and negative (atomic) electrons released during the decay of several important radionuclides (compiled from data in References 3, 5, 12 , 13,14 , and 15 ).

\begin{tabular}{lcc} 
& \multicolumn{2}{c}{ Released electron energy } \\
\cline { 2 - 3 } \multicolumn{1}{c}{ Radionuclide } & $\begin{array}{c}\text { Average Energy } \\
(\mathrm{keV})\end{array}$ & $\begin{array}{c}\text { Maximum Energy } \\
(\mathrm{keV})\end{array}$ \\
\hline Nickel-59 $\left({ }^{59} \mathrm{Ni}\right)$ & $\mathbf{4 . 1 ^ { \mathrm { b } }}$ & $\sim 7.7^{\mathrm{b}}$ \\
Tritium $\left({ }^{3} \mathrm{H}\right)$ & 5.68 & 19.0 \\
Iodine-129 $\left({ }^{129} \mathrm{I}\right)$ & 40.0 & 150.0 \\
Carbon-14 $\left({ }^{14} \mathrm{C}\right)$ & 49.0 & 156.0 \\
Technetium-99 $\left({ }^{99} \mathrm{Tc}\right)$ & 85.0 & 293.0 \\
Iodine-131 $\left({ }^{131} \mathrm{I}\right)$ & 180.0 & $806.0^{\mathrm{c}}$ \\
Cesium-137 $\left({ }^{137} \mathrm{Cs}\right)$ & 195.0 & 1176.0 \\
Potassium-40 $\left({ }^{40} \mathrm{~K}\right)$ & 541.0 & 1330.0 \\
Phosphorous-32 $\left({ }^{32} \mathrm{P}\right)$ & 694.0 & 1710.0
\end{tabular}

a. $1,000 \mathrm{keV}=1 \mathrm{MeV}$ (million-electron volt). Beta particle energy unless noted.

b. The data for ${ }^{59} \mathrm{Ni}$ represents Auger or atomic electrons and not electrons emitted from the nucleus (i.e., beta particles). The maximum atomic electron energy was estimated based on the assumption that an electron from the ${ }^{59} \mathrm{Co}$ atom absorbs a maximum energy $\mathrm{x}$-ray.

c. $90.4 \%$ of the beta particle intensity for I- 131 occurs at $606 \mathrm{keV}$, and only $0.6 \%$ occurs at $806 \mathrm{keV}$.

Nickel readily reacts to form compounds with oxygen (e.g., $\mathrm{NiO}$ ), sulfur (e.g., $\mathrm{NiS}, \mathrm{NiSO}_{4}$ ), and the halogens (e.g., $\mathrm{NiF}_{2}, \mathrm{NiCl}_{2}$, and $\mathrm{NiI}_{2}$ ). In addition, at high temperatures, nickel forms compounds with hydrogen, boron, carbon, nitrogen, silicon, and phosphorus. Nickel is important as a constituent in a wide variety of corrosion-resistant metal alloys including, stainless steels, Inconels, and Monel.

The colors of the familiar $\mathrm{Ni}^{2+}$ solutions used as laboratory reagents are not representative of the colors of the salts from which they are derived. Although the majority of anhydrous nickel salts are yellow (e.g., $\mathrm{NiBr}_{2}$ is yellow), several compounds exhibit other colors: $\mathrm{Ni}(\mathrm{SCN})_{2}$ is brown, and $\mathrm{NiI}_{2}$ is black. Nickel forms an interesting variety of chemical complexes. Some of the most familiar are $\mathrm{Ni}\left(\mathrm{H}_{2} \mathrm{O}\right)_{6}{ }^{2+}$, and $\mathrm{Ni}\left(\mathrm{NH}_{3}\right)_{6}{ }^{2+}$, which are both octahedral in structure. 
Table 8-4. Physical properties of nickel. (Obtained from References 16, 17, and 18).

\begin{tabular}{lc}
\multicolumn{1}{c}{ Physical property (units) } & Nickel data \\
\hline Melting point (degrees Kelvin, K) & $1,725.0$ \\
Boiling point (degrees Kelvin, K) & $3,173.0$ \\
Heat of fusion (cal/g) & $4,323.0$ \\
Heat of vaporization (cal/g) & $90,800.0$ \\
Solid density (g/cm ${ }^{\mathrm{a}}$ ) & 8.9 \\
Liquid density (g/cm $\left.{ }^{3}\right)$ & $-{ }^{\mathrm{b}}$ \\
Oxidation potential (V) & 0.25 \\
Ionization potential (eV) & 7.635 \\
Work function (eV) & $-{ }^{\mathrm{b}}$ \\
Crystal form & face-centered-cubic
\end{tabular}

a. Note that zero degrees kelvin $(0 \mathrm{~K})$ equals $-273.15^{\circ} \mathrm{C}$ or $-459.67^{\circ} \mathrm{F}$.

b. Data not available.

\section{Nickel-59 Production}

The structural materials inside the vessel of a nuclear reactor are exposed to neutron radiation. This radiation can cause many components of these materials to become radioactive with time. Those elements most susceptible to neutron activation are iron ( $\mathrm{Fe})$, nickel $(\mathrm{Ni})$, and cobalt $(\mathrm{Co})$, found primarily in stainless steel and other important alloys (e.g., Inconel). Depending upon the amount of time these materials are irradiated and the neutron fluence (i.e., integrated neutron flux), any of these isotopes may be become the critical activation product affecting the dismantling activities of the reactor.

The primary means of producing ${ }^{59} \mathrm{Ni}$ is via neutron capture of ${ }^{58} \mathrm{Ni}$, a stable isotope of nickel that exists in nickel alloys, primarily stainless steels. Nuclear fission does not play any significant role in producing ${ }^{59} \mathrm{Ni}$. This can be seen in Figure 8-1 where the ${ }^{59} \mathrm{Ni}$ position is shown with respect to the fission product yield distribution for thermal neutron fission of ${ }^{235} \mathrm{U}$. This information was obtained from the fission yield data from the ORIGEN $2{ }^{19}$ computer code. The cumulative fission yield of ${ }^{59} \mathrm{Ni}$ from fission of ${ }^{235} \mathrm{U}$ atoms is basically zero.

Since ${ }^{58} \mathrm{Ni}$ atoms have a small thermal neutron absorption cross-section (i.e., $\sigma_{\mathrm{a}}=4.6$ barns $=$ $4.6 \times 10^{24} \mathrm{~cm}^{2}$ ), and since ${ }^{58} \mathrm{Ni}$ comprises only a small fraction of the stainless steel in a nuclear reactor $(\sim 6 \%)$, it generally takes many years of neutron irradiation to produce any significant quantity of ${ }^{59} \mathrm{Ni}$. 
Fission yield from thermal fission of $\mathrm{U}-235$

(Total fission yield summed over all mass numbers $=200 \%$ )

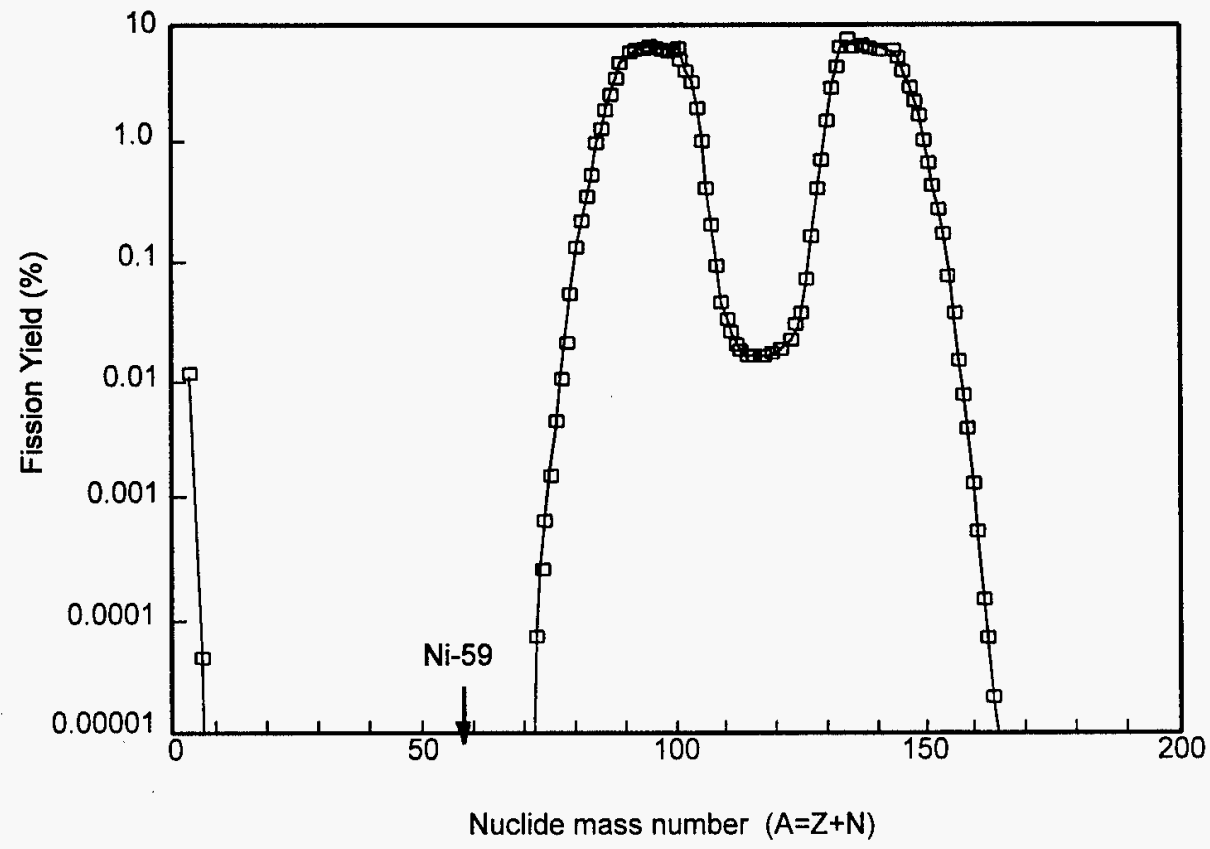

Figure 8-1. Fission product yield curve for thermal fission of ${ }^{235} \mathrm{U}$. Note that the fission yield for ${ }^{59} \mathrm{Ni}$ should appear at the mass number of 59 (indicated by the Ni-59 position); however, the yield curve falls below the smallest value $(0.00001 \%)$ shown for mass number 59 .

Also, since ${ }^{59} \mathrm{Ni}$ has such a long half-life $\left(\sim 76,000\right.$ years), essentially all of the ${ }^{59} \mathrm{Ni}$ that is produced within the reactor structure, remains with the reactor until it is dismantled. In other words, the ${ }^{59} \mathrm{Ni}$ inventory increases linearly with reactor operation and does not significantly decrease. Figure 8-2 shows the buildup of several different activation products in a pressurized water reactor (PWR) vessel, including ${ }^{59} \mathrm{Ni}$, as a function of reactor operation.

${ }^{59} \mathrm{Ni}$ has not been considered a controlling radionuclide in nuclear reactor decommissionings until recently. This has occurred because the periods of reactor operation have not been long enough to generate significant quantities of this radionuclide, relative to other activation products $\left(\right.$ e.g., $\left.{ }^{60} \mathrm{Co}\right)$. However, as can be seen from Figure 8-2, the activity of ${ }^{59} \mathrm{Ni}$ will exceed that from ${ }^{55} \mathrm{Fe}$ and ${ }^{60} \mathrm{Co}$ after 30 years of continuous operation, or 40 years of operation with an average plant factor of $75 \%$. 


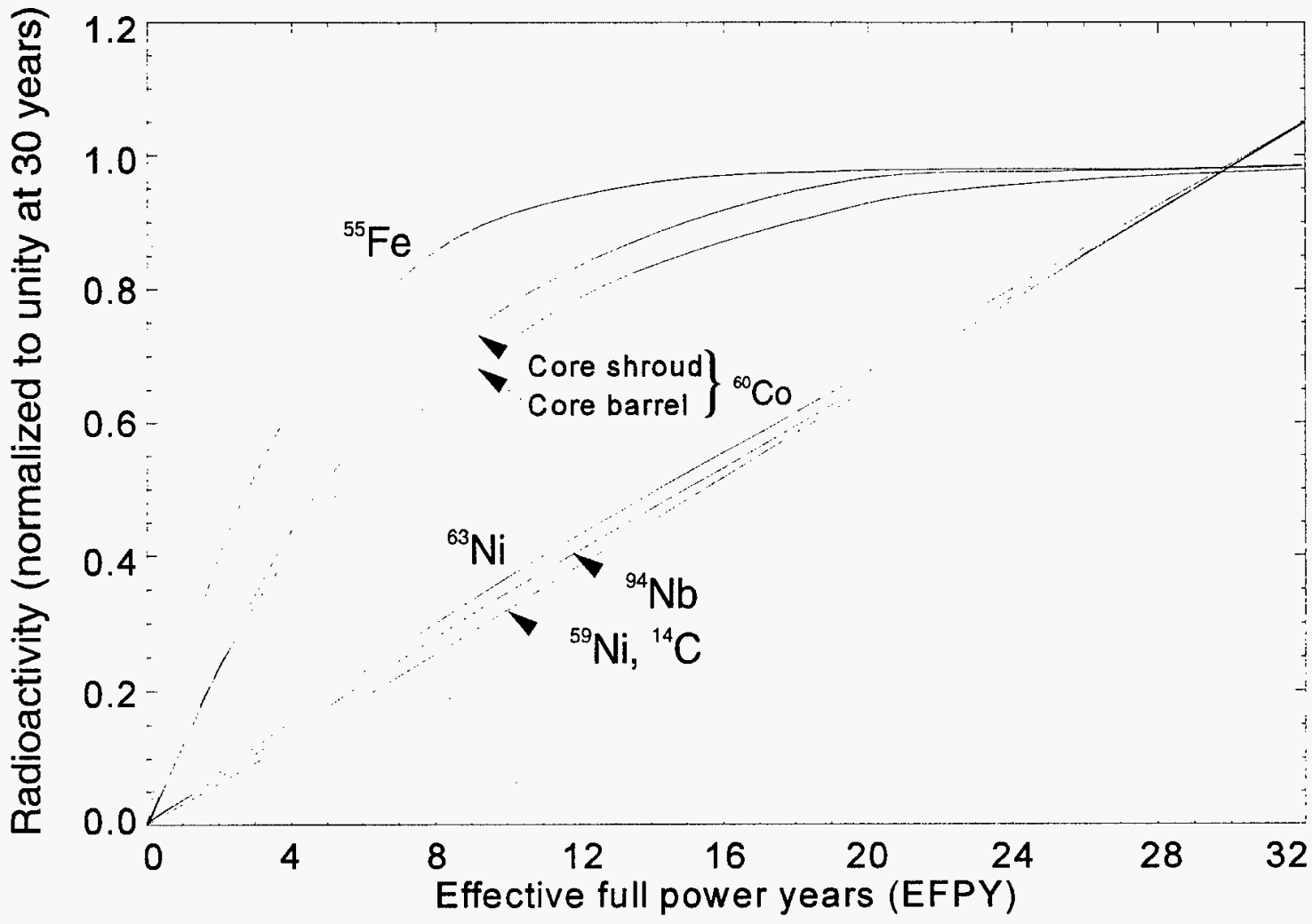

Figure 8-2. Buildup of some important activation products in a PWR as a function of reactor operation. Note that the lowest curve from 0 to 29 years represents ${ }^{59} \mathrm{Ni}$.

\section{Waste and Disposal Data on Nickel-59}

This section discusses the types of activities that generate ${ }^{59} \mathrm{Ni}$ LLW, waste types and forms that contain ${ }^{59} \mathrm{Ni}$, and disposal data on ${ }^{59} \mathrm{Ni}$.

\section{Nuclear Reactors}

The quantity of ${ }^{59} \mathrm{Ni}$ generated within the structural components of a nuclear reactor increases linearly with burnup; that is, double the reactor operation and the ${ }^{59} \mathrm{Ni}$ inventory doubles. Since the half-life of ${ }^{59} \mathrm{Ni}$ is much longer than the life of the reactor, no process effectively decreases the ${ }^{59} \mathrm{Ni}$ inventory over the reactor's useful lifetime.

LLW usually contains small quantities of fission products or activation products including ${ }^{59} \mathrm{Ni}$. The primary waste forms containing radionuclides that result from nuclear reactor operations are contaminated scrub water, decontamination solutions, demineralizers; contaminated clothing; contaminated tools and equipment used in radioactive areas; pumps, valves, seals, bearings, scrap materials, and ion-exchange resins and filters. However, none of ihe principal LLW forms contain radiologically significant quantities of ${ }^{59} \mathrm{Ni}$. In the case of ${ }^{59} \mathrm{Ni}$, only extremely small quantities of this radionuclide are found in the primary coolant system of operating reactors due to activation of suspended metals or crud. The equipment and systems used to cleanup this water will contain many radionuclides in much higher concentrations than ${ }^{59} \mathrm{Ni}$, that the ${ }^{59} \mathrm{Ni}$ concentration does not enter into the eventual 
classification of these typical reactor waste materials. For example, the ${ }^{59} \mathrm{Ni}$ concentration in the primary coolant water of many PWRs is usually less than $3 \times 10^{-5} \mu \mathrm{Ci} /$ liter, compared with ${ }^{137} \mathrm{Cs}$ concentrations of $>1 \mu \mathrm{Ci} /$ liter. $^{20}$

The primary LLW containing ${ }^{59} \mathrm{Ni}$ are those solid waste forms existing within the reactor vessel as structural materials, mainly stainless steels components. It is during decommissioning and dismantling of these components that LLW is produced which contains ${ }^{30} \mathrm{Ni}$.

\section{Medical, Academic Institutions, and Commercial Nickel-59 Waste}

Since ${ }^{59} \mathrm{Ni}$ has such a long half-life ( $~ 76,000$ years) and only very weak radiations, medical or commercial applications of the radionuclide do not exist. In addition, since ${ }^{59} \mathrm{Ni}$ decays directly to the ground state of ${ }^{59} \mathrm{Co}$ by electron capture, there would be neither alpha, beta, nor gamma radiations-only weak x-ray radiation. Therefore, the use of ${ }^{59} \mathrm{Ni}$ as an external radiation source would be severely limited. There are also no known waste streams of ${ }^{59} \mathrm{Ni}$ from academic institutions. ${ }^{21}$

No commercial or medical wastes containing or using ${ }^{59} \mathrm{Ni}$ have been identified; however, ${ }^{59} \mathrm{Ni}$ has been available in the form of nickel-chloride $\left({ }^{59} \mathrm{NiCl}_{2}\right)$ suspended in a hydrogen-chloride $(\mathrm{HCl})$ solution.

\section{Disposal Data on Nickel-59}

${ }^{59} \mathrm{Ni}$ has been deposited in three LLW sites in Richland, Washington; Barnwell, South Carolina; and Beatty, Nevada over a period of several years. Data on the activity, sources, and waste types for this nuclide in these sites have been obtained from the Manifest Information Management System Database. ${ }^{2}$ Figure 8-3 shows the total annual ${ }^{59} \mathrm{Ni}$ activity deposited in the three sites for each year between 1986 and 1995 . Over half of the total activity for this nuclide $(59 \%)$ was deposited in $1989 .{ }^{59} \mathrm{Ni}$ deposits were spread fairly uniformly over the other nine years.

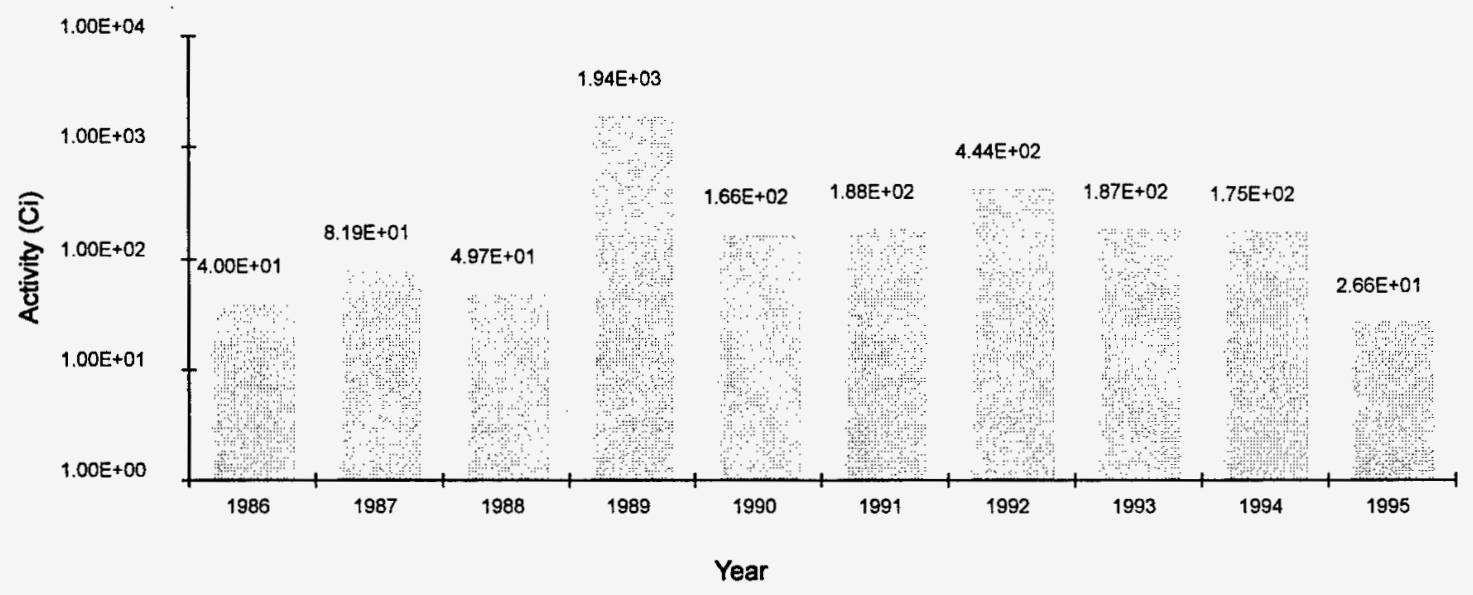

Figure 8-3. ${ }^{59} \mathrm{Ni}$ activity deposited at the Richland, Beatty, and Barnwell sites by year (log scale).

a. Information provided through the DOE waste management system maintained by the National Low-Level Waste Management Program, Idaho National Engineering Laboratory (INEL). 
Figure 8-4 shows the activity of ${ }^{59} \mathrm{Ni}$ deposited in these three sites as a function of waste source. Utilities accounted for more than $98 \%$ of the total deposited in these three sites. The other sources accounted for the remaining $<2 \%$ of the deposits.

The definition of disposal categories given in Figure 8-4 is as follows: academic - sources associated with university laboratories; government - sources associated with the government, such as military hospitals; industry - sources associated with manufacturing, other than utilities; medical - sources associated with hospitals and medical laboratories, excluding pharmaceutical manufacturing; utility sources generated by nuclear utilities and stored onsite or sent to one of the three disposal sites. Waste treatment facilities are included in the utility category.

Figure 8-5 shows the activity of ${ }^{59} \mathrm{Ni}$ deposited in the Richland and Beatty sites as a function of waste type. The waste disposal manifests for the Barnwell site did not break down the waste by type, which is unfortunate since $90 \%$ of this nuclide has been stored at this site. As shown in this figure, more than $90 \%$ of the deposits for this nuclide were in the form of activated reactor hardware.

The waste types illustrated in Figure 8-5 are from nuclear reactors, academic institutions, and medical facilities.

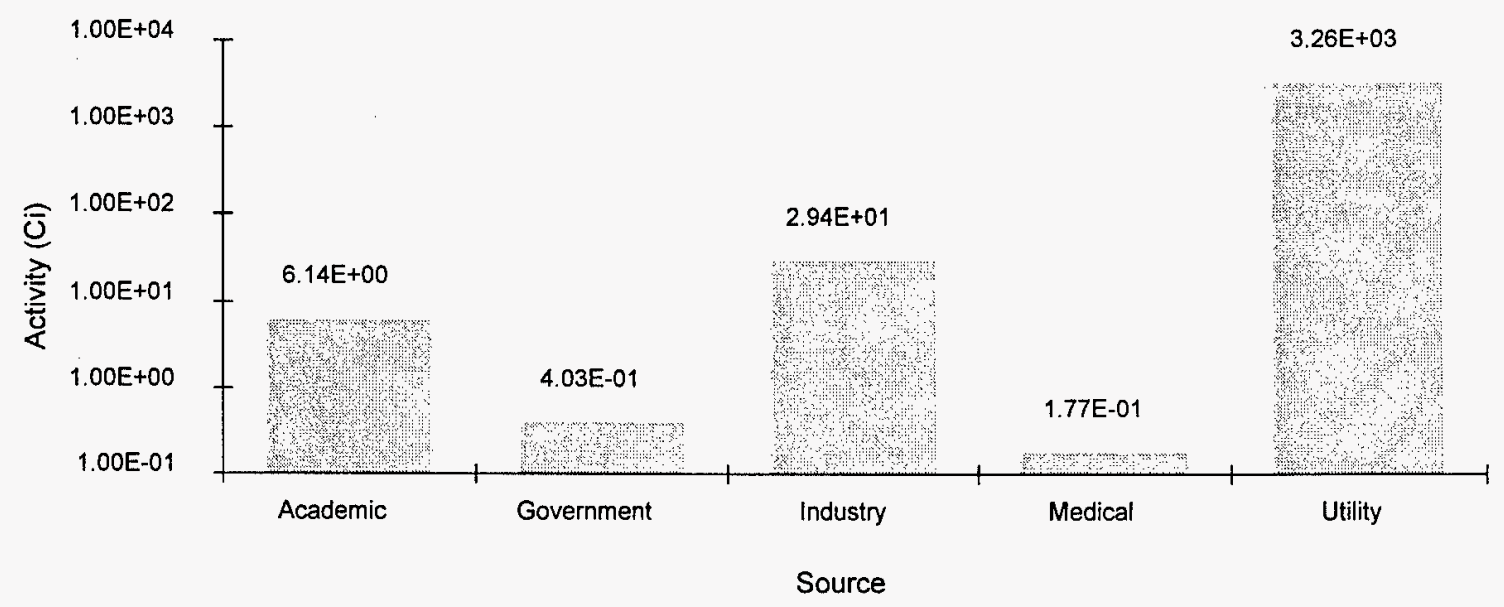

Figure 8-4. ${ }^{59} \mathrm{Ni}$ activity deposited at the Richland, Beatty, and Barnwell sites by source (log scale). 


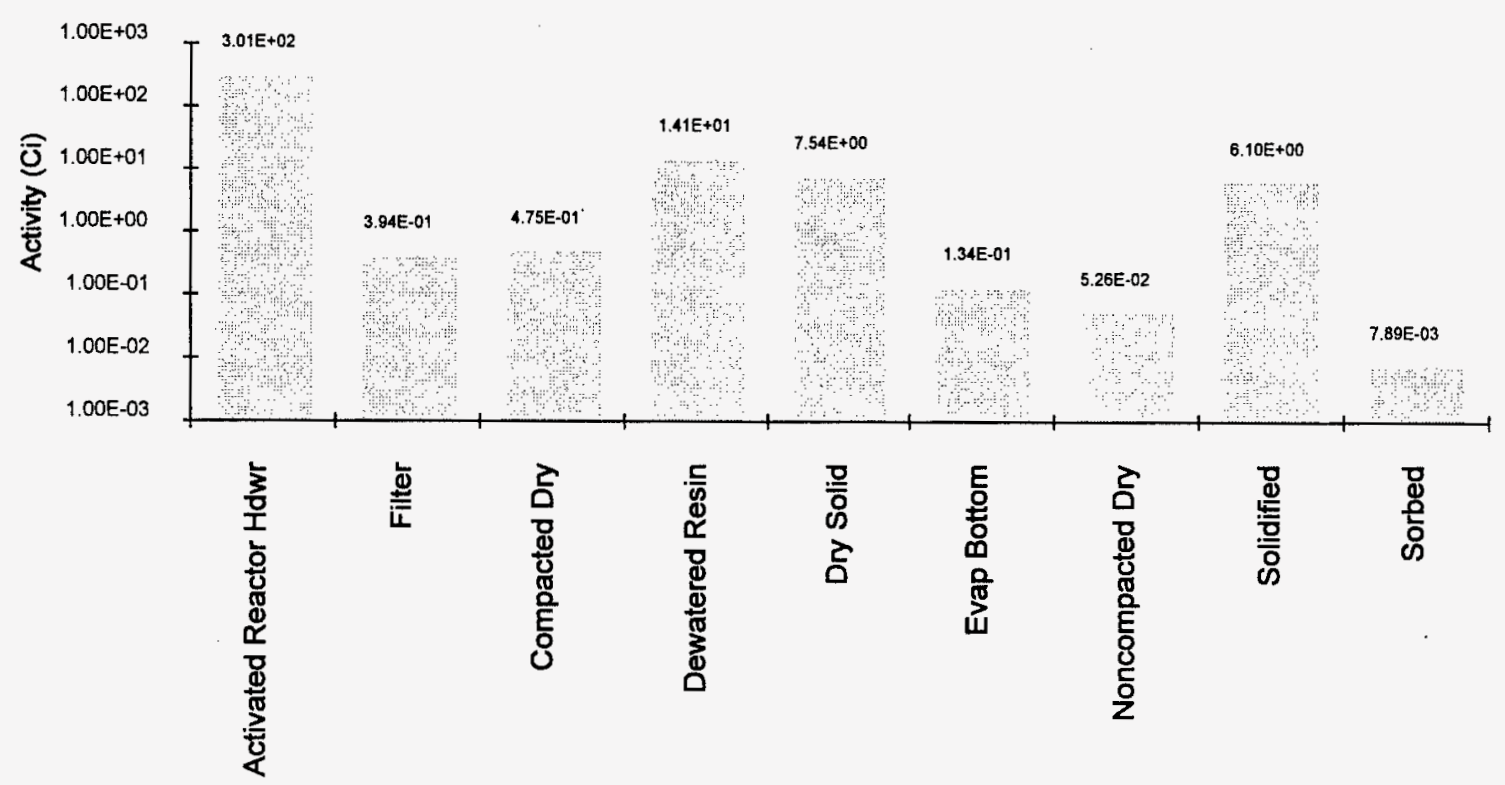

Waste Type

Figure 8-5. ${ }^{59} \mathrm{Ni}$ activity deposited at the Richland and Beatty sites by waste type (log scale).

\section{Behavior of Nickel-59 in the Environment}

\section{Nickel-59 in Soils}

Understanding of the behavior of fission products such as nickel in the soil is important in predicting the dissolution of radioactive waste in underground vaults and the subsequent transport of radionuclides through the biosphere. ${ }^{22}$ It is important to understand the interactions between radionuclides and various media along the path to the biosphere, whether disposal is in deep or shallow rock caverns or in shallow overburden facilities.

Nickel occurs naturally in many soils. In fact, on an elemental basis, the naturally occurring forms of nickel can be much more prevalent than the trace amounts of ${ }^{59} \mathrm{Ni}$ found in typical waste streams. ${ }^{23}$ The typical range for naturally occurring nickel concentrations in soils is 5 to 1,000 parts per million (ppm), with some soils containing up to $6,200 \mathrm{ppm}$ nickel. Concentrations, either expected or actual, for radionuclides, including ${ }^{59} \mathrm{Ni}$, are much lower. Nickel also occurs naturally in groundwater, with typical concentrations up to $50 \mathrm{ppm}$, also much higher than radionuclide concentrations. For water with a pH less than 8 , the dominant ionic form for nickel is $\mathrm{Ni}^{2+}$.

Four parameters were reported to be essential in accurately predicting soil concentrations from either contaminated ground water or irrigation water. ${ }^{22}$ The four parameters, in order of decreasing importance, are: (a) soil retention, (b) annual precipitation, (c) soil texture, and (d) depth to the water table. The soil retention parameter represents the solid/liquid partition coefficient and is denoted by the symbol: $K_{d}$. $K_{d}$ is defined by $\mathrm{K}_{d}=\mathrm{C}_{\mathrm{s}} / \mathrm{C}_{1}$, where $\mathrm{C}_{\mathrm{s}}$ is the nickel concentration in the soil (solid) and $\mathrm{C}_{1}$ is the nickel concentration in the groundwater (liquid). This empirical model combines all soil retention mechanisms into a simple linear partition relation between the soil and the surrounding groundwater. This model assumes that the nickel concentration in groundwater and soil are in equilibrium with each other; that is, 
are not changing with time. Using this definition for $\mathrm{K}_{\mathrm{d}}$, it follows that the larger the value (that is, the higher the radionuclide concentration in the soil relative to that in the groundwater) the slower the migration of the radionuclide relative to groundwater flow. Therefore, $K_{d}$ can be thought of as a measure of the amount of "fixing" or holdup in the soil.

Typically, $\mathrm{K}_{\mathrm{d}}$ is measured under laboratory conditions, using samples that are relatively homogenous, and where it can be assured that equilibrium conditions are met. Applying these values to specific soils in the field can be difficult because actual soils are generally inhomogeneous and there are uncertainties as to how long it takes for the nickel concentrations in the soil and groundwater $\left(\mathrm{C}_{\mathrm{s}}\right.$ and $\left.\mathrm{C}_{1}\right)$ to be in equilibrium with each other. Therefore, one must be careful to ensure that soil samples used in laboratory studies are as closely representative of the field as possible. Even though the soil samples do not precisely match conditions in the field, $K_{d}$ values from these laboratory studies can be used in computer models that extrapolate data from laboratory experiments and field studies. In addition, some experiments are conducted using intact field samples to validate the laboratory $\mathrm{K}_{\mathrm{d}}$ values and to study the effects due to soil inhomogeneity.

The Environmental Protection Agency (EPA) performed a study of $\mathrm{K}_{d}$ values for a number of radionuclides, including one isotope of nickel as part of the LLW program. ${ }^{24}$ In this study, the EPA characterized the soils covering most of the USA into three major deposits: the Glaciated Central Region, Atlantic and Gulf Coastal Plains, and the Alluvial Basin. They then researched $\mathrm{K}_{\mathrm{d}}$ values for each radionuclide and soil type. The values for nickel ranged from 2000 to 5000 for the alluvial basin (soil retention high) to between 100 and 500 for the coastal plains (soil retention moderate) to less than 100 for the central region (soil retention low). The differences between these values is judged to be due to soil $\mathrm{pH}$ differences - higher $\mathrm{pH}$ values result in higher retention. To verify this conclusion, the EPA quotes a separate effects study ${ }^{25}$ performed on soil samples taken from Hanford, Washington. First, the $\mathrm{K}_{\mathrm{d}}$ for the as-collected soil with a $\mathrm{pH}=9$ was measured to be $1300 \mathrm{~mL} / \mathrm{g}$. Then, the soil $\mathrm{pH}$ was adjusted to a value of 6 and the $\mathrm{K}_{\mathrm{d}}$ again measured. The $\mathrm{K}_{\mathrm{d}}$ value for the high $\mathrm{pH}$ soil sample was about an order of magnitude higher than in the $\mathrm{pH}$-adjusted sample. In The Soil Chemistry of Hazardous Materials, ${ }^{23}$ the absorption of nickel is presented as a function of $\mathrm{pH}$ in two different complexing environments, an iron-gel and an aluminum-gel. For the aluminum-gel environment, there is almost a step change in percent absorption of nickel from less than $10 \%$ to nearly $100 \%$ as the $\mathrm{pH}$ is increased above 6 . A similar step change occurs for the iron-gel environment, but at the lower $\mathrm{pH}$ value of 5 .

Soil composition may also play a significant role. The central plains soil has a clay-silt composition, resulting in the least nickel soil retention. The Alluvial Basin soil has a sandy composition and the highest retention. The coastal plain soils lie between these two (e.g., a clay-sandy composition), and has an intermediate retention. ${ }^{24}$

As a final conclusion of the EPA study, nickel absorption in soil is also known to be significantly affected by precipitation and coprecipitation reaction with hydrous oxides of iron and manganese.

Reference 25 reports an investigation by Pacific Northwest Laboratory into the effect of organic complexing agents on the absorption of nickel in soils. Several organic complexants were used, including ethylenediaminetetraacetic acid (EDTA), diethylenetriaminepentaacetic acid (DPTA), oxalate, and citrate. Each of these complexants is widely used in the commercial nuclear industry as a 
decontaminating agent and will, therefore, be present in untreated nuclear wastes. The presence of these complexants tends to make the nickel more soluble in water and less likely to be absorbed in soils.

Of the complexants, EDTA seemed to have the largest effect in that a nickel solution that was pretreated with this complexant did not appreciably absorb onto soil from the Hanford, Washington, area even though it was in contact with the soil for more than one year. These tests were repeated one year later-while the absorption rate was still very slow, there was some absorption of nickel-EDTA solution in the Hanford soil. ${ }^{26}$ This illustrates the difficulties involved in generating reproducible results using field samples of soils. There was a significant difference between nickel that was treated with EDTA prior to coming in contact with soil and nickel that was absorbed in the soil prior to being treated with EDTA, however. Nickel that had been absorbed in the Hanford soil $(\mathrm{pH}=9)$ prior to being treated with EDTA was only slowly dissolved by the complexant. After 6 months, only $1 / 2$ of the sorbed nickel was dissolved, whereas pretreated nickel remained completely dissolved. Very little additional nickel redissolved, even though the test ran for an additional nine months, indicating that an equilibrium between dissolved and sorbed nickel may have been reached. The study was repeated using soil from the Savannah River Site (near Aiken, South Carolina). The $\mathrm{pH}$ of the Savannah River soils was lower, $\sim 6$ and the nickel behavior was significantly different. First, in the pretreated case, about $1 / 2$ of the nickel in solution was absorbed in the soil, which was the same amount of nickel that was redissolved in the non pretreated case. Second, the equilibrium was reached much sooner, in a few weeks.

Similar studies were conducted using DTPA as the complexing agent. In the Hanford soil, pretreated nickel slowly absorbed into the soil and non-pretreated nickel slowly redissolved. Equilibrium was not reached, even after one year. As was the case with EDTA, equilibrium was reached much more rapidly with the Savannah River soil, after a couple of days. The absorbed fraction at equilibrium was approximately $20 \%$. A separate test was conducted with Savannah River soil but at a lower $\mathrm{pH}(\sim 4)$. Equilibrium was reached at an absorbed fraction of $70 \%$, also within a couple of days.

Oxalate is known to form much weaker complexes with metal ions, such as nickel, than either EDTA or DTPA. In tests involving this complexant and Hanford soil, the equilibrium was reached much more rapidly, within a few days, than with the other two complexants. Possibly because of the shorter equilibration times, parametric studies were conducted, varying concentrations of nickel and oxalate, solution to soil ratio, soil particle size, and direction of approach to equilibrium. Of these, only the complexant concentration seemed to affect the results. The equilibrium absorbed fraction decreased nearly 100 -fold with a 10 -fold increase in complexant concentration. Decreasing the soil $\mathrm{pH}$ from 9 to 5 (using oxalic acid) resulted in an absorbed fraction decrease by $1 / 3$. Repeating these tests using Savannah River soil indicated less of a dependence on oxalate concentration than with the Hanford soil.

Finally, tests were conducted using citrate as the complexing agent. Citrate, like oxalate, forms much weaker complexes with nickel than EDTA or DTPA. In the Hanford soil tests, the equilibrium was reached within a few days and $\sim 90 \%$ of the nickel absorbed into the soil. The Savannah River soil tests did not reach an equilibrium, even after 25 days, though the absorbed fraction was increasing throughout the test time.

The Reference 25 study was expanded to include two additional complexants, HEDTA and NTA in $1983 .{ }^{26}$ These two complexants are of intermediate strength, between the strong EDTA and DTPA and the weak citrate and oxalate. In addition, one more soil type was included, Oak Ridge soil, which was 
soil from an Oak Ridge waste burial ground and was significantly finer than either the Hanford or Savannah River soil samples. The Oak Ridge soil $\mathrm{pH}$ was close to that of Savannah River soil, $\mathrm{pH}=5.5$.

There were, however, significant differences between the absorption characteristics of nickel in the Oak Ridge and Savannah River soil samples. For example, in the Savannah River soil tests using preabsorbed nickel (that is, nickel that was absorbed into the soil prior to addition of the complexant), a significant amount of the nickel was redissolved when an EDTA-laden solution was passed through the soil. However, no redissolution of nickel occurred with the Oak Ridge soil sample.

Equilibrium conditions were not met with the HEDTA-complexed nickel, even after two months of testing. Equilibrium was met with the NTA-complexed nickel after approximately one month. The equilibrium absorption fraction with NTA-complexed nickel ranged between 70 and $90 \%$, depending on the molarity of the NTA. This was in Hanford soil. Similar tests conducted with Oak Ridge soil samples were more complex. The dependence of the absorbed fraction on NTA concentration was greater than with the EDTA-complexed nickel.

An analytical study of the leakage of ${ }^{59} \mathrm{Ni}$ from an underground vault is presented in "Utlackning av $\mathrm{Ni}-59$ Fran Ett Bergforvar" (Release of ${ }^{59} \mathrm{Ni}$ from a Mountain Vault). ${ }^{27}$ In this study, radioactive structural components of a reactor are placed in a 500 meter deep tunnel, lined with concrete and covered with a clay/quartz mixture. Given best estimates on soil and groundwater conditions, it was calculated that the nickel would escape over a period of 20,000,000 years. Even if the concrete and clay/quartz were to become completely permeable to the groundwater (an extremely unlikely event), the maximum leach rate for the nickel is calculated to be $2 \times 10^{-6}$ parts per year.

In summary, the behavior of nickel in soils depends on a variety of parameters. These include soil/groundwater $\mathrm{pH}$, soil type and texture, and the presence or absence of complexing agents.

\section{Nickel-59 in Water}

Nickel tends to be easily absorbed by soils, removing it from groundwater. However, this is dependent on a number of parameters, especially groundwater $\mathrm{pH}$ and whether or not complexing agents are present. For example, in a Hanford soil sample $(\mathrm{pH}=9)$ and completed with EDTA, nickel was not appreciably removed from the solution even after contact with the soil for over one year. Thus, the presence of complexing agents can significantly slow removal of nickel from groundwater. The equilibrium water concentration of nickel depends on $\mathrm{pH}$ and the particular complexant used, as discussed in the previous section. In another study, the concentration of ${ }^{59} \mathrm{Ni}$ in river sediment below the Hanford Reservation was measured. ${ }^{28}$ The inventory of this nuclide could not be directly measured and was estimated to be less than $2 \mathrm{Ci}$.

Since the radioactive nuclides are intended to remain in LLW waste storage indefinitely, it is important to characterize those nuclides that dominate the release hazard via the groundwater during various times in the future. For short times, nuclides such as ${ }^{60} \mathrm{Co}$ and ${ }^{55} \mathrm{Fe}$ dominate. For intermediate times (the first 1,000 years), ${ }^{137} \mathrm{Cs}$ and ${ }^{63} \mathrm{Ni}$ will dominate. However, for times in excess of 1,000 years, ${ }^{59} \mathrm{Ni}$ dominates. ${ }^{29}$ 
This nuclide is removed from the groundwater by sorption onto mineral surfaces. The degree to which it is sorbed is affected by such environmental factors as $\mathrm{pH}$ and the presence of $\mathrm{Ca}$ and $\mathrm{Mg}$ ions. A scientist at the Atomic Energy of Canada Limited laboratory at Whiteshell performed a series of experiments to measure the effects of these factors on the sorption..$^{30}$ He determined that the sorption decreased with increased $\mathrm{Ca}$ and $\mathrm{Mg}$ concentrations and with lower $\mathrm{pH}$. Based on his observations, he concluded that nickel sorption is a combination of ion exchange and surface complexation.

Because of its long half-life, ${ }^{59} \mathrm{Ni}$ is a dominate part of the long-term hazard in an LLW depository. A Swedish study was made of the leaching of this nuclide from a bedrock depository. ${ }^{31}$ While the design of the depository included placing the radioactive waste in concrete boxes and overpacking the boxes in a clay/quartz mixture, it was assumed that these barriers were somehow breached to allow groundwater to flow through the waste. Even with these, very conservative, assumptions, the calculated maximum fractional leach rate for this nuclide was calculated to be of the order of $10^{-6} /$ year. This maximum rate would not occur until the clay and concrete degraded sufficiently to allow groundwater to enter the depository, which is not estimated to occur until 100,000 years after the depository is sealed.

\section{Nickel-59 in Plants}

All information that was located on the absorption of nickel by plants is based on naturally occurring or stable isotopes of nickel. No information was located that specifically discussed ${ }^{59} \mathrm{Ni}$; however, ${ }^{59} \mathrm{Ni}$ should follow the behavior of its stable isotopes. One summary reference, $\underline{\mathrm{Nickel}},{ }^{32}$ contains a discussion of naturally occurring nickel in plants. Naturally occurring nickel concentrations range from a few ppm to several thousand ppm. Typical plant nickel concentrations in grains, fruits, and vegetables range from a few tenths of a ppm to a few ppm. Thus, the uptake of nickel from soil to these plants appears to be a very small fraction of the soil concentration. Some grasses, including field-grown oats, may contain more than $100 \mathrm{ppm}$ nickel and some flowers (alyssum, forget-me-nots, rice flowers), up to several thousand ppm. The highest concentrations of nickel in alyssum were in the leaves with less than 1/10th the concentration in the seeds. Nickel can enter plants via the roots and/or absorption through the leaves.

Reference 33 contains a detailed summary of the information known about nickel interactions with plants. The transfer factors (ratio of the concentration of nickel in various plant parts to that in the soil in which the plants were grown) depend strongly on the "availability" of the nickel to plant uptake. For example, assuming that the nickel concentration in the soil is $30 \mu \mathrm{g} / \mathrm{g}$ ( $30 \mu \mathrm{g}$ of nickel in one $\mathrm{g}$ of soil) and the plant concentration is $3 \mu \mathrm{g} / \mathrm{g}$, the transfer factor is 0.1 , which is consistent with the data in this reference. However, some factors can make the nickel more available for plant uptake, resulting in transfer factors in the range of $1-5$. Of course, it should be recognized that these data are for relatively large soil concentrations of nickel and may not be representative of transfer factors when the soil concentrations are much lower, such as would be expected for ${ }^{59} \mathrm{Ni}$. This reference contains transfer factor data for several types of plants, as well as distribution data for various plant parts.

\section{Nickel-59 in Air}

Nickel isotopes (radioactive or non-radioactive) are not normally found in air, except possibly for small amounts generated and released following an atmospheric test of a thermonuclear weapon. Radioactive ${ }^{59} \mathrm{Ni}$ is produced principally as an activation product in the reactor structural components (e.g., $\left.{ }^{58} \mathrm{Ni}(\mathrm{n}, \gamma)->^{59} \mathrm{Ni}\right)$ and it does not appear as a fission product radioisotope. Therefore, even if a 
severe core damage accident occurred in a nuclear reactor, releasing significant amounts of fission products, this would not necessarily mean that significant amounts of ${ }^{59} \mathrm{Ni}$ would be released into the air.

There is some indirect evidence of air-borne radioactive nickel isotopes having resulted from nuclear explosions. ${ }^{28}$ Very small amounts of ${ }^{63} \mathrm{Ni}$ have been measured in soil and marine life in the area of the Pacific Proving Ground, the site of several atmospheric nuclear tests. The maximum concentrations of this isotope are in the parts per trillion range. ${ }^{63} \mathrm{Ni}$ is also principally produced as an activation product of structural products, namely: ${ }^{62} \mathrm{Ni}(\mathrm{n}, \gamma)->{ }^{63} \mathrm{Ni}$. Based on a simple comparison of thermal neutron absorption cross-sections $\left(\sigma_{58}=4.4\right.$ barns and $\sigma_{62}=15$ barns $)$ and the natural abundance of the stable nickel isotopes $\left({ }^{58} \mathrm{Ni}=68 \%\right.$ and $\left.{ }^{62} \mathrm{Ni}=4 \%\right)$, it appears that if ${ }^{63} \mathrm{Ni}$ has been produced and dispersed during nuclear explosions, then ${ }^{59} \mathrm{Ni}$ must also have been produced and dispersed in roughly comparable quantities.

\section{Behavior of Nickel-59 in the Human Body and in Animals}

Nickel is present in all human tissue in trace amounts. Even newborn infants have measurable amounts (of the order of $10^{-5} \mathrm{~g} /$ liter of the umbilical cord serum). There is evidence that nickel may be an "essential micronutrient" for health and growth. ${ }^{28}$

Distribution of nickel is generally uniform throughout the human body. Data from the "Reference Man," used in studies of the International Commission of Radiation Protection, indicate that there is typically 10 milligrams of nickel in a typical adult, with $\sim 5$ milligrams in the soft tissues and $\sim 5$ milligrams in the skeletal tissues. ${ }^{34}$ Table 8-5 lists the maximum permissible burden in the total body for nickel. There are studies that have investigated the effects of health problems associated with either an overabundance or deprivation of nickel. All of the studies located in conjunction with this chapter, however, deal with naturally occurring, stable isotopes of nickel and not with radioactive isotopes such as ${ }^{59} \mathrm{Ni}$. Reference 35 states that the liver is the critical organ with respect to ingestion of ${ }^{59} \mathrm{Ni}$.

Reference 32 does contain some information regarding the metabolism of nickel in laboratory animals. After injection of nickel-chloride into rats (stable Ni), nearly $70 \%$ was excreted within 72 hours (61\% in urine and $6 \%$ in feces). All blood and plasma nickel had disappeared within 48 hours. After 72 hours, only the kidneys exhibited significant amounts of the radioactive isotope. The initial excretion of injected nickel differed from nickel that was orally administered in that the orally ingested nickel was preferentially $(90 \%)$ excreted in the feces, indicating only minimal absorption via the intestines. A separate study included injections in both rats and rabbits. The conclusions from this study did not differ substantially from those of the previous study-preferential excretion via urine during the first 48 hours and then more gradual excretion over 3 to 7 days. Due to the long radiological half-life of ${ }^{59} \mathrm{Ni}$, the effective half-life of ${ }^{59} \mathrm{Ni}$ in the human body is equivalent to only its biological half-life. The biological half-life refers to the amount of time required to remove half of the initial material from the body via a combination of chemical, physical, or biological processes. The effective half-life incorporates both the radiological and biological half-lives. For ${ }^{59} \mathrm{Ni}$, the biological half-life has been reported as 667 days for the total body, 800 days for bone, and 500 days for the liver. ${ }^{36}$ Table 8-6 lists the annual limits on intake for nickel through ingestion and inhalation. 
Table 8-5. Maximum permissible body burdens and maximum permissible concentrations.

\begin{tabular}{|c|c|c|c|}
\hline Reference organ & $\begin{array}{c}\text { Maximum } \\
\text { permissible burden } \\
\text { in total body } \\
(\mu \mathrm{Ci})\end{array}$ & $\begin{array}{c}\text { Maximum } \\
\text { permissible } \\
\text { concentrations in } \\
\text { water } \\
\left(\mu \mathrm{Ci} / \mathrm{cm}^{3}\right)\end{array}$ & $\begin{array}{c}\text { Maximum } \\
\text { permissible } \\
\text { concentrations in air } \\
\left(\mu \mathrm{Ci} / \mathrm{cm}^{3}\right)\end{array}$ \\
\hline $\begin{array}{l}\text { Total body } \\
\text { (soluble) }\end{array}$ & 30 & $4 \times 10^{-4}$ & $6 \times 10^{-8}$ \\
\hline Liver (soluble) & 40 & $5 \times 10^{-4}$ & $8 \times 10^{-8}$ \\
\hline Spleen (soluble) & 50 & $6 \times 10^{-4}$ & $9 \times 10^{-8}$ \\
\hline Muscle (soluble) & 50 & $7 \times 10^{-4}$ & $1 \times 10^{-7}$ \\
\hline Bone (soluble) & 100 & $1 \times 10^{-3}$ & $2 \times 10^{-7}$ \\
\hline Kidney (soluble) & 100 & $1 \times 10^{-3}$ & $2 \times 10^{-7}$ \\
\hline Lung (soluble) & 300 & $5 \times 10^{-3}$ & $6 \times 10^{-7}$ \\
\hline GI (SI) (soluble) & & $2 \times 10^{-2}$ & $5 \times 10^{-6}$ \\
\hline Lung (insoluble) & & & $1 \times 10^{-8}$ \\
\hline $\begin{array}{l}\text { GI (LLI) } \\
\text { (insoluble) }\end{array}$ & & $1 \times 10^{-3}$ & $2 \times 10^{-7}$ \\
\hline
\end{tabular}

Table 8-6. Annual limits on intake (ALI) and the derived air concentrations (DAC) for ${ }^{59} \mathrm{Ni}$ (obtained from References 37 and 38).

\begin{tabular}{lccc} 
Radionuclide & Component & Ingestion & Inhalation $^{\mathrm{a}}$ \\
\hline${ }^{59} \mathrm{Ni}$ & $\mathrm{ALI}$ & $8,000 \mu \mathrm{Ci}$ & $1,600 / \mathrm{D}-2,200 / \mathrm{W}-800 / \mathrm{Y} \mu \mathrm{Ci}$ \\
& & & \\
& DAC & $-{ }^{\mathrm{b}}$ & $1.6 / \mathrm{D}-2.7 / \mathrm{W} \mu \mathrm{Ci} / \mathrm{m}^{3}$ \\
& $\mathrm{MPC}$ & $-{ }^{\mathrm{b}}$ &
\end{tabular}

a. Values depend upon the removal time of the specific chemical form of ${ }^{59} \mathrm{Ni}$ and is classified as either $\mathrm{D}$ for days, $\mathrm{W}$ for weeks, or Y for years.

b. Data not available. 


\section{Summary}

${ }^{59} \mathrm{Ni}$ is not a naturally occurring radionuclide. Its half-life is approximately 76,000 years and decays by electron capture; that is, the nucleus captures an atomic electron and forms a new atom. When it decays, x-rays, Auger electrons, and/or bremsstrahlung radiation (similar to x-rays) are released. The released radiation is less penetrating than that of most radionuclides, and in particular less than tritium. Both ${ }^{59} \mathrm{Ni}$ and tritium are classified in the same radiological hazard group.

${ }^{59} \mathrm{Ni}$ is produced in the structural steels of nuclear reactor vessel and internal components from neutron activation of ${ }^{58} \mathrm{Ni}$, a naturally occurring and stable isotope of nickel. These reactor components serve as the primary LLW material containing ${ }^{59} \mathrm{Ni}$. The major concern surrounding ${ }^{59} \mathrm{Ni}$ is in limiting the dose received by people associated with the decommissioning and dismantling of the reactors, primarily for reactors in service for more than 30 years. At that point, the ${ }^{59} \mathrm{Ni}$ activity will exceed that from the other major activation products: ${ }^{55} \mathrm{Fe}$ and ${ }^{60} \mathrm{Co}$.

No medical or commercial uses of ${ }^{59} \mathrm{Ni}$ are known for this radionuclide. Although ${ }^{59} \mathrm{NiCl}_{2}$ has been available, no applications of this material were identified.

The chemistry of this element is dominated by the $4 \mathrm{~s}$ subshell electrons. While other oxidation states can be produced, the principal form is $\mathrm{Ni}^{2+}$. Nickel is resistant to attack by water or air and, therefore, is often used as a protective coating for other metals or as an alloy to create a corrosion-resistant metal such as stainless steel.

The ability of soils to absorb nickel out of groundwater varies widely, depending on soil $\mathrm{pH}$ and soil type. The absorption coefficient, $\mathrm{K}_{\mathrm{d}}$ can range from less than 100 to more than 5000 . Soil absorption is also significantly affected by the presence or absence of decontamination agents such as EDTA and DPTA, which complex with nickel to depress absorption in the soil. The effect of these agents is also sensitive to the soil $\mathrm{pH}$.

The biological half-life of ${ }^{59} \mathrm{Ni}$ in the human body has been reported to be 667 days (total body), 800 days for bone, and 500 days for the liver. Other information regarding the health effects of ${ }^{59} \mathrm{Ni}$ in the human body appears to be limited. 


\section{References}

1. Nickel, Committee on Medical and Biologic Effects of Environmental Pollutants, Division of Medical Sciences, National Research Council, National Academy of Sciences, Washington, D.C., 1975, p. 39.

2. E. Browne, J. M. Dairiki, and R. E. Doebler, Table of Isotopes, Seventh Edition, New York: John Wiley \& Sons, 1978, pp. 174 and 175.

3. E. Browne, R. B. Firestone, and V. S. Shirley (Editor), Table of Radioactive Isotopes, New York: John Wiley \& Sons, 1986, Data concerning ${ }^{59} \mathrm{Ni}$ : Photons, Atomic Electrons, and Cont. Radiation.

4. Oak Ridge National Laboratory, Integrated Data Base for 1992: U.S. Spent Fuel and Radioactive Waste Inventories, Projections, and Characteristics, October 1992, Prepared for the U.S. Department of Energy, DOE/RW-0006, Rev. 8, p. 256.

5. General Electric Company, Nuclides and Isotopes, Fourteenth Edition, 1989, p. 25.

6. U.S. Department of Health, Education, and Welfare, Radiological Health Handbook, Revised Edition, January 1970, pp. 122, 163, and 204.

7. R. E. Bolz and G. L. Tuve (Editors), CRC Handbook of Tables for Applied Engineering Science, Second Edition, Boca Raton, Florida: CRC Press, Inc., Table 2-3, Electromagnetic Frequency Spectra on p. 206.

8. J. R. Bradford (Editor), Radioisotopes in Industry, Reinhold Publishing Corporation, 1953, p. 266.

9. R. Granier and D. Gambini, Applied Radiobiology and Radiation Protection, Ellis Horwood Limited, English edition published in 1990, pp. 194, 195, 201, Table 7.1 on p. 205, 251, 252, 253 , 257, Table 10.3 on 273 , p. 285 , Table 11.2 on p. 300 , and Table 11.3 on p. 301.

10. F. A. Cotton and G. Wilkinson, Advanced Inorganic Chemistry - A Comprehensive Text, New York: Interscience Publishers, 1962.

11. E. S. Gould, Inorganic Reactions and Structure, New York: Holt, Rinehart and Winston, Inc., 1963.

12. C. M. Lederer, J. M. Hollander, I. Perlman, Table of Isotopes, Sixth Edition, New York: John Wiley \& Sons, Inc., 1967, p. 3 and p. 155.

13. P. C. Souers, Hydrogen Properties for Fusion Energy, University of California Press, 1986, Chapters 1, 16, and 17, and p. 6.

14. R. C. Weast (ed.), CRC Handbook of Chemistry and Physics, 58th Edition, Boca Raton, Florida: CRC Press, 1977, pp. B270-354 (Table of Isotopes).

15. Bureau of Radiological Health, Radiological Health Handbook, Revised Edition January 1970, U.S. Government Printing Office, pp. 92-94 (Average and Maximum Beta Energy by Radionuclide). 
16. International Critical Tables of Numerical Data, Physics, Chemistry, and Technology Vol. I, New York: McGraw-Hill Book Company, Inc., 1926, pp. 102.

17. Metals Handbook, 8th Ed., Vol. 8, American Society for Metals, 1973.

18. McGraw-Hill Encyclopedia of Science and Technology, 6th Ed., Vol. 11, New York: McGraw-Hill Book Company.

19. A. G. Croff, $A$ User's Manual for the ORIGEN2 Computer Code, ORNL/TM-7175, July 1980.

20. J. M. Deconinck, P. V. Iseghem, R. Boden, et al., "Investigation on the Determination of Disposal Critical Nuclides in Waste from PWR Power Plants Task 3 Characterization of Radioactive Waste Forms A Series of Final Reports (1985-89) - No 45," Published by the Commission of the European Communities, ISBN 92-826-5239-4, pp. 8, 21, 23, 42 (Table 10), 49 (Table 16).

21. "The Handling, Storage, Use, and Disposal of Unsealed Radionuclides in Hospitals and Medical Research Establishments," Annals of the ICRP - ICRP Publication 15, Vol. 1, No. 2, New York: Pergamon Press, 1977.

22. P. C. Bergamini, G. Palmas, F. Piantelli, and M. Rigato, "Absorption and Distribution of ${ }^{137}$ Cs by Trifolium Pratense," Health Physics, Vol. 19, October 1970, pp. 521-528.

23. J. Dragun, The Soil Chemistry of Hazardous Materials, Hazardous Materials Control Research Institute, Silver Spring, MD, 1988.

24. J. Neiheisel, "Preliminary Results of a Study to Develop Prediction Parameters for Radionuclide Retention at Future Low-Level Waste Disposal Sites," Proceedings of the Fifth Annual Participants Information Meeting - DOE Low-Level Waste Management Program, Denver, CO, August 30-September 1, 1983, CONF-8308106, pp. 591-608.

25. J. L. Swanson, Effect of Organic Complexants on the Mobility of Nickel and Cobalt in Soils: Status Report, PNL-4389, September 1982.

26. J. L. Swanson, Mobility of Organic Complexes of Nickel and Cobalt in Soils, PNL-4796, September 1983.

27. I. Neretnieks, K. Andersson, and L. Henstam, "Utlackning av Ni-59 Fran Ett Bergforvar," Kungl Tekniska Hogskolan, Stockholm, Sweden, April 24, 1978.

28. T. M. Beasley, "Nickel-63 in Columbia River Sediments Below the Hanford Reservation," Journal of Environmental Radioactivity, Vol. 4, No. 1, 1986, pp. 1-10.

29. M. Wiborgh, Prestudy of Final Disposal of Long-Lived Low and Intermediate Level Waste, SKB-TR-95-03, January 1995.

30. K. V. Ticknor, "Sorption of Nickel on Geological Materials," Radiochimica Acta, Vol. 66-67, 1994, pp. 341-348.

31. I. Neretnieks, Leaching of Ni-59 From a Bedrock Depository, KBS-TR-101, April 1978. 
32. Nickel, Committee on Medical and Biologic Effects of Environmental Pollutants, Division of Medical Sciences, National Research Council, National Academy of Sciences, Washington, D.C., 1975.

33. P. J. Coughtrey and M. C. Thorne, Radionuclide Distribution and Transport in Terrestrial and Aquatic Ecosystems: A Critical Review of Data, Vol. 2, A. A.Balkema, 1983, pp. 218-227.

34. "Limits for Intakes of Radionuclides by Workers," Annals of the ICRP - ICRP Publication 30 , Part 3, Vol. 6, No. 3, New York: Pergamon Press, 1981.

35. Safe Handling of Radioisotopes, International Atomic Energy Agency, Vienna, 1958.

36. Y. Wang, M.D. (Editor), CRC Handbook of Radioactive Nuclides, Boca Raton, Florida: CRC Press, 1969, Table 16 (p. 27).

37. "Limits for Intakes of Radionuclides by Workers," Annals of the ICRP - ICRP Publication 30, Part 3, Supplement A, New York: Pergamon Press, 1978.

38. "Annual Limits on Intake of Radionuclides by Workers Based on the 1990 Recommendations," Annals of the ICRP-ICRP Publication 61, Vol. 21, No. 4, New York: Pergamon Press, 1991. 


\section{Bibliography}

Abel, K. H., et al., Residual Radionuclide Contamination Within and Around Commercial Nuclear Power Plants, NUREG/CR-4289, PNL-5429, pp. 13, 14, 15, 19, 41, 42, 50, 59, 64, C.96 (Table C.7.9).

Ames, L. L. and D. Rai, Radionuclide Interactions with Soil and Rock Media, Vol 1, EPA 520/6-78-007a, U.S. Environmental Protection Agency, August 1978.

Bolz, R. E. , and G. L. Tuve (eds), CRC Handbook of Tables for Applied Engineering Science, Second Edition, 1977, Table 2-3 p. 206.

Eckerman, F. K., A. G. Wolbarst, and A. C. B. Richardson, Limiting Values of Radionuclide Intake and Air Concentration and Dose Conversion Factors for Inhalation, Submersion, and Ingestion, Federal Guidance Report No. 11, EPA-520/1-88-020, Oak Ridge National Laboratory, September 1988.

Fuierer, A. A., "Characterization and Classification of Spent-Fuel Hardware for Storage and Disposal," Transactions of the American Nuclear Society, Volume 62, TANSAO 62 1-722 (1990), ISSN: 0003018X, November 11-15, 1990, p. 431.

Garner, R. John, Transfer of Radioactive Materials from the Terrestrial Environment to Animals and Man, CRC Press, 1972, pp. 11, 13, 25, 38, 42.

International Directory of Radioisotopes, Second Edition, Part I, Published by the International Atomic Energy Agency, 1962, p. 173.

Lederer, C. M., J. M. Hollander, I. Perlman, Table of Isotopes, Sixth Edition, John Wiley \& Sons, Inc., 1967 , pp. 75 and 285.

Louria, B. D., M. M. Joselow, A. A. Browder, "The Human Toxicity of Certain Trace Elements," Annals of Internal Medicine, 76:307-319, 1972, pp. 313-314.

Miller, C. E., "Retention and Distribution of ${ }^{137} \mathrm{Cs}$ after Accidental Inhalation," Health Physics, 10, 1964, p. 1065.

Nielsen , F. H., and D. A. Ollerich, "Nickel: A New Essential Trace Element," Federation Proceedings, Volume 33, No. 6, June 1974, pp. 1767-1772.

Rahn, F. J., A. G. Adamantiades, J. E. Kenton, C. Braun, A Guide to Nuclear Power Technology, John Wiley \& Sons, 1984, Chapter 15, pp. 697-701, and Figure 16.5.

Resnik, M. C., O. R. Lunt, and A. Wallace, "Cs, K, Sr, and Ca Transport in Two Different Plant Species," Soil Science 108 (1), 1969, p. 64. 
Robertson, D. E., C. W. Thomas, N. L. Wynhoff, and D. C. Hetzer, "Characterization of Long-lived Activation Products in Spent Fuel Assembly Hardware and Reactor Pressure Vessel Steel," Nuclear Engineering and Design, 118 (1990) pp. 463-486.

Robertson, D., D. Haggard, C. Thomas, N. Wynhoff, "Radiological Characterization of NeutronActivated Metal Wastes from Nuclear Power Stations," Proceedings of the Second International Conference on Methods and Applications of Radioanalytical Chemistry, Kona, Hawaii, April 21-27, 1992, Articles published by the Journal of Radioanalytical and Nuclear Chemistry, Volume 161, No. 2, August 1992, 62, TANSAO 62 1-722 (1990), ISSN: 0003-018X, November 11-15, 1990 , p. 585-595.

Rogers, R. D. and S. E. Williams, "Vesicular Arbuscular Mycorrhiza: Influence on Plant Uptake of Cesium and Cobalt," Soil Biology Biochemistry, 18 (4), 1986, p. 371.

Sanders, C. L., R. H. Busch, J. E. Ballou, D. D. Mahlum (eds), Radionuclide Carcinogenesis, U.S. Atomic Energy Commission Office of Information Services, 1972, pp. 13 and 262.

Schroeder, H. A., J. J. Balassa, I. H. Tipton, "Abnormal Trace Metals in Man - Nickel," J. chron. Dis., Published by Pergamon Press Ltd., Vol. 15, pp. 51-65.

Sheppard, M. I., D. I. Beals, D. H. Thibault, P. O'Connor, Soil Nuclide Distribution Coefficients and Their Statistical Distributions, AECL-8364, Atomic Energy of Canada, Limited, December 1984.

Sunderman, F. W. Jr., et al., "Increased Concentrations of Serum Nickel after Acute Myocardial Infarction," The New England Journal of Medicine, October 22, 1970, pp. 896-899.

U.S. Department of Energy, Characteristics of Spent Fuel, High-Level Waste, and Other Radioactive Wastes Which May Require Long-Term Isolation, DOE/RW-0184, Volume 2 of 6, December 1987.

Weast, R. C. (ed), CRC Handbook of Chemistry and Physics, CRC Press, 1977, 58th Edition, pp. B270B354 (Table of Isotopes). 


\section{PLUTONIUM-241}

\section{Introduction}

This chapter discusses the basic radiological, chemical, and physical characteristics of plutonium-241 $\left({ }^{241} \mathrm{Pu}\right)$ and examines how these characteristics affect the behavior of ${ }^{241} \mathrm{Pu}$ in various environmental media such as soils, water, plants, the atmosphere, and the human body. Discussions also include methods of ${ }^{241} \mathrm{Pu}$ production and provide information on waste and disposal data on ${ }^{241} \mathrm{Pu}$.

All plutonium atoms contain 94 protons $(Z=94)$ and various numbers of neutrons (usually $N=142$ to 150 neutrons) within the atom's nucleus. A total of 15 isotopes of plutonium are known to exist (namely, ${ }^{232} \mathrm{Pu}$ through $\left.{ }^{246} \mathrm{Pu}\right) .{ }^{1}$ All isotopes of plutonium are radioactive. Except for trace quantities of plutonium in pitchblende (i.e., one part ${ }^{239} \mathrm{Pu}$ in $10^{11}$ atoms), ${ }^{2}$ and small amounts produced in natural reactors (e.g., the Oklo natural reactor in Gabon produced several tons of ${ }^{239} \mathrm{Pu}$ and contained ${ }^{241} \mathrm{Pu}$ to a concentration of between 2 and 6 parts per million of the uranium-238 $\left({ }^{238} \mathrm{U}\right)$ concentration during the reactor's active lifetime of $\sim 500,000$ years approximately 2 billion years ago), ${ }^{241} \mathrm{Pu}$ does not exist as a naturally occurring nuclide. Although ${ }^{241} \mathrm{Pu}$ does not constitute a normal component of the natural background activity, small quantities have been released into the environment, primarily from plutonium weapons and nuclear reactor accidents. ${ }^{241} \mathrm{Pu}$ is present in plutonium-based nuclear weapons to an extent of approximately $0.38 \%$ (e.g., $0.02 \%{ }^{238} \mathrm{Pu}, 93.65 \%{ }^{239} \mathrm{Pu}, 5.91 \%{ }^{240} \mathrm{Pu}, 0.38 \%{ }^{241} \mathrm{Pu}, 0.04 \%{ }^{242} \mathrm{Pu}$ ); however, the exact quantity is classified. ${ }^{3}$

${ }^{241} \mathrm{Pu}$ is the third most common isotope of plutonium, with ${ }^{239} \mathrm{Pu}$ and ${ }^{240} \mathrm{Pu}$ representing the first and second most common forms. ${ }^{241} \mathrm{Pu}$ is a fissile material, meaning that it will fission with slow or thermalized neutrons.

Small amounts of ${ }^{241} \mathrm{Pu}$ have been released to the environment from plutonium-based weapons testing, much of it deposited in the Northern Hemisphere. ${ }^{4,5}$ The beta decay of ${ }^{241} \mathrm{Pu}$ has resulted in increased quantities of americium-241 $\left({ }^{241} \mathrm{Am}\right)$, its decay product. The ${ }^{241} \mathrm{Am}$ activity in soil during the early 1970 s was $25 \%$ of the plutonium $\left({ }^{239} \mathrm{Pu}+{ }^{240} \mathrm{Pu}\right)$ activity; however, due to the eventual decay of ${ }^{241} \mathrm{Pu}$, this ratio will increase to $40 \% .{ }^{4}$ Additional quantities of ${ }^{24} \mathrm{Pu}$ have been released to the environment due to the Windscale accident in $1957^{4}$ and the Chernobyl reactor accident ${ }^{6}$ in 1986. Many other accidents have released various amounts of plutonium to the environment, but the fraction of this plutonium that was ${ }^{241} \mathrm{Pu}$ has not been reported. ${ }^{7}$ Small quantities of ${ }^{241} \mathrm{Pu}(>93 \%$ pure) can be purchased from the Isotope Distribution Office of the Oak Ridge National Laboratory at a cost of $\$ 13.25$ per milligram plus $\$ 1,250$ per package plus shipping charges. ${ }^{8}$

A radionuclide considered sensitive at one low-level radioactive waste (LLW) disposal facility may not be considered sensitive at another facility. The behavior of a radionuclide at a particular LLW disposal site will depend primarily upon the radiological, chemical, and physical characteristics of the waste, and the inventory of the radionuclide. The behavior of a radionuclide also depends upon the geology, hydrology, and climate at the disposal site. This chapter reports characteristics and potential difficulties in dealing with ${ }^{241} \mathrm{Pu}$. However, since ${ }^{241} \mathrm{Pu}$ behavior and appropriate handling, storage, or disposal will vary depending on particular sites or waste form, this chapter does not attempt to discuss the extent of a difficulty or appropriate solutions. Each disposal site facility design should consider and address the specific waste content and behavior under that site's particular circumstances. 


\section{Radiological Characteristics}

Plutonium-241 has a relatively short half-life $\left(\mathrm{T}_{1 / 2}\right)$ of 14.4 years, ${ }^{1,9,10}$ and is formed through neutron capture $(\mathrm{n}, \gamma)$ of ${ }^{240} \mathrm{Pu}$ (i.e., ${ }^{240} \mathrm{Pu}+\mathrm{n}->{ }^{241} \mathrm{Pu}+\gamma$-ray), or multiple neutron capture of ${ }^{238} \mathrm{U}$ or ${ }^{239} \mathrm{Pu} .{ }^{11}{ }^{241} \mathrm{Pu}$ undergoes radioactive decay by emitting a beta particle $\left(\beta ;\right.$ a negative electron emitted from the ${ }^{241} \mathrm{Pu}$ nucleus) $\sim 99.9976 \%$ of the time or $\sim 0.0024 \%$ of the time by alpha $(\alpha)$ emission. ${ }^{9,11}$ It also has a very low probability of emitting a $145-\mathrm{keV}$ (thousand electron volt) gamma-ray (i.e., U x-rays); emission probability is $0.00016 \% .{ }^{11}$ The probability of alpha and/or gamma-ray emission is extremely small for ${ }^{241} \mathrm{Pu}$. In fact, the average alpha and gamma-ray energies associated with ${ }^{241} \mathrm{Pu}$ decay are, respectively, $0.1 \mathrm{keV}$ and $0.52 \mathrm{keV}$ per disintegration. ${ }^{12}$ These values are very small compared with the maximum or average beta particle energies.

The ${ }^{241} \mathrm{Pu}$ nucleus decays to the radioactive daughter product ${ }^{241} \mathrm{Am}$ with the emission of a $21-\mathrm{keV}$ maximum energy beta particle. The average beta particle energy from ${ }^{241} \mathrm{Pu}$ decay is $5 \mathrm{keV}^{8,9}$

The primary decay scheme for ${ }^{241} \mathrm{Pu}$, showing the emission of a beta $(\beta)$ particle, is illustrated in Equation (1). Also shown are the maximum particle energies, event probabilities, and isotope half-lives. The secondary decay scheme is shown in Equation (2).

\begin{tabular}{|c|c|c|}
\hline \multirow{2}{*}{\multicolumn{3}{|c|}{$\begin{array}{c}\sim 99.9976 \% \\
{ }^{241} \mathrm{Pu}-99.98 \%\end{array}$}} \\
\hline & & \\
\hline $14.4 \mathrm{y}$ & $433 \mathrm{y}$ & $2.14 \times 10^{6} \mathrm{y}$ \\
\hline$\sim 0.0024 \%$ & $\sim 99.5 \%$ & $100 \%$ \\
\hline${ }^{1} \mathrm{Pu}$ & $\mathrm{U}$ & (-....... \\
\hline $14.4 \mathrm{y}$ & 6.75 day & $2 \times 10^{6} y$ \\
\hline
\end{tabular}

The 21-keV beta particle energy shown in Equation (1) represents the maximum particle energy with a continuous range of possible energies between zero and the maximum possible value, usually occurring with the simultaneous emission of an antineutrino particle (not shown) carrying off the energy difference. The average beta particle energy following ${ }^{241} \mathrm{Pu}$ decay is only $5 \mathrm{keV}$, in which case an antineutrino particle and the recoiling nucleus would carry off about $16 \mathrm{keV}$ of energy. The decay event probabilities are shown as percentage numbers above the arrows, and the isotope half-lives are shown below the arrows. Notice that ${ }^{241} \mathrm{Am}$, the decay product of ${ }^{241} \mathrm{Pu}$, decays to neptunium-237 $\left({ }^{237} \mathrm{~Np}\right)$ with the emission of an alpha particle and gamma rays. Because of the alpha and gamma rays, the radiological hazard associated with ${ }^{241} \mathrm{Am}$ is more significant than that due to the weak beta particle emitted from ${ }^{241} \mathrm{Pu}$.

Table 9-1 lists the maximum range for a $21-\mathrm{keV}$ beta particle emitted from ${ }^{241} \mathrm{Pu}$, which is very small. Since it requires a $70-\mathrm{keV}$ electron to penetrate the protective layer of human skin, these particles lack sufficient energy to penetrate the $0.07 \mathrm{~mm}$ of human skin. ${ }^{13}$ In fact, the beta particles emitted by ${ }^{241} \mathrm{Pu}$ decay cannot penetrate more than $0.002^{14}$ inches of water. The beta particles from ${ }^{241} \mathrm{Pu}$ are about as hazardous as the $19-\mathrm{keV}$ maximum energy beta particles emitted from tritium $\left({ }^{3} \mathrm{H}\right)$ decay.

Table 9-2 lists the radiotoxicity of several important radionuclides. Both ${ }^{241} \mathrm{Pu}$ and ${ }^{241} \mathrm{Am}$ appear in the same very high radiotoxicity (Group 1) classification. This is also true of the other isotopes of plutonium. However, the reason for grouping ${ }^{241} \mathrm{Pu}$ with the other isotopes of plutonium is based more on the classification of ${ }^{241} \mathrm{Am}$ than the fact that ${ }^{241} \mathrm{Pu}$ is a plutonium isotope. The reason is as follows: ${ }^{241} \mathrm{Pu}$ is different from the other plutonium isotopes in that it is primarily a beta emitter and not an 
Table 9-1. Comparison of the estimated maximum ranges for a $21-\mathrm{keV}$ maximum energy beta particle emitted from ${ }^{241} \mathrm{Pu}$ decay for various materials.

\begin{tabular}{lc} 
& $\begin{array}{c}\text { Estimated maximum range for } \\
\text { Material (description) }\end{array}$ \\
\hline Air (1 atmosphere pressure) & $21-\mathrm{keV}^{-}(\mathrm{mm})^{\mathrm{a}}$ \\
Water & 18.0 \\
Plastic (Lucite) & 0.022 to 0.051 \\
Concrete & 0.017 \\
Al (aluminum) or glass & 0.011 \\
Fe (iron) & 0.009 \\
Pb (lead) & 0.003 \\
\end{tabular}

a. Estimates based on extrapolations of the maximum beta particle range data shown on page 122 of Reference 13 . The $0.051 \mathrm{~mm}$ value for water represents the 0.002 inches reported on p. 235 of Radioactive Waste Disposal. ${ }^{14}$

Table 9-2. Comparison of the radiotoxicity of several important radionuclides including ${ }^{241} \mathrm{Pu}$.

\begin{tabular}{lll}
\multicolumn{2}{c}{ Radiotoxicity } & \multicolumn{1}{c}{ Species } \\
\hline Very high & Group 1 & ${ }^{241} \mathrm{Pu},{ }^{242} \mathrm{Cm},{ }^{241} \mathrm{Am},{ }^{237} \mathrm{~Np}$, \\
High & Group 2 & ${ }^{60} \mathrm{Pu},{ }^{639} \mathrm{Pu},{ }^{240} \mathrm{Pu},{ }^{242} \mathrm{Pu}$ \\
Moderate & Group 3 & $\mathrm{Sr},{ }^{94} \mathrm{Nb}$ \\
Low & Group 4 & ${ }^{14} \mathrm{C},{ }^{63} \mathrm{Ni},{ }^{137} \mathrm{Cs}$ \\
\end{tabular}

Source: Obtained from Appendix 2 of Reference 5.

important alpha emitter. Although an alpha particle is generally less hazardous than many other forms of radiation outside the human body (i.e., alpha particles are stopped by very thin materials), inside the human body (e.g., in the lung) alpha particles deposit all of their energy within a thin layer of living tissue, resulting in an increased chance of cell damage. ${ }^{241} \mathrm{Pu}$, unlike the other plutonium isotopes, generally does not emit an alpha particle upon decay (i.e., ${ }^{241} \mathrm{Pu}$ is a weak beta emitter); however, ${ }^{241} \mathrm{Pu}$ does decay to the alpha-emitting nuclide ${ }^{241} \mathrm{Am}$, which also emits some penetrating gamma rays.

Table 9-3 illustrates how the maximum and average beta particle emission energies associated with ${ }^{241} \mathrm{Pu}$ decay compare with the emissions of other beta emitters. Since it takes about a $70-\mathrm{keV}$ beta particle to penetrate the $0.07 \mathrm{~mm}$ of human $\mathrm{skin}^{13}$ the beta particles associated with ${ }^{241} \mathrm{Pu}$ decay are not directly hazardous. Although the beta particles from ${ }^{241} \mathrm{Pu}$ decay are not particularly hazardous, the decay daughter from ${ }^{241} \mathrm{Pu}$, namely ${ }^{241} \mathrm{Am}$, is an alpha emitter. Therefore, ${ }^{241} \mathrm{Pu}$ is associated with ${ }^{241} \mathrm{Am}$ and not with the other beta emitters. 
Table 9-3. Average and maximum kinetic energies of beta particles and negative (atomic) electrons released during the decay of several important radionuclides.

\begin{tabular}{lcc}
\hline \multicolumn{1}{c}{ Radionuclide } & Released electron energy \\
\cline { 2 - 3 } & $\begin{array}{c}\text { Average energy } \\
(\mathrm{keV}){ }^{\mathrm{a}}\end{array}$ & $\begin{array}{c}\text { Maximum energy } \\
(\mathrm{keV})^{\mathrm{a}}\end{array}$ \\
\hline Nickel-59 $\left({ }^{59} \mathrm{Ni}\right)$ & $4.1^{\mathrm{b}}$ & $\sim 7.7^{\mathrm{b}}$ \\
Tritium $\left({ }^{3} \mathrm{H}\right)$ & 5.68 & 19.0 \\
Plutonium-241 $\left({ }^{241} \mathrm{Pu}\right)$ & $\mathbf{5 . 0}$ & $\mathbf{2 1 . 0}$ \\
Iodine-129 $\left({ }^{129} \mathrm{I}\right)$ & 40.0 & 150.0 \\
Carbon-14 $\left({ }^{14} \mathrm{C}\right)$ & 49.0 & 156.0 \\
Technetium-99 $\left({ }^{99} \mathrm{Tc}\right)$ & 85.0 & 293.0 \\
Iodine-131 $\left({ }^{131} \mathrm{I}\right)$ & 180.0 & $806.0^{\mathrm{c}}$ \\
Cesium-137 $\left({ }^{137} \mathrm{Cs}\right)$ & 195.0 & $1,176.0$ \\
Potassium-40 $\left({ }^{40} \mathrm{~K}\right)$ & 541.0 & $1,330.0$ \\
Phosphorous-32 $\left({ }^{32} \mathrm{P}\right)$ & 694.0 & $1,710.0$ \\
\hline
\end{tabular}

\section{Chemical and Physical Characteristics}

Plutonium (element 94 ) is a member of the actinide series of elements (i.e., elements 89 through 103) of the periodic table. Its chemical characteristics are similar to that of the rare earth elements (a series of metallic elements ranging from lanthanum [element 57] through lutetium [element 71]). In particular, plutonium is in the same chemical family as the rare earth element samarium. Plutonium is similar to uranium, neptunium, and americium in that all of these elements have four possible oxidation (valence) states (i.e., $+3,+4,+5$, and +6 ). In aqueous solutions, plutonium may exist in all four valence states. The +4 state is the most stable oxidation state for plutonium. Plutonium occurs in six different crystalline structures, or allotropic states, each existing within a unique temperature range. The existence of these six allotropes complicates its metallurgical properties. Also, the metallurgical properties of plutonium are very sensitive to the presence of impurities. Table 9-4 summarizes some of the most important physical properties of plutonium. In the absence of surface oxidation, plutonium is a silvery-white metal resembling nickel. ${ }^{18}$ As the metal is oxidized (by air or water), plutonium acquires a bronzelike color, followed by a gunmetal-blue color, and finally a dull black or green at complete oxidation. Besides oxygen, plutonium metal is chemically attacked by ammonia $\left(\mathrm{NH}_{3}\right)$, nitrogen $(\mathrm{N})$, hydrogen $(\mathrm{H})$, halogens (e.g., fluorine, chlorine, bromine, iodine), carbon monoxide $(\mathrm{CO})$, and carbon dioxide $\left(\mathrm{CO}_{2}\right)$. 
Table 9-4. Physical properties of plutonium.

\begin{tabular}{|c|c|c|}
\hline Physical property (units) & \multicolumn{2}{|c|}{ Plutonium data } \\
\hline Melting point (degrees Kelvin, $\mathrm{K})^{\mathrm{a}}$ & \multicolumn{2}{|l|}{$913^{b}$} \\
\hline Boiling point (degrees Kelvin, $\mathrm{K})^{\mathrm{a}}$ & \multicolumn{2}{|l|}{$\sim 3500$} \\
\hline Heat of fusion at melting point $(\mathrm{kJ} / \mathrm{mole})$ & \multicolumn{2}{|l|}{$2.84^{c}$} \\
\hline Heat of vaporization (Kcal/mole) & \multicolumn{2}{|l|}{$80.49^{\mathrm{e}}$} \\
\hline Solid density $\left(\mathrm{g} / \mathrm{cm}^{3}\right)$ & \multicolumn{2}{|l|}{19.84 to $15.92^{d}$} \\
\hline Liquid density $\left(\mathrm{g} / \mathrm{cm}^{3}\right)$ & \multicolumn{2}{|l|}{$-^{f}$} \\
\hline Oxidation potential for the first electron $(\mathrm{V})$ & \multicolumn{2}{|l|}{$6.06^{\mathrm{c}}$} \\
\hline Ionization potential $(\mathrm{eV})$ & \multicolumn{2}{|l|}{$-\mathrm{f}$} \\
\hline Work function (eV) & \multicolumn{2}{|l|}{$-_{f}^{f}$} \\
\hline Crystal forms and temperature ranges ${ }^{e}$ & $\begin{array}{c}\text { alpha (monoclinic) } \\
\text { beta (monoclinic) } \\
\text { gamma (orthorhombic) } \\
\text { delta (cubic) } \\
\text { delta prime (tetrahedral) } \\
\text { epsilon (cubic) }\end{array}$ & $\begin{array}{c}<395 \mathrm{~K} \\
395-479 \mathrm{~K} \\
479-592 \mathrm{~K} \\
592-724 \mathrm{~K} \\
724-758 \mathrm{~K} \\
758-912 \mathrm{~K}\end{array}$ \\
\hline \multicolumn{3}{|c|}{ a. Note that zero degrees kelvin $(0 \mathrm{~K})$ equals $-273.15^{\circ} \mathrm{C}$ or $-459.67^{\circ} \mathrm{F}$. } \\
\hline \multicolumn{3}{|c|}{$\begin{array}{l}\text { b. The melting point of plutonium varies with its initial crystalline phase designation and lattice structure as follows: alpha }(\alpha) \\
\text { monoclinic } 914 \mathrm{~K} \text {, beta }(\beta) \text { monoclinic } 395-480 \mathrm{~K} \text {, gamma }(\gamma) \text { orthorhombic } 480-592 \mathrm{~K} \text {, delta }(\delta) \text { cubic } 592-724 \mathrm{~K} \text {, delta prim } \\
\left(\delta^{\prime}\right) \text { tetrahedral } 724-749 \mathrm{~K} \text {, epsilon }(\varepsilon) \text { cubic } 749-913 \mathrm{~K} \text {. Data obtained from s } 17 \text { and } 19 \text {. }\end{array}$} \\
\hline \multicolumn{3}{|c|}{$\begin{array}{l}\text { c. Obtained from the "Sargent-Welch Table of Periodic Properties of the Elements," Sargent-Welch Scientific Company, } \\
\text { Skokie, Illinois, } 1979 .\end{array}$} \\
\hline \multicolumn{3}{|c|}{$\begin{array}{l}\text { d. The density of plutonium varies with crystalline form: } \alpha \text { monoclinic } 19.84 \mathrm{~g} / \mathrm{cm}^{3} ; \beta \text { monoclinic } 17.70 \mathrm{~g} / \mathrm{cm}^{3} ; \gamma \text { orthorhombi } \\
17.14 \mathrm{~g} / \mathrm{cm}^{3} ; \delta \text { cubic } 15.92 \mathrm{~g} / \mathrm{cm}^{3} ; \delta^{\prime} \text { tetrahedral } 16.00 \mathrm{~g} / \mathrm{cm}^{3} ; \text { and } \epsilon \text { cubic } 16.51 \mathrm{~g} / \mathrm{cm}^{3} \text {. }\end{array}$} \\
\hline
\end{tabular}

Plutonium reacts with many elements to form at least 90 known binary compounds. ${ }^{19}$ Some of the most well-known plutonium compounds are plutonium oxides ( $\mathrm{PuO}, \mathrm{Pu}_{2} \mathrm{O}_{3}, \mathrm{PuO}_{2}$, etc.), plutonium hydrides $\left(\mathrm{PuH}_{2}, \mathrm{PuH}_{3}\right.$, etc.), plutonium fluorides $\left(\mathrm{PuF}_{3}\right.$ and $\mathrm{PuF}_{4}$, both highly insoluble in water and acids), plutonium chlorides $\left(\mathrm{PuCl}_{3}\right.$ and $\mathrm{PuCl}_{4}$ ), plutonium carbides $\left(\mathrm{PuC}, \mathrm{Pu}_{2} \mathrm{C}_{3}\right.$, and $\left.\mathrm{PuC}_{2}\right)$, plutonium nitrides ( $\mathrm{PuN}, \mathrm{Pu}_{2} \mathrm{~N}_{3}$, and $\mathrm{PuN}_{2}$ ), plutonium sulfides ( $\mathrm{PuS}, \mathrm{Pu}_{2} \mathrm{~S}_{3}$, etc.), and many others. Most of these compounds are important in the production of plutonium-based nuclear fuels (e.g., mixtures of $\mathrm{PuO}_{2}$ and $\mathrm{UO}_{2}$ ), uranium and plutonium separation processes, or the production of plutonium metal. Metallic plutonium appears to be more chemically reactive than metallic uranium at similar temperatures. ${ }^{2}$ Because of the highly electropositive nature of plutonium, the metal is soluble or attacked by many acids (e.g., $\mathrm{HCl}, \mathrm{HBr}, 72 \% \mathrm{HClO}_{4}, 85 \% \mathrm{H}_{3} \mathrm{PO}_{4}$, trichloroacetic acid, and other acids). 
Plutonium is a highly reactive metal that combines readily with oxygen to form plutonium oxide $\left(\mathrm{PuO}_{2}\right)$. Plutonium is also hydroscopic in that it combines with water or water vapor; however, it reacts only slowly with water at room temperature and slightly faster at the boiling point. ${ }^{18}$ Machining and manufacturing activities of plutonium are usually conducted in a dry inert gas atmosphere of helium or argon and sometimes in a vacuum. Plutonium metal, in the form of a powder or finely divided material, such as machine filings, is pyrophoric at temperatures of about $753 \mathrm{~K}\left(480{ }^{\circ} \mathrm{C}\right) .{ }^{3}$ Fires involving plutonium produce plutonium oxide smoke particles.

Both ${ }^{239} \mathrm{Pu}$ and ${ }^{241} \mathrm{Pu}$ can be fissioned with slow neutrons, and are called fissile isotopes. These two isotopes can form critical assemblies (i.e., a mass of material that can sustain a fission chain reaction) under certain conditions of geometry and mass. Because plutonium is fissionable, careful planning must be exercised in its handling and machining. The critical mass of plutonium varies over a wide range, depending on such factors as geometry, reflectors, material mass or density, and the effect of diluents. For example, in an optimal configuration the minimum critical mass for ${ }^{241} \mathrm{Pu}$ is $260 \mathrm{~g}$ in a water solution; this is compared to ${ }^{239} \mathrm{Pu}$, with a minimum critical mass of $511 \mathrm{~g}$ (fully reflected geometry) or $10.2 \mathrm{~kg}$ for a bare metal assembly. ${ }^{10}$ In fact, plutonium in a liquid solution is more likely to become critical than solid metallic plutonium.

\section{Plutonium-241 Production}

${ }^{241} \mathrm{Pu}$ is an artificially produced radionuclide that does not normally exist in nature. It is created in nuclear reactors by either a single neutron capture of ${ }^{240} \mathrm{Pu}$ (e.g., ${ }^{240} \mathrm{Pu}+\mathrm{n}->{ }^{241} \mathrm{Pu}+$ gamma rays), or multiple neutron captures and subsequent decays of other actinides; for example, ${ }^{238} \mathrm{U}$ and ${ }^{239} \mathrm{Pu}$. The majority of the plutonium that is produced in nuclear reactors is contained within the spent fuel elements. The plutonium isotopes most commonly found in nuclear reactors consist of a mixture ranging from ${ }^{236} \mathrm{Pu}$ to ${ }^{242} \mathrm{Pu}$.

Due to the high neutron absorption and fission cross sections of ${ }^{241} \mathrm{Pu}\left(\sigma_{\gamma}=361\right.$ barns $=361 \times 10^{-}$ ${ }^{24} \mathrm{~cm}^{2}$, and $\sigma_{f}=1010$ barns), a significant fraction of the ${ }^{241} \mathrm{Pu}$ that is produced in a reactor is also destroyed. A small amount of ${ }^{241} \mathrm{Pu}$ will also naturally decay to ${ }^{241} \mathrm{Am}$. The amount of ${ }^{241} \mathrm{Pu}$ existing in a reactor will depend upon a complex function of the initial fuel composition, reactor power, fuel burnup, and the fuel irradiation history. Table 9-5 shows the ORIGEN $2^{21}$ calculated amount of ${ }^{241} \mathrm{Pu}$ in a typical 3,200 -MW light-water reactor (LWR), initially fueled with $100 \mathrm{Mt}$ of ${ }^{235} \mathrm{U}(3.3 \%)+{ }^{238} \mathrm{U}(96.7 \%)$ and operated for 3 years. The only source of plutonium is through reprocessing irradiated fuel; however, it can be recovered from decommissioned weapons.

Figure 9-1 shows the fission product yields from ${ }^{241} \mathrm{Pu}$ and ${ }^{235} \mathrm{U}$. A significant difference exists in these two yield curves, with ${ }^{241} \mathrm{Pu}$ producing more heavier-fission products than fission of ${ }^{235} \mathrm{U}$. 
Table 9-5. ${ }^{241} \mathrm{Pu}$, total plutonium, total actinide, and total fission product inventories calculated as a function of decay time following a 3-year irradiation in a 3,200-MW thermal power LWR producing a total fuel burnup of 33,400 MWD/MTU. Results are presented in terms of millions of curies (first list) and kilograms (second list). These results are based on an ORIGEN2 calculation of a 100-MTU (3.3-MT ${ }^{235} \mathrm{U}+96.7 \mathrm{MT}{ }^{238} \mathrm{U}$ ) pressurized water reactor (PWR).

Reactor core inventory (millions of curies)

\begin{tabular}{|c|c|c|c|c|c|c|}
\hline \multirow{2}{*}{$\begin{array}{c}\text { Radioactive } \\
\text { material }\end{array}$} & \multirow{2}{*}{$\begin{array}{c}\text { Completion } \\
\text { of fuel } \\
\text { irradiation } \\
\mathrm{T}_{0} \\
\end{array}$} & \multicolumn{5}{|c|}{ Decay time (years) following reactor irradiation } \\
\hline & & $\mathrm{T}_{0}+1$ & $\mathrm{~T}_{0}+5$ & $\mathrm{~T}_{0}+10$ & $\mathrm{~T}_{0}+50$ & $\mathrm{~T}_{0}+100$ \\
\hline${ }^{241} \mathrm{Pu}$ & 16.1 & 15.3 & 12.6 & 9.94 & 1.45 & 0.131 \\
\hline All $\mathrm{Pu}$ isotopes & 58.8 & 15.7 & 13.0 & 10.3 & 1.73 & 0.340 \\
\hline All actinides & 3900.0 & 17.6 & 13.4 & 10.7 & 2.25 & 0.836 \\
\hline $\begin{array}{l}\text { All fission } \\
\text { products (FPs) }\end{array}$ & $15,000.0$ & 200.0 & 46.4 & 31.6 & 11.3 & 3.51 \\
\hline $\begin{array}{l}\text { Actinides plus } \\
\text { fission products }\end{array}$ & $18,900.0$ & 217.6 & 59.8 & 42.3 & 13.6 & 4.34 \\
\hline \multirow{3}{*}{$\begin{array}{c}\text { Radioactive } \\
\text { material }\end{array}$} & \multicolumn{6}{|c|}{ Reactor core inventory (kilograms) } \\
\hline & \multirow{2}{*}{$\begin{array}{l}\text { Completion } \\
\text { of fuel } \\
\text { irradiation } \\
\mathrm{T}_{0}\end{array}$} & \multicolumn{5}{|c|}{ Decay time (years) following reactor irradiation } \\
\hline & & $\mathrm{T}_{0}+1$ & $\mathrm{~T}_{0}+5$ & $\mathrm{~T}_{0}+10$ & $\mathrm{~T}_{0}+50$ & $\mathrm{~T}_{0}+100$ \\
\hline${ }^{241} \mathrm{Pu}$ & 156.1 & 148.8 & 122.7 & 96.5 & 14.1 & 12.7 \\
\hline All $\mathrm{Pu}$ isotopes & 857.0 & 859.6 & 833.8 & 807.2 & 720.8 & 703.0 \\
\hline All actinides & $96,380.0$ & $96,380.0$ & $96,380.0$ & $96,380.0$ & $96,380.0$ & $96,380.0$ \\
\hline $\begin{array}{l}\text { All fission } \\
\text { products (FPs) }\end{array}$ & $3,620.0$ & $3,620.0$ & $3,620.0$ & $3,620.0$ & $3,620.0$ & $3,620.0$ \\
\hline $\begin{array}{l}\text { Actinides plus } \\
\text { fission products }\end{array}$ & $100,000.0$ & $100,000.0$ & $100,000.0$ & $100,000.0$ & $100,000.0$ & $100,000.0$ \\
\hline
\end{tabular}




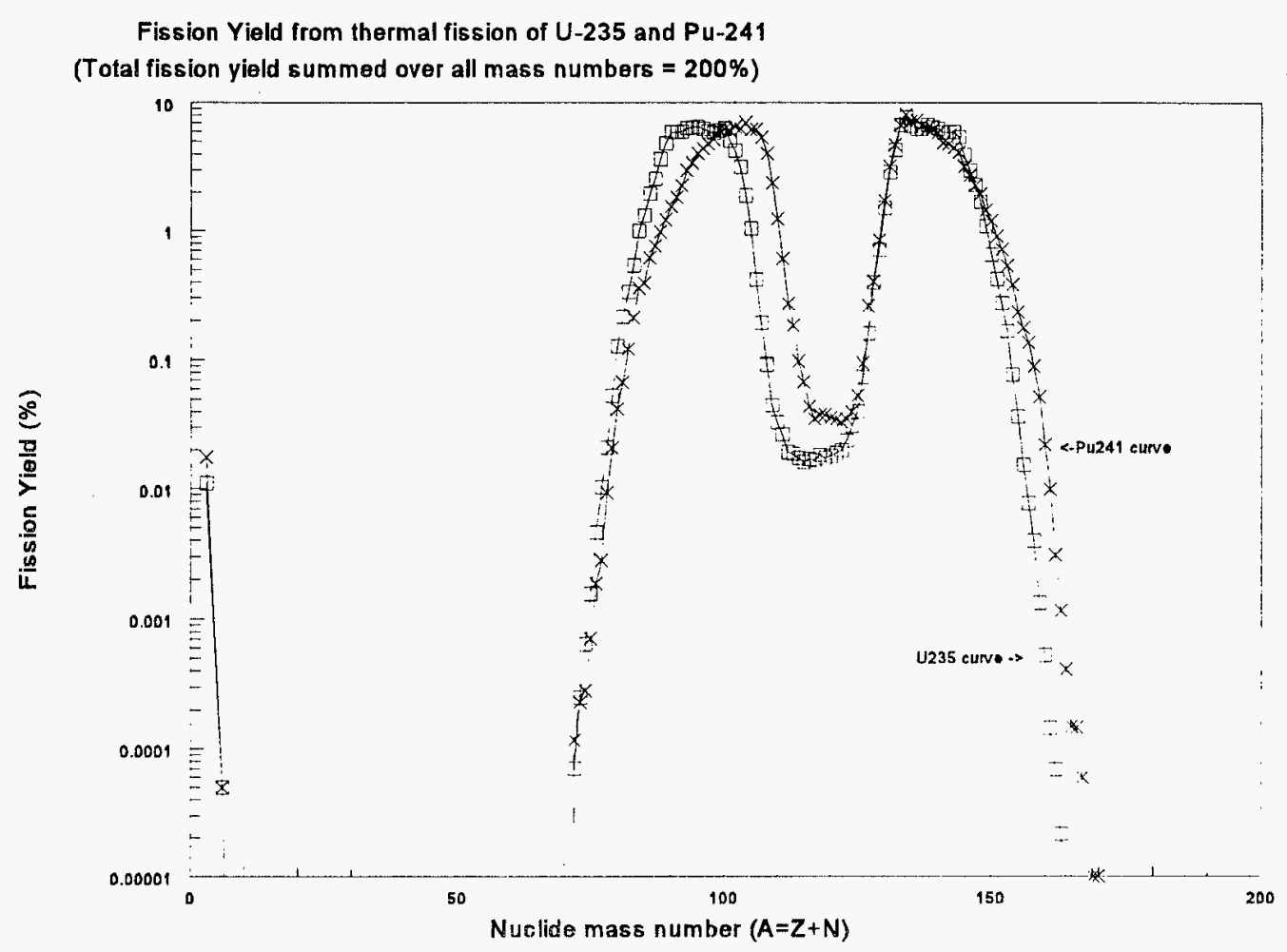

Figure 9-1. Fission product yield curve for thermal fission of ${ }^{235} \mathrm{U}$ and ${ }^{241} \mathrm{Pu}$. The curve with open boxes represents ${ }^{235} \mathrm{U}$, and the curve labeled with Xs represents ${ }^{241} \mathrm{Pu}$.

\section{Waste and Disposal Data on Plutonium-241}

This section discusses the types of activities that generate ${ }^{241} \mathrm{Pu}$ LLW, waste types and forms that contain ${ }^{241} \mathrm{Pu}$, and disposal data on ${ }^{241} \mathrm{Pu}$.

\section{Nuclear Reactors}

The primary waste associated with plutonium is the radioactive waste generated from weapons production processes; however, plutonium waste is also produced as a result of reactor fuel reprocessing and the routine operation of LWRs, including decontamination resins and filters. Waste and scrap plutonium can be produced as a result of weapons dismantling and storage operations (stored plutonium metal can oxidize to form $\mathrm{PuO}_{2}$ ). The ultimate disposition of weapons-grade plutonium from retired or dismantled weapons (e.g., disposal as waste material, processing to convert plutonium metal to an oxide, or use of the plutonium as an energy source) has not been decided. ${ }^{22}$

LLW is waste not classified as spent fuel, high-level waste, transuranic waste, or by-product material like uranium mill tailings. Generally, plutonium waste ends up as transuranic or high-level waste; however, small amounts of plutonium (including ${ }^{241} \mathrm{Pu}$ ) can exist with LLW. The limit on the amount of ${ }^{241} \mathrm{Pu}$ that can be accepted with LLW waste is 3,500 nanocuries per gram $\left(3.5 \times 10^{-6} \mathrm{Ci} / \mathrm{g}\right){ }^{23}$ 
The quantity of ${ }^{241} \mathrm{Pu}$ that is produced each year as a result of domestic commercial LWR spent fuel is $2,320 \mathrm{~kg}$ with a corresponding activity of 239 million curies. The cumulative quantity of ${ }^{241} \mathrm{Pu}$ that existed in spent fuel as of 1991 was $19,200 \mathrm{~kg}$ with an activity of 1,980 million curies. ${ }^{12}$ Only a very small fraction of this potential inventory of ${ }^{241} \mathrm{Pu}$ is disposed of as LLW. For example, for a boiling water reactor, ${ }^{241} \mathrm{Pu}$ accounts for $0.00085 \%\left(1.121 \times 10^{-4} \mathrm{Ci} / \mathrm{MWe}\right.$-year) of the LLW (irradiated components) and $0.042 \%\left(6.751 \times 10^{-4} \mathrm{Ci} / \mathrm{MWe}\right.$-year $)$ of the routine LLW. ${ }^{12}$ For a PWR, ${ }^{241} \mathrm{Pu}$ accounts for $0.000083 \%\left(1.991 \times 10^{-6} \mathrm{Ci} / \mathrm{MWe}\right.$-year) of the LLW (irradiated components) and $0.065 \%(3.965$ $\times 10^{-4} \mathrm{Ci} / \mathrm{MWe}$-year) of the routine $\mathrm{LLW} .^{12}$

Plutonium isotopes sometimes appear in LLW materials, but are usually associated with TRU (transuranic) waste. Class C LLW can contain a maximum of 3,500 nanocuries (nCi) per gram (g) of waste (e.g., $3.5 \times 10^{-6} \mathrm{Ci} / \mathrm{g}$ ) or $3.4 \times 10^{-8}$ grams of ${ }^{241} \mathrm{Pu}$ per gram of waste. If the ${ }^{241} \mathrm{Pu}$ concentration does not exceed $10 \%$ of the above value (e.g., $350 \mathrm{nCi} / \mathrm{g}$ ), then the waste is classified as class $\mathrm{A} \mathrm{LLW}$. If the ${ }^{241} \mathrm{Pu}$ concentration exceeds the $3,500 \mathrm{nCi} / \mathrm{g}$ rule (with additional concentration rules applying for other radionuclides), then the waste is not acceptable for near-surface disposal and will be classified as greater-than-Class C low-level radioactive waste (GTCC LLW) material.

Generally, ${ }^{241} \mathrm{Pu}$ occurs with other isotopes of plutonium, and the waste classification will depend upon all radionuclides present. For example, Class $\mathrm{C}$ waste can contain $100 \mathrm{nCi}$ per gram of alphaemitting transuranic nuclides (e.g., ${ }^{239} \mathrm{Pu},{ }^{240} \mathrm{Pu}$ ) with a maximum of 3,500 nCi per gram of ${ }^{241} \mathrm{Pu}$. In the case of 1 gram of LLW material consisting of a mixture of ${ }^{239} \mathrm{Pu}$ and ${ }^{241} \mathrm{Pu}$, the above limits would require that no more than $1.6 \mu \mathrm{g}$ of ${ }^{239} \mathrm{Pu}$ or $0.03 \mu \mathrm{g}$ of ${ }^{24 !} \mathrm{Pu}$ be present for this material to be considered Class $\mathrm{C}$ LLW. In other words, a very small quantity of plutonium can have a very large impact on the waste classification of the given material.

Most LLW produced at commercial nuclear reactor facilities contains fission products, induced activity, and other radioactive materials and occasionally small amounts of plutonium. For example, small amounts of transuranic radionuclides and ${ }^{241} \mathrm{Pu}$ appear in reactor process wastes (e.g., wet wastes generated from the cleanup of liquids containing soluble and insoluble radioactive materials and fuel particles), including decontamination resin beds. For instance, $\sim 0.1 \%$ of the activity of the decontamination resins from a PWR cleanup system is the result of ${ }^{241} \mathrm{Pu}^{24}$ Possible LLW consists of cartridge filters (control rod drive strainers, reactor coolant filters, seal water injection filters, cavity drain filters, fuel pool filters, or other filters), and spent decontamination resin beds. Approximately half of these filters end up as GTCC waste, and about half represent Class $\mathrm{C}$ radioactive waste material. At fuel fabrication facilities, liquid LLW is generated from washing, etching, and solvent extraction operations. The waste types from a mixed oxide fabrication operation contain only trace quantities of fission products, but contain significant amounts of transuranic materials, including plutonium.

\section{Medical, Academic Institution, and Industrial Plutonium-241 Wastes}

Pure sources of ${ }^{241} \mathrm{Pu}$ have only been available since about $1960 .{ }^{18}$ Currently, ${ }^{241} \mathrm{Pu}$ is available from Oak Ridge National Laboratory in the following units: (a) $>93 \%{ }^{241} \mathrm{Pu}$ at $\$ 13.25$ per milligram, (b) $85-93 \%{ }^{241} \mathrm{Pu}$ at $\$ 13$ per milligram, and (c) $80-85 \%{ }^{241} \mathrm{Pu}$ at $\$ 10.75$ per milligram. A packaging fee of $\$ 1,250$ and freight charges are extra.

There are no known medical or academic applications that specifically use ${ }^{241} \mathrm{Pu}$. Most past medical and biological experiments and studies have concentrated on the plutonium isotopes ${ }^{238} \mathrm{Pu},{ }^{239} \mathrm{Pu}$, and ${ }^{240} \mathrm{Pu} .^{25,26,27}$ The behavior of plutonium in animals, plants, and soils has been based on these radionuclides. However, the chemical behavior of ${ }^{241} \mathrm{Pu}$ should be similar. Some cardiac pacemakers are 
powered by thermoelectric batteries containing plutonium; however, the radionuclide used for this application is ${ }^{238} \mathrm{Pu}$.

Some plutonium waste sources also appear from manufacture and decommissioning activities. ${ }^{12}$ According to Oak Ridge National Laboratory, ${ }^{24} \mathrm{Pu}$ accounts for only $0.018 \%$ of industrial and institutional LLW, with no values listed for the amount of ${ }^{241} \mathrm{Pu}$ waste generated as a result of bioresearch, medical, or nonbioresearch activities. ${ }^{12}$ The amount of ${ }^{241} \mathrm{Pu}$ used in these activities is expected to be very small compared with other radionuclides or other plutonium isotopes.

${ }^{241} \mathrm{Pu}$ does not appear to be an important waste form produced from medical and institutional research. If ${ }^{241} \mathrm{Pu}$ were used in such applications, then it would probably follow the same chemical forms that have been used in past plutonium research. These possible chemical forms include plutonium nitrate, plutonium citrate, plutonium oxides, plutonium chloride, and plutonium ascorbic acid. ${ }^{25}$

\section{Disposal Data on Plutonium-241}

${ }^{241} \mathrm{Pu}$ has been deposited in three LLW sites in Richland, Washington; Barnwell, South Carolina; and Beatty, Nevada over a period of several years. Data concerning the activity, sources, and waste types for this nuclide have been obtained from the Manifest Information Management System Database. ${ }^{a}$ Figure 9-2 shows the total annual ${ }^{241} \mathrm{Pu}$ activity deposited in the three sites for each year between 1986 and 1995 . Nearly $40 \%$ of the total activity for this nuclide was deposited during $1986 .{ }^{241} \mathrm{Pu}$ was deposited approximately uniformly during the other years.

Figure 9-3 shows the activity of ${ }^{241} \mathrm{Pu}$ deposited in these three sites as a function of waste source. Utility and industrial sources account for more than $99 \%$ of the total deposited in these three sites. The rest $(<1 \%)$ came from the other sources.

Figure 9-4 shows the activity of ${ }^{241} \mathrm{Pu}$ deposited in the Richland and Beatty sites as a function of waste type. The waste disposal manifests for the Barnwell site did not break down the waste by type, which is unfortunate since more than $85 \%$ of this nuclide has been stored at this site. As shown in this figure, three waste types (solidified, noncompacted dry, and dewatered resin) account for more than $80 \%$ of the deposits for this nuclide. The sources for the remaining deposits were distributed, more or less uniformly, among the other waste types.

a. Information provided through the DOE waste management system maintained by the National Low-Level Waste Management Program, Idaho National Engineering Laboratory (INEL). 


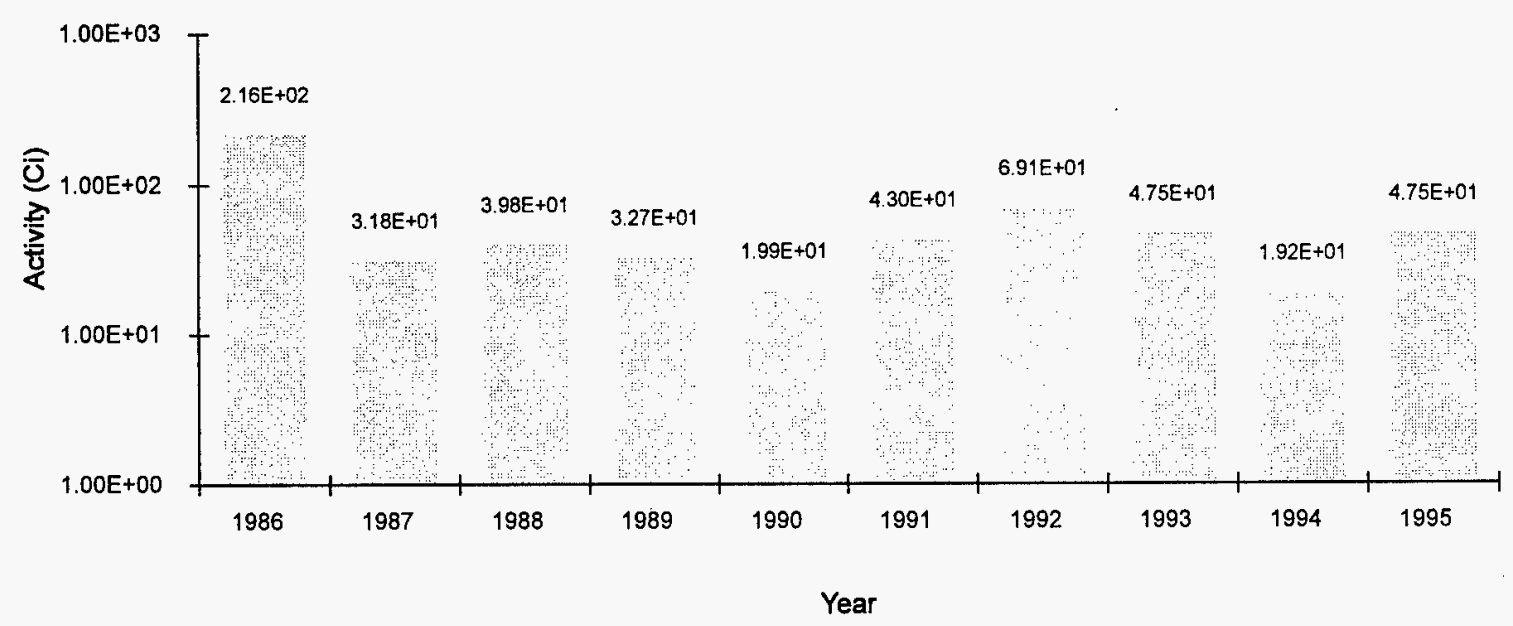

Figure 9-2. ${ }^{241} \mathrm{Pu}$ activity deposited at the Richland, Beatty, and Barnwell sites by year (log scale).

The definition of disposal categories given in Figure 9-3 is as follows: academic - sources associated with university laboratories; government - sources associated with the government, such as military hospitals; industry - sources associated with manufacturing, other than utilities; medical sources associated with hospitals and medical laboratories, excluding pharmaceutical manufacturing; utility - sources generated by nuclear utilities and stored onsite or sent to one of the three disposal sites. Waste treatment facilities are included in the utility category.

The waste types illustrated in Figure 9-4 are from nuclear reactors, academic institutions, and medical facilities.

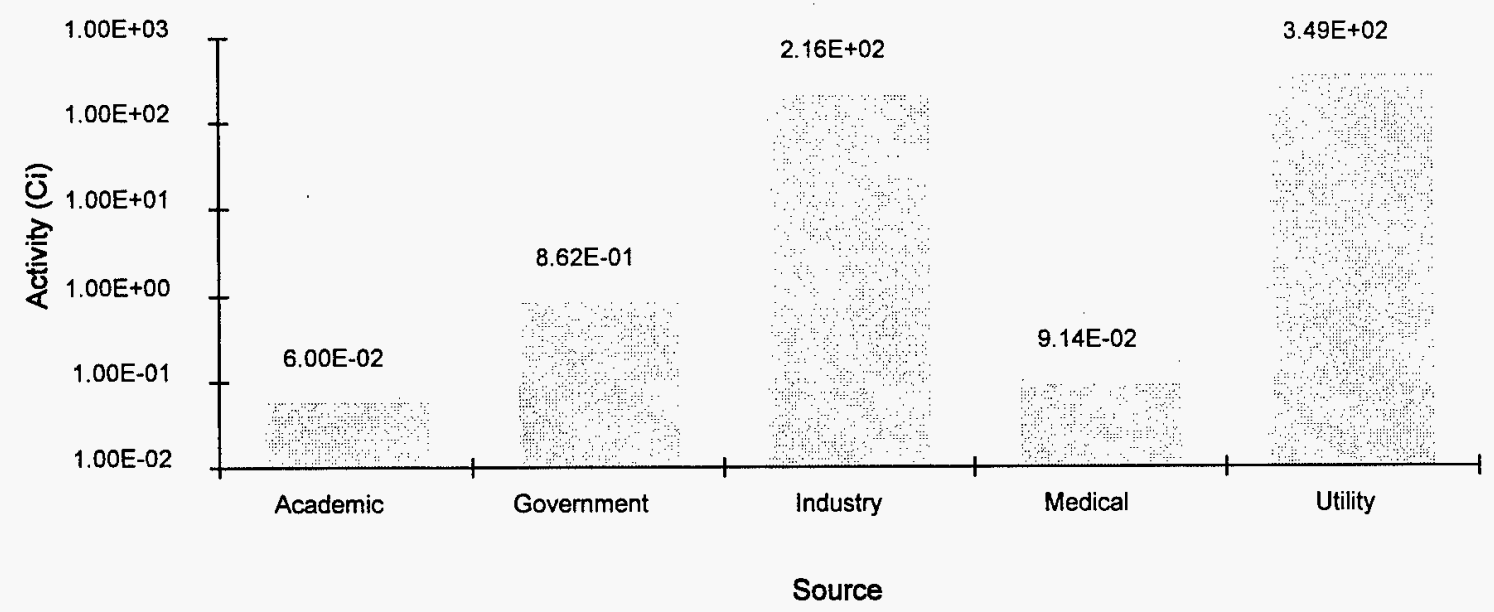

Figure 9-3. ${ }^{24 I} \mathrm{Pu}$ activity deposited at the Richland, Beatty, and Barnwell sites by source (log scale). 


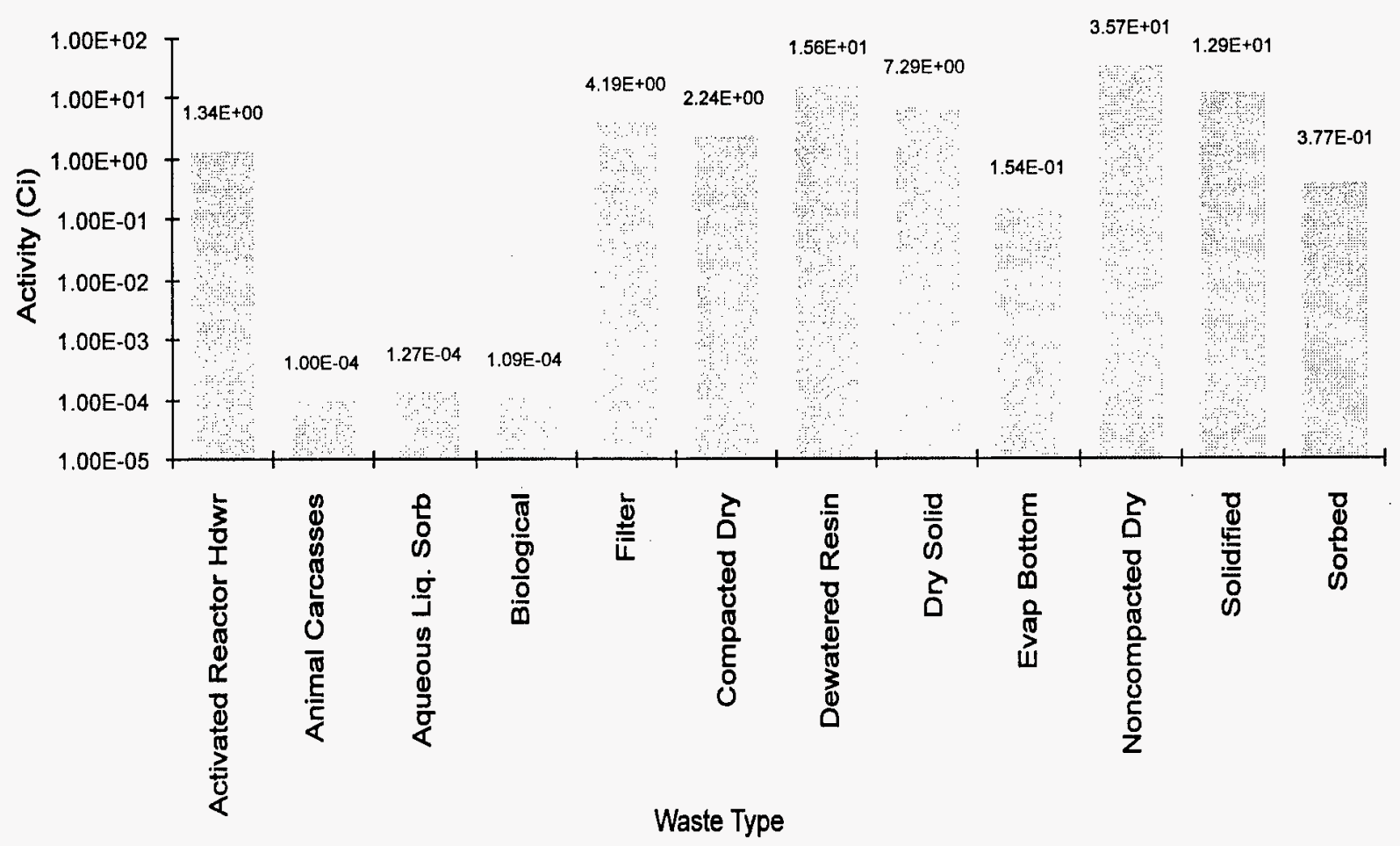

Figure 9-4. ${ }^{241} \mathrm{Pu}$ activity deposited at the Richland and Beatty sites by waste type (log scale).

\section{Behavior of Plutonium-241 in the Environment}

\section{Plutonium-241 in Soils}

Understanding the behavior of plutonium in the soil is important in predicting the dissolution of radioactive waste in LLW disposition (e.g., burial) and the possible transport of plutonium through the biosphere. It is important to understand the interactions between radionuclides and various media along the path to the biosphere, whether disposal is in deep or shallow rock caverns or in shallow overburden facilities.

Plutonium does not naturally occur in soils; however, plutonium is present in many soils because of a variety of reasons. The primary sources of environmental plutonium include (a) releases from research facilities, (b) nuclear weapons testing, (c) waste disposal, (d) nuclear weapons production facilities, (e) experimental operations, and (f) accidents. Nevertheless, the major source of plutonium in most soils is primarily due to radioactive fallout from weapons testing. ${ }^{28}$

Past investigations have indicated that plutonium sources from fallout and industrial releases behave in a similar fashion, and that when soluble or insoluble forms of organic matter are present in either alkaline or acid soils, any contaminating plutonium in the soil has the potential of high mobility. ${ }^{28}$ In addition, the important factors affecting plutonium chemistry and, therefore, mobility and sorption in soil, are (a) soil $\mathrm{pH}$, (b) clay content, (c) calcium carbonate content, and (d) organic matter content. ${ }^{28}$ For example, studies of plutonium concentrations due to fallout on soils from Ohio (a humid area with high lime-glacial tills) showed a significant correlation with clay content. However, experimental investigations showed that $\sim 95 \%$ of the plutonium in solution at a $\mathrm{pH}$ of 6.5 could be removed by calcium-saturated clays. 
An additional factor affecting plutonium chemistry and binding capabilities to soil is microbial activity. It has been suggested ${ }^{28}$ that up to $10 \%$ of the plutonium present in soil may become bound to or associated with organic compounds present in the soil. Even plutonium added to a culture medium as $\mathrm{PuO}_{2}$ (as very small particles) can be assimilated by common soil fungi. The diffusion of plutonium in soil is also affected by the sorption characteristics of the various chemical forms present. However, plutonium may be more mobile in soil than the diffusion theory can explain. In particular, micro-organism activity can increase plutonium mobility in soil. Microbiological and plant actions can influence plutonium mobility in soil, and these factors will be of increased importance as larger quantities of plutonium become bound to living and dead organic materials. It has also been noted that the movement of $\mathrm{PuO}_{2}$ was approximately 100 times faster than that of $\mathrm{Pu}\left(\mathrm{NO}_{3}\right)_{4}{ }^{28}$ Also, physical processes (e.g., wind and water transport) may be more important than chemical processes in transporting plutonium to vegetation.

It appears that in the majority of soil types, and especially those that contain significant quantities of clay, soluble forms of plutonium can be adsorbed rapidly by the soil. Several studies have been made on the vertical distribution of plutonium in soil profiles contaminated as a result of nuclear fallout and accidental releases. ${ }^{28}$ Generally, these studies show slight concentrations in surface soils relative to subsurface soils. In fact, it is reported in Reference 28 that more than $95 \%$ of the plutonium present was in the top $5 \mathrm{~cm}$ layer. Several authors report a decreasing exponential relationship between plutonium concentration and soil depth. In the case of the Trinity nuclear test site in New Mexico, consisting of sandy loam soil, about $50 \%$ of the plutonium residing in the top $0-$ to $5-\mathrm{cm}$ layer of soil has moved downward to the 5 - to 20 -cm layer over a 20 -year period. ${ }^{28}$ It has also been noted that the mobility of plutonium in soil profiles can be expected to be the greatest when the chemical form of plutonium is largely as the oxide $\left(\mathrm{PuO}_{2}\right)$, or when the soil is low in clay content, high in soluble organic material, and subject to vegetation cover. In farming areas, the effect of plowing on plutonium movement has to be considered.

The soil retention parameter represents the solid/liquid partition coefficient and is denoted by the symbol $K_{d}$ (e.g., a distribution coefficient). $K_{d}$ is defined by $K_{d}=C_{s} / C_{1}$, where $C_{s}$ is the plutonium concentration in the soil (solid) and $\mathrm{C}_{1}$ is the plutonium concentration in the groundwater (liquid). This empirical model combines the soil retention mechanisms into a simple linear partition relation between the soil and the surrounding groundwater. This model assumes that the $C_{s}$ and $C_{1}$ are in equilibrium with each other; that is, they are not changing with time. Using this definition for $\mathrm{K}_{\mathrm{d}}$, it follows that the larger the value (that is, the higher the radionuclide concentration in the soil relative to that in the groundwater) the slower the migration of the radionuclide relative to groundwater flow. Therefore, $K_{d}$ can be thought of as a measure of the amount of "holdup" in the soil.

Typically, $\mathrm{K}_{\mathrm{d}}$ is measured under laboratory conditions, using samples that are relatively homogenous, and where it can be ensured that equilibrium conditions are met. Applying these values to specific soils in the field can be difficult because actual soils are generally inhomogeneous and there are uncertainties as to how long it takes for the plutonium concentrations in the soil and groundwater $\left(\mathrm{C}_{\mathrm{s}}\right.$ and $\mathrm{C}_{1}$ ) to be in equilibrium with each other. Therefore, one must be careful to ensure that soil samples used in the laboratory studies are as closely representative of the field as possible. However, even though the soil samples do not precisely match conditions in the field, $\mathrm{K}_{\mathrm{d}}$ values from these laboratory studies can be used in computer models that extrapolate data from laboratory experiments and field studies. In addition, some experiments are conducted using intact field samples to validate the laboratory $\mathrm{K}_{\mathrm{d}}$ values and to study the effects due to soil inhomogeneity. 
Early studies on plutonium soil sorption showed that, at a $\mathrm{pH}$ of 4 , plutonium in solution was removed by Hanford soil, while at a $\mathrm{pH}$ of 10 , plutonium passed through the soil column ${ }^{28}$ Also, $\mathrm{K}_{\mathrm{d}}$ was found to be affected by the $\mathrm{pH}$ of the leaching solution as follows: below a $\mathrm{pH}$ of $2.2, \mathrm{~K}_{\mathrm{d}}$ varied between 18 and $28 ; \mathrm{K}_{\mathrm{d}}$ was larger than 1,980 at $\mathrm{pH}$ values of 2.2 to $5.3 ; \mathrm{K}_{\mathrm{d}}$ dropped to 888 at a $\mathrm{pH}$ of 6 and then increased again to $>1,980$ at $\mathrm{pH}$ values of between 7.1 and 8.4. At higher $\mathrm{pH}$ values $(\mathrm{pH}=12), \mathrm{K}_{\mathrm{d}}$ decreased to 96 , and in even more alkaline conditions it increased again to values $>1,980$. It was observed that the desorption of plutonium from soil was difficult to accomplish with organic solutions. Other soil studies have reported that sorption of plutonium was greatest on the inorganic mineral phase and that a similar degree of sorption could be obtained with calcium carbonate. ${ }^{28}$ Table 9-6 shows the average sorption ratio $\left(\mathrm{K}_{d}\right.$, sometimes reported at $\mathrm{R}_{\mathrm{d}}$ ) values for plutonium transport in several different materials.

\section{Plutonium-241 in Water}

Plutonium does not naturally occur in the environment, including ground or surface waters. However, as a result of past atmospheric nuclear weapons testing, some isotopes of plutonium do exist in very small concentrations $\left(\sim 10^{-15}\right.$ becquerels/liter where 1 becquerel-or simply $1 \mathrm{~Bq}$-is defined as 1 disintegration per second; and, 1 curie is defined as $3.7 \times 10^{10} \mathrm{~Bq}$ ) in almost all surface water bodies. ${ }^{28}$ Due to the relatively short half-life of ${ }^{241} \mathrm{Pu}$, and the moratorium on atmospheric testing of nuclear weapons for the last 30 years, very little ${ }^{241} \mathrm{Pu}$ is expected to exist in surface waters and even less is expected to exist in groundwater due to radioactive fallout. The plutonium that does exist in groundwater is generally associated with the intentional injection of radioactive material. Because ${ }^{241} \mathrm{Pu}$ is fairly difficult to measure, only total plutonium $\left({ }^{239} \mathrm{Pu}+{ }^{240} \mathrm{Pu}\right.$; it is not possible to differentiate between these two isotopes by radiometric methods) is usually reported. However, ${ }^{241} \mathrm{Pu}$ concentrations can be estimated if the initial isotope mass fractions and the amount of time since the plutonium was released into the water are known. In most cases, it is expected that ${ }^{241} \mathrm{Pu}$ concentrations in groundwater are exceedingly small or essentially zero.

\section{Plutonium-241 in Plants}

The plutonium uptake by plants (e.g., from soil) has been studied in both laboratory and field experiments. However, most of the field studies have relied upon fallout plutonium deposited on plant surfaces. The concentration of plutonium in both types of experiments, on a dry weight basis, has been reported to be less than 0.001 times that in the growth medium, and usually was about 0.0001 times the concentration in the soil..$^{25}$

Table 9-6. Average sorption ratios $\left(K_{d}\right.$ or $\left.R_{d}\right)$ as reported in Reference 10.

\begin{tabular}{lcc}
\multicolumn{1}{c}{ Material } & $\mathrm{K}_{\mathrm{d}}(\mathrm{mL} / \mathrm{g})$ at $22^{\circ} \mathrm{C}$ & $\mathrm{K}_{\mathrm{d}}(\mathrm{mL} / \mathrm{g})$ at $70^{\circ} \mathrm{C}$ \\
\hline Quartz monzonite & 1,300 & 3,600 \\
Alluvium & $>1,000$ & not reported \\
Vitric tuff & 170 & not reported \\
Devitrified tuff & 110 & not reported \\
Zeolitized tuff & 280 & not reported
\end{tabular}


Several studies have been made on the occurrence of plutonium in the Arctic. Lichens have been identified as important to understanding the time deposition of plutonium. Field studies have shown that the biological half-life of plutonium in lichens is of the order of 2 or 3 years. Lichens have also been found to contain appreciable amounts of plutonium near Oak Ridge Laboratory and Los Alamos. ${ }^{28}$ Mosses also tend to be enriched in plutonium compared with other forms of plant life at contaminated sites.

A large number of studies have been made on the occurrence of plutonium in agricultural crops. The general conclusion of many investigators is that the majority of plutonium found in vegetation represents surface contamination rather than uptake from soil. Additional observations suggest that the relationship between soil, air, and plant concentrations is somewhat species dependent, and influenced by seasonal factors. One study (see p. 20 of Reference 28 ) showed plutonium concentrations $\sim 10$ times higher in legumes than grasses or cereals. Clover and soybeans generally showed a greater uptake than other crops. Another study noted that higher concentrations of plutonium were found in grasses than in other forms of vegetation, and that lower concentrations were found in forbs, shrubs, and trees. A number of factors have been identified as being of importance with plutonium absorption and the soilplant relations. These factors include (a) the vegetation type, (b) species, (c) age and status of the plant, (d) soil $\mathrm{pH}$, (e) positive ion-exchange capacity, (f) organic matter and/or clay content, (g) plutonium chemical form added to the soil, and $(\mathrm{h})$ the duration of the contamination. Some authors have remarked that results obtained under experimental conditions differ substantially from field results, mainly due to plutonium uptake from the soil. It is likely that the chemical and physical form of the plutonium source material does affect the plant concentrations derived from the atmosphere, and that the plutonium derived from the soil is controlled by the soil chemistry. Generally, most researchers have concluded that root uptake of plutonium is limited, especially when contrasted with atmospheric sources of plutonium..$^{28}$ These results are mainly based on studies in which only the aboveground portions of plants have been analyzed and compared with plutonium soil concentrations. In only a few cases have concentration ratios been determined for root material. On the basis of limited data, it appears that plutonium can be adsorbed by plant roots. In a majority of cases, less than $0.01 \%$ of the plutonium present in soil is recovered in aboveground parts of plants over periods ranging from 18 to 50 days. ${ }^{28}$

\section{Plutonium-241 in Air}

Plutonium isotopes are not normally found in air, except for those amounts that result from fallout due to an atmospheric test of a thermonuclear weapon or from nuclear accident (reactor accidents such as the Chernobyl reactor accident; weapons facility accidents such as the fire at Rocky Flats; or military accidents). Plutonium that is released to the atmosphere will eventually deposit (fall out) on the land or ocean.

\section{Behavior of Plutonium-241 in the Human Body and in Animals}

Many studies have been performed on the behavior of plutonium in humans and animals; however, most data are based on laboratory studies of animal experiments, with most human studies relying on accidental exposures (including fragmentary data on contaminated puncture wounds in man). Plutonium that is injected into animals or man tends to be absorbed, after a period of time, by bones and the liver. ${ }^{25}$ In man, after about 150 days, $66 \%$ of the initial dose injected into the blood stream is eventually found in the bones, $23 \%$ in the liver, $0.4 \%$ in the spleen, and $0.4 \%$ in the kidneys. The remaining amount is usually lost from blood within a matter of minutes. The skeleton (bone) is generally considered the major site of plutonium deposition, with the liver being the second most important tissue or organ. 
Within a few minutes of injecting plutonium into an animal, the plutonium remaining in the circulatory system is combined with protein, and it then is only slowly lost from the blood system. Plutonium retained in the blood system for any extended period of time is almost entirely associated with protein. After about five months after intravenous injection, the blood plutonium in man averaged $0.2 \%$ of the initial injected dose. ${ }^{25}$ Little information is known about the nature of plutonium that has entered the blood system by pathways other than intravenous injection. Studies in mice and rats have shown that plutonium in blood is transmitted across the placenta from the mother to baby in concentrations of 6 to $8 \%$. Also, plutonium is transmitted by the milk of lactating animals.

The interaction of plutonium in an animal or man is complicated by the complex chemistry and the five possible oxidation states that the element can occupy, and role that hydrolysis plays in producing complex polymers of plutonium.

There is little information available for the gastrointestinal absorption of plutonium in humans. ${ }^{28}$ However, it has been found that absorption of plutonium from the gastrointestinal tract is extremely low in adult animals, although combining plutonium with organic compounds can markedly increase its absorption. The primary factors that are thought to affect the gastrointestinal absorption of plutonium are (a) age of the animal and dietary regime, (b) chemical form or solubility of the plutonium ingested, and incorporation of the plutonium in the food source, and (c) $\mathrm{pH}$ of the solution and plutonium particle size in the case of nonbiologically incorporated plutonium. Some plutonium absorption $\left(f_{1}\right)$ values are shown in Table 9-6. In general, the organic complex plutonium-citrate is more readily absorbed than inorganic forms such as plutonium-nitrate, which in turn are more readily absorbed than the insoluble plutonium-oxide compounds. ${ }^{28}$

The principal pathway for human exposure of plutonium is usually inhalation of airborne particles. Most data on inhalation of plutonium are based on laboratory studies of animals. The retention of plutonium in lungs is known to be biologically complex. Some of the most important factors affecting the retention of inhaled plutonium are (a) chemical form of plutonium inhaled, (b) physical characteristics of the plutonium (e.g., particle size and temperature), (c) presence of chelating agents (i.e., a complex compound with a metallic atom bound at two or more points to form a ring structure), and (d) the quantity of plutonium inhaled (this would affect the immediate amount of lung damage). On the basis of available data, the long-term component of retention of organic complexes in the lung (i.e., plutonium-citrate) is generally associated with a half-life of 30 to 300 days, and that of plutonium-oxide half-life is 250 to 650 days in man. ${ }^{28}$ Plutonium in the upper respiratory tract, including the trachealbronchial region, may be cleared with a biological half-life of 0.5 to 0.8 days in man. ${ }^{28}$ The rate of clearance at times long after exposure is mostly determined by the initial solubility of the plutonium compound. For example, particles that dissolve in the lung might pass through the lung tissue and subsequently appear in the blood system.

Table 9-7 shows the maximum permissible body burdens of ${ }^{24} \mathrm{Pu}$ as reported by the Environmental Protection Agency in Reference 29. However, information published in Management and Disposition of Excess Weapons Plutonium ${ }^{30}$ indicates that new regulations were scheduled to go into force on January 1, 1994, limiting the allowable plutonium (presumably ${ }^{239} \mathrm{Pu}$ ) concentration in water available to the general public at $2 \times 10^{-8}$ curies per cubic meter. These restrictions are 250 times more stringent than previous standards. These new regulations may also affect the ${ }^{241} \mathrm{Pu}$ dose concentrations shown in Table 9-7. 
Table 9-7. Annual limits on intake (ALI) and the derived air concentrations (DAC) for ${ }^{241} \mathrm{Pu}$ for ingestion and inhalation.

\begin{tabular}{|c|c|c|c|}
\hline Species & Component & $\begin{array}{c}\text { Ingestion per year and } \\
\left(f_{1} \text { value }\right)^{a}\end{array}$ & $\begin{array}{c}\text { Inhalation and } \\
\left(/ \text { Class and } f_{1} \text { value }\right)^{a}\end{array}$ \\
\hline $\begin{array}{l}{ }^{241} \mathrm{Pu} \text {-oxides } \\
{ }^{241} \mathrm{Pu} \text {-nitrates } \\
{ }^{241} \mathrm{Pu} \text {-all others }\end{array}$ & $\mathrm{ALI}$ & $\begin{array}{c}4000 \mu \mathrm{Ci}\left(f_{1}=10^{-5}\right) \\
400 \mu \mathrm{Ci}\left(f_{1}=10^{-4}\right) \\
40 \mu \mathrm{Ci}\left(f_{1}=10^{-3}\right)\end{array}$ & $0.8 \mu \mathrm{Ci} / \mathrm{Y}\left(\mathrm{f}_{1}=10^{-5}\right)$ \\
\hline $\begin{array}{l}{ }^{241} \mathrm{Pu} \text {-oxides } \\
{ }^{241} \mathrm{Pu} \text {-all others }\end{array}$ & DAC & $\sim^{b}$ & $\begin{array}{l}3 \times 10^{-10} \mu \mathrm{Ci} / \mathrm{cm}^{3} / \mathrm{Y}\left(\mathrm{f}_{1}=10^{-5}\right) \\
1 \times 10^{-10} \mu \mathrm{Ci} / \mathrm{cm}^{3} / \mathrm{W}\left(\mathrm{f}_{1}=10^{-3}\right)\end{array}$ \\
\hline
\end{tabular}

a. Values depend upon the removal time of the specific chemical form of ${ }^{241} \mathrm{Pu}$ and are placed in the three possible lung clearance classes: $D$ representing days, $W$ for weeks, or $Y$ for years. $f_{1}$ represents the fraction of the substance that enters the blood-stream through the gastrointestinal tract or from the lung with a clearance class of $D$, $\mathrm{W}$, or $\mathrm{Y}$. For ingestion calculations, plutonium oxides (or hydroxides) have a $\mathrm{f}_{1}=10^{-5}$, nitrates have a $\mathrm{f}_{1}=10^{-4}$, and all other plutonium compounds have a $\mathrm{f}_{1}=10^{-3}$.

b. Data not available.

Source: Data obtained from Reference 29.

The biological half-life $\left(T_{1 / 2 b}\right)$ of plutonium (which includes ${ }^{241} \mathrm{Pu}$ ) in the human body has been reported as follows: 65,000 days for the entire body, 73,000 days for bone, 64,000 days for kidneys, and 54,000 days for the liver. ${ }^{30}$ Since the physical half-life $\left(\mathrm{T}_{1 / \mathrm{p}}\right)$ of ${ }^{241} \mathrm{Pu}$ is 14.4 years $(52,600$ days $)$, then the effective half-life ( $\mathrm{T}_{\text {eff }}$ includes both biological and physical processes) is computed as follows:

$T_{1 / 2 \text { eff }}=\left(T_{1 / 2 b} \times T_{1 / 2 p}\right) /\left(T_{1 / 2 b}+T_{1 / 2 p}\right)$. ${ }^{31}$ Performing these calculations, the effective half-life for ${ }^{241} \mathrm{Pu}$ in the human body is 29,000 days for the entire body, 30,600 days for bone, 28,900 days for kidneys, and 26,600 days for the liver. These half-life results are very high, and indicate that once ${ }^{241} \mathrm{Pu}$ enters the blood system it would be retained for a long time.

\section{Summary}

${ }^{241} \mathrm{Pu}$ is an artificially produced radionuclide that does not normally exist in nature. Its half-life is approximately 14.4 years and it decays primarily by beta particle emission to ${ }^{241} \mathrm{Am}$; however, a very small fraction decays to ${ }^{237} \mathrm{U}$. When it decays, it releases mostly beta particles with a maximum energy of $21 \mathrm{keV}$. The released radiation is less penetrating than that of most radionuclides, and in particular is comparable with that of tritium. However, ${ }^{241} \mathrm{Pu}$ is classified in the very high radiological hazard group, primarily because of its main daughter product, ${ }^{241} \mathrm{Am}$ (an alpha emitter with emission of 5,500-keV particles), and the few gamma rays emitted by its secondary daughter product, ${ }^{237} \mathrm{U}$.

${ }^{241} \mathrm{Pu}$ is produced within nuclear reactors through the neutron absorption in ${ }^{240} \mathrm{Pu}$ or through multiple absorptions and decays of other transuranic isotopes. Due to the short half-life of ${ }^{24 l} \mathrm{Pu}$, about $27 \%$ of the activity (or $18 \%$ of the mass) from plutonium isotopes in recently irradiated fuel is due to ${ }^{241} \mathrm{Pu}$. 
No medical or industrial uses of ${ }^{241} \mathrm{Pu}$ are known for this isotope. Most medical and industrial uses of plutonium center around ${ }^{238} \mathrm{Pu}$ for cardiac pacemakers and radioisotopic thermoelectric generators (space applications), and ${ }^{238} \mathrm{Pu},{ }^{239} \mathrm{Pu},{ }^{240} \mathrm{Pu}$ used in biological studies (e.g., soil-plant and animal experiments).

The chemistry of this element is complex in that it can form hundreds of different compounds. In the absence of surface oxidation, plutonium is a silvery-white metal, similar to nickel. The better-known plutonium compounds that are important to the nuclear industry and fuel fabricators are plutoniumoxides, plutonium-hydrides, plutonium-fluorides, plutonium-chlorides, plutonium-carbides, plutonium-nitrides, and plutonium-sulfides, as well as many other compounds.

Most data on plant uptake of plutonium have concluded that the majority of plutonium found in native plants and agricultural crops comes from surface contamination rather than soil-plant absorption through the roots. Plutonium concentrations are dependent on plant species, plant age, vegetation type, soil $\mathrm{pH}$, positive ion-exchange capability, mineral and organic composition, the plutonium chemical form, and duration of contamination. Root absorption of plutonium, when present in soil, does occur; however, translocation to the aboveground portions of the plant is limited to less than $0.01 \%$ of the total plutonium concentration in the soil.

The majority of data concerning plutonium effects on man are based on extrapolation of laboratory studies of small animals, although a small number of humans injected with plutonium or accidentally exposed with plutonium have been studied. Plutonium is generally difficult to absorb from the gastrointestinal tract; however, once it enters the blood system it is carried throughout the body. The factors thought to affect gastrointestinal absorption of plutonium include age of the animal and diet, chemical form or solubility of plutonium ingested, $\mathrm{pH}$ of the administered material, and particle size. The eventual sites where plutonium is deposited are in the skeleton (bones) and the liver. The effective half-life of ${ }^{241} \mathrm{Pu}$ in a human is 29,000 days ( 79 years) for the overall body, 30,600 days ( 84 years) for bone, 28,900 days ( 79 years) for the kidneys, and 26,600 days ( 73 years) for the liver. These half-life results are very high and indicate that, once plutonium enters the human blood system, it will be retained by the body for a long time. 


\section{References}

1. General Electric Company, Nuclides and Isotopes, Fourteenth Edition, 1989, p. 46.

2. M. M. Benjamin, Nuclear Reactor Materials and Applications, New York: Van Nostrand Reinhold Company, 1983, p. 208, and Chapter 8.

3. F. J. Rahn et al., A Guide to Nuclear Power Technology, New York: John Wiley \& Sons, 1984, Chapter 5.3, pp. 171-181.

4. B. G. Bennett, "Transfer of Plutonium from the Environment to Man," Proceedings of the International Symposium on the Management of Wastes from the LWR Fuel Cycle, July 11-16, 1976, Denver, Colorado, Energy Research and Development Administration, CONF-76-0701, July 1976, pp. 554-564.

5. R. Granier and D. Gambini, Applied Radiobiology and Radiation Protection, Ellis Horwood Limited, 1990, p. 283, and Appendix 2.

6. Z. A. Medvedev, The Legacy of Chernobyl, W. W. Norton \& Company, 1990, pp. 78 (Table 3.1), 98 , and 99.

7. J. Shapiro, Radiation Protection: A Guide for Scientist and Physicians, Second Edition, Harvard University Press, 1981, pp. 384-393.

8. Isotope Distribution Office of Oak Ridge National Laboratory, "Radioisotope Price List," Revised October 1, 1993, p. 2 (concerning ${ }^{241} \mathrm{Pu}$ ).

9. E. Browne, J. M. Dairiki, R. E. Doebler, Table of Isotopes, Seventh Edition, New York: John Wiley \& Sons, 1978, pp. 1472 and 1473.

10. D. C. Stewart, Data for Radioactive Waste Management and Nuclear Application, John Wiley \& Sons, 1985, pp. 57-59 and Figure 2.2, pp. 64-67 (Table 2.1), p. 73 (Table 2.3), p. 145, pp. 221-227, Table 8.12, pp. 251 and 263.

11. C. M. Lederer, J. M. Hollander, I. Perlman, Table of Isotopes, Sixth Edition, New York: John Wiley and Sons, Inc., 1967, p. 145 for ${ }^{241}$ Pu principal means of production, and p. 435.

12. Oak Ridge National Laboratory, Integrated Data Base for 1992: U.S. Spent Fuel and Radioactive Waste Inventories, Projections, and Characteristics, DOE/RW-0006, Rev. 8, October 1992, pp. 260, 272, 273, 284, 292, and 294.

13. U.S. Department of Health, Education, and Welfare, Radiological Health Handbook, Revised Edition, January 1970, pp. 92-94 (Average and Maximum Beta Energy by Radionuclide), 122, and 204.

14. W. R. Gilmore (ed.), Radioactive Waste Disposal-Low and High Level, Noyes Data Corporation, 1977, p. 235.

15. E. Browne, R. B. Firestone, V. S. Shirley (ed.), Table of Radioactive Isotopes, New York: John Wiley \& Sons, 1986, Data concerning ${ }^{59} \mathrm{Ni}$ : Photons, Atomic Electrons, and Continuous Radiation. 
16. P. C. Souêrs, Hydrogen Properties for Fusion Energy, University of California Press, 1986, Chapters 1, 16, and 17, and p. 6.

17. R. C. Weast (ed.), CRC Handbook of Chemistry and Physics, Boca Raton, Florida: CRC Press, 58th Edition, 1977-1978, pp. B270-B354 (Table of Isotopes), pp. B-141 and B-142.

18. O. J. Wick (ed.), Plutonium Handbook: A Guide to the Technology, Volume I, Gordon and Breach, Science Publishers, 1967, pp. 13, 331, and Chapters 11 and 12.

19. A. R. Kaufmann, Nuclear Reactor Fuel Elements Metallurgy and Fabrication, New York: Interscience Publishers, 1962, p. 105 (Table 4-3), or p. 115.

20. M. M. Benjamin, Nuclear Reactor Materials and Applications, New York: Van Nostrand Reinhold Company, 1983, p. 210 (Table 8.2).

21. A. G. Croff, $A$ User's Manual for the ORIGEN2 Computer Code, ORNL/TM-7175, July 1980.

22. U.S. Congress Office of Technology Assessment, Dismantling the Bomb and Managing the Nuclear Materials, September 1993, pp. 82 and 83.

23. Code of Federal Regulations, 10 CFR 61, Office of the Federal Register, 1994, Chapter I, p. 136 (Table 1).

24. R. A. Hulse, Greater-Than-Class C Low-Level Radioactive Waste Characterization: Estimated Volumes, Radionuclide Activities, and Other Characteristics, DOE/LLW-114, August 1991, pp. 47-55, Table 10-4, Table 10-6, Table 10-7, Table 10-5, Appendix F.

25. O. J. Wick (ed.), Plutonium Handbook: A Guide to the Technology, Volume II, Gordon and Breach Science Publishers, 1967, pp. 787-829, 787, 795, and Chapter 23.

26. C. F. Gehrens and E. R. King, Atomic Medicine, Fourth Edition, Williams \& Wilkins Company, 1964, p. 261.

27. R. John Garner, Transfer of Radioactive Materials from the Terrestrial Environment to Animals and Man, Boca Raton, Florida: CRC Press, 1972, p. 41.

28. P. J. Coughtrey et al., Radionuclide Distribution and Transport in Terrestrial and Aquatic Ecosystems: A Critical Review of Data, Volume Four, A. A. Balkema, 1984, pp. 1, 2, 5, 7, 8, 9, 19, 20, 21, 26, 27, 34, 118, 224 (Chapter 29).

29. K. F. Eckerman, A. G. Wolbarst, A. C. B. Richardson, Limiting Values of Radionuclide Intake and Air Concentration and Dose Conversion Factors for Inhalation, Submersion, and Ingestion, Federal Guidance Report No. 11, EPA-520/1-88-020, Oak Ridge National Laboratory, September 1988, pp. 13-16, 113 (Table 1.b), 183, and Table 3.

30. National Academy of Sciences (Committee on International Security and Arms Control), Management and Disposition of Excess Weapons Plutonium, 1994, Appendix C, p. 278.

31. Y. Wang (ed.), CRC Handbook of Radioactive Nuclides, Boca Raton, Florida: CRC Press, 1969, pp. 33, 194, and 625 . 


\section{Bibliography}

Ames, L. L., and D. Rai, Radionuclide Interactions with Soil and Rock Media, Vol. 1, EPA 520/6-78007-a, U.S. Environmental Protection Agency, August 1978.

Armantrout, G. A., et al., Recovery of Weapon Plutonium as Feed Material for Reactor Fuel, UCRL-ID-117010, March 16, 1994, p. 2.

Blatz, H., (ed.), Radiation Hygiene Handbook, McGraw-Hill Book Company, 1959, p. 6-188.

Commission of the European Communities, A Plutonium Recycling Scenario in Light Water Reactors, Harwood Academic Publishers, 1982.

Dragun, J., The Soil Chemistry of Hazardous Materials, Hazardous Materials Control Research Institute, Silver Spring, MD, 1988.

International Atomic Energy Agency, "Impact of Nuclear Releases into the Aquatic Environment," Proceedings of a Symposium, Otaniemi, June 30-July 4, 1975, Vienna.

International Atomic Energy Agency, Treatment of Low- and Intermediate-Level Solid Radioactive Wastes, Technical Reports Series No. 223, January 1983, pp. 6-8.

International Commission on Radiological Protection, "The Metabolism of Compounds of Plutonium and Other Actinides," ICRP Publication 19, Pergamon Press, May 1972.

International Commission on Radiological Protection, "The Metabolism of Plutonium and Related Elements," Annals of the International Commission on Radiological Protection, ICRP Publication 48, Pergamon Press, 1986, pp. 58-66.

Mays, C. W., (ed.), et al., Delayed Effects of Bone-Seeking Radionuclides, University of Utah Press, 1969.

Meinhold, C. B., (Chairman), Proceedings of the Nineteenth Annual Meeting of the National Council on Radiation Protection and Measurements, Environmental Radioactivity, April 6-7, 1983, Washington, D.C., issued November 1983.

National Council on Radiation Protection and Measurements, "The Control of Exposure of the Public to Ionizing Radiation in the Event of Accident or Attack," National Council on Radiation Protection and Measurements Proceedings, April 27-29 1981, Reston, Virginia, p. 270 (Table 2).

National Council on Radiation Protection and Measurements, Radiation Exposure of the U.S. Population from Consumer Products and Miscellaneous Sources, NCRP Report No. 95, December 1987, p. 21.

Pershagen, B., Light Water Reactor Safety, New York: Pergamon Press, 1989, p. 105.

Stone, R. S., (ed.), Industrial Medicine on the Plutonium Project, First Edition, New York: McGraw-Hill Book Company, 1951.

Warf, J. C., All Things Nuclear, Southern California Federation of Scientists, 1989, pp. 55, 80, 83, 95, $108,117$. 


\section{NICKEL-63}

\section{Introduction}

This chapter discusses the basic radiological, chemical, and physical characteristics of nickel-63 $\left({ }^{63} \mathrm{Ni}\right)$ and examines how these characteristics affect the behavior of ${ }^{63} \mathrm{Ni}$ in various environmental media, such as soils, water, plants, animals, the atmosphere, and the human body. Also included are methods of ${ }^{63} \mathrm{Ni}$ production and waste and disposal data on ${ }^{63} \mathrm{Ni}$.

All nickel atoms contain 28 protons $(Z=28)$ and various numbers of neutrons (typically $N=28$ to 38 neutrons) within the atom's nucleus. Five stable isotopes of nickel exist, namely ${ }^{58} \mathrm{Ni},{ }^{60} \mathrm{Ni},{ }^{61} \mathrm{Ni},{ }^{62} \mathrm{Ni}$, and ${ }^{64} \mathrm{Ni}$. Their average naturally occurring abundances are $68.3 \%\left({ }^{58} \mathrm{Ni}\right), 26.1 \%\left({ }^{60} \mathrm{Ni}\right), 1.1 \%\left({ }^{61} \mathrm{Ni}\right), 3.6 \%$ $\left({ }^{62} \mathrm{Ni}\right)$, and $0.9 \%\left({ }^{64} \mathrm{Ni}\right)$. All other nickel isotopes, including ${ }^{63} \mathrm{Ni}$, are radioactive, with ${ }^{63} \mathrm{Ni}$ having a 100 year half-life. The radioactive nuclides of nickel are not a normal constituent of the natural environment and are generated as a result of human activities.

The primary source of ${ }^{63} \mathrm{Ni}$ in the environment has been low-level radioactive waste (LLW) material generated as a result of neutron activation of stable ${ }^{62} \mathrm{Ni}$ that is present in the structural components of nuclear reactor vessels. ${ }^{63} \mathrm{Ni}$ enters the environment from the dismantling activities associated with nuclear reactor decommissioning. However, small amounts of ${ }^{63} \mathrm{Ni}$ have been detected in the environment following the testing of thermonuclear weapons in the South Pacific. ${ }^{\prime}$ Concentrations as high as $2.7 \mathrm{~Bq}^{\mathrm{a}}$ per gram of sample (or equivalently 0.0022 parts per billion) were observed on Bikini Atoll (May 1954). ${ }^{63} \mathrm{Ni}$ was not created as a fission product species (e.g., from ${ }^{235} \mathrm{U}$ or ${ }^{239} \mathrm{Pu}$ fissions), but instead was produced as a result of neutron capture in ${ }^{62} \mathrm{Ni}$, a common nickel isotope present in the stainless steel components of nuclear weapons (e.g., stainless-304 contains $\sim 9 \%$ total $\mathrm{Ni}$ or $\sim 0.3 \%{ }^{62} \mathrm{Ni}$ ).

A radionuclide considered sensitive at one LLW disposal facility may not be considered sensitive at another facility. The behavior of a radionuclide at a particular LLW disposal site will depend primarily upon the radiological, chemical, and physical characteristics of the waste, and the inventory of the radionuclide. The behavior of a radionuclide also depends upon the geology, hydrology, and climate at the disposal site. This chapter reports characteristics and potential difficulties in dealing with ${ }^{63} \mathrm{Ni}$. However, since ${ }^{63} \mathrm{Ni}$ behavior and appropriate handling, storage, or disposal will vary depending on particular sites or waste form, this chapter does not attempt to discuss the extent of a difficulty or appropriate solutions. Each disposal site facility design should consider and address the specific waste content and behavior under that site's particular circumstances.

\section{Radiological Characteristics}

The half-life $\left(\mathrm{T}_{1 / 2}\right)$ of ${ }^{63} \mathrm{Ni}$ has been difficult to estimate accurately. Historically, it has been reported anywhere from 61 to 300 years. ${ }^{2,3,4}$ The most recent and best available information concerning ${ }^{63} \mathrm{Ni}$ reports a half-life of 100 years. ${ }^{5}{ }^{63} \mathrm{Ni}$ is formed via neutron capture $(\mathrm{n}, \gamma)$ of ${ }^{62} \mathrm{Ni}(\mathrm{e} . \mathrm{g}$., ${ }^{62} \mathrm{Ni}+\mathrm{n}-->{ }^{63} \mathrm{Ni}+\gamma$-ray). ${ }^{63} \mathrm{Ni}$ undergoes radioactive decay via negative beta particle $\left(\beta^{-}\right)$emission (i.e., $100 \%$ of all decays result in an electron being emitted from the nucleus) leading to the creation of a stable copper- $63\left({ }^{63} \mathrm{Cu}\right)$ nucleus.

a. One becquerel or $1 \mathrm{~Bq}$ is defined as 1 disintegration/second, and 1 curie $(1 \mathrm{Ci})$ is defined as $3.7 \times 10^{10} \mathrm{~Bq}$. 
The maximum beta particle energy is $67 \mathrm{keV}$ (thousand-electron volts). ${ }^{1,2}$ However, the average beta particle energy is only $17 \mathrm{keV}$ per ${ }^{63} \mathrm{Ni}$ disintegration. ${ }^{6}$ Since the released beta particle is usually emitted with an energy less than its maximum theoretical (e.g., $67 \mathrm{keV}$ for ${ }^{63} \mathrm{Ni}$ decay), an antineutrino particle is simultaneously emitted and carries off the energy difference between $67 \mathrm{keV}$ and that of the released beta particle. Consequently, beta particles are emitted with a continuous energy spectrum ranging from 0 to $67 \mathrm{keV}$. Since neutrinos (or antineutrinos) very rarely interact with matter, they are not considered radiologically important. Therefore, the antineutrino particle is usually not shown in the overall decay equation.

The decay sequence for ${ }^{63} \mathrm{Ni}$ showing the emission of a negative beta particle is illustrated in the following nuclear transformation:

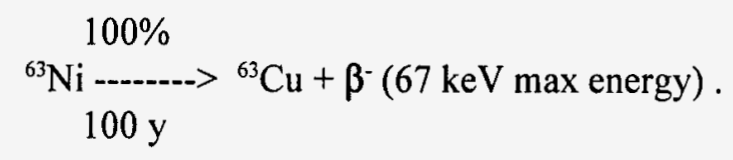

The probability that a neutron passing through nickel will be absorbed by a ${ }^{62} \mathrm{Ni}$ nucleus is very small. However, due to the large amount of ${ }^{62} \mathrm{Ni}$ in a nuclear reactor vessel and the relatively long halflife of ${ }^{63} \mathrm{Ni}$, the total amount of this radioactive nuclide present in the vessel will continue to increase during the reactor lifetime. By the time the reactor is decommissioned, a significant amount of ${ }^{63} \mathrm{Ni}$ will be generated and will pose special problems in the decommissioning of the reactor. Although the particle emissions from ${ }^{63} \mathrm{Ni}$ decay are not very energetic, large quantities of ${ }^{63} \mathrm{Ni}$ can pose significant radiological hazards. For example, under some conditions, ${ }^{63} \mathrm{Ni}$ can contribute a large fraction of the total radioactive dose received by persons involved in the dismantling of nuclear reactors. This situation can occur if the reactor has been operated for a long time (e.g., $>30$ years). In other words, ${ }^{63} \mathrm{Ni}$ does not normally represent a major concern in shielding or waste classification, but can be an important contributor to the overall radioactivity from activation nuclides and can affect the classification of certain reactor hardware as LLW material.

The 67-keV maximum energy beta particle emitted by the ${ }^{63} \mathrm{Ni}$ nucleus is weak. Table $10-1$ lists the estimated maximum ranges for a $17-\mathrm{keV}$ (average energy) beta particle emitted from ${ }^{63} \mathrm{Ni}$ decay. Note that the maximum particle ranges are small, and because it requires at least $70 \mathrm{keV}$ for an electron to penetrate the protective layer of human skin, the ${ }^{63} \mathrm{Ni}$ beta particles lack sufficient energy to penetrate the $0.07 \mathrm{~mm}$ (dead layer) of human skin. ${ }^{63} \mathrm{Ni}$ is primarily considered a hazard internally and to the unshielded eye.

Table 10-2 lists the radiotoxicity of several important radionuclides, and Table 10-3 compares the average and maximum electron energies associated with ${ }^{63} \mathrm{Ni}$ decay with other well-known electron (beta particle) emitters. Notice that ${ }^{63} \mathrm{Ni}$ is shown in the same radiological group as carbon- $14\left({ }^{14} \mathrm{C}\right)$ and cesium-137 $\left({ }^{137} \mathrm{Cs}\right)$; however, based on the information presented in Table $10-3,{ }^{63} \mathrm{Ni}$ emits a beta particle of smaller energy than either ${ }^{14} \mathrm{C}$ or ${ }^{137} \mathrm{Cs}$. 
Table 10-3. Average and maximum kinetic energies of beta particles and Auger electrons released during the decay of several important radionuclides. (Information compiled from data presented in References $1,2,5,11,12,13$.)

\begin{tabular}{lcc} 
& \multicolumn{2}{c}{ Released electron energy } \\
\cline { 2 - 3 } \multicolumn{1}{c}{ Radionuclide } & $\begin{array}{c}\text { Average Energy } \\
(\mathrm{keV})^{\mathrm{a}}\end{array}$ & $\begin{array}{c}\text { Maximum Energy } \\
(\mathrm{keV})\end{array}$ \\
\hline Nickel-59 $\left({ }^{59} \mathrm{Ni}\right)$ & $4.1^{\mathrm{b}}$ & $\sim 7.7^{\mathrm{b}}$ \\
Tritium $\left({ }^{3} \mathrm{H}\right)$ & 5.7 & 19.0 \\
Nickel-63 $\left({ }^{63} \mathrm{Ni}\right)$ & $\mathbf{1 7 . 1}$ & $\mathbf{6 7 . 0}$ \\
Iodine-129 $\left({ }^{129} \mathrm{I}\right)$ & 40.0 & 150.0 \\
Carbon-14 $\left({ }^{14} \mathrm{C}\right)$ & 49.0 & 156.0 \\
Technetium-99 $\left({ }^{99} \mathrm{Tc}\right)$ & 85.0 & 293.0 \\
Iodine-131 $\left({ }^{131} \mathrm{I}\right)$ & 180.0 & $806.0^{\mathrm{c}}$ \\
Cesium-137 $\left({ }^{137} \mathrm{Cs}\right)$ & 195.0 & 1176.0 \\
Potassium-40 $\left({ }^{40} \mathrm{~K}\right)$ & 541.0 & 1330.0 \\
Phosphorous-32 $\left({ }^{32} \mathrm{P}\right)$ & 694.0 & 1710.0
\end{tabular}

a. $1,000 \mathrm{keV}=1 \mathrm{MeV}$ (million-electron volt). Beta particle energy unless noted.

b. The data for ${ }^{59} \mathrm{Ni}$ represent Auger electrons and not electrons emitted from the nucleus (i.e., beta particles). The maximum electron energy was estimated based on the assumption that an electron from the cobalt- $59\left({ }^{59} \mathrm{Co}\right)$ atom (e.g., the daughter product from ${ }^{59} \mathrm{Ni}$ decay) absorbs a maximum energy $\mathrm{x}$-ray.

c. $90.4 \%$ of the beta particle intensity for ${ }^{131} \mathrm{I}$ occurs at $606 \mathrm{keV}$, and only $0.6 \%$ occurs at $806 \mathrm{keV}$.

\section{Chemical and Physical Characteristics}

Nickel is a silver-white metal with metallic properties. It has high electrical and thermal conductivities and can be drawn, rolled, forged, and polished. It is ferromagnetic, though not as strongly as iron. The finely divided metal is reactive to air and may be pyrophoric under some conditions. ${ }^{14}$

Nickel occurs in nature primarily in combination with arsenic, antimony, and sulfur. The largest nickel deposits are garnierite, a magnesium-nickel silicate, and certain varieties of pyrrhotite, an ironsulfur compound that can contain 3 to $5 \%$ nickel. ${ }^{14}$ The center of the earth is believed to contain considerable quantities of iron and nickel.

Nickel shares some chemical characteristics with its two neighboring elements in the periodic table, iron and cobalt. Palladium and platinum are in the same chemical family as nickel, although they are not as chemically active as iron and cobalt. The most abundant oxidation state for nickel is $\mathrm{Ni}^{2+}$. Nickel may be oxidized to the +3 and +4 states, or reduced to the +1 state, in the presence of a suitable complexing agent (nickel can even form compounds as $\mathrm{Ni}^{0}$ ), but such reactions are seldom carried out. The melting and boiling points for nickel are 1,453 and $2,732^{\circ} \mathrm{C}$, respectively. ${ }^{15}$ The oxidation potential 
of nickel (to remove two electrons from an atom) is $0.25 \mathrm{eV}$. The metal dissolves readily in dilute mineral acids, but does not dissolve in concentrated nitric acid (similar to iron) because it is rendered passive by this reagent. Nickel is quite resistant to attack by air or water at ordinary temperatures (when compact) and is often electroplated on other metals as a protective coating. Table 10-4 summarizes some of the more important chemical and physical properties of nickel, extracted from various references. ${ }^{16,17,18}$

Nickel readily reacts to form compounds with oxygen (e.g., $\mathrm{NiO}$ ), sulfur (e.g., $\mathrm{NiS}, \mathrm{NiSO}_{4}$ ), and the halogens (e.g., $\mathrm{NiF}_{2}, \mathrm{NiCl}_{2}$, and $\mathrm{NiI}_{2}$ ). In addition, at high temperatures, nickel forms compounds with hydrogen, boron, carbon, nitrogen, silicon, and phosphorus. Nickel is important as a constituent in a wide variety of corrosion-resistant metal alloys including stainless steels, Inconels, and Monel.

The majority of anhydrous nickel salts are yellow (e.g., colors of the salts from which they are derived). Nickel forms an interesting variety of chemical complexes. Some of the most familiar of these are $\mathrm{Ni}\left(\mathrm{H}_{2} \mathrm{O}\right)_{6}{ }^{2+}$, and $\mathrm{Ni}\left(\mathrm{NH}_{3}\right)_{6}{ }^{2+}$, which are both octahedral in structure.

Table 10-4. Chemical and physical properties of nickel. Obtained from References 16, 17, and 18.

\begin{tabular}{lc}
\multicolumn{1}{c}{ Physical property (units) } & Nickel data \\
\hline Melting point (degrees Kelvin) $^{\mathrm{a}}$ & $1,726.0$ \\
Boiling point (degrees Kelvin) $^{\mathrm{a}}$ & $3,005.0$ \\
Heat of fusion (cal/g) & $4,323.0$ \\
Heat of vaporization (cal/g) & $90,800.0$ \\
Solid density (g/cm ${ }^{3}$ ) & 8.9 \\
Oxidation potential (V) & 0.25 \\
Ionization potential (eV) & 7.635 \\
Crystal form & face-centered-cubic
\end{tabular}

a. Note that zero degrees Kelvin equals $-273.15^{\circ} \mathrm{C}$ and $-459.67^{\circ} \mathrm{F}$.

b. For $\mathrm{Ni}=\mathrm{Ni}^{2+}+2 \mathrm{e}^{-}$. 


\section{Nickel-63 Production}

The structural materials inside the reactor vessel of a nuclear power plant are exposed to neutron radiation. This radiation can cause many components of these materials to become radioactive with time via neutron activation. Those elements most susceptible to neutron activation are iron, nickel, and cobalt, found primarily in stainless steel and other important alloys (e.g., Inconel). Depending upon the amount of time these materials are irradiated and the integrated neutron flux, any of these nuclides may become the critical activation product affecting the dismantling activities of the reactor.

The principal means of producing ${ }^{63} \mathrm{Ni}$ is through neutron capture of ${ }^{62} \mathrm{Ni}$, a stable isotope of nickel that exists in stainless steels and other nickel alloys. Nuclear fission does not play a significant role in producing ${ }^{63} \mathrm{Ni}$. This process can be seen in Figure 10-1, where the ${ }^{63} \mathrm{Ni}$ position is shown with respect to the fission product yield distribution for thermal neutron fission of ${ }^{235} \mathrm{U}$. The cumulative fission yield of ${ }^{63} \mathrm{Ni}$ from fission of ${ }^{235} \mathrm{U}$ atoms is essentially zero. This information was obtained from the fission yield data from the ORIGEN $2^{19}$ computer code cross-section data.

Fission yield from thermal fission of U-235

(Total fission yield summed over all mass numbers $=200 \%$ )

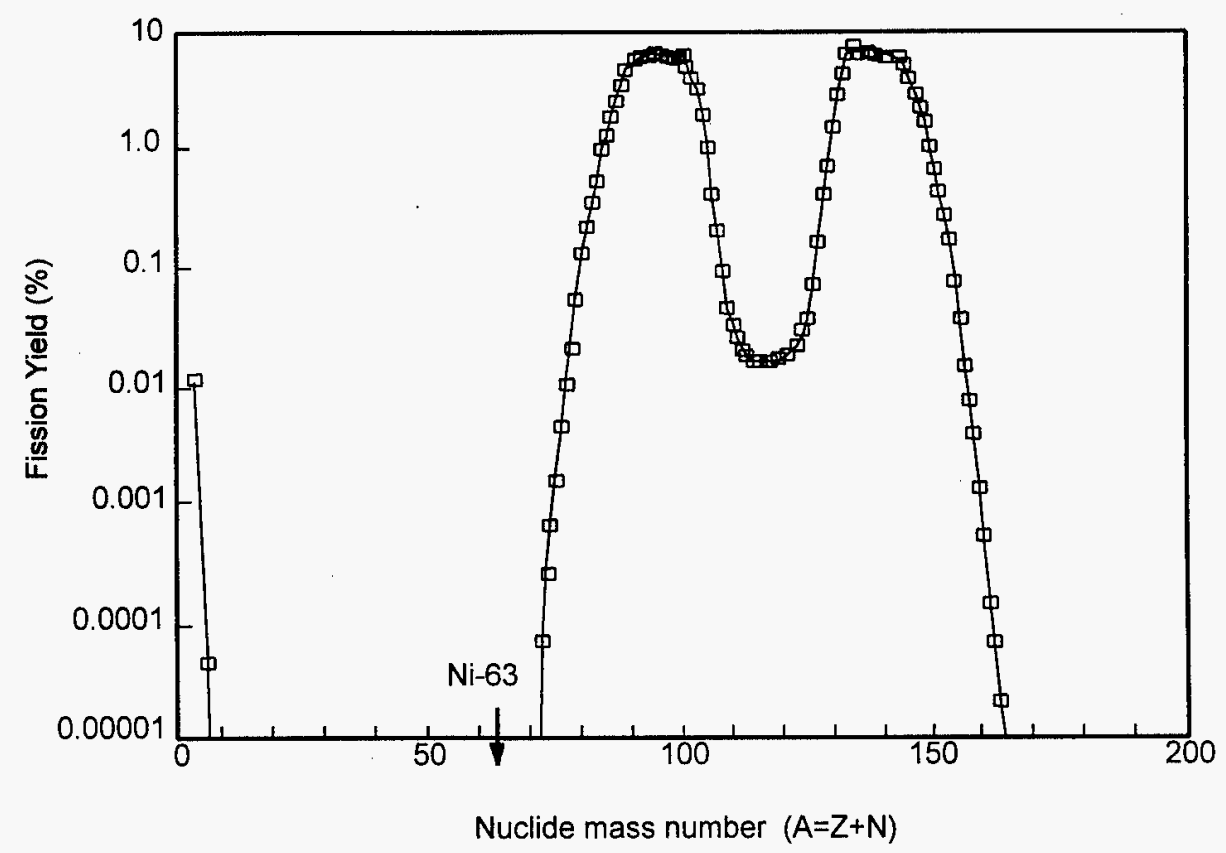

Figure 10-1. Fission product yield curve for thermal fission of ${ }^{235} \mathrm{U}$. Note that the fission yield for ${ }^{63} \mathrm{Ni}$ should appear at the mass number of 63 (indicated by the "Ni-63" position in the figure); however, the yield curve falls below the smallest displayed value (e.g., $0.00001 \%$ ) shown for mass number 63 . 
Because ${ }^{62} \mathrm{Ni}$ atoms do not readily absorb thermal neutrons, and because ${ }^{62} \mathrm{Ni}$ comprises only a small fraction of the stainless steel in a nuclear reactor ( $\sim 3.6 \%$ of the total nickel mass), it generally takes many years of neutron irradiation to produce a significant quantity of ${ }^{63} \mathrm{Ni}$. However, because ${ }^{63} \mathrm{Ni}$ has a half-life that is longer than the normal life of a nuclear reactor (e.g., 100 years versus $\sim 30$ years for most reactors), nearly all of the ${ }^{63} \mathrm{Ni}$ that is produced within the reactor structure remains with the reactor until it is dismantled. A small fraction of ${ }^{63} \mathrm{Ni}$ can be released through corrosion of structural components and transport to other sites via the reactor coolant system. In other words, the ${ }^{63} \mathrm{Ni}$ inventory increases linearly with reactor operation and does not significantly decrease with time. Figure 10-2 shows the buildup of several different activation products in a pressurized water reactor (PWR) vessel, including ${ }^{63} \mathrm{Ni},{ }^{59} \mathrm{Ni},{ }^{94} \mathrm{Nb}$, and ${ }^{60} \mathrm{Co}$, as a function of reactor operation.

${ }^{63} \mathrm{Ni}$ has not been considered a controlling radionuclide in nuclear reactor decommissioning until recently. This change has occurred because the periods of reactor operation have not been long enough to generate significant quantities of this nuclide. Figure 10-2 shows the relative importance of several radioactive activation products as a function of reactor operation. Reference 20 reported that if the internal components of a nuclear reactor are removed and shipped to licensed disposal facilities, then ${ }^{63} \mathrm{Ni}$ can become the controlling activated radionuclide.

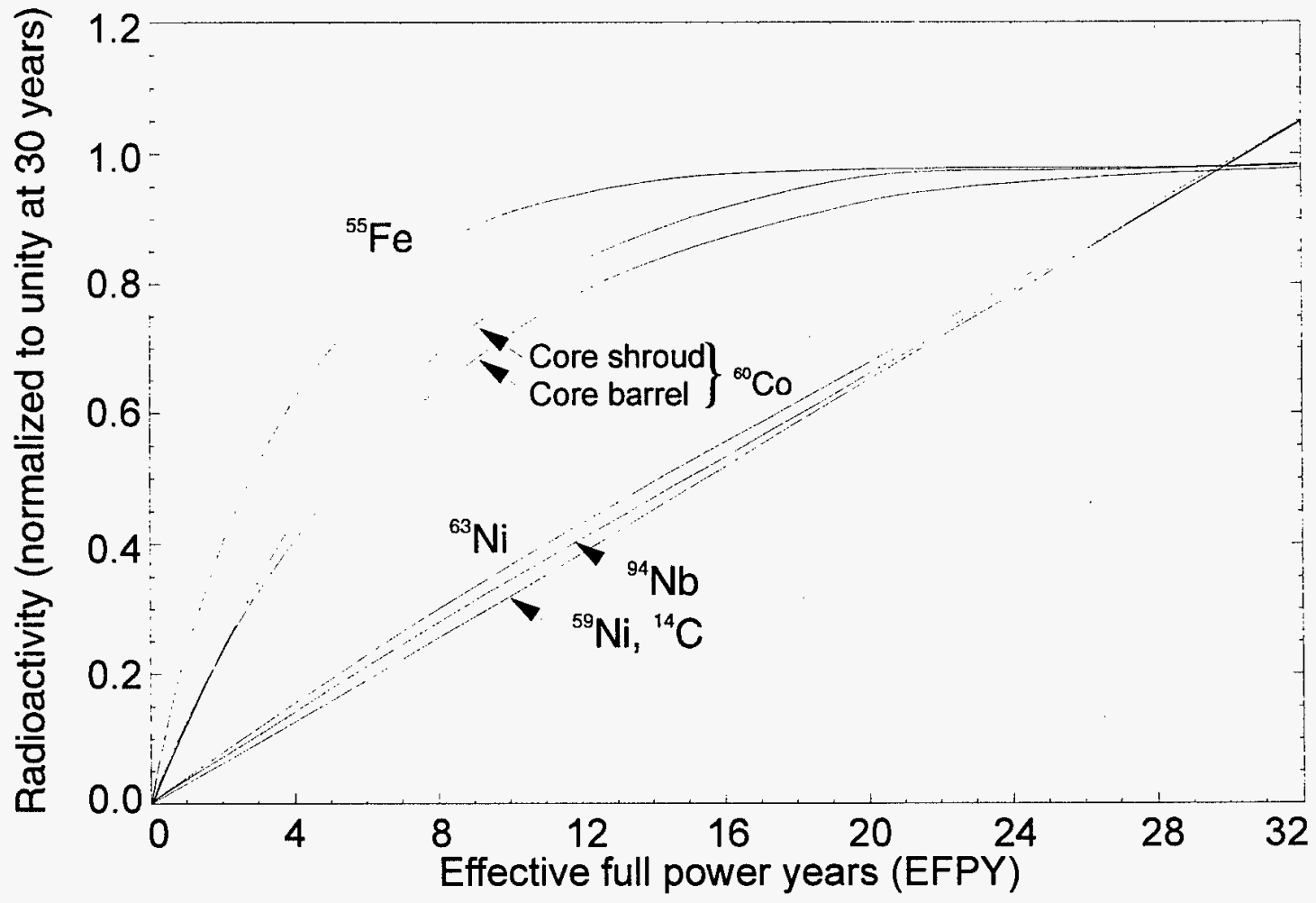

Figure 10-2. Buildup of some important activation products in a PWR as a function of reactor operation. Note that the lowest curve from 0 to $\sim 30$ years represents ${ }^{59} \mathrm{Ni}$, and the third lowest curve from 0 to $\sim 30$ years is ${ }^{63} \mathrm{Ni}$. (Obtained from References 21 and 22.) 


\section{Waste and Disposal Data on Nickel-63}

This section discusses the types of activities that generate ${ }^{63} \mathrm{Ni}$ LLW, waste types and forms that contain ${ }^{63} \mathrm{Ni}$, and disposal data on ${ }^{63} \mathrm{Ni}$.

\section{Nuclear Reactors}

The quantity of ${ }^{63} \mathrm{Ni}$ generated within the structural components of a nuclear reactor increases linearly with burnup; that is, double the reactor operation and the ${ }^{63} \mathrm{Ni}$ inventory doubles. Because the half-life of ${ }^{63} \mathrm{Ni}$ is much longer than the life of the reactor, no process effectively decreases the ${ }^{63} \mathrm{Ni}$ inventory over the reactor's useful lifetime. The inventory of ${ }^{63} \mathrm{Ni}$ in a reactor that operated at $80 \%$ power $(880 \mathrm{MWe})$ for 40 years would be approximately $1 \times 10^{6} \mathrm{Ci}^{23}$ Consequently, ${ }^{63} \mathrm{Ni}$ is important in the classification of radioactive wastes from nuclear power plants. ${ }^{24}$ Because nickel and cobalt are chemically similar, much of what is known about the presence of radioactive nickel in radioactive waste has been inferred from similar studies involving cobalt, especially ${ }^{60} \mathrm{Co}$, a species that is easier to detect and measure.

The primary LLW containing ${ }^{63} \mathrm{Ni}$ are those solid waste forms produced by activation of structural materials, mainly stainless steel components. During decommissioning and dismantling of these components, LLW are produced that contain ${ }^{63} \mathrm{Ni}$. For example, it is possible that structural components from decommissioned nuclear power plants will be melted down for recycling. For this reason, a laboratory study was conducted by the German company, Siemens, to investigate the mobility of various radioactive species in melted steel. ${ }^{25}$ The results from this study indicate that nuclides of iron, cobalt, and nickel remain in the melt and that release to the slag and off-gas systems was negligible.

LLW from nuclear reactors always contain small quantities of fission products or activation products, including ${ }^{63} \mathrm{Ni}$. During the operation of a light-water reactor, oxide corrosion films form on the surfaces of piping, pumps, valves, steam generator tubing, and many other components in contact with the primary coolant. Some of these corrosion products dissolve or erode in the circulating coolant, are deposited on the fuel cladding, and become activated by the neutron flux. The principal radionuclides formed by this activation process are ${ }^{58} \mathrm{Co},{ }^{60} \mathrm{Co},{ }^{55} \mathrm{Fe},{ }^{59} \mathrm{Fe},{ }^{54} \mathrm{Mn},{ }^{51} \mathrm{Cr},{ }^{65} \mathrm{Zn}$, and ${ }^{63} \mathrm{Ni}$. These radionuclides are eventually released from the core region of the reactor and are carried by the coolant and incorporated into oxide films on the surfaces of the primary coolant system (PCS) components. ${ }^{26}$ The principal waste types that can contain radionuclides that are produced as a result of nuclear reactor operations are contaminated scrub water and decontamination solutions; contaminated clothing; contaminated tools and equipment used in radioactive areas; pumps, valves, seals, bearings, scrap materials, and ion-exchange resins and filters. However, none of the principal LLW types contain radiologically significant quantities of ${ }^{63} \mathrm{Ni}$. In the case of ${ }^{63} \mathrm{Ni}$, only very small quantities of this radionuclide are found in the primary coolant system of operating reactors as a result of activation of suspended metals or other substances. However, the equipment and systems used to clean this water will contain much higher concentrations of ${ }^{63} \mathrm{Ni}$, as well as other radionuclides. In some cases, ${ }^{63} \mathrm{Ni}$ may be the limiting radionuclide that determines handling, storage, and disposal requirements. ${ }^{27}$ The types of safeguards to be used in the disposal of decommissioned reactor parts and the long-term safety of the disposal of these parts are dictated by the amount of radionuclides, including ${ }^{63} \mathrm{Ni}$, contained in the parts.

In a European laboratory study, representative batches of primary water, evaporator concentrates, ion-exchange resins, and filter cartridges were collected at different PWRs and destructively analyzed to determine the content of, among other species, ${ }^{63} \mathrm{Ni}^{24}$ On the basis of this study, the researchers concluded that the isotopes of nickel, including ${ }^{63} \mathrm{Ni}$, were principally suspended in the water samples, rather than dissolved in the water itself. 
The presence of ${ }^{63} \mathrm{Ni}$ in reactor waste types is routinely measured at the Palisades Nuclear Power Plant ${ }^{28}$ Of the waste types listed in this reference, ${ }^{63} \mathrm{Ni}$ was listed as showing up in only one specific location, the laundry system drain effluent, comprising a few percent of the total radioactivity in this stream.

\section{Medical, Academic Institutions, and Commercial Nickel-63 Waste}

Because ${ }^{63} \mathrm{Ni}$ has a relatively long half-life and because it emits only weak beta radiation, medical applications of the radionuclide do not exist. In addition, since ${ }^{63} \mathrm{Ni}$ decays directly to the ground state of ${ }^{63} \mathrm{Cu}$, there would be neither alpha nor gamma radiations. Therefore, the use of ${ }^{63} \mathrm{Ni}$ as an external radiation source would be severely limited. ${ }^{29}$ No significant commercial or medical wastes containing or using ${ }^{63} \mathrm{Ni}$ have been identified; however, ${ }^{63} \mathrm{Ni}$ has been used in the form of a nickel sulfate solution in some small scale laboratory experiments. ${ }^{30}{ }^{63} \mathrm{Ni}$ has also been used in some experiments involving radionuclide imaging (e.g., autoradiography) of cells. ${ }^{31}$ There are also no significant waste containing ${ }^{63} \mathrm{Ni}$ from academic institutions; however, some small quantities of ${ }^{63} \mathrm{Ni}$ have been used in a limited number of experiments. Most ${ }^{63} \mathrm{Ni}$ wastes from small laboratory or commercial experiments become the same LLW types as other commonly used radioactive materials. Personnel at the American College of Radiologists reported that ${ }^{63} \mathrm{Ni}$ is not used for the diagnosis of disease or for medical treatments. ${ }^{b}$

Nevertheless, ${ }^{63} \mathrm{Ni}$ has been used in the laboratory during tests on experimental medications. For example, this nuclide was used as part of the measurement system during an experimental study of Nitrazepam (a drug used in the treatment of insomnia). ${ }^{32}$ As such, it will eventually enter the environment in some waste streams.

Use was made of ${ }^{63} \mathrm{Ni}$ in an epidemiology study conducted by the Lovelace Biomedical and Environmental Research Institute. ${ }^{30}$ This study investigated the exposure of refinery workers to airborne nickel. The radioactive nuclide was used to trace the nickel contamination in laboratory animals and was not itself the subject of the investigation.

This radionuclide is also used in laboratory studies at the Chalk River Nuclear Laboratories. ${ }^{33}$ In a study investigating the release of several laboratory nuclides to the environment, researchers assumed that the radionuclides would be incinerated and that the ash would be transported to a municipal landfill. From the landfill, the radionuclides could be leached into the ground water. Even with worst case assumptions, the study concluded that only very low exposure to the public would occur from landfill disposal of all the studied nuclides.

Historically, ${ }^{63} \mathrm{Ni}$ compounds have also been available in the following chemical forms: $\mathrm{NiCl}_{2}$ in solution (e.g., $1 \mathrm{~N} \mathrm{HCl}$ ) and $\mathrm{Ni}\left(\mathrm{NO}_{3}\right)_{3}$ in solution (e.g., in $\left.1 \mathrm{~N} \mathrm{HNO}_{3}\right)$. $^{34}$ These materials have been used in some unspecified industrial applications, possibly small research experiments.

In summary, ${ }^{63} \mathrm{Ni}$, though not used specifically to diagnose or treat diseases, has been used in a small number of laboratory studies. Although it can enter the environment via several methods, the small amount would pose very little risk to the public.

b. Private communication between C. Sperry (ACR) and J. Adams (INEL) on November 7, 1994. 


\section{Disposal Data on Nickel-63}

${ }^{63} \mathrm{Ni}$ has been deposited in three LLW sites in Richland, Washington; Barnwell, South Carolina; and Beatty, Nevada over a period of several years. Data for this nuclide concerning the activity, sources, and waste types deposited at these sites have been obtained from the Manifest Information Management System Database. ${ }^{6}$ Figure 10-3 shows the total annual ${ }^{63} \mathrm{Ni}$ activity deposited in the three sites for each year between 1986 and 1995 . Over $80 \%$ of the total activity for this nuclide was deposited during the years $1989-1994 .{ }^{63} \mathrm{Ni}$ was deposited approximately uniformly during the other years.

Figure 10-4 shows the activity of ${ }^{63} \mathrm{Ni}$ deposited in these three sites as a function of waste source. Utilities account for more than $97 \%$ of the total deposited in these three sites. An additional $1.5 \%$ came from industrial sources and the rest from the other sources. The definition of disposal categories given in Figure 10-4 is as follows: academic - sources associated with university laboratories; government sources associated with the government, such as military hospitals; industry - sources associated with manufacturing, other than utilities; medical - sources associated with hospitals and medical laboratories, excluding pharmaceutical manufacturing; utility - sources generated by nuclear utilities and stored onsite or sent to one of the three disposal sites. Waste treatment facilities are included in the utility category.

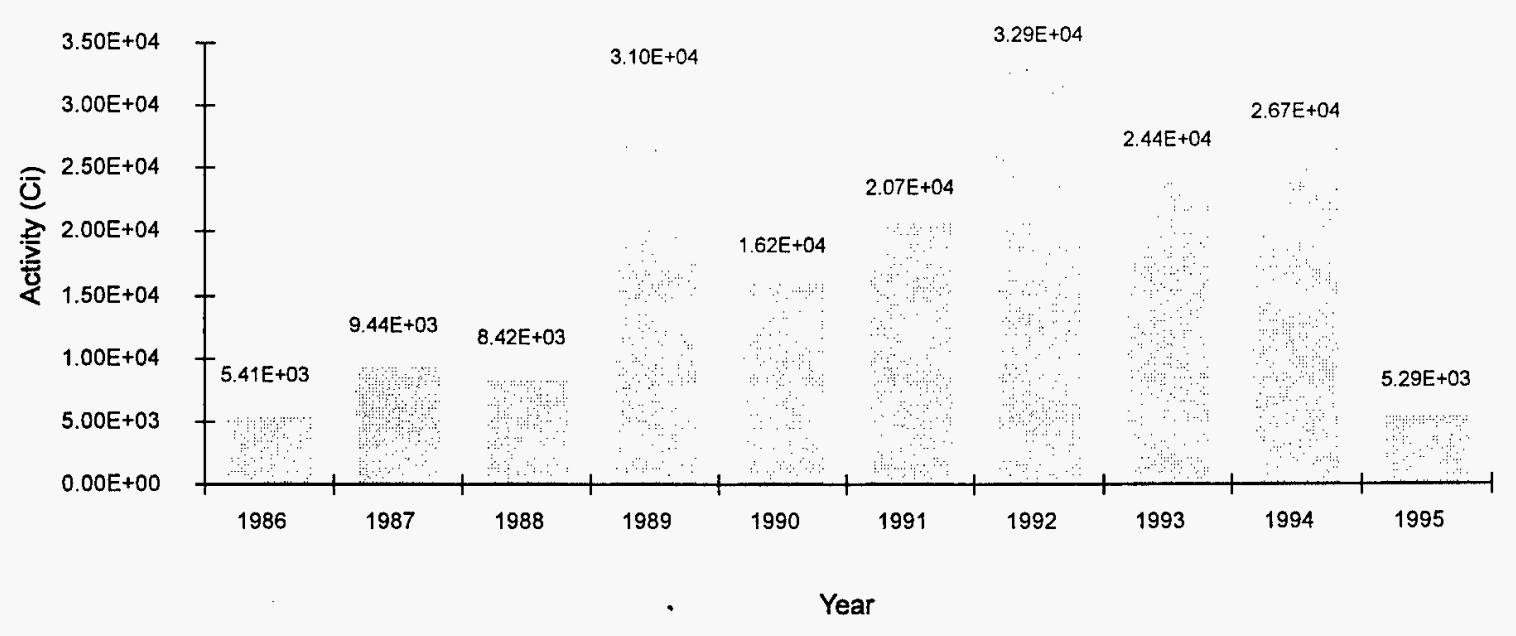

Figure 10-3. ${ }^{63} \mathrm{Ni}$ activity deposited at the Richland, Beatty, and Barnwell sites by year (log scale).

c. Information provided through the DOE waste management system maintained by the National Low-Level Waste Management Program, Idaho National Engineering Laboratory (INEL). 


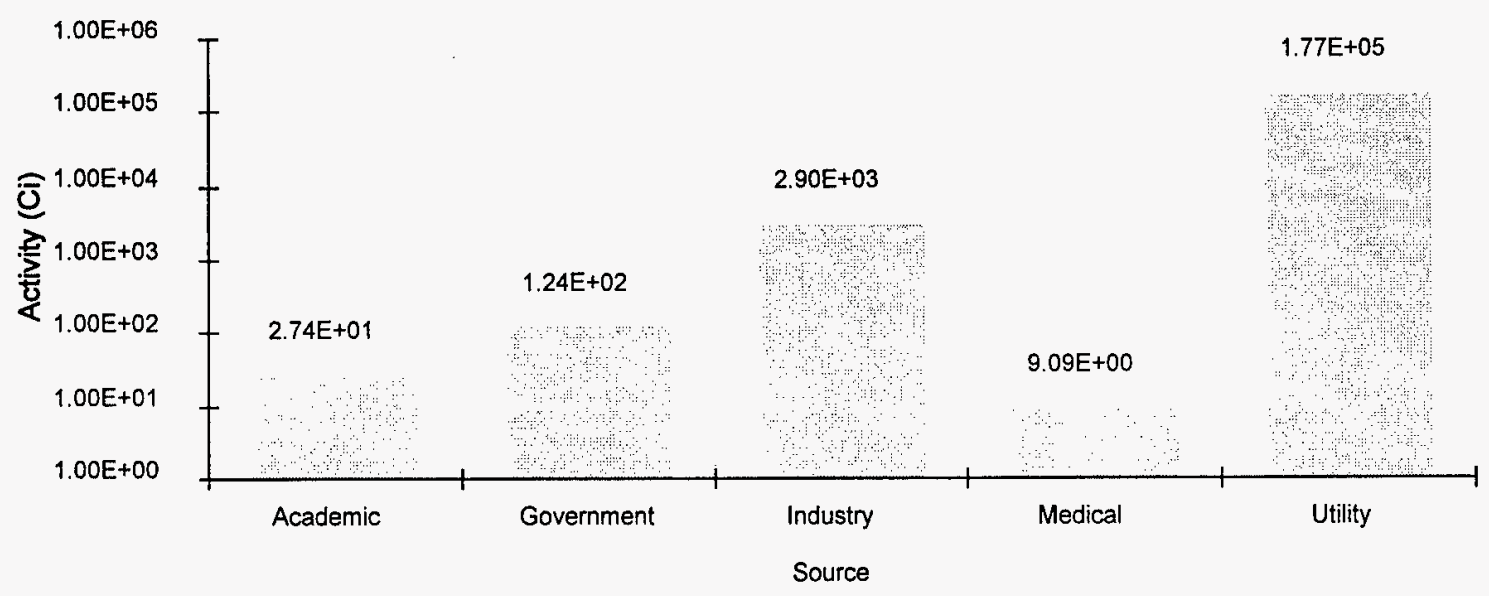

Figure 10-4. ${ }^{63} \mathrm{Ni}$ activity deposited at the Richland, Beatty, and Barnwell sites by source (log scale).

Figure 10-5 shows the activity of ${ }^{63} \mathrm{Ni}$ deposited in the Richland and Beatty sites as a function of waste type. The waste disposal manifests for the Barnwell site did not break down the waste by type, which is unfortunate since $92 \%$ of this nuclide has been stored at this site. As shown in this figure, more than $90 \%$ of this nuclide was in the form of activated reactor hardware, dewatered resins, or dry solids. The waste types illustrated in Figure 10-5 are from nuclear reactors, academic institutions, and medical facilities.

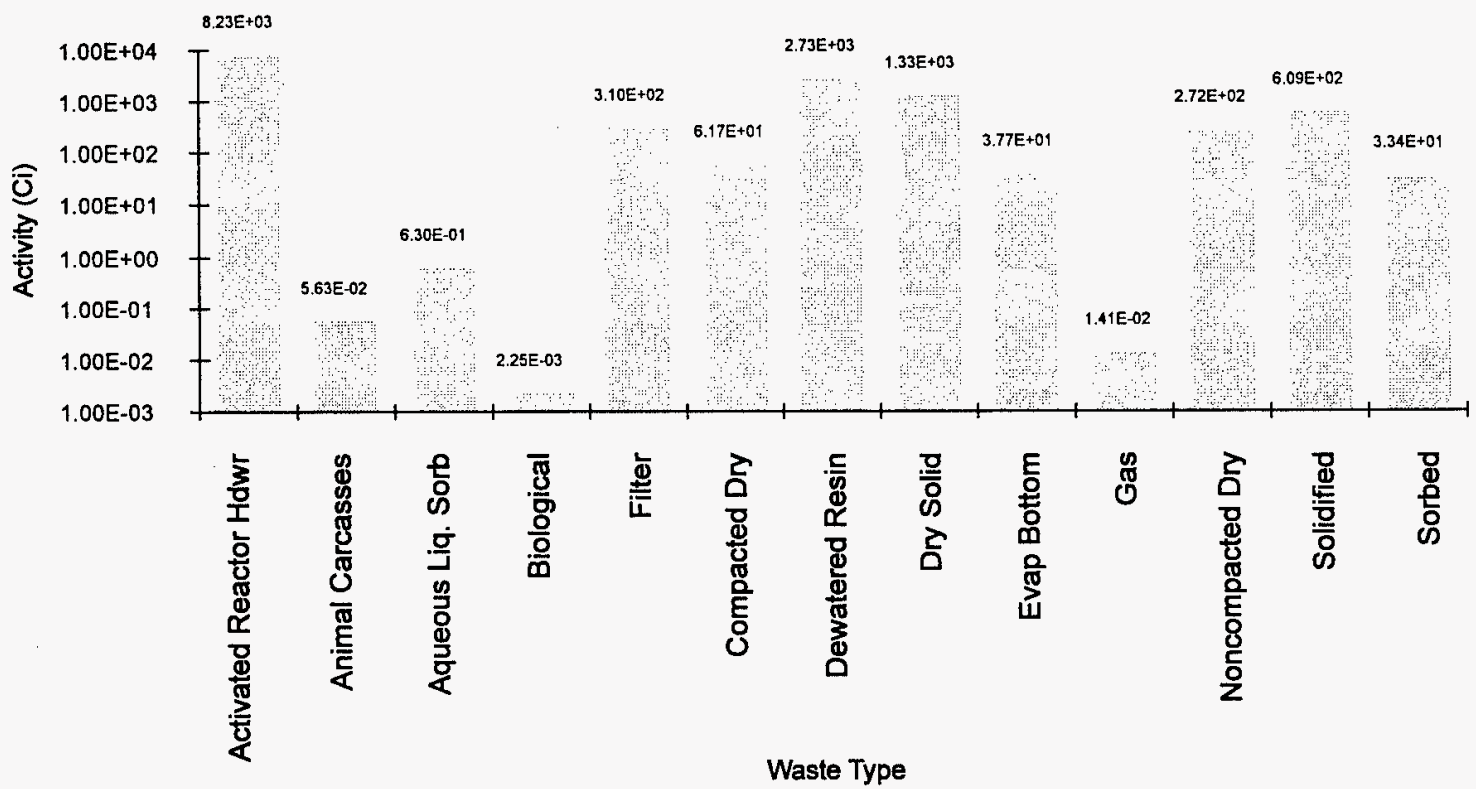

Figure 10-5. ${ }^{63} \mathrm{Ni}$ activity deposited at the Richland and Beatty sites by waste type (log scale). 


\section{Behavior of Nickel-63 in the Environment}

\section{Nickel-63 in Soils}

Understanding the behavior of radioactive materials such as ${ }^{63} \mathrm{Ni}$ in the soil is important in assessing the possibility that these radionuclides will be transported through the biosphere. ${ }^{35}$ It is important to understand the interactions between radionuclides and various media along the path to the biosphere, whether disposal is in deep or shallow rock caverns or in shallow overburden facilities.

Nickel occurs naturally in many soils. In fact, on an elemental basis, the naturally occurring forms of nickel can be much more prevalent than the trace amounts of ${ }^{63} \mathrm{Ni}$ found in typical waste streams. ${ }^{36}$ The typical range for naturally occurring nickel concentrations in soils is 5 to 1,000 parts per million (ppm), with some soils containing up to $6,200 \mathrm{ppm}$ nickel. Concentrations, either expected or actual, for radionuclides, including ${ }^{63} \mathrm{Ni}$, are much lower. Nickel also occurs naturally in groundwater, with typical concentrations up to $50 \mathrm{ppm}$, much higher than radionuclide concentrations. For water with a pH less than 8 , the dominant ionic form for nickel is $\mathrm{Ni}^{2+}$.

Four parameters were reported to be essential in accurately predicting soil concentrations from either contaminated ground water or irrigation water. ${ }^{35}$ The four parameters, in order of decreasing importance, are (a) soil retention, (b) annual precipitation, (c) soil texture, and (d) depth to the water table. The soil retention parameter represents the solid/liquid partition coefficient and is denoted by the symbol $K_{d} . K_{d}$ is defined by $K_{d}=C_{s} / C_{l}$, where $C_{s}$ is the nickel concentration in the soil (i.e., $\mu \mathrm{g} / \mathrm{gram}$ of soil) and $C_{l}$ is the nickel concentration in the groundwater (i.e., $\mu \mathrm{g} / \mathrm{mL}$ of liquid). Therefore, the units of $\mathrm{K}_{\mathrm{d}}$ are $\mathrm{mL} / \mathrm{g}$ (i.e., $\mathrm{mL}$ of water per gram of soil). This empirical model combines all soil retention mechanisms into a simple linear partition relation between the soil and the surrounding groundwater. This model assumes that the nickel concentrations in groundwater and soil are in equilibrium with each other. Using this definition for $\mathrm{K}_{\mathrm{d}}$, it follows that the larger the value (that is, the higher the radionuclide concentration in the soil relative to that in the groundwater), the slower the migration of the radionuclide relative to groundwater flow. Therefore, $K_{d}$ can be thought of as a measure of the amount of "fixing" or holdup in the soil.

Typically, $K_{d}$ is measured under laboratory conditions, using samples that are relatively homogenous, and where it can be ensured that equilibrium conditions are met. Applying these values to specific soils in the field can be difficult because actual soils are generally nonhomogeneous and there are uncertainties as to how long it takes for the nickel concentrations in the soil and groundwater $\left(\mathrm{C}_{\mathrm{s}}\right.$ and $\mathrm{C}_{1}$ ) to reach equilibrium with each other. Therefore, one must be careful to ensure that soil samples used in laboratory studies are as closely representative of the field as possible. Even though the soil samples do not precisely match conditions in the field, $K_{d}$ values from laboratory studies can be used in computer models that extrapolate data from laboratory experiments and field studies. In addition, some experiments are conducted using intact field samples to validate the laboratory $\mathrm{K}_{d}$ values and to study the effects associated with soil nonhomogeneity.

The Environmental Protection Agency (EPA) performed a study of $K_{d}$ values for a number of radionuclides, including ${ }^{63} \mathrm{Ni}$, as part of the LLW program. ${ }^{37}$ In this study, the EPA characterized the soils covering most of the United States into three major deposits: the glaciated central region, Atlantic and Gulf coastal plains, and the alluvial basin. They then researched $K_{d}$ values for each radionuclide and soil type. The values of $\mathrm{K}_{\mathrm{d}}$ for ${ }^{63} \mathrm{Ni}$ ranged from 2,000 to $5,000 \mathrm{~mL} / \mathrm{g}$ for the alluvial basin (soil retention 
high) to between 100 and $500 \mathrm{~mL} / \mathrm{g}$ for the coastal plains (soil retention moderate) to less than $100 \mathrm{~mL} / \mathrm{g}$ for the central region (soil retention low). The differences between these values are judged to result from soil $\mathrm{pH}$ differences - higher $\mathrm{pH}$ values result in higher retention.

To verify this conclusion, the EPA quotes a separate effects study ${ }^{38}$ performed on soil samples taken from Hanford, Washington. First, the $\mathrm{K}_{d}$ for the as-collected soil with a $\mathrm{pH}=9$ was measured to be $1,300 \mathrm{~mL} / \mathrm{g}$. Then, the soil $\mathrm{pH}$ was adjusted to a value of 6 and the $\mathrm{K}_{\mathrm{d}}$ again measured. The $\mathrm{K}_{\mathrm{d}}$ value for the high $\mathrm{pH}$ soil sample was about an order of magnitude higher than in the $\mathrm{pH}$-adjusted sample.

A summary of the environmental interactions of various radioactive species, including ${ }^{63} \mathrm{Ni}$, has been published in Reference 39. In this summary, it is concluded that when ${ }^{63} \mathrm{Ni}$ enters a soil system, most of it $(90 \%)$ is rapidly adsorbed in the soil and therefore removed from groundwater migration.

In The Soil Chemistry of Hazardous Materials, ${ }^{36}$ the adsorption of nickel is presented as a function of $\mathrm{pH}$ in two different complexing environments, an iron-gel and an aluminum-gel. For the aluminumgel environment, there is almost a step change in percent adsorption of nickel from less than $10 \%$ to nearly $100 \%$ as the $\mathrm{pH}$ is increased above 6 . A similar step change occurs for the iron-gel environment, but at the lower $\mathrm{pH}$ value of 5 .

Soil composition may also play a significant role. The central plains soil has a clay-silt composition, resulting in the least nickel soil retention. The alluvial basin soil has a sandy composition and the highest retention. The coastal plain soils lie between these two (e.g., a clay-sandy composition), and has an intermediate retention. ${ }^{37}$

As a final conclusion of the EPA study, nickel adsorption in soil is also known to be significantly affected by precipitation and coprecipitation reaction with hydrous oxides of iron and manganese.

Reference 38 reports on an investigation by Pacific Northwest Laboratory into the effect of organic complexing agents on the adsorption of nickel in soils. Several organic complexants were used, including ethylenediaminetetraacetic acid (EDTA), diethylenetriaminepentaacetic acid (DTPA), oxalate, and citrate. Each of these complexants is widely used in the commercial nuclear industry as a decontaminating agent and will, therefore, be present in untreated nuclear wastes. The presence of these complexants tends to make the nickel more soluble in water and less likely to be adsorbed in soils. However, it should be noted that these are mixed wastes (both hazardous [as defined by the Resource Conservation and Recovery Act] and radioactive); they will not be co-disposed with commercial LLW.

Of the complexants studied, EDTA seemed to have the largest effect. In a nickel solution that was pretreated with this complexant, nickel did not appreciably adsorb onto soil from the Hanford, Washington, area even though it was in contact with the soil for more than one year. These tests were repeated one year later-while the adsorption rate was still very slow, there was some adsorption of nickel-EDTA solution in the Hanford soil. ${ }^{40}$ This experience illustrates the difficulties involved in generating reproducible results using field samples of soils. There was a significant difference between nickel that was treated with EDTA before coming in contact with soil and nickel that was adsorbed in the soil before being treated with EDTA. Nickel that had been adsorbed in the Hanford soil $(\mathrm{pH}=9)$ before being treated with EDTA was only slowly dissolved by the complexant. After 6 months, only about onehalf of the sorbed nickel was dissolved, whereas pretreated nickel remained completely dissolved. Very little additional nickel redissolved, even though the test ran for an additional 9 months, indicating that an equilibrium between dissolved and sorbed nickel may have been reached. The study was repeated using soil from the Savannah River Site (near Aiken, South Carolina). The pH of the Savannah River soils was 
lower, $\sim 6$, and the nickel behavior was significantly different. First, in the pretreated case, about onehalf of the nickel in solution was adsorbed in the soil, which was the same amount of nickel that was redissolved in the soil that was not pretreated. Second, the equilibrium was reached much sooner, within a few weeks.

Similar studies were conducted using DTPA as the complexing agent. In the Hanford soil, pretreated nickel slowly adsorbed into the soil and untreated nickel slowly redissolved. Equilibrium was not reached, even after one year. As was the case with EDTA, equilibrium was reached much more rapidly with the Savannah River soil, after a couple of days. The adsorbed fraction at equilibrium was approximately $20 \%$. A separate test was conducted with Savannah River soil, but at a lower $\mathrm{pH}(\sim 4)$. Equilibrium was reached at an adsorbed fraction of $70 \%$, also within a couple of days.

Oxalate is known to form much weaker complexes with metal ions, such as nickel, than either the EDTA or DTPA. In tests involving this complexant and Hanford soil, the equilibrium was reached much more rapidly, within a few days, than with the other two complexants. Possibly because of the shorter equilibration times, parametric studies were conducted, varying concentrations of nickel and oxalate, solution to soil ratio, soil particle size, and direction of approach to equilibrium. Of these, only the complexant concentration seemed to affect the results. The equilibrium adsorbed fraction decreased nearly 100 -fold with a 10 -fold increase in complexant concentration. Decreasing the soil $\mathrm{pH}$ from 9 to 5 (using oxalic acid) resulted in an adsorbed fraction decrease by one-third. Repeating these tests using Savannah River soil indicated less of a dependence on oxalate concentration than with the Hanford soil.

Finally, tests were conducted using citrate as the complexing agent. Citrate, like oxalate, forms much weaker complexes with nickel than EDTA or DTPA. In the Hanford soil tests, the equilibrium was reached within a few days and $\sim 90 \%$ of the nickel was adsorbed into the soil. The Savannah River soil tests did not reach an equilibrium, even after 25 days, though the adsorbed fraction was increasing throughout the test time.

The study reported in Reference 38 was expanded to include two additional complexants, HEDTA and NTA in 1983. ${ }^{40}$ These two complexants are of intermediate strength, between the strong EDTA and DTPA and the weak citrate and oxalate. In addition, one more soil type was included, Oak Ridge soil, which was taken from an Oak Ridge waste burial ground and was significantly finer than either the Hanford or Savannah River soil samples. The Oak Ridge soil pH was close to that of Savannah River soil, $\mathrm{pH}=5.5$.

There were, however, significant differences between the adsorption characteristics of nickel in the Oak Ridge and Savannah River soil samples. For example, in the Savannah River soil tests using preadsorbed nickel (that is, nickel that was adsorbed into the soil before addition of the complexant), a significant amount of the nickel was redissolved when an EDTA-laden solution was passed through the soil. However, no redissolution of nickel occurred with the Oak Ridge soil sample.

In Hanford soil, equilibrium conditions were not met with the HEDTA-complexed nickel, even after 2 months of testing. Equilibrium was met with the NTA-complexed nickel after approximately 1 month. The equilibrium adsorption fraction with NTA-complexed nickel ranged between 70 and $90 \%$, depending on the molarity of the NTA. Similar tests conducted with Oak Ridge soil samples were more complex. The dependence of the adsorbed fraction on NTA concentration was greater than with the EDTA-complexed nickel. 
An analytical study of the leakage of ${ }^{59} \mathrm{Ni}$ from an underground vault is presented in Reference 41 . Although this study is specific to ${ }^{59} \mathrm{Ni}$ migration from an underground storage facility, it also has implications for any isotope of nickel, including ${ }^{63} \mathrm{Ni}$. In this study, radioactive structural components of a reactor were placed in a 500-meter deep tunnel, lined with concrete and covered with a clay/quartz mixture. Given best estimates on soil and groundwater conditions, it was calculated that the nickel would escape over a period of 20,000,000 years. Even if the concrete and clay/quartz were to become completely permeable to the groundwater (an extremely unlikely event), the maximum leach rate for the nickel was calculated to be $2 \times 10^{-6}$ parts per year.

Independent studies have been made of the behavior of ${ }^{63} \mathrm{Ni}$ in soil by European scientists. ${ }^{42}$ In this laboratory study, the diffusion of ${ }^{63} \mathrm{Ni}$ through various sedimentary rock samples in Germany was measured and compared with retention coefficients, $\mathrm{K}_{\mathrm{d}}$. The scientists concluded that diffusion coefficients could be measured and used to model transport of ${ }^{63} \mathrm{Ni}$ through various soil types. The diffusion coefficient for ${ }^{63} \mathrm{Ni}$ was comparable to that for other radioactive species included in the study (e.g., $2.63 \times 10^{-9} \mathrm{~cm}^{2} / \mathrm{s}$ for ${ }^{63} \mathrm{Ni}$ compared with a range of $3.29 \times 10^{-8} \mathrm{~cm}^{2} / \mathrm{s}$ to $5.64 \times 10^{-9} \mathrm{~cm}^{2} / \mathrm{s}$ for uranium and radium nuclides for the same soil type).

In summary, the behavior of nickel in soils depends on a variety of parameters. These include soil/groundwater $\mathrm{pH}$, soil type and texture, and the presence or absence of complexing agents.

\section{Nickel-63 in Water}

Nickel tends to be easily adsorbed by soils, removing it from groundwater. However, this condition is dependent on a number of parameters, especially groundwater $\mathrm{pH}$ and whether or not complexing agents are present. For example, in a Hanford soil sample (with a $\mathrm{pH}=9$ and complexed with EDTA) nickel was not appreciably removed from the solution even after contact with the soil for over one year. Thus, the presence of complexing agents can significantly slow removal of nickel from groundwater. The equilibrium water concentration of nickel depends on $\mathrm{pH}$ and the particular complexant used, as discussed in the previous section.

Personnel at the Pacific Northwest Laboratories studied the transport and chemical behavior of a number of radionuclides in a slightly contaminated groundwater plume..$^{43}$ In this study, they observed that several radioactive species, including ${ }^{63} \mathrm{Ni}$, were transported, principally in a nonionic form. In this form, these species are fairly mobile. At least for the case of ${ }^{63} \mathrm{Ni}$, this behavior (nonionic chemical form) was not predicted using chemical thermodynamics. They assumed that complexing nickel with organic contaminants may explain the anomalous chemical form.

Reference 39 includes estimates on the uptake of ${ }^{63} \mathrm{Ni}$ from dilute concentrations in an aquatic environment into the underlying soil. The transfer factors (ratio of nickel concentration in the water to that in the soil) were in the range of $10^{-4}$, indicating that very little of the original nickel would remain in solution and was, therefore, not available for transportation with the water.

While not specifically a groundwater issue, the contamination of sediment and deep sea water were studied near two nuclear-powered submarines that were lost at sea in the $1960 \mathrm{~s} .{ }^{44}$ In this study, there were measurable, though small, concentrations of ${ }^{63} \mathrm{Ni}$ in the sediment surrounding the submarines (probably resulting from corrosion of activated reactor structural parts or release of corrosion products from the reactor plants). However, no measurable ${ }^{63} \mathrm{Ni}$ was found in the water, marine animals, or in fauna. 


\section{Nickel-63 in Plants}

Nearly all information that was located on the uptake of nickel by plants is based on naturally occurring or stable isotopes of nickel. Little information specifically discussed ${ }^{63} \mathrm{Ni}$; however, ${ }^{63} \mathrm{Ni}$ should follow the behavior of its stable isotopes. One summary reference, Nickel, ${ }^{1}$ contains a discussion of naturally occurring nickel uptake into plants. Naturally occurring nickel concentrations in the soil range from a few parts per million (ppm) to several thousand ppm. Typical plant nickel concentrations in grains, fruits, and vegetables range from a few tenths of a part per million to a few part per million. Thus, the uptake of nickel from soil to these plants appears to be a very small fraction of the soil concentration. Some grasses, including field-grown oats, may contain more than $100 \mathrm{ppm}$ nickel, and some flowers (alyssum, forget-me-nots, rice flowers), up to several thousand parts per million. In alyssum, the highest concentrations of nickel were in the leaves, with less than one-tenth of the concentration in the seeds. Nickel can enter plants via the roots, via adsorption through the leaves or a combination.

Laboratory tests summarized in Reference 39 include studies of the uptake of ${ }^{63} \mathrm{Ni}$ by various plant species. Based on these tests (which were conducted on sunflowers), it was concluded that ${ }^{63} \mathrm{Ni}$ is very mobile within the plant; that is, it is distributed throughout the plant structure, although more than half of it migrates to newly developing organs within the plant, such as new leaves.

The transfer ratio between soil and plants (ratio of nickel concentration in the soil to that in the plant) is approximately $10 \%$ for most plants, although it can be as high as $50 \%$ for legumes. There was no evidence of accumulation of this nuclide in the seeds, fruits, or tubers of these plants.

Reference 39 also includes a study of the uptake of nickel by marine plants. In this study, the marine plants tended to concentrate the nickel by a factor of 1,000 over that in the water. Thus, any nickel in solution would tend to be taken up by marine plants where it would be available for ingestion by animals.

\section{Nickel-63 in Air}

Nickel isotopes (radioactive or nonradioactive) are not normally found in air, except possibly for small amounts generated and released following an atmospheric test of a thermonuclear weapon. Measurements were made of ${ }^{63} \mathrm{Ni}$ in marine animals near the Pacific Ocean nuclear test sites, Bikini and Eniwetok Atolls. ${ }^{45}$ Measurable amounts of ${ }^{63} \mathrm{Ni}$ were discovered in clams as a direct result of the atmospheric tests conducted at these sites.

Radioactive ${ }^{63} \mathrm{Ni}$ is produced entirely as an activation product in the reactor structural components and does not appear as a fission product radionuclide. Therefore, even if a severe core damage accident in a nuclear reactor released significant amounts of fission products, this would not necessarily mean that significant amounts of ${ }^{63} \mathrm{Ni}$ would be released into the air.

There is some indirect evidence of airborne radioactive nickel isotopes having resulted from nuclear explosions. ${ }^{1}$ Very small amounts of ${ }^{63} \mathrm{Ni}$ have been measured in soil and marine life around the Pacific Proving Ground, the site of several atmospheric nuclear tests. The maximum concentrations of this nuclide are in the parts per trillion range. 


\section{Behavior of Nickel-63 in the Human Body and in Animals}

The presence and behavior of nickel has been studied both in humans and in a number of animal species. Annual limits for ${ }^{63} \mathrm{Ni}$ are based on this research, which is summarized in the following paragraphs.

\section{Human Body}

Nickel is present in all human tissue in trace amounts. Even newborn infants have measurable amounts (of the order of $10^{-5} \mathrm{~g} /$ liter of the umbilical cord serum). There is evidence that nickel may be an "essential micronutrient" for health and growth.'

Distribution of nickel is generally uniform throughout the human body. Data from the "Reference Man," used in studies of the International Commission of Radiation Protection, indicate that there are approximately 10 milligrams of nickel in a typical adult, with $\sim 5$ milligrams in the soft tissues and $\sim 5$ milligrams in the skeleton tissues. ${ }^{46}$ Studies have investigated the effects of health problems associated with either an overabundance or deprivation of nickel. Many of the studies reviewed for this chapter, however, deal with naturally occurring, stable isotopes of nickel and not with radioactive nuclides such as ${ }^{63} \mathrm{Ni}$. Safe Handling of Radioisotopes ${ }^{47}$ states that the liver is the critical organ with respect to ingestion of ${ }^{63} \mathrm{Ni}$.

Reference 39 concludes that nickel distributes uniformly throughout the human body. Ingested nickel is only poorly adsorbed by the intestinal tract (e.g., the fraction adsorbed is of the order of $1 \%$ ). In animal studies, between 60 and $90 \%$ of intravenously injected nickel was excreted within 24 hours. The biological half-life of the remaining nickel in the human body (after the initial excretion) is estimated to be approximately 500 days.

Radionuclides have been classified as to their relative toxicity in man. ${ }^{48}$ In this study, radionuclides are grouped into three classifications: high toxicity, medium toxicity, and low toxicity. Because of the large number of nuclides in the middle group, it was further subdivided into an upper (Group A) and lower (Group B) group. ${ }^{63} \mathrm{Ni}$ is included in the Medium Toxicity Group B.

The dose to the various body organs from ${ }^{63} \mathrm{Ni}$ inhalation has been reported in the Health Physics and Radiological Health Handbook. ${ }^{49}$ In Table 11.3.1 of this reference, the dose (per exposure) for the internal organs (including lungs, gonads, bone marrow, and thyroid) is fairly uniform at $\sim 8 \times 10^{-10} \mathrm{~Sv} / \mathrm{Bq}$ for a one day exposure. The dose from ingestion is also uniform at $\sim 8 \times 10^{-11} \mathrm{~Sv} / \mathrm{Bq}$.

\section{Animal Studies}

Reference 1 contains some information regarding the metabolism of nickel in laboratory animals. After nickel-chloride was injected into rats (stable Ni), nearly $70 \%$ was excreted within 72 hours (61\% in urine and $6 \%$ in feces). All blood and plasma nickel disappeared within 48 hours. After 72 hours, only the kidneys exhibited significant amounts of nickel. The initial excretion of injected nickel differed from nickel that was orally administered in that the orally ingested nickel was preferentially $(90 \%)$ excreted in the feces, indicating only minimal adsorption via the intestines. A separate study included injections in both rats and rabbits. The conclusions from this study did not differ substantially from those of the previous study - preferential excretion via urine during the first 48 hours and then more gradual 
excretion over 3 to 7 days. Because of the long radiological half-life of ${ }^{63} \mathrm{Ni}$, the effective half-life of ${ }^{63} \mathrm{Ni}$ in the human body is primarily a result of its biological half-life. The biological half-life refers to the amount of time required to remove half of the initial material from the body via a combination of chemical, physical, or biological processes. The effective half-life incorporates both the radiological and biological half-lives. For ${ }^{63} \mathrm{Ni}$, the biological half-life has been reported as 667 days for the total body, 800 days for bone, and 500 days for the liver ${ }^{50}$ However, Reference 51 of the International Commission of Radiological Protection reports the biological half-life of all nickel isotopes as 1,200 days.

Reference 52 reports a study of the bioaccumulation in the food chain. Researchers noted that ${ }^{63} \mathrm{Ni}$ concentrated mainly in the pancreas and exoskeleton of shrimp and in the skin and viscera of fish. This distribution is consistent with previous studies wherein ${ }^{63} \mathrm{Ni}$ was observed to concentrate in the shell of clams. $^{53}$

In addition, personnel at the Battelle/Marine Research Laboratory studied the biological uptake of ${ }^{63} \mathrm{Ni}$ into the food chain. ${ }^{52}$ In this laboratory study, various stainless steel corrosion products, including ${ }^{63} \mathrm{Ni}$, were introduced into marine sediments. Naturally occurring worms were exposed to these sediments and then fed to shrimp and fish. The accumulation of ${ }^{63} \mathrm{Ni}$ in the soil, worms, shrimp, and fish were then measured. They concluded that ${ }^{63} \mathrm{Ni}$ will be transported from the soil up the food chain, though there was no evidence that this nuclide was biologically concentrated in any of the animals. Indeed, there was some evidence that the ${ }^{63} \mathrm{Ni}$ concentration decreased as it was passed up the food chain. Researchers noticed that ${ }^{63} \mathrm{Ni}$ was more readily bioaccumulated from the sediment than was ${ }^{60} \mathrm{Co}$, the other radioactive material studied.

In a separate study, ${ }^{30}$ male and female rats were injected with nickel-sulfate that contained trace amounts of ${ }^{63} \mathrm{Ni}$, and the metabolism of the nickel was investigated. The results indicated that the internal organs contained the highest concentrations of nickel and that the principal excretion route (accounting for $50 \%$ to $80 \%$ of the ingested $\mathrm{Ni}$ ) was urine. The other two routes were fecal excretion $(13 \%$ to $30 \%)$ and expiration. The half-life for excretion was dose dependent; ranging from 4.6 hours for the highest dose $\left(1800 \times 10^{-9}\right.$ moles $\left.\mathrm{Ni}\right)$ to 23 hours at the lowest dose $\left(17 \times 10^{-9}\right.$ moles $\left.\mathrm{Ni}\right)$.

The annual limits on ${ }^{63} \mathrm{Ni}$ intake (ALI) and the derived air concentration (DAC) for ${ }^{63} \mathrm{Ni}$ are shown in Table 10-5. Historically, maximum permissible concentrations (MPC) in air and water have been used to determine safety guidelines for released radionuclide concentrations. Currently, the derived guidelines are presented in terms of ALIs for inhalation or ingestion, and DACs for inhalation (or submersion). For a radionuclide whose derived value does not change from the old definition, the DAC is numerically equal to the MPC value in air. ${ }^{54}$ The information in Table $10-5$ applies only to ${ }^{63} \mathrm{Ni}$. In the case of multiple radionuclides released in a mixture, additional guidelines outlined in Title 10 of the Code of Federal Regulations, Part $20^{55}$ must be followed. 
Table 10-5. Annual limits on intake (ALI) and the derived air concentrations (DAC) for ${ }^{63} \mathrm{Ni}$. (Data obtained from References 54 and 55).

\begin{tabular}{lccc}
\hline Radionuclide & Component & $\begin{array}{c}\text { Ingestion } \\
(\mu \mathrm{Ci})\end{array}$ & Inhalation $^{\mathrm{a}}$ \\
\hline${ }^{63} \mathrm{Ni}$ & ALI & $9,000^{\mathrm{b}} \mu \mathrm{Ci}$ & $2,000 / \mathrm{D}^{\mathrm{b}}$ or $3,000 / \mathrm{W}^{\mathrm{b}}$ or $800[\mathrm{vapor}] \mu \mathrm{Ci}$ \\
& & & \\
& DAC & $\mathrm{C}^{\mathrm{c}}$ & $0.7 / \mathrm{D}$ or $1.0 / \mathrm{W} \quad 0.3[$ vapor $] \mu \mathrm{Ci} / \mathrm{m}^{3}$
\end{tabular}

a. Clearance from the lung directly to the blood stream or to the gastrointestinal (GI) tract depends upon the chemical form of the radionuclide and is classified as $\mathrm{D}, \mathrm{W}$, and $\mathrm{Y}$, respectively, for clearance times of the order of days, weeks, and years.

b. Removal class is $f_{1}=0.05$. A simple model of the lung was used to describe the translocation and retention of material by the body after inhalation. In this model, $25 \%$ of the inhaled activity was exhaled and $25 \%$ was deposited in the lower respiratory tract. The $50 \%$ that was deposited in the upper respiratory tract was eventually cleared by means of mucociliary processes and swallowed. What happens then depends on whether the inhaled material was in either a soluble or insoluble chemical form. Any soluble material deposited in the lower respiratory tract is assumed to be transferred directly to the blood stream. The activity cleared from the upper respiratory tract and then swallowed, a fraction $\left(\mathrm{f}_{1}\right)$, and in the case of ${ }^{63} \mathrm{Ni} \mathrm{f}_{1}=0.05$, entered the blood-stream via the GI tract. Additional details of this model are described in Reference 54.

c. Data not available.

\section{Summary}

${ }^{63} \mathrm{Ni}$ is not a naturally occurring radionuclide. Its half-life is approximately 100 years and decays by beta particle emission. When it decays, no x-rays or gamma rays are emitted. ${ }^{63} \mathrm{Ni}$ has been used in a small number of biological experiments; however, no specific medical application of ${ }^{63} \mathrm{Ni}$ has been identified.

${ }^{63} \mathrm{Ni}$ is produced in the structural steels of nuclear reactor vessel and internal components from neutron activation of ${ }^{62} \mathrm{Ni}$, a naturally occurring and stable isotope of nickel. These reactor components serve as the primary LLW material containing ${ }^{63} \mathrm{Ni}$. The major concern surrounding ${ }^{63} \mathrm{Ni}$ is in limiting the dose received by persons associated with the decommissioning and dismantling of the reactors, primarily for reactors in service for more than 30 years. At that point, the ${ }^{63} \mathrm{Ni}$ activity will become an important activation product with regard to decommissioning activities. Limited amounts of ${ }^{63} \mathrm{Ni}$ can enter the environment through operational wastes from a nuclear reactor (i.e., corrosion of stainless steel surfaces and circulation of coolant).

The chemistry of nickel is dominated by the $4 \mathrm{~s}$ subshell electrons. While other oxidation states can be produced, the principal form is $\mathrm{Ni}^{2+}$. Nickel is resistant to attack by water or air and, therefore, is often used as a protective coating for other metals or as an alloy to create a corrosion-resistant metal such as stainless steel.

The ability of soil to adsorb ${ }^{63} \mathrm{Ni}$ out of groundwater varies depending on the soil type and water $\mathrm{pH}$. In general, however, nearly all of the ${ }^{63} \mathrm{Ni}$ present in groundwater is expected to be adsorbed by the 
soil, with only $1 \%$ or less of the nickel remaining dissolved in the water. Soil adsorption can be affected, however, by the presence or absence of certain decontamination agents such as EDTA and DPTA, which can significantly reduce the ability of the soil to adsorb the nickel.

When ${ }^{63} \mathrm{Ni}$ comes into contact with the soil and groundwater, most of it will become fixed in the soil and will not migrate appreciably from the original site. Plants and animals can take up ${ }^{63} \mathrm{Ni}$ from the soil and propagate it into the food chain. When this nuclide is ingested in mammals, most of it is immediately excreted within 24 hours. That part that is absorbed tends to be uniformly distributed throughout the body and consequently remains within the body for a long time. The biological half-life of ${ }^{63} \mathrm{Ni}$ in the human body has been reported to be 500 to 1,200 days (total body). 


\section{References}

1. Committee on Medical and Biologic Effects of Environmental Pollutants, Nickel, Division of Medical Sciences, National Research Council, National Academy of Sciences, Washington, D.C., 1975 , pp. 38 and 39.

2. C. M. Lederer, J. M. Hollander, I. Perlman, Table of Isotopes, Sixth Edition, New York: John Wiley \& Sons, Inc., 1967, pp. 23 and 197.

3. D. C. Stewart, Data for Radioactive Waste Management and Nuclear Applications, New York: John Wiley \& Sons, 1985, p. 251.

4. J. Kohl, R. D. Zentner, H. R. Lukens, Radioisotope Applications Engineering, New York: D. Van Nostrand Company, 1961, p. 547.

5. General Electric Company, Nuclides and Isotopes, Fourteenth Edition, 1989, p. 25.

6. B. Shleien and M. S. Terpilak (Eds.), The Health Physics and Radiological Health Handbook, Nucleon Lectern Associates, 1984, pp. 165 (Table 8.3), 173 (Table 8.6).

7. B. Shleien and M. S. Terpilak (Eds.), The Health Physics and Radiological Health Handbook, Nucleon Lectern Associates, 1984, pp. 146 (Table 6.11).

8. J. R. Brandford (Ed.), Radioisotopes in Industry, Reinhold Publishing Corporation, 1953, p. 266 (Figure 13.3).

9. W. R. Gilmore, Radioactive Waste Disposal Low and High Level, Noyes Data Corporation, 1977, p. 235.

10. R. Granier and D. Gambini, Applied Radiobiology and Radiation Protection, Ellis Horwood, 1990, pp. 346 and 347.

11. R. C. Weast (Ed.), CRC Handbook of Chemistry and Physics, Boca Raton, Florida: CRC Press, 1977, 58th Edition, pp. B-270 through B-354 (Table of the Isotopes), and pp. B-429.

12. Bureau of Radiological Health, Radiological Health Handbook, Revised Edition, U.S. Government Printing Office, January 1970, pp. 92-94 (average and maximum beta energy by radionuclide).

13. B. Shleien and M. S. Terpilak (Eds.), The Health Physics and Radiological Health Handbook, Published by Nucleon Lectern Associates, 1984, pp. 165-167 (Table 8.3), 172-177 (Table 8.6).

14. F. A. Cotton and G. Wilkinson, Advanced Inorganic Chemistry-A Comprehensive Text, New York: Interscience Publishers, 1962.

15. R. C. Weast (Ed.), CRC Handbook of Chemistry and Physics, Boca Raton, Florida: CRC Press, 1977, 58th Edition, pp. B-135 (Table of Physical Constants of Inorganic Compounds).

16. International Critical Tables of Numerical Data, Physics, Chemistry, and Technology, Vol. I, New York: McGraw-Hill Book Company, 1926, p. 102.

17. Metals Handbook, 8th Ed., Vol. 8, American Society for Metals, 1973. 
18. McGraw-Hill Encyclopedia of Science and Technology, 6th Ed., Vol. 11, New York: McGraw-Hill Book Company, 1987.

19. A. G. Croff, $A$ User's Manual for the ORIGEN2 Computer Code, ORNL/TM-7175, Oak Ridge National Laboratory, July 1980.

20. F. J. Rahn et al., A Guide to Nuclear Power Technology, New York: Wiley-Interscience, 1984, p. 697.

21. F. J. Rahn et al., A Guide to Nuclear Power Technology, New York: John Wiley \& Sons, 1984, p. 699 (Figure 16.5).

22. A. H. Schilling, Decommissioning Commercial Nuclear Facilities: A Review and Analysis of Current Regulations, NUREG/CR-0671, 1979.

23. T. M. Beasley, "Nickel-63 in Columbia River Sediments Below the Hanford Reservation," Journal of Environmental Radioactivity, 4, pp. 1-10, 1986.

24. J. Deconinck, P. Van Iseghem, R. Boden, et al., Investigation on the Determination of Disposal Critical Nuclides in Waste from PWR Power Plants-Task 3: Characterization of Radioactive Waste Forms-A Series of Final Reports (1985-89), No. 45, EUR-14364, 1993.

25. E. Schuster and E. Haas, Behavior of Actinides and Other Radionuclides that are Difficult to Measure in the Melting of Contaminated Steel, EUR-12875, 1990.

26. Proceedings of the U.S. Nuclear Regulatory Commission, Fifteenth Water Reactor Safety Information Meeting, Volume 6, "Decontamination and Decommissioning," NUREG/CP-0091 Vol. 6, February 1988, p. 29.

27. J. M. Deconinck, P. Van Iseghem, R. Boden, et al., Investigation on the Determination of Disposal Critical Nuclides in Waste From PWR Power Plants: Task 3-Characterization of Radioactive Waste Forms, A Series of Final Reports (1985-89) No. 45, Commission of the European Communities, ISBN 92-826-5239-4, 1993.

28. Letter from D. P. Hoffman (Consumers Power Company) to J. G. Keppler (U.S.NRC), "Docket 50255, License DPR-20, Palisades Plant, Semiannual Radioactive Effluent Report," February 28, 1997.

29. "The Handling, Storage, Use, and Disposal of Unsealed Radionuclides in Hospitals and Medical Research Establishments," Annals of the ICRP-ICRP Publication 15, 1, No. 2, New York: Pergamon Press, 1977.

30. M. Medinsky, J. Benson, C. Hobbs, "Lung Clearance and Disposition of ${ }^{63} \mathrm{Ni}$ in F344/N Rats After Intratracheal Instillation of Nickel Sulfate Solutions," Environmental Research, June 1987, pp. 168178.

31. M. F. L'Annunziata, Radionuclide Tracers Their Detection and Measurement, Academic Press, 1987, pp. 330-331, 333-335, 360.

32. L. Kangas, J. Kanto, V. Lehtinen, J. Salminen, "Long-Term Nitrazepam Treatment in Psychiatric Out-Patients with Insomnia," Psychopharmacology, Vol. 63, 1979, pp. 63-66. 
33. W. Eedy, P. McKee, W. Snodgrass, R. Maloney, "Spreadsheet Modelling of Radiological Impacts from Radioisotope Disposal in Municipal Waste Systems," Proceedings of the Canadian Nuclear Society, International Conference on Radioactive Waste Management, Winnipeg, Canada, September 7-11, 1986, pp. 491-495.

34. International Directory of Radioisotopes, Volume I, The International Atomic Energy Agency, 1959 , pp. 142 and 143.

35. P. C. Bergamini, G. Palmas, F. Piantelli, M. Rigato, "Absorption and Distribution of ${ }^{137} \mathrm{Cs}$ by Trifolium Pratense," Health Physics, Vol. 19, No. 4, October 1970, pp. 521-528.

36. J. Dragun, The Soil Chemistry of Hazardous Materials, Hazardous Materials Control Research Institute, Silver Spring, MD, 1988.

37. J. Neiheisel, "Preliminary Results of a Study to Develop Prediction Parameters for Radionuclide Retention at Future Low-Level Waste Disposal Sites," Proceedings of the Fifth Annual Participants Information Meeting, DOE Low-Level Waste Management Program, Denver, Colorado, August 30-September 1, 1983, CONF-8308106, pp. 591-608.

38. J. L. Swanson, Effect of Organic Complexants on the Mobility of Nickel and Cobalt in Soils: Status Report, PNL-4389, September 1982.

39. P. J. Coughtrey and M. C. Thorne, Radionuclide Distributions and Transport in Terrestrial and Aquatic Ecosystems-A Critical Review of Data, Vol. 2, A. A. Balkema of Rotterdam, 1983, pp. 218-227.

40. J. L. Swanson, Mobility of Organic Complexes of Nickel and Cobalt in Soils, PNL-4796, September 1983.

41. I. Neretnieks, K. Andersson, L. Hanstam, "Utlackning av Ni-59 Fran Ett Bergforvar," (Release of ${ }^{59} \mathrm{Ni}$ from a Mountain Vault), Kugl Tekniska Hogskolan, Stockholm, Sweden, April 24, 1978.

42. H. Meier, E. Zimmerhackl, W. Hecker, G. Zeitler, P. Menge, "Measurement of Diffusion of Radionuclides in Sediment Rocks," Radiochimica Acta, Vol. 44/45, 1988, pp. 239-244.

43. D. Robertson, A. Toste, K. Abel, C. Cowan, E. Jenne, and C. Thomas, Speciation and Transport of Radionuclides in Groundwater, NUREG/CP-0052, May 1984.

44. United States Department of the Navy, Final Environmental Impact Statement on the Disposal of Decommissioned, Defueled Naval Submarine Reactor Plants, Vol. 1, 1984.

45. T. Beasley and E. Held, "Nickel-63 in Marine and Terrestrial Biota, Soil and Sediment," Science, Vol. 164, 169, pp. 1161-1163.

46. "Limits for Intakes of Radionuclides by Workers," Annals of the ICRP-ICRP Publication 30, Part 3, Vol. 6, No. 3, Pergamon Press, 1981.

47. Safe Handling of Radioisotopes, International Atomic Energy Agency, Vienna, 1958. 
48. A Basic Toxicity Classification of Radionuclides, Report of Joint Study of a Group of Consultants to the International Atomic Energy Agency, Technical Reports Series No. 15, International Atomic Energy Agency, Vienna, Austria, 1963.

49. B. Shleien and M. Terpilak, Supplement 1 (1986): The Health Physics and Radiological Health Handbook, Nucleon Lectern Associates, Inc., 1986.

50. Y. Wang, M. D. (Ed.), CRC Handbook of Radioactive Nuclides, Boca Raton, Florida: CRC Press, 1969, p. 27 (Table 16).

51. Annals of the ICRP Limits for Intakes of Radionuclides by Workers, ICRP Publication 30, Part 3, 1981 (This report supersedes ICRP publication 2), Pergamon Press, pp. 25-28.

52. J. Young, The Bioaccumulation and Food Chain Transfer of Corrosion Products from Radioactive Stainless Steel, PNL-5923, July 1986.

53. J. T. Hardy and G. Roesijadi, "Bioaccumulation Kinetics and Organ Distribution of Nickel in the Marine Clam (Protothaca staminea)," Bulletin of Environmental Contamination \& Toxicology, Vol. 28, No. 5, 1982, pp. 566-572.

54. K. F. Eckerman, A. B. Wolbarst, A. C. B. Richardson, Limiting Values of Radionuclide Intake and Air Concentration and Dose Conversion Factors for Inhalation, Submersion, and Ingestion, Federal Guidance Report No. 11, Oak Ridge National Laboratory, EPA-520/1-88-020, September 1988, Table 1.b, Table 3, and p. 21.

55. U.S. Nuclear Regulatory Commission, 10 CFR 20, Chap I (January 1, 1992), "Standards for Protection Against Radiation," Appendix B, p. 354 (data concerning ${ }^{63} \mathrm{Ni}$ ). 


\section{Bibliography}

Abel, K. H., et al., Residual Radionuclide Contamination Within and Around Commercial Nuclear Power Plants, NUREG/CR-4289, PNL-5429, pp. 13, 14, 15, 19, 41, 42, 50, 59, 64, C.96

(Table C.7.9).

Ames, L. L., and D. Rai, Radionuclide Interactions with Soil and Rock Media, Vol. 1, EPA 520/6-78007-a, U.S. Environmental Protection Agency, August 1978.

Fuierer, A. A., "Characterization and Classification of Spent-Fuel Hardware for Storage and Disposal," Transactions of the American Nuclear Society, Volume 62, TANSAO 62 1-722 (1990), ISSN: 0003-018X, November 11-15, 1990.

Garner, R. John, Transfer of Radioactive Materials from the Terrestrial Environment to Animals and Man, Boca Raton, Florida: CRC Press, 1972, pp. 11, 13, 25, 38, 42.

Hulse, R. A., Greater-Than-Class C Low-Level Radioactive Waste Characterization: Estimated Volumes, Radionuclide Activities, and Other Characteristics, DOE/LLW-114, Greater-Than-Class C Low-Level Waste Management Program, August 1991, pp. 20, 22, 23, 53, 54, 55-60.

International Directory of Radioisotopes, Second Edition, Part I, International Atomic Energy Agency, 1962.

Louria, D. B., M. M. Joselow, A. A. Browder, "The Human Toxicity of Certain Trace Elements," Annals of Internal Medicine, Vol. 76, 1972, pp. 307-319.

Nielsen, F. H., and D. A. Ollerich, "Nickel: A New Essential Trace Element," Federation Proceedings, Vol. 33, No. 6, June 1974, pp. 1767-1772.

Rahn, F. J., A. G. Adamantiades, J. E. Kenton, C. Braun, A Guide to Nuclear Power Technology, New York: John Wiley \& Sons, 1984, Chapter 15, pp. 697-701, and Figure 16.5.

Robertson, D. E., C. W. Thomas, N. L. Wynhoff, and D. C. Hetzer, "Characterization of Long-Lived Activation Products in Spent Fuel Assembly Hardware and Reactor Pressure Vessel Steel," Nuclear Engineering and Design, Vol. 118, 1990, pp. 463-486.

Robertson, D., D. Haggard, C. Thomas, N. Wynhoff, "Radiological Characterization of NeutronActivated Metal Wastes from Nuclear Power Stations," Proceedings of the Second International Conference on Methods and Applications of Radioanalytical Chemistry, Kona, Hawaii, April 21-27, 1992, Articles published by the Journal of Radioanalytical and Nuclear Chemistry, 161, No. 2, August 1992, 62, TANSAO 62 1-722 (1990), ISSN: 0003-018X, November 11-15, 1990, pp. 585-595.

Schroeder, H. A., J. J. Balassa, I. H. Tipton, "Abnormal Trace Metals in Man - Nickel," Journal Chron. Dis., 15, Pergamon Press Ltd., pp. 51-65.

Sheppard, M. I., D. I. Beals, D. H. Thibault, P. O'Connor, Soil Nuclide Distribution Coefficients and their Statistical Distributions, AECL-8364, Atomic Energy of Canada, Limited, December 1984. 
Sunderman, Jr., F. W., et al., "Increased Concentrations of Serum Nickel after Acute Myocardial Infarction," The New England Journal of Medicine, October 22, 1970, pp. 896-899.

U.S. Department of Energy, Characteristics of Spent Fuel, High-Level Waste, and Other Radioactive Wastes Which May Require Long-Term Isolation, DOE/RW-0184, Volume 2 of 6, December 1987. 


\section{NIOBIUM-94}

\section{Introduction}

This chapter outlines the basic radiological, chemical, and physical characteristics of niobium-94 $\left({ }^{94} \mathrm{Nb}\right)$ and examines how these characteristics affect the behavior of ${ }^{94} \mathrm{Nb}$ in various environmental media, such as soils, water, plants, animals, the atmosphere, and the human body. Also included are methods of ${ }^{94} \mathrm{Nb}$ production and waste and disposal data on ${ }^{94} \mathrm{Nb}$.

All niobium atoms contain 41 protons $(Z=41)$ and various numbers of neutrons (typically $N=47$ to 65 neutrons) within the atom's nucleus. There is only one stable isotope of niobium, namely ${ }^{93} \mathrm{Nb}$. All other niobium isotopes, including ${ }^{94} \mathrm{Nb}$, are radioactive. The radioactive isotopes of niobium have halflives ranging from a few seconds $\left({ }^{104} \mathrm{Nb}, 1.0\right.$ seconds) to millions of years $\left({ }^{92} \mathrm{Nb}, 37,000,000\right.$ years $) .{ }^{94} \mathrm{Nb}$ has a 20,000 year half-life. ${ }^{1}$ The radioactive isotopes of niobium are not a normal constituent of the natural environment and are generated as a result of human activities.

The primary source of ${ }^{94} \mathrm{Nb}$ in the environment has been low-level radioactive waste (LLW) generated from the neutron activation of stable ${ }^{93} \mathrm{Nb}$ that is present in the structural components of nuclear reactor vessels, especially those constructed of Inconel. ${ }^{94} \mathrm{Nb}$ enters the environment from the dismantling activities associated with nuclear reactor decommissioning.

A radionuclide considered sensitive at one LLW disposal facility may not be considered sensitive at another facility. The behavior of a radionuclide at a particular LLW disposal site will depend primarily upon the radiological, chemical, and physical characteristics of the waste, and the inventory of the radionuclide. The behavior of a radionuclide also depends upon the geology, hydrology, and climate at the disposal site. This chapter reports characteristics and potential difficulties in dealing with ${ }^{94} \mathrm{Nb}$. However, since ${ }^{94} \mathrm{Nb}$ behavior and appropriate handling, storage, or disposal will vary depending on particular sites or waste form, this chapter does not attempt to discuss the extent of a difficulty or appropriate solutions. Each disposal site facility design should consider and address the specific waste content and behavior under that site's particular circumstances.

\section{Radiological Characteristics}

Confusion regarding the half-life of ${ }^{94} \mathrm{Nb}$ may occur because of an excited state $\left(T_{1 / 2}=6.6 \mathrm{~min}\right)$ that decays to the ground state of the nuclide by ejection of an atomic electron. ${ }^{2}$ The most recent and best available information concerning ${ }^{94} \mathrm{Nb}$ reports a half-life of 20,000 years. ${ }^{1,3}{ }^{94} \mathrm{Nb}$ can be formed as a fission product. However, the principal means of production is via neutron capture $(n, \gamma) \circ{ }^{93} \mathrm{Nb}$, namely

$$
{ }^{93} \mathrm{Nb}+n \rightarrow{ }^{94} \mathrm{Nb}+\gamma-\mathrm{ray} .
$$

${ }^{94} \mathrm{Nb}$ undergoes radioactive decay via negative beta particle $\left(\beta^{-}\right)$emission (i.e., $100 \%$ of all decays result in an electron being emitted from the nucleus) leading to the creation of a stable molybdenum-94 $\left({ }^{94} \mathrm{Mo}\right)$ nucleus.

The maximum beta particle energy is $500 \mathrm{keV}$ (thousand-electron volts). However, the average beta particle energy is only $156 \mathrm{keV}$ per ${ }^{94} \mathrm{Nb}$ disintegration. ${ }^{4}$ Because the released beta particle is usually emitted with an energy less than its maximum theoretical (e.g., $500 \mathrm{keV}$ for ${ }^{94} \mathrm{Nb}$ decay), an 
antineutrino particle is simultaneously emitted, which carries off the energy difference between $500 \mathrm{keV}$ and that of the released beta particle. Consequently, beta particles are emitted with a continuous energy spectrum ranging from 0 to $500 \mathrm{keV}$. Because neutrinos (or antineutrinos) very rarely interact with matter, they are not considered radiologically important. Therefore, the antineutrino particle is usually not shown in the overall decay equation.

The probability that a neutron passing through niobium will be absorbed by a ${ }^{93} \mathrm{Nb}$ nucleus is very small. However, even with the relatively small amount of ${ }^{93} \mathrm{Nb}$ in the Inconel in a nuclear reactor vessel, the extremely long half-life of ${ }^{94} \mathrm{Nb}$ means that the total amount of this radioactive nuclide present in the vessel will continue to increase during the reactor lifetime. By the time the reactor is decommissioned, a significant amount of ${ }^{94} \mathrm{Nb}$ will be generated in those reactor vessels with large amounts of Inconel (and, to a lesser extent, in those reactor vessels with stainless steels containing niobium) and will pose special problems when the reactor is decommissioned. Large quantities of ${ }^{94} \mathrm{Nb}$ can pose significant radiological hazards. For example, under some conditions (especially after several decades when the shorter-lived nuclides have largely decayed away), ${ }^{94} \mathrm{Nb}$ can contribute a large fraction of the total radioactive dose received by persons who dismantle nuclear reactors. This situation can occur if the reactor has been operated for a long time (e.g., $>30$ years). In other words, ${ }^{94} \mathrm{Nb}$ does not normally represent a major concern in shielding, but can be an important contributor to the overall radioactivity from activation ru:clides and can affect the classification of certain reactor hardware as LLW.

The $500-\mathrm{keV}$ maximum energy beta particle emitted by the ${ }^{94} \mathrm{Nb}$ nucleus is relatively strong. Table 11-1 lists the estimated maximum ranges for a $150-\mathrm{keV}$ (average energy) beta particle emitted from ${ }^{94} \mathrm{Nb}$ decay. Note that the maximum particle ranges are large, and because it requires only $70 \mathrm{keV}$ for an electron to penetrate the protective layer of human skin, the ${ }^{94} \mathrm{Nb}$ beta particles have plenty of energy to penetrate the $0.07 \mathrm{~mm}$ (dead layer) of human skin. Therefore, exposure to the $500 \mathrm{keV}$ maximum energy beta particles from the decay of ${ }^{94} \mathrm{Nb}$ can result in a beta dose to some internal organs.

In addition to beta particle radiation, each ${ }^{94} \mathrm{Nb}$ decay results in two high-energy gamma rays, 700 and $870 \mathrm{keV}$. Both of these are more energetic than the $660 \mathrm{keV}$ gamma ray associated with the decay of cesium-137 $\left({ }^{137} \mathrm{Cs}\right)$. Table 11-2 illustrates this fact by listing the "half-value layers," or the thicknesses of various materials required to attenuate a beam of $870 \mathrm{keV}$ gamma rays to one-half the original intensity. As shown, shielding the environment from ${ }^{94} \mathrm{Nb}$ requires a substantial thickness, as opposed to some of the nuclides in this report, such as ${ }^{6 \hat{}} \mathrm{Ni}$, which is only a beta emitter (see Chapter 10 ). 
Table 11-1. Comparison of the estimated maximum ranges for a 156-keV average energy beta particle emitted from ${ }^{94} \mathrm{Nb}$ decay for various materials.

\begin{tabular}{lc}
\hline \multicolumn{1}{c}{$\begin{array}{c}\text { Material } \\
\text { (description) }\end{array}$} & $\begin{array}{c}\text { Estimated maximum range for } \\
\text { a } 156-\mathrm{keV}^{\mathrm{a}} \boldsymbol{\beta}^{-} \\
(\mathrm{mm})^{\mathrm{a}}\end{array}$ \\
\hline Air (1 atmosphere pressure) & 250 \\
Water & 0.30 \\
Plastic (Lucite) & 0.24 \\
Concrete & 0.15 \\
Glass & 0.13 \\
Aluminum & 0.11 \\
Iron & 0.033 \\
Copper & 0.028 \\
Lead & 0.025 \\
\hline
\end{tabular}

a. Estimates are based on the maximum beta particle range data shown in References 4 and 5 as a function of energy and materials.

Table 11-2. Half-value layers for the $870-\mathrm{keV}$ gamma ray emitted from the decay of a ${ }^{94} \mathrm{Nb}$ nucleus. ${ }^{\mathrm{a}}$

\begin{tabular}{ll}
\multicolumn{1}{c}{ Material } & $\begin{array}{c}\text { Half-value layer thickness } \\
(\mathrm{cm})^{\mathrm{b}}\end{array}$ \\
\hline Lead & 0.70 \\
Iron & 1.4 \\
Aluminum & 3.9 \\
Stone concrete & 4.3 \\
Water & 9.2 \\
Air & $7.9 \times 10^{3}$ \\
\hline & \\
a. The "half-value layer" for a given material is the thickness of that material that will attenuate a beam of \\
gamma rays (of a specific energy) to one-half its intensity. \\
b. These values were interpolated from Table 6.2 of Reference 4.
\end{tabular}


The decay sequence for ${ }^{94} \mathrm{Nb}$ showing the emission of a negative beta particle (e.g., an electron) and the two gamma rays is illustrated in the following nuclear transformation:

$$
{ }^{94} \mathrm{Nb} \underset{20,000 \mathrm{y}}{\stackrel{100 \%}{\rightarrow}}+\beta^{-}(500 \mathrm{keV} \max \text { energy })+\gamma(700 \text { and } 870 \mathrm{keV})
$$

Table 11-3 lists the radiotoxicity of several important radionuclides, and Table 11-4 compares the average and maximum electron energies associated with ${ }^{94} \mathrm{Nb}$ decay with other well-known electron (beta particle) emitters. Notice that ${ }^{94} \mathrm{Nb}$ is shown in the same radiological group as cobalt-60 $\left({ }^{60} \mathrm{Co}\right)$ and strontium-90 $\left({ }^{90} \mathrm{Sr}\right) .{ }^{94} \mathrm{Nb}$ decay results in both a lower beta energy emission and gamma energy emission than either ${ }^{60} \mathrm{Co}$ or ${ }^{90} \mathrm{Sr}$. (Note: the high-energy gamma radiation from ${ }^{90} \mathrm{Sr}$ is from the decay of its relatively short-lived $\left[\mathrm{T}_{1 / 2}=64 \mathrm{~h}\right]$ daughter, yttrium- $\left.90\left[{ }^{90} \mathrm{Y}\right]\right)$.

\section{Chemical and Physical Characteristics}

Niobium is a member of the fifth group of the periodic table, which includes zirconium, molybdenum, technetium, ruthenium, rhodium, palladium, and silver. ${ }^{6}$ Commercially, pure niobium is ductile, easy to fabricate at room temperature by conventional forming practices, and used extensively in aerospace applications. It is a lustrous platinum-white metal that is relatively light in weight and has good high-temperature strength. In combination with zirconium, it is used in nuclear applications because it resists corrosion and radiation damage well and has a small probability for absorption of neutrons. ${ }^{7}$ Most niobium is used in special stainless steels, Inconels, high-temperature alloys, and superconducting alloys.

Niobium was originally called "columbium" in the United States and is still sometimes referred to by this name in the metallurgist and metals industry. It is chemically very similar to tantalum and is often found in nature in combination with this element. Niobium, which is 10 times more abundant than tantalum, composes approximately $2.4 \times 10^{-3} \%$ of the earth's crust. ${ }^{8}$

Table 11-3. Comparison of the radiotoxicity of several important radionuclides (obtained from Appendix 2 of Reference 9).

\begin{tabular}{lll}
\hline \multicolumn{2}{c}{ Radiotoxicity } & \multicolumn{1}{c}{ Species } \\
\hline Very high & Group 1 & ${ }^{241} \mathrm{Pu},{ }^{242} \mathrm{Cm},{ }^{241} \mathrm{Am}$, \\
& & ${ }^{237} \mathrm{~Np}$ \\
High & Group 2 & ${ }^{60} \mathrm{Co},{ }^{90} \mathrm{Sr},{ }^{94} \mathrm{Nb}$ \\
Moderate & Group 3 & ${ }^{14} \mathrm{C},{ }^{63} \mathrm{Ni},{ }^{137} \mathrm{Cs}$ \\
Low & Group 4 & ${ }^{3} \mathrm{H},{ }^{59} \mathrm{Ni},{ }^{99 \mathrm{~m}} \mathrm{Tc},{ }^{99} \mathrm{Tc}$, \\
\hline
\end{tabular}


Table 11-4. Average and maximum kinetic energies of beta particles and negative (atomic) electrons released during decay of several important radionuclides. (Information compiled from data presented in References 1, 3, 4, 10,11, and 12.)

\begin{tabular}{lcc}
\hline & \multicolumn{2}{c}{ Released electron energy } \\
\cline { 2 - 3 } Radionuclide & $\begin{array}{c}\text { Average energy } \\
(\mathrm{keV})\end{array}$ & $\begin{array}{c}\text { Maximum energy } \\
(\mathrm{keV})\end{array}$ \\
\hline Nickel-59 $\left({ }^{59} \mathrm{Ni}\right)$ & $4.1^{\mathrm{b}}$ & $\sim 7.7^{\mathrm{b}}$ \\
Tritium $\left({ }^{3} \mathrm{H}\right)$ & 5.7 & 19.0 \\
Nickel-63 $\left({ }^{63} \mathrm{Ni}\right)$ & 17.1 & 67.0 \\
Iodine-129 $\left({ }^{129} \mathrm{I}\right)$ & 40.0 & 150.0 \\
Carbon-14 $\left({ }^{14} \mathrm{C}\right)$ & 49.0 & 156.0 \\
Technetium-99 $\left({ }^{99} \mathrm{Tc}\right)$ & 85.0 & 293.0 \\
Niobium-94 $\left({ }^{94} \mathrm{Nb}\right)$ & 156.0 & 500.0 \\
Iodine-131 $\left({ }^{131} \mathrm{I}\right)$ & 180.0 & $806.0^{\mathrm{c}}$ \\
Cesium-137 $\left({ }^{137} \mathrm{Cs}\right)$ & 195.0 & 1176.0 \\
Potassium-40 $\left({ }^{40} \mathrm{~K}\right)$ & 541.0 & 1330.0 \\
Phosphorous-32 $\left({ }^{32} \mathrm{P}\right)$ & 694.0 & 1710.0
\end{tabular}

a. $1000 \mathrm{keV}=1 \mathrm{MeV}$ (million electron volts). Beta particle energy unless otherwise noted.

b. The data for ${ }^{59} \mathrm{Ni}$ represent Auger electrons and not electrons emitted from the nucleus (i.e., beta particles). The maximum electron energy was estimated based on the assumption that an electron from the cobalt-59 $\left({ }^{59} \mathrm{Co}\right)$ atom (e.g., the daughter product from ${ }^{59} \mathrm{Ni}$ decay) absorbs a maximum energy $\mathrm{x}$-ray.

c. $90.4 \%$ of the beta particle intensity for iodine- $131\left({ }^{131} \mathrm{I}\right)$ occurs at $606 \mathrm{keV}$, and only $0.6 \%$ occurs at $806 \mathrm{keV}$.

Niobium forms an oxide coating in most acid environments, which provides excellent protection against acid attack, especially for nitric and hydrochloric acids. However, hydrofluoric acid and strong alkaline solutions can attack niobium severely. At elevated temperatures, the metal reacts with halogens, oxygen, nitrogen, carbon, hydrogen, and sulfur. It forms high-melting-point compounds with light elements such as carbon, boron, silicon, and nitrogen.

The mechanical properties of niobium are very dependent on the purity of the metal. Often, hightemperature strength is compromised by other alloying materials that are added for increased fabricability. Niobium and its alloys are readily machined; the characteristics of machining vary in ease from those of copper to those of stainless steel. However, special attention should be paid to lubrication to avoid galling. Niobium and its alloys are easily forged, rolled, or otherwise worked directly from ingots at room temperature.

Niobium typically forms compounds with an oxidation state of +5 . Its most common oxide is $\mathrm{Nb}_{2} \mathrm{O}_{5}$, which is produced by heating the metal in an oxygen environment. This oxide forms a white 
powder, which is a dense, relatively inert substance. The oxide dissolves readily in concentrated alkali, but does not appreciably dissolve in common acids such as nitric or hydrochloric acids. ${ }^{13}$ Dissolving the oxide in acids can produce compounds with halogens such as fluorine and chlorine. Again, the most common halides are formed with niobium in an oxidation state of +5 . The resulting fluorides are volatile white solids. Other halides, such as iodine and chlorine, form yellow to brown or purple-red solids by direct reaction of the metal with excess halogen. Reduction of this oxide by hydrogen results in oxides with lower oxidation states, such as $\mathrm{NbO}_{2}$ and $\mathrm{NbO}$.

Table 11-5 summarizes some of the chemical and physical characteristics of the element.

\section{Niobium-94 Production}

The structural materials inside the reactor vessel of a nuclear power plant are exposed to neutron radiation. This radiation can cause many components of these materials to become radioactive with time via neutron activation. Those elements most susceptible to neutron activation are iron, nickel, and cobalt, found primarily in stainless steel and other important alloys (e.g., Inconel). Depending upon the amount of time these materials are irradiated and the integrated neutron flux, any of these nuclides may become the critical activation product affecting the dismantling activities of the reactor.

Though not a principal structural material based on total mass, niobium does form an important constituent of some materials, especially stainless steels and Inconels. Typical amounts of niobium in stainless steel range from a few to as much as several hundred parts per million (ppm) mass. The amount of niobium in Inconels can be as high as a few percent. ${ }^{14,15}$

Table 11-5. Chemical and physical characteristics of niobium. Obtained from References 7, 8, 16, and 17.

\begin{tabular}{ll}
\hline $\begin{array}{c}\text { Physical property } \\
\text { (units) }\end{array}$ & Niobium data \\
\hline Melting point $(\mathrm{K})^{\mathrm{a}}$ & 2,741 \\
Boiling point $(\mathrm{K})^{\mathrm{a}}$ & 5,200 \\
Solid density & 8.6 \\
$\left(\mathrm{~g} / \mathrm{cm}^{3}\right)$ & \\
Crystal form & Body-centered cubic
\end{tabular}

a. Note that zero Kelvin equals $-273.15^{\circ} \mathrm{C}$ and $-459.67^{\circ} \mathrm{F}$. 
The principal means of producing ${ }^{94} \mathrm{Nb}$ is through neutron capture of ${ }^{93} \mathrm{Nb}$, the only stable isotope of niobium. The total niobium mass is relatively small. However, because ${ }^{93} \mathrm{Nb}$ constitutes the only stable isotope, all of the niobium mass is available for activation, which increases the total amount of ${ }^{94} \mathrm{Nb}$ that can be produced.

Based on the mass number for ${ }^{94} \mathrm{Nb}$, one might suppose that nuclear fission would also be a major source of this nuclide, as illustrated in Figure 11-1, which shows the fission yield for uranium-235 $\left({ }^{235} \mathrm{U}\right)$. This figure shows that mass number 94 is near the maximum yield for fission products. However, when ${ }^{235} \mathrm{U}$ fissions, the fission products are produced with a large number of excess neutrons and usually decay, via beta-decay, to stable isotopes. For mass number 94, a typical fission product is bromine-94 $\left({ }^{94} \mathrm{Br}\right.$ ), which comprises $3.2 \%$ of all fission products (or $6.4 \%$ on Figure 11-1). As this fission product beta-decays, it will eventually transmute into zirconium-94 $\left({ }^{94} \mathrm{Zr}\right)$. However, ${ }^{94} \mathrm{Zr}$ is a stable isotope and does not decay to ${ }^{94} \mathrm{Nb}$. Therefore, essentially no ${ }^{94} \mathrm{Nb}$ is produced by fissioning and ${ }^{93} \mathrm{Nb}$ is principally produced by neutron activation. This information was obtained from the fission yield data from the ORIGEN2 ${ }^{18}$ computer code cross-section data.

Because ${ }^{94} \mathrm{Nb}$ atoms do not readily absorb thermal neutrons, and because niobium comprises only a small fraction of the total structural mass in a nuclear reactor, it generally takes many years of neutron irradiation to produce a significant quantity of ${ }^{94} \mathrm{Nb}$. However, ${ }^{94} \mathrm{Nb}$ has a half-life that is much longer

Fission yield from thermal fission of $U-235$

(Total fission yield summed over all mass numbers $=200 \%$ )

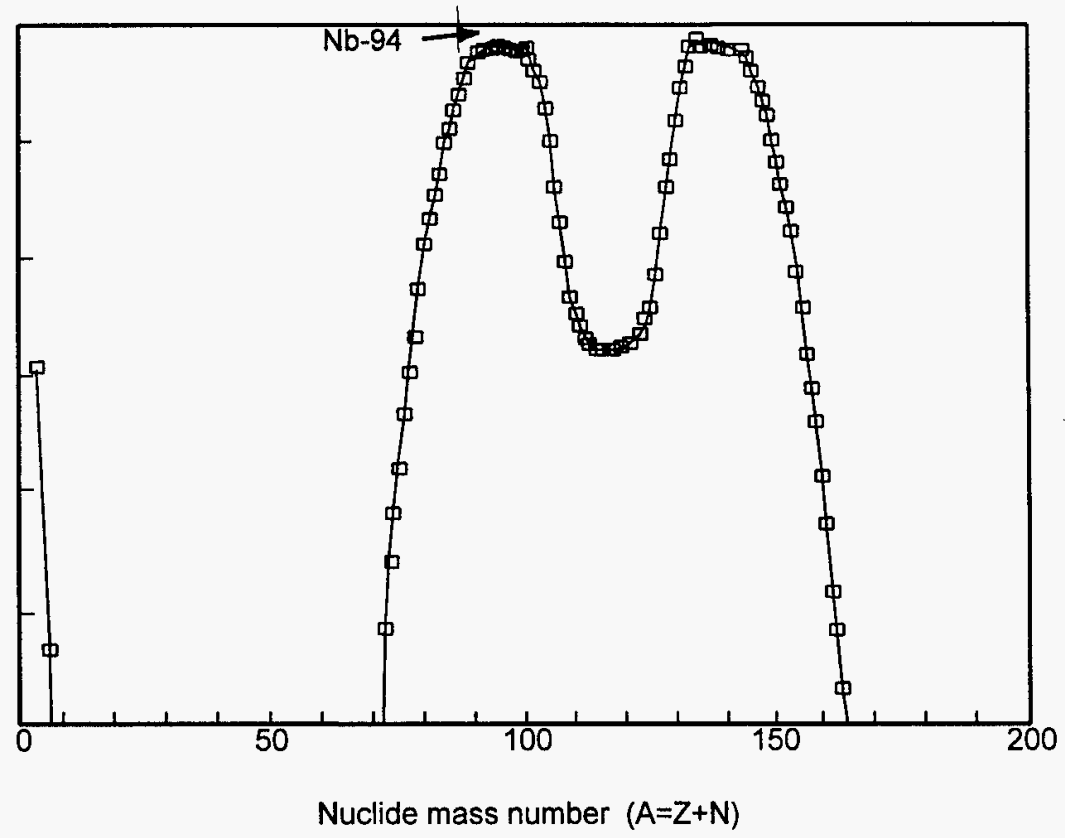

Figure 11-1. Fission product yield curve for thermal fission of ${ }^{235} \mathrm{U}$. Note that the total fission yield summed over all mass numbers is $200 \%$ since a single fission event results in two fission products.

than the normal life of a nuclear reactor (e.g., 20,000 years versus $\sim 30$ years for most reactors). Therefore, essentially all of the ${ }^{94} \mathrm{Nb}$ that is produced within the reactor structure remains with the reactor 
until it is dismantled. A small fraction of ${ }^{94} \mathrm{Nb}$ can be released from the corrosion of structural components and transported to other sites via the reactor coolant system. In other words, the ${ }^{94} \mathrm{Nb}$ inventory increases linearly with reactor operation and does not significantly decrease with time. Figure 11-2 shows the buildup of several different activation products in a presssurized water reactor (PWR) vessel, including ${ }^{63} \mathrm{Ni},{ }^{59} \mathrm{Ni},{ }^{94} \mathrm{Nb}$, and ${ }^{60} \mathrm{Co}$, as a function of reactor operation. The data in Figure 11-2 were normalized to 1 at 30 years and do not reflect absolute activities.

There are two groups in Figure 11-2: those that build up relatively rapidly and reach a saturated condition, such as ${ }^{60} \mathrm{Co}$ and iron-55 $\left({ }^{55} \mathrm{Fe}\right)$; and those, whose half-lives are long compared with the relevant reactor lifetime, that never reach saturated conditions, such as ${ }^{94} \mathrm{Nb}$ and ${ }^{63} \mathrm{Ni}$. Significantly, the nuclides in the first category also tend to decay more rapidly. In fact, after 100 years subsequent to reactor shutdown, these nuclides have effectively disappeared from the structural materials and ${ }^{94} \mathrm{Nb}$ represents the principal potential contributor to personnel exposure. ${ }^{14}$ Once this condition has been established, ${ }^{94} \mathrm{Nb}$ remains the dominant gamma-emitting nuclide for any time scale of human interest.

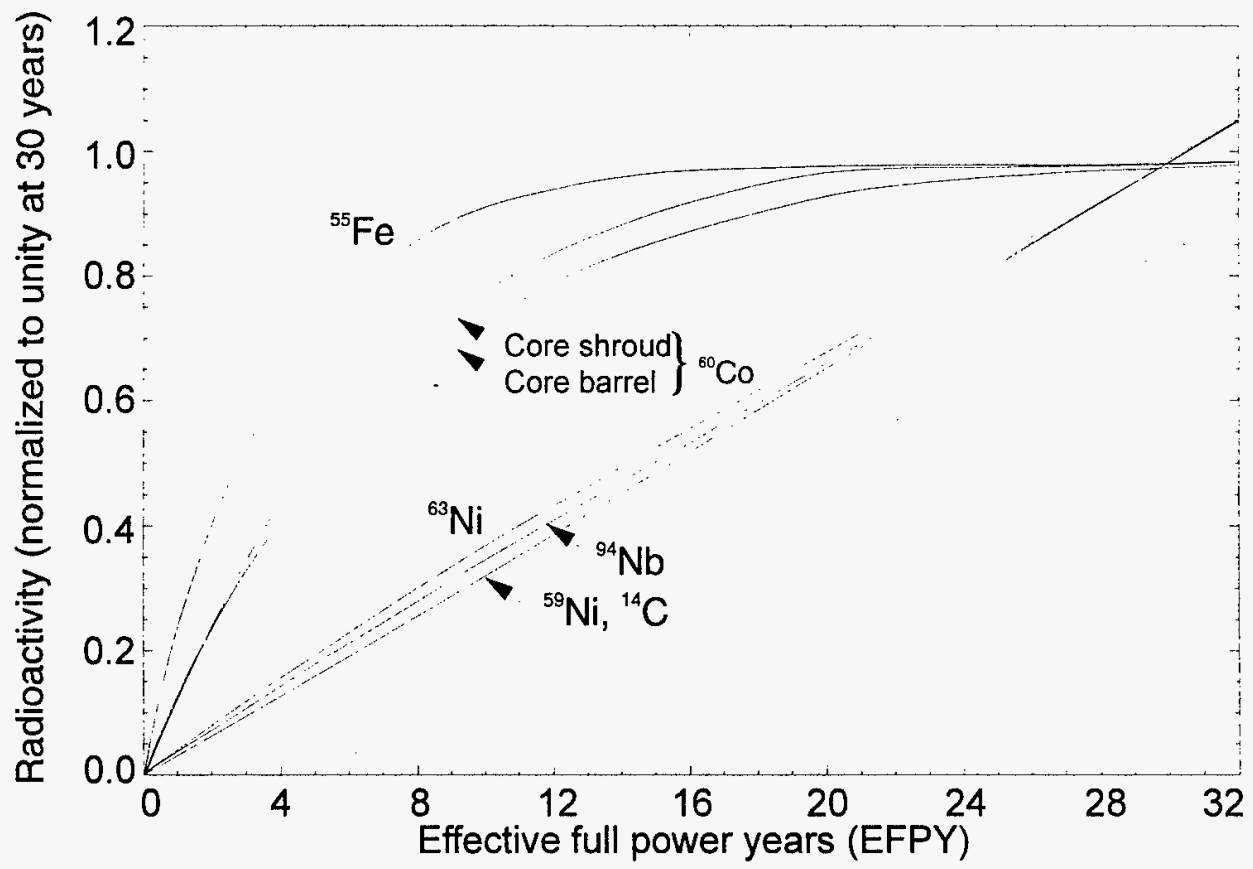

Figure 11-2. Buildup of some important activation products in a PWR as a function of reactor operation. Note that the lowest curve from 0 to $\sim 30$ years represents ${ }^{59} \mathrm{Ni}$, and the second lowest curve from 0 to $\sim 30$ years is ${ }^{94} \mathrm{Nb}$. (Obtained from References 19 and 20.)

\section{Waste and Disposal Data on Niobium-94}

This section discusses the types of activities that generate ${ }^{94} \mathrm{Nb}$ LLW, waste types and forms that contain ${ }^{94} \mathrm{Nb}$, and disposal data on ${ }^{94} \mathrm{Nb}$.

\section{Nuclear Reactors}

The quantity of ${ }^{94} \mathrm{Nb}$ generated within the structural components of a nuclear reactor increases linearly with burnup; that is, double the reactor operation and the ${ }^{94} \mathrm{Nb}$ inventory doubles. Because the half-life of ${ }^{94} \mathrm{Nb}$ is much longer than the life of the reactor $\left(T_{1 / 2}=20,000\right.$ years versus 30 -year lifetime for 
a reactor) no process effectively decreases the ${ }^{94} \mathrm{Nb}$ inventory over the reactor's useful lifetime. If decommissioning is delayed for several decades after reactor shutdown, the residual gamma flux may be dominated by ${ }^{94} \mathrm{Nb}$.

The NRC has adopted formal guidelines for classification of waste for shallow-land disposal of radioactive waste. ${ }^{21}$ These guidelines specify three different class definitions, with increasing activity inventory limits and commensurately increasing disposal requirements. Class $\mathrm{C}$ is the classification with the highest inventory limits, allowing $0.2 \mathrm{Ci} / \mathrm{m}^{3}$ inventory for ${ }^{94} \mathrm{Nb}$. (The lowest classification, Class $\mathrm{A}$, allows only $0.02 \mathrm{Ci} / \mathrm{m}^{3}$ inventory for ${ }^{94} \mathrm{Nb}$.) Radioactive waste with inventories exceeding the Class $\mathrm{C}$ limits cannot be placed in a shallow-land disposal without specific authorization by the NRC.

The Department of Energy has published a program document, DOE/LLW-114, that includes information concerning the difficulty of measuring some nuclides that are very important for waste classification from nuclear power plants. ${ }^{22}$ Most of the total activity in activated reactor parts results from short-lived nuclides such as ${ }^{60} \mathrm{Co}$ (a gamma emitter) and ${ }^{55} \mathrm{Fe}$ (a beta emitter). However, because these are short-lived, the waste disposal classification for these parts is dominated by longer-lived nuclides, primarily ${ }^{63} \mathrm{Ni}$ and ${ }^{94} \mathrm{Nb}$. Because of the high background radiation caused by the presence of the short-lived nuclides, it is very difficult to measure these latter nuclides. Therefore, in most cases, the inventories of the long-lived nuclides are correlated with the inventories of the more dominant nuclides, usually ${ }^{60} \mathrm{Co}$. Measurements that determine ${ }^{60} \mathrm{Co}$ content are then used in conjunction with scaling factors to estimate the activities of ${ }^{59} \mathrm{Ni},{ }^{63} \mathrm{Ni}$, and ${ }^{94} \mathrm{Nb}$. This technique introduces uncertainties in the expected amount of ${ }^{94} \mathrm{Nb}$ because of the uncertainties associated with the amounts of ${ }^{93} \mathrm{Nb}$ in the various stainless steels and Inconels in the reactors. For example, the actual quantity of $\mathrm{Nb}$ in a given component can vary by as much as $\pm 50 \%$ from the value used in the analysis.

Reference 14 documents a study of the activities of several activation products in nuclear reactors, including ${ }^{94} \mathrm{Nb}$. This reference includes both theoretical and experimental results. The experimental results were based on analysis of samples from eight reactors. The measured activities were less than 1 $\mu \mathrm{Ci} / \mathrm{g}$ for stainless steels but up to $60 \mu \mathrm{Ci} / \mathrm{g}$ for Inconel. This study also included analysis of concrete samples for activation products. While ${ }^{94} \mathrm{Nb}$ was found in measurable amounts, its contribution to the overall activity was relatively small. One interesting conclusion of this chapter is that while most of the samples resulted in activities close to calculated values, one specific datum was considerably higher than calculated. This sample was from the core of a reactor where there is a large flux of epithermal neutrons (neutrons that have not yet been slowed down to thermal energies). Stable niobium $\left({ }^{93} \mathrm{Nb}\right.$ ) has a relatively high probability for absorption of these more energetic neutrons (a phenomena known as "resonance" absorption), and small uncertainties in the epithermal neutron flux can result in large errors in the calculated absorption.

Reference 23 documents a study of the nature of the radioactive contamination and distribution expected to be encountered during light water power reactor decommissioning. A principal conclusion of this study is that ${ }^{94} \mathrm{Nb}$ and ${ }^{63} \mathrm{Ni}$ concentrations in Inconel and stainless steel components in these components exceed Class C LLW limits for shallow-land burial and are the radionuclides that determine waste-class for these components (for many samples, ${ }^{94} \mathrm{Nb}$ and ${ }^{63} \mathrm{Ni}$ were the only radionuclides that exceeded the Class $\mathrm{C}$ limits). In fact, for some samples, the ${ }^{94} \mathrm{Nb}$ activity levels exceeded the Class $\mathrm{C}$ limits by a factor of several hundred to several thousand, especially for fuel assembly hardware and grids and springs in the core. The highest ${ }^{94} \mathrm{Nb}$ levels were measured in PWR components. The levels in boiling-water reactor (BWR) components were much lower, but did exceed the Class $\mathrm{C}$ limits for some fuel assembly parts. Separate studies also concluded that some of the stainless steel reactor vessel components are expected to exceed the Class $\mathrm{C}$ waste limits for ${ }^{94} \mathrm{Nb}$ (as well as those limits for ${ }^{59} \mathrm{Ni}$ and $\left.{ }^{63} \mathrm{Ni}\right) \cdot{ }^{24,25,26,27}$ 
LLW usually contains small quantities of fission products or activation products, including ${ }^{94} \mathrm{Nb}$. During the operation of a light-water reactor, oxide corrosion films form on the surfaces of piping, pumps, valves, steam generator tubing, and many other components in contact with the primary coolant. Some of these corrosion products dissolve or erode in the circulating coolant, are deposited on the fuel cladding, and become activated by the neutron flux. The principal radionuclides formed by this activation process are ${ }^{58} \mathrm{Co},{ }^{60} \mathrm{Co},{ }^{55} \mathrm{Fe},{ }^{59} \mathrm{Fe}$, manganese-54 $\left({ }^{54} \mathrm{Mn}\right)$, chromium-51 $\left({ }^{51} \mathrm{Cr}\right),{ }^{65} \mathrm{Zn}$, ${ }^{63} \mathrm{Ni}$, and ${ }^{94} \mathrm{Nb}$. These radionuclides are eventually released from the core region of the reactor and are carried by the coolant and incorporated into oxide films on the surfaces of the primary coolant system (PCS) components. ${ }^{28}$ The primary waste types that can contain radionuclides produced as a result of nuclear reactor operations are contaminated scrub water and decontamination solutions; contaminated clothing; contaminated tools and equipment used in radioactive areas; pumps, valves, seals, bearings, and scrap materials; ion-exchange resins; and filters. However, none of these waste types contain radiologically significant quantities of ${ }^{94} \mathrm{Nb}$. Only very small quantities of ${ }^{94} \mathrm{Nb}$ are found in the primary coolant system of operating reactors. This small amount results from activation of suspended metals or other substances. Most of the niobium in reactor systems is found in Inconel structures, which are very corrosion resistant. The equipment and systems used to clean this water will contain much higher concentrations of ${ }^{94} \mathrm{Nb}$, as well as other radionuclides. The types of safeguards to be used in the disposal of decommissioned reactor parts and the long-term safety of the disposal of these parts are dictated by th. $E$ amount of radionuclides, including ${ }^{94} \mathrm{Nb}$, contained in the parts. In some cases, ${ }^{94} \mathrm{Nb}$ may be the limiting radionuclide that determines handling and storage requirements. ${ }^{14}$

The primary LLW containing ${ }^{94} \mathrm{Nb}$ are solid waste forms produced by activation of structural materials, mainly Inconel and, to a lesser extent, stainless steel components. When these components are decommissioned and dismantled, LLWs are produced that contain ${ }^{94} \mathrm{Nb}$. For example, it is possible that structural components from decommissioned nuclear power plants will be melted down for recycling. Especially if the reactor contained Inconel structures, residual amounts of ${ }^{94} \mathrm{Nb}$ will either end up in new structures or, more probably, be processed out of the metals and enter the waste stream. Depending on the mode of reprocessing, the ${ }^{94} \mathrm{Nb}$ could take either the elemental form or become an oxide or halide. The exact form would depend on the processing procedure.

One study investigated the presence of ${ }^{94} \mathrm{Nb}$ in corrosion films deposited on the insides of pipes in nuclear power plants. ${ }^{29}$ In this study, samples of corrosion product depositions were taken from the insides of pipes exposed to reactor coolant in several pressurized and BWRs. Though ${ }^{94} \mathrm{Nb}$ was measured in several of the samples, the concentration range was very low, from $<1.2 \times 10^{-5}$ to $5.0 \times 10^{-4} \mu \mathrm{Ci} / \mathrm{cm}^{2}$. These concentrations were very small compared with the principal corrosion product constituents such as ${ }^{60} \mathrm{Co}$ and ${ }^{63} \mathrm{Ni}$. The ${ }^{94} \mathrm{Nb}$ concentrations measured in this study were much lower than the Class A shallow-land burial criterion for this nuclide. This study indicated that ${ }^{60} \mathrm{Co},{ }^{55} \mathrm{Fe},{ }^{63} \mathrm{Ni}$, and ${ }^{137} \mathrm{Cs}$ were the most abundant radionuclides associated with the contaminated piping, hardware, and concrete for up to 20 years after reactor shutdown.

\section{Medical, Academic Institutions, and Commercial Niobium-94 Waste}

Because ${ }^{94} \mathrm{Nb}$ has such a long half-life (compared with most radioactive applications), it is unlikely that this nuclide would be injected or ingested for either medical diagnosis or treatment. The relatively strong gamma ray emission ( 700 and $870 \mathrm{keV}$ ), together with the long half-life, could make it an ideal external radiation source for medical treatment. However, personnel at the American College of Radiologists stated that ${ }^{94} \mathrm{Nb}$ is not used either for the diagnosis of disease or for medical treatments. ${ }^{1}$

a. Private communication between C. Sperry (ACR) and J. Adams (INEL) on January 26, 1995. 
This nuclide is used in laboratory work and is included in Reference 30, which is a list of certified reference materials of radioactivity. ${ }^{94} \mathrm{Nb}$ is available from the National Bureau of Standards, Office of Standard Reference Materials in activities ranging from 0.1 to $0.2 \mu \mathrm{Ci}$. These sources are packaged in aluminum/plastic cases. Because of the long half-life, the sources will not decay within a human time scale.

\section{Disposal Data on Niobium-94}

${ }^{94} \mathrm{Nb}$ has been deposited in three LLW sites in Richland, Washington; Barnwell, South Carolina; and Beatty, Nevada over a period of several years. Data have been obtained on this nuclide from the Manifest Information Management System Database. ${ }^{2}$ Figure 11-3 shows the total annual ${ }^{94} \mathrm{Nb}$ activity deposited in the three sites for each year between 1986 and 1995 . Nearly $80 \%$ of the total activity for this nuclide was deposited in $1989 .{ }^{94} \mathrm{Nb}$ was deposited approximately uniformly during the other years.

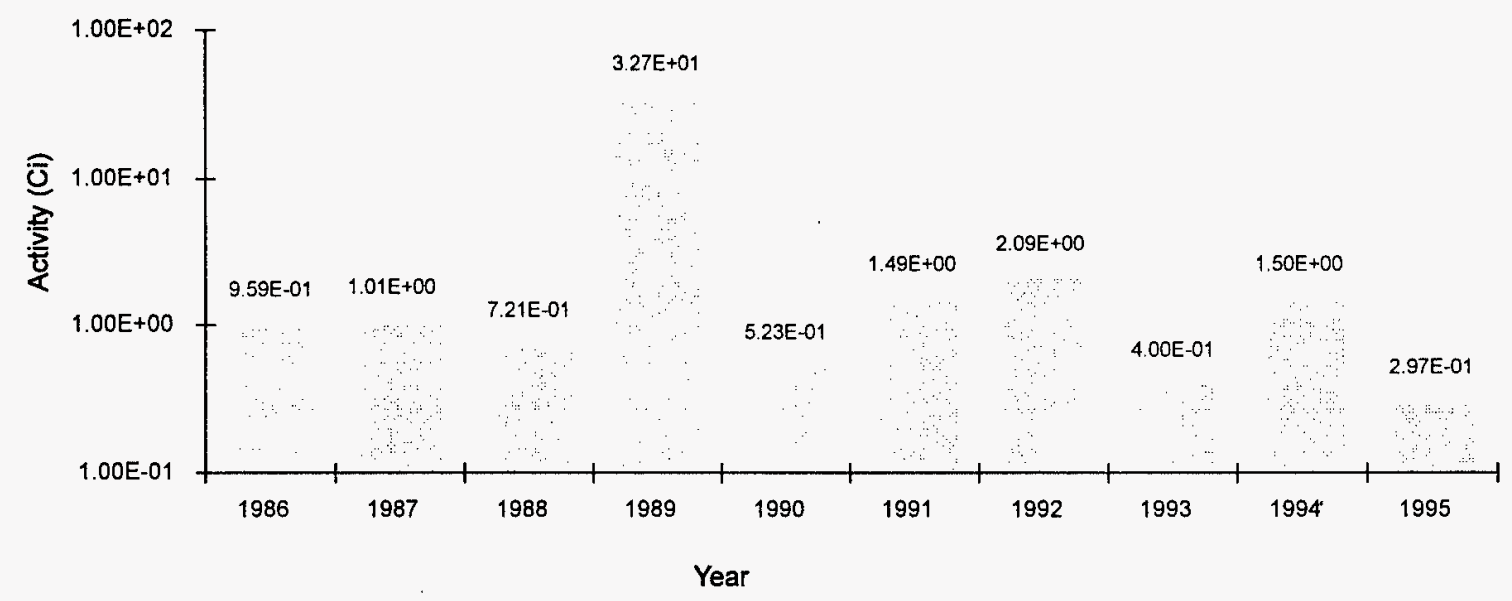

Figure 11-3. ${ }^{94} \mathrm{Nb}$ activity deposited at the Richland, Beatty, and Barnwell sites by year (log scale).

Figure 11-4 shows the activity of ${ }^{94} \mathrm{Nb}$ deposited in these three sites as a function of waste source. Utility sources account for more than $99 \%$ of the total deposited in these three sites. The definition of disposal categories given in Figure 11-4 is as follows: academic - sources associated with university laboratories; government - sources associated with the government, such as military hospitals; industry sources associated with manufacturing, other than utilities; medical - sources associated with hospitals and medical laboratories, excluding pharmaceutical manufacturing; utility - sources generated by nuclear utilities and deposited onsite or sent to one of the three disposal sites. Waste treatment facilities are included in the utility category.

b. Information provided through the DOE waste management system maintained by the National Low-Level Waste Management Program, Idaho National Engineering Laboratory (INEL). 
Figure 11-5 shows the activity of ${ }^{94} \mathrm{Nb}$ deposited in the Richland and Beatty sites as a function of

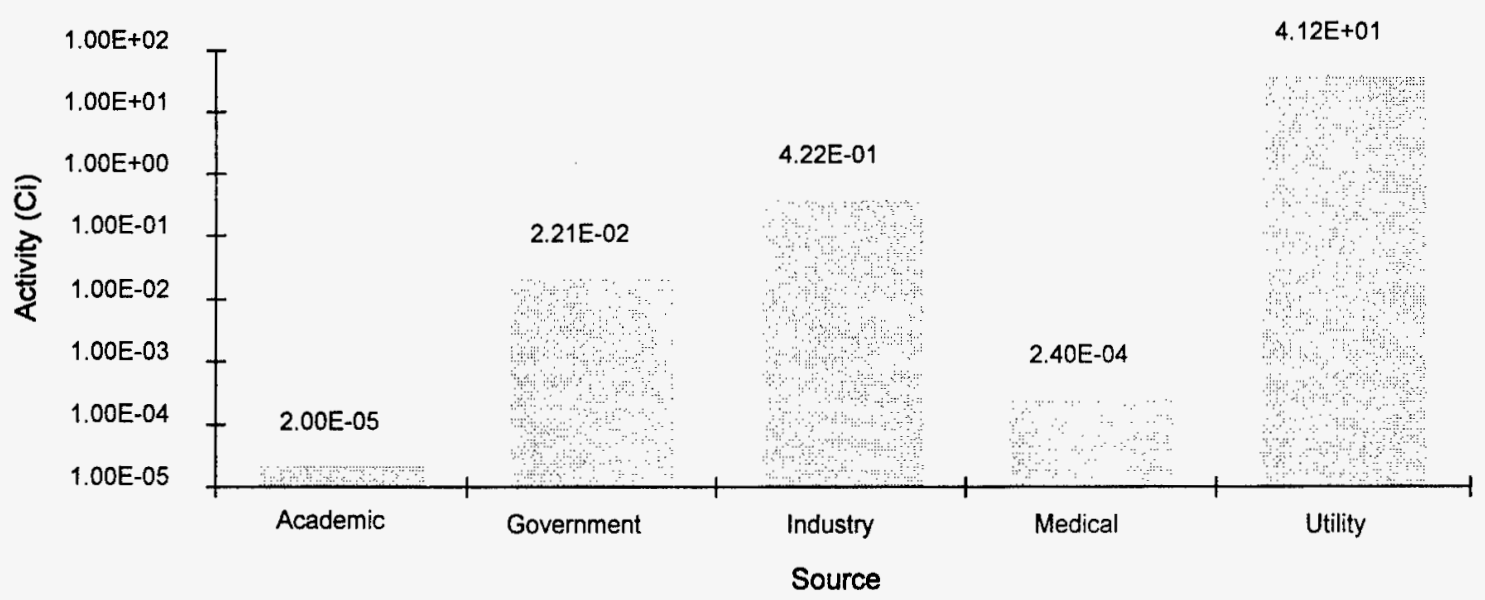

Figure 11-4. ${ }^{94} \mathrm{Nb}$ activity deposited at the Richland, Beatty, and Barnwell sites by source (log scale).

waste type. The waste disposal manifests for the Barnwell site did not break down the waste by type, which is unfortunate since more than $98 \%$ of this nuclide has been deposited at this site. As shown in this figure, more than $80 \%$ of this nuclide was in the form of activated reactor hardware and dewatered resins. The waste types illustrated in Figure 11-5 are from nuclear reactors, academic institutions, and medical facilities.

\section{Behavior of Niobium-94 in the Environment}

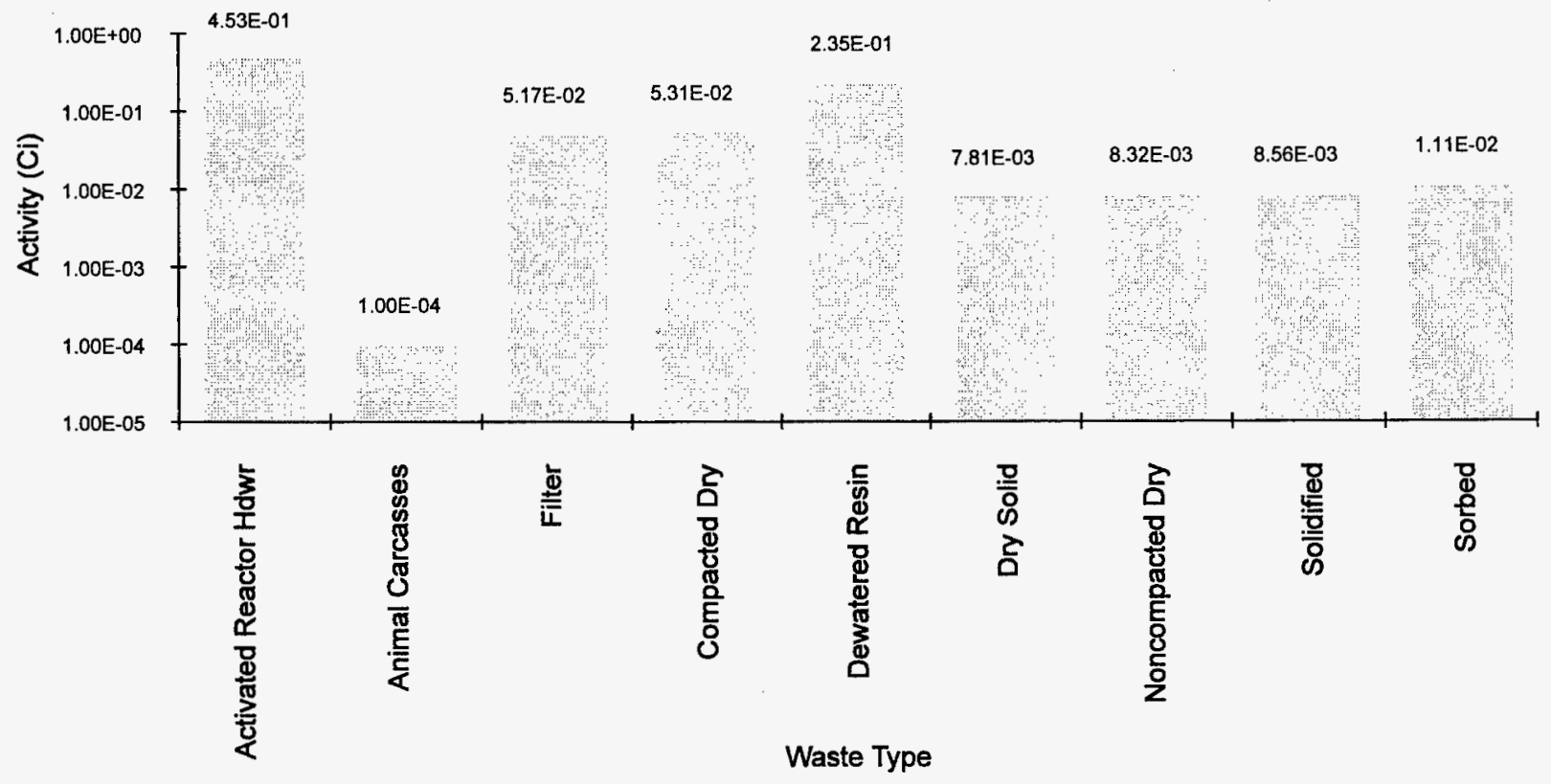

Figure 11-5. ${ }^{94} \mathrm{Nb}$ activity deposited at the Richland and Beatty sites by waste type (log scale). 


\section{Niobium-94 in Soils}

Understanding the behavior of radioactive materials such as ${ }^{94} \mathrm{Nb}$ in the soil is important in assessing the possibility of transport of these radionuclides through the biosphere. ${ }^{31}$ It is important to understand the interactions between radionuclides and various media along the path to the biosphere, whether disposal is in deep or shallow rock caverns or in shallow overburden facilities.

Four parameters were reported to be essential in accurately predicting soil concentrations from either contaminated ground water or irrigation water. ${ }^{31}$ The four parameters, in order of decreasing importance, are (a) soil retention, (b) annual precipitation, (c) soil texture, and (d) depth to the water table. The soil retention parameter represents the solid/liquid partition coefficient and is denoted by the symbol, $K_{d} . K_{d}$ is defined by $K_{d}=C_{s} / C_{l}$, where $C_{s}$ is the niobium concentration in the soil $(\mu \mathrm{g} \mathrm{Nb} / \mathrm{g}$ of soil) and $C_{l}$ is the niobium concentration in the groundwater ( $\mu \mathrm{g} \mathrm{Nb} / \mathrm{mL}$ of liquid). Therefore, the units of $\mathrm{K}_{\mathrm{d}}$ are $\mathrm{mL} / \mathrm{g}$ (i.e., $\mathrm{mL}$ of water per gram of soil). This empirical model combines all soil retention mechanisms into a simple linear partition relation between the soil and the surrounding groundwater. This model assumes that the niobium concentrations in groundwater and soil are in equilibrium with each other. Using this definition for $\mathrm{K}_{\mathrm{d}}$, it follows that the larger the value (that is, the higher the radionuclide concentration in the soil relative to that in the groundwater) the slower the migration of the radionuclide relative to groundwater flow. Therefore, $K_{d}$ can be thought of as a measure of the amount of "fixing" or holdup in the soil.

Typically, $\mathrm{K}_{\mathrm{d}}$ is measured under laboratory conditions with samples that are relatively homogenous and where it can be ensured that equilibrium conditions are met. Applying these values to specific soils in the field can be difficult because actual soils are generally nonhomogeneous and there are uncertainties as to how long it takes for the niobium concentrations in the soil and groundwater $\left(\mathrm{C}_{\mathrm{s}}\right.$ and $\mathrm{C}_{1}$ ) to reach equilibrium with each other. Therefore, one must be careful to ensure that soil samples used in laboratory studies are as closely representative of the field as possible. Even though the soil samples do not precisely match conditions in the field, $\mathrm{K}_{\mathrm{d}}$ values from laboratory studies can be used in computer models that extrapolate data from laboratory experiments and field studies. In addition, some experiments are conducted using intact field samples to validate the laboratory $K_{d}$ values and to study the effects associated with soil nonhomogeneity.

An experimental study of $\mathrm{K}_{\mathrm{d}}$ values for niobium in an oxalate complex and in various rock forms was performed in Sweden. ${ }^{32}$ The results from this study indicated a range of $K_{d}$ from $8-11 \mathrm{~m}^{3} / \mathrm{kg}$.

Niobium occurs naturally in many soils. In fact, on an elemental basis, the naturally occurring forms of niobium can be much more prevalent than the trace amounts of ${ }^{94} \mathrm{Nb}$ found in typical waste types. ${ }^{33}$ In a study of surface soil samples from Bull Island, South Carolina, the typical range for naturally occurring niobium concentrations in soils was measured to be from $<2$ to $7 \mathrm{ppm}^{34}$ In a similar study of Polish soils, the baseline concentrations of several elements, including niobium, were measured in approximately 130 representative samples of arable soils. ${ }^{35}$ Areas of expected pollution were avoided. The measured average concentration of niobium was $3.2 \mathrm{mg} / \mathrm{kg}$, which was significantly smaller than all of the other elements except beryllium and arsenic. All elements included in this study had significantly higher concentrations in silty and loamy soils than in sandy soils. These concentrations are much lower than many other constituents. For example, the aluminum and potassium concentrations in the same samples ranged from 930,000 to $1,700,000$ and from 330,000 to $840,000 \mathrm{ppm}$, respectively.

Reference 36 lists niobium concentrations in various soil types as igneous rocks $-20 \mu \mathrm{g} / \mathrm{g}$; shales $-11 \mu \mathrm{g} / \mathrm{g}$; sandstones- $-0.05 \mu \mathrm{g} / \mathrm{g}$; and limestones $-0.30 \mu \mathrm{g} / \mathrm{g}$. Concentrations, either expected or actual, for radionuclides, including ${ }^{94} \mathrm{Nb}$, are much lower. 
A water-saturated soil system with a relatively high organic content in the presence of buried waste nuclides could lead to effective complex formation and increased solubility and mobility of the buried waste nuclides. Some of these organic complexing agents include EDTA, DTPA, NTA, HEDTA, and organic acids that are used in laboratories for processing and decontaminating radioactivity. These conditions may enhance the mobility of nuclides because of complex formation with organics, which in turn may be a dominant mechanism of nuclide transportation in soils and groundwater. For example, the organic molecules can bond very strongly with the nuclide and form a variety of charged and uncharged complexed species. Uncharged and negatively charged complexes will tend not to be attached to negatively charged soil sites, and positively charged complexes will not attach to positively charged soil sites. In any case, these complexes will be transported more easily through the soil with the groundwater than would have been the case if the nuclide were not complexed.

For this reason, the U.S. Department of Energy commissioned the Pacific Northwest Laboratory to study the effects of complex formation on the mobility of various nuclides. ${ }^{37}$ (Note: in this study, one of the radioactive isotopes of niobium, ${ }^{93 \mathrm{~m}} \mathrm{Nb}$, was used as a tracer. This nuclide has a much shorter halflife than ${ }^{94} \mathrm{Nb}$ and is, therefore, a more desirable nuclide to be used for such studies. However, because the study involved the chemistry of niobium, rather than the radioactivity or physics of this element, the results should be directly applicable to ${ }^{94} \mathrm{Nb}$.) EDTA and some of the organic acid complexes form the most stable complexes with niobium, while other organic acids, such as $\alpha$-hydroxy carboxylic acids, are less stable. Overall, however, and in the absence of extensive experimental data, Reference 37 predicts that the mobility of niobium is not significantly affected by any of these complexes (because interaction of the complexed niobium with water forms an insoluble hydrated form of niobium oxide, which precipitates out of the water and is fixed in the soil) and that niobium, either in elemental form or as a complex, would be readily adsorbed by soils and not travel very far with the groundwater.

The Savannah River Laboratory conducted experiments into the adsorption of niobium in soils, on behalf of the U.S. Atomic Energy Commission.$^{38}$ One should exercise care in interpreting the results from this study because the experimenters used a combination of zirconium and niobium in their tests (based, presumably, on the observation that ${ }^{95} \mathrm{Nb}$ is a decay daughter of ${ }^{95} \mathrm{Zr}$ and is often found in combination with it). However, zirconium and niobium chemistries are fairly similar (though by no means identical) because both are in the second transition series of the periodic table. The results from this study indicate that niobium is readily adsorbed in the soil, even when complexed with an oxalate ion, so long as the $\mathrm{pH}$ of the soil was in the range of 4 to 8 (this is the range studied and the results may still be true for $\mathrm{pH}>8$ ).

A more recent study also used the ${ }^{95} \mathrm{Zr}-{ }^{95} \mathrm{Nb}$ combination. This study, conducted by the University of Manchester in Great Britain, examined the desorption behavior of nuclides adsorbed onto silt. ${ }^{39}$ In this study, silt contaminated with radioactive waste from the Sellafield fuel reprocessing plant was used to study the desorption of the $\mathrm{Zr}-\mathrm{Nb}$ pair. Even though the chemistries of these two elements are similar, the study attempted to separate the desorption characteristics of the two. Various chemicals were used in an attempt to remove the niobium from the soil samples. Some of these chemicals successfully removed a significant amount of niobium, namely, oxalic acid, citric acid, and concentrated hydrochloric acid. The other chemicals were generally not successful, namely, water, potassium chloride, sodium phosphate tribasic, sodium fluoride, more dilute hydrochloric acid, sodium hydroxide, and concentrated nitric acid.

By contrast, one study was made of the mobility of radioactive niobium in the soil surrounding the Chernobyl Nuclear Power Plant. ${ }^{40}$ In this study, various stable and radioactive species were studied and their solubility and mobility in the soil samples were measured. For example, researchers concluded that radioactive cesium and strontium nuclides do not necessarily behave like their stable isotopes in that the radioactive nuclides tend to be more mobile, apparently because of the much larger concentrations of the 
stable isotopes in the soil and groundwater. The study did not include a similar conclusion regarding radioactive isotopes of niobium. However, ${ }^{95} \mathrm{Nb}$ was categorized as being as mobile as the radioactive cesium isotopes (actually lying between ${ }^{134} \mathrm{Cs}$ and ${ }^{137} \mathrm{Cs}$ ).

In summary, niobium will tend to become fixed in soils and not be significantly transported with the groundwater. There are some decontamination solutions that can alter this characteristic and cause the niobium to be more mobile, but most will not. There may be differences in soil mobility between radioactive and stable niobium isotopes.

\section{Niobium-94 in Water}

Niobium tends to be easily adsorbed by soils, removing it from groundwater. However, this may be dependent on a number of parameters, such as the groundwater $\mathrm{pH}$ and whether or not complexing agents are present. For example, in Savannah River silt, niobium preadsorbed in the soil could be complexed and removed from the soil by some agents but not others. ${ }^{38}$ Thus, the presence of complexing agents can significantly slow removal of niobium from groundwater.

A theoretical study was underwritten by Ontario Hydro to investigate the potential for onsite burial of decommissioned waste at a nuclear reactor site to contaminate groundwater. ${ }^{41}$ Specifically, this study involved an option to bury all radioactive waste associated with decommissioning the Bruce Nuclear Generating Station A nuclear power plants. The plan envisioned excavating 55-meter-deep pits for each of the four nuclear reactors, placing all contaminated primary components in the pits, backfilling the pits with the excavated rock plus concrete, and capping the pits. Assumptions regarding this analysis included no credit for the backfill in the pits (that is, the groundwater was assumed to be in immediate and intimate contact with the contaminated components) and conservatively high corrosion and leaching rates for the activation products. The principal sources for ${ }^{94} \mathrm{Nb}$ are the pressure and clandria tubes, which have a large initial inventory of stable zirconium and niobium. After leaching the ${ }^{94} \mathrm{Nb}$ from the tubes, the groundwater was assumed to transport the radioactivity to Lake Huron, where it would contaminate the water, fish, and crops irrigated by the lake. Transport to the lake was calculated to be 100 years after leaching from the components. The maximum dose to the public from ${ }^{94} \mathrm{Nb}$ was $2 \times 10^{-}$ ${ }^{8} \mathrm{~Sv} /$ year $\left(2 \times 10^{-6} \mathrm{rem} /\right.$ year $)$ and occurred 4,700 years after burial of the reactor components. This dose is insignificant compared with the allowable public dose rate of $5 \times 10^{-3} \mathrm{~Sv} /$ year $(0.5 \mathrm{rem} /$ year $)$.

A similar study was made of an underground rock repository currently being considered in Sweden. ${ }^{32}$ In this case, the activated and contaminated metal parts of a reactor would be buried in a deep tunnel excavated in granitic rock. The components would be encapsulated in concrete blocks, placed in the tunnels, and the tunnels would be backfilled by a bentonite/quartz mixture. Only the very long-lived radionuclides were included in the study, including carbon- $14\left({ }^{14} \mathrm{C}\right),{ }^{59} \mathrm{Ni},{ }^{63} \mathrm{Ni},{ }^{93} \mathrm{Zr} /{ }^{93 \mathrm{~m}} \mathrm{Nb}$, and ${ }^{94} \mathrm{Nb}$. Chemical effects were modeled, and it was concluded that in the groundwater, $\mathrm{Nb}$ would probably have oxidation states of either +3 or +5 . The formation of fluorides and niobates was also considered, and the solubility of the most probable chemical forms was modeled. Unlike the study in Reference 41, the diffusion of the niobium species through the concrete and bentonite/quartz was modeled, which resulted in a much longer release time from the tunnel. The shortest time to release all niobium into the groundwater is 400 million years. The best estimate time was more than four times longer. Even if the backfill material were somehow removed, the release time (from the tunnel into the groundwater) would be 200 million years (this is the best estimate; the most conservative [low] time is 40 million years). 
The Finnish nuclear power companies, Imatran Voima Oy and Teollisuuden Voima Oy, plan to dispose of their nuclear power plant components in repositories located near their respective power plant sites. In preparation for this, these companies commissioned a study of the behavior of activation products, ${ }^{59} \mathrm{Ni},{ }^{93} \mathrm{Zr}$, and ${ }^{94} \mathrm{Nb}$ in the cement/bentonite/crush-rock environment expected to exist surrounding the components. Specifically, the study was designed to estimate the most realistic solubilities of these nuclides in the environment and to calculate the rate of migration of the nuclides through this environment. The solubility and chemical speciation of these nuclides will be dependent on water $\mathrm{pH}$, solubility is expected to be lower for lower $\mathrm{pH}$. The results from the analysis indicate essentially no migration beyond the boundary of the repositories for at least 300,000 years.

In summary, the studies included in this chapter indicate that it would take from hundreds of thousands to hundreds of millions of years for niobium to be significantly leached from geologic repositories.

\section{Niobium-94 in Plants}

Most of the information regarding the behavior of niobium in plants consists of data regarding the uptake of this element from soil and groundwater into various types of vegetation. Reference 34 reports the investigation into the uptake of various elements from soil to plants in the Bull Island, South Carolina, Cape Romain National Wildlife Refuge. This study was commissioned by the U.S. Geological Survey as part of their responsibility to determine the effects of atmospheric pollutants in wildlife refuges through the U.S. Specifically, the researchers took soil samples and measured trace element contamination levels. They also took samples of two vegetation types, Spanish moss and loblolly pine, and measured their uptake of the soil constituents. Niobium was measured in 7 of the 16 soil samples with concentrations up to $7 \mathrm{ppm}$, which meant that a complete statistical analysis of the concentration could not be performed (because fewer than $70 \%$ of the samples contained measurable amounts of this element). Niobium was detected in 16 of the 38 Spanish moss samples and in 2 of the 59 loblolly pine needle samples with concentrations up to $0.58 \mathrm{ppm}$. The plants appeared to not have concentrated the niobium as they extracted it from the soil. This study used stable isotopes.

Another study also used stable isotopes. ${ }^{36}$ This study listed a transfer factor of 0.11 from soil to plants. Based on a comparison of uptake factors for zirconium and niobium, this study concluded that for the case of ${ }^{95} \mathrm{Zr} /{ }^{95} \mathrm{Nb}$ from soil to plants, the uptake would be dominated by the effects of the niobium, rather than the zirconium, nuclide. This study also indicated that of the niobium that is taken up into plants, approximately $10-15 \%$ is absorbed by the plant shoots and nearly one-half of this remains in the grain of cereals at harvest.

A similar study was performed of the uptake of fission products from underground nuclear explosions at the Nevada Test Site into the local grass. ${ }^{42}$ As previously stated, ${ }^{94} \mathrm{Nb}$ is not a fission product and this study did not include this particular niobium isotope. However, ${ }^{95} \mathrm{Nb}$ is a fission product (the daughter of ${ }^{95} \mathrm{Zr}$ ) and this nuclide was included. Care must be taken in applying the results from this study to ${ }^{94} \mathrm{Nb}$ because of the potential perturbing effects of the zirconium precursor. The results from this study are consistent with those of Reference 34 , in that the soil concentrations of niobium were 
larger than those in the plants, that is, there is no measurable concentrating effect. The niobium that was taken up into the plant tended to be distributed throughout the parts of the grass, though, on a mass basis, approximately twice as much niobium was found in the leaf as in the stem.

Following the Chernobyl reactor accident, a sampling program was instituted in Japan to monitor the fallout and uptake into the food chain. The results were documented in Reference 43. While trace amounts of radioactive niobium (specifically ${ }^{95} \mathrm{Nb}$, a fission product) were found in soil samples, none were measured in plants or the milk supply. Of course, conclusions based on this "preresult" are at best tenuous. At least, these results are consistent with other observations that niobium appears not to be concentrated to any significant degree by plants.

Finally, a study was made of the uptake of radioactive niobium into fruits and vegetables grown near Oak Ridge National Laboratory. ${ }^{44}$ In this study, the researchers obtained samples of 22 types of fruits and vegetables from local grocery stores and analyzed them for radionuclide and trace element compositions. The purpose of the study was to determine the effects of the operation of the Oak Ridge National Laboratory on the population in the vicinity of the lab. As in the Reference 42 study, the researchers measured the ${ }^{95} \mathrm{Nb}$ uptake so care should be taken in applying these results to ${ }^{94} \mathrm{Nb}$. Typical concentrations of ${ }^{95} \mathrm{Nb}$ in the fruits and vegetables were of the order of $10^{-15} \mathrm{Ci} / \mathrm{g}$. The ${ }^{95} \mathrm{Nb}$ concentrations tended to be fairly uniform, and no specific fruit or vegetable exhibited an obvious preference for this nuclide.

Reference 36 summarizes several studies into the uptake of niobium from water to aquatic plants. These studies indicate an uptake factor ranging from $0.01 \mu \mathrm{g} / \mathrm{g}$ for marine (ocean) plants to $0.8 \mu \mathrm{g} / \mathrm{g}$ for freshwater plants. However, these data should be used with caution because they are based on measurements involving the ${ }^{95} \mathrm{Zr} /{ }^{95} \mathrm{Nb}$ nuclide combination and the results may be influenced by the presence of the zirconium.

\section{Niobium-94 in Air}

Niobium isotopes (radioactive or nonradioactive) are not normally found in air, except possibly for small amounts generated and released following an atmospheric test of a thermonuclear weapon.

Radioactive ${ }^{94} \mathrm{Nb}$ is produced entirely as an activation product in the reactor structural components (e.g., ${ }^{93} \mathrm{Nb}(\mathrm{n}, \gamma) \rightarrow{ }^{94} \mathrm{Nb}$ ) and does not appear as a fission product radionuclide. Therefore, even if a severe core damage accident occurred in a nuclear reactor and released significant amounts of fission products, the result would not necessarily be the release of significant amounts of ${ }^{94} \mathrm{Nb}$ into the air.

The presence of ${ }^{95} \mathrm{Nb}$ in soil and plant samples in Malaysia has been reported as a result of nuclear fallout. ${ }^{45}$ However, this nuclide is a fission product, and ${ }^{94} \mathrm{Nb}$ is an activation product. Therefore, the presence of one does not necessarily imply the presence of the other. While the literature search represented in this study was not complete, no references were found that specifically addressed either the presence or behavior of ${ }^{94} \mathrm{Nb}$ in air. 


\section{Behavior of Niobium-94 in the Human Body and in Animals}

Radionuclides have been classified as to their relative toxicity in man. ${ }^{46}$ In this study, radionuclides are grouped into four classifications: very high toxicity, high toxicity, medium toxicity, and low toxicity. ${ }^{94} \mathrm{Nb}$ is included in the high toxicity group.

The biological hazard associated with a radionuclide can be characterized by the equivalent dose per unit exposure. The exposure can be by either external radiation (primarily from gamma rays, neutron flux, or both, or to a lesser extent, from beta rays if they are sufficiently energetic) or internal radiation (from ingestion or inhalation). Reference 47 lists the equivalent dose (Sv or rem) per unit exposure (Bq or $\mathrm{Ci}$ ) for the principal human organs of concern, gonad, breast, lung, red bone marrow, bone surface, thyroid, as well as the overall dose equivalent. For the case of ${ }^{94} \mathrm{Nb}$, the equivalent doses are all in the range of $10^{-9}$ to $10^{-10} \mathrm{~Sv} / \mathrm{Bq}(100$ to $1000 \mathrm{rem} / \mathrm{Ci})$. These doses are fairly uniform, that is, no one organ dominates the whole-body dose because niobium does not seem to concentrate in any single organ more than others, as opposed to iodine, which tends to concentrate in the thyroid. In addition, the dose values are fairly low, compared with ${ }^{137} \mathrm{Cs}$, for example, which has dose equivalents of the order of $10^{-8} \mathrm{~Sv} / \mathrm{Bq}$ $(10,000 \mathrm{rem} / \mathrm{Ci})$, also uniform across all listed organs.

Two independent means can remove any radionuclide from the human body. The first is radioactive decay, characterized by the radiological half-life, $T_{r}$, wherein the nuclide is transmuted into another nuclide. For the case of ${ }^{94} \mathrm{Nb}$, the other nuclide is molybdenum- $94\left({ }^{94} \mathrm{Mo}\right)$, which is a stable nuclide. After decay to ${ }^{94} \mathrm{Mo}$, no further biological hazard is expected because the concentration usually is too small for chemical effects to be present. The second means is by normal biological processes, such as exhalation (for airborne nuclides) and excretion (for ingested nuclides). This second process is quantified by the "biological half-life," $T_{b}$, which is a measure of the time for removal of one-half of the nuclide from the affected organ(s) and can differ for different body parts. The total removal rate is characterized by the effective half-life, $T_{e f f}$, which is defined by:

$T_{e f f}=\frac{T_{r} \times T_{b}}{T_{r}+T_{B}}$.

The following ${ }^{94} \mathrm{Nb}$ biological half-lives are given for various body parts: spleen-950 days; liver -845 days; kidneys -760 days; bone $-1,000$ days; and total body- -760 days. ${ }^{48}$ Thus, the radiological half-life for ${ }^{94} \mathrm{Nb}$ is much longer than any of the biological half-lives, and the only significant removal mechanism(s) is biological.

Studies summarized in Reference 49 indicate that inhalation is a major exposure route in humans. For this reason, deposition and retention of inhaled niobium aerosols $\left({ }^{95} \mathrm{Nb}\right)$ were studied in dogs. Although a nuclide other than ${ }^{94} \mathrm{Nb}$ was used in this study, the chemical processes would dominate the results and they should be applicable to ${ }^{94} \mathrm{Nb}$ as well. In this study, approximately one-half of the inhaled niobium (in aerosol form) was retained in the lungs, independent of whether an oxide or oxalate chemical form was used. For the oxide particles, most of the upper respiratory tract deposits were removed within a couple of days, and less than $1 \%$ were absorbed into the circulation system. The redistribution of the oxalate particles was very different. About one-half was excreted in urine or feces. The rest was deposited in the skeleton, liver, and other soft tissues. The lung was projected to receive the largest dose of all the body organs, but both the skeleton and kidneys were also identified as being potential organs of concern for radiation exposure from the inhaled niobium nuclides.

Reference 36 indicates that the fractional absorption of niobium from the gastrointestinal tract of 
adult animals is in the range of $0.05-1 \%$, with the best estimate of $0.2 \%$. In very young animals (that is, those that are still nursing), the fractional absorption is somewhat higher, on the order of $5 \%$. The results summarized in Reference 49 are consistent with this finding that young animals tend to retain more than mature ones. The highest retention was in the bone tissues, and the lowest retention, in the spleen for rats. The transfer from the body to the milk in lactating animals was not significant. Thus, it is probably justifiable to neglect milk as a route of exposure to ${ }^{94} \mathrm{Nb}$.

Reference 36 also summarizes the distribution of niobium in aquatic invertebrates. However, these results are based on measurements involving the ${ }^{95} \mathrm{Zr} /{ }^{95} \mathrm{Nb}$ nuclide combination and are suspect regarding conclusions for niobium. Therefore, they are not included in this chapter. The interested reader is referred to Section 4.2 .2 of Reference 36 for further details.

The uptake of several radionuclides by marine animals, prawns, mussels, and winkles was studied in the waters off the western coast of England, near the Sellafield nuclear reprocessing center ${ }^{50}$ Among the nuclides studied was ${ }^{95} \mathrm{Nb}$. No niobium was detected in the prawns. However, niobium was consistently measured in the mussels and winkels, primarily in the soft tissues, such as the viscera and gills.

The annual limits on ${ }^{94} \mathrm{Nb}$ intake (ALI) and the derived air concentration (DAC) for ${ }^{94} \mathrm{Nb}$ are shown in Table 11-6. The ALI is defined as that annual intake of a radionuclide that would result in a radiation dose to a man (for calculational purposes, the characteristics of the "Reference Man" are used) equal to the allowable limit. The DAC is defined as that concentration of a radionuclide in air which, if breathed for a work-year, would result in an intake corresponding to the ALI (or, in the case of submersion, to an external exposure corresponding to the primary guide for limiting annual dose). DACs are, thus, used for limiting radionuclide intake through the breathing of, or submersion in, contaminated air. ALIs are used primarily for assessing doses that result from accidental ingestion of radionuclides.

Historically, maximum permissible concentrations (MPC) in air and water have been used to determine safety guidelines for released radionuclide concentrations. Currently, the derived guidelines are presented in terms of ALIs for inhalation or ingestion and DACs for inhalation (or submersion). For a radionuclide whose derived value does not change from the old definition, the DAC is numerically equal to the MPC value in air. The information in Table 11-6 applies only to ${ }^{94} \mathrm{Nb}$. In the case of multiple radionuclides released in a mixture, additional guidelines outlined in Title 10 of the Code of Federal Regulations, ${ }^{51}$ Part 20 must be followed. 
Table 11-6. Annual limits on intake (ALI) and the derived air concentrations (DAC) for ${ }^{94} \mathrm{Nb}$ (data obtained from Reference 47).

\begin{tabular}{|c|c|c|c|}
\hline Radionuclide & Component & $\begin{array}{c}\text { Ingestion } \\
(\mu \mathrm{Ci})\end{array}$ & Inhalation $^{\mathrm{a}}$ \\
\hline \multirow[t]{2}{*}{${ }^{94} \mathrm{Nb}$} & ALI & $900^{b}$ & $\begin{array}{l}200 / \mathrm{W} \\
20 / \mathrm{Y}\end{array}$ \\
\hline & DAC & $-^{c}$ & $\begin{array}{l}8 \times 10^{-8} / \mathrm{W} \\
6 \times 10^{-9} / \mathrm{Y}\end{array}$ \\
\hline
\end{tabular}

a. Clearance from the lung directly to the blood stream or to the gastrointestinal (GI) tract depends upon the chemical form of the radionuclide and is classified as $\mathrm{D}, \mathrm{W}$, and $\mathrm{Y}$, respectively, for clearance times of the order of days, weeks, and years. For ${ }^{94} \mathrm{Nb}$, the two listed classifications are $\mathrm{Y}$ for oxides and hydroxides and $\mathrm{W}$ for all other compounds. $^{52}$

b. Removal class is $f^{1}=0.01$. A simple model of the lung was used to describe the translocation and retention of material by the body after inhalation. In this model, $25 \%$ of the inhaled activity was exhaled and $25 \%$ was deposited in the lower respiratory tract. The $50 \%$ that was deposited in the upper respiratory tract was eventually cleared by means of mucociliary processes and swallowed. What happens then depends on whether the inhaled material was in either a soluble or insoluble chemical form. Any soluble material deposited in the lower respiratory tract is assumed to be transferred directly to the blood stream. The activity cleared from the upper respiratory tract and then swallowed, a fraction $\left(f_{1}\right)$, and in the case of ${ }^{94} \mathrm{Nb}, \mathrm{f}_{1}=0.01$, entered the blood-stream via the GI tract. Additional details of this model are described in Reference 47.

c. Data not available.

The potential use of fusion power to generate electricity in the next century has generated considerable interest in the potential biological hazards associated with the energy source. One of the principal concerns involves activation of structural components followed by spalling off the walls and transport of the activation products into the environment. One of the nuclides of concern is ${ }^{94} \mathrm{Nb}$. An analysis was performed to assess the environmental impact of fusion energy. ${ }^{53}$ This study summarized terrestrial and aquatic environmental effects of the production of radioactive niobium. Terrestrial effects include absorption of niobium, which places it into the food chain. Niobium was found to decrease growth rates in mice, particularly female mice, and to concentrate in the major organs of mammals. Aquatic effects include the concentration of radioactive niobium in the shell and byssus of shellfish. 


\section{Summary}

${ }^{94} \mathrm{Nb}$ has a half-life of 20,000 years and decays by beta particle emission to stable ${ }^{94} \mathrm{Mo}$. Both high-energy beta particles (maximum energy $500 \mathrm{keV}$, average energy $150 \mathrm{keV}$ ) and gamma-ray (energies 700 and $870 \mathrm{keV}$ ) emissions characterize this nuclide.

${ }^{94} \mathrm{Nb}$ is produced in the structural steels and other alloys of nuclear reactor vessels and internal components from the neutron activation of ${ }^{93} \mathrm{Nb}$, the only stable isotope of niobium. These reactor components serve as the primary LLW material containing ${ }^{94} \mathrm{Nb}$. The major concern surrounding ${ }^{94} \mathrm{Nb}$ is in limiting the dose received by persons associated with the decommissioning and dismantling of the reactors, primarily for reactors in service for several decades. If decommissioning is delayed for a long time after reactor shutdown, this nuclide would provide the dominant, long-term source of gamma radiation from these components.

${ }^{94} \mathrm{Nb}$ is commercially available and has been used as an external source of gamma rays for laboratory use. No medical uses for this nuclide have been identified.

The chemistry of niobium is dominated by the outermost five 5 s subshell electrons. The principal oxidation state is +5 . The metal has good high-temperature strength and corrosion characteristics and is used in the aerospace and nuclear industries.

The ability of soil to adsorb ${ }^{94} \mathrm{Nb}$ out of the groundwater depends on a number of factors, including $\mathrm{pH}$ and the presence or absence of complexing agents. However, in general, niobium is easily adsorbed by soils and is not easily leached into the groundwater.

The greatest source of ${ }^{94} \mathrm{Nb}$ generation is in nuclear reactors, where it is produced by neutron absorption via the ${ }^{93} \mathrm{Nb}(\mathrm{n}, \gamma)^{9.4} \mathrm{Nb}$ reaction. This nuclide can enter waste streams through corrosion of stainless steel and Inconel surfaces in nuclear power plants with subsequent discharge with the primary coolant. The amount of ${ }^{94} \mathrm{Nb}$ that has reached the environment is very small, and most studies of its hazard have been theoretical.

When ${ }^{94} \mathrm{Nb}$ comes into contact with the soil and groundwater, most of it will become fixed in the soil and will not migrate appreciably from the original site. Plants and animals can absorb this nuclide from the soil and propagate it into the food chain. When this nuclide is ingested in mammals, most if it is removed within a few days. The part that remains is generally uniformly distributed in the body. The effective removal half-life for this nuclide is dominated by the biological half-life, which is approximately 760 days, though individual organs may have different values. 


\section{References}

1. General Electric Company, Nuclides and Isotopes, Fourteenth Edition, 1989, p. 28.

2. J. Kohl, R. D. Zentner, and H. B. Lukens, Radioisotope Applications Engineering, D. Van Nostrand Company, 1961, p. 547.

3. C. M. Lederer, J. M. Hollander, and I. Perlman, Table of Isotopes, Sixth Edition, New York: John Wiley and Sons, Inc., 1967, pp. 43 and 231.

4. B. Shleien and M. S. Terpilak (Eds.), The Health Physics and Radiological Health Handbook, Nucleon Lectern Associates, 1984.

5. J. R. Bradford (Ed.), Radioisotopes in Industry, Reinhold Publishing Corporation, 1953.

6. F. A. Cotton and G. Wilkinson, Advanced Inorganic Chemistry-A Comprehensive Text, Interscience Publishers, 1962.

7. Metals Handbook, 9th Edition, Vol. 3, American Society for Metals, 1980.

8. McGraw-Hill Encyclopedia of Science and Technology, 6th Edition, Vol. 12, McGraw-Hill Book Company, 1987.

9. R. Granier and D. Gambini, Applied Radiobiology and Radiation Protection, Ellis Horwood, 1990, pp. 346 and 347.

10. Committee on Medical and Biologic Effects of Environmental Pollutants, Nickel, Division of Medical Sciences, National Research Council, National Academy of Sciences, Washington, D.C., 1975 , pp. 38 and 39.

11. R. C. Weast (Ed.), CRC Handbook of Chemistry and Physics, Boca Raton, Florida: CRC Press, 1977, 58th Edition, pp. B-270-B-354 (Table of Isotopes), and pp. B-429.

12. Bureau of Radiological Health, Radiological Health Handbook, Revised Edition, U.S. Government Printing Office, January 1970, pp. 92-94 (average and maximum beta energy by radionuclide).

13. E. S. Gould, Inorganic Reactions and Structure, Holt, Rinehart, and Winston, 1963.

14. J. C. Evans, E. L. Lepel, R. W. Sanders, C. L. Wilkerson, W. Silker, C. W. Thomas, K. H. Abel, and D. R Robertson, Long-Lived Activation Products in Reactor Materials, NUREG/CR-3474, August 1984.

15. J. C. Evans, E. A. Lepel, R. W. Sanders, C. W. Thomas, and D. E. Robertson, "Long-Lived Activation Products in Light Water Reactor Construction Materials: Implications for Decommissioning," Radioactive Waste Management and the Nuclear Fuel Cycle, Vol. 11, pp. 1-39, 1988.

16. International Critical Tables of Numerical Data, Physics, Chemistry, and Technology Vol. I, McGraw-Hill Book Company, New York, 1926, pp. 102. 
17. Smithsonian Physical Tables, 9th Edition, Smithsonian Institution Publishers, 1954.

18. A. G. Croff, A User's Manual for the ORIGEN2 Computer Code, ORNL/TM-7175, Oak Ridge National Laboratory, July 1980.

19. F. J. Rahn et al., A Guide to Nuclear Power Technology, New York: John Wiley \& Sons, 1984, p. 699 (Figure 16.5).

20. A. J. Schilling, Decommissioning and Commercial Nuclear Facilities: A Review and Analysis of Current Regulations, NUREG/CR-0671, 1979.

21. U.S. Nuclear Regulatory Commission, "Part 61 - Licensing Requirements for Land Disposal of Radioactive Wastes," Code of Federal Regulations, Title 10, Federal Register 61.55, January 1, 1994.

22. M. R. Winberg, Greater-Than-Class C Low-Level Radioactive Waste Characterization: Estimated Volumes, Radionuclide Activities, and Other Characteristics, DOE/LLW-114, Rev. 1, 1994.

23. D. E. Robertson, C. W. Thomas, N. L. Wynhoff, and D. L. Hagard, Radionuclide Characterization of Reactor Decommissioning Waste and Neutron-Activated Metals, NUREG/CR-5894, PNL-8106, June 1993.

24. E. S. Murphy, C. Feldman, F. P. Cardile, B. L. Baumann, and K. M. Edwards, "Classification of Reactor Decommissioning Wastes," Proceedings of the International Nuclear Reactor Decommissioning Planning Conference, Bethesda, MD, July 16, 1985.

25. D. Williamson and J. S. Tulenko, "Method for Waste Classification of Non-Fuel Assembly Core Components," Transactions of the American Nuclear Society, Vol. 65, 1992, pp. 90-91.

26. D. E. Robertson, C. W. Thomas, N. L. Wynhoff, and D. C. Hetzer, Radionuclide Characterization of Reactor Decommissioning Waste and Spent Fuel Assembly Hardware, NUREG/CR-5343, PNL6806, 1991.

27. D. E. Robertson, Compilation of Contract Research for the Materials Engineering Branch, Division of Engineers, Annual Report for FY 1988, NUREG-0975-Vol. 7, 1989.

28. Proceedings of the U.S. Nuclear Regulatory Commission, Fifteenth Water Reactor Safety Information Meeting, 6, "Decontamination and Decommissioning," NUREG/CP-0091, February 1988, p. 1-88.

29. D. E. Robertson, K. H. Abel, C. W. Thomas, E. A. Lepel, W. V. Thomas, L. C. Carrick, M. W. Leale, and J. C. Evans, "Residual Radionuclide Contamination Within and Around Nuclear Power Plants: Origin, Distribution, Inventory, and Decommissioning Assessment," Radioactive Waste Management and the Nuclear Fuel Cycle, Vol. 5, No. 4, 1984, pp. 285-310.

30. International Directory of Certified Radioactive Materials, International Atomic Energy Agency, Vienna, 1975.

31. P. C. Bergamini, G. Palmas, F. Piantelli, and M. Rigato, "Absorption and Distribution of ${ }^{137} \mathrm{Cs}$ by Trifolium Pratense," Health Physics, Vol. 19, No. 4, October 1970, pp. 521-528. 
32. K. Andersson, B. Torstenfelt, and J. Rydberg, Leakage of Niobium-94 from an Underground Rock Repository, SKBF/KBS-TR-79-26, Kaernbraenslesaekerhet, Stockholm, Svensk Kaernbraenslefoersoerjning AB, 1979.

33. J. Dragun, The Soil Chemistry of Hazardous Materials, Hazardous Materials Control Research Institute, Silver Spring, MD, 1988.

34. L. P. Gough, R. C. Severson, and L. L. Jackson, "Baseline Element Concentrations in Soils and Plants, Bull Island, Cape Romain National Wildlife Refuge, South Carolina, U.S.A.," Water, Air and Soil Pollution, Vol. 74, No. 1-2, 1994, pp. 1-17.

35. S. Dudka and B. Markert, "Base-Line Concentrations of As, Ba, Be, Li, Nb, Sr, and V in Surface Soils of Poland," Science of the Total Environment, Vol. 122, No. 3, 1992, pp. 279-290.

36. P. J. Coughtrey and M. C. Thorne, Radionuclide Distribution and Transport in Terrestrial and Aquatic Ecosystems, A. A. Balkema, 1983.

37. D. J. Wiggins and J. A. Franz, Mobility of Organic Complexes of Some Non-TRU Fission and Activation Products: A Selective Review, PNL-2607, UC-70, May 1978.

38. W. E. Prout, Adsorption of Fission Products by Savannah River Plant Soil, DP-394, TID-4500, Savannah River Laboratory, July 1959.

39. D. Charles and D. Prime, "Desorption Behavior of Artificial Radionuclides Sorbed onto Estuarine Silt: I Caesium-137 and Ruthenium-106, II Zirconium-95 and Niobium-95," Environmental Pollution (Series B), Vol. 5, 1983, pp. 273-295.

40. Y. P. Virchenko and G. I. Agapkina, "Organic Radionuclide Compounds in Soils Surrounding the Chernobyl Nuclear Power Plant," Eurasian Soil Science, Vol. 25, No. 12, 1993, pp. 51-59.

41. S. B. Russel, "Preliminary Dose Assessment of On Site Burial of Decommissioning Waste," Proceedings of the Canadian Nuclear Society - Canadian Nuclear Society International Conference on Radioactive Waste Management, Winnipeg, Canada, September 7-11, 1986, pp. 487-490, 1986.

42. H. L. Mills and L. M. Shields, "Root Absorption of Fission Products by Bromus Rubens L. From the AEC Nevada Test Site Soil Contaminated by an Underground Nuclear Explosion," Radiation Botany, Vol. 1, No. 1, 1961, pp. 84-91.

43. J. Ishida, N. Miyagawa, H. Watanabe, T. Asano, and Y. Kitahara, "Environmental Radioactivity Around the Tokai-Works After the Reactor Accident at Chernobyl," Journal of Environmental Radioactivity, Vol. 7, No. 1, 1988, pp. 17-27.

44. T. W. Oakes, K. E. Shank, C. E. Easterly, and L. R. Quintana, "Concentrations of Radionuclides and Selected Stable Elements in Fruits and Vegetables," Proceedings of University of Missouri's Annual Conference on Trace Substances in Environmental Health, 1977.

45. B. G. Lowe, "Fresh Fission Products in the West Malaysian Environment," Health Physics, Vol. 30, No. 3, 1976, pp. 302-303.

46. R. Granier and D. Gambini, Applied Radiobiology and Radiation Protection, Ellis Horwood, 1990, pp. 346-347. 
47. K. F. Eckerman, A. B. Wolbarst, and A. C. B. Richardson, Limiting Values of Radionuclide Intake and Air Concentration and Dose Conversion Factors of Inhalation, Submersion, and Ingestion, Federal Guidance Report No. 11, Oak Ridge National Laboratory, EPA-520/1-88-020, September 1988.

48. Y. Wang, M. D. (Ed.), CRC Handbook of Radioactive Nuclides, Boca Raton, Florida: CRC Press, 1969.

49. R. G. Cuddihy, "Deposition and Retention of Inhaled Niobium in Beagle Dogs," Health Physics, Vol. 34, No. 2, 1978, pp. 167-176.

50. P. McDonald, M. S. Baxter, and S. W. Fowler, "Distribution of Radionuclides in Mussels, Winkels, and Prawns. Part 1. Study of Organisms under Environmental Conditions Using Conventional Radio-Analytical Techniques," Journal of Environmental Radioactivity, Vol. 18, No. 3, 1993, pp. 181-202.

51. Nuclear Regulatory Commission, 10 CFR 20, Chapter I (January 1, 1992), "Standards for Protection Against Radiation," Appendix B.

j2. B. Shleien and M. Terpilak, Supplement 1 (1986): The Health Physics and Radiological Health Handbook, Nucleon Lectern Associates, Inc., 1986.

53. J. A. Strand and T. M. Poston, Biological Effects of Activation Products and Other Chemicals Released from Fusion Power Plants, BNWL-2033, UC-20, September 1976. 


\section{Bibliography}

Abel, K. H., D. E. Robertson, C. W. Thomas, E. A. Lepel, and V. W. Thomas, Topical Report Residual Radionuclide Distribution and Inventory at the Humboldt Bay Nuclear Plant, PNL-4628, 1983.

Abel, K. H., D. E. Robertson, E. A. Lepel, and M. W. Leale, Residual Radionuclide Distribution and Inventory at the Dresden Unit One Nuclear Generating Plant, PNL-4961, 1983.

Abel, K. H., D. E. Robertson, J. C. Evans, and L. C. Carrick, Residual Radionuclide Distribution and Inventory at Turkey Point Power Station Units No. 3 and 4, PNL-5010, 1984.

Bryant, E. A., G. A. Cowan, W. R. Daniels, and W. J. Maeck, "Oklo, an Experiment in Long Term Geologic Storage,". ACS Symposium Series, American Chemical Society, 1976.

Cline, J. E., J. R. Noyce, L. J. Coe, and K. W. Wright, Assay of Long-Lived Radionuclides in Low-Level Wastes from Power Reactors, NUREG/CR-4101, April 1985.

Evans, J. C., E. L. Lepel, R. W. Sanders, C. L. Wilkerson, W. B. Silker, C. W. Thomas, K. H. Abel, and D. E. Robertson, Long-Lived Activation Products in Reactor Materials, PNL-4824, 1984.

Fairbrother, F., D. Robinson, and J. B. Taylor, "Some Water-Soluble Complexes of Pentavalent Niobium and Tantalum," Journal of Inorganic and Nuclear Chemistry, Vol. 8, 1958, p. 296.

Fairbrother, F., and J. B. Taylor, "Water-Soluble Complexes of Niobium and Tantalum, Part I. Complexes with Alpha-Hydroxy Acids and Amines," Journal of the Chemical Society, p. 4946, 1956.

Fletcher, C. R., "The Radiological Hazards of Zirconium-95 and Niobium-95," Health Physics, 16, p. 209, 1969.

Furchner, J. E., and G. A. Drake, "Comparative Metabolism of Radionuclides in Mammals-VI. Retention of ${ }^{95} \mathrm{Nb}$ in the Mouse, Rat, Monkey, and Dog," Health Physics, 21, p. 173, 1971.

Gibalo, I. M., Analytical Chemistry of Niobium and Tantalum, Ann Arbor-Humphrey Science Publishers, 1970.

Hamilton, J. G., "The Metabolism of Fission Products and the Heaviest Elements," Radiology, 49, p. 325, 1947.

International Atomic Energy Agency, A Basic Toxicity Classification of Radionuclides, Report of a Joint Study of a Group of Consultants to the International Atomic Energy Agency, Technical Reports Series No. 15, Vienna, Austria, 1963.

International Commission on Radiological Protection, "Limits for Intakes of Radionuclides by Workers," Annals of the ICRP-ICRP Publication 30, Part 3, Vol. 6, No. 3, Pergamon Press, 1981.

Lepel, E. A., D. E. Robertson, K. H. Abel, W. V. Thomas, J. C. Evans, and L. C. Carrick, Residual Radionuclide Distribution and Inventory at Indian Point One, PNL-5020, 1984. 
Matthews, C. M. E., and J. M. Gartside, "Tumor Uptake and Distribution of Niobium Isotopes in Rats," British Journal of Cancer, 19, p. 551, 1965.

Misura, U. K., "Distribution of ${ }^{95} \mathrm{Nb}$ in Tissues and Liver Subcellular Fractions of Rat," Indian Journal of Experimental Biology, 5, p. 23, 1967.

Nelson, J. L., Soil Column Studies with Radiostrontium I: Effects of Temperature and of Species of Accompanying Ion, H-62035, General Electric, Hanford Laboratories Operation, 1959.

Nelson, J. L., Soil Column Studies with Radiostrontium II: Effects of Soil Column Length and Diameter, H-63930, General Electric, Hanford Laboratories Operation, 1959.

Oak, H. D., G. M. Holter, W. E.Kennedy, Jr., and G. J. Konzek, Technology, Safety and Costs of Decommissioning a Reference Boiling Water Reactor Power Station, NUREG/CR-0672, Vols. 1 and 2, June, 1980.

Organization for Economic Cooperation and Development, The Environmental and Biological Behavior of Plutonium and Some Other Transuranium Elements, Nuclear Energy Agency, Paris, 1981.

Qureshi, M., K. G. Varshney, and R. C. Kaushik, "Cation Exchange Studies of $\mathrm{Ti}^{4+}, \mathrm{V}^{5+}, \mathrm{Fe}^{3+}, \mathrm{Nb}^{5+}$, and $\mathrm{UO}_{2}{ }^{2+}$ in Formic, Oxalic, Tartaric, and Citric Acid Media," Annals of Chemistry, 45, p. 2433, 1973.

Robertson, D. E., C. W. Thomas, N. L. Synhoff, and D. C. Hetzer, "Characterization of Long-Lived Activation Products in Spent Fuel Assembly Hardware and Reactor Pressure Vessel Steel," Nuclear Engineering Design, 118, pp. 463-486, 1990.

Robertson, D. E., C. W. Thomas, K. H. Abel, J. C. Evans, M. W. Leale, E. A. Lepel, and E. M. Woodruff, Topical Report - Residual Radionuclide Distribution and Inventory at the Pathfinder Generating Plant, PNL-4326, 1982.

Robertson, D. E., C. W. Thomas, K. H. Abel, E. A. Lepel, W. V. Thomas, L. C. Carrick, and J. C. Evans, Topical Report - Residual Radionuclide Distribution and Inventory at the Monticello Nuclear Generating Plant, PNL-4794, 1983.

Smith, R. I., G. J. Konzek, and W. E. Kennedy, Jr., Technology, Safety, and Costs of Decommissioning a Reference Pressurized Water Reactor Power Station, NUREG/CR-0130, Vols. 1 and 2, June 1978.

Stewart, D. C., Data for Radioactive Waste Management and Nuclear Applications, New York: John Wiley \& Sons, 1985.

Thomas, R. G., S. A. Walker, and R. O. McClellan, "Relative Hazard for Inhaled ${ }^{95} \mathrm{Zr}-{ }^{95} \mathrm{Nb}$ Particles Formed Under Various Thermal Conditions," Proceedings of the Society of Experimental Biological Medicine, 138, p. 228, 1971.

Thomas, R. G., R. L. Thomas, and J. K. Scott, "Distribution and Excretion of Niobium Following Inhalation Exposure of Rats," Journal of the American Industrial Hygiene Association, 28, p. 1, 1967.

U.S. Department of Energy, Catalog of Radioactive and Stable Isotopes, 1992. 
Wildung, R. E., R. C. Routson, R. J. Serne, and T. R. Garland, Pertechnetate, Iodide, and Methyl Iodide Retention by Surface Soils, BNWL-SA-5195, Battelle Northwest Laboratories, 1974. 


\section{COBALT-60}

\section{Introduction}

This chapter outlines the basic radiological, chemical, and characteristics of cobalt- $60\left({ }^{60} \mathrm{Co}\right)$ and examines how these characteristics affect the behavior of ${ }^{60} \mathrm{Co}$ in various environmental media, such as soils, water, plants, animals, the atmosphere, and the human body. Also included are methods of ${ }^{60} \mathrm{Co}$ production and waste and disposal data for ${ }^{60} \mathrm{Co}$.

All cobalt atoms contain 27 protons $(Z=27)$ and various numbers of neutrons (typically $N=27$ to 37 neutrons) within the atom's nucleus. There is only one stable isotope of cobalt, namely ${ }^{59} \mathrm{Co}$. All other cobalt isotopes, including ${ }^{60} \mathrm{Co}$, are radioactive. The radioactive isotopes of cobalt have half-lives ranging from less than a second $\left({ }^{54} \mathrm{Co}-0.19 \mathrm{~s}\right)$ to 5.2 years $\left({ }^{60} \mathrm{Co}\right) .{ }^{1}$ The radioactive isotopes of cobalt are not a normal constituent of the natural environment and are generated as a result of human activities.

The primary source of ${ }^{60} \mathrm{Co}$ in the environment has been low-level radioactive waste (LLW) generated as a result of neutron activation of stable ${ }^{59} \mathrm{Co}$ that is present in the structural components of nuclear reactor vessels. This isotope is also intentionally produced, usually in reactors but also to some degree in accelerators for industrial and medical uses, such as for radiation sources for cancer treatment and nondestructive testing of metals and welds. ${ }^{60} \mathrm{Co}$ may enter the environment as a result of the activities associated with nuclear reactor operations and decommissioning and when industrial and medical sources are being used, manufactured, or disposed.

A radionuclide considered sensitive at one LLW disposal facility may not be considered sensitive at another facility. The behavior of a radionuclide at a particular LLW disposal site will depend primarily upon the radiological, chemical, and physical characteristics of the waste, and the inventory of the radionuclide. The behavior of a radionuclide also depends upon the geology, hydrology, and climate at the disposal site. This chapter reports characteristics and potential difficulties in dealing with ${ }^{60} \mathrm{Co}$. However, since ${ }^{60} \mathrm{Co}$ behavior and appropriate handling, storage, or disposal will vary depending on particular sites or waste form, this chapter does not attempt to discuss the extent of a difficulty or appropriate solutions. Each disposal site facility design should consider and address the specific waste content and behavior under that site's particular circumstances.

\section{Radiological Characteristics}

The most recent and best available information concerning ${ }^{60} \mathrm{Co}$ reports a half-life of 5.2 years. ${ }^{1,2}$ There is, however, an isometric excited state of ${ }^{60} \mathrm{Co}$ with a measurable half-life of 10.5 minutes. This isometric state has a long enough half-life that in a small fraction $(<1 \%)$ of the time it can decay directly to nickel-60 $\left.{ }^{60} \mathrm{Ni}\right)$ with the emission of a negative beta particle $\left(\beta^{-}\right)$. Otherwise, this isometric state decays to the ground state of ${ }^{60} \mathrm{Co}$ with the emission of a gamma ray. ${ }^{60} \mathrm{Co}$ is perhaps the best known of the gamma emitters and has been o primary importance to the radiological exposure of power plant personnel. The principal means of ${ }^{60} \mathrm{Co}$ production is by neutron capture $(n, \gamma)$ of ${ }^{59} \mathrm{Co}$, namely

$$
{ }^{59} \mathrm{Co}+\mathrm{n} \rightarrow{ }^{60} \mathrm{Co}+\gamma \text {-ray } .
$$


${ }^{60} \mathrm{Co}$ undergoes radioactive decay via $\beta$ - emission (i.e., $100 \%$ of all decays, both of the ground state and isometric state, results in an electron being emitted from the nucleus) leading to the creation of a stable ${ }^{60} \mathrm{Ni}$ nucleus.

The maximum beta-particle energy due to decay of the ground state of ${ }^{60} \mathrm{Co}$ is $1,480 \mathrm{keV}$ (thousand-electron volts). Even though the maximum beta-particle energy is $1,480 \mathrm{keV}$, more than $95 \%$ of the decay results in beta-particle energies less than or equal to $314 \mathrm{keV}$. The decay of the excited isometric state can result in a maximum beta-particle energy of $1,550 \mathrm{keV}$, but this only happens for a small fraction of the decays. However, the average beta-particle energy is only $94 \mathrm{keV}$ per ${ }^{60} \mathrm{Co}$ disintegration ( $600 \mathrm{keV}$ for the isometric state) ${ }^{3}$ Since the released beta particle is usually emitted with an energy less than its theoretical maximum (e.g., $1,480 \mathrm{keV}$ for ${ }^{60} \mathrm{Co}$ decay), an antineutrino particle is simultaneously emitted and this particle carries off the energy difference between the released beta particle and total energy given off by the decay process. Consequently, beta particles are emitted with a continuous energy spectrum ranging from 0 to $1,480 \mathrm{keV}$. Since neutrinos (or antineutrinos) rarely interact with matter, they are not considered radiologically important. Therefore, the antineutrino particle is usually not shown in the overall decay equation.

The probability that a neutron passing through cobalt will be absorbed by a ${ }^{59} \mathrm{Co}$ nucleus is moderate (about the same as in the production of ${ }^{63} \mathrm{Ni}$ and 20 times greater than in the production of niobium-94 $\left.\left[{ }^{94} \mathrm{Nb}\right]\right)$. However, there is a relatively large mass of cobalt in a reactor system, and ${ }^{59} \mathrm{Co}$ is the only stable isotope of this element. Therefore, all of the cobalt that is in the reactor system is capable of being transmuted into ${ }^{60} \mathrm{Co}$ by the absorption of a neutron. The half-life of ${ }^{60} \mathrm{Co}$ is long enough that the equilibrium activity of this radionuclide can be large. This, coupled with the high-energy gamma rays that are emitted during ${ }^{60} \mathrm{Co}$ decay $(1,170$ and $1,330 \mathrm{keV})$, means that the radiation from this radionuclide is often the limiting radiation for personnel exposure during reactor maintenance activities. However, it is feasible (due to the 5.2 year half-life) to wait long enough after final shutdown of a reactor plant for this nuclide to significantly decay, reducing the personnel exposure during plant decommissioning activities. In other words, ${ }^{60} \mathrm{Co}$ normally represents a major concern in shielding during reactor plant operations, but its contribution to the overall radioactivity during decommissioning and waste storage activities can be reduced by simply waiting until it decays.

The $1,480-\mathrm{keV}$ maximum energy beta particle emitted by the ${ }^{60} \mathrm{Co}$ nucleus is high, although the average beta-particle energy, $94 \mathrm{keV}$, is only moderately high. Table $12-1$ lists the estimated maximum ranges for a $94-\mathrm{keV}$ (average energy) beta particle emitted from ${ }^{60} \mathrm{Co}$ decay. The ranges for the maximum energy beta particles are large. Since it requires only $70 \mathrm{keV}$ for an electron to penetrate the protective layer of human skin, the $1,480-\mathrm{keV}$ beta particles have sufficient energy to penetrate the $0.07 \mathrm{~mm}$ (dead layer) of human skin. Therefore, exposure to the $1,480-\mathrm{keV}$ maximum energy beta particles from the decay of ${ }^{60} \mathrm{Co}$ can result in a beta dose to some internal organs.

In addition to beta-particle radiation, each ${ }^{60} \mathrm{Co}$ decay results in two high-energy gamma rays, 1,170 and $1,330 \mathrm{keV}$. Both of these are more energetic than the $660-\mathrm{keV}$ gamma ray associated with the decay of cesium-137 $\left({ }^{137} \mathrm{Cs}\right)$. Table 12-2 illustrates this by listing the half-value layers, or the thicknesses of various materials required to reduce a beam of $1,330-\mathrm{keV}$ gamma rays to one-half of its original intensity. As shown, shielding the environment from ${ }^{60} \mathrm{Co}$ requires a substantial thickness, as opposed to some of the nuclides in this document, such as ${ }^{63} \mathrm{Ni}$, which is only a beta emitter. ${ }^{4}$ 
Table 12-1. Comparison of the estimated maximum ranges for a $94-\mathrm{keV}$ average energy beta particle emitted from ${ }^{60} \mathrm{Co}$ decay for various materials.

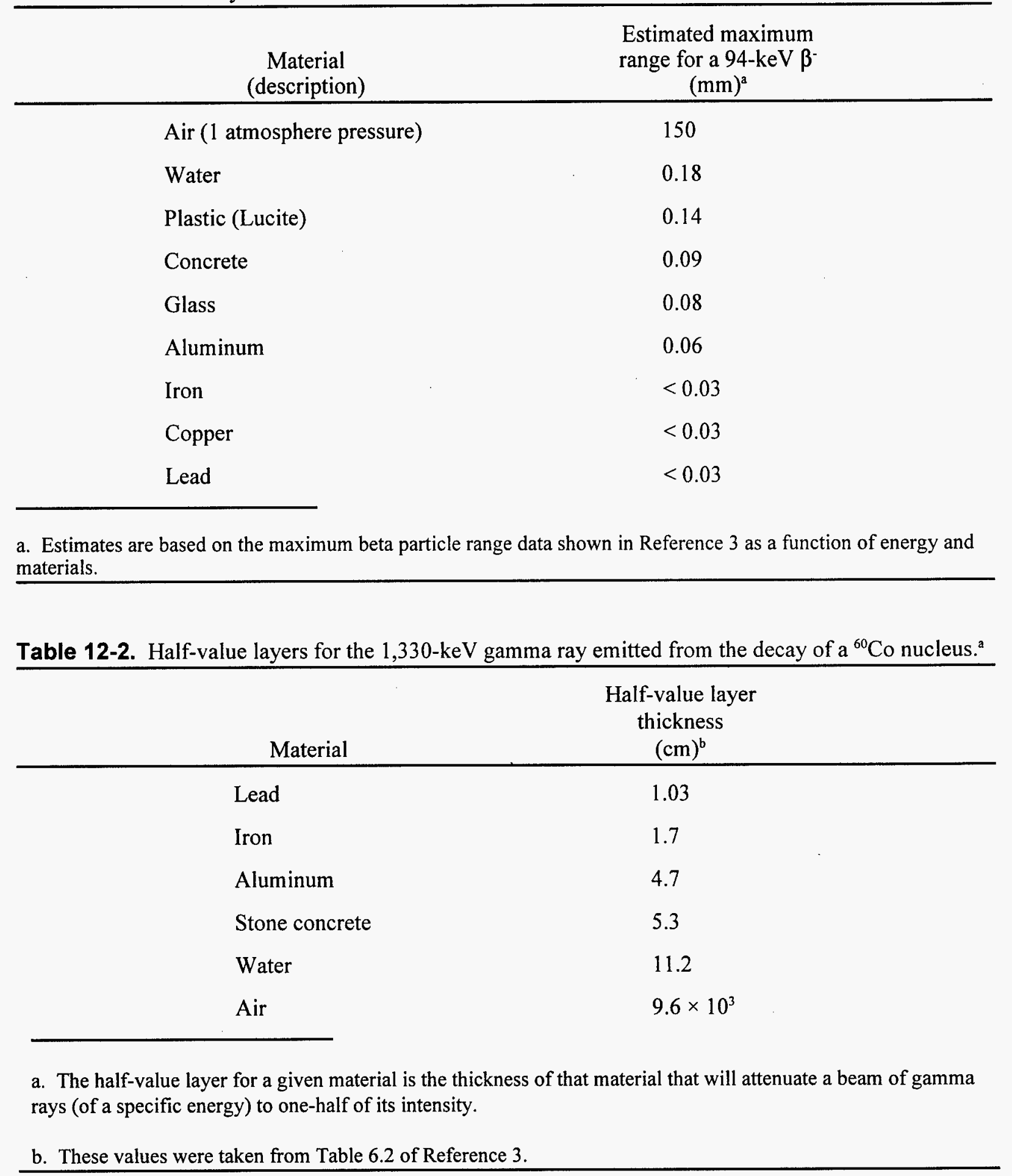


The decay sequence for ${ }^{60} \mathrm{Co}$ showing the emission of a negative beta particle (e.g., an electron) and the two gamma rays is illustrated in the following nuclear transformation:

$$
\begin{gathered}
{ }^{60} \mathrm{Co} \underset{5.2 \mathrm{y}}{\stackrel{100 \%}{\rightarrow}}{ }^{60} \mathrm{Ni}+\beta^{-}(1,480 \mathrm{keV} \text { max energy; } 314 \mathrm{keV} \text { major energy })+\gamma \\
(1,170 \& 1,330 \mathrm{keV}) .
\end{gathered}
$$

Table 12-3 lists the radiotoxicity of several important radionuclides, and Table 12-4 compares the average and maximum electron energies associated with ${ }^{60} \mathrm{Co}$ decay with other well-known electron (beta particle) emitters. Notice that ${ }^{60} \mathrm{Co}$ is shown in the same radiological group as ${ }^{94} \mathrm{Nb}$ and strontium-90 $\left({ }^{90} \mathrm{Sr}\right) .{ }^{60} \mathrm{Co}$ decay results in a lower average (but higher maximum) beta energy emission and higher gamma energy emission than ${ }^{94} \mathrm{Nb} .{ }^{60} \mathrm{Co}$ decay also results in lower average and higher maximum beta energy but lower gamma energy emissions than ${ }^{90} \mathrm{Sr}$. (The high-energy $[1,75-\mathrm{keV}]$ gamma radiation due to ${ }^{90} \mathrm{Sr}$ decay is actually from the decay of its relatively short-lived $\left[\mathrm{T}_{1 / 2}=64 \mathrm{~h}\right]$ daughter, yttrium-90 $\left.\left[{ }^{90} \mathrm{Y}\right].\right)^{2,3}$

\section{Chemical and Physical Characteristics}

Cobalt is a member of the eighth group, or the First Transition Series of the periodic table, which includes iron, nickel, scandium, titanium, vanadium, chromium, manganese, copper, and zinc. ${ }^{5}$ Of these, cobalt is chemically most like iron and nickel. In nature, cobalt always occurs in association with nickel and usually arsenic.

Cobalt is a hard, bluish white metal. It is ferromagnetic with a Curie temperature of about $1,150^{\circ} \mathrm{C}$. The metal is relatively unreactive and does not combine directly with either hydrogen or nitrogen. However, it will combine with carbon, phosphorus, and sulfur at high temperatures. It is also attacked by atmospheric oxygen and water vapor at elevated temperatures.

Cobalt is widely distributed in nature, making up about $0.001 \%$ of the igneous rocks in the Earth's crust, compared with $0.02 \%$ for nickel. ${ }^{6}$ The most important cobalt ore deposits are located in Canada, Zaire, Morocco, and the Soviet Union. The most common Cobalt ore is cobaltite, a combination of $\mathrm{CoAsS}$ and FeS. About $80 \%$ of cobalt is used in the metallic state. Reactors use the alloy, stellite, which contains cobalt and is hard and used for valve surfaces. The most important commercial applications are in making alloys for use at high temperatures, magnetic alloys, and alloys for use in machine tools.

Table 12-3. Comparison of the radiotoxicity of several important radionuclides (from Appendix 2 of Reference 7).

\begin{tabular}{lll}
\hline Radiotoxicity & \multicolumn{1}{c}{ Species } \\
\hline Very high & Group 1 & ${ }^{241} \mathrm{Pu},{ }^{242} \mathrm{Cm},{ }^{241} \mathrm{Am},{ }^{237} \mathrm{~Np}$ \\
High & Group 2 & ${ }^{60} \mathrm{Co},{ }^{90} \mathrm{Sr},{ }^{94} \mathrm{Nb}$ \\
Moderate & Group 3 & ${ }^{14} \mathrm{C},{ }^{63} \mathrm{Ni},{ }^{137} \mathrm{Cs}$ \\
Low & Group 4 & ${ }^{3} \mathrm{H},{ }^{59} \mathrm{Ni},{ }^{99 \mathrm{~m}} \mathrm{Tc},{ }^{99} \mathrm{Tc},{ }^{129} \mathrm{I}$ \\
\hline
\end{tabular}


Table 12-4. Average and maximum kinetic energies of beta particles and negative (atomic) electrons released during decay of several important radionuclides. (Information compiled from data presented in References $1,2,3,8$, and 9.)

\begin{tabular}{|c|c|c|}
\hline \multirow[b]{2}{*}{ Radionuclide } & \multicolumn{2}{|c|}{ Released electron energy } \\
\hline & $\begin{array}{c}\text { Average energy } \\
(\mathrm{keV})^{\mathrm{a}}\end{array}$ & $\begin{array}{c}\text { Maximum energy } \\
(\mathrm{keV})\end{array}$ \\
\hline Nickel-59 $\left({ }^{59} \mathrm{Ni}\right)$ & $4.1^{b}$ & $\sim 7.7^{b}$ \\
\hline Tritium-3 $\left({ }^{3} \mathrm{H}\right)$ & 5.7 & 19.0 \\
\hline Nickel-63 $\left({ }^{63} \mathrm{Ni}\right)$ & 17.1 & 67.0 \\
\hline Iodine-129 $\left({ }^{129} \mathrm{I}\right)$ & 40.0 & 150.0 \\
\hline Carbon-14 $\left({ }^{14} \mathrm{C}\right)$ & 49.0 & 156.0 \\
\hline Technetium-99 $\left({ }^{99} \mathrm{Tc}\right)$ & 85.0 & 293.0 \\
\hline Niobium-94 $\left({ }^{94} \mathrm{Nb}\right)$ & 156.0 & 500.0 \\
\hline Iodine-131 $\left({ }^{131} \mathrm{I}\right)$ & 180.0 & $806.0^{c}$ \\
\hline Cesium-137 ( $\left.{ }^{137} \mathrm{Cs}\right)$ & 195.0 & $1,176.0$ \\
\hline Potassium- $40\left({ }^{40} \mathrm{~K}\right)$ & 541.0 & $1,330.0$ \\
\hline Cobalt-60 $\left({ }^{60} \mathrm{Co}\right)$ & 94.0 & $1,480.0^{d}$ \\
\hline Phosphorous-32 $\left({ }^{32} \mathrm{P}\right)$ & 694.0 & $1,710.0$ \\
\hline \multicolumn{3}{|c|}{$1,000 \mathrm{keV}=1 \mathrm{MeV}$ (million-electron volt). Beta particle energy unless otherwise noted. } \\
\hline \multicolumn{3}{|c|}{$\begin{array}{l}\text { b. The data for }{ }^{59} \mathrm{Ni} \text { represent Auger electrons and not electrons emitted from the nucleus (i.e., beta particles). The } \\
\text { maximum electron energy was estimated based on the assumption that an electron from the }{ }^{59} \mathrm{Co} \text { atom (e.g., the } \\
\text { daughter product from }{ }^{59} \mathrm{Ni} \text { decay) absorbs a maximum energy } \mathrm{x} \text {-ray. }\end{array}$} \\
\hline \multicolumn{3}{|c|}{ c. $90.4 \%$ of the beta-particle intensity for ${ }^{131} \mathrm{I}$ occurs at $606 \mathrm{keV}$ and only $0.6 \%$ occurs at $806 \mathrm{keV}$. } \\
\hline \multicolumn{3}{|c|}{ d. $99 \%$ of the beta-particle intensity of ${ }^{60} \mathrm{Co}$ occurs at $314 \mathrm{keV}$. } \\
\hline
\end{tabular}

The radionuclide, ${ }^{60} \mathrm{Co}$, is widely used in industry, research, and medicine. This nuclide is widely used as a gamma radiation source to examine internal structures, such as welds, for defects or foreign objects. It is also employed in cancer therapy and as a radioactive tracer in biology and industry. ${ }^{60} \mathrm{Co}$ is also used in medical supplies and food irradiators. 
Cobalt oxidizes primarily to two oxidation states, II and III. The most common state is II. Its most common oxide, $\mathrm{CoO}$, is olive-green, has the rock salt structure, and is antiferromagnetic. Cobalt, in the II oxidation state, forms an extensive group of simple and hydrated salts, including hydroxide, sulfides, and various halides. The only apparently simple III salts are $\mathrm{CoF}_{3}$ and hydrated forms of $\mathrm{CoF}_{3}$ and $\mathrm{Co}_{2}\left(\mathrm{SO}_{4}\right)_{3}$.

Cobalt(II) forms numerous complexes with implications for waste storage, which will be discussed later. The complexes include ammonia and chelate amines such as ethylenediamine-tetraacetic acid (EDTA). Cobalt(III) also forms a number of complexes, especially those containing ammonia, amines, and halide ions. Cobalt(I) can also form complexes, although it is more difficult to obtain this oxidation state.

The most common oxide, $\mathrm{CoO}$, can show significant deviation from this stoichiometry without exhibiting heterogeneity. The majority of soluble $\mathrm{Co}$ (II) salts are pink. However, the halides range from pale blue $\left(\mathrm{CoCl}_{2}\right)$ to green $\left(\mathrm{CoBr}_{2}\right) .{ }^{10}$

The mechanical properties of cobalt are dependent on the purity of the metal. Certain minor and trace elements fulfill necessary functions in cobalt alloys. For example, rupture strength and ductility benefit from adding boron, zirconium, titanium, and aluminum. Manganese and silicon additions aid castability and minimize grain boundary reactions. Conversely, the presence of parts per million amounts of elements such as lead, tellurium, bismuth, and selenium can be detrimental to creep and fatigue properties. Cobalt-based alloys have been extensively used in medicine and dentistry for surgical instruments and implants. ${ }^{11}$

Table 12-5 summarizes some of the chemical and physical characteristics of the element.

Table 12-5. Chemical and physical characteristics of cobalt (from References 12, 13, and 14).

Physical property

(units)

Cobalt data

$\begin{array}{ll}\text { Melting point }(\mathrm{K})^{\mathrm{a}} & 1,753 \\ \text { Boiling point }(\mathrm{K})^{\mathrm{a}} & 3,173 \\ \text { Solid density }\left(\mathrm{g} / \mathrm{cm}^{3}\right) & 8.9 \\ \text { Ionization potential }(\mathrm{V}) & 7.81 \\ \text { Oxidation potential }(\mathrm{V}) & 0.28 \\ \text { Crystal form } & \text { Face-centered cubic }\end{array}$

a. Zero Kelvin equals $-273.15^{\circ} \mathrm{C},-459.67^{\circ} \mathrm{F}$. 


\section{Cobalt-60 Production}

The structural materials inside the reactor vessel of a nuclear power plant are exposed to neutron radiation. This radiation can cause many components of these materials to become radioactive with time via neutron activation. Those elements most susceptible to neutron activation are iron, nickel, and cobalt, which are found primarily in stainless steel and other important alloys (e.g., Inconel). Depending on the amount of time these materials are irradiated and the neutron fluence (i.e., integrated neutron flux), any of these nuclides may become the critical activation product affecting the dismantling activities of the reactor.

Although not a principal structural material, based on total mass, cobalt does form an important constituent of some materials, especially those structures that require a high degree of hardness, such as valve bearing surfaces and core internal components. Much of this material is outside of the reactor vessel, and over time, cobalt-alloy surfaces can corrode/erode and the material can be transported to the reactor with the coolant where it is irradiated and then transported and deposited in various "hot spots" in the primary coolant system.

The principal means of producing ${ }^{60} \mathrm{Co}$ is through neutron capture of ${ }^{59} \mathrm{Co}$, the only stable isotope of cobalt. Even though the total cobalt mass is relatively small and because ${ }^{59} \mathrm{Co}$ constitutes the only stable isotope, all of the cobalt mass is available for activation and this fact increases the total amount of ${ }^{60} \mathrm{Co}$ that can be produced.

Nuclear fission does not play a significant role in the production of ${ }^{60} \mathrm{Co}$. This can be seen in Figure 12-1, which illustrates the fission yield for ${ }^{235} \mathrm{U}$. The ${ }^{60} \mathrm{Co}$ position is shown with respect to the fission product yield information for other mass numbers. The cumulative fission yield of ${ }^{60} \mathrm{Co}$ from the fission of ${ }^{235} \mathrm{U}$ is essentially zero. This information was obtained from the fission yield data from the ORIGEN $2{ }^{15}$ computer code cross-section data.

${ }^{59} \mathrm{Co}$ atoms have a moderately high probability to absorb thermal neutrons. However, cobalt comprises only a small fraction of the total structural mass in a nuclear reactor. Therefore, the total mass of ${ }^{60} \mathrm{Co}$ in a reactor system is never large. However, the 5.2 year half-life means that the inventory of this nuclide is close to the equilibrium mass by the end of reactor operations (based on a reactor life of 30 years). In addition, radioactive decay during normal maintenance shutdowns will not appreciably reduce the inventory between irradiations.

Therefore, the buildup of ${ }^{60} \mathrm{Co}$ in a reactor system can be approximated by assuming a continuous irradiation throughout the reactor lifetime, as shown in Figure 12-2. Figure 12-2 shows the buildup of several different activation products in a pressurized water reactor vessel, including ${ }^{63} \mathrm{Ni},{ }^{59} \mathrm{Ni}$, ${ }^{94} \mathrm{Nb}$, and ${ }^{60} \mathrm{Co}$, as a function of reactor operation. The data in Figure 12-2 were normalized to 1 at 30 years and do not reflect absolute activities.

There are two groups in Figure 12-2: those that buildup relatively rapidly and reach a saturated condition, such as ${ }^{60} \mathrm{Co}$ and iron-55 $\left({ }^{55} \mathrm{Fe}\right)$; and those, typically with half-lives long compared to the relevant reactor lifetime, that never reach saturated conditions, such as ${ }^{94} \mathrm{Nb}$ and ${ }^{63} \mathrm{Ni}$. The significance is that the nuclides in the first category also tend to decay more rapidly. Therefore, the attaining nearequilibrium inventories coupled with the high-energy gamma rays associated with the decay of ${ }^{60} \mathrm{Co}$, results in this nuclide being one of the dominant sources of personnel exposure during the first few years following reactor shutdown, especially for those areas removed from the core with its high inventory of fission products. Due to the 5.2 year half-life, it is feasible to delay decommissioning and decontamination activities after final shutdown to significantly reduce the ${ }^{60} \mathrm{Co}$ activity. 


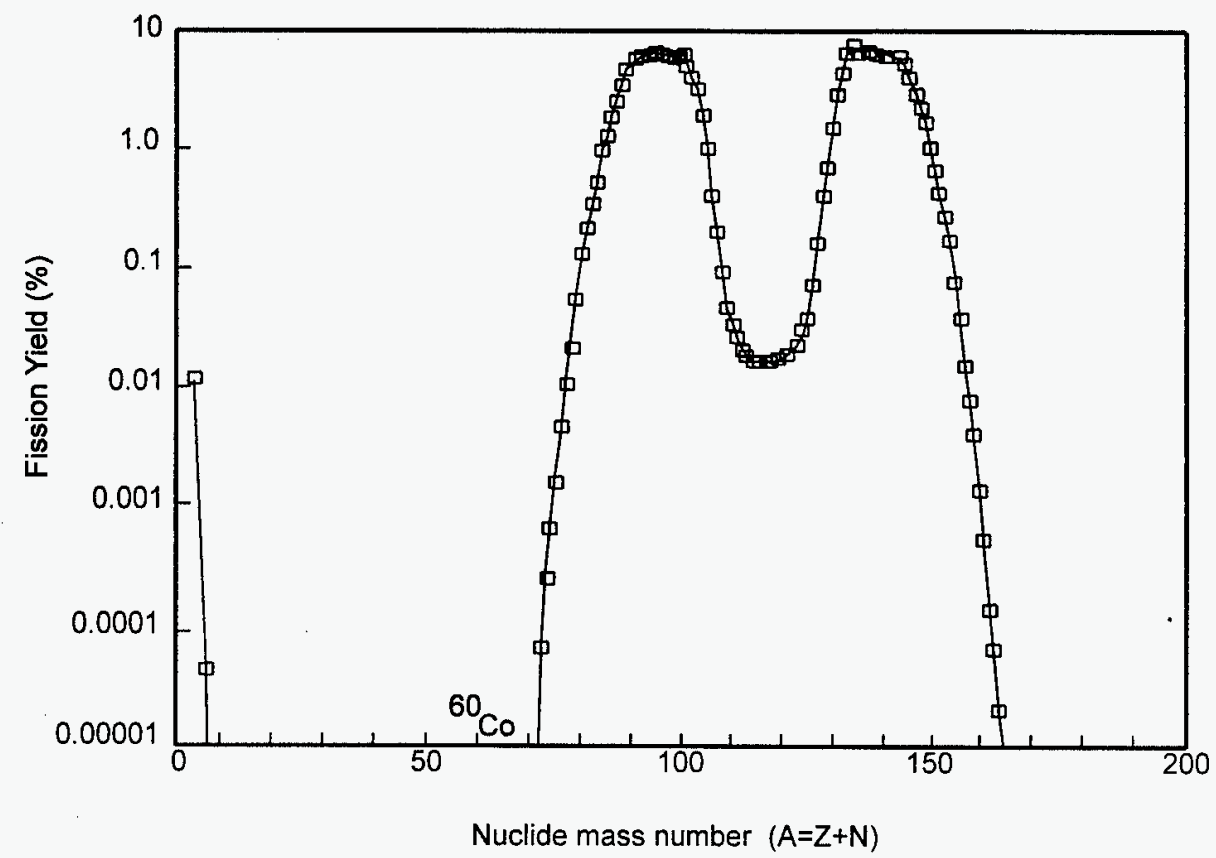

Figure 12-1. Fission product yield curve for thermal fission of ${ }^{235} \mathrm{U}$.

\section{Waste and Disposal Data on Cobalt-60}

This section discusses the types of activities that generate ${ }^{60} \mathrm{Co} L \mathrm{LW}$, waste types and forms that contain ${ }^{60} \mathrm{Co}$, and disposal data on ${ }^{60} \mathrm{Co}$.

\section{Nuclear Reactors}

Cobalt is used in many reactor materials. It is a trace element in zircaloy- 2 and -4 and is a major constituent of several types of Inconel and stainless steel. ${ }^{16}$ The only stable isotope of cobalt is ${ }^{59} \mathrm{Co}$, which can become radioactive by capturing a neutron and being transmuted into ${ }^{60} \mathrm{Co}$. As previously mentioned, ${ }^{60} \mathrm{Co}$ emits highly energetic beta and gamma rays during the decay process and is a major source of gamma radiation from activated metal components. For a typical light water reactor, the activity of ${ }^{60} \mathrm{Co}$ ranges from $640,000 \mathrm{Ci}\left(2.47 \times 10^{16} \mathrm{~Bq}\right)$ at reactor shutdown down to $170,000 \mathrm{Ci}(6.3 \times$ $10^{15} \mathrm{~Bq}$ ) after 10 years of decay. The maximum concentration of this nuclide that would qualify for waste disposal as Class $\mathrm{A}$ is $700 \mathrm{Ci} / \mathrm{m}^{3}\left(2.6 \times 10^{13} \mathrm{~Bq} / \mathrm{m}^{3}\right)$ of waste. ${ }^{17}$ Therefore, after 10 years of decay, the $170,000 \mathrm{Ci}\left(6.3 \times 10^{15} \mathrm{~Bq}\right)$ would have to be distributed throughout $243 \mathrm{~m}^{3}$ of reactor structural materials to qualify for this waste disposal classification. The limits for Class B or Class $\mathrm{C}$ waste depend on additional considerations such as the effects of external radiation and internal-heat generation on the transportation, handling, and disposal. 


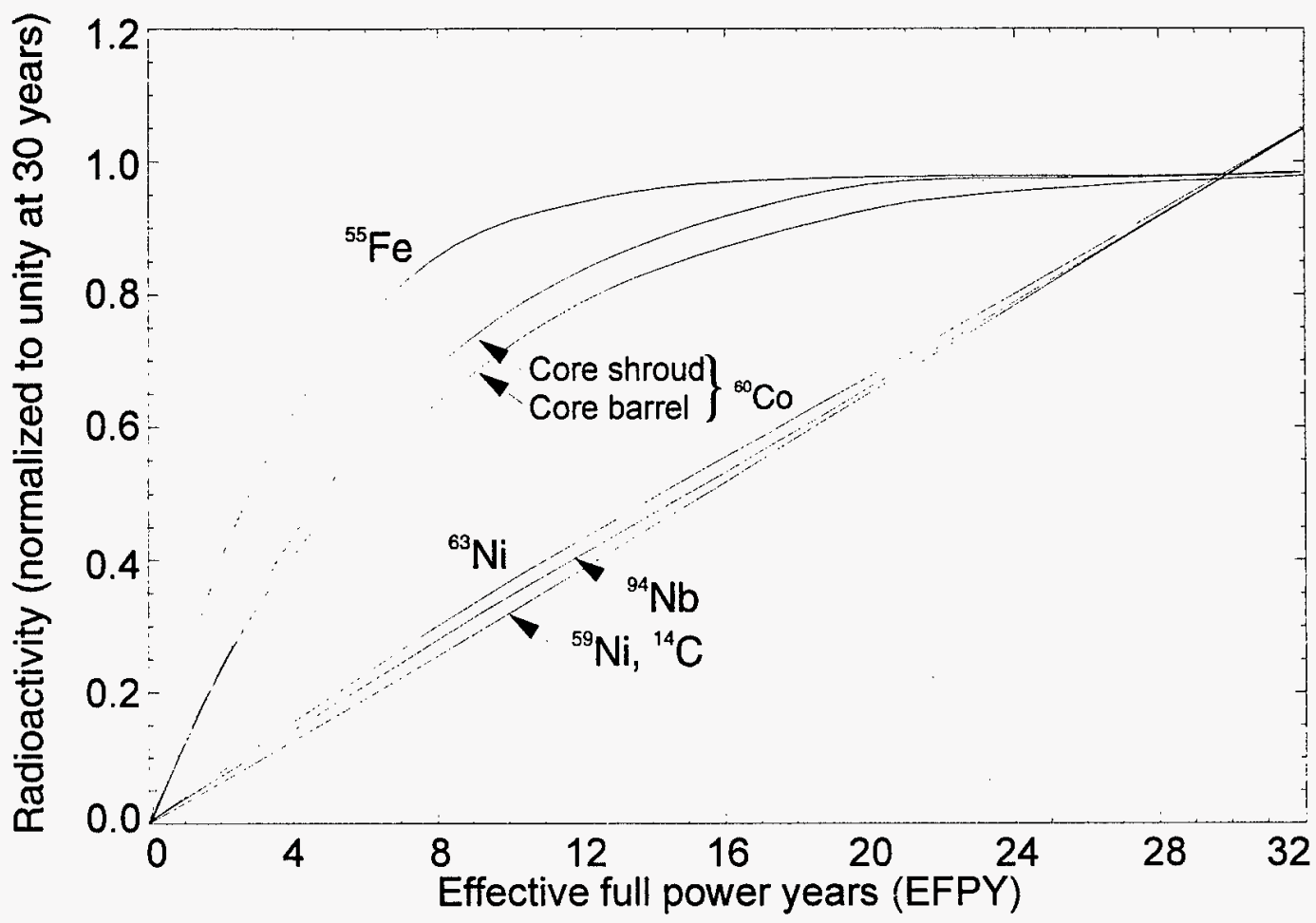

Figure 12-2. Buildup of some important activation products in a pressurized water reactor as a function of reactor operation. Note that the lowest curve from 0 to $\sim 30$ years represents ${ }^{59} \mathrm{Ni}$, and the second lowest curve from 0 to $\sim 30$ years is ${ }^{94} \mathrm{Nb}$ (from References 18 and 19).

Since this nuclide is produced exclusively by activation of stable cobalt in the reactor structural materials, the reactor fuel will only contain it in the cladding and end pieces of the fuel rods and not in the fuel itself. Removal of the fuel will not eliminate this nuclide from the nuclear waste. In addition, corrosion of cobalt-bearing materials can create special problems for decommissioning and dismantling activities. Although the materials that contain cobalt are largely corrosion resistant, some corrosion does occur. If the material is part of the reactor vessel (high neutron flux area), the activated ${ }^{60} \mathrm{Co}$ is transported with the reactor coolant to other parts of the plant where it can be deposited in low flow velocity volumes such as elbows and valves. This creates "hot spots" that must be specially shielded to prevent excessive personnel exposure during plant maintenance and decommissioning activities. If the structural material is outside the reactor vessel (low neutron flux areas), the corrosion products are transported into the reactor vessel where the cobalt is irradiated. The, now activated, ${ }^{60} \mathrm{Co}$ is then transported outside the vessel where it follows the same deposition patterns.

Although ${ }^{60} \mathrm{Co}$ has a relatively short half-life, compared with other nuclides studied in this report (e.g. ${ }^{137} \mathrm{Cs}$, [see Chapter 6] which has a half-life of 30.2 years, and ${ }^{63} \mathrm{Ni},{ }^{4}$ which has a half-life of 100 years), it still persists well into expected plant decommissioning/decontamination activities. 


\section{Medical, Academic Institutions, and Commercial Cobalt-60 Waste}

There are a number of commercial applications for ${ }^{60} \mathrm{Co}$. The transportation industry uses this nuclide as a radiation source to measure the thickness of automobile sheet steel. ${ }^{20}$ This nuclide has found extensive use in the metals industry as a radiography source to detect flaws in welded joints and castings. The electrical industry uses ${ }^{60} \mathrm{Co}$ to preionize gases in electronic tubes. There are several applications in the chemical-processing industry, including gauging of liquid or solid levels, a catalyst in flow studies, drug-metabolism studies, sterilization of medical supplies, and measuring the effects of polymerization in the initiating chemical reactions. This nuclide is used in the consumer-products industry to sterilize and pasteurize food and to control solid and liquid levels in foods and beverages. It is used to measure pipeline flow, level, and density gauging for the crude-petroleum and natural gas industries. Utilities also use ${ }^{60} \mathrm{Co}$ to measure snowpack densities for water resource management. In the agriculture industry, this nuclide is used to study the movement of insect larvae through soil, study mineral metabolism in animals, and to sterilize insects for control. Uses in the aerospace industry include radiographic inspection of parts and as a power source for locations remote from utility resources $\left({ }^{60} \mathrm{Co}\right.$ has been considered for application as fuel for the Systems for Nuclear Auxiliary Power reactor, but it is not clear whether it has ever actually been used in this application).

Because of its high-energy gamma radiation, ${ }^{60} \mathrm{Co}$ has been used extensively as a radiation source for both commercial and medical uses. It is used in place of $x$-rays or radium in materials inspection to reveal internal structure, flaws, or foreign objects. ${ }^{6}$ Its use is enhanced by its relatively long half-life that enables production of a reproducible gamma radiation field for a long time and its penetrating, highenergy gamma rays. It is also used as a standard spectroscopic calibration source for gamma-ray energies in the 1- to $2-\mathrm{MeV}$ range.

Because of the high gamma-ray energy associated with this nuclide, extreme care must be exercised when using a source. A rule of thumb for external exposure is $1.32 \mathrm{R} / \mathrm{h}$ per Ci $\left(3.56 \times 10^{-7} \mathrm{~Gy} / \mathrm{h}\right.$ per $\left.\mathrm{MBq}\right)$ of ${ }^{60} \mathrm{Co}$ for a source $1 \mathrm{~m}$ from a person. ${ }^{21}$

For example, an employee at the Nevada Test Site was attempting to manually replace the shield plug on a ${ }^{60} \mathrm{Co}$ shipping cask when he accidentally received a $1,200 \mathrm{rem}(12 \mathrm{~Sv})$ radiation dose to his right hand and a $42.5 \mathrm{rem}(0.43 \mathrm{~Sv})$ dose to his pelvis. This was due to his mistakenly thinking the source was still in the cask when it actually had been removed and was unshielded during the operation. ${ }^{22}$

In another incident, the U.S. Nuclear Regulatory Commission reported high levels of ${ }^{60} \mathrm{Co}$ in the ash generated during sewer sludge incineration at a treatment plant in Cleveland, Ohio. ${ }^{23}$ The contamination was caused by the disposal methods of a company licensed to manufacture radiation sources for cancer therapy.

${ }^{60} \mathrm{Co}$ is commercially available in multiple forms. It is available as the element dissolved in hydrogen chloride $(\mathrm{HCl})$ with concentrations ranging from $10^{-5}$ to $2,000 \mu \mathrm{Ci} / \mathrm{mL}\left(0.7\right.$ to $\left.7 \times 10^{7} \mathrm{~Bq} / \mathrm{mL}\right)$ and as $\mathrm{CoCl}_{2}$ dissolved in $\mathrm{HCl}$ with concentrations ranging from 1 to $1,000 \mu \mathrm{Ci} / \mathrm{mL}\left(3.7 \times 10^{4}\right.$ to $3.7 \times 10^{7} \mathrm{~Bq} / \mathrm{mL}$ ). ${ }^{24}{ }^{60} \mathrm{Co}$ is also available as a beta source (with thin-walled encapsulation to minimize attenuation of the beta-rays) in either aluminum or stainless steel backing materials with activities ranging from $8 \times 10^{-4}$ to $0.1 \mu \mathrm{Ci}(30$ to $37,000 \mathrm{~Bq})$. Finally, it is available as a gamma source in a variety of encapsulation materials (plastic, aluminum, polystyrene, Plexiglas, and epoxy resin) with activities ranging from 0.01 to $100,000 \mu \mathrm{Ci}\left(370\right.$ to $\left.3.7 \times 10^{9} \mathrm{~Bq}\right)$. Some suppliers, however, provide sources in multiple curies. ${ }^{60} \mathrm{Co}$ is commercially produced in the United States by the U.S. Department of Energy (DOE) in the Advanced Test Reactor at the Idaho National Engineering Laboratory (INEL) by irradiating cobalt rods or wire or nickel-plated pellets. It is then shipped in welded stainless steel containers. ${ }^{25}$ 
Thus, there is a variety of material types associated with this nuclide as a commercial gamma source, and the waste treatment/storage methods used to isolate it from the environment must take this variety into account.

\section{Disposal Data on Cobalt-60}

${ }^{60} \mathrm{Co}$ has been deposited in three LLW disposal sites in Richland, Washington; Barnwell, South Carolina; and Beatty, Nevada over a period of several years. Data have been obtained on this nuclide from the Manifest Information Management System Database. ${ }^{a}$ Figure 12-3 shows the total annual ${ }^{60} \mathrm{Co}$ activity deposited in the three sites for each year between 1986 and 1995. The total activity deposited each year ranged from 34,600 to $372,000 \mathrm{Ci}$.

Figure 12-4 shows the activity of ${ }^{60} \mathrm{Co}$ deposited in these three sites as a function of waste source. Utility sources account for more than $97 \%$ of the total deposited in these three sites. An additional $3 \%$ came from industrial sources and the rest $(<1 \%)$ from the other sources. The definition of disposal categories given in Figure 12-4 is as follows: academic - sources associated with university laboratories; government - sources associated with the government, such as military hospitals; industry - sources associated with manufacturing, other than utilities; medical - sources associated with hospitals and medical laboratories, excluding pharmaceutical manufacturing; utility - sources generated by nuclear utilities and stored onsite or sent to one of the three disposal sites. Waste treatment facilities are included in the utility category.

Figure 12-5 shows the activity of ${ }^{60} \mathrm{Co}$ deposited in the Richland and Beatty sites as a function of waste type. The waste disposal manifests for the Barnwell site did not break down the waste by type, which is unfortunate since more than $90 \%$ of this nuclide has been stored at this site. As shown in this figure, nearly $80 \%$ of this nuclide was in the form of activated reactor hardware. The waste types illustrated in Figure 12-5 are from nuclear reactors, academic institutions, and medical facilities.

\section{Behavior of Cobalt-60 in the Environment}

\section{Cobalt in Soils}

Understanding the behavior of radioactive materials such as ${ }^{60} \mathrm{Co}$ in the soil is important in assessing the possibility of transport of these radionuclides through the biosphere. ${ }^{26}$ It is important to understand the interactions between radionuclides and various media along the path to the biosphere, whether disposal is in deep or shallow rock caverns or in shallow overburden facilities.

a. Information provided through the DOE waste management system maintained by the National Low-Level Waste Management Program, Idaho National Engineering Laboratory (INEL). 


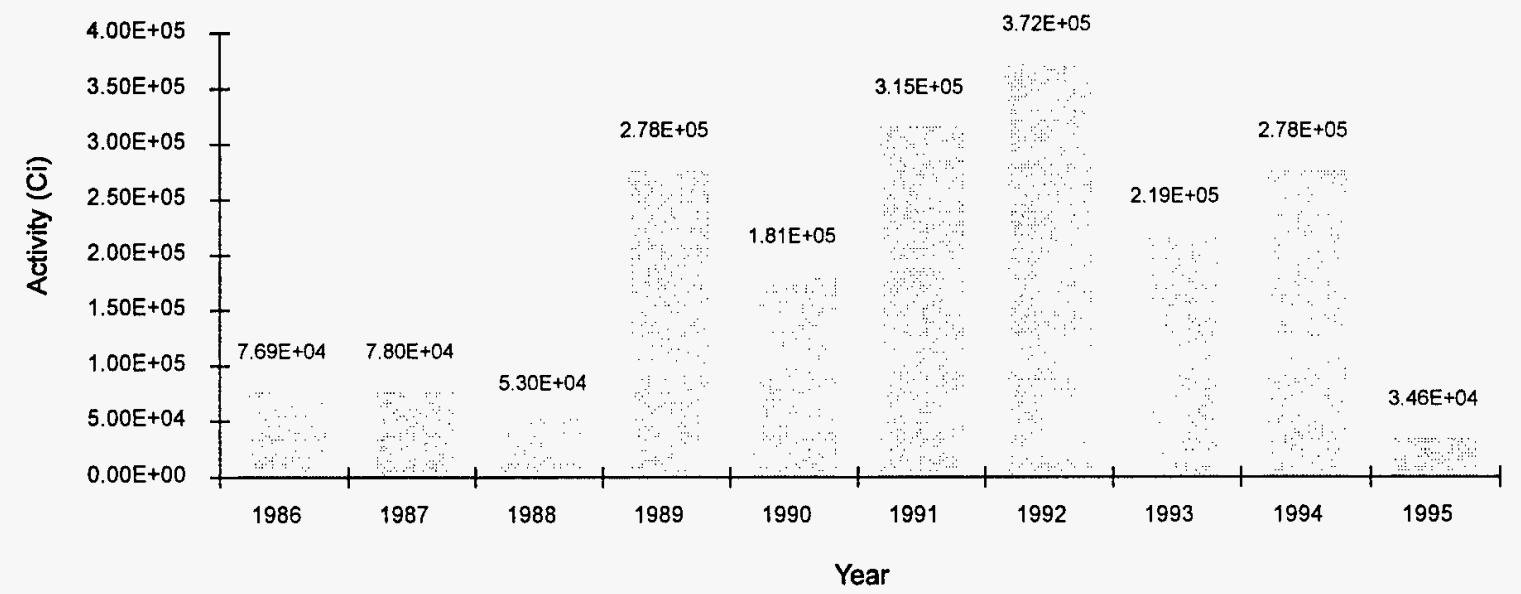

Figure 12-3. ${ }^{60} \mathrm{Co}$ activity deposited at the Richland, Beatty, and Barnwell sites by year (log scale).

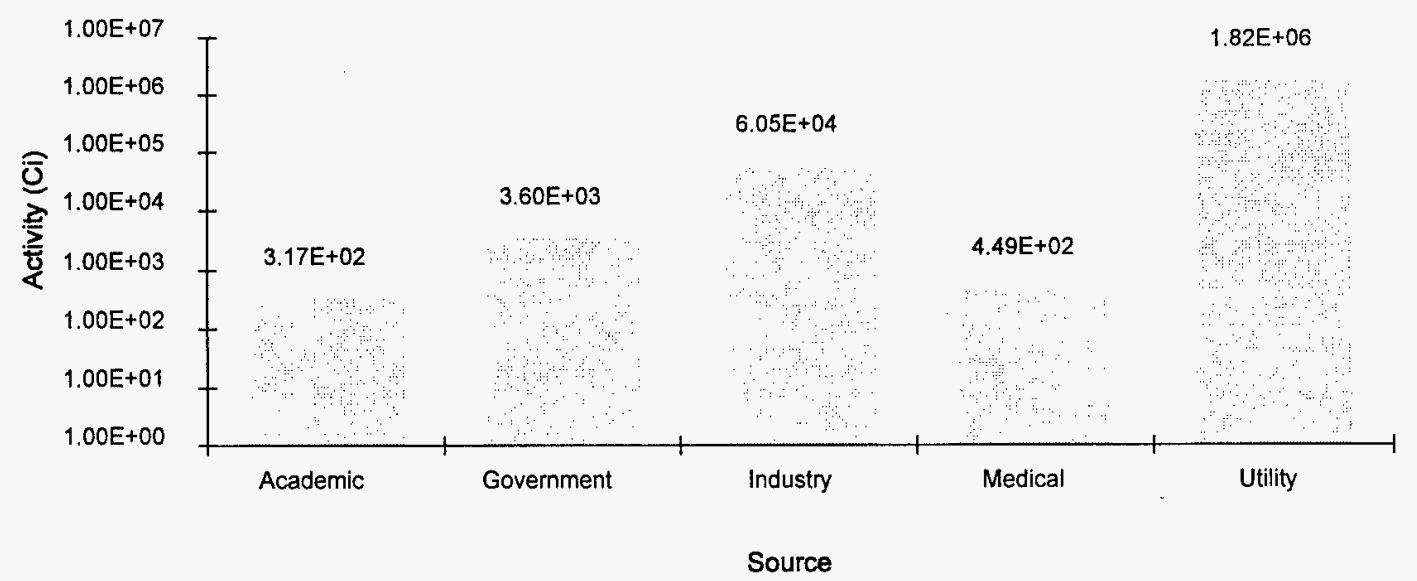

Figure 12-4. ${ }^{60} \mathrm{Co}$ activity deposited at the Richland, Beatty, and Barnwell sites by source (log scale). 


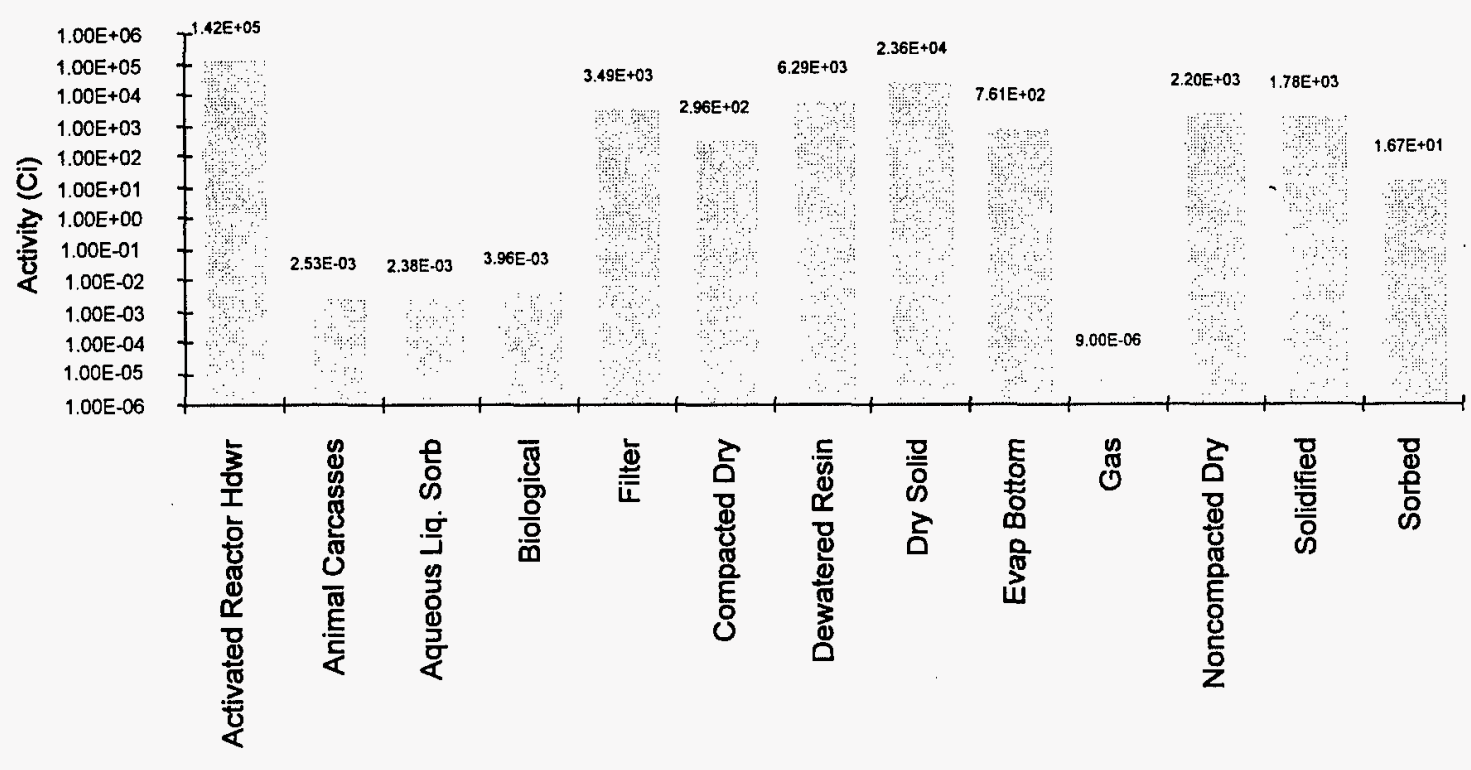

Waste Type

Figure 12-5. ${ }^{60} \mathrm{Co}$ activity deposited at the Richland and Beatty sites by waste type (log scale).

Four parameters were reported to be essential in accurately predicting soil concentrations from either contaminated ground water or irrigation water. ${ }^{26}$ The four parameters, in order of decreasing importance, are (1) soil retention, (2) annual precipitation, (3) soil texture, and (4) depth to the water table. The soil retention parameter represents the solid/liquid partition coefficient and is denoted by the symbol $K_{d} . K_{d}$ is defined by $K_{d}=C_{s} / C_{l}$, where $C_{s}$ is the cobalt concentration in the soil ( $\mu \mathrm{g}$ Co/gram of soil), and $\mathrm{C}_{1}$ is the cobalt concentration in the groundwater ( $\mu \mathrm{g} \mathrm{Co} / \mathrm{mL}$ of liquid). Therefore, the units of $\mathrm{K}_{\mathrm{d}}$ are $\mathrm{mL} / \mathrm{g}$ (i.e., $\mathrm{mL}$ of water per gram of soil). This empirical model combines all soil retention mechanisms into a simple linear partition relation between the soil and surrounding groundwater. This model assumes that the cobalt concentrations in groundwater and soil are in equilibrium with each other. Using this definition for $\mathrm{K}_{\mathrm{d}}$, it follows that the larger the value (i.e., the higher the radionuclide concentration in the soil relative to that in the groundwater), the slower the migration of the radionuclide relative to groundwater flow. Therefore, $K_{d}$ can be thought of as a measure of the amount of "fixing" or holdup in the soil.

Typically, $K_{d}$ is measured under laboratory conditions, using samples that are relatively homogenous, and where it can be ensured that equilibrium conditions are met. Applying these values to specific soils in the field can be difficult because actual soils are generally inhomogeneous and there are uncertainties as to how long it takes for the cobalt concentrations in the soil and groundwater $\left(\mathrm{C}_{\mathrm{s}}\right.$ and $\left.\mathrm{C}_{\mathrm{l}}\right)$ to reach equilibrium with each other. Therefore, soil samples used in laboratory studies should be as representative of the field as possible. Even though the soil samples do not precisely match conditions in the field, $K_{d}$ values from laboratory studies can be used in computer models that extrapolate data from laboratory experiments and field studies. In addition, some experiments are conducted using intact field samples to validate the laboratory $\mathrm{K}_{\mathrm{d}}$ values and to study the effects associated with soil inhomogeneity.

The range of $\mathrm{K}_{\mathrm{d}}$ for ${ }^{60} \mathrm{Co}$ has been reported in Reference 27 to be from 0.2 to $3,800 \mathrm{~mL} / \mathrm{g}$. The mean value is 55 . This illustrates the large variation of soil properties as well as variations of the tendency of ${ }^{60} \mathrm{Co}$ to be adsorbed depending on chemical form. This reference also indicates the effects of this nuclide on microorganisms in the soil. For ${ }^{60} \mathrm{Co}$ soil concentrations ranging from 10 to $100 \mathrm{ppm}$, there is a decrease of 4 to $23 \%$ in the respiration of loamy sand. 
In another experimental study of the soil retention of ${ }^{60} \mathrm{Co}$, the effect of complexing agents was measured. ${ }^{28} \mathrm{~K}_{\mathrm{d}}$ values for ${ }^{60} \mathrm{Co}$ were measured to be in the range of $1.2 \times 10^{3}$ to $7.0 \times 10^{4}$ for Conasauga shale with $\mathrm{pH} 12$ and 6.7, respectively. These values were reduced to between 0.8 and 2.9 with the addition of EDTA, an organic complexing agent often used for decontamination of nuclear plants. These $\mathrm{K}_{\mathrm{d}}$ values were corroborated by in situ measurements of soil and water ${ }^{60} \mathrm{Co}$ concentrations in wells near the Oak Ridge National Laboratory (ORNL). The $\mathrm{K}_{\mathrm{d}}$ values averaged 35, which was close to but somewhat larger than those in the experiment for the measured EDTA concentrations of $3.4 \times 10^{-7} \mathrm{M}$. Similar reductions in $\mathrm{K}_{\mathrm{d}}$ were also measured for conditions including other chelating agents such as diethylenetriaminepentaacetic acid (DTPA), EDTA, and natural organics such as humic and fulvic acids.

In a separate study, these results were qualitatively corroborated in the short term (for experiments lasting a few days). ${ }^{29}$ However, in the long term (for experiments lasting up to 500 days), the amount of cobalt remaining in solution decreased from $90 \%$ to less than $10 \%$. These results were corroborated with field tests at the Savannah River burial grounds where water concentrations of ${ }^{60} \mathrm{Co} / \mathrm{EDTA}$ decreased from $30 \%$ in 5 days to less than $1 \%$ after 15 days. This suggests that cobalt/EDTA has a tendency to dissociate, leaving uncomplexed cobalt, which is readily adsorbed by the soil. The implication to waste management is that the potential for transport of cobalt by EDTA may not be as serious at all burial sites as previously thought.

Reference 30 includes a good summary of the soil characteristics of elemental cobalt in general and ${ }^{60} \mathrm{Co}$ in particular. Soil concentrations of ${ }^{60} \mathrm{Co}$ have been measured to be in the range of 0.1 to $50 \mathrm{pCi} / \mathrm{g}$ ( 3.7 to $1,900 \mathrm{~Bq} / \mathrm{g}$ ) in surface soils and from 0.05 to $5 \mathrm{pCi} / \mathrm{g}$ (2 to $180 \mathrm{~Bq} / \mathrm{g}$ ) in subsurface $(11$ to $15 \mathrm{~cm}$ ) soils in the vicinity of a liquid disposal trench. Elemental cobalt and many of the simple compounds involving this element tend to be easily deposited in soil. Generally speaking, it appears that cobalt is adsorbed to the surface of clay materials in the soil through iron and manganese oxides. Only a small fraction is adsorbed onto the mineral lattice. Therefore, it would be expected that removal of cobalt from the soil could be achieved using extracting solutions such as acetic acid, dilute $\mathrm{HCl}$, and chelating compounds such as EDTA. Much of the information regarding the soil characteristics of cobalt were derived using different soil-extraction solutions. In this respect, acetic acid and EDTA compounds have been shown to extract a major proportion of cobalt from soil.

Because of the fixing ability of soils to remove cobalt from solutions, ${ }^{60} \mathrm{Co}$ tends to be found in the top $5 \mathrm{~cm}$ of soils. In addition, the activity of this nuclide was measured to decrease by $99 \%$ within $5 \mathrm{~m}$ of a waste disposal trench at DOE's Hanford, Washington, reservation. In a separate study, also reported in Reference 30 , it was shown that ${ }^{60} \mathrm{Co}$ penetrated soil very little and that $78 \%$ of the total activity was within the top $3-\mathrm{cm}$ layer of soil. In percolation tests, simulating rainfall, cobalt was shown to be removed from the soil at a slow rate of $5 \%$ per year.

The retention of ${ }^{60} \mathrm{Co}$ is strongly dependent on the type of soil and amount of rainfall. For example, a study was made of the effect of both of these parameters on cobalt retention, where it was shown that for low rain intensity $(2 \mathrm{~mm} / \mathrm{h}$ ), the organic (humic layer) top layer of soil retained nearly all of the percolating cobalt whereas for high rainfall $(30 \mathrm{~mm} / \mathrm{h})$ intensity, up to $10 \%$ was released from this layer. In the mineral soil layer, ${ }^{60} \mathrm{Co}$ was much more mobile. This type of information is important to determine initial distribution of fallout during rain and can affect the initial soil-to-plant transfer, initial outdoor radiation exposure, and subsequent transport in the groundwater. The humic layer consisted of $82 \%$ organic material while the mineral layer was primarily sand with up to $17 \%$ silt and only a few percent of clay. The ${ }^{60} \mathrm{Co}$ was introduced as $\mathrm{CoCl}_{2}$.

A study was made of the speed with which ${ }^{60} \mathrm{Co}$ moved in sandy soils. ${ }^{31}$ The chemical form of cobalt was $\mathrm{CoCl}_{2}$ and positively charged (cationic) cobalt was eliminated so that the noncationic 
behavior could be studied and rapid groundwater conditions were replicated. Some of the results of this study were that the noncationic species migrated independently from cationic species and that the noncationic cobalt was not adsorbed much by the sandy soil.

A Japanese study was conducted where the sorption and migration of ${ }^{60} \mathrm{Co}$ (and other nuclides ${ }^{85} \mathrm{Sr}$ and ${ }^{137} \mathrm{Cs}$ ) in coastal sandy soil were measured ${ }^{32}$ In particular, the effects of added humic acid (a complexing agent) on the sorption/migration behavior were studied. This study modeled the presence of dissolved organic substances in natural waters, which originate from the decay of organic matter in soils and waters. The resultant humic acid tends to be stable and complex in molecular structure. Since it is widely present in many soil structures, it is important to understand how it would affect the ability of waste disposal sites to retain radioactive nuclides, especially in the presence of rain or other sources of groundwater. It should be noted that sandy soil has little sorbing capacity for humic acid. Therefore, the results were not masked by any sorption of the acid independent of the radionuclides. Some geological materials, however, do adsorb humic acid and the results from this study should only be applied with care to these other conditions. All of the nuclides studied in this experiment, including ${ }^{60} \mathrm{Co}$, were chlorides in chemical form (e.g., $\mathrm{CoCl}_{2}$ ). The results from this study indicate that the sorption ratio (related to $\mathrm{K}_{\mathrm{d}}$ ) of ${ }^{60} \mathrm{Co}$ decreased from $300 \mathrm{~mL} / \mathrm{g}$ for the case with no humic acid, to approximately $20 \mathrm{~mL} / \mathrm{g}$ for the case of $35 \mathrm{ppm}$ humic acid. The other two nuclides did not exhibit any significant decrease in sorption ratio.

The Yankee Rowe Nuclear Power Plant has been shut down and is in the planning stage for decommissioning and decontamination activities. Reference 33 summarizes remediation plans for this site. Based on measurements taken in 1993 and 1994 (after final shutdown in 1992), it was concluded that the primary radionuclide that migrated beyond the reactor control area of the plant was ${ }^{60} \mathrm{Co}$, which was measured in a few areas immediately adjacent to the plant. Additionally, since most of the site was covered with asphalt, the ability of this material to minimize migration of nuclides was also assessed. It was concluded that asphalt is porous, at least as related to the nuclides of interest. In some instances, the ${ }^{60} \mathrm{Co}$ concentrations immediately below the asphalt were higher than those in the asphalt samples. Approximately $98 \%$ of the activity resides within 6 in. from the surface, independent of which specific nuclide was being measured. The dose rate for a person exposed to the highest levels of radiation at the site would be $100 \mathrm{mrem} /$ year, leaving soil removal as the only realistic option for decommissioning. If the locations of high concentration could be administratively averaged with adjacent areas, it was concluded that little remediation would be required other than waiting a few years for the levels to decrease.

The last two references in this section summarize in situ studies of ${ }^{60} \mathrm{Co}$ in soil samples. Reference 34 summarizes the sampling in areas surrounding the Browns Ferry Nuclear Power Plant and included samples taken of various substances including air, water, milk, foods, vegetation, fish, sediment, and soil. This study is a direct measure of the soil contamination due to the operation of this commercial nuclear reactor. There were no measurable radioactivities in the soils that could be identified with operation of this plant (there was measurable ${ }^{137} \mathrm{Cs}$ activity, but this was identified with fallout, not plant operations). There was some ${ }^{60} \mathrm{Co}$ activity measured in sediment samples, but the activity levels were low and did not represent a hazard to the public.

Reference 35 summarizes sampling conducted at the Maxey Flats, Kentucky, shallow land burial site and involved measuring several radionuclides, including ${ }^{60} \mathrm{Co}$. This reference concluded that some ${ }^{60} \mathrm{Co}$ was measured in sediment samples adjacent to the site. This was due to surface runoff of rain into the adjacent woods, rather than subsurface migration. The only nuclide activity that exceeded expected nuclear fallout levels was ${ }^{60} \mathrm{Co}$, and its level was low (approximately 1 to $2 \mathrm{pCi}$ [0.04 to $0.07 \mathrm{~Bq}$ ] of ${ }^{60} \mathrm{Co} / \mathrm{g}$ of soil) in areas outside of the waste disposal site. 


\section{Cobalt in Water}

Reference 30 discusses cobalt in aquatic ecosystems, including both water and sediments. According to this reference, there are relatively few data relating to ${ }^{60} \mathrm{Co}$ concentrations in sediments. One study reported that the sediment concentration of ${ }^{60} \mathrm{Co}$ was 20 times higher than the concentration in the surrounding water. This indicates that the soil in these sediments does a good job of extracting the ${ }^{60} \mathrm{Co}$ from the water, consistent with much of the data in the preceding section. Other studies summarized by this reference (including measurements taken in the White Oak Lake and in water near the Humboldt Bay Power Reactor) corroborate these findings, namely that ${ }^{60} \mathrm{Co}$ in water tends to be readily adsorbed by the sediment. One included study concluded that the accumulation ratios for sediments would be expected to differ in short-term studies compared to long-term studies because they tend to be cyclic in nature. The cyclic behavior would be affected by sediment accumulation cycles, which tend to peak in spring and early summer due to runoff of winter snow. This reference concluded that the distribution of ${ }^{60} \mathrm{Co}$ between water and bottom sediments can be assumed, in general, to be $5 \%$ in the water and $95 \%$ in the sediment and that this balance can be expected to be achieved rapidly. The concentration ratios for marine and freshwater aquatic systems are expected to be of the order of $10^{4}$ and $10^{3}$, respectively.

Reference 34 included measurements of radioactive concentrations in river and reservoir water as well as from wells in the vicinity of the Browns Ferry Nuclear Power Plant. This indicates contamination of the surrounding surface and groundwaters because of operation of this plant. All radioactivity in surface water samples was below the lower level of detectability for all species except the gross beta activity and naturally occurring nuclides. Similar results were reported for groundwater samples. Therefore, there were no measurable concentrations of ${ }^{60} \mathrm{Co}$ in any of the water samples. However, ${ }^{60} \mathrm{Co}$ was measured in some sediment samples. Because of the low levels of measured activities of this nuclide, sediment samples were taken both upstream and downstream of the plant so that the effects of fallout could be determined. The upstream (fallout dominated) concentrations were $0.02 \mathrm{pCi} / \mathrm{g}\left(7 \times 10^{-4} \mathrm{~Bq} / \mathrm{g}\right)$ compared with $0.05 \mathrm{pCi} / \mathrm{g}\left(2 \times 10^{-3} \mathrm{~Bq} / \mathrm{g}\right)$ in the downstream (fallout plus plant release) samples. Thus, there is a measurable difference, although the levels of ${ }^{60} \mathrm{Co}$ are extremely low.

The remediation plan, summarized by Reference 33, also included groundwater sampling. The groundwater in the vicinity of the Yankee Rowe Nuclear Power Plant lies between 3 and $18 \mathrm{ft}$ below the ground surface. There was no measurable ${ }^{60} \mathrm{Co}$ in any of the groundwater samples taken for this study.

Radionuclide concentrations are periodically measured for systems in the vicinity of the Calvert Cliffs Nuclear Power Plant. ${ }^{36}$ Low concentrations of ${ }^{60} \mathrm{Co}$ were measured in most of the sediment samples in the vicinity of this power plant. The samples were taken from the shoreline of the Chesapeake Bay, in marine water locations. The report concludes that $227 \mathrm{mCi}\left(8.40 \times 10^{9} \mathrm{~Bq}\right)$ of ${ }^{60} \mathrm{Co}$ were released during 1985 and 1986 into the bay via cooling water discharge. The maximum ${ }^{60} \mathrm{Co}$ concentration measured in the (sandy) sediment samples was $280 \mathrm{pCi} / \mathrm{kg}(10 \mathrm{~Bq} / \mathrm{kg})$.

A study was made of the groundwater contamination in the vicinity of ORNL. ${ }^{37}$ A seep has developed near one of the burial trenches associated with the laboratory. Water samples taken from this seep showed ${ }^{60} \mathrm{Co}$ concentrations above normal background levels, and it was decided to attempt to correlate these findings with the water chemistry in the trench. Specifically, the effect of the presence of complexing agents, such as EDTA, in the water was studied. EDTA is used in cleanup and decontamination operations at the laboratory and is found in liquid waste. However, the presence of EDTA in the groundwater could not be verified. The principal conclusions of the report are that uncomplexed ${ }^{60} \mathrm{Co}$ is expected to be bound with the soil and not be transported with the groundwater; the 
principal adsorbents in the (Conasauga shale) soil are manganese oxides; and complexed ${ }^{60} \mathrm{Co}$ (with, for example, EDTA) is the principal chemical form of cobalt that did migrate to the seep.

The corrosion of ${ }^{60} \mathrm{Co}$-laden stainless steel samples by seawater and the subsequent fate of the release nuclide were the subject of a study conducted by the Pacific Northwest Laboratory. ${ }^{38}$ In this study, irradiated stainless steel samples were placed in the flowstream of seawater. The flow carried the ${ }^{60} \mathrm{Co}$ into another chamber where marine animals and sediment absorbed the nuclide and the final concentrations in the animals, seawater, and sediment were measured. This study simulated what would be expected to occur as a result of disposal of activated stainless steel components in the oceans. It was concluded that most of the activity absorbed by the animals was from the interstitial water in the sediment and not from the bulk water.

Groundwater contamination patterns beneath the Hanford Project reservation have been studied periodically throughout the history of the site. Two studies are summarized here, the one for the period up to $1972^{39}$ and the one for the period of January to December $19766^{40}$ In the first report, the principal radionuclides (other than naturally occurring radionuclides) detected in the groundwater were ${ }^{60} \mathrm{Co}$ and ruthenium-106 $\left({ }^{106} \mathrm{Ru}\right)$. Reactor coolant had been discharged directly into the Columbia River but had been terminated before this first report. As a result, although the ${ }^{60} \mathrm{Co}$ levels were detectable, they were decreasing. Maximum ${ }^{60} \mathrm{Co}$ concentrations in either river or groundwater were less than $12 \mathrm{pCi} / \mathrm{L}(0.4$ $\mathrm{Bq} / \mathrm{L})$.

In the second report, the extent of underground "plumes" were measured. Although not specifically stated, the mobility of the ${ }^{60} \mathrm{Co}$ with the groundwater suggests the presence of complexing agents. The only Hanford-related nuclide that was measured in the Columbia River water was ${ }^{60} \mathrm{Co}$. The presence of this nuclide is attributed to reactor coolant discharge into the river. Therefore, no contamination of the river due to underground migration was detected.

The leaching of ${ }^{60} \mathrm{Co}$ from soil was measured in an experiment conducted by personnel of the Belgium Department of Radioprotection. ${ }^{41}$ In this study, homogeneously contaminated sandy soils were exposed to water flows, simulating rain water. The study concluded that up to $1.7 \%$ of the $15 \mathrm{mCi} / \mathrm{m}^{2}$ $\left(5.3 \mathrm{MBq} / \mathrm{m}^{2}\right){ }^{60} \mathrm{Co}$ was leached over a 2-year period.

An experimental study was made by the Japan Atomic Energy Research Institute (JAERI) of the migration of ${ }^{60} \mathrm{Co}$ under steady-state water flow conditions. ${ }^{42}$ Two different coastal sand soils were used in this experiment. The study concluded that most of the ${ }^{60} \mathrm{Co}$ was adsorbed on the soil near the injection point. This adsorption was believed to be due to ion exchange. A small fraction of the ${ }^{60} \mathrm{Co}$ did migrate beyond the injection point, primarily as particulates.

A separate JAERI study was made of the effects of nonsteady state water flow conditions on the migration of ${ }^{60} \mathrm{Co}^{43}$ This was done to simulate intermittent rainfall and evaporation cycles. This study concluded that there were two natural chemical forms for cobalt under these conditions. First, cationic ${ }^{60} \mathrm{Co}$ was postulated, which readily adsorbed on the soil and remained fixed. Second, ${ }^{60} \mathrm{Co}(\mathrm{OH})_{2}$ was postulated, which was generated as a result of hydrolysis in the interstitial water during the evaporation phases and which was more mobile. The migration of this hydroxide form was sensitive to the cycling of the water flow and comprised approximately $1 \%$ of the total ${ }^{60} \mathrm{Co}$ injected during the test.

\section{Cobalt in Plants}

In addition to the previously summarized results, Reference 30 also contains a summary of the uptake of ${ }^{60} \mathrm{Co}$ into terrestrial plants. For example, one study, summarized in this reference, reported 
${ }^{60} \mathrm{Co}$ concentrations ranging from 4.22 to $13.2 \times 10^{-3} \mu \mathrm{Ci} / \mathrm{g}(156$ to $490 \mathrm{~Bq} / \mathrm{g}$ ) in the roots and from 1.1 to $3.0 \mathrm{pCi} / \mathrm{g} \mathrm{(39}$ to $112 \mathrm{~Bq} / \mathrm{g}$ ) in aboveground parts of plants growing near a trench storage site. Another study reported between 0.002 and $2 \mathrm{pCi} / \mathrm{g}(0.074$ and $7.4 \mathrm{~Bq} / \mathrm{g})$ of ${ }^{60} \mathrm{Co}$ in plants from the Enewetak Atoll, which lies close to the site of numerous aboveground nuclear explosion tests. This study further states that the fraction of ${ }^{60} \mathrm{Co}$ fixed to magnesium oxides in the soil is not available for uptake by plants. Other factors affecting plant uptake include soil $\mathrm{pH}$ (decreasing cobalt uptake with increasing $\mathrm{pH}$ ) and soil type (plants grown on coarse textured soils tend to have higher concentrations of cobalt than those grown on heavy textured soils containing high amounts of organic matter).

In an experiment involving maize and bushbeans, it was found that most of the ${ }^{60} \mathrm{Co}$ in maize was retained by the roots $(>95 \%)$ and the rest was in the aboveground parts of the plant. For bushbeans, the roots also exhibited the highest concentrations, although the total fraction in the roots was less than for maize.

In a study involving rice, it was determined that the rice plant could accumulate $0.3 \%$ of the ${ }^{60} \mathrm{Co}$ in the soil. Again, the roots exhibited most of the storage of ${ }^{60} \mathrm{Co}(68 \%)$. In summary, for the plants considered in the Reference 30 report, the fraction of soil-applied ${ }^{60} \mathrm{Co}$ that remained in the roots, relative to that absorbed by the entire plant, was $68 \%, 70 \%$, and $96 \%$ for rice, bushbeans, and corn.

This conclusion that most of ${ }^{60} \mathrm{Co}$ absorbed by plants remains in the roots was also noted in a separate study performed by the Atomic Energy Authority of Egypt. ${ }^{44}$ Approximately $70 \%$ of the absorbed nuclide remained in the roots. The soil used in the experiments was sandy loam soil and clover was used as the plant. This experiment was designed to investigate the ability of clover to extract ${ }^{60} \mathrm{Co}$ from soil as part of a decontamination effort. Several complexing agents were also introduced to measure their effects on cobalt extraction. Of the complexing agents used in this study, it was concluded that Fe-DTPA enhanced ${ }^{60} \mathrm{Co}$ extraction the most.

A different type study was performed by scientists at the Institute for Radiation and Botany of the Organization for Radiation and Environmental Research, Ltd. ${ }^{45}$ In the study, partially grown grasses were brought into contact with ${ }^{60} \mathrm{Co}$-contaminated slime. The nuclide surface contamination (from the direct contact of the slime with the plant parts) as well as the internal contamination (uptake from the soil) were measured. The mean value for the transfer coefficient (the ratio of the concentration of ${ }^{60} \mathrm{Co}$ in the plant to that in the soil) was about $2 \times 10^{-2} \mathrm{pCi} / \mathrm{kg}$ (plant) per $\mathrm{pCi} / \mathrm{kg}$ (soil).

The influence of residence time on the uptake of ${ }^{60} \mathrm{Co}$ from soil to barley plants was measured in an experiment conducted at the Institute of Radioagronomy in Juelich, Germany. ${ }^{46}$ Two different soil types were used: parabraunerde (mixture of fine sand, silt, and clay) and podsol (primarily fine and coarse sand). The chemical form for cobalt was $\mathrm{CoCl}_{2}$. The transfer factor (concentration in plants divided by the concentration in the soil) was approximately 0.04 for podsol and 0.02 for parabraunerde. In both cases, only limited amounts of ${ }^{60} \mathrm{Co}$ could be extracted from the soils.

A similar experiment extended the results to a number of other plants, including winter wheat, summer barley, radishes, and lettuce. ${ }^{47}$ This study used the same soils as did Reference 46 . The transfer factors varied from 0.004 to 0.01 in the parabraunerde soil and from 0.007 to 0.26 in the podsol soil. In each case, the winter wheat exhibited the largest transfer factor and lettuce exhibited the smallest.

A large database of soil/plant transfer factors has been developed by the International Union of Radioecologists. ${ }^{48}$ This database contains approximately 2,000 soil-to-plant transfer facters and this reference contains an update to this database. Included in the database are soil/plant transfer factors for ${ }^{60} \mathrm{Co}$ for a variety of plants and for four soils: sand, loam, clay, and silt. Ten different crop types are 
included: cereal (both grain and flour), fodder (maize, clover, alfalfa), grass, leaves of root crops, pods (pods and seeds of peas and beans), roots of root crops (beets, radishes), shoots (stems and shoots of cereals, pears, beans, potatoes, and bran), tubers, green vegetables (cabbage, spinach, leek, lettuce), and nonedible roots. The transfer factors for ${ }^{60} \mathrm{Co}$ range from 0.04 to 0.3 for sand soil, 0.001 to 0.18 for loam, 0.001 to 0.19 for clay, and 0.003 to 0.53 for silt. In each case, the highest transfer factor was measured for green vegetables and the lowest for cereal. There were no data for roots, which in some earlier-mentioned studies exhibited the highest concentrations.

The uptake of ${ }^{60} \mathrm{Co}$ in the vicinity of the Hanford Reach of the Columbia River (near the DOE's Hanford site) was measured for several types of wild plants and farm crops. ${ }^{49}$ The wild plants were the mulberry tree, willows, and reed canary grass. The ${ }^{60} \mathrm{Co}$ concentrations were about $0.03 \mathrm{pCi} / \mathrm{g}$ $(0.001 \mathrm{~Bq} / \mathrm{g})$ in the mulberry foliage and ranged from 0.02 to $0.1 \mathrm{pCi} / \mathrm{g}(0.0007$ to $0.004 \mathrm{~Bq} / \mathrm{g})$ in the fruit. Of the farm crops collected in the survey (asparagus, pumpkin, and tomatoes), only tomatoes had measurable concentrations of ${ }^{60} \mathrm{Co}$. The nuclide concentration for this vegetable was approximately $0.02 \mathrm{pCi} / \mathrm{g}(0.0007 \mathrm{~Bq} / \mathrm{g})$, which would result in an estimated dose of $3 \times 10^{-5} \mathrm{mrem}\left(3 \times 10^{-7} \mathrm{mSv}\right)$ if $1 \mathrm{~kg}$ were consumed.

The final study included in this report was performed by personnel at the Institute for Radioactivity and Agronomy of the Nuclear Research Laboratory in Juelich on the influence of aging on ${ }^{60} \mathrm{Co}$-uptake by young barley plants. ${ }^{50}$ In this study, the same ${ }^{60} \mathrm{Co}$-contaminated soil samples were used to raise three successive plantings of barley. There was a significant dropoff in the uptake of ${ }^{60} \mathrm{Co}$ by the plants with succeeding plantings, indicating some "aging" effects on the soil/plant transfer. There was no clear indication of what aging phenomena caused the decrease in the transfer factor.

\section{Cobalt in Air}

The injection of ${ }^{60} \mathrm{Co}$ into air can occur as a result of either atmospheric nuclear weapons testing activities or a severe core damage accident. In either case, since ${ }^{60} \mathrm{Co}$ is not a fission product, the production occurs as a result of the neutron irradiation of structural materials associated with either the weapon or the reactor. Atmospheric weapons testing was terminated several half-lives ago, and the residual ${ }^{60} \mathrm{Co}$ contamination has been reduced significantly by radioactive decay. Thus, only small amounts would be expected to persist from this activity. For example, Reference 34 includes an assessment of the persistent fallout activity in the region of the Browns Ferry Nuclear Plant. This report concluded that the only measurable fallout activity at this time (1992) is ${ }^{137} \mathrm{Cs}$. However, comparison of ${ }^{60} \mathrm{Co}$ activities in water upstream and downstream of the plant indicate some source of this nuclide external to the plant.

In an earlier study of the Maxey Flats (Kentucky) burial site contamination (1984), measurable amounts of ${ }^{60} \mathrm{Co}$ were detected whose distribution clearly suggested fallout as a source. ${ }^{35}$ This conclusion is based on comparison of ${ }^{60} \mathrm{Co}$ concentrations (in the soil and in the groundwater) in samples taken near and far from the burial site. The fallout-originated soil contamination levels are not specifically stated in the report, but the implication is that these levels are less than or approximately $0.1 \mathrm{pCi} / \mathrm{g}(0.004 \mathrm{~Bq} / \mathrm{g})$. Since this report predates the nuclear reactor accident at Chernobyl, these contamination levels are presumably due to atmospheric testing of nuclear weapons.

Residents of Bikini Island were contaminated by radionuclides from fallout of atmospheric testing, and in 1978, they were removed from their homes and relocated to the Marshall Islands to avoid additional contamination. ${ }^{51}$ At the time the residents were moved, exposure was estimated to result in annual doses in excess of $0.5 \mathrm{rem}(0.005 \mathrm{~Sv})$ in some cases (this was due to the total exposure and not 
just that of $\left.{ }^{60} \mathrm{Co}\right)$. Body burdens of ${ }^{60} \mathrm{Co}$ ranged from 1.6 to $3.0 \mathrm{pCi}(60$ to $110 \mathrm{~Bq})$ in a sample of the population.

Reference 52 is a summary of the radionuclide concentrations found in game birds that frequent the area within and surrounding the Hanford site. This report concludes that "radionuclide concentrations attributable to Hanford operations were only slightly greater than (within a factor of 10) or indistinguishable from expected levels attributed to worldwide fallout." Concentrations of ${ }^{60} \mathrm{Co}$ in duck meat were as high as $1.8 \mathrm{pCi} / \mathrm{g}(0.07 \mathrm{~Bq} / \mathrm{g})$, which would imply that at least one-tenth of this contamination would be due to fallout. This study was conducted during the period of atmospheric testing when the ${ }^{60} \mathrm{Co}$ levels due to fallout would be highest.

In summary, ${ }^{60} \mathrm{Co}$ can enter the air from atmospheric testing of nuclear weapons (this practice was ended 30 years ago) or from a severe core damage accident in a nuclear plant.

\section{Behavior of Cobalt-60 in the Human Body and in Animals}

This section summarizes several studies of the behavior of ${ }^{60} \mathrm{Co}$ in the human body and in animals. This behavior is complex and depends on whether the nuclide is taken into the body (either by ingestion or inhalation) or irradiates the body externally. There are numerous such studies and only a small number are included here. First, the behavior of this nuclide in animals is discussed, followed by a discussion of the behavior in humans.

\section{Behavior of Cobalt-60 in Animals}

Cobalt is required in small amounts by plants and animals and is part of vitamin $\mathrm{B}_{12}$. Cobalt compounds are typically added to salt licks in those areas of the world where it is naturally deficient to avoid serious cattle and sheep diseases. ${ }^{5}$

Retention of radionuclides has been measured in various game birds that reside in or around the Hanford site. ${ }^{52}$ Various birds, including coots, ducks, geese, and pheasants, were collected from areas on the site and along the adjacent stretch of the Columbia River during the period from 1971 to 1975 . These birds were selected because they represent a potential route for ${ }^{60} \mathrm{Co}$ to get from the environment into the human food chain. Of these birds, ${ }^{60} \mathrm{Co}$ was found mainly in ducks and was found more frequently in pond ducks (ducks that were harvested from ponds on the Hanford site) than for river ducks (ducks that were harvested from the Columbia River). This is not unexpected because the ${ }^{60} \mathrm{Co}$ water concentrations were higher in the ponds than in the river. The highest concentration of ${ }^{60} \mathrm{Co}$ in the meat was $1.8 \mathrm{pCi} / \mathrm{g}$ $(0.07 \mathrm{~Bq} / \mathrm{g})$ and the range of concentrations was from 0.01 to $1.8 \mathrm{pCi} / \mathrm{g}(0.0004$ to $0.07 \mathrm{~Bq} / \mathrm{g})$. It is estimated that ingestion of $500 \mathrm{~g}$ of duck meat contaminated with $1.8 \mathrm{pCi} / \mathrm{g}(0.07 \mathrm{~Bq} / \mathrm{g})$ of ${ }^{60} \mathrm{Co}$ would result in a whole body dose of $0.004 \mathrm{mrem}(40 \mu \mathrm{Sv})$. The ${ }^{60} \mathrm{Co}$ concentrations in the sampled pheasant, coot, and geese populations were much less and were near the lower level of detectability.

A similar study was performed on various animals that reside on the INEL near Idaho Falls, Idaho. ${ }^{53}$ Barn swallows were collected in this study and exhibited levels of ${ }^{60} \mathrm{Co}$ in all adult and most of the immature birds analyzed. Concentrations ranged from 4 to $8 \mathrm{pCi} / \mathrm{g}(0.1$ to $0.3 \mathrm{~Bq} / \mathrm{g})$ for immature birds to $50 \mathrm{pCi} / \mathrm{g}(2 \mathrm{~Bq} / \mathrm{g})$ for adult birds. Relative to filtered pond water on the site, the concentration factor] (ratio of the ${ }^{60} \mathrm{Co}$ concentration in the bird $[\mathrm{pCi} / \mathrm{g}]$ to that in the water $[\mathrm{pCi} / \mathrm{mL}]$ ) for ${ }^{60} \mathrm{Co}$ was 1.3 to 2.7 for immature birds and 17 for adult birds. Other birds included in the study included ducks and coots that were harvested from the leaching pond at the Test Reactor Area at the INEL. This study included an analysis of the distribution of ${ }^{60} \mathrm{Co}$ between the various body parts. The edible parts of the bird (muscle) contained ${ }^{60} \mathrm{Co}$ concentrations approximately $35 \mathrm{pCi} / \mathrm{g}(1.3 \mathrm{~Bq} / \mathrm{g})$, where nonedible parts 
contained concentrations of $1,879 \mathrm{pCi} / \mathrm{g}(70.5 \mathrm{~Bq} / \mathrm{g})$ and $540 \mathrm{pCi} / \mathrm{g}(20.0 \mathrm{~Bq} / \mathrm{g})$ for gut and feathers, respectively. Thus, the ${ }^{60} \mathrm{Co}$ tended to not concentrate in the edible parts as much as in the nonedible parts. Similar, although not quite as dramatic, differences in ${ }^{60} \mathrm{Co}$ concentrations between edible and nonedible parts were also measured in sage grouse collected near the same area.

Reference 30 lists concentration factors for ${ }^{60} \mathrm{Co}$ for various animals, such as mice, dogs, and monkeys. There is a wide range of concentration factors (including distribution among body parts) too numerous to be included in this document.

Reference 38 was a experimental study of the transfer of ${ }^{60} \mathrm{Co}$ from activated stainless steel to marine animals. In this study, activated stainless steel was exposed to seawater, which contained various common marine animals. The uptake of the radionuclide into these animals was measured. The results showed that the concentration factor for ${ }^{60} \mathrm{Co}$ varied widely among the various animals. For mollusks, the concentration factor ranged from 1 to 210 , for crustacea, from 300 to 4,000 , and for fish, from 20 to 5,000 .

Reference 36 summarizes radionuclide concentrations in marine animals attributable to emissions from the Calvert Cliffs Nuclear Power Plant. This report concludes that there are measurable amounts of ${ }^{60} \mathrm{Co}$ in oysters harvested from the Chesapeake Bay in the vicinity of the plant. The ${ }^{60} \mathrm{Co}$ ranged in concentration from 2 to $5 \mathrm{pCi} / \mathrm{kg}(0.07$ to $0.2 \mathrm{~Bq} / \mathrm{kg})$ and was only found in a couple of the samples. No measurable concentrations of ${ }^{60} \mathrm{Co}$ were found in samples of blue crabs, grass shrimp, or finfish.

\section{Behavior of Cobalt-60 in Humans}

The fractional absorption of ${ }^{60} \mathrm{Co}$ from the gastrointestinal tract after ingestion is variable and depends on the mass of cobalt ingested and whether ingestion takes place with a meal or after a period of fasting. ${ }^{30}$ The assumption of a fractional absorption of 0.2 is conservatively high and may overestimate the actual value by as much as a factor of 10 in some cases. For most animals, the inhalation classification is W (Week) for any cobalt compound. However, for humans, the recommended classification is $\mathrm{Y}$ (Year) for oxides, hydroxides, halides, and nitrates and $\mathrm{W}$ for all other compounds. The reason for this difference is that cobalt tends to reside longer in the lungs for humans than for animals. According to this reference, cobalt distributes itself relatively uniformly throughout a human with the possible exception of the liver, which tends to have a higher concentration. Reference 54 was a study of ${ }^{60} \mathrm{Co}$ uptake in various soil, plant, and animal materials due to fallout from atmospheric testing. This study showed higher concentrations in both the liver and kidneys of rats. Reference 20 also indicates that ${ }^{60} \mathrm{Co}$ tends to concentrate in the liver.

Reference 55 includes a detailed listing of the equivalent dose per unit intake of various radionuclides by inhalation, including ${ }^{60} \mathrm{Co}$. This reference indicates that the dose, which is class dependent, is approximately $2,700 \mathrm{rem} / \mathrm{Ci}\left(1 \times 10^{-8} \mathrm{~Sv} / \mathrm{Bq}\right)$ for Class $\mathrm{W}$ and $16,000 \mathrm{rem} / \mathrm{Ci}$ $\left(6 \times 10^{-8} \mathrm{~Sv} / \mathrm{Bq}\right)$ for Class $\mathrm{Y}$. For ingestion, the equivalent dose per unit intake, is approximately 800 to $1,900 \mathrm{rem} / \mathrm{Ci}\left(3 \times 10^{-9}\right.$ to $\left.7 \times 10^{-9} \mathrm{~Sv} / \mathrm{Bq}\right)$, depending on the gastrointestinal uptake fraction, $\mathrm{f}_{1}(0.05$ to 0.3 ). In both cases, the dose is relatively uniform for all included organs. In this reference, Class $Y$ and $f_{1}=0.05$ are for oxides, hydroxides, and trace inorganics. Class $W$ and $f_{1}=0.3$ are for organic complexed compounds and all other inorganics.

${ }^{60} \mathrm{Co}$ is also used extensively in the medical industry to treat various types of cancer. Standard treatments have been developed for cancers of various organs including the bladder, ${ }^{56}$ kidney, ${ }^{57}$ and ovary. ${ }^{58}$ Each of these treatments involves exposure of the affected area with the gamma radiation from ${ }^{60} \mathrm{Co}$ to achieve a specific dose: $5,000,6,000$, and $4,000 \mathrm{rad}(50,60$, and 40 Gray [Gy]) for cancer of the 
bladder, kidney, and ovary, respectively. Another paper reported the use of ${ }^{60} \mathrm{Co}$ for treatment of cancer of the eye. ${ }^{59}$ The typical dose to the cancer was $10,000 \mathrm{rad}(100 \mathrm{~Gy})$ and of the 116 patients in the study, only 20 had recurrences of the cancer. While other gamma sources could be used instead, if ${ }^{60} \mathrm{Co}$ is to be used, it is typically done as an external source.

This nuclide is also used outside of the United States for cancer treatment. Reference 60 summarizes experience in the use of ${ }^{60} \mathrm{Co}$ for the treatment of cervical, endometrial, and vaginal cancers in Yugoslavia. Doses were in the thousands of rad for each of these cancers and for either cervical or endometrial cancers, the survival rates were approximately $75 \%$. Some of the short-term side effects were diarrhea, abdominal pain, rectal bleeding, and vaginal stenosis.

Reference 51 reports the results of a study of ${ }^{60} \mathrm{Co}$ removal rates for residents of the Bikini Atoll. These residents were internally contaminated by ingestion of food that contained ${ }^{60} \mathrm{Co}$ from fallout by atmospheric testing. The biological half-life of ${ }^{60} \mathrm{Co}$ has three components, short, intermediate, and long. Based on this population, the long half-life is 124 days for adult males, 160 days for adult females, and 217 days for adolescents. Approximately $90 \%$ of the ingested cobalt was estimated to exhibit the longterm biological half-life. In another study, three accidentally contaminated radiation workers were used to measure the elimination rate of various nuclides. ${ }^{61}$ The contamination by ${ }^{60} \mathrm{Co}$ was $1.8 \mu \mathrm{Ci}$ $\left(6.7 \times 10^{7} \mathrm{~Bq}\right)$ of ${ }^{60} \mathrm{CoCl}_{2}$, ingested by mouth. Analysis of the whole-body scan data indicated a threecomponent biological removal rate of 0.5 days $(33 \%) ; 2.7$ days $(4 \%)$; and 59 days $(63 \%)$, where the numbers in parentheses indicate the relative amount of ${ }^{60} \mathrm{Co}$ in each half-life group. The calculated whole body dose due to this ingestion was $3.2 \mathrm{mrem}(0.03 \mathrm{mSv})$.

In a report by the International Commission on Radiological Protection, a four component biological removal rate equation is presented. ${ }^{62}$ First, cobalt is assumed to be retained in a transfer compartment with a half-life of 0.5 days. Then, $60 \%, 20 \%$, and $20 \%$ are assumed to be eliminated from the body with biological half-lives of 6,60 , and 800 days, respectively. This same reference indicates that $50 \%$ of ingested cobalt will be immediately excreted from the body without absorption. Of the rest, $10 \%$ is concentrated in the liver and the rest is uniformly distributed throughout the body.

Elimination rates for inhaled ${ }^{60} \mathrm{Co}$ were reported by Reference 63 . Four components for the biological removal rate were measured: 0.5 days $(50 \%) ; 6$ days $(30 \%) ; 60$ days $(10 \%)$; and 800 days $(10 \%)$. This report also includes calculated doses for given amounts of ${ }^{60} \mathrm{Co}$ that were inhaled. These were of the order of $0.01 \mathrm{mrem}$ for $540 \mathrm{pCi}(1 \mathrm{mSv}$ for $20 \mathrm{kBq})$ of ${ }^{60} \mathrm{Co}$ intake. Reference 3 lists the inhalation dose factors for various ages of humans. These factors (expected dose per unit inhaled activity) are $32,19,11$, and $7.5 \times 10^{-4} \mathrm{mrem} / \mathrm{pCi}$ for infants, children, teenagers, and adults, respectively.

As a final source for the biological removal rate information, Reference 20 lists the biological halflife for cobalt to be 9.5 days, independent on the body part. This reference also lists $0.021 \mathrm{rem} / \mu \mathrm{Ci}$ $(0.0007 \mathrm{~Sv} / \mathrm{Bq})$ as the maximum dose to any body organ for inhaled ${ }^{60} \mathrm{Co}$.

The high gamma radiation strength of ${ }^{60} \mathrm{Co}$ results in relatively large doses due to external exposure to this nuclide. For example, the exposure rates in millirad per hour for a $100 \mathrm{mCi}\left(3.7 \times 10^{9} \mathrm{~Bq}\right){ }^{60} \mathrm{Co}$ source are $520,130,33$, and $14 \mathrm{mrad} / \mathrm{h}(0.0052,0.0013,0.00033$, and $0.00014 \mathrm{~Gy} / \mathrm{h})$ for an individual who is situated $50 \mathrm{~cm}, 1 \mathrm{~m}, 2 \mathrm{~m}$, and $3 \mathrm{~m}$ from the source. ${ }^{64}$ For comparison, the exposure rates for ${ }^{137} \mathrm{Cs}$ is $130,33,8.3$, and $3.8 \mathrm{mR} / \mathrm{h}(0.0013,0.00033,0.000083$, and $0.000038 \mathrm{~Gy} / \mathrm{h})$ for an individual situated $50 \mathrm{~cm}, 1 \mathrm{~m}, 2 \mathrm{~m}$, and $3 \mathrm{~m}$ from the source (see Chapter 6 for details).

${ }^{60} \mathrm{Co}$ is also used as an industrial irradiation source for testing the effects of radiation on animals. ${ }^{65}$ In this reference, a radiation research facility is described where ${ }^{60} \mathrm{Co}$ was used to study the effects of 
low-level, continuous, whole body exposure to mammals. The irradiation took place outside and concern was raised as to whether people in the surrounding areas might have been excessively irradiated due to lack of shielding. The report concluded that the worst case exposure to the public due to use of an encapsulated $190 \mathrm{Ci}\left(7.0 \times 10^{12} \mathrm{~Bq}\right){ }^{60} \mathrm{Co}$ source was approximately $200 \mathrm{mrem} / \mathrm{y}(2 \mathrm{mSv} / \mathrm{y})$, which is well within the DOE regulatory limits at the time of facility operation.

The annual limits on intake (ALI) and derived air concentration (DAC) for ${ }^{60} \mathrm{Co}$ are shown in Table 12-6.

Table 12-6. Annual limits on intake and the derived air concentrations for ${ }^{60} \mathrm{Co}$ (from Reference 55).

\begin{tabular}{llll}
\hline Radionuclide & Component & \multicolumn{1}{c}{$\begin{array}{c}\text { Ingestion } \\
(\mu \mathrm{Ci})\end{array}$} & Inhalation $^{\mathrm{a}}$ \\
\hline${ }^{60} \mathrm{Co}$ & $\mathrm{ALI}$ & $500(0.05)^{\mathrm{b}}$ & $200 / \mathrm{W}$ \\
& & $200(0.3)$ & $30 / \mathrm{Y}$ \\
& $\mathrm{DAC}$ & $-{ }^{\mathrm{c}}$ & $7 \mathrm{E}-8 / \mathrm{W}^{\mathrm{d}}$ \\
& & & $1 \mathrm{E}-8 / \mathrm{Y}$
\end{tabular}

a. Clearance from the lung directly to the blood stream or to the gastrointestinal (GI) tract depends upon the chemical form of the radionuclide and is classified as $\mathrm{D}, \mathrm{W}$, and $\mathrm{Y}$, respectively, for clearance times of the order of days, weeks, and years. For ${ }^{60} \mathrm{Co}$, the two listed classifications are $\mathrm{Y}$ for oxides and hydroxides and $\mathrm{W}$ for all other compounds. ${ }^{64}$

b. The removal class, $\mathrm{f}_{1}$ for each ALI is in parenthesis. A simple model of the lung was used to describe the translocation and retention of material by the body after inhalation. In this model, $25 \%$ of the inhaled activity was exhaled and $25 \%$ was deposited in the lower respiratory tract. The $50 \%$ that was deposited in the upper respiratory tract was eventually cleared by means of mucociliary processes and swallowed. What happens then depends on whether the inhaled material was in either a soluble or insoluble chemical form. Any soluble material deposited in the lower respiratory tract is assumed to be transferred directly to the blood stream. The activity cleared from the upper respiratory tract and then swallowed, a fraction $\left(f_{1}\right)$, and in the case of ${ }^{60} \mathrm{Co}, \mathrm{f}_{1}=0.05$ or 0.3 , depending on the ALI, entered the blood stream via the GI tract. Additional details of this model are described in References 55 and 66.

c. Data are not available.

d. $8 \mathrm{E}-8$ denotes $8 \times 10^{-8}$.

The ALI is defined as the annual intake of a radionuclide resulting in a radiation dose to a human (for calculational purposes, the characteristics of the Reference Man are used) equal to the allowable limit. The DAC is defined as that concentration of a radionuclide in air, which if breathed for a work-year would result in an intake corresponding to the ALI (or, in the case of submersion, to an external exposure corresponding to the primary guide for limiting annual dose). DACs are used for limiting radionuclide intake through the breathing of, or submersion in, contaminated air. ALIs are used primarily for assessing doses due to accidental ingestion of radionuclides.

Historically, maximum permissible concentrations (MPC) in air and water have been used to determine safety guidelines for released radionuclide concentrations. Currently, the derived guidelines are presented in terms of ALIs for inhalation or ingestion, and DACs for inhalation (or submersion). For a radionuclide whose derived value does not change from the old definition, the DAC is numerically equal to the MPC value in air. The information in Table 12-6 applies only to ${ }^{60} \mathrm{Co}$. In the case of 
multiple radionuclides released in a mixture, additional guidelines outlined in Chapter 10 of the Code of Federal Regulations, ${ }^{66}$ Part 20 must be followed.

\section{Summary}

Cobalt- 60 has a half-life of 5.2 years and decays by beta particle emission to stable ${ }^{60} \mathrm{Ni}$. Both high-energy beta particles (maximum energy 1,480 keV, average energy $94 \mathrm{keV}$ ) and gamma-ray emissions (energies 1,170 and $1,330 \mathrm{keV}$ ) characterize this nuclide.

${ }^{60} \mathrm{Co}$ is produced in the structural steels and other alloys of nuclear reactor vessel and internal components from neutron activation of ${ }^{59} \mathrm{Co}$, the only stable isotope of cobalt. These reactor components serve as the primary LLW material containing ${ }^{60} \mathrm{Co}$. However, wide use of ${ }^{60} \mathrm{Co}$ radiation sources also contribute to the LLW inventory for this nuclide. The principal concern surrounding ${ }^{60} \mathrm{Co}$ is in limiting the dose received by persons associated with the decommissioning and dismantling of the reactors, primarily for reactors in service for several decades. If decommissioning is delayed for a long time after reactor shutdown, this nuclide would significantly decay, reducing the personnel dose and making the decommissioning and decontamination activities easier to accomplish.

${ }^{60} \mathrm{Co}$ is commercially available and has been used as an external source of gamma rays for laboratory use. This nuclide is one of the principal irradiation sources for treatment of cancer in humans.

The chemistry of cobalt is dominated by the outermost two $4 \mathrm{~s}$ subshell electrons. The principal oxidation state is +2 , although several compounds with an oxidation state of +3 can be formed, particularly with organic and other complexes. Cobalt is primarily used to form specific alloys that have good high-temperature strength and corrosion characteristics and that are hard and durable for use in the aerospace, medical, and nuclear industries.

The ability of soil to adsorb ${ }^{60} \mathrm{Co}$ out of the groundwater depends on a number of factors, including $\mathrm{pH}$ and the presence or absence of complexing agents. However, in general, cobalt is easily adsorbed by soils and is not easily leached into the groundwater.

The principal source of ${ }^{60} \mathrm{Co}$ generation is in nuclear reactors, where it is produced by neutron absorption via the ${ }^{59} \mathrm{Co}(\mathrm{n}, \gamma)^{60} \mathrm{Co}$ reaction. This nuclide can enter waste streams through corrosion of stainless steel and Inconel surfaces in nuclear power plants with subsequent discharge with the primary coolant. The amount of ${ }^{60} \mathrm{Co}$ that has reached the environment has been the subject of numerous studies, both experimental and in the field. Since ${ }^{60} \mathrm{Co}$ has such high gamma-ray energies, it is easily detected and has been used to indicate the corrosion and transport of other, less easily detected, radionuclides.

When ${ }^{60} \mathrm{Co}$ comes into contact with the soil and groundwater, most of it will become fixed in the soil and will not migrate appreciably from the original site. Plants and animals can absorb this nuclide from the soil and propagate it into the food chain and several studies of this phenomena have been conducted. Most plants tend to concentrate ${ }^{60} \mathrm{Co}$ in the root systems. When this nuclide is ingested in mammals, much if it is removed within a few days although a significant amount may persist in the body for several hundred days. The amount that remains is generally uniformly distributed in the body, with the exception of the liver, which tends to concentrate the nuclide. The effective removal half-life for this nuclide is dominated by the biological half-life. The biological half-life has been extensively studied, but values among the various studies vary widely. The biological half-life is complex, indicating several competing mechanisms, and has been characterized with up to four components of different relative fractions and decay constants. 


\section{References}

1. General Electric Company, Nuclides and Isotopes, Fourteenth Edition, 1989, p. 28.

2. C. M. Lederer, J. M. Hollander, and I. Perlman, Table of Isotopes, Sixth Edition, New York: John Wiley and Sons, Inc., 1967, pp. 43 and 231.

3. B. Shleien and M. S. Terpilak (Eds.), The Health Physics and Radiological Health Handbook, Nucleon Lectern Associates, 1984.

4. M. L. Carboneau and J. P. Adams, National Low-Level Waste Management Program Radionuclide Report Series - Volume 10: Nickel-63, DOE-LLW-126, U.S. Department of Energy, February 1995.

5. F. A. Cotton and G. Wilkinson, Advanced Inorganic Chemistry - A Comprehensive Text, New York: Interscience Publishers, 1962.

6. McGraw-Hill Encyclopedia of Science and Technology, 6th Edition, Volume 4, New York: McGraw-Hill Book Company, 1987.

7. R. Granier and D. Gambini, Applied Radiobiology and Radiation Protection, Ellis Harwood, 1990 , pp. 346 and 347.

8. R. C. Weast (Ed.), CRC Handbook of Chemistry and Physics, Boca Raton, Florida: CRC Press, 1977 58th Edition, pp. B-270-B-354 (Table of Isotopes) and pp. B-429.

9. Bureau of Radiological Health, Radiological Health Handbook, Revised Edition, U.S. Government Printing Office, January 1970, pp. 92-94 (average and maximum beta energy by radionuclide).

10. E. S. Gould, Inorganic Reactions and Structure, New York: Holt, Rinehart, and Winston, 1963.

11. M. B. Bever (Ed.), Encyclopedia of Materials Science and Engineering, Volume 1, New York: Pergamon Press, 1986.

12. International Critical Tables of Numerical Data, Physics, Chemistry, and Technology Volume I, New York: McGraw-Hill Book Company, 1926.

13. C. D. Hodgman (Ed.), Handbook of Chemistry and Physics, 43rd Edition, Boca Raton, Florida: The Chemical Rubber Company, 1961.

14. Smithsonian Physical Tables, 9th Edition, Smithsonian Institution Publishers, 1954.

15. A. G. Croff, $A$ User's Manual for the ORIGEN2 Computer Code, ORNL/TM-7175, Oak Ridge National Laboratory, July 1980.

16. D. C. Stewart, Data for Radioactive Waste Management and Nuclear Applications, New York: John Wiley \& Sons, 1985.

17. U.S. Nuclear Regulatory Commission, Licensing Requirements for Land Disposal of Radioactive Waste, Final Environmental Impact Statement, Code of Federal Regulations, 10 CFR 61. 
18. F. J. Rahn, et al., A Guide to Nuclear Power Technology, New York: John Wiley \& Sons, 1984, p. 699 (Figure 16.5).

19. A. H. Schilling, Decommissioning Commercial Nuclear Facilities: A Review and Analysis of Current Regulations, NUREG/CR-0671, U.S. Nuclear Regulatory Commission, 1979.

20. Y. Wang, M.D. (Ed.), Handbook of Radioactive Nuclides, Volume 1, Boca Raton, Florida: The Chemical Rubber Company, 1969.

21. Radiological Health Handbook Revised Edition, U.S. Department of Health, Education, and Welfare, January 1970.

22. Operational Accidents and Radiation Exposures at DOE Facilities - Fiscal Year 1979, DOE/EV-0091/2, UC-41, U.S. Department of Energy, December 1980.

23. G. Marino, "The Nuclides in Town," Science News, Vol. 146, No. 14, October 1, 1994, pp. 218-219.

24. International Directory of Certified Radioactive Materials, International Atomic Energy Agency, Vienna, Austria, 1975.

25. U. S. Department of Energy, Isotope Production \& Distribution, Westinghouse Hanford Company Isotope Program Office, Richland, Washington, April 1992.

26. P. C. Bergamini, et al., "Absorption and Distribution of ${ }^{137} \mathrm{Cs}$ by Trifolium Pratense," Health Physics, Vol. 19, October 1970, pp. 521-528.

27. J. Dragun, The Soil Chemistry of Hazardous Materials, Hazardous Materials Control Research Institute, Silver Spring, Maryland, 1988.

28. J. Means and D. A. Crerar, "Migration of Radioactive Wastes: Radionuclide Mobilization by Complexing Agents," Science, Vol. 200, June 30, 1978, pp. 1477-1481.

29. T. L. Jones, et al., "A Laboratory and Field Evaluation of the Mobility of Cobalt-60/EDTA," Waste Management '83, Volume 2, Tucson, Arizona, February 27, 1983, pp. 331.

30. P. J. Coughtrey and M. C. Thorn, Radionuclide Distributions and Transport in Terrestrial and Aquatic Ecosystems - A Critical Review of Data, Vol. 2, A. A. Galkema of Rotterdam, 1983.

31. H. Ogawa, "Kinetic Study on Migration of Non-Cationic Species of ${ }^{60}$ Co through Sandy Soil Layer," Journal of Nuclear Science and Technology, Vol. 26, No. 5, May 1989, pp. 530-535.

32. T. Tanaka and S. Ni, Influence of Humic Acid on Migration of ${ }^{60} \mathrm{Co},{ }^{85} \mathrm{Sr}$, and ${ }^{13^{-}} \mathrm{Cs}$ in Coastal Sandy Soil, JAERI-M-93-185, Japanese Atomic Energy Research Institute, October 1993.

33. E. R. Cumming, P. S. Littlefield, and F. X. Bellini, "The Impact of Site Release Criteria on Remediation Programs," Nuclear News, Vol. 38, No. 2, February 1995, pp. 38-40.

34. Annual Radiological Environmental Operating Report - Browns Ferry Nuclear Plant 1992, Tennessee Valley Authority Operations Services Technical Programs, April 1993. 
35. L. J. Kirby and R. M. Campbell, "In Situ Gamma-Ray Spectrometric Analysis of Radionuclide Distributions at a Commercial Shallow Land Burial Site," The International Conference of Nuclear and Radiochemistry, Lindau, Federal Republic of Germany, October 8 - 12, 1984, PALSA-12113, Pacific Northwest Laboratory, October 1984.

36. S. L. Domotor and R. I. McLean, Environmental Radionuclide Concentrations in the Vicinity of the Calvert Cliffs Nuclear Power Plant: 1985 - 1986, PPER-R-10, Power Plant and Environmental Review Division, Tidewater Administration, November 1988.

37. J. L. Means, D. A. Crerar, and J. O. Duguid, Chemical Mechanisms of ${ }^{60}$ Co Transport in Ground Water from Intermediate-Level Liquid Waste Trench 7: Progress Report for Period Ending June 30, 1975, ORNL/TM-5348, Oak Ridge National Laboratory, 1976.

38. J. S. Young, Biological Fate of Cobalt-60 Released During the Corrosion of Neutron-Activated Stainless Steel in Seawater, PAL-4217, UC-11, Pacific Northwest Laboratory, 1982.

39. F. P. Brauer and H. G. Rieck, $\mathrm{Jr},{ }^{129} \mathrm{I},{ }^{60} \mathrm{Co}$, and ${ }^{106} \mathrm{Ru}$ Measurements on Water Samples from the Hanford Project Environs, BNWL-SA-4478, Battelle Northwest Laboratories, 1973.

40. D. A. Myers, J. J. Fix, and J. R. Raymond, Environmental Monitoring Report on the Status of Ground Water Beneath the Hanford Site - January - December 1976, BNWL-2199, UC-41, Battelle Northwest Laboratories, 1977.

41. E. Fagniart, J. Colard, and R. Kirchmann, "Leaching of Co-60 and Cs-134 from the Rooting Zone of an Experimental Field," Proceeding of the XIXth ESNA Conference, Vienna, Austria, August 29-September 2, 1988.

42. Y. Ohtsuka, S. Takebe, T. Yamamoto, and Y. Wadachi, "Migration Behavior of Radionuclides $\left({ }^{60} \mathrm{Co},{ }^{85} \mathrm{Sr}\right.$, and $\left.{ }^{137} \mathrm{Cs}\right)$ in Aquifer," Journal of Nuclear Science and Technology, Vol. 25, No. 2, February 1988, pp. 165-168.

43. R. Tanaka and T. Yamamoto, "Migration of Cobalt-60 Through Aerated Zone under Discontinuous Flow Condition," Journal of Nuclear Science and Technology, Vol. 31, No. 4, April 1994, pp. 308-313.

44. M. F. Abdel Sabour, H. A. El-Naggar, and S. M. Soliman, "Use of Some Inorganic and Organic Compounds as Decontaminants for Cobalt-60 and Cesium-134 by Clover Plant Grown on Inshas Sandy Soil," Isotopenpraxis, Vol. 27, No. 6, 1991, pp. 292-295.

45. J. Handl and W. Kuehn, "Determination of Transfer Coefficients for ${ }^{137} \mathrm{Cs}$ and ${ }^{60} \mathrm{Co}$ in a SlimeSoil-Grassland Ecosystem," Health Physics, Vol. 38, No. 4, 1980, pp. 703-705.

46. H. Foerstel, W. Goeres, and W. Steffens, "Variation of the Transfer Factor Soil/Plant During the Time of Equilibrium After Contamination with ${ }^{90} \mathrm{Sr},{ }^{137} \mathrm{Cs},{ }^{60} \mathrm{Co}$, and ${ }^{54} \mathrm{Mn}$, "Proceedings of the 3rd International Symposium of the Society for Radiological Protection, Inverness, United Kingdom, June 6, 1982.

47. W. Steffens, W. Mittlestaedt, and F. Fuehr, "The Transfer of Sr-90, Cs-137, Co-60, and Mn-54 from Soils to Plants - Results from Lysimeter Experiments," Proceedings of the 5th International Congress of the International Radiation Protection Association, Jerusalem, Israel, March 8, 1980. 
48. 3rd Report of the Workgroup on Soil-to-Plant Transfer Factors, INIS-MF-10171, CONF8404304, International Nuclear Information System, 1984.

49. E. J. Antonio, T. M. Poston, and W. H. Rickard, Jr., Radiological Survey of Shoreline Vegetation from the Hanford Reach of the Columbia River, 1990 - 1992, PAL-8797, UC-600, Pacific Northwest Laboratory, 1993.

50. H. Foerstel and W. Steffens, "Influence of Aging Effects on the Soil-Plant Radionuclide Transfer After Application of Carrier-Free Sr-90, Cs-137, Co-60, and Mn-54 to the Soil," Proceedings of the 6th Congress of the International Radiation Protection Association, Berlin, Germany, May 7, 1984.

51. R. P. Miltenberger, E. T. Lessard, and N. A. Greenhouse, ${ }^{60} \mathrm{Co}$ and ${ }^{137} \mathrm{Cs}$ Long-Term Biological Removal Rate Constants for the Marshallese Population," Health Physics, Vol. 40, No. 5, May 1981, pp. 615-623.

52. J. J. Fix and P. J. Blumer, Radiochemical Analyses of Game Birds Collected from the Hanford Environs 1971 - 1975, BNWL-2089, UC-41, Batelle Northwest Laboratories, 1977.

53. O. D. Markham (Ed.), Ecological Studies on the Idaho National Engineering Laboratory Site 1978 Progress Report, IDO-12087, U.S. Department of Energy Idaho Operations Office, 1978.

54. R. K. Bastian and W. B. Jackson, ${ }^{137} \mathrm{Cs}$ and ${ }^{60} \mathrm{Co}$ in a Terrestrial Community at Enewetak Atoll," 4th National Symposium on Radioecology, Corvallis, Oregon, May 12, 1975, 1976.

55. K. F. Eckerman, A. B. Wolbarst, and A. C. B. Richardson, Limiting Values of Radionuclide Intake and Air Concentration and Dose Conversion Factors for Inhalation, Submersion, and Ingestion, Federal Guidance Report No. 11, Oak Ridge National Laboratory, EPA-520/1-88-020, September 1988.

56. T. A. Hazra, M. Cohen, and J. S. Mitchell, "Bladder, Strategy for Management of Carcinoma of the Bladder, Treatment Information," Cobalt-60 Teletherapy: A Compendium of International Practice, International Atomic Energy Agency, Vienna, Austria, 1984, pp. 567.

57. J. S. Abbatucci, M. Cohen, and J. S. Mitchell, "Kidney. Strategy for Management of Primary Renal Carcinoma in the Adult Treatment Information," Cobalt-60 Teletherapy: A Compendium of International Practice, International Atomic Energy Agency, Vienna, Austria, 1984, pp. 527.

58. F. Ellis, M. Cohen, and J. S. Mitchell, "Ovary, Strategy for Management of Cancer of the Ovary, Treatment Information," Cobalt-60 Teletherapy: A Compendium of International Practice, International Atomic Energy Agency, Vienna, Austria, 1984, pp. 509.

59. J. J. Beitler, et al., "Ocular Melanoma: Total Dose and Dose Rate Effects with Co-60 Plaque Therapy," Radiology, Vol. 176, No. 1, 1990, pp. 275-278.

60. B. Ristic, et al., "Experience in the Treatment of Gynecological Malignancy Using High Intensity Cobalt 60 Sources," International Workshop on High Dose-Rate Afterloading in the Treatment of Cancer of the Uterus, London, United Kingdom, April 10, 1978.

61. S. M. Morsy and F. M. El-Assaly, "Body Elimination Rates of ${ }^{134} \mathrm{Cs},{ }^{60} \mathrm{Co}$, and ${ }^{203} \mathrm{Hg}$," Health Physics, Vol. 19, No. 6, December 1970, pp. 769-773. 
62. Annals of the ICRP Limits for Intakes of Radionuclides by Workers, ICRP Publication 30, Part 1, New York: Pergamon Press, 1979, pp. 73.

63. D. D. Rao, A. Buburajan, and A. G. Hegde, "A Methodology for Evaluation of Effective Dose to Occupational Workers due to Inhalation of Cobalt-60," Bulletin of Radiation Protection, Vol. 16, No. 1-2, 1993, pp. 108-111.

64. B. Shleien and M. S. Terpilak, The Health Physics and Radiological Health Handbook Supplement 1 (1986), Nucleon Lectern Associates, Inc., 1986.

65. T. E. Chapman and R. I. Scherpelz, Reconstruction of Exposures to the Public from a Cobalt-60 Irradiator Facility, PNL-SA-20031, Pacific Northwest Laboratory, 1992.

66. U.S. Nuclear Regulatory Commission, 10 CFR 20, Chapter I (January 1, 1992), "Standards for Protection Against Radiation," Appendix B. 


\section{Bibliography}

Adriano, D. C., M. Delaney, and D. D. Paine, "Availability of Co-60 to Corn and Bean Seedlings as Influenced by Soil Types, Lime, and DTPA," Comm. Soil Sci. Plant Analy., Volume 8, 1977, pp. 615 .

Beleznay, E. and M. Osvay, "Long-Term Clearance of Accidentally Inhaled ${ }^{60}$ Co Aerosols in Humans," Austrian-Italian-Hungarian Radiation Protection Symposium, Obergurgl/Tyrol, Austria, April 28-30, 1993, 1994, pp. 460.

Bloom, P. E., J. B. Johnson, and S. K. Rope, "Concentrations of Cesium-137 and Cobalt-60 in Nests of the Harvester Ant Pogonomyrmex-Salinus and Associated Soils Near Nuclear Reactor Waste Water Disposal Ponds," American Midland Naturalist, Volume 126, 1991, pp. 140.

Brauer, F. P. and H. G. Rieck, Jr., " ${ }^{129} \mathrm{I},{ }^{60} \mathrm{Co}$, and ${ }^{106} \mathrm{Ru}$ Measurements on Water Samples from the Hanford Project Environs," CONF-730111-2, 1973.

Bunzl, K. and W. Schimmack, "Kinetics of Sorption of ${ }^{137} \mathrm{Cs},{ }^{85} \mathrm{Sr},{ }^{57} \mathrm{Co},{ }^{65} \mathrm{Zn}$, and ${ }^{109} \mathrm{Cd}$ by the Organic Horizons of a Forest Soil, Radiochimica Acta, Volume 54, 1991, pp. 97.

Clancy, J. J., D. F. Gray, and O. I. Oztunali, Data Base for Radioactive Waste Management, NUREG/CR-1759, U.S. Nuclear Regulatory Commission, 1981.

Conrad, R. A., et al., A Twenty-Year Review of Medical Findings in a Marshallese Population Accidently Exposed to Radioactive Fallout, BNL-50424, Brookhaven National Laboratory, 1975.

Harrisson, F. L., Interaction of Radionuclides in Water Particulates in Oysters in the Discharge Canal of a Nuclear Power Plant, UCRL-51974, University of California Research Laboratories, 1976.

Hegde, A. G., D. M. Thakker, and I. S. Bhat, "Long Term Clearance of Inhaled ${ }^{60} \mathrm{Co}$," 5th Indian Association for Radiation Protection Conference on Radiation Protection, Gwalior, India, February 14-16, 1978, pp. 37.

Higgins, P. D., et al., "Calculational Methods for Estimating Skin Dose from Electrons in Co-60 Gamma-Ray Beams," Medical Physics, Volume 10, 1983, pp. 622.

Kee, N. S. and C. Bloomfield, "The Solution of Some Minor Element Oxides by Decomposing Plant Materials," Geochimica et Cosmochimica Acta, Volume 24, 1961, pp. 206.

Kerpen, W., T. H. Sibley, and C. Myttenaere, "Bioavailability of the Radionuclides Cesium-137, Cobalt60, Manganese-54, and Strontium-85 in Various Soils as a Function of Their Soil Properties," Scientific Seminar on Application of Distribution Coefficients to Radiological Assessment Models, Louvain, Belgium, October 7, 1985.

Kulikov, N. V., et al., "Influence of Plant Extracts on the Mobility of Radionuclides in the Soil as a Function of Conditions of Moistening," Journal of Ecology, Volume 8, 1977, pp. 162.

Lessard, E. T., R. P. Miltenberger, and N. A. Greenhouse, "Dietary Radioactivity Intake from Bioassay Data: A Model Applied to ${ }^{137} \mathrm{Cs}$ Intake by Bikini Island Residents," Health Physics, Volume 39, 1979, pp. 177. 
Lowe, V. P. W. and A. D. Horrill, "Transfer of Radionuclides to Man from Greylay Geese Anser and Wigeon Anas Penelope Grazing the Saltmarshes at Ravenglass," Journal of Environmental Radioactivity Volume 4, 1986, pp. 101.

Malcolm, R. L., et al., "Conditional Stability Constants of a North Carolina Soil Fulvic Acid with $\mathrm{Co}^{2+}$ and $\mathrm{Fe}^{3+}$," Proceedings of the Symposium of Organic Matter in Natural Waters, 1968, pp. 485.

Means, J. L., D. A. Crerar, and J. O. Duguid, "Migration of Radioactive Wastes: Radionuclide Mobilization by Complexing Agents," Science Volume 200, 1978, pp. 1477.

Mehenderge, S. T., et al., "Soil to Vegetation Transfer Factors for ${ }^{137} \mathrm{Cs}$ and ${ }^{60} \mathrm{Co}$ in Tarapur Environment," Bulletin of Radiation Protection (India), Volume 14, 1991, pp. 22.

Miltenberger, R. P., N. A. Greenhouse, and E. T. Lessard, "Whole Body Counting Results from 1974 to 1979 for Bikini Island Residents," Health Physics, Volume 39, 1979, pp. 395.

Rashid, M. A. and L. H. King, "Molecular Weight Distribution Measurement on Humic and Fulvic Acid Fractions from Marine Clays of the Scotian Shelf," Geochimica et Cosmochimica Acta, Volume 33, 1969 , pp. 147.

Schimmack, W. and K. Bunzl, "Transport of ${ }^{85} \mathrm{Sr},{ }^{60} \mathrm{Co},{ }^{65} \mathrm{Zn}$, and ${ }^{109} \mathrm{Cd}$ in Two Forest Soils, as Observed in Undisturbed Soil Columns, Radiochimica Acta, Volume 58/59, 1992, pp. 297.

Schnitzer, M. and S. I. M. Skimmer, "Organo-Metallic Interactions in Soils: 7. Stability Constants of $\mathrm{Pb}^{2+}, \mathrm{Ni}^{2+}, \mathrm{Co}^{2+}$, and $\mathrm{Mg}^{2+}$ Fulvic Acid Complexes," Soil Science, Volume 103, 1967, pp. 247.

Steffens, W., W. Mittelstaedt, and F. Fuhr, "Lysimeter Experiments on the Transfer of ${ }^{90} \mathrm{Sr},{ }^{137} \mathrm{Cs},{ }^{60} \mathrm{Co}$, and ${ }^{54} \mathrm{Mn}$ from Soil to Plant," 2nd International Symposium on Radioecology, Cadarache, France, June 19, 1979.

Thomas, W. A., "Cerium and Cobalt Movement with Litter Leachate in a Forest Soil," Mineral Cycling in Southeastern Ecosystems, CONF-740513, 1975, pp. 625.

Toste, A. P., L. J. Kirby, and T. R. Pahl, in Geochemical Behavior of Disposed Radioactive Waste, American Chemical Society, Washington, DC, 1984.

Willard, W. K., Radiocobalt Cycling in a Small Mammal Food Web, CONF-750503-8, 1975.

Witkamp, M. and N. L. Franc, "Loss of Weight, Co-60 and Cs-137 from Tree Letter in Three Subsystems of a Watershed," Environmental Science Technology, Volume 3, 1969, pp. 1195.

Zeevaert, T., R. Kirchmann, and C. M. Vandecasteele, "Assessment of Doses to Man from Liquid Releases of ${ }^{60} \mathrm{Co}$-Important Pathways and Transfer Parameters," Workshop in Radioecology, Neuherberg, Germany, November 5-7, 1986, 1989, pp. 43. 


\section{CURIUM-242}

\section{Introduction}

This chapter discusses the basic radiological, chemical, and physical characteristics of curium-242 $\left({ }^{242} \mathrm{Cm}\right)$ and examines how these characteristics affect the behavior of ${ }^{242} \mathrm{Cm}$ in various environmental media, such as soils, water, plants, animals, the atmosphere, and the human body. Also included are methods of ${ }^{242} \mathrm{Cm}$ production and waste and disposal data on ${ }^{242} \mathrm{Cm}$.

${ }^{242} \mathrm{Cm}$ is important to low-level radioactive waste (LLW) disposal primarily because of the radiological daughters produced through the ${ }^{242} \mathrm{Cm}$ decay scheme. Although ${ }^{242} \mathrm{Cm}$ decays with a relatively short half-life (163 days), its radiological daughters, such as plutonium-238 $\left({ }^{238} \mathrm{Pu}\right)$ with a half-life of 86 years, can persist for much longer in radioactive waste.

A radionuclide considered sensitive at one LLW disposal facility may not be considered sensitive at another facility. The behavior of a radionuclide at a particular LLW disposal site will depend primarily upon the radiological, chemical, and physical characteristics of the waste, and the inventory of the radionuclide. The behavior of a radionuclide also depends upon the geology, hydrology, and climate at the disposal site. This chapter reports characteristics and potential difficulties in dealing with ${ }^{242} \mathrm{Cm}$. However, since ${ }^{242} \mathrm{Cm}$ behavior and appropriate handling, storage, or disposal will vary depending on particular sites or waste form, this chapter does not attempt to discuss the extent of a difficulty or appropriate solutions. Each disposal site facility design should consider and address the specific waste content and behavior under that site's particular circumstances.

All curium atoms contain 96 protons $(Z=96)$ and various numbers of neutrons (typically $N=142$ to 155 neutrons) within the atom's nucleus. There are no stable isotopes of curium and all are radioactive. The radioactive isotopes of curium have half-lives ranging from a few minutes to millions of years. ${ }^{1}$ Despite the extremely long half-life of some curium isotopes, they do not exist naturally in the environment but may be produced artificially. The first curium isotope to be synthesized, ${ }^{242} \mathrm{Cm}$, was produced in 1944 by G. T. Seaborg, R. A. James, and A. Ghiorso. They synthesized the isotope by bombarding ${ }^{239} \mathrm{Pu}$ with high-energy helium nuclei (alpha particles), according to the following reaction: ${ }^{2}$

${ }^{239} P u+\alpha \rightarrow{ }^{242} \mathrm{Cm}+n$.

Larger amounts of this nuclide, produced by the prolonged neutron irradiation of americium-241 $\left({ }^{241} \mathrm{Am}\right)$, provided material for the first isolation of visible amounts of curium by L. B. Werner and I. Perlman in 1947 according to

${ }^{241} \mathrm{Am}+n \rightarrow{ }^{242 m} \mathrm{Am}+\gamma \rightarrow{ }^{242} \mathrm{Cm}+\beta^{-}$

The original metallurgy and chemistry research on this manmade element was performed using ${ }^{242} \mathrm{Cm}$, which has a half-life of 163 days. However, higher mass and longer-lived isotopes, especially

${ }^{244} \mathrm{Cm}$ (half-life of 18 years), ${ }^{247} \mathrm{Cm}$ (half-life of 15.6 million years), and ${ }^{248} \mathrm{Cm}$ (half-life of 370,000 years), are now the principal sources of this element. 
The primary source of ${ }^{242} \mathrm{Cm}$ in the environment has been radioactive waste material generated from neutron irradiation of ${ }^{241} \mathrm{Am}$ (ultimately from neutron irradiation of uranium-238 [ $\left.{ }^{238} \mathrm{U}\right]$ ) in nuclear reactor fuel. This is the principal direct source of this nuclide. However, a metastable state of americium, ${ }^{242 \mathrm{~m}} \mathrm{Am}$, is also produced by neutron irradiation of fuel materials. This nuclide has a half-life of more than 150 years and ultimately decays to ${ }^{242} \mathrm{Cm}$. Therefore, ${ }^{242} \mathrm{Cm}$ is continually produced as a decay product for several hundred years after the fuel from a reactor has been removed and can, at least theoretically, enter the environment during this time. ${ }^{242} \mathrm{Cm}$ enters the environment from the activities associated with nuclear reactor operations and decommissioning and when the sources (such as sources used for remote electric power generation) are being used, manufactured, or disposed.

\section{Radiological Characteristics}

The most recent and best available information concerning ${ }^{242} \mathrm{Cm}$ reports a half-life of 163 days. ${ }^{1,3}$ The principal means of ${ }^{242} \mathrm{Cm}$ production is via neutron capture $(n, \gamma)$ interactions with ${ }^{241} \mathrm{Am}$ or multiple neutron capture interactions with ${ }^{238} \mathrm{U}$ or ${ }^{239} \mathrm{Pu}$.

The decay of ${ }^{242} \mathrm{Cm}$ and its radiological daughters is complex. The principal decay chain from ${ }^{242} \mathrm{Cm}$ to the stable nuclide lead-206 $\left({ }^{206} \mathrm{~Pb}\right)$ is

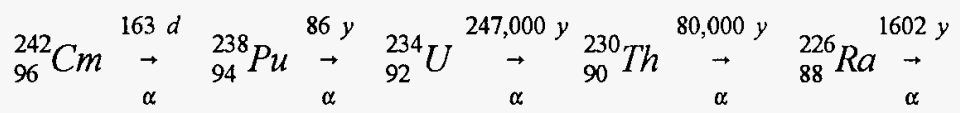

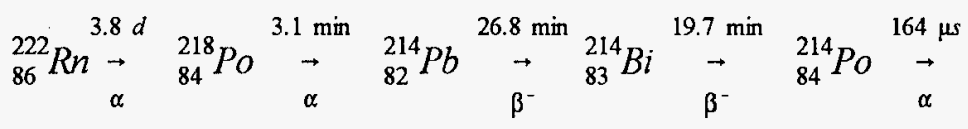

$$
\begin{aligned}
& { }_{82}^{210} \mathrm{~Pb} \underset{\beta^{-}}{\stackrel{21 y}{\rightarrow}}{ }_{83}^{210} \mathrm{Bi} \underset{\beta^{-}}{\stackrel{5}{\rightarrow}}{ }_{84}^{210} \mathrm{Po} \underset{\alpha}{\vec{\alpha}} \stackrel{{ }_{82}^{138 d}}{\rightarrow} \mathrm{Pb} \text { (stable) } .
\end{aligned}
$$

This is the most likely decay process based on the principal branch for the decay of each nuclide ground state. For several of these decay processes, there is a competing process. Many of the alpha-decay processes also result in the emission of various energy gamma rays, and the beta-decay processes result in the emission of various energy beta particles and gamma rays. In addition, there is a small but finite probability that this nuclide will spontaneously undergo fission, resulting in fission products and neutron emission. Thus, due to the complexity of the decay of ${ }^{242} \mathrm{Cm}$, the resultant alpha-, beta-, and gamma-spectra (and also neutron spectrum) are also complex and do not lend themselves to a simple presentation. With the possible exception of the ${ }^{241} \mathrm{Pu}$ decay scheme, this is the most complex decay scheme of all of the nuclides included in this report. With the exception of ${ }^{241} \mathrm{Pu}$, all of the other nuclides decay either directly to a stable nuclide or reach a stable nuclide with two decays.

No attempt has been made in this study to correlate the potential effects of radiation associated with the nuclide decay listed in Equation (3). Only the effects associated with the direct decay of ${ }^{242} \mathrm{Cm}$ will be included. The types and energies of the radiation associated with the subsequent decay are provided in the references. 
The decay of ${ }^{242} \mathrm{Cm}$ results in alpha particles of two principal energies, 6.12 and 6.07 million electron volts (MeV). ${ }^{4}$ Approximately $75 \%$ of the time, the higher energy alpha particle is emitted, and $25 \%$ of the time, the lower energy particle is emitted. There have been at least four additional alpha energies measured from the decay of this nuclide, but they represent less than $1 \%$ of the decay. There are also gamma rays that result from the decay of this nuclide, with energies ranging from 44 to 890 thousand electron volts $(\mathrm{keV})$. Finally, electron emissions with maximum energies ranging from 22 to $39 \mathrm{keV}$ are also associated with the decay of this nuclide. ${ }^{3}$ Again, these emissions are only from the direct decay of ${ }^{242} \mathrm{Cm}$ and do not include the emissions from the subsequent decay of the ground states of resultant nuclides, as shown in Equation (3).

Since the released beta particle is usually emitted with an energy less than its theoretical maximum, an antineutrino particle is simultaneously emitted and this particle carries off the energy difference between the released beta particle and the total energy given off by the decay process. Consequently, beta particles are emitted with a continuous energy spectrum ranging from zero to the maximum energy. Since neutrinos (or antineutrinos) rarely interact with matter, they are not considered radiologically important. Therefore, the antineutrino particle is usually not shown in the overall decay equation.

As stated above, approximately $75 \%$ of the decays of ${ }^{242} \mathrm{Crn}$ result in the emission of an alpha particle with an energy of $6.12 \mathrm{MeV}$. The range of these alpha particles is approximately $4.7 \mathrm{~cm}$ in air. Thus, even a small distance removed from a ${ }^{242} \mathrm{Cm}$ source is sufficient to be shielded from the alpha radiation. The maximum energy beta ray would be stopped within a range of $2.5 \mathrm{mg} / \mathrm{cm}^{2}$ (to get the linear range in a given material, divide this value by the density of the material). Table 13-1 lists the approximate range of a $39-\mathrm{keV}$ beta particle in various common materials. As seen, it does not require much of these materials to shield the environment from the beta particles associated with the direct decay of ${ }^{242} \mathrm{Cm}$.

In addition to beta particle radiation, each ${ }^{242} \mathrm{Cm}$ decay results in several relatively high-energy gamma rays with energies ranging from 44 to $890 \mathrm{keV}$. This is more energetic than the $660-\mathrm{keV}$ gamma ray associated with the decay of cesium-137 $\left({ }^{137} \mathrm{Cs}\right)$ but less than the $1,330-\mathrm{keV}$ gamma ray associated with the decay of ${ }^{60} \mathrm{Co}$. Table 13-2 illustrates this by listing the half-value layers, or the thicknesses of various materials required to attenuate a beam of $890-\mathrm{keV}$ gamma rays to one-half of the original intensity. As shown, shielding the environment from ${ }^{242} \mathrm{Cm}$ requires a substantial thickness, as opposed to some of the nuclides in this report, such as nickel-63 $\left({ }^{63} \mathrm{Ni}\right)$, which is only a beta emitter that emits $\mathrm{x}$-rays of significantly lower energy (see Chapter 10). These results are from Reference 3 . Reference 5 lists a large number of gamma rays resulting from the ${ }^{242} \mathrm{Cm}$ decay, with an energy range from 44 to $1,220 \mathrm{keV}$ and the most probable energy being $44 \mathrm{keV}$. The high-energy $\mathrm{x}$-rays are low probability, which should be taken into account in any disposal analysis.

The decay sequence for ${ }^{242} \mathrm{Cm}$ showing the emission of an alpha particle (principal emission) and associated gamma rays and beta rays is illustrated in the following nuclear transformation:

$$
{ }_{96}^{242} \mathrm{Cm} \stackrel{{ }^{163} d}{\rightarrow}{ }_{94}^{238} \mathrm{Pu}+\alpha(6.16 \mathrm{MeV} \max )+\gamma \text {-rays }(890 \mathrm{keV} \max )
$$


The beta energy is maximum energy listed by Reference 3 as being major radiation. This does not represent the maximum beta energy associated with this decay. The maximum energy was not found in the literature search for this report.

Table 13-3 lists the radiotoxicity of several important radionuclides, and Table 13-4 compares the electron energy associated with ${ }^{242} \mathrm{Cm}$ decay together with the maximum and average electron energies associated with electron (beta particle) emitters. Notice that ${ }^{242} \mathrm{Cm}$ is shown in the same radiological group as ${ }^{241} \mathrm{Pu},{ }^{241} \mathrm{Am}$, and neptunium-237 $\left({ }^{237} \mathrm{~Np}\right)$. All of these are actinide metals and each primarily decays by alpha decay. The principal radiological danger for these nuclides results from the high-energy alpha particles emitted during decay. The $6.12 \mathrm{MeV}$ alpha particle, emitted by the decay of ${ }^{242} \mathrm{Cm}$, is more energetic than that emitted by ${ }^{241} \mathrm{Am}(5.49 \mathrm{MeV}),{ }^{241} \mathrm{Pu}(4.85 \mathrm{MeV})$, and ${ }^{237} \mathrm{~Np}(4.78 \mathrm{MeV})$.

Because of the radiological danger resulting from ingestion or inhalation of these actinides, this group is assigned the highest radiological risk. The specific activity of ${ }^{242} \mathrm{Cm}$ is $3,300 \mathrm{Ci} / \mathrm{g}$. The maximum concentration of ${ }^{242} \mathrm{Cm}$ that is acceptable for near-surface disposal without specific U.S. Nuclear Regulatory Commission authorization is $20,000 \mathrm{Ci} / \mathrm{g}$ (this corresponds to Class $\mathrm{C}$ waste). Class A waste is limited to a $2,000 \mathrm{Ci} / \mathrm{g}$ concentration. ${ }^{6}$

Table 13-1. Comparison of the estimated maximum ranges for a $39-\mathrm{keV}$ average energy beta particle emitted from ${ }^{242} \mathrm{Cm}$ decay for various materials.

\begin{tabular}{lll}
\hline & $\begin{array}{c}\text { Material } \\
\text { (description) }\end{array}$ & \multicolumn{1}{c}{$\begin{array}{c}\text { Estimated maximum } \\
\text { range for a 39-keV } \beta^{-} \\
(\mathrm{mm})^{\mathrm{a}}\end{array}$} \\
\hline Air (1 atmosphere pressure) & 2 \\
Water & 0.0025 \\
Paper & Wood & 0.002 \\
& Glass & 0.013 \\
& Aluminum & 0.0009 \\
Iron & 0.0009 \\
Copper & 0.0003 \\
Lead & 0.0003 \\
materials. & 0.0002 \\
\hline
\end{tabular}


Table 13-2. Half-value layers for the $890-\mathrm{keV}$ gamma ray emitted from the decay of a ${ }^{242} \mathrm{Cm}$ nucleus. ${ }^{2}$

\begin{tabular}{ll}
\hline \multicolumn{1}{c}{ Material } & $\begin{array}{c}\text { Half-value } \\
\text { layer thickness } \\
(\mathrm{cm})^{\mathrm{b}}\end{array}$ \\
\hline Lead & 0.73 \\
Iron & 1.4 \\
Aluminum & 4.0 \\
Stone concrete & 5.1 \\
Water & 9.3 \\
Air & $8.0 \times 10^{3}$ \\
\hline & \\
a. The half-value layer for a given material is the thickness of the material that will attenuate a beam of gamma \\
rays (of a specific energy) to one-half of its intensity. \\
b. These values were taken from Table 6.2 of Reference 4. \\
\hline
\end{tabular}

Table 13-3. Comparison of the radiotoxicity of several important radionuclides (from Appendix 2 of Reference 7).

\begin{tabular}{lcl}
\hline Radiotoxicity & Group & \multicolumn{1}{c}{ Species } \\
\hline Very high & 1 & ${ }^{241} \mathrm{Pu},{ }^{242} \mathrm{Cm},{ }^{241} \mathrm{Am},{ }^{237} \mathrm{~Np}$ \\
High & 2 & ${ }^{60} \mathrm{Co},{ }^{90} \mathrm{Sr},{ }^{94} \mathrm{Nb}$ \\
Moderate & 3 & ${ }^{14} \mathrm{C},{ }^{63} \mathrm{Ni},{ }^{137} \mathrm{Cs}$ \\
Low & 4 & ${ }^{3} \mathrm{H},{ }^{59} \mathrm{Ni},{ }^{99 \mathrm{~m}} \mathrm{Tc},{ }^{99} \mathrm{Tc},{ }^{129} \mathrm{I}$ \\
\hline
\end{tabular}


Table 13-4. Average and maximum kinetic energies of beta particles and atomic electrons released during decay of several important radionuclides. (Information compiled from data presented in References $1,3,4,8$, and 9.)

\begin{tabular}{lcc} 
& \multicolumn{2}{c}{ Released electron energy } \\
\cline { 2 - 3 } \multicolumn{1}{c}{ Radionuclide } & $\begin{array}{c}\text { Average energy } \\
(\mathrm{keV})\end{array}$ & $\begin{array}{c}\text { Maximum energy } \\
(\mathrm{keV})\end{array}$ \\
\hline Nickel-59 $\left({ }^{59} \mathrm{Ni}\right)$ & $4.1^{\mathrm{b}}$ & $\sim 7.7^{\mathrm{b}}$ \\
Tritium $\left({ }^{3} \mathrm{H}\right)$ & 5.7 & 19.0 \\
Nickel-63 $\left({ }^{63} \mathrm{Ni}\right)$ & 17.1 & 67.0 \\
Curium-242 $\left({ }^{242} \mathrm{Cm}\right)$ & $39^{\mathrm{c}}$ & - \\
Iodine-129 $\left({ }^{129} \mathrm{I}\right)$ & 40.0 & 150.0 \\
Carbon-14 $\left({ }^{14} \mathrm{C}\right)$ & 49.0 & 156.0 \\
Technetium-99 $\left({ }^{99} \mathrm{Tc}\right)$ & 85.0 & 293.0 \\
Niobium-94 $\left({ }^{94} \mathrm{Nb}\right)$ & 156.0 & 500.0 \\
Iodine-131 $\left({ }^{131} \mathrm{I}\right)$ & 180.0 & $806.0^{\mathrm{d}}$ \\
Cesium-137 $\left({ }^{137} \mathrm{Cs}\right)$ & 195.0 & $1,176.0$ \\
Potassium-40 $\left({ }^{40} \mathrm{~K}\right)$ & 541.0 & $1,330.0$ \\
Cobalt-60 $\left({ }^{60} \mathrm{Co}\right)$ & 94.0 & $1,480.0$ \\
Phosphorous-32 $\left({ }^{32} \mathrm{P}\right)$ & 694.0 & $1,710.0$ \\
\hline
\end{tabular}

\section{Chemical and Physical Characteristics}

Curium is a member of the actinide series of the periodic table, which includes actinium, thorium, protactinium, and uranium and the transuranium elements, neptunium, plutonium, americium, berkelium, californium, einsteinium, fermium, mendelevium, nobelium, and lawrencium. ${ }^{10,11,12}$ This series lies between radium and rutherfordium and is chemically similar to the lanthanide series, which is the group of elements between barium and hafnium. In both cases, the series consists of elements whose inner electron shell of 14 " $\mathrm{f}$ " electrons is being filled. In the case of the actinides, the $\mathrm{f}$ shell is being filled, and in the case of the lanthanides, the $4 \mathrm{f}$ shell is being filled. This results in two series, each of whose members are chemically similar to a member of the other series. For the case of curium, it is chemically 
similar to gadolinium in that in both cases the inner " $\mathrm{f}$ " shell is half filled. In fact, it is so similar to gadolinium that in the absence of its radioactivity, it could easily be mistaken for this lathanide element.

All of the actinide elements are chemically similar. They typically form trivalent ions; complex ions and organic chelates; soluble sulfates, nitrates, halides, perchlorates; and sulfides and acid-insoluble fluorides and oxalates.

Curium is unlike any of the lighter elements included in this series in that all of its isotopes are manmade, with none appearing naturally in the environment. Of the 16 curium isotopes, either discovered or postulated, ${ }^{242} \mathrm{Cm}$ was the first to actually be produced and isolated in the laboratory. This was done by bombarding ${ }^{239} \mathrm{Pu}$ with high-energy helium-4 $\left({ }^{4} \mathrm{He}\right)$. Curium was first isolated in 1947 using the isotope ${ }^{242} \mathrm{Cm}$ in the form of a pure hydroxide.

Curium exists primarily in the +3 oxidation state, with colors ranging from colorless to yellow, in a water environment. Solid compounds include $\mathrm{Cm}_{2} \mathrm{O}_{3}, \mathrm{CmO}_{2}$, (and oxides of intermediate composition), $\mathrm{CmF}_{3}, \mathrm{CmF}_{4}, \mathrm{CmCl}_{3}, \mathrm{CmBr}_{3}$, and $\mathrm{CmI}_{3}$. The +4 oxide ion is unstable in water.

The metal is silvery and shiny in appearance, is chemically reactive, and has two crystalline structures depending on the temperature. The low-temperature crystal structure is a close-packed double hexagonal (alpha state at temperatures less than $1,176^{\circ} \mathrm{C}$ ) and face-centered cubic (beta state at a temperature higher than $\left.1,176^{\circ} \mathrm{C}\right) .{ }^{13}$ The metal may be produced by reducing $\mathrm{CmF}_{3}$ with barium vapor at high temperatures. This metal tarnishes in air and dissolves readily in common mineral acids with the formation of the +3 oxidation state ion. This is an exothermic reaction and evolves approximately 140 kilocalories of heat per mole of dissolved curium.

Table 13-5 summarizes some of the important chemical and physical characteristics of this element.

\section{Curium-242 Production}

The structural and fuel materials inside the reactor vessel of a nuclear power plant are exposed to neutron radiation. This radiation can cause many components of these materials to become radioactive with time via neutron activation. Usually, it is the structural materials that are of concern relative to activation by irradiation. However, although the vast majority of the radioactivity associated with the reactor fuel is a direct result of the fissioning process, activation can and does occur in these materials as well. A practical result of this activation is the breeding of fuel (transmutation of nonfissile fuel materials, such as ${ }^{238} \mathrm{U}$, into fissile material such as ${ }^{239} \mathrm{Pu}$ ). Another byproduct of the irradiation of fuel materials is the production of ${ }^{242} \mathrm{Cm}$ by the multiple neutron absorption of ${ }^{238} \mathrm{U}$, with appropriate subsequent decay. This is the principal production means of this nuclide. 
Table 13-5. Chemical and physical characteristics of curium (from References 14, 15, and 16).

\begin{tabular}{|c|c|}
\hline $\begin{array}{l}\text { Physical property } \\
\text { (units) }\end{array}$ & Curium data \\
\hline Melting point $(\mathrm{K})^{\mathrm{a}}$ & 1,615 \\
\hline Boiling point $(K)^{\mathrm{a}}$ & $3,570^{\mathrm{b}}$ \\
\hline Solid density $\left(\mathrm{g} / \mathrm{cm}^{3}\right)$ & 13.5 \\
\hline Crystal form ${ }^{\mathfrak{c}}$ & $\begin{array}{l}\text { alpha-close-packed double hexagonal (lt) } \\
\text { beta-face-centered cubic (ht) }\end{array}$ \\
\hline \multicolumn{2}{|c|}{ a. Zero Kelvin equals $-273.15^{\circ} \mathrm{C},-459.67^{\circ} \mathrm{F}$. } \\
\hline \multicolumn{2}{|c|}{$\begin{array}{l}\text { b. The boiling point is not listed in any of the references as a measured value. Instead, this value was calculated } \\
\text { from the thermodynamic data for this element, using the computer program HSC Chemistry for Windows. }{ }^{17}\end{array}$} \\
\hline \multicolumn{2}{|c|}{$\begin{array}{l}\text { c. (It) refers to low temperature or the crystal structure for temperatures below } 1,176^{\circ} \mathrm{C} \text {; (ht) refers to high } \\
\text { temperature or the crystal structure for temperatures above } 1,176^{\circ} \mathrm{C} \text {. }\end{array}$} \\
\hline
\end{tabular}

When the neutron source is stopped, the directly produced ${ }^{242} \mathrm{Cm}$ decays with a half-life of 163 days and within a few years is essentially gone. However, there can still be a significant source of this nuclide in spent nuclear fuel due to the presence of ${ }^{242 \mathrm{~m}} \mathrm{Am}$, also a product of multiple neutron absorption of ${ }^{238} \mathrm{U}$. ${ }^{242 \mathrm{~m}} \mathrm{Am}$ is a long-lived isomeric state of ${ }^{242} \mathrm{Am}$ that decays to ${ }^{242} \mathrm{Cm}$ via the following reaction:

$$
{ }_{95}^{242 m} A m \underset{\gamma}{\rightarrow}{ }_{95}^{152 y} A m \underset{\beta}{\rightarrow}{ }^{\rightarrow}{ }^{246} \mathrm{Cm}
$$

Since ${ }^{242 m} \mathrm{Am}$ has such a long half-life (relative to that for either ${ }^{241} \mathrm{Am}$ or ${ }^{242} \mathrm{Cm}$ ), after a few weeks following termination of the neutron source, these three nuclides will be in secular equilibrium, where for every disintegration of an americium nucleus, there will be a corresponding disintegration of a curium nucleus. Thus, ${ }^{242} \mathrm{Cm}$ can persist for hundreds of years following reactor shutdown. Also, as mentioned in the introduction and an important aspect of low-level waste, the radiological daughters of ${ }^{242} \mathrm{Cm}$ can persist for long periods of time.

In addition to the production of this nuclide in nuclear reactors, it can also be produced in an accelerator. In fact, the first production of ${ }^{242} \mathrm{Cm}$ was in the University of California's 60 -in. cyclotron. Helium ions were used to bombard ${ }^{239} \mathrm{Pu}$, forming ${ }^{242} \mathrm{Cm}$ via the following reaction:

$$
{ }_{94}^{239} \mathrm{Pu}+{ }_{2}^{4} \mathrm{He} \rightarrow{ }_{96}^{242} \mathrm{Cm}+n .
$$

Early chemical studies of this manmade element principally used two isotopes, ${ }^{242} \mathrm{Cm}$ (half-life of 163 days) and ${ }^{244} \mathrm{Cm}$ (half-life of 18 years). Subsequent chemical studies were conducted using isotopes with much longer half-lives such as ${ }^{247} \mathrm{Cm}$ and ${ }^{248} \mathrm{Cm}$, which have half-lives of $1.6 \times 10^{7}$ and $3.5 \times 10^{5}$ years, respectively. ${ }^{10}$ 
A study conducted at the Commission of the European Communities - Joint Research Center and the Reactor Research Center in Karlsruhe characterized spent fuel using nondestructive assay. ${ }^{18}$ It was concluded that this could be effected by measuring the neutron flux caused by spontaneous fission of the fuel, due mainly to the presence of ${ }^{242} \mathrm{Cm}$ and ${ }^{244} \mathrm{Cm}$.

Finally, significant quantities of ${ }^{242} \mathrm{Cm}$ were produced and released to the environment during nuclear weapon testing activities. ${ }^{19}$ However, atmospheric testing was halted in the early 1970 s, and due to the relatively short half-life, essentially all of the direct residual activity of this nuclide from weapons testing has decayed away. The underground testing-associated activity of this nuclide is essentially gone, so it is expected that the direct, weapons-associated ${ }^{242} \mathrm{Cm}$ is no longer in the environment. However, as stated above, residual ${ }^{242} \mathrm{Cm}$ may exist from the weapons program due to the decay of ${ }^{242 \mathrm{~m}} \mathrm{Am}$.

\section{Waste and Disposal Data on Curium-242}

This section discusses the types of activities that generate ${ }^{242} \mathrm{Cm}$ LLW, waste types and forms that contain ${ }^{242} \mathrm{Cm}$, and disposal data on ${ }^{242} \mathrm{Cm}$.

\section{Nuclear Reactors}

Although not as widespread as for some nuclides (for example ${ }^{60} \mathrm{Co}$, see Chapter 12), there are some applications of ${ }^{242} \mathrm{Cm}$. For example, this nuclide has been used as the power source for an isotopic power reactor. ${ }^{20}$ In this application, a practical power density of 150 watts $/ \mathrm{cm}^{3}$ can be achieved, which is among the highest densities for this type of application. This nuclide was used in the design of the SNAP-11 (Systems for Nuclear Auxiliary Power) generator, which was to be used in the Surveyor experiment (lunar surface use). However, the rapid development of solar cell technology superseded the use of this generator.

The principal production means for this nuclide is in nuclear reactors, where the actinides in the fuel (principally ${ }^{238} \mathrm{U}$ and ${ }^{239} \mathrm{Pu}$ ) are transmuted into ${ }^{242} \mathrm{Cm}$ by multiple neutron absorption. In general, this nuclide is retained in the fuel rods and does not enter the environment. However, entry into the environment can occur if a severe reactor accident occurs, such as the one at the Chernobyl reactor, or if some of the fuel rods develop leaks and the curium enters the primary coolant. In the latter case, ${ }^{242} \mathrm{Cm}$ can be removed from the primary coolant by filters and/or cleanup resins and enter the environment coupled with these media. Then, this nuclide can contaminate various environmental ecosystems until it has decayed away.

Other historical uses of this nuclide may exist, but none were found in the literature search. In any case, the short half-life of this nuclide means that it will decay to insignificant levels within a relatively short time. 


\section{Medical, Academic Institutions, and Commercial Curium-242 Waste}

There are no known medical uses for this nuclide, either for diagnosis or treatment of diseases (this was confirmed by a communication with personnel at the American College of Radiologists). ${ }^{a}$ This nuclide has been used in some laboratory studies (for example, in early laboratory studies of the chemistry of curium), although these are limited. If sources of ${ }^{242 \mathrm{~m}} \mathrm{Am}$ were made for laboratory/medical use, these would also be a source of ${ }^{242} \mathrm{Cm}$. Although another curium isotope is available from standard commercial sources $\left({ }^{244} \mathrm{Cm}\right.$ is available from two commercial sources $\left.{ }^{21,22}\right)$, no listing for ${ }^{242} \mathrm{Cm}$ was located.

An older reference discussed general guidelines for fabrication of laboratory equipment. ${ }^{23}$ This reference included guidelines for handling ${ }^{242} \mathrm{Cm}$ in a laboratory. The use of stainless steel and rounded corners is recommended and a comparison between the handling of this nuclide and that of ${ }^{238} \mathrm{U}$ (both alpha emitters) is made. The point is made that ${ }^{242} \mathrm{Cm}$ has a much higher specific activity (for example, a $1 \mathrm{mCi}$ source of ${ }^{238} \mathrm{U}$ would comprise of the order of $1 \mathrm{~kg}$ of mass whereas a $1 \mathrm{mCi}$ source of ${ }^{242} \mathrm{Cm}$ would comprise only $0.25 \mathrm{mg}$ ) and that, therefore, the handling techniques would be much different.

\section{Disposal Data on Curium-242}

${ }^{242} \mathrm{Cm}$ has been deposited in three LLW disposal sites in Richland, Washington; Barnwell, South Carolina; and Beatty, Nevada over a period of several years. Data have been obtained for this nuclide from the Manifest Information Management System Database. ${ }^{b}$ Figure 13-1 shows the total annual ${ }^{242} \mathrm{Cm}$ activity deposited in the three sites for each year between 1986 and 1995 . Over half of the total activity for this nuclide was deposited during two years, 1989 and $1991 .{ }^{242} \mathrm{Cm}$ was deposited approximately uniformly during the other years.

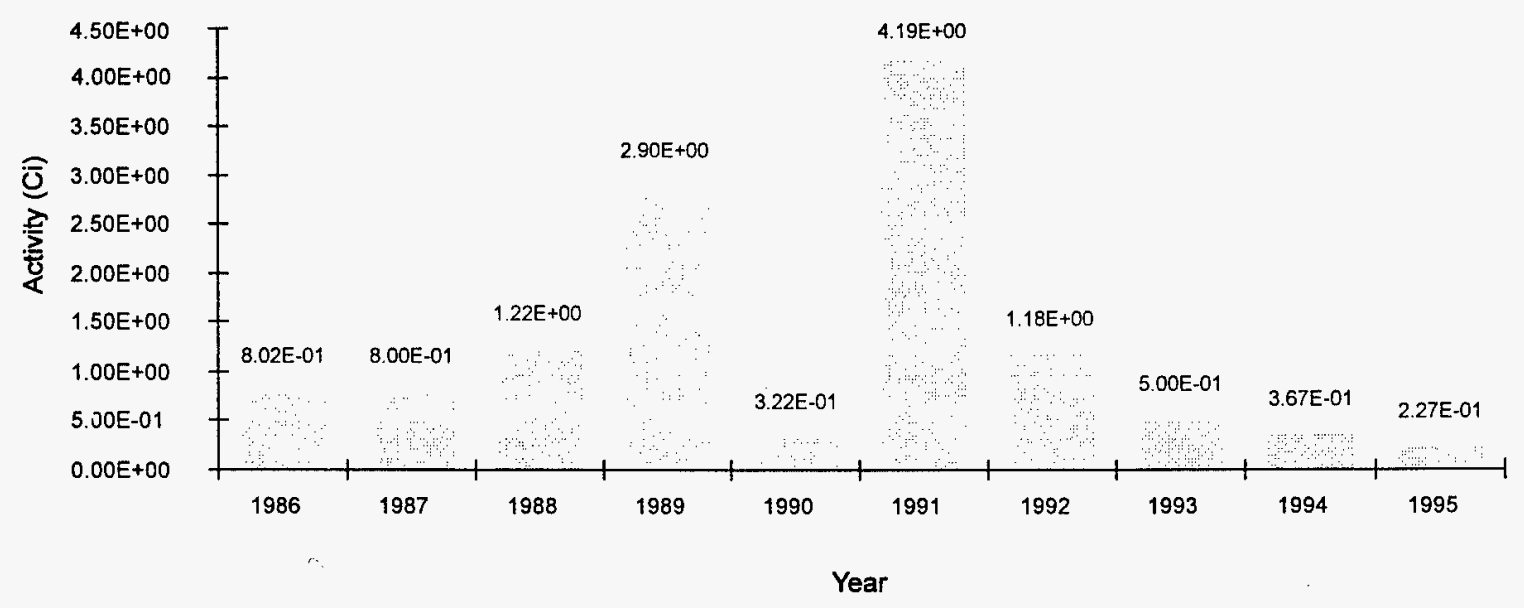

Figure 13-1. ${ }^{242} \mathrm{Cm}$ activity deposited at the Richland, Beatty, and Barnwell sites by year.

a. Private communication between C. Sperry (American Colleges of Radiologists) and J. P. Adams (Idaho National Engineering Laboratory), May 15, 1995.

b. Provided through the DOE waste management system maintained by the National Low-Level Waste Management Program, Idaho National Engineering Laboratory (INEL). 
Figure 13-2 shows the activity of ${ }^{242} \mathrm{Cm}$ deposited in these three sites as a function of waste source. Utility sources account for more than $99 \%$ of the total deposited in these three sites. The definition of disposal categories given in Figure 13-2 is as follows: academic - sources associated with university laboratories; government - sources associated with the government, such as military hospitals; industry sources associated with manufacturing, other than utilities; medical - sources associated with hospitals and medical laboratories, excluding pharmaceutical manufacturing; utility - sources generated by nuclear utilities and stored onsite or sent to one of the three disposal sites. Waste treatment facilities are included in the utility category.

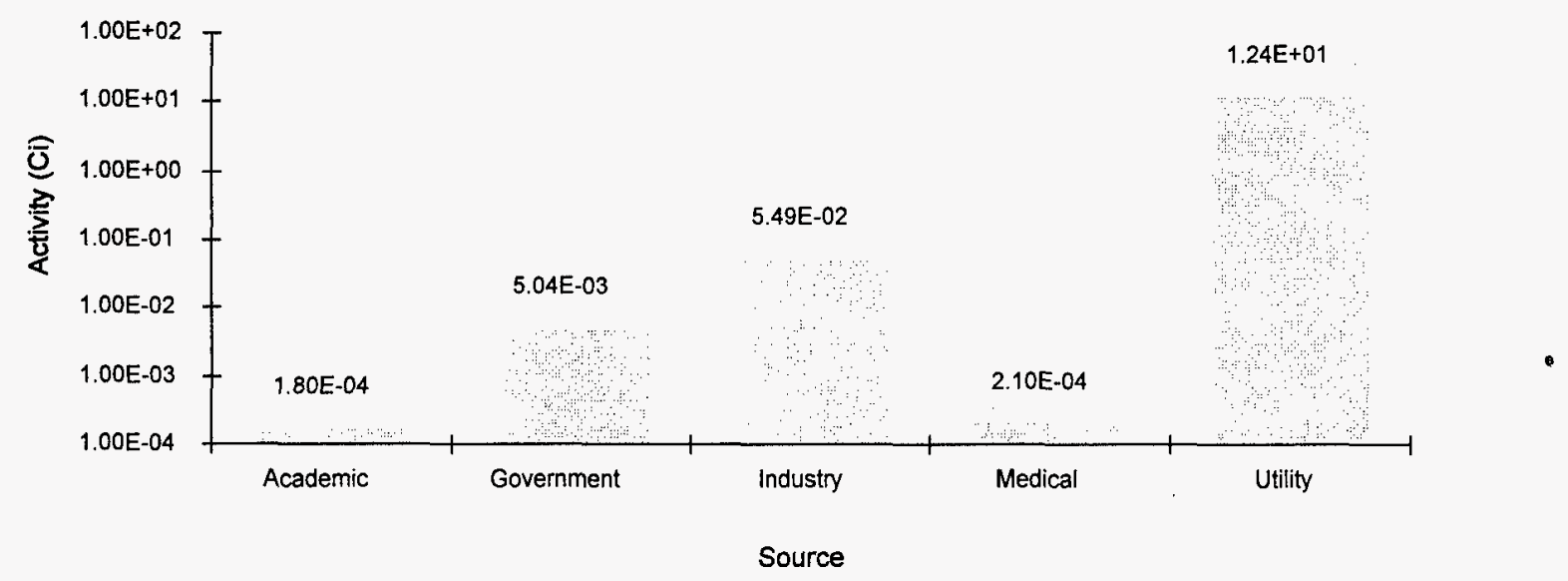

Figure $13-2 .{ }^{242} \mathrm{Cm}$ activity deposited at the Richland, Beatty, and Barnwell sites by source (log scale).

Figure 13-3 shows the activity of ${ }^{242} \mathrm{Cm}$ deposited in the Richland and Beatty sites as a function of waste type. The waste disposal manifests for the Barnwell site did not break down the waste by type, which is unfortunate since more than $96 \%$ of this nuclide has been stored at this site. As shown in this figure, more than half of this nuclide was in the form of compacted dry wastes and dewatered resins. The waste types illustrated in Figure 13-3 are from nuclear reactors, academic institutions, and medical facilities.

\section{Behavior of Curium-242 in the Environment}

\section{Curium-242 in Soils}

Understanding the behavior of radioactive materials such as ${ }^{242} \mathrm{Cm}$ in the soil is important in assessing the possibility of transport of these radionuclides through the biosphere. ${ }^{24}$ It is important to understand the interactions between radionuclides and various media along the path to the biosphere, whether disposal is in deep or shallow rock caverns or in shallow overburden facilities. 


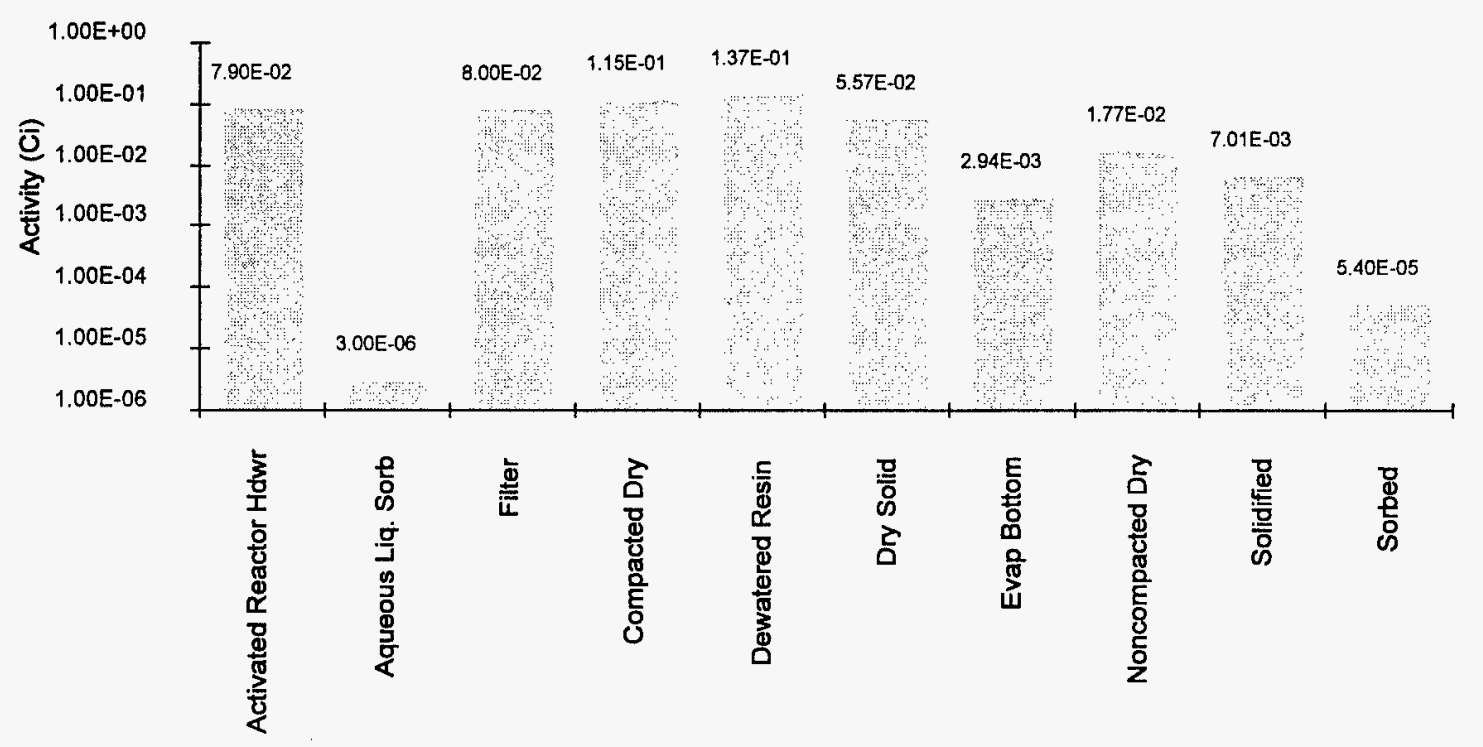

Waste Type

Figure 13-3. ${ }^{242} \mathrm{Cm}$ activity deposited at the Richland and Beatty sites by waste type (log scale).

Four parameters were reported to be essential in accurately predicting soil concentrations from either contaminated ground water or irrigation water. ${ }^{24}$ The four parameters, in order of decreasing importance, are (a) soil retention, (b) annual precipitation, (c) soil texture, and (d) depth to the water table. The soil retention parameter represents the solid/liquid partition coefficient and is denoted by the symbol $K_{d} . K_{d}$ is defined by $K_{d}=C_{s} / C_{l}$, where $C_{s}$ is the curium concentration in the soil (microgram centimeters per gram of soil), and $C_{1}$ is the curium concentration in the groundwater (microgram centimeters per milliliters of liquid). Therefore, the units of $K_{d}$ are milliliters per gram (i.e., milliliters of water per gram of soil). This empirical model combines all soil retention mechanisms into a simple linear partition relation between the soil and surrounding groundwater. This model assumes that the curium concentrations in groundwater and soil are in equilibrium with each other. Using this definition for $\mathrm{K}_{\mathrm{d}}$, it follows that the larger the value (i.e., the higher the radionuclide concentration in the soil relative to that in the groundwater), the slower the migration of the radionuclide relative to groundwater flow. Therefore, $K_{d}$ can be thought of as a measure of the amount of "fixing" or holdup in the soil.

Typically, $\mathrm{K}_{\mathrm{d}}$ is measured under laboratory conditions, using samples that are relatively homogenous, and where it can be ensured that equilibrium conditions are met. Applying these values to specific soils in the field can be difficult because actual soils are generally inhomogeneous and there are uncertainties as to how long it takes for the curium concentrations in the soil and groundwater $\left(\mathrm{C}_{\mathrm{s}}\right.$ and $\left.\mathrm{C}_{1}\right)$ to reach equilibrium with each other. Therefore, soil samples used in laboratory studies should be as closely representative of the field as possible. Even though the soil samples do not precisely match conditions in the field, $K_{d}$ values from laboratory studies can be used in computer models that extrapolate data from laboratory experiments and field studies. In addition, some experiments are conducted using intact field samples to validate the laboratory $\mathrm{K}_{\mathrm{d}}$ values and to study the effects associated with soil inhomogeneity.

One study measured the diffusion of curium in various types of soils, including silt/loam, loamy sand, and sand. ${ }^{19}$ There was a wide range in $\mathrm{K}_{\mathrm{d}}$ values in these experiments. The values ranged from 98 
to $51,900 \mathrm{~mL} / \mathrm{g}$. The authors state that this range is not solely due to variations in the physical and chemical properties of the soils but also partially due to variations in the experimental technique. (In a separate study, also included in this reference, the range of $K_{d}$ values was from 71 to $11,000 \mathrm{~mL} / \mathrm{g}$ - this time for the clay fraction of Miami silt loam.) The authors further state that there are no available data of the distribution and mobility of curium in soil under field conditions. However, it is expected that curium will act identically to americium and the other higher actinides so much of its behavior can be inferred from the behavior of these other elements. In this study, the diffusion coefficients of curium were also inferred from the data. These values were more uniform, ranging from $6 \times 10^{-10}$ to $2.1 \times 10^{-11}$ $\mathrm{cm}^{2} / \mathrm{s}$. Based on these diffusion coefficients, the movement of curium in soil, due to diffusion, is calculated to be of the order of $1 \mathrm{~cm}$ every 1,000 years. Curium, thus, does not diffuse much and movement in soils is likely to be dominated by adsorption on the soils and the mobilities of the soil particles to which it is adsorbed. The formation of soluble complexes and adsorption onto relatively mobile particles would increase its mobility.

Curium chemistry in soils is dominated by the +3 oxidation state. Its soil chemistry is similar to both americium and neodymium, which could be used to infer the long-term behavior and distribution of curium. Curium forms stable complexes with EDTA as well as with organic acids such as citric, tartaric, and lastic acids. ${ }^{19}$

There are few studies of the adsorption behavior of curium in soils. Of those which do exist, none are field studies and the majority are in the form of batch equilibrium experiments. In one study, conducted using ${ }^{242} \mathrm{Cm}$, the adsorption of curium by several clays was measured in a $\mathrm{NaCl}$ solution at neutral $\mathrm{pH}$. This study indicated that adsorption was dominated by precipitation rather than by ion exchange. A second study, using silt loam, also indicated that ion exchange was not an important adsorption mechanism. ${ }^{19}$ This was further confirmed by a study conducted at the Oak Ridge Laboratory. ${ }^{25}$ The authors indicated that the behavior of curium in laboratory studies of clay slurries was dominated by complexes of curium. The movement of curium through these slurries indicated that its mobility in soils would be dominated by filtration and surface adsorption rather than by ion-exchange processes.

A study was made of the effects of the nuclear reactor accident in Chernobyl in 1986 by the Finnish Center for Radiation and Nuclear Safety. ${ }^{26}$ This study concluded that although ${ }^{242} \mathrm{Cm}$ was the dominant alpha-emitting transuranic nuclide in the fallout from Chernobyl, it represented only $0.02 \%$ of the fallout due to ${ }^{137} \mathrm{Cs}$, a dominant gamma emitter. Samples were taken over several periods in the vicinity of Helsinki (south-central Finland). Most of the deposition of ${ }^{242} \mathrm{Cm}$ occurred during the time between May 23 and June 2, resulting in a surface contamination of $210 \mathrm{mBq} / \mathrm{m}^{2}$ (1 becquerel [Bq] is equal to 1 disintegration per second $[\mathrm{d} / \mathrm{s}]$ as compared to 1 curie [Ci], which is equal to $3.7 \times 10^{10} \mathrm{~d} / \mathrm{s}$ ). Other samples were taken in the Kuhmo region (east-central Finland-nearer to the reactor) between April 1 and May 5, and this sample had a surface contamination of $14,000 \mathrm{mBq} / \mathrm{m}^{2}$. The report concluded that the distribution of fallout in Finland was uneven. Even within this conclusion, the distribution of ${ }^{242} \mathrm{Cm}$ was not uniform (i.e., the ratio of this nuclide to other nuclides, either other actinides or other nonactinides, varied greatly from site to site). For example, the ratio of surface contamination by ${ }^{242} \mathrm{Cm}$ to that by ${ }^{239,240} \mathrm{Pu}$ varied from 0.42 to 160 , a range of nearly 400 . The ratio of ${ }^{242} \mathrm{Cm}$ to ${ }^{137} \mathrm{Cs}$ contamination varied from 0.017 to $0.02 \%$. 
Another study was directed to the classification of radioactive fallout in the immediate vicinity of the Chernobyl reactor. ${ }^{27}$ Approximately 50 soil samples were taken and analyzed for several radionuclides from the reactor and there was a relatively wide range of contamination levels in the soil. The range of ${ }^{242} \mathrm{Cm}$ activity was 0.01 to $6.9 \mathrm{~Bq} / \mathrm{g}$, a range of more than 50 .

A study of the fallout in Germany from the accident in Chernobyl was jointly sponsored by the University of Mainz and Institute for Heavy Ion Research of the Federal Republic of Germany. ${ }^{28}$ Based on the measurements from this study, it was estimated that about $3 \%$ of the actinide elements were released from the fuel, with most of the nuclides released in the form of dispersed fuel. Although no actual numbers were presented, it was stated that ${ }^{242} \mathrm{Cm}$ was the most dominant alpha emitter of the material released from the reactor.

The Department of Radiation Physics at the University of Lund studied the fallout in Scandinavia caused by the Chernobyl accident. ${ }^{29}$ The dominant alpha emitter in the fallout from this accident was identified to be ${ }^{242} \mathrm{Cm}$, which was more than 14 times the activity due to ${ }^{239,240} \mathrm{Pu}$. It was concluded that all of the curium was due to the accident at Chernobyl.

In addition to the other mentioned soil contamination studies associated with the Chernobyl accident, one study also looked at the particle size distribution for the various fallout products. ${ }^{30}$ In this study, soil samples were taken, in the northwest direction from the reactor, from five different regions. The soil layers from 0.005 to $0.01 \mathrm{~m}$ in depth were collected and separated into particle size fraction. The soils were sandy and had little humus. In general, the highest activities of actinides, including

${ }^{242} \mathrm{Cm}$, were found in the smallest particles, which would be expected to be the most mobile soil particles. The results from all five soil samples were listed in the reference and in every case the ${ }^{242} \mathrm{Cm}$ activity peaked for particle sizes in the range from 0.005 to $0.05 \mathrm{~mm}$.

\section{Curium-242 in Water}

Reference 19 includes a summary of the behavior of curium, including ${ }^{242} \mathrm{Cm}$, in aquatic ecosystems. The concentration of curium isotopes in water depends on several parameters, concentration of the nuclide in the radioactive waste, distance from the point of discharge, and speed of removal from the water (which, in turn, depends on the physical and chemical characteristics of the released curium and of the water). ${ }^{242} \mathrm{Cm}$ is of greater relative importance in aquatic ecosystems than in terrestrial ecosystems because more of this nuclide is discharged to the environment in liquid wastes. Typically, curium is present in water in insoluble form, which means that it may be transported with the water or may deposit out, depending on the size of the particles and fluid velocities. However, sometimes it will be in soluble form, usually due to having formed soluble curium complexes. Although not confirmed in experimental studies, the chemical form of curium in seawater is usually assumed to be in the +3 oxidation state. The adsorption behavior of curium strongly depends on $\mathrm{pH}$. The $\log$ of the $\mathrm{K}_{\mathrm{d}}$ values increases linearly between $\mathrm{pH}=4$ and 7 , plateaus, and then increases between $\mathrm{pH}=8$ and 10 . The concentration of curium in waters can change seasonally, with a significant decline in concentration in spring and early summer. This behavior may have been due to uptake by algae in the water, although identification of a specific mechanism was not possible.

A study was made of the activity of certain actinides and beta emitters in the process water used in the Loviisa VVER-440-design nuclear power plant in Finland. ${ }^{31}$ This study concluded that curium is 
approximately evenly distributed between the cation and anion resins in the normal operation state. The total radioactivity of ${ }^{242} \mathrm{Cm}$ in the process water was $0.7 \mathrm{MBq}$, compared with $3.1 \mathrm{MBq}$ for ${ }^{239,240} \mathrm{Pu}$.

${ }^{242} \mathrm{Cm}$ was detected in two of the three primary coolant samples taken from this plant in this study. The concentrations ranged from $<2$ to $1.0 \mathrm{kBq} / \mathrm{m}^{3}$ in these samples, taken during 1983 and 1984 . The concentration range for the anion-exchange resin samples was from $<2$ to $1,050 \mathrm{kBq} / \mathrm{m}^{3}$ and in the cation-exchange resin samples, from 3 to $380 \mathrm{kBq} / \mathrm{m}^{3}$. The concentrations in the mixed resin bed samples ranged from 63 to $1,420 \mathrm{kBq} / \mathrm{m}^{3}$. This report also includes a determination of the ratio of ${ }^{242} \mathrm{Cm}$ to ${ }^{239,240} \mathrm{Pu}$ in the ion-exchange resin bed samples. This ratio ranged from 0.03 to 2.33 , indicating a two-order of magnitude range in the relative concentrations. These values are much lower than other reported ratios, which ranged from 1.5 to 127 for VVER-440 reactors. $^{32}$

A similar study was made of the Doel II and III pressurized-water reactors. ${ }^{33}$ Evidence was found for the presence of ${ }^{242} \mathrm{Cm}$ in samples obtained during steady state operations, after reactor shutdown, and during the soluble activity peak. However, most of the alpha-emitting activity had an energy of 5.3 $\mathrm{MeV}$, as opposed to that for ${ }^{242} \mathrm{Cm}$, which has a $6.13 \mathrm{MeV}$ alpha energy. Overall, the total alpha activity concentration ranged from $3 \times 10^{-11}$ to $1.6 \times 10^{-9} \mu \mathrm{Ci} / \mathrm{mL}$ during normal operations where there was no evidence of failed fuel. If failed fuel was present, the levels rose to a range of $2.2 \times 10^{-9}$ to $6.3 \times 10^{-9}$ $\mu \mathrm{Ci} / \mathrm{mL}$. The majority of this activity was found to be insoluble under normal operating conditions. The solubility increased during shutdown, when the concentrations of gamma-emitting species also increased. The shutdown concentration of ${ }^{242} \mathrm{Cm}$ ranged from $1.57 \times 10^{-10}$ to $1.73 \times 10^{-8} \mu \mathrm{Ci} / \mathrm{mL}$ and the normal operations concentrations varied from $1.26 \times 10^{-10}$ to $4.0 \times 10^{-9} \mu \mathrm{Ci} / \mathrm{L}$.

Scientists at the Woods Hole Oceanographic Institute performed an environmental study of the releases of radionuclides from three pressurized-water reactors, Millstone Point 1 and 2 and Maine Yankee, including the release of ${ }^{242} \mathrm{Cm} .{ }^{34}$ The Millstone Point 1 reactor discharged this nuclide at a rate of 30 to $100 \mathrm{nCi} /$ month, with the exception of a brief time in early 1977 when more than $3,000 \mathrm{nCi} /$ month were discharged. A new waste treatment process was installed at Millstone Point, which greatly reduced the discharge. Millstone Point 2 discharged at a rate of a few to $40 \mathrm{nCi} / \mathrm{month}$. There were no measurable discharges of this nuclide from Maine Yankee.

The concentrations of various actinides in the primary coolant of a boiling-water reactor was the subject of a study by the Institute for Radiation Protection in Neuherberg, Germany. ${ }^{35}$ The ratio of ${ }^{242} \mathrm{Cm}$ to ${ }^{239,240} \mathrm{Pu}$ ranged from 0.13 to 100 . The principal concern is that if there are actinides in the primary coolant of a reactor, it may be expected that they will be transported via primary leakage into waste water and airborne effluents and injected into the environment.

An environmental study was made of the radionuclides in the effluent from the Argonne National Laboratory that was discharged into streams in the vicinity. ${ }^{36}$ The maximum concentration of ${ }^{242} \mathrm{Cm}$ in the Sawmill Creek was $<1 \times 10^{-17} \mathrm{Ci} / \mathrm{cm}^{3}$.

Personnel at the Woods Hole Oceanographic Institute conducted an investigation into the presence of fission products and actinides in the Black Sea caused by the accident at the Chernobyl RMBK reactor. ${ }^{37}$ Among the nuclides included in this study was ${ }^{242} \mathrm{Cm}$. One hundred to one thousand liter seawater samples were taken from a variety of locations in the Black Sea and analyzed for alpha emitters using standard spectrometric analysis techniques. The range of ${ }^{242} \mathrm{Cm}$ concentrations was 0.4 to 
$34 \mathrm{mBq} / \mathrm{m}^{3}$. This study concluded that the measured curium originated from the Chernobyl reactor accident.

Scientists from the German Hydrographical Institute, Hamburg, Germany, performed a study of the transfer of actinides from the English Channel into the North Sea. ${ }^{38}$ Large volume $(60$ to $200 \mathrm{~L})$ samples of seawater were collected from 13 different locations in the channel and North Sea in 1975. Only a small fraction of these samples contained detectable concentrations of ${ }^{242} \mathrm{Cm}$ and a typical concentration was $7 \mathrm{fCi} / \mathrm{kg}$. The ratio of ${ }^{242} \mathrm{Cm}$ to ${ }^{239,240} \mathrm{Pu}$ activities was of the order of 0.2 to 0.7 and the paper concluded that these actinides originated from the La Hague fuel reprocessing plant.

During the era of atmospheric testing, studies were initiated of the behavior of transuranic radionuclides in Lake Ontario. Following the termination of the atmospheric testing, these studies were continued because of the recognized potential for leakage from the nuclear fuel reprocessing facility at Springville, New York. An update to these studies was performed by scientists at the Woods Hole Oceanographic Institute in the late 1970s. ${ }^{39}$ Sediment samples were taken and analyzed for the presence of the actinides. The concentration of ${ }^{242} \mathrm{Cm}$ ranged from $<0.05$ to $0.11 \mathrm{pCi} / \mathrm{kg}$ of sediment.

A summary of several studies of curium behavior in sediments is included in Reference 19. Curium is believed to be rapidly removed from a water column by deposition in sediments. The values for $\mathrm{K}_{\mathrm{d}}$ vary widely, depending on the specific conditions for the experiment. Some values are of the order of $100 \mathrm{~mL} / \mathrm{g}$ and others as high as $10,000 \mathrm{~mL} / \mathrm{g}$. The reason for the different units is not discussed. The equilibrium $\mathrm{K}_{d}$ values increase significantly with increasing $\mathrm{pH}$.

\section{Curium-242 in Plants}

Published information on the occurrence and distribution of curium in plants is restricted in scope. There are few data from field studies. Most of the relevant data are derived from experiments where the only method of uptake is via the roots. Often, experiments designed to investigate the effects of different factors (e.g., soil chemistry, plant species) have experienced analytical problems and, therefore, the results are not conclusive. ${ }^{19}$

A couple of field studies are included in this reference. During the 1960s, the curium content of lichen was measured on a regular basis in Sweden. This was during the period of intensive atmospheric testing of nuclear weapons and the purpose of this testing was to determine the effects of fallout. Typical concentrations of ${ }^{242} \mathrm{Cm}$ were from 0.003 to $0.015 \mathrm{pCi} / \mathrm{kg}$ for this nuclide. Another study was conducted, this time using vegetation growing on the shore of radioactive waste ponds near a test reactor at the Idaho National Engineering Laboratory. The concentrations ranged from 0.1 to $14 \mathrm{mBq} / \mathrm{g}$, depending on the species studied. Additionally, it was concluded that the dominant contamination mechanism was from surface deposition, not root uptake.

Reference 19 includes a discussion of the effects of various soil factors on the uptake of curium into various types of plants. For example, the presence of large amounts of organic matter in the soil will greatly reduce the plant concentration levels of curium because the curium preferentially is adsorbed to the organic matter, reducing the amount available for plant uptake. The presence of lime in the soil also reduced the uptake into plants. The lime increased the $\mathrm{pH}$ of the soil, resulting in nearly complete hydrolysis and adsorption of curium onto soil solids or the formation of insoluble carbonate complexes 
that were not taken up into the plants. However, adding a complexing agent, either DTPA or, to a much lesser extent, EDTA, with the lime increased the concentration factor significantly, sometimes more than two orders of magnitude. However, these were laboratory experiments where the DTPA was added to the curium nitrate solution before it was added to the soil. If the DTPA were applied to curium-laden soil, the effects would probably be much less. Plants used in these studies include tumbleweed, rice, barley, bush bean, soybean, wheat, corn, and clover.

The studies included in Reference 19 also drew conclusions regarding the distribution of curium among the various (aboveground) plant parts. Measurements of curium concentration in the roots were not included. In general, the concentrations were highest in the leaves, followed by the stems, chaff, and seed. Thus, ingestion of leafy vegetables would result in the highest transfer of curium to humans and grains, the least. Fruits are also believed to have high curium concentrations. Where curium is chemically bonded with a complexing agent, more of the curium is available for uptake into plants.

A fairly early study of the behavior of curium in plants was conducted by the Oak Ridge National Laboratory. ${ }^{25}$ This study used both beans and grass. The study concluded that the curium concentrations in the grass samples did not exceed the control sample concentrations (which were grown with no curium contamination). However, the bean plants exhibited significant activity in the foliage and stem tissues. An additional observation was made by relocating bean plants from the soil directly into the curium-laded solution. Some of the plants had their roots severed before being placed into the solution. The uptake of curium into the plants was actually enhanced in those plants without roots. The authors concluded that any mechanism to discriminate against curium uptake in plants is probably in the roots and that removal of the roots also removes this mechanism.

Researchers at the Pacific Northwest National Laboratory have investigated the effects of aging on the uptake of curium into various plants. ${ }^{40}$ In this lysimeter experiment, cheat grass, peas, barley, and alfalfa plants were grown in an environment that included curium. (Note, this experiment was conducted using ${ }^{244} \mathrm{Cm}$, rather than ${ }^{242} \mathrm{Cm}$, but since chemical effects should dominate, the behavior of both nuclides should be similar.) The uptake ratio (ratio of vegetation concentration of curium [picocuries/gram] to the curium in the lysimeter [millicuries])was 65 to 80 for cheat grass; 0.16 to 0.9 for barley seed and 10 to 39 for barley stem-leaf; 3.0 to 4.7 for pea seed and 4.8 to 6.3 for pea stem-leaf-pod; and from 1.5 to 7.8 for alfalfa. Overall, the uptake ratio was approximately 10 times higher for curium than for plutonium.

A study was recently conducted by scientists at the Westinghouse Savannah River Company to investigate the uptake of curium into vegetation adjacent to the seepage basins at the laboratory. ${ }^{41}$ This report concluded that the concentration of curium decreased significantly with distance from the surface of the soil, indicating that curium is relatively immobile in this soil. There was a slight difference in concentrations between the leaves and wood in the trees, with higher concentrations in the wood. Also, curium concentrations in hardwood trees were about twice as high as in pine. The concentration factors ranged from 0.005 to 0.02 , which values are in the range of previously reported numbers in the literature.

The accident in the Chernobyl reactor prompted numerous scientific investigations into fallout phenomena, including one conducted by the Institute for Radiation Protection in Neuherberg, Germany. ${ }^{42}$ This study looked at the uptake of various radioactive reactor byproducts in grass growing in South Bavaria, Germany, where the deposition of Chernobyl-derived radionuclides was comparatively high. Grass samples were collected in May 1986 in an area near Boeblingen, approximately $60 \mathrm{~km}$ west of 
Munich. The activity of ${ }^{242} \mathrm{Cm}$ in these samples was $3.0 \mathrm{~Bq} / \mathrm{kg}$. This activity was 20 times higher than that for ${ }^{239+240} \mathrm{Pu}$ and was nearly 40 times higher than that for ${ }^{238} \mathrm{Pu}$.

The global fallout of curium was studied by scientists in 1978 at the University of Lund in Sweden. ${ }^{43}$ Their study involved measuring the concentration of ${ }^{242} \mathrm{Cm}$ in a specific lichen (Cladonia alpestris), collected from various locations in central Sweden. The ${ }^{242} \mathrm{Cm}$ activity measured in these samples is actually that produced by the decay of ${ }^{242 \mathrm{~m}} \mathrm{Am}$, which decays with a two-step decay process and a half-life of 152 years to ${ }^{242} \mathrm{Cm}$. The concentrations of ${ }^{242} \mathrm{Cm}$ in lichen varied about an average value of $0.006 \mathrm{pCi} / \mathrm{kg}$ during measurements taken in the $1960 \mathrm{~s}$.

\section{Curium-242 in Air}

From a biological hazard standpoint, the most important pathway for actinides to contaminate humans is inhalation. For example, the maximum dose to any body organ (rem) per microcurie inhaled is 57. The maximum external dose range from a point source (rem per hour) per microcurie source is $<1 \times 10^{-8} .{ }^{20}$ Ingestion is less hazardous than inhalation because the uptake from the gastrointestinal tract is relatively small. ${ }^{29}$ Fallout from the Chernobyl reactor accident was studied by scientists at the Lund University in Sweden. They concluded that ${ }^{242} \mathrm{Cm}$ was the principal alpha emitter in the fallout from this accident. Precipitation concentrations were measured in Southern Europe $\left(4,000 \mathrm{mBq} / \mathrm{m}^{3}\right)$ and in South Sweden $\left(500 \mathrm{mBq} / \mathrm{m}^{3}\right)$. Air samples were taken and measured for this nuclide. The concentrations were as high as $3,000 \mu \mathrm{Bq} / \mathrm{m}^{3}$ in South Finland, compared to $250 \mu \mathrm{Bq} / \mathrm{m}^{3}$ for Denmark and South Sweden. The mean residence time for this nuclide was generally one to three days in air and 24 days in rain. There was some question as to whether the measured concentrations were due to Chernobyl fallout or residual ${ }^{242} \mathrm{Cm}$ from the decay of ${ }^{242 \mathrm{~m}} \mathrm{Am}$ from the fallout of earlier atmospheric tests. However, the ratio of ${ }^{242} \mathrm{Cm}$ to ${ }^{239+240} \mathrm{Pu}$ would be expected to be in the range of 0.004 . In these tests, the ratio was 14 , indicating the presence of original ${ }^{242} \mathrm{Cm}$.

Reference 26 discusses the fallout from the Chernobyl accident. The authors concluded that ${ }^{242} \mathrm{Cm}$ was the dominant alpha-emitting transuranic nuclide in the fallout from this accident. However, they also concluded that overall the concentrations of these transuranic elements comprised only a small fraction of the total fallout - the total activity of ${ }^{242} \mathrm{Cm}$ in the fallout was only $0.01 \%$ of that due to ${ }^{137} \mathrm{Cs}$. Most of the ${ }^{242} \mathrm{Cm}$ deposition occurred between May 23 and June 2, 1986, and resulted in a surface contamination level of $210 \mathrm{mBq} / \mathrm{m}^{2}$.

An environmental study was made of the radionuclide releases from the Savannah River Plant in $1981 .{ }^{44}$ During 1981 , approximately $1.6 \times 10^{-4} \mathrm{Ci}$ of ${ }^{242,244} \mathrm{Cm}$ were released, primarily in particulate form, into the atmosphere. The study included a dose assessment of all of the radionuclides released from the plant and concluded that less than $0.03 \mathrm{mrem} /$ year of dose would result from the release of the curium nuclides (actually, the dose due to the curium nuclides was grouped into the dose from several of the released radioactive species and this number represents the dose from all of these except ${ }^{3} \mathrm{H},{ }^{24} \mathrm{C}$, and argon-41 ( $\left.{ }^{41} \mathrm{Ar}\right)$, which were the principal airborne release components). 


\section{Behavior of Curium-242 in the Human Body and in Animals}

This section summarizes several studies of the behavior of ${ }^{242} \mathrm{Cm}$ in the human body and in animals. Since ${ }^{242} \mathrm{Cm}$ is principally an alpha emitter, the human hazard from this nuclide is dominated by internal dose when the nuclide is either ingested or inhaled. Of these two, inhalation is the more important method. ${ }^{45}$ A number of factors may influence the dose to the lung and other tissues and the subsequent biological effects, including chemical form, specific activity, and particle size distribution.

Reference 19 contains an extensive summary of the behavior of curium isotopes, including ${ }^{242} \mathrm{Cm}$ in animals and humans. One conclusion is that the isotopes of curium are metabolized in humans in a manner similar to americium. Thus, much can be inferred about curium behavior in the human body based on the extensive data base for americium. Some general observations mentioned in this reference include (a) the fractional gastrointestinal absorption is low, typically less than $10^{3}$ in adults (both humans and animals); (b) curium and the higher actinides (e.g., berkelium, californium, fermium, einsteinium) behave more like americium than like plutonium; (c) and data indicate that curium initially deposits on bone surfaces and is only slowly redistributed into the volume of mineral bone. Specific information in this reference to ${ }^{242} \mathrm{Cm}$ indicates that the fractional gastrointestinal absorption is approximately $3 \times 10^{-4}$ for both soluble and oxide forms. After inhalation of ${ }^{242} \mathrm{Cm}$ (in the nitrate form), the percent that was redistributed to the bone grew from $6 \%$ after 1 day to $20 \%$ after 3 months. The removal rate data for rats (following inhalation of monodisperse aerosols) indicate that up to $85 \%$ of the initial body burden is eliminated in feces with a half-life of 1 day and the rest is eliminated with a half-life of about 20 days. Other studies, also summarized in this reference, indicate half-lives between 0.8 and 4.0 for the initial reduction, followed by 47 to 94 days for the longer value. The fractions corresponding to these two components are approximately 85 and $15 \%$, respectively.

Reference 19 also discusses distribution of curium isotopes within the body. In rats, at 1 day following intermuscular injection, less than $10 \%$ of the total injected curium had been transported from the injection site. Of that transported, approximately $50 \%$ was located in the liver, and $20 \%$ in the bones. The remainder was removed via urine. After 45 days over half of the original injected curium had been transported from the injection site. Of this, $41 \%$ was in the bone, $30 \%$ in the urine, $6 \%$ in the liver, and $20 \%$ in feces. Other animals included in curium studies are baboons, goats, and cows. In these animals, the initial concentration seemed to favor the liver, kidneys, and skeleton. Only limited data were reported on the behavior of curium in humans due to accidental exposure.

Scientists at the Nuclear Research Center in Karlsruhe, Germany, performed a study into the effectiveness of two chelates in removing ${ }^{242} \mathrm{Cm}$ from contaminated rats. Specifically, this study examined the relative effectiveness of CaDTPA and $\mathrm{ZnDTPA}$ in curium removal. This was done because at the time using CaDTPA was the preferred method of curium removal and this chelate was relatively toxic. If $\mathrm{ZnDTPA}$ could be shown to be effective in curium removal, this would be preferred because it is less toxic. The experimental approach involved injecting rats with ${ }^{242} \mathrm{Cm}$ in the form of a citrate. After various delay times, either CaDTPA or ZnDTPA were injected and the rats were monitored as to the curium removal rate. The initial curium distribution in the rats was determined to be primarily in the skeleton and liver, with approximately equal amounts in each. For the time frame immediately following injection of the chelates, CaDTPA was shown to be superior in removing curium from the 
body. However, this advantage was only transitory and for prolonged treatment, $\mathrm{ZnDTPA}$ is equally as good. The study also showed that even after the curium has been deposited in the liver, it can still be removed using either chelate.

Reference 19 also includes some information regarding the distribution of ${ }^{242} \mathrm{Cm}$ in rats following intravenous injection. The curium is located primarily in the liver and skeleton 6 days after injection and with no specific treatment to remove the nuclide. By day 13, a significant fraction of the liver burden was removed by natural body processes assisted with a saline injection. If the rats were treated with a chelate (either CaDTPA or ZnDTPA), the liver burden was significantly reduced (by more than $90 \%$ ), but the skeleton burden remained nearly constant. There was not significant deposition in other tissues.

Another study using rats was performed by researchers of the National Radiological Protection Board in Harwell, England. ${ }^{46}$ In this study, the retention and translocation of two forms of curium (nitrate and citrate) were measured after deposition in the three anatomical regions of the respiratory system, namely, the nasopharyngeal, tracheobronchial, and pulmonary regions. These two chemical forms are classed as "W" compounds (i.e., retention in the pulmonary compartment is of the order of weeks). The study concluded that there is significant translocation out of the lung, especially for the citrate form. The nitrate form remained in the lung in significant amounts, even after 1 week following deposition. However, in another study, it was determined that curium nitrate cleared the lungs much more rapidly than plutonium nitrates. ${ }^{47}$

Concentrations of various radionuclides were measured in duck populations that stayed for prolonged times on radioactive leaching ponds on the Idaho National Engineering Laboratory. ${ }^{48}$ First, the ${ }^{242} \mathrm{Cm}$ concentrations were measured in the water, plankton, periphyton, and sediments. These concentrations were $4.8 \times 10^{-5}, 0.12,1.1$, and $0.02 \mathrm{~Bq} / \mathrm{g}$, respectively. Fourteen mallard ducks were used in this controlled study. After letting the ducks feed on the pond for either 75 or 145 days, they were killed and samples were taken from the bones, gastrointestinal (GI) tracts, muscles, lungs, livers, and feathers and analyzed for ${ }^{242} \mathrm{Cm}$ content. Measurable concentrations of this nuclide were found only in bone, GI tract, and feather samples, with the highest concentration in the GI tract and feather samples. All other samples were below the detectable limits for this nuclide.

Reference 34 includes a study of the uptake of various radionuclides due to the effluent released from the Millstone Point reactors. The researchers measured between 3 and $9 \mathrm{dpm} / \mathrm{kg}$ of radioactivity in oysters harvested in the vicinity of this plant.

Reference 47 is a study of the biological effects of, among other nuclides, ${ }^{242} \mathrm{Cm}$ in rats and dogs. This study concluded that all of the transuranics, including the curium isotopes, tend to translocate from the lung to the bone and liver, and to a lesser extent, to the spleen and kidney. For example, in dogs that inhaled curium oxide aerosols, the curium was relatively uniformly distributed among the lung, liver, bone, and muscle 1 month after exposure. Additionally, in studies of pregnant rats, it was shown that the placenta and placental membranes are an effective barrier to the transfer of curium from the mother to the fetus. It would take high quantities of curium in the mother before appreciable contamination of the fetus would occur. The biological hazard of curium isotopes seems to be greatest in the bone. Osteogenic sarcomas were measured as a direct result of curium exposure in mice, rats, and dogs. However, these studies used ${ }^{244} \mathrm{Cm}$ instead of ${ }^{242} \mathrm{Cm}$ and these results may not be directly applicable to the latter. 
As stated earlier, studies of the behavior of ${ }^{242} \mathrm{Cm}$ in the human body are not numerous. However, a few do exist and are discussed here. A human-based study was performed by researchers at the National Radiological Protection Board in Chilton, United Kingdom. ${ }^{49}$ Five human volunteers were administered small amounts of ${ }^{242} \mathrm{Cm}$ in citrate form and the GI absorption was measured. The fractional absorption was measured to be approximately $2 \times 10^{-4}$. The authors conclude that the fractional absorption is somewhat less in humans than in rats.

An accident resulted in contamination of a technician at the European Institute for Transuranium Elements in Karlsruhe, Germany. ${ }^{50}$ The technician was preparing targets for a mass spectrometer when some ${ }^{242} \mathrm{Cm}$ escaped, contaminating the laboratory air. The average concentration of the curium in the air was of the order of $10^{-9} \mathrm{Ci} / \mathrm{m}^{3}$. Measurable activities of curium were detected in the feces and urine samples, ranging from $<0.1$ to $50 \mathrm{pCi} / \mathrm{g}$. Measured contamination of the nose and pulmonary tract were 500 and $<6,000 \mathrm{pCi}$, respectively. The authors further stated that the biological half-life is 360 days, which combined with the radiological half-life of 163 days results in an overall half-life of 110 days.

Scientists at the National Radiological Protection Board in Harwell, United Kingdom, have conducted an investigation into the development of chromosome changes caused by alpha exposure. ${ }^{51}$ In this study, human blood samples were irradiated by alpha particles from ${ }^{242} \mathrm{Cm}$, and the average number of mutations (dicentrics) per blood cell were measured as a function of dose. It was shown that the dose-effect curve is linear up to 400 rad exposure.

Reference 52 contains interesting information regarding the distribution of and subsequent dose to various human body parts caused to the intake of ${ }^{242} \mathrm{Cm}$. The principal doses due to inhalation are in the bones and lungs. If the nuclide is ingested, the principal dose is in the bones and the lungs are not affected appreciably.

The annual limits for intake (ALI) on ${ }^{242} \mathrm{Cm}$ and the derived air concentration (DAC) for ${ }^{242} \mathrm{Cm}$ are shown in Table 13-6. The ALI is defined as that annual intake of a radionuclide that would result in a radiation dose to a human (for calculational purposes, the characteristics of the Reference Man are used) equal to the allowable limit. The DAC is defined as that concentration of a radionuclide in air which, if breathed for a work-year, would result in an intake corresponding to the ALI (or, in the case of submersion, to an external exposure corresponding to the primary guide for limiting annual dose). DACs are, thus, used for limiting radionuclide intake through the breathing of, or submersion in, contaminated air. ALIs are used primarily for assessing doses due to accidental ingestion of radionuclides.

Historically, maximum permissible concentrations (MPC) in air and water have been used to determine safety guidelines for released radionuclide concentrations. Currently, the derived guidelines are presented in terms of ALIs for inhalation or ingestion, and DACs for inhalation (or submersion). For a radionuclide whose derived value does not change from the old definition, the DAC is numerically equal to the MPC value in air. The information in Table13-6 applies only to ${ }^{242} \mathrm{Cm}$. In the case of multiple radionuclides released in a mixture, additional guidelines outlined in the Code of Federal Regulations, Part 20 of Title $10^{53}$ must be followed. 
Table 13-6. Annual limits on intake and the derived air concentrations for ${ }^{242} \mathrm{Cm}$ (from Reference 54).

\begin{tabular}{clll}
\hline Radionuclide & \multicolumn{1}{c}{ Component } & \multicolumn{1}{c}{ Ingestion } & Inhalation $^{\mathrm{a}}$ \\
\hline${ }^{242} \mathrm{Cm}$ & $\mathrm{ALI}(\mu \mathrm{Ci})$ & $54\left(5 \times 10^{-4}\right)^{\mathrm{b}}$ & $0.3 / \mathrm{W}$ \\
& & $81\left(5 \times 10^{-4}\right)$ & $0.3 / \mathrm{W}$ \\
& & $($ bone $)$ & \\
& $\mathrm{DAC}(\mu \mathrm{Ci} / \mathrm{mL})$ & $-{ }^{c}$ & $1.1 \mathrm{E}-10 / \mathrm{W}^{\mathrm{d}}$
\end{tabular}

a. Clearance from the lung directly to the blood stream or to the GI tract depends on the chemical form of the radionuclide and is classified as $\mathrm{D}, \mathrm{W}$, and $\mathrm{Y}$, respectively, for clearance times of the order of days, weeks, and years. For ${ }^{242} \mathrm{Cm}$, the classification is $\mathrm{W}$.

b. The removal class, $f_{1}$ for each ALI is in parenthesis. A simple model of the lung was used to describe the translocation and retention of material by the body after inhalation. In this model, $25 \%$ of the inhaled activity was exhaled and $25 \%$ was deposited in the lower respiratory tract. The $50 \%$ that was deposited in the upper respiratory tract was eventually cleared by means of mucociliary processes and swallowed. What happens then depends on whether the inhaled material was in either a soluble or insoluble chemical form. Any soluble material deposited in the lower respiratory tract is assumed to be transferred directly to the blood stream. The insoluble activity is cleared from the upper respiratory tract and then swallowed; a fraction $\left(f_{1}\right)$ enters the blood stream via the GI tract. In the case of ${ }^{242} \mathrm{Cm}, \mathrm{f}_{1}=5 \times 10^{-4}$. Additional details of this model are described in References 55 and 53.

c. Data not available.

d. $\quad 8 \mathrm{E}-8$ denotes $8 \times 10^{-8}$.

\section{Summary}

${ }^{242} \mathrm{Cm}$ has a half-life of 163 days and decays by alpha particle emission to ${ }^{238} \mathrm{Pu}$. After a combination of 13 alpha and beta decays, the stable ${ }^{206} \mathrm{~Pb}$ nucleus finally results. High-energy alpha particles, medium-energy gamma rays, and low-energy beta particles are emitted when this nuclide decays. The total particle and photon spectrum is complex because of the complex decay scheme.

${ }^{242} \mathrm{Cm}$ is important from the point of view of LLW disposal primarily because of the radiological daughters produced through the ${ }^{242} \mathrm{Cm}$ decay scheme. Although ${ }^{242} \mathrm{Cm}$ decays with a relatively short half-life (163 days), its radiological daughters, such as ${ }^{238} \mathrm{Pu}$ with a half-life of 86 years, can persist for much longer in radioactive waste.

The principal source of ${ }^{242} \mathrm{Cm}$ generation is in nuclear reactors, where it is produced by multiple-neutron absorption of nuclear fuel constituents such as ${ }^{238} \mathrm{U}$ and ${ }^{239} \mathrm{Pu}$. Upon reactor shutdown, this nuclide quickly decays away and the original inventory disappears. However, this nuclide is also the decay daughter of ${ }^{242} \mathrm{Am}$, which has a half-life of 152 years and, therefore, ${ }^{242} \mathrm{Cm}$ will persist in spent nuclear fuel for a long time. 
There are no naturally occurring isotopes of curium as it is a totally manmade element. Although ${ }^{242} \mathrm{Cm}$ was the original curium isotope produced, several other isotopes have been produced and are also available.

Some laboratory usage of ${ }^{242} \mathrm{Cm}$ has occurred (for example, early laboratory studies of the chemistry of this manmade element), but currently there are no known medical uses for this nuclide, either for diagnosis or treatment of diseases.

There are some applications of ${ }^{242} \mathrm{Cm}$. For example, this nuclide has been used as the power source for an isotopic power reactor. In this application, a practical power density of $150 \mathrm{watts} / \mathrm{cm}^{3}$ can be achieved, which is among the highest densities for this type of application. This nuclide was used in the design of the SNAP-11 (Systems for Nuclear Auxiliary Power) generator, which was to be used in the Surveyor experiment (lunar surface use). However, the rapid development of solar cell technology superseded the use of this generator.

The chemistry of curium is dominated by the half-filled inner $5 \mathrm{f}$ subshell. The principal oxidation state is +3 , although a limited number of compounds exist with other oxidation states. This element has an analogue in the lanthanum series of the periodic table. The lanthanide most similar to curium is gadolinium, which has a half-filled $4 \mathrm{f}$ subshell.

The ability of soil to adsorb ${ }^{242} \mathrm{Cm}$ out of the groundwater depends on a number of factors, including $\mathrm{pH}$ and the presence or absence of complexing agents. However, in general, curium is easily adsorbed by soils and is not easily leached into the groundwater.

The principal radiological hazard associated with this nuclide is due to its high-energy alpha particles. Since these alpha particles do not penetrate materials easily, external exposure to this nuclide does not pose a high risk. The principal risk is due to inhalation of this nuclide. When inhaled, curium tends to concentrate in either the lung or bone tissues and is removed from the body with an overall half-life of approximately 110 days. 


\section{References}

1. General Electric Company, Nuclides and Isotopes, 14th ed., 1989.

2. McGraw-Hill Encyclopedia of Science and Technology, 6th ed., Volume 4, New York: McGraw-Hill Book Company, 1987.

3. C. M. Lederer, J. M. Hollander, I. Perlman, Table of Isotopes, 6th ed., New York: John Wiley and Sons, Inc., 1967, pp. 43 and 231.

4. B. Shleien and M. S. Terpilak, The Health Physics and Radiological Health Handbook, Nucleon Lectern Associates, 1984.

5. E. Browne and R. B. Firestone, Table of Radioactive Isotopes, New York: John Wiley and Sons, 1986.

6. D. C. Steward, Data for Radioactive Waste Management and Nuclear Applications, New York: John Wiley and Sons, 1985.

7. R. Granier and D. Gambini, Applied Radiobiology and Radiation Protection, Ellis Harwood, 1990, pp. 346-347.

8. R. C. Weast (ed.), CRC Handbook of Chemistry and Physics, 58th ed., Boca Raton, Florida: CRC Press, 1977, pp. B-270-B-354 (Table of Isotopes) and p. B-429.

9. Bureau of Radiological Health, Radiological Health Handbook, revised edition, U.S. Government Printing Office, January 1970, pp. 92-94 (average and maximum beta energy by radionuclide).

10. McGraw-Hill Encyclopedia of Science and Technology, 6th ed., Volume 18, New York: McGraw-Hill Book Company, 1987.

11. F. A. Cotton and G. Wilkinson, Advanced Inorganic Chemistry-A Comprehensive Text, New York: Interscience Publishers, 1962.

12. McGraw-Hill Encyclopedia of Science and Technology, 6th ed., Volume 1, New York: McGraw-Hill Book Company, 1987.

13. Metals Handbook, 9th ed., Volume 2, American Society for Metals, 1979.

14. International Critical Tables of Numerical Data, Physics, Chemistry, and Technology Volume I, New York: McGraw-Hill Book Company, 1926.

15. C. D. Hodgman, (ed.), Handbook of Chemistry and Physics, 43rd ed., Boca Raton, Florida: The Chemical Rubber Company, 1961.

16. Smithsonian Physical Tables, 9th ed., Smithsonian Institution Publishers, 1954.

17. A. Roine, Outokumpu HSC Chemistry for Windows, Chemical Reaction and Equilibrium Software with Extensive Thermochemical Database, 94027-ORC-T, Version 2.0, 1994. 
18. G. Nicolaou, H. Wuerz, L. Koch, "LWR Spent Fuel Characterization by Non-Destructive Assay," Proceedings of an International Symposium on Geologic Disposal of Spent Fuel, High Level, and Alpha Bearing Wastes, IAEA, Antwerp, October 1992.

19. P. J. Coughtrey et al., Radionuclide Distribution and Transport in Terrestrial and Aquatic Ecosystems-A Critical Review of Data Volume 5, A. A. Balkema of Rotterdam, 1984.

20. Y. Wang (ed.), Handbook of Radioactive Nuclides, Boca Raton, Florida: The Chemical Rubber Company, 1969.

21. International Directory of Certified Radioactive Materials, International Atomic Energy Agency, Vienna, Austria, 1975.

22. Oak Ridge National Laboratory Radioisotope Price List, Isotope Distribution Office, Oak Ridge National Laboratory, October 1993.

23. J. R. Bradford (ed.), Radioisotopes in Industry, Reinhold Publishing Corporation, 1953.

24. P. C. Bergamini et al., "Absorption and Distribution of ${ }^{137} \mathrm{Cs}$ by Trifolium Pratense," Health Physics Vol. 19, October 1970, pp. 521-528.

25. W. A. Thomas and D. G. Jacobs, "Curium Behavior in Plants and Soil," Soil Science, Vol. 108, No. 4, 1969, pp. 305-307.

26. R. Saxen, T. K. Taipale, H. Aaltonen, Radioactivity of Wet and Dry Deposition and Soil in Finland after the Chernobyl Accident in 1986, STUK-A57, June 1987.

27. Y. V. Dubasov, A. S. Krivokhatskii, N. N. Khramov, "Classification of Radioactive Fallout to the Southeast of Chernobyl," Soviet Radiochemistry, Vol. 34, No. 4, March 1993, p. 515-518.

28. H. O. Denschlag et al., "Fallout in the Mainz Area from the Chernobyl Reactor Accident, Radiochimica Acta, Vol. 41, 1987, pp. 163-172.

29. E. Holm, J. Rioseco, H. Pettersson, "Fallout of Transuranium Elements Following the Chernobyl Accident," Journal of Radioanalytical and Nuclear Chemistry, Vol. 156, 1992, pp. 183-200.

30. V. I. Berezhnoi et al., "Some Data on Transuranium Element Distribution in Particle Size Fractions of Chernobyl Soils," Journal of Radioanalytical and Nuclear Chemistry, Vol. 150, No. 2, 1991, pp. $445-454$.

31. E. Puukko and T. Jaakkola, Actinides and Beta Emitters in the Process Water and Ion-Exchange Resin Samples from the Loviisa Nuclear Power Plant, YJT-92-22, IVO, 1992.

32. A. Stepanov et al., "Determination of Burnup and Isotopic Composition of VVER-440 Spent Fuel," Soviet Atomic Energy, Vol. 55, No. 3, 1983, pp. 565-571.

33. W. J. Symons, M. D. H. Amey, W. R. Cox, Actinide Levels Measured in the Primary Coolant of Belgian PWRs, AEEW-R 2089, 1986. 
34. V. T. Bowen, The Environmental Behavior of Transuranic Nuclides Released from Water Cooled Nuclear Power Plants, NUREG/CR-1658, 1981.

35. G. Rosner, "Measurements of Actinide Nuclides in Water Samples from the Primary Circuit of a Nuclear Power Plant," Journal of Radioanalytical Chemistry, Vol. 64, 1981, pp. 55-64.

36. N. W. Golchert, T. L. Duffy, J. Sedlet, Environmental Monitoring at Argonne National Laboratory-Annual Report for 1984, ANL-85-17, 1985.

37. K. O. Buesseler et al., "Determination of Fission-Products and Actinides in the Black Sea Following the Chernobyl Accident," Journal of Radioanalytical and Nuclear Chemistry, Vol. 138, No. 1, 1990, pp. 33-47.

38. C. N. Murray, H. Kautsky, H. F. Eicke, "Transfer of Actinides from the English Channel into the Southern North Sea," Nature, Vol. 278, April 12, 1979, pp. 617-620.

39. V. T. Bowen, Plutonium and Americium Concentration Along Fresh-Water Food Chains of the Great Lakes, U.S.A., COO-3568-18, 1977.

40. R. G. Schreckhise et al., Pacific Northwest Laboratory Annual Report for 1977 to the DOE Assistant Secretary for Environment. Part 2-Weathering and Aging of Transuranics, PNL-200, Part 2, 1978.

41. C. E. Murphy, Jr., The Concentration of Radionuclides and Metals in Vegetation Adjacent to and in the SRL Seepage Basins, WSRC-TR-92-583, 1992.

42. K. Bunzl and W. Kracke, "Simultaneous Determination of ${ }^{238} \mathrm{Pu},{ }^{239+240} \mathrm{Pu},{ }^{241} \mathrm{Pu},{ }^{241} \mathrm{Am},{ }^{242} \mathrm{Cm}$, ${ }^{244} \mathrm{Cm},{ }^{89} \mathrm{Sr}$, and ${ }^{90} \mathrm{Sr}$ in Vegetation Samples and Application to Chernobyl-Fallout Contaminated Grass," Journal of Radioanalytical and Nuclear Chemistry, Vol. 138, No. 1, 1990, pp. 83-91.

43. E. Holm and B. R. R. Persson, "Global Fallout of Curium," Nature, Vol. 273, May 25, 1978, pp. 289-290.

44. U.S. Environmental Protection Agency, An Airborne Radioactive Effluent Study at the Savannah River Plant, EPA-520/5-84-012, 1984.

45. B. A. Muggenburg et al., Toxicity of Inhaled Alpha-Emitting Radionuclides: An Experimental Approach, LF-60(12-78), 1978.

46. F. E. H. Crawley and E. A. Goddard, "The Translocation of 241-Americium and 242-Curium from the Respiratory System of the Rat," Health Physics, Vol. 30, No. 2, 1976, pp. 191-197.

47. W. J. Bair, The Biological Effects of Transuranium Elements in Experimental Animals, BNWL-SA-5339, 1975.

48. O. D. Markham et al., "Plutonium, Am, Cm, and $\mathrm{Sr}$ in Ducks Maintained on Radioactive Leaching Ponds in Southeastern Idaho," Health Physics, Vol. 55, No. 3, September 1988, pp. 517-524.

49. D. S. Popplewell, G. J. Ham, J. D. Harrison, "Measurements of Actinide Gut-Transfer Factors in Humans," Applied Radiation and Isotopes, Vol. 43, No. 1-2, 1992, p. 339-347. 
50. J. P. Vaane and E. M. M. De Ras, "Analysis of a Case of Internal Contamination with ${ }^{242} \mathrm{Cm}$," Health Physics, Vol. 21, No. 6, December 1971, pp. 821-826.

51. A. A. Edwards et al., "The Induction of Chromosome Aberrations in Human Lymphocytes by Alpha-Radiation," International Journal of Radiation Biology, Vol. 38, No. 1, 1980, pp. 83-91.

52. B. Shleien and M. S. Terpilak, The Health Physics and Radiological Health Handbook-Supplement 1 (1986), Nucleon Lectern Associates, Inc., 1987.

53. Nuclear Regulatory Commission, "Standards for Protection Against Radiation," 10 CFR 20, Chapter I (January 1, 1992), Appendix B.

54. Limits for Intakes of Radionuclides by Workers, Annals of the ICRP, ICRP Publication 30, Part 1, 1979.

55. K. F. Eckerman, A. B. Wolbarst, A. C. B. Richardson, Limiting Values of Radionuclide Intake and Air Concentration and Dose Conversion Factors of Inhalation, Submersion, and Ingestion, Federal Guidance Report No. 11, Oak Ridge National Laboratory, EPA-520/1-88-020, 1988. 


\section{Bibliography}

Bondietti E. A. et al., Chemistry of Plutonium, Americium, Curium, and Uranium in Pond 3513 Water, ORNL-5365, 1978.

Bondietti, E. A., "Mobile Species of Pu, Am, Cm, Np, and Tc in the Environment," Environmental Migration of Long-Lived Radionuclides, IAEA-SM-257/42, 1982.

Bondietti, E. A. and T. Tamura, "Physicochemical Associations of Plutonium and Other Actinides in Soils," Transuranic Elements in the Environment, DOE-TIC-22800, 1980.

Bulman, R. A., "The Movement of Plutonium, Americium, and Curium Through the Food Chain," Naturwissinschaft, 65, 1978, p. 137.

Bukart W. and H. Linder, "Hot Particles in the Environment: Assessment of Dose and Health Detriment," Soz Praventivmed, 32, 1987, p. 310.

DahIman, R. C., E. A. Bondietti, L. D. Eyman, "Biological Pathways and Chemical Behavior of Plutonium and Other Actinides in the Environment," Actinides in the Environment, American Chemical Society, 1976.

Harrison J. D. et al., "Gastrointestinal Absorption of Neptunium and Curium in Volunteers," Radiology Protection Bulletin, 93, 1988, p. 11.

Holm, E. et al., "Transuranium Elements in Macroalgae at Monaco Following the Chernobyl Accident," International Conference on F-Elements, Leuven, Belgium, September 4-7, 1990, 1991, p. 375.

Johnson, J. R. and P. S. Stansbury, "Implications of Scientific And Developments for Radiation Protection in the Next Decade," Workshop on Radiation Protection Toward the Turn of the Century, Paris, France, January 11-13, 1993, p. 187.

Kershaw, P. J. et al., "Incorporation of Plutonium, Americium and Curium into the Irish Sea Seabed by Biological Activity," Science and the Total Environment, 40, 1984, p. 61.

Komosa, A., M. Szymula, J. Szczypa, "Some Problems Connected with Determination of Alpha Isotopes in Eastern Part of Poland," Austrian-Italian-Hungarian Radiation Protection Symposium, Obergurgl/Tyrol, Austria, April 28-30, 1993, 1994, p. 300.

Kuzo, G. B. et al., "Comparative Behavior and Distribution of Transuranium Nuclides in Selected Components of Test Reactor Leaching Ponds," Symposium on Environmental Research for Actinide Elements, Hilton Head Island, South Carolina, November 7, 1984, 1987, p. 319.

Kuzo, G. B., L. Fraley, Jr., O. D. Markham, "Transuranic Concentrations in Selected Biotic and Abiotic Components of the INEL Test Reactor Area Ponds," Ecological Studies on the Idaho National Engineering Laboratory Site - 1978 Progress Report, IDO-12087, 1978. 
Nishita, H., D. C. Adriano, I. L. Brisbin, Jr.; "Extractability of Plutonium-238 and Curium-242 From a Contaminated Soil as a Function of $\mathrm{pH}$ and Certain Soil Components," Proceedings of the Mineral Cycling Symposia on Environmental Chemistry and Cycling Processes, Augusta, Georgia, April 28, 1976, 1978, p. 403.

Olsen, C. R. et al., "Geochemical and Environmental Processes Affecting Radionuclide Migration from a Formerly Used Seepage Trench," Geochimica et Cosmochimica Acta, Vol. 50, 1986, p. 593.

Parker, H. G., M. D. Thaxter, M. W. Briggs, Current Status of Curium Inhalation Exposure to Humans, UCRL-9361, 1960.

Pentreath, R. J. et al., "Alpha-Emitting Nuclides in Commercial Fish Species Caught in the Vicinity of Windscale, United Kingdom, and Their Radiological Significance to Man," Proceedings of the International Symposium on Biological Implications of Radionuclides Released from Nuclear Industries, Vienna, Austria, March 26, 1979, p. 227.

Pentreath, R. J. and M. B. Lovett, "Transuranic Nuclides in Plaice (Pleuronectes platessa) from the North-Eastern Irish Sea," Marine Biology, Vol. 48, 1978, p. 19.

Popplewell, D. S. et al., "The Gastrointestinal Absorption of Neptunium and Curium in Humans," Health Physics, Vol. 60, 1991, p. 797.

Rosner, G., H. Hoetzl, R. Winkler, "Actinide Nuclides in Environmental Air and Precipitation Samples After the Chernobyl Accident," Environment International, Vol. 14, 1988, p. 331.

Rosner, G., H. Hoetzl, R. Winkler, "Measurements of Transuranium Nuclides in the Environment at the Strahlen-und Umweltforshung mbH, Munich," Proceedings of the Conference on Metrology Needs in the Measurement of Environmental Radioactivity, Paris, France, October 4-6, 1976, 1978, p. 85.

Sanders, J. E. et al., "Some Aspects of Fast Reactor Operation Studied in Zebra," IAEA International Symposium on Fast Reactor Physics, Ais-en-Provence, France, September 24, 1979, 1980, p. 567.

Suutarinen, R., T. Jaakkola, J. Paatero, "Behavior of Transuranic Elements in Lake Paeijaenne After the Chernobyl Accident," 15th Regional Congress of the International Radiation Protection Association (IRPA) on the Radioecology of Natural and Artificial Radionuclides, Visby, Sweden, September 10-14, 1989, 1989, p. 350. 


\section{AMERICIUM-241}

\section{Introduction}

This chapter discusses the basic radiological, chemical, and physical characteristics of americium-241 $\left({ }^{241} \mathrm{Am}\right)$ and examines how these characteristics affect the behavior of ${ }^{241} \mathrm{Am}$ in various environmental media, such as soils, water, plants, air, animals, and the human body. Also included are methods of production and waste and disposal data on ${ }^{241} \mathrm{Am}$.

All americium atoms contain 95 protons $(Z=95)$ and various numbers of neutrons (typically 142 to 151 neutrons) within the nucleus. Americium is classified as one of the transuranic elements. Americium is not a normal constituent of the natural environment and is generated as a result of human activities. There are no stable isotopes of americium. The radioactive isotopes of americium have half-lives ranging from 0.9 minutes $\left({ }^{232} \mathrm{Am}\right)$ to 7,370 years $\left({ }^{243} \mathrm{Am}\right)$. The most common isotope and subject of this chapter is ${ }^{241} \mathrm{Am}$ with a half-life of 432 years. ${ }^{1}$

The regulatory limits for ${ }^{24 !} \mathrm{Am}$ disposal and personnel exposure are very restrictive. Relatively small concentrations of ${ }^{241} \mathrm{Am}$ can become a major contributor to the calculated doses to individuals in performance assessment calculations or as a result of an accidental release involving this radionuclide. Therefore, knowledge of the basic radiological and chemical characteristics, waste forms, and environmental behavior of ${ }^{241} \mathrm{Am}$ is important.

The primary source of ${ }^{241} \mathrm{Am}$ in the environment originates from the manufacture of atomic weapons. ${ }^{241} \mathrm{Am}$ is also used in commercial radioactive sealed sources (e.g., smoke detectors). This nuclide is produced in nuclear reactors. ${ }^{241} \mathrm{Am}$ enters the environment from activities such as reactor operations and decommissioning, atomic weapons production, and sealed source manufacturing, use, and disposal.

A radionuclide considered sensitive at one low-level radioactive waste (LLW) disposal facility may not be considered sensitive at another facility. The behavior of a radionuclide at a particular LLW disposal site will depend primarily upon the radiological, chemical, and physical characteristics of the waste, and the inventory of the radionuclide. The behavior of a radionuclide also depends upon the geology, hydrology, and climate at the disposal site. This chapter reports characteristics and potential difficulties in dealing with ${ }^{241} \mathrm{Am}$. However, since ${ }^{241} \mathrm{Am}$ behavior and appropriate handling, storage, or disposal will vary depending on particular sites or waste form, this chapter does not attempt to discuss the extent of a difficulty or appropriate solutions. Each disposal site facility design should consider and address the specific waste content and behavior under that site's particular circumstances.

Information for this chapter was taken from standard reference materials and specific studies related to ${ }^{241} \mathrm{Am}$.

\section{Radiological Characteristics}

${ }^{241}$ Am was discovered in 1945 by American scientists G. T. Seaborg, R. A. James, and L. O. Morgan, who named it after the Americas. ${ }^{2}$ The most recent information available concerning ${ }^{241} \mathrm{Am}$ reports a half-life of 432.2 years. Reference 2 also states that the principal means of producing ${ }^{241} \mathrm{Am}$ is by bombarding plutonium atoms in a nuclear reactor in the following reaction:

${ }^{239} \mathrm{Pu}(\mathrm{n}, \gamma){ }^{240} \mathrm{Pu}(\mathrm{n}, \gamma){ }^{241} \mathrm{Pu} \rightarrow \beta^{-} \rightarrow{ }^{241} \mathrm{Am}$. 
${ }^{241} \mathrm{Am}$ can also be produced as a result of bombarding ${ }^{238} \mathrm{U}$ with $40-\mathrm{MeV}$ (million electron volt) helium ions in the following reaction:

${ }^{238} \mathrm{U}(\alpha, \mathrm{n}){ }^{241} \mathrm{Pu} \rightarrow \beta^{-} \rightarrow{ }^{241} \mathrm{Am}$.

Reference 1 lists the various energies and types of decay emissions from ${ }^{241} \mathrm{Am} .{ }^{241} \mathrm{Am}$ undergoes radioactive decay via alpha particle emission from the nucleus to the radionuclide neptunium-237 $\left({ }^{237} \mathrm{~Np}\right)$. This decay results in a maximum alpha particle energy of $5.54 \mathrm{MeV}(0.3 \%$ probability $)$. The greatest intensity alpha energy in the decay process is $5.48 \mathrm{MeV}(85.2 \%$ probability $)$ followed by 5.43 $\mathrm{MeV}$ (12.8\% probability). Since these alpha particles are easily shielded and have a relatively short range in air, they are of little concern for external radiation exposure. Figure 14-1 shows the alpha particle range in air as a function of energy (note that alpha particles with energies above $4 \mathrm{MeV}$ tend to travel farther in air).

Since the half-life of the parent nuclide plutonium-241 ( $\left.{ }^{241} \mathrm{Pu}\right)(14.4$ years) is considerably less than the half-life of ${ }^{241} \mathrm{Am}$, the activity of ${ }^{241} \mathrm{Am}$ will continue to grow over time unless the americium is chemically separated from the plutonium.

The decay process of ${ }^{241} \mathrm{Am}$ also produces gamma rays and x-rays. The gamma-ray and x-ray energies range from 11.9 to $955.7 \mathrm{keV}$. The most intense gamma-ray energy is $59.5 \mathrm{keV}(35.9 \%$ probability) followed by a $17.61-\mathrm{keV}(20.2 \%$ probability $) \mathrm{x}$-ray. Nearly $77 \%$ of all of the photons emitted during the decay of ${ }^{241} \mathrm{Am}$ occur in the range of 11.9 to $69.8 \mathrm{keV}$. The specific activity of ${ }^{241} \mathrm{Am}$ is $1.27 \times 10^{11} \mathrm{~Bq} / \mathrm{g}(3.44 \mathrm{Ci} / \mathrm{g}){ }^{1}$ Table $14-1$ shows the thickness of lead shielding requirements as a function of energy to reduce a useful beam of gamma rays or $\mathrm{x}$-rays to $5 \%$.

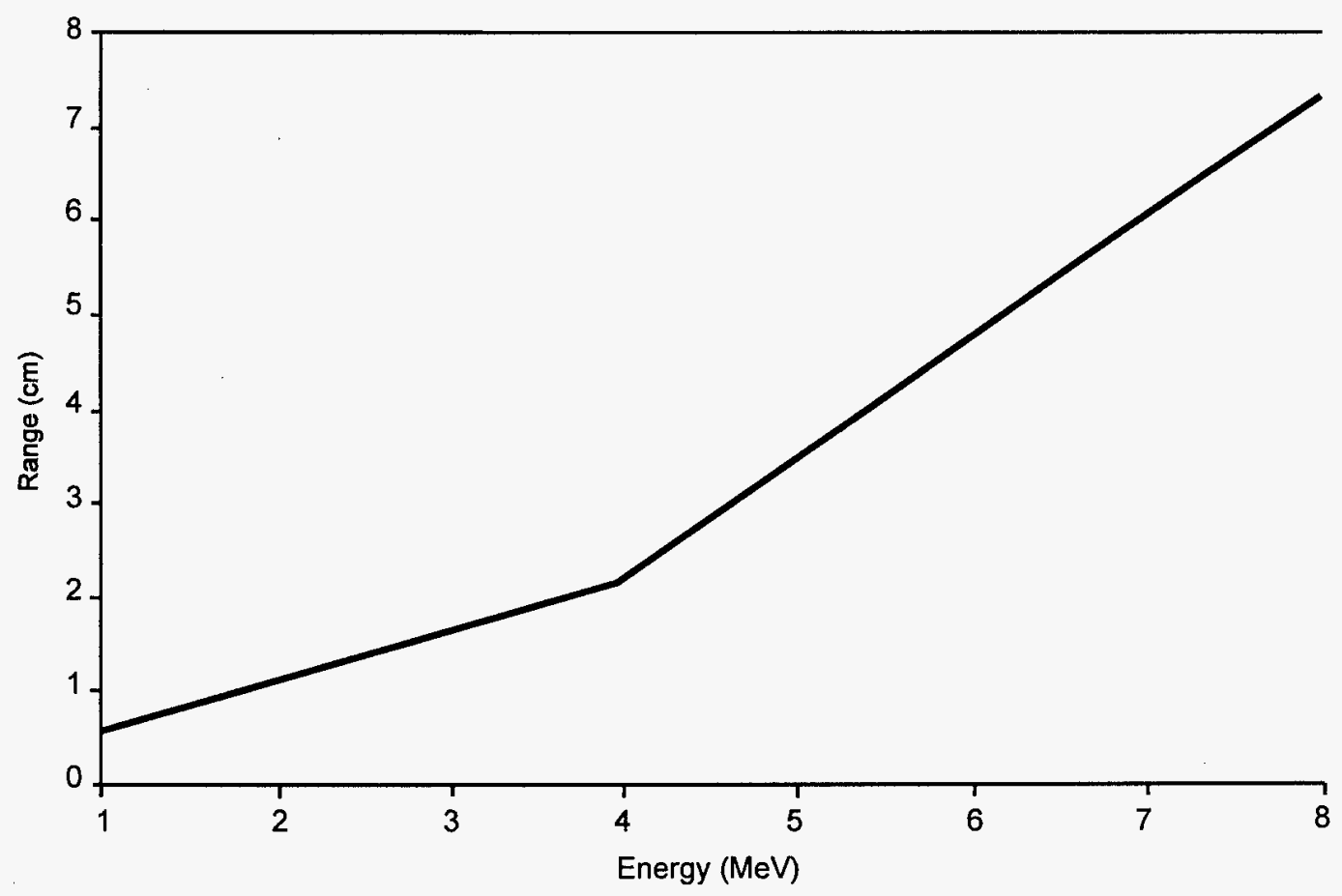

Figure 14-1. Alpha particle ranges in air as a function of energy. 
The primary decay sequence for ${ }^{241} \mathrm{Am}$ showing the emissions of the alpha particle, $\mathrm{x}$-rays, gamma rays, and their respective decay probabilities is shown in Figure 14-2.

${ }^{241} \mathrm{Am}$ also undergoes a spontaneous fission with a half-life of $2 \times 10^{14}$ years. The calculated neutron (n) emission rate is $0.6 \mathrm{n} \backslash \mathrm{sec} / \mathrm{g} .{ }^{3}$ This makes ${ }^{241} \mathrm{Am}$ a suitable source for use in neutron sources in combination with a multiplication material such as beryllium (Be). A typical AmBe source yields 2.2 $\times 10^{6} \mathrm{n} / \mathrm{s}$ per $\mathrm{Ci}$ of radioactive material.

Table 14-2 lists the radiotoxicity of several important radionuclides. Notice that ${ }^{241} \mathrm{Am}$ and its decay product ${ }^{237} \mathrm{~Np}$ are listed with the very high radiotoxicity radionuclides.

The very high radiotoxicity of ${ }^{241} \mathrm{Am}$ is due to the long half-life and high energies of the alpha particles emitted during the decay process. Because of the limited range of alpha particles, they can be easily shielded from external exposure. A sheet of paper or dead layer of skin will attenuate most alpha particles. The danger from alpha particles comes from possible internal exposure due to inhalation, ingestion, or injection where the alpha particles can come in contact with living tissue. Alpha particles can cause extreme damage when they interact with living tissue. The biological effects of ${ }^{24 \mathrm{~A}} \mathrm{Am}$ will be discussed in more detail in a later section of this chapter.

\section{Chemical and Physical Characteristics}

Americium is a member of the seventh series known as the actinide series of elements. In addition, americium is part of the transuranium group of the periodic table (all elements after uranium in the periodic table with a $Z>92$ ). This group includes plutonium, curium, neptunium, berkelium, californium, einsteinium, fermium, mendelevium, nobelium, and lawrencium. Like all transuranium elements, americium does not naturally occur in nature and all isotopes are radioactive. Americium can only be produced by the nuclear reactions described in the previous section of this chapter. ${ }^{4}$

Americium in metal form is more silvery in appearance than neptunium or plutonium metal and is malleable and ductile as compared to uranium or neptunium metal. Americium is thought to exist in two forms: an alpha form that has a double hexagonal close-packed structure and a loose-packed cubic beta form. The melting point of americium is $994^{\circ} \mathrm{C}$ and the boiling point is estimated at $2,607^{\circ} \mathrm{C}$. The average density of americium is $13.7 \mathrm{~g} / \mathrm{cm}^{3}$ at $20^{\circ} \mathrm{C}$.

Table 14-1. Thickness of lead required to reduce useful beam to $5 \%{ }^{3}$

\begin{tabular}{lccc}
\hline & $\begin{array}{c}\text { Energy of } \\
\text { source }\end{array}$ & $\begin{array}{c}\text { Half-value layer } \\
(\mathrm{cm})\end{array}$ & $\begin{array}{c}\text { Required lead } \\
(\mathrm{cm})\end{array}$ \\
\hline X-rays/gamma rays & $50 \mathrm{keV}$ & 0.005 & 0.02 \\
& $70 \mathrm{keV}$ & 0.010 & 0.04 \\
& $100 \mathrm{keV}$ & 0.025 & 0.11
\end{tabular}

a. The half-value layer is defined as the thickness of shielding material (in this case lead) required to reduce the beam of $x$-rays or gamma rays by one-half. 


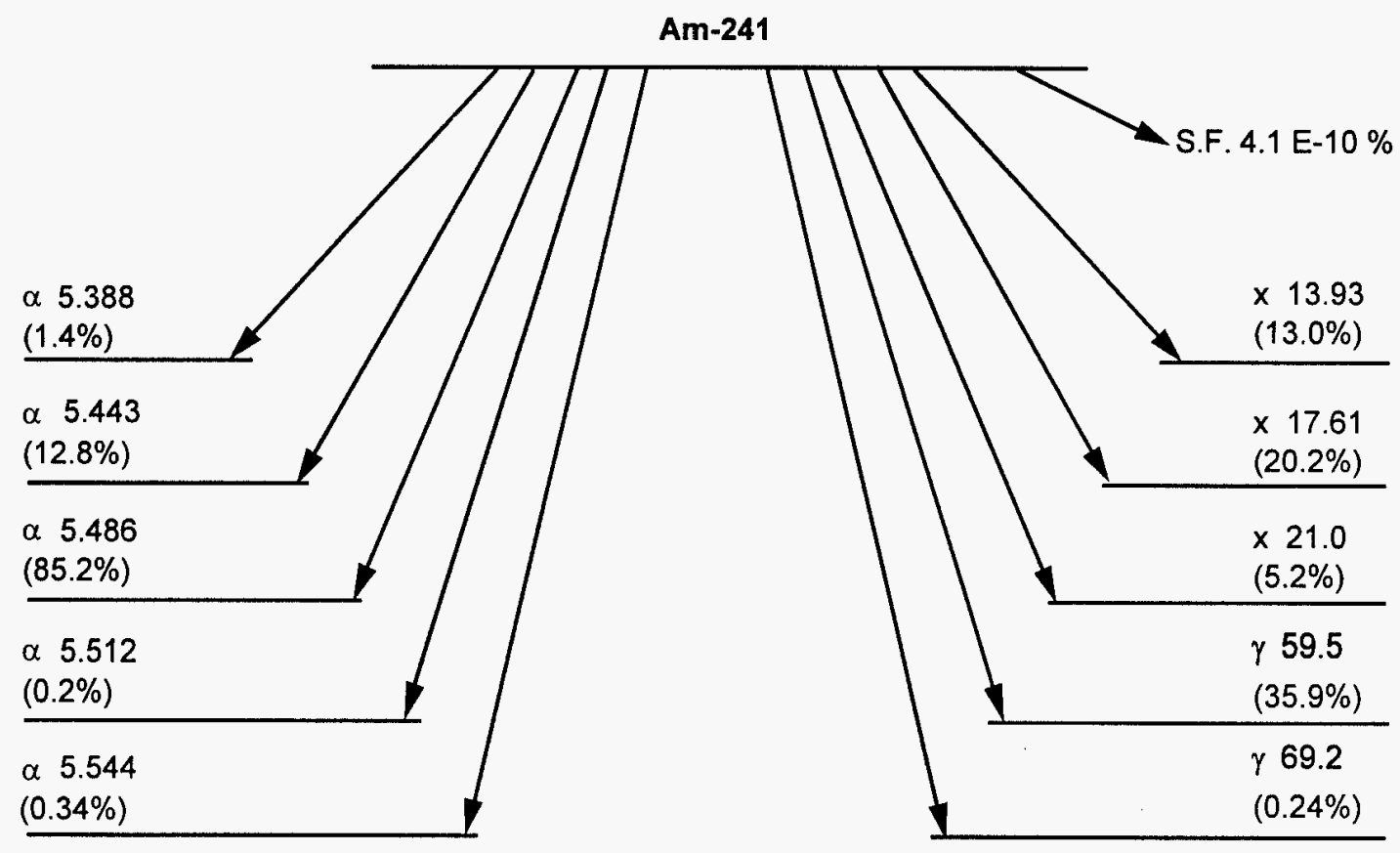

S.F. $=$ spontaneous fission

\section{Np-237}

Figure 14-2. Diagram for the primary decay sequence for ${ }^{241} \mathrm{Am}$ (alpha particle energies are in million electron volts, and $\mathrm{x}$-ray, and gamma-ray energies are in kiloelectron volts).

Americium can be combined with several different elements to make compounds such as americium bromide $\left(\mathrm{AmBr}_{3}\right)$, americium chloride $\left(\mathrm{AmCl}_{3}\right)$, americium fluoride $\left(\mathrm{AmF}_{3}\right)$, americium iodide $\left(\mathrm{AmI}_{3}\right)$ and americium oxide $\left(\mathrm{Am}_{2} \mathrm{O}_{3}\right)$. Table 14-3 shows the physical properties of the different forms of americium.

Table 14-2. Comparison of the radiotoxicity of several important radionuclides. ${ }^{5}$

\begin{tabular}{lll}
\hline Radiotoxicity & \multicolumn{1}{c}{ Species } \\
\hline Very high & Group 1 & ${ }^{241} \mathrm{Pu},{ }^{242} \mathrm{Cm}$, \\
High & Group 2 & ${ }^{241} \mathrm{Am},{ }^{237} \mathrm{~Np}$ \\
Moderate & Group 3 & ${ }^{60} \mathrm{Co},{ }^{90} \mathrm{Sr},{ }^{94} \mathrm{Nb}$ \\
Low & Group 4 & ${ }^{14} \mathrm{C},{ }^{63} \mathrm{Ni},{ }^{137} \mathrm{Cs}$ \\
& & ${ }^{3} \mathrm{H},{ }^{59} \mathrm{Ni},{ }^{99} \mathrm{~m} \mathrm{Tc}$ \\
\hline
\end{tabular}


Table 14-3. Physical properties of americium and its compounds. ${ }^{5}$

\begin{tabular}{lllccc}
\hline Name & $\begin{array}{c}\text { Molecular } \\
\text { weight }\end{array}$ & \multicolumn{1}{c}{ Crystal form } & $\begin{array}{c}\text { Density } \\
\left(\mathrm{g} / \mathrm{cm}^{3}\right)\end{array}$ & $\begin{array}{c}\text { Melting point } \\
\left({ }^{\circ} \mathrm{C}\right)\end{array}$ & $\begin{array}{c}\text { Boiling point } \\
\left({ }^{\circ} \mathrm{C}\right)\end{array}$ \\
\hline $\mathrm{Am}$ & 243 & Silvery, hex & 13.7 & $994 \pm 4$ & 2,607 \\
$\mathrm{AmBr}_{3}$ & 482.7 & White, orthorhomb & - & Sublimes & - \\
$\mathrm{AmCl}_{3}$ & 349.5 & Pink, hex & 5.8 & Sublimes 850 & - \\
$\mathrm{AmF}_{3}$ & 300 & Pink, hex & 9.5 & - & - \\
$\mathrm{AmI}_{3}$ & 623.7 & Yellow, orthorhomb & 6.9 & - & - \\
$\mathrm{Am}_{2} \mathrm{O}_{3}$ & 534 & $\begin{array}{l}\text { Reddish-brown, } \\
\text { cube or tan, or hex }\end{array}$ & - & - & - \\
\hline
\end{tabular}

\section{Americium-241 Production}

As previously mentioned, ${ }^{241} \mathrm{Am}$ is produced by the beta decay of ${ }^{241} \mathrm{Pu}$. Figure $14-3$ shows the in-growth of the activity of ${ }^{241} \mathrm{Am}$ from the decay of $1 \mathrm{~g}$ of ${ }^{241} \mathrm{Pu}$ for 50 years.

Pure ${ }^{241} \mathrm{Am}$ is produced by chemically separating the americium from its ${ }^{24 !} \mathrm{Pu}$ parent. ${ }^{241} \mathrm{Pu}$ is dissolved totally into a solution. After standing for a period of time, perhaps on the order of several years, the americium is then separated from the plutonium solution. The operation of recovering americium has been termed "milking" and the plutonium then is naturally designated as a "cow." As in the case of its bovine counterpart, it takes a big cow to provide even a little milk. ${ }^{6}$

The separation of americium is facilitated by the fact that $\mathrm{Am}^{3+}$ is more stable than the trivalent ions of plutonium, which pass into higher oxidation states in conditions under which americium remains trivalent. This allows americium to be separated from other transuranics by means of ion exchange and extraction with organic solvents.

The only other method known to produce ${ }^{241} \mathrm{Am}$ is as a result of the bombardment of ${ }^{238} \mathrm{U}$ with 40 $\mathrm{MeV}$ helium ions. This method produces ${ }^{241} \mathrm{Am}$, but it still has to be separated chemically from its uranium and plutonium parents using the same type chemical extraction methods described above.

The major source of ${ }^{241} \mathrm{Am}$ production is the manufacturing process for atomic weapons. National production reactors are designed to generate fissile material in the form of plutonium. As part of this process, some residual ${ }^{241} \mathrm{Pu}$ is produced along with the preferred isotope of ${ }^{239} \mathrm{Pu}$. The target plutonium is processed to remove the unwanted plutonium isotopes until it is approximately $95 \%{ }^{239} \mathrm{Pu}$. This material is commonly referred to as weapons-grade plutonium. The unwanted portion containing the excess ${ }^{241} \mathrm{Pu}$ is then sold for producing ${ }^{241} \mathrm{Am}$ for commercial use. The remaining $5 \%$ of the weapons-grade plutonium does contain some trace amounts of ${ }^{241} \mathrm{Pu}$ plus other plutonium isotopes. Therefore, atomic weapons will contain some trace amounts of ${ }^{241} \mathrm{Am}$. 


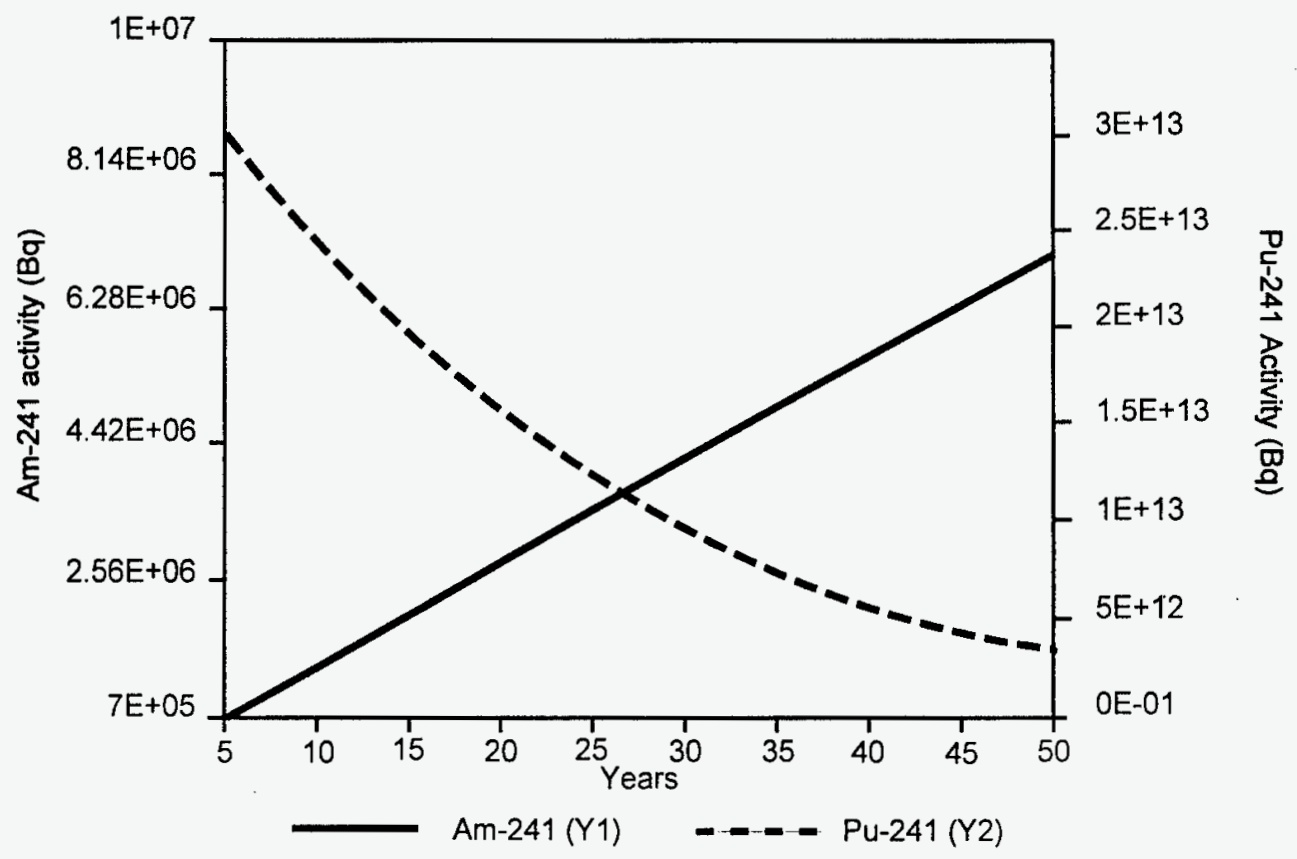

Figure 14-3. In-growth of ${ }^{241} \mathrm{Am}$ activity from $1 \mathrm{~g}$ of ${ }^{24 !} \mathrm{Pu}$ over a 50 -year period.

\section{Waste and Disposal Data on Americium-241}

This section discusses the types of activities that generate ${ }^{241} \mathrm{Am}$ LLW, waste types and forms that contain ${ }^{241} \mathrm{Am}$, and disposal data on ${ }^{241} \mathrm{Am}$.

\section{Nuclear Reactors}

${ }^{241} \mathrm{Am}$ is produced within the fuel and operational wastes from cleanup systems of nuclear reactors. The quantity of ${ }^{241} \mathrm{Am}$ in spent fuel that is produced each year is proportional to the amount of ${ }^{241} \mathrm{Pu}$ produced and continues to increase as the fuel is stored. Each year the operations of domestic light-water reactors generate approximately $2,302 \mathrm{~kg}$ of ${ }^{241} \mathrm{Pu}$ contained in the spent fuel. The cumulative quantity of ${ }^{241} \mathrm{Pu}$ that existed in spent fuel as of 1991 was $19,200 \mathrm{~kg} .{ }^{7}$ All of the ${ }^{241} \mathrm{Am}$ associated with spent commercial fuel is expected to stay with the fuel and be disposed of in the planned national high-level waste repository.

${ }^{241} \mathrm{Am}$ associated with operational wastes from commercial reactors appears in spent radioactive resins, filter sludges, and evaporator bottom wastes.

The Code of Federal Regulations, 10 CFR 61.55, regulates the concentrations of radionuclides that are suitable for near-surface disposal. This regulation requires that wastes be classified for disposal as Class $\mathrm{A}, \mathrm{B}$, or $\mathrm{C}$ with Class $\mathrm{C}$ waste having the most rigorous disposal requirements. Wastes that exceed the Class $\mathrm{C}$ limits are not suitable for near-surface disposal. The Class $\mathrm{C}$ limit for ${ }^{241} \mathrm{Am}$ is included in 
the category of "alpha-emitting transuranic radionuclides with half-lives greater than 5 years." This limit is $100 \mathrm{nCi} / \mathrm{g}$ of waste. ${ }^{8}$

\section{Government Waste}

Government waste streams containing ${ }^{241} \mathrm{Am}$ are associated primarily with the manufacturing of atomic weapons and the decommissioning of the associated Government facilities. The majority of the waste forms containing ${ }^{241} \mathrm{Am}$ are located at the U.S. Department of Energy (DOE) facilities located in the United States. These waste forms consist of drums and boxes containing small amounts of weapons-grade plutonium and associated decay products. The waste consists of contaminated personal protective equipment, tools, plastic, plant equipment, salts, solvents, and sludges. These wastes are referred to in the DOE system as transuranic waste. The total volume of transuranic waste currently stored at DOE facilities is $104,116 \mathrm{~m}^{3}$ (Reference 7). These wastes are designated to be disposed of at the DOE Waste Isolation Pilot Plant in New Mexico when that facility is allowed to open.

\section{Medical, Academic Institutions, and Commercial Americium-241 Waste}

There are no known medical uses and resultant waste types for ${ }^{241} \mathrm{Am}$. Academic waste types for ${ }^{241} \mathrm{Am}$ consist primarily of sealed sources, liquids and sludges, and contaminated materials from research projests and operation of university reactors.

Industrial waste types containing ${ }^{241} \mathrm{Am}$ include sealed sources, liquids, sludges, and contaminated materials from the manufacture of sealed sources, including smoke detectors. Fuel burn-up laboratories and commercial research facilities with small reactors can also generate liquids, sludges, and contaminated materials that contain ${ }^{241} \mathrm{Am}$.

Volumes and activities from these wastes are relatively small and are disposed of at commercial LLW disposal facilities.

\section{Disposal Data on Americium-241}

${ }^{241} \mathrm{Am}$ has been deposited in three LLW disposal sites in Richland, Washington; Barnwell, South Carolina; and Beatty, Nevada over a period of several years. Data have been obtained on this nuclide from the Manifest Information Management System Database. ${ }^{2}$ Figure 14-4 shows the total annual ${ }^{241} \mathrm{Am}$ activity deposited in the three sites for each year between 1986 and 1995 . Over $60 \%$ of the total activity for this nuclide was deposited during 1992.

Figure 14-5 shows the activity of ${ }^{241} \mathrm{Am}$ deposited in these three sites as a function of waste source. Government and industrial sources account for more than $92 \%$ of the total deposited in these three sites. An additional $7.8 \%$ came from utilities and the rest from the other sources. The definition of disposal categories given in Figure 14-5 is as follows: academic - sources associated with university laboratories; government - sources associated with the government, such as military hospitals; industry - sources associated with manufacturing, other than utilities; medical - sources associated with hospitals and medical laboratories, excluding pharmaceutical manufacturing; utility - sources generated by nuclear utilities and stored onsite or sent to one of the three disposal sites. Waste treatment facilities are included in the utility category.

a. Information provided through the DOE waste management system maintained by the National Low-Level Waste Management Program, Idaho National Engineering Laboratory (INEL). 


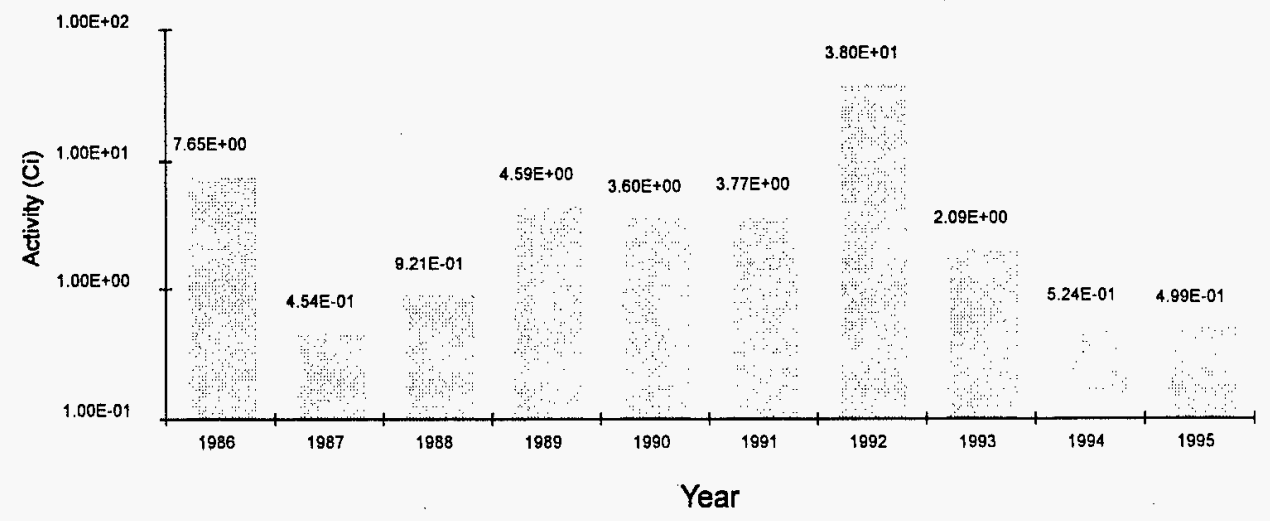

Figure 14-4. ${ }^{241} \mathrm{Am}$ activity deposited at the Richland, Beatty, and Barnwell sites by year (log scale).

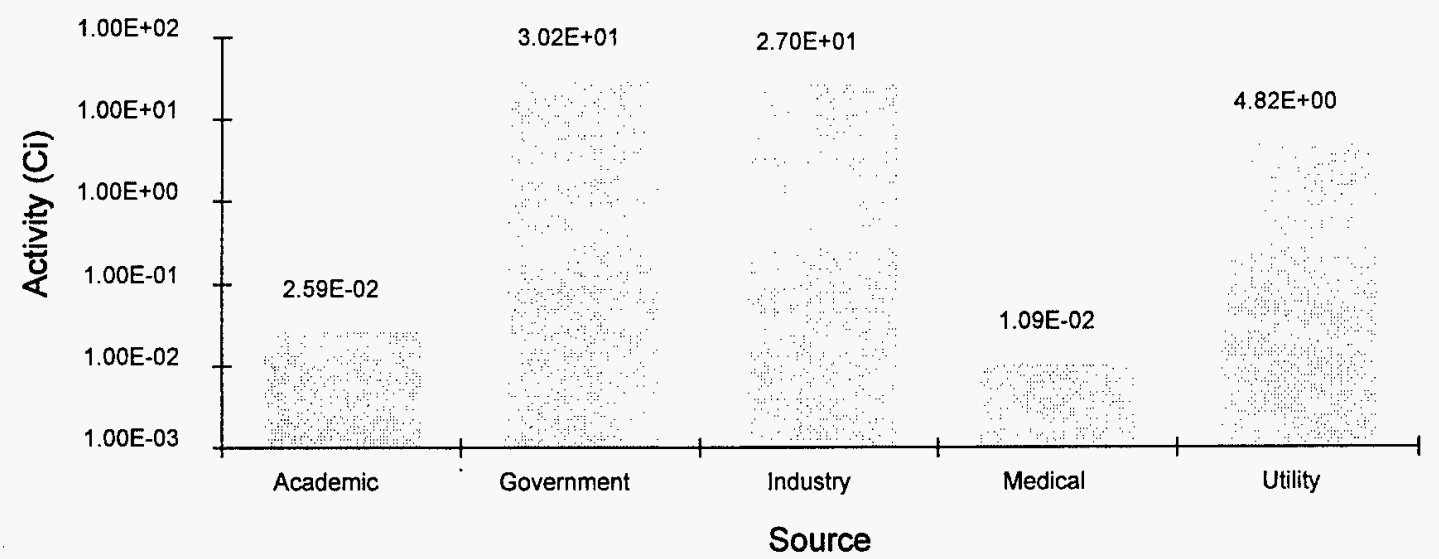

Figure 14-5. ${ }^{241} \mathrm{Am}$ activity deposited at the Richland, Beatty, and Barnwell sites by source (log scale).

Figure 14-6 shows the activity of ${ }^{241}$ Am deposited in the Richland and Beatty sites as a function of waste type. The waste disposal manifests for the Barnwell site did not break down the waste by type. Twenty-two percent of this nuclide has been stored at this site. As shown in this figure, more than $96 \%$ of this nuclide was in the form of dry solids. The waste types illustrated in Figure 14-6 are from nuclear reactors, academic institutions, and medical facilities. 


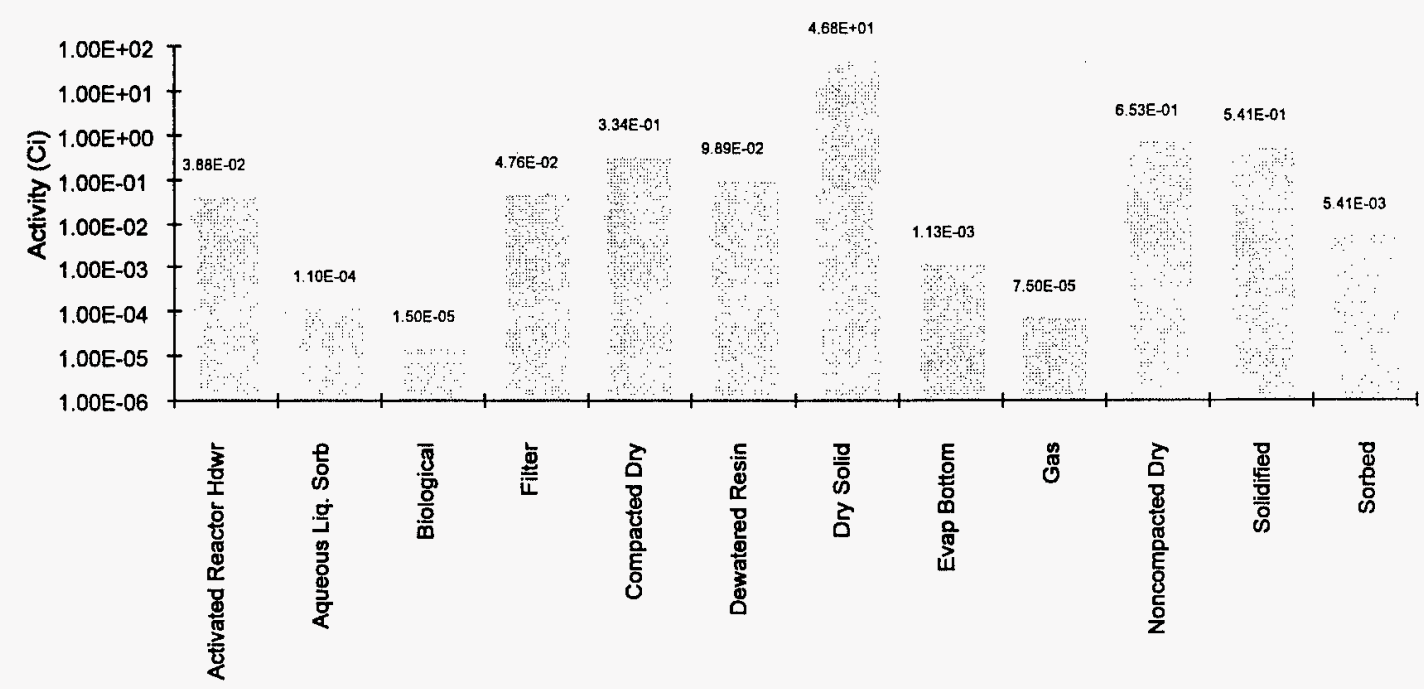

Waste Type

Figure 14-6. ${ }^{241} \mathrm{Am}$ activity deposited at the Richland and Beatty sites by waste type (log scale).

\section{Behavior of Americium-241 in the Environment}

\section{Americium-241 in Soils}

Understanding the behavior of radioactive materials such as ${ }^{241} \mathrm{Am}$ is important in assessing the possibility of transport of this radionuclide to the biosphere. It is also important to understand the interactions between radionuclides and various media along the path to the biosphere, whether disposal is in deep or shallow geologic formations or in near-surface disposal facilities.

Four parameters were reported to be essential in accurately predicting soil concentrations from either contaminated groundwater or irrigation water. The four parameters, in order of importance, are

1. Soil retention

2. Annual precipitation

3. Soil texture

4. Depth to the water table.

The soil retention parameter represents the solid/liquid partition coefficient and is denoted by the symbol $K_{d} . K_{d}$ is defined by $K_{d}=C_{s} / C_{1}$, where $C_{s}$ is the americium concentration in the soil $(\mu \mathrm{g} \mathrm{Am} / \mathrm{g}$ of soil), and $C_{1}$ is the americium concentration in the water ( $\mu \mathrm{g} \mathrm{Am} / \mathrm{mL}$ of liquid). Therefore, the units of $\mathrm{K}_{\mathrm{d}}$ are $\mathrm{mL} / \mathrm{g}$ (i.e., $\mathrm{mL}$ of water per gram of soil). This empirical model combines all soil retention mechanisms into a simple linear partition relationship between the soil and the surrounding water. This model assumes the americium concentrations in the water and soil are in equilibrium. Using this definition for $\mathrm{K}_{\mathrm{d}}$, it follows that the larger the value, the slower the migration of the radionuclide relative to the groundwater flow. Therefore, $K_{d}$ can be thought of as a measure of the amount of "fixing" or holdup in the soil. 
Typically, $K_{d}$ is measured under laboratory conditions with samples that are relatively homogenous and where equilibrium conditions can be met. Applying these values to specific soils in the field can be difficult because the actual soils are generally nonhomogeneous and there are uncertainties as to how long it takes americium concentrations in the soil and water $\left(\mathrm{C}_{s}\right.$ and $\left.\mathrm{C}_{1}\right)$ to reach equilibrium with each other. Therefore, one must be careful to ensure that soil samples used in laboratory studies are as closely representative of the field as possible. Even though the soil samples do not precisely match conditions in the field, $\mathrm{K}_{\mathrm{d}}$ values from laboratory studies can be used in computer models to extrapolate data from laboratory experiments and field studies. In addition, some experiments are conducted using intact field studies to validate laboratory $K_{d}$ values and to study the effects associated with soil nonhomogeneity.

Since americium is not naturally found in soils, studies of values for $\mathrm{K}_{d}$ are focused around soil types at sites where americium contamination of soils has occurred. These sites are typically associated with Government weapons production and testing activities, such as the Hanford Site in Washington and the Savannah River Site in South Carolina.

An experimental study was performed looking at the sorption of ${ }^{241} \mathrm{Am}$ on subsoils from both South Carolina and Washington. This study examined the differences in $\mathrm{K}_{\mathrm{d}}$ values as a function of calcium and sodium concentrations in the soil. For the South Carolina site, $\mathrm{K}_{\mathrm{d}}$ values ranged from 1.0 to 67 for calcium concentrations and 1.6 to 280 for sodium concentrations. ${ }^{9}$ This study indicated that for the South Carolina soils, the $K_{d}$ values tended to increase as the calcium and sodium concentrations in the soil increased. The $K_{d}$ values for Washington soils were $>1,200$ and were independent of the calcium or sodium concentrations.

Another study looked at $\mathrm{K}_{\mathrm{d}}$ values from seven different soil types and $\mathrm{pH}$. $^{10}$ This study determined the effect of soil type and $\mathrm{pH}$ on the extractability of ${ }^{241} \mathrm{Am}$. It was determined that the extractability of ${ }^{241} \mathrm{Am}$ was high between $\mathrm{pH} 1.2$ and 2 and then decreased to a slower rate to lower levels with increasing $\mathrm{pH}$. $\mathrm{K}_{\mathrm{d}}$ values for ${ }^{241} \mathrm{Am}$ ranged from 182 to 47,230 depending on the soil type at $\mathrm{pH}$ ranges from 4.4 to 8.0. This study suggested that soils with strong humic or fulvic acid concentrations would tend to allow ${ }^{241} \mathrm{Am}$ to migrate more freely than soils with higher $\mathrm{pH}$ contents.

Rockwell International conducted a study to evaluate radionuclide transport in relationship to the Columbia River Basalt Geohydrologic Basalt System. " This study was trying to determine if the basalt formations would be suitable for a geologic repository. The study looked at the Umtanum basalt and Mabton interbed formations under oxidizing and reducing conditions. $K_{d}$ values for ${ }^{241} \mathrm{Am}$ ranged from 340 for the basalt formations to $>10,000$ for interbed formations. These $K_{d}$ values are similar to those found in other studies.

In summary, studies have shown that the behavior of ${ }^{241} \mathrm{Am}$ in soils is dependent on soil type and $\mathrm{pH}$. The studies agree that for most soil types (except those with low calcium or sodium concentrations) ${ }^{241} \mathrm{Am}$ is not mobile in soils and that only small quantities can be expected to migrate within the soil to the biosphere. 


\section{Americium-241 in Water}

Americium does not naturally occur in the environment, including ground or surface waters. However, as a result of past atmospheric nuclear weapons testing, some nuclides of americium do exist in small concentrations on land, and in the oceans, and may be detectable in some groundwater systems due to radioactive fallout.

Americium, as is true for all actinides, typically does not move more than a few meters in the subsurface. ${ }^{12}$ The high molecular weight fraction of americium (about half) attaches itself to colloids and is moved with groundwater. Mobile americium becomes tightly and irreversibly associated with colloidal material between 25 and 450 nanometer $(\mathrm{nm})$ in size. Once the americium is bound to these colloids, it is removed only gradually by the groundwater. These colloids can, however, move slowly through a groundwater system. When attached to these colloids, americium typically does not migrate more than a few tens of meters. $K_{d} s$ for americium in groundwater can be as high as 10,000 , meaning the americium will move about one ten-thousandth as fast as the groundwater. One study of the interstitial chemistry of this nuclide concluded that the apparent $\mathrm{K}_{d}$ for ${ }^{241} \mathrm{Am}$ was of the order of $10^{5}$, though it was possible that equilibrium between the soil and groundwater had not been fully reached. ${ }^{13}$ The source of the radioactivity was effluent from the Sellafield fuel reprocessing plant.

Based on the above information, ${ }^{241} \mathrm{Am}$ generally migrates only short distances (meters) within groundwater and tends to bind with colloidal mixtures and clays found within the ground.

The main route of uptake for plants is through the roots. The area of collection of the radionuclide in the plant may vary with each species, though most seem to collect americium in the root with only a small amount going into the shoot (see Table 14-4). This table also illustrates that diethylenetriaminepentaacetate (DTPA) enhances the ${ }^{241} \mathrm{Am}$ uptake to areas of the plant included in the study.

Table 14-4. ${ }^{241} \mathrm{Am}$ in bush beans for 96 hours to three different concentrations of ${ }^{241} \mathrm{Am}$ in solution culture..$^{14}$

\begin{tabular}{lclccc}
\hline \multicolumn{2}{c}{ Treatment } & \multicolumn{4}{c}{ Concentration ratios } \\
\hline $\begin{array}{l}{ }^{241} \mathrm{Am}, \\
(\mu \mathrm{Ci} / \mathrm{mL})\end{array}$ & $\begin{array}{c}\text { DTPA } \\
\left(10 \mathrm{E}-4 \mathrm{M}^{2}\right)\end{array}$ & Leaves & $\begin{array}{c}\text { Stem } \\
\mathrm{s}\end{array}$ & Roots & Whole plant \\
\hline 1.0 & - & 0.005 & 0.011 & 24.8 & 2.63 \\
1.0 & + & 3.39 & 0.9 & 11.2 & 3.36 \\
0.5 & - & 0.008 & 0.007 & 16.2 & 2.17 \\
0.5 & + & 2.55 & 0.37 & 5.0 & 2.04 \\
0.25 & - & 0.006 & 0.007 & 15.5 & 2.83 \\
0.25 & + & 0.81 & 0.13 & 6.7 & 1.35 \\
& & &
\end{tabular}


Concentration ratios (CR) are a common method of measuring the uptake of radionuclides by plants. The measured ratio is the activity in the plant per weight of the plant to the activity in soil or other growth medium. Concentration ratios were calculated for ${ }^{241} \mathrm{Am},{ }^{237} \mathrm{~Np},{ }^{244} \mathrm{Cm}$, and ${ }^{238} \mathrm{Pu}$. The CR for americium is 0.002 , while the $\mathrm{CR}$ for neptunium is 0.04 . The CR for plutonium is 0.0001 .

Studies performed on the effect of chelating agents on the transport of americium within plants has shown that chelating agents increase the transport of americium through a plant as opposed to leaving it in the root as shown in Table 14-5. Americium is especially available to the plant at pH 7.7 and americium, being a metal, is transported through the plant as a metal chelate.

Tests by Schreckhise and Cline showed that americium and other transuranics behave differently in the biosphere. ${ }^{15}$ The phytoavailability of four transuranics (americium, plutonium, curium, and neptunium) was tested in field conditions to measure their uptake into four plant species including alfalfa, barley, peas, and cheatgrass (tumbleweeds). The soil concentration did not appear to affect the plant uptake of ${ }^{238} \mathrm{Pu},{ }^{239} \mathrm{Pu},{ }^{241} \mathrm{Am},{ }^{244} \mathrm{Cm}$, or ${ }^{237} \mathrm{~Np}$. The relative plant uptake of the radionuclides was ${ }^{237} \mathrm{~Np}>{ }^{244} \mathrm{Cm} z^{241} \mathrm{Am}>{ }^{239} \mathrm{Pu} z^{238} \mathrm{Pu}$

Relative uptake values for americium were 10 to 20 times greater than plutonium.

Based on the above information, ${ }^{241} \mathrm{Am}$ tends to deposit within the roots of plants. The total uptake of ${ }^{241} \mathrm{Am}$ within plants can be increased by using a chelating agent such as DTPA. The uptake in plants seems to be most accomplished within a soil $\mathrm{pH}$ range of 7 to 8 .

Table 14-5. ${ }^{241} \mathrm{Am}$ in roots, stems, and leaves of plants grown in contaminated soil in a glasshouse. ${ }^{16}$ $\mu \mathrm{Ci}{ }^{241} \mathrm{Am}$ per gram (dry weight)

\begin{tabular}{llccccc}
\hline Soil pH & Roots & Lower stem & $\begin{array}{c}\text { Primary } \\
\text { leaf }\end{array}$ & Upper stem & $\begin{array}{c}\text { Trifoliate } \\
\text { leaf }\end{array}$ & $\begin{array}{c}\text { Ratio } \\
\text { upper stem }\end{array}$ \\
\hline 5.3 & 6.87 & 0.40 & 0.76 & 1.56 & 0.17 & 0.11 \\
6.4 & 5.03 & 0.47 & 0.21 & 0.64 & 0.18 & 0.28 \\
7.7 & 4.14 & 0.44 & 0.24 & 0.68 & 0.24 & 0.35 \\
8.7 & 2.87 & 0.07 & 0.11 & 0.43 & 0.65 & 1.51 \\
\hline & & & Without DTPA DTPA & & \\
\hline 5.3 & 10.38 & 0.51 & 7.69 & 0.70 & 0.74 & 1.06 \\
6.4 & 13.25 & 0.88 & 12.88 & 1.41 & 1.27 & 0.90 \\
7.7 & 35.64 & 1.49 & 48.63 & 2.33 & 16.75 & 7.19 \\
8.7 & 28.65 & 1.53 & 32.13 & 5.65 & 10.34 & 1.83 \\
\hline
\end{tabular}




\section{Americium-241 in Air}

${ }^{241} \mathrm{Am}$ is not normally found in air, except for those amounts that result from fallout due to an atmospheric test of a thermonuclear weapon or from a nuclear accident (reactor accident such as the Chernobyl disaster or weapons facility accident such as the fire at Rocky Flats). ${ }^{241} \mathrm{Am}$ that has been released will eventually deposit in the land or ocean as fallout. As a result, there are detectable amounts of americium in soils, water, and, in some cases, air.

The air concentrations of various nuclides, including ${ }^{241} \mathrm{Am}$, are measured in the vicinities of some commercial reactors. ${ }^{17}$ These nuclides are in the air as a result of reactor operations. The concentration of ${ }^{241} \mathrm{Am}$ can be measured as low as $2 \mathrm{mBq} / \mathrm{m}^{3}{ }^{18}$ In addition, the concentration of this nuclide in the air resulting from the Chernobyl reactor accident has also been measured. ${ }^{19}$ In the latter case, ${ }^{241} \mathrm{Am}$ resulted from direct release from the exposed and damaged core plus as a decay product of ${ }^{241} \mathrm{Pu}$. Once the air concentrations and the deposition from air to the soil are known, models exist to calculate the transport of this, and other nuclides, into the food chain. ${ }^{20}$ Typically, ${ }^{241} \mathrm{Am}$ concentrates in leafy-green vegetables and offal. Models also exist to calculate the dose due to a fire in a contaminated facility that includes release of atmospheric ${ }^{241} \mathrm{Am}$, precipitation to the ground due to rain, and subsequent contamination of the groundwater. ${ }^{21}$

The major concern related to ${ }^{241} \mathrm{Am}$ is the resuspension in air associated with dusts and other particulates. Because of the highly charged valence states of $\mathrm{Am}^{+3,+4,+5}$, this radionuclide tends to bind easily with dust particles that can become suspended in air. Researchers at DOE's Idaho National Engineering Laboratory study the behavior of transuranic radionuclides in air. ${ }^{22}$ One study used contaminated soil from the DOE's Rocky Flats facility and suspended dust particles into the air containing transuranic radionuclides in a wind tunnel having laminar air flows. The respirable fraction ( $<5$ microns in particle size) of ${ }^{241} \mathrm{Am}$ suspended in the air averaged $38 \%$ of the total activity of ${ }^{241} \mathrm{Am}$ in the source soil. The ${ }^{241} \mathrm{Am}$ was found to be extremely mobile downstream of the generation point. While ${ }^{241} \mathrm{Am}$ is not normally found in air, extreme care must be used when working in areas that may contain transuranic radionuclide contamination to limit the possibility of the spread of contamination and possible inhalation from the resuspension of contaminated dust particles.

In the mid to late 1970s, concern was raised that fallout from nuclear weapons testing could result in hazardous levels of actinides being released in the air and eventually reaching the food chain. Consequently, a study was made of the concentrations of, among other nuclides, ${ }^{241} \mathrm{Am}$ in the water and organic fertilizer (from the Metropolitan Sanitary District plant at Stickney, Illinois) in the Chicago, Illinois, region. ${ }^{23}$ The results from this study indicate that any ${ }^{241} \mathrm{Am}$ fallout into Lake Michigan was efficiently retained by the lake sediment, in that the concentration of this nuclide was much lower than that of the Pu nuclides. However, there were measurable concentrations of this nuclide in the organic fertilizer, indicating that the source of the contamination was fallout within the metropolitan area, rather than into the lake. The concentrations were low enough that it was concluded there would be no significant health hazard to humans from the use of this fertilizer.

\section{Behavior of Americium-241 in the Human Body and in Animals}

Radionuclides have been classified as to their relative toxicity in humans. In this chapter, radionuclides are grouped into four classifications: very high toxicity, high toxicity, medium toxicity, and low toxicity. ${ }^{241} \mathrm{Am}$ is included in the very high toxicity group.

${ }^{241} \mathrm{Am}$ is primarily an alpha emitter. In addition, ${ }^{241} \mathrm{Am}$ emits $\mathrm{X}$-rays and gamma rays with energies up to $955.7 \mathrm{keV}$. As previously discussed, alpha particles have a short range in air and are easily shielded with paper or plastic and do not pose an external radiation hazard. However, alpha particles pose an extreme hazard if they are internally ingested or inhaled. Alpha particles tend to deposit all of 
their energy in a small space or area when they interact with other matter. Because of this, alpha particles tend to cause damage when they interact with living tissue. For this reason, ${ }^{241} \mathrm{Am}$ is included in the very high toxicity group.

Several animal studies have been performed to determine the behavior of ${ }^{241} \mathrm{Am}$ in animals. Studies have been performed on ducks, baboons, and monkeys. ${ }^{24,25,26}$ In all of these studies, the dose from internal exposure to ${ }^{241} \mathrm{Am}$ was primarily deposited, in order of greatest dose to least, to the bone surface, liver, and lung.

The biological hazard associated with a radionuclide can be characterized by the equivalent dose per unit of exposure. The exposure can be either by external radiation (primarily from gamma rays, neutron flux, or both, or to a lesser extent, from beta rays if they are sufficiently energetic). In addition, internal exposure can result from ingestion or inhalation. Table 14-6 lists the ${ }^{241} \mathrm{Am}$ equivalent dose (sievert $[\mathrm{Sv}]$ or rem dose per internal unit of exposure becquerel $[\mathrm{Bq}]$ or curie [Ci])for the principal human organs of concern, gonad, breast, lung, bone, thyroid, as well as overall dose equivalent.

Table 14-6. Committed dose equivalents per unit uptake via ingestion and inhalation. ${ }^{3}$

\begin{tabular}{|c|c|c|}
\hline Organ & $\begin{array}{c}\text { Ingestion effective } \\
\text { dose } \\
\mathrm{Sv} / \mathrm{Bq}^{\mathrm{a}} \\
\end{array}$ & $\begin{array}{c}\text { Inhalation effective } \\
\text { dose } \\
\mathrm{Sv} / \mathrm{Bq}^{\mathrm{a}} \\
\end{array}$ \\
\hline Gonad & $2.70 \mathrm{E}-07$ & $3.25 \mathrm{E}-05$ \\
\hline Breast & $2.62 \mathrm{E}-11$ & $2.67 \mathrm{E}-09$ \\
\hline Lung & $3.36 \mathrm{E}-11$ & $1.80 \mathrm{E}-05$ \\
\hline Red marrow & $1.45 \mathrm{E}-06$ & $1.74 \mathrm{E}-04$ \\
\hline Bone & $1.81 \mathrm{E}-05$ & $2.17 \mathrm{E}-03$ \\
\hline Thyroid & $1.32 \mathrm{E}-11$ & $5.64 \mathrm{E}-10$ \\
\hline Other (e.g., liver, kidney) & $6.66 \mathrm{E}-07$ & $7.48 \mathrm{E}-05$ \\
\hline Effective dose & $1.58 \mathrm{E}-08$ & $1.20 \mathrm{E}-04$ \\
\hline
\end{tabular}

Two independent means can remove any radionuclide from the human body. The first is radioactive decay, characterized by the radiological half-life, where the nuclide is transmuted into another nuclide. For ${ }^{241} \mathrm{Am}$, the daughter decay product is ${ }^{237} \mathrm{~Np}$, which itself is primarily an alpha emitter. This decay product can continue to pose a biological hazard. The second process is quantified by the "biological half-life," which is a measure of time from removal of one-half of the nuclide from the affected organ(s) and can differ for different body parts. The total removal rate is characterized by the "effective half-life," which is defined as 
$T_{\text {eff }}=\quad \frac{T_{r} * T_{b}}{T_{r}+T_{b}}$

where:

$$
\begin{aligned}
& T_{\text {eff }}=\text { Effective half-life } \\
& T_{r}=\text { Radiological half-life } \\
& T_{b}=\text { Biological half-life. }
\end{aligned}
$$

The biological half-life of ${ }^{241} \mathrm{Am}$ to the critical organs is 70,000 days for the bone, 30,000 days to the liver, 30,000 days to the kidneys, and 70,000 days to the total body. ${ }^{27}$ Thus, the radiological half-life is longer than the biological half-life and the only removal mechanism is biological. However, studies have been conducted showing that zinc-diethylenetriaminepentaacetate (Zn-DTPA) is an effective chelating agent to enhance the removal of ${ }^{241} \mathrm{Am}$ from the body and to limit the uptake of ${ }^{241} \mathrm{Am}$ to the critical organs. In addition, Zn-DTPA has been found to be effective in limiting the maternal transfer of ${ }^{241} \mathrm{Am}$ to unborn mice. ${ }^{28}$

Several studies have been performed on humans who have been subjected to accidental exposures to ${ }^{241} \mathrm{Am}$. On August 30, 1976, a worker at DOE's Hanford facility received an accidental exposure to ${ }^{241} \mathrm{Am} .{ }^{29}$ The estimated total dose received by the worker was 130 rad to the lung, 160 rad to the liver, and $105 \mathrm{rad} /$ year to the bone. (The actual energy absorption is measured in rads, with $1 \mathrm{rad}$ as 0.01 watt-second energy absorbed per kilogram of tissue weight.) This worker was subjected to Zn-DTPA therapy some 2.5 hours after the accident. It was reported that if the chelating therapy had been administered immediately after the accident that the majority of the dose to the lungs, liver, and bone might have been avoided.

The Los Alamos National Laboratory (LANL) published a report analyzing bone and tissues from individuals who had occupational exposures to ${ }^{241} \mathrm{Am} .{ }^{30}$ Samples were taken after the natural death of the individuals, and the ${ }^{241} \mathrm{Am}$ activity of tissues and bones were calculated years after exposure. The results confirmed that the bones had the greatest ${ }^{241} \mathrm{Am}$ activity followed by the liver and lung. The study concluded that $83 \%$ of the total ${ }^{241} \mathrm{Am}$ was located in the bones and teeth. The remaining $17 \%$ was located within the soft tissues.

The annual limits on intake (ALI) and derived air concentrations (DAC) for ${ }^{241} \mathrm{Am}$ are shown in Table 14-7. The ALI is defined as that annual intake of a radionuclide that would result in a radiation dose to a human (for calculational purposes, the characteristics of the "reference or standard" man are used) equal to the allowable limit. The DAC is defined as that concentration of a radionuclide in air which, if breathed for a work-year, would result in an intake corresponding to the ALI (or, in case of submersion, to an external exposure corresponding to the primary guide for limiting the annual dose). DACs are used for limiting radionuclides through breathing, or submersion in, contaminated air. ALIs are used primarily for assessing doses that result from accidental ingestion of radionuclides.

Historically, maximum permissible concentrations (MPC) in air and water have been used to determine safety guidelines for released radionuclide concentrations. Currently, the derived guidelines are presented in terms of ALIs and DACs. For a radionuclide whose derived value does not change from the old definition, the DAC is numerically equal to the MPC value in air. The information in Table 14-7 applies only to ${ }^{241} \mathrm{Am}$. In the case of multiple radionuclides released in a mixture, additional guidelines outlined in the 10 CFR 20 must be followed. ${ }^{31}$ 
In summary, ${ }^{241} \mathrm{Am}$ is primarily an alpha emitter. It is most dangerous in animals and humans when it is taken into the body via inhalation or ingestion, where it can interact with living tissue. The critical organs of concern in internal exposures to ${ }^{241} \mathrm{Am}$ are the bone, liver, and lung. Chelating therapy using Zn-DTPA has been found to be effective in limiting the internal exposure and dose to the critical organs when administered as quickly as possible after exposure occurs. Because of the internal hazard posed by ${ }^{241} \mathrm{Am}$, the regulatory guidance gives very low ALIs and DACs to protect individuals from hazardous exposures.

Table 14-7. Annual limits on intake and derived air concentrations for ${ }^{241} \mathrm{Am} .{ }^{\mathrm{a}}$

\begin{tabular}{lllr}
\hline Radionuclide & \multicolumn{1}{c}{ Component } & $\begin{array}{c}\text { Ingestion } \\
(\mu \mathrm{Ci})\end{array}$ & $\begin{array}{c}\text { Inhalation } \\
(\mu \mathrm{Ci} / \mathrm{mL})\end{array}$ \\
\hline${ }^{241} \mathrm{Am}(\mathrm{W})^{\mathrm{b}}$ & ALI & $8 \mathrm{E}-01$ & $6 \mathrm{E}-03$ \\
& ALI bone surface & 1 & $1 \mathrm{E}-02$ \\
& DAC & $\mathrm{NA}^{\mathrm{c}}$ & $3 \mathrm{E}-12$ \\
& $\mathrm{f}_{1}{ }^{\mathrm{d}}$ & $3 \mathrm{E}-3$ & $3 \mathrm{E}-3$ \\
\end{tabular}

a. Data taken from 10 CFR 20 [20.1001-20.2402], Nuclear Regulatory Commission Regulations Appendix B.

b. $\mathrm{W}=\mathrm{ALIs}$ and DACs for this nuclide are based on a weekly exposure.

c. Not applicable.

d. The $f_{1}$ is the fractional uptake to the blood from the gastrointestinal tract from the common chemical forms of the radionuclide.

\section{Summary}

${ }^{241} \mathrm{Am}$ is an alpha-emitting transuranic radionuclide with a half-life of 432.2 years. The regulatory limits for ${ }^{241} \mathrm{Am}$ disposal and personnel exposure are very restrictive. Relatively small concentrations of ${ }^{241} \mathrm{Am}$ can become a major contributor to the calculated doses to individuals in performance assessment calculations or an accidental release involving this radionuclide.

The principal means of production of ${ }^{241} \mathrm{Am}$ is by the bombardment of plutonium atoms in a nuclear reactor in the following reaction:

${ }^{239} \mathrm{Pu}(\mathrm{n}, \gamma){ }^{240} \mathrm{Pu}(\mathrm{n}, \gamma){ }^{241} \mathrm{Pu} \rightarrow \beta^{-} \rightarrow{ }^{241} \mathrm{Am}$.

${ }^{241} \mathrm{Am}$ can also be produced as a result of the bombardment of ${ }^{238} \mathrm{U}$ with $40-\mathrm{Mev}$ helium ions in the following reaction:

${ }^{238} \mathrm{U}(\alpha, \mathrm{n}){ }^{241} \mathrm{Pu} \rightarrow \beta^{-} \rightarrow{ }^{241} \mathrm{Am}$.

${ }^{241} \mathrm{Am}$ is primarily an alpha emitter. The alpha particle energies range from 4.75 to $5.54 \mathrm{MeV}$ with the most intense alpha particle energy at $5.48 \mathrm{MeV}(85.2 \%)$. The radionuclide also emits gamma rays and $\mathrm{x}$-rays ranging from 11.87 to $955.7 \mathrm{keV}$ with the most intense gamma energy emitted at $59.5 \mathrm{keV}$ $(35.7 \%)$. 
Pure ${ }^{241} \mathrm{Am}$ is produced by chemically separating the Am from its ${ }^{241} \mathrm{Pu}$ parent. ${ }^{241} \mathrm{Pu}$ is dissolved totally into a solution. After standing for a period of time, perhaps on the order of several years, the americium is then chemically separated from the plutonium solution.

${ }^{241} \mathrm{Am}$ is produced within the fuel and operational wastes from cleanup systems of nuclear reactors. The quantity of ${ }^{241} \mathrm{Am}$ in spent fuel that is produced each year is proportional to the amount of ${ }^{241} \mathrm{Pu}$ produced and continues to increase as the fuel is stored. All of the ${ }^{241} \mathrm{Am}$ associated with spent commercial fuel is expected to stay with the fuel and be disposed of in the national high-level waste repository.

The largest producer of ${ }^{241} \mathrm{Am}$ is the U.S. Government. Government waste streams containing ${ }^{241} \mathrm{Am}$ are associated primarily with the manufacturing of atomic weapons and decommissioning of the associated Government facilities. The majority of the waste forms containing ${ }^{241} \mathrm{Am}$ are located at the DOE facilities located around the country.

Studies have shown that the behavior of ${ }^{241} \mathrm{Am}$ in soils depends on soil type and $\mathrm{pH}$. Most studies agree that ${ }^{241} \mathrm{Am}$ is not very mobile in soils and that only small quantities can be expected to migrate within the soil to the biosphere.

${ }^{241} \mathrm{Am}$ generally does not migrate within water and tends to bind with colloidal mixtures and clays found within the ground.

${ }^{241} \mathrm{Am}$ tends to deposit within the roots of plants. The total uptake of ${ }^{241} \mathrm{Am}$ within plants can be increased by using a chelating agent such as DTPA. The uptake in plants seems to be most accomplished within a soil $\mathrm{pH}$ range of 7 to 8 .

${ }^{241} \mathrm{Am}$ is not normally found in air. However, extreme care must be used when working in areas that may contain transuranic radionuclide contamination to limit the possibility of contamination spread and possible inhalation from the resuspension of contaminated dust particles.

As stated, ${ }^{241} \mathrm{Am}$ is primarily an alpha emitter. It is most dangerous to animals and humans when it is taken into the body via inhalation or ingestion where it can interact with living tissue. The critical organs of concern in internal exposures to ${ }^{241} \mathrm{Am}$ are the bone, liver, and lung. Chelating therapy using $\mathrm{Zn}$-DTPA has been found to be effective in limiting the internal exposure and dose to the critical organs when administered as quickly as possible after exposure occurs. Because of the internal hazard posed by ${ }^{241} \mathrm{Am}$, the regulatory guidance gives low ALIs and DACs to protect individuals from hazardous exposures. 


\section{References}

1. E. Brown and R. B. Firestone, Table of Radioactive Isotopes, New York: John Wiley \& Sons, 1986, p. 241-2.

2. G. Seaborg and J. Katz, The Actinide Elements, 1st edition, New York: McGraw-Hill, 1954, pp. 492-494.

3. B. Shleien, The Health Physics and Radiological Health Handbook, revised edition, Scinta, Inc., 1992, pp. 173, 238.

4. D. Lide, Handbook of Chemistry and Physics, 71 st edition, Boca Raton, Florida: CRC Press., 1990-1991, pp. 4-42.

5. R. Ranier and D. Gambini, Applied Radiobiology and Radiation Protection, Ellis Horwood, 1990, pp. 346-347.

6. J. Katz and G. Seaborg, The Chemistry of the Actinide Elements, New York: John Wiley \& Sons, 1957, pp. 333-334.

7. Oak Ridge National Laboratory, Integrated Database Report-1993: U.S. Spent Nuclear Fuel and Radioactive Waste Inventories, Projections, and Characteristics, DOE/RW-006, Revision 10, December 1994, pp. 19-37, 111-120.

8. Code of Federal Regulations, 10 CFR 61.55, "Licensing Requirements for Land Disposal of Radioactive Wastes," Federal Register, Vol. 47, No. 248, December 1982.

9. H. Nishita et al., "Effect of Soil Type on the Extractability of ${ }^{237} \mathrm{~Np},{ }^{239} \mathrm{Pu},{ }^{241} \mathrm{Am}$, and ${ }^{244} \mathrm{Cm}$ as a Function of pH," Soil Science Magazine, Vol.132, No. 1, July 1981, pp. 25-34.

10. B. Hajek, Plutonium and Americium Mobility in Soils, Pacific Northwest Laboratories, BNLW-CC-925, November 1966.

11. P. Salter and G. Jacobs, Evaluation of Radionuclide Transport: Effect of Radionuclide Sorption and Solubility, Rockwell International, Hanford, RHO-BW-SA-192 P, June 1982.

12. W. Penrose et al., "Mobility of Plutonium and Americium Through a Shallow Aquifer in a SemiArid Region," Environmental Science \& Technology, Vol. 24, No. 2, February 1990, pp. 228-234.

13. S. J. Malcolm, et al., "The Interstitial Water Chemistry of ${ }^{239,240} \mathrm{Pu}$ and ${ }^{241} \mathrm{Am}$ in the Sediments of the North-East Irish Sea," Geochimica et Cosmochimica Acta, Vol. 54, No. 1, 1990, pp. 29-35.

14. A. Wallace, E. Romney, R. Mueller, S. Soufi, "Effect of Concentration on ${ }^{241}$ Am Uptake by Plants With and Without DTPA Treatment," Soil Science, Vol. 132, No. 1, July 1981, pp. 108-113.

15. R. G. Schreckhise and J. Cline, "Comparative Uptake and Distribution of Plutonium, Americium, Curium, and Neptunium in Four Plant Species," Health Physics, Vol. 38, May 1980, pp. 817-824.

16. A. Wallace, "Effect of Soil pH and Chelating Agent (DTPA) on Uptake by and Distribution of ${ }^{241}$ Am in Plant Parts of Bush Beans," Radiation Botany, Vol. 12, No. 6, 1972, pp. 433-435. 
17. Z. Hoelgye, R. Filgas, and I. Bucina, "Monitoring of the Release of ${ }^{238} \mathrm{Pu},{ }^{239,240} \mathrm{Pu},{ }^{241} \mathrm{Am},{ }^{242} \mathrm{Cm}$, and ${ }^{244} \mathrm{Cm}$ in the Airborne Effluents from Czech and Slovak Nuclear Power Plants," Environment International, Vol. 21, No. 6, 1995, pp. 833-838.

18. T. Bereznai, "Limits of Detection of Americium-241 in Air," Atomwirtschaft, Atomtechnik, Vol. 40, 1995, pp. 27.

19. A. Ivanov, et al., "Radioactive Contamination of the Environment with ${ }^{241} \mathrm{Am}$ as a Result of the Chernobyl Accident," Atomic Energy, Vol. 77, No. 2 1994, pp. 629-634.

20. D. Jackson, P. J. Coughtrey, and D. F. Crabtree, "Predicted Concentrations of ${ }^{137} \mathrm{Cs},{ }^{131} \mathrm{I},{ }^{129} \mathrm{I},{ }^{241} \mathrm{Pu}$, and ${ }^{241} \mathrm{Am}$ in Various Foodstuffs Following Deposition to Ground," Journal of Environmental Radioactivity, Vol. 5, No. 2, 1987, pp. 143-158.

21. J. Wang and J. Y. Yang, "Environmental Impact of a Teratogenic Actinide: A Case Study of Americium-241," Conference on Technology and Science, Newton, MA, November 29, 1985, p. 22.

22. D. Scott and M. Winberg, Background Ventilation Studies for TRU-Waste Retrieval, EG\&G Idaho, EGG-WM-8802, October 1989.

23. J. J. Alberts and M. A. Wahlgren, "Concentrations of ${ }^{239,240} \mathrm{Pu}$ and ${ }^{241} \mathrm{Am}$ in Drinking Water and Organic Fertilizer," Health Physics, Vol. 32, No. 4, April 1977, pp. 295-297.

24. O. D. Markham et al., "Plutonium, Am, Cm, and $\mathrm{Sr}$ in Ducks Maintained on Radioactive Leaching Ponds in Southeastern Idaho," Health Physics, Vol. 55, No. 3, September 1988, pp. 517-524.

25. J. Rosen, N. Cohen, M. Wrenn, "Short-Term Metabolism of ${ }^{241} \mathrm{Am}$ in the Adult Baboon," Health Physics, Vol. 22, June 1972, pp. 621-626.

26. T. Lynch et al., "Comparative Skeletal Distribution of Am and Pu in Man, Monkey, and Baboon," Health Physics, 5, Supplement 1, pp. 81-89.

27. Y. Wang, M. D. (ed.), Handbook of Radioactive Nuclides, Boca Raton, Florida: CRC Press, 1969, p. 33.

28. R. Lloyd et al., "Effect of ZN-DTPA Therapy on the Maternal Transfer of ${ }^{241} \mathrm{Am}$ or ${ }^{237} \mathrm{Pu}$ to Young Mice," Health Physics, Vol. 49, No. 3, September 1985, pp. 405-410.

29. R. Thompson, 1976, "Hanford Americium Exposure Incident: Overview and Perspective," Health Physics, Vol. 45, No. 4, October 1983, pp. 837-845.

30. J. McInroy et al., "Part IV: Preparation and Analysis of the Tissues and Bones," Health Physics, Vol. 49, No. 4, October 1983, pp. 587-621.

31. Code of Federal Regulations, 10 CFR 20, "Standards for Protection Against Radiation," U.S. Nuclear Regulatory Commission. 


\section{Bibliography}

Browne, E. and R. B. Firestone, Table of Radioactive Isotopes, New York: John Wiley \& Sons, 1986.

Linde, D. R., Handbook of Chemistry and Physics, Boca Raton, Florida: CRC Press, 71st Edition, 1990-1991.

National Low-Level Waste Management Program, Characterization of Greater-Than-Class C Sealed Sources, Volumes 1-3, DOE/LLW-163, 1994.

Oak Ridge National Laboratory, Integrated Database Report - 1993: U.S. Spent Fuel and Radioactive Waste Inventories, Projections, and Characteristics, DOE/RW-0006, Revision 10, December 1994.

Shleien, B., The Health Physics and Radiological Handbook, revised edition, Scinta, Inc., 1986.

Shapiro, J., Radiation Protection, second edition, Harvard Press, 1972. 


\section{URANIUM-238}

\section{Introduction}

This chapter discusses the basic radiological, chemical, and physical characteristics of uranium-238 $\left({ }^{238} \mathrm{U}\right)$ and examines how these characteristics affect the behavior of ${ }^{238} U$ in various environmental media, such as soils, water, plants, animals, the atmosphere, and the human body. Also included are methods of ${ }^{238} \mathrm{U}$ production and waste and disposal data on ${ }^{238} \mathrm{U}$.

Because of the long half-life (and consequently low specific activity) of ${ }^{238} \mathrm{U}$, it is not, itself, a major factor in the ability of a low-level radioactive waste (LLW) disposal facility to meet performance objectives. The presence of the nuclide, however, can be relatively significant in assessing the long-term performance of such a site due to the quantity, radiotoxicity, and mobility of its daughter products, which include isotopes of radium and radon. For this reason, it was decided to include ${ }^{238} \mathrm{U}$ in this report.

A radionuclide considered sensitive at one LLW disposal facility may not be considered sensitive at another facility. The behavior of a radionuclide at a particular LLW disposal site will depend primarily upon the radiological, chemical, and physical characteristics of the waste, and the inventory of the radionuclide. The behavior of a radionuclide also depends upon the geology, hydrology, and climate at the disposal site. This chapter reports characteristics and potential difficulties in dealing with ${ }^{238} U$. However, since ${ }^{238} U$ behavior and appropriate handling, storage, or disposal will vary depending on particular sites or waste form, this chapter does not attempt to discuss the extent of a difficulty or appropriate solutions. Each disposal site facility design should consider and address the specific waste content and behavior under that site's particular circumstances.

Uranium was first isolated by Martin Heinrich Klaproth in 1789 from a sample of pitchblende in Saxony. ${ }^{1}$ At first, it was assumed that the new "element" was a semi-metal due to its apparent chemical and physical characteristics. In 1841, Eugene-Melchior Peligot showed that the original "element" was, in fact, the oxide and was able to reduce the oxide to obtain the first pure metal. In 1896, Antoine-Henri Becquerel discovered that uranium undergoes radioactive decay. In 1939, Otto Hahn and Fritz Strassmann discovered the phenomenon of spontaneous fissioning, which ultimately vaulted uranium from a position of relative obscurity to a role of major importance.

All uranium atoms contain 92 protons $(Z=92)$ and various numbers of neutrons $(\mathrm{N}=135$ to 148$)$ within the atom's nucleus. There are no stable isotopes of uranium; all are radioactive. The half-lives of uranium isotopes range from less than 2 minutes $\left({ }^{227} \mathrm{U}\right)$ to billions of years $\left({ }^{238} \mathrm{U}\right)$. Even though all of the isotopes of uranium are radioactive, three of the isotopes have sufficiently long life-times and exist in nature for long periods of time. ${ }^{234} \mathrm{U}$ half-life $=2.5 \times 10^{5} \mathrm{yr}, 0.0057 \%$ of naturally occurring uranium; ${ }^{235} \mathrm{U}$ half-life $=7.1 \times 10^{8} \mathrm{yr}, 0.71 \%$ of naturally occurring uranium; and ${ }^{238} \mathrm{U}$, half-life $=4.5 \times 10^{9} \mathrm{yr}, 99.3 \%$ of naturally occurring uranium.) Essentially all of the existing ${ }^{238} U$ is naturally occurring, although a small fraction is produced by neutron activation of lower mass nuclides. For the purpose of this chapter, it will be assumed that all of this nuclide is natural and none is manmade.

Before 1942, uranium was used principally as a coloring agent in glass and ceramic glazes, resulting in a yellow, orange, or red (depending on the chemical form) tint to objects wnere it was used. ${ }^{2}$ The principal source for this coloring agent was as a byproduct of the production of radium and vanadium. However, discovery by Otto Hahn and Fritz Strassmann in 1939 of the ability of uranium to fission, creating enormous amounts of energy in the process, led to greatly heightened interest in this element. ${ }^{1}$ After demonstrating controlled nuclear fission in 1942, this element was sought after as a source of heat to drive steam generators 
and as an explosive material for military uses. Additional uses for this element have been discovered and will be discussed in later sections of this chapter.

Although ${ }^{238} \mathrm{U}$ is the predominant isotope of uranium, a lower mass isotope, ${ }^{235} \mathrm{U}$, is the nuclide most often used for energy purposes. This has given rise to a new term to describe ${ }^{238} \mathrm{U}$, namely "depleted uranium." This is because as ${ }^{235} \mathrm{U}$ is extracted from uranium, that which is left is uranium "depleted" of this desirable isotope and contains an even higher fraction of ${ }^{238} \mathrm{U}$. Thus, depleted uranium and ${ }^{238} \mathrm{U}$ are used interchangeably in this chapter.

The primary source of ${ }^{238} \mathrm{U}$ in the environment is a natural ore, undisturbed by humans. The principal manmade source of this nuclide is uranium that has been depleted of its original store of ${ }^{235} \mathrm{U}$ either by the enrichment process (whereby the ${ }^{235} U$ is extracted from the uranium, leaving depleted uranium as a byproduct) or by removal of ${ }^{235} \mathrm{U}$ from uranium in the fissioning process. The enrichment process results in large masses of depleted uranium that can be used for other purposes (discussed later in this chapter). The fissioning process results in large amounts of ${ }^{238} \mathrm{U}$ that are contaminated with highly radioactive fission and activation products and which are generally disposed of as high-level wastes. Because it does not generally result in disposal of ${ }^{238} \mathrm{U}$ as LLW, the second process (fissioning) is discussed only briefly in this chapter.

The specific activity of ${ }^{238} \mathrm{U}$ is relatively small. Therefore, this nuclide can be handled with standard laboratory equipment, includiny ventilated hoods or enclosures used for general laboratory purposes. ${ }^{3}$ However, as discussed later in this chapter, the radiotoxicity of this nuclide is classified as high. This may be because of the radiotoxicity of its decay daughters.

\section{Radiological Characteristics}

The most recent information regarding ${ }^{238} \mathrm{U}$ reports a radiological half-life of $4.47 \times 10^{9} \mathrm{yr} .{ }^{4}$ Despite the fact that this nuclide is radioactive, the principal source is natural uranium ore, of which ${ }^{238} \mathrm{U}$ comprises more than $99 \%$.

As is the case for curium-242 $\left({ }^{242} \mathrm{Cm}\right)$, reported in Chapter 13 , the decay of ${ }^{238} \mathrm{U}$ is very complex. The principal decay chain from ${ }^{238} \mathrm{U}$ to the stable nuclide lead- $206\left({ }^{206} \mathrm{~Pb}\right)$ is ${ }^{5}$

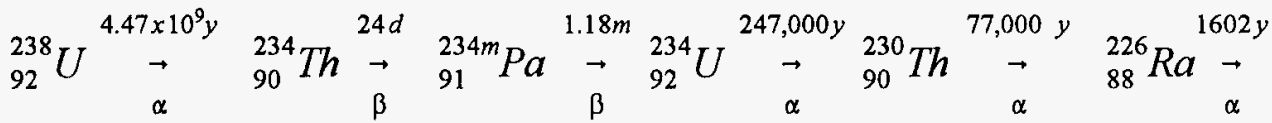

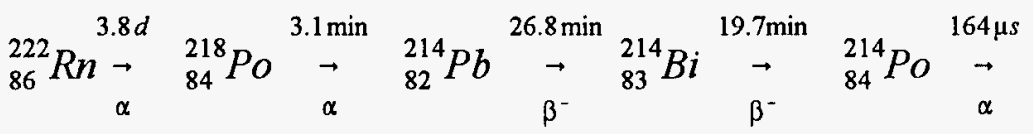

$$
\begin{aligned}
& { }_{82}^{210} \mathrm{~Pb} \underset{\beta^{-}}{\stackrel{22 y}{\rightarrow}}{ }_{83}^{210} \mathrm{Bi} \underset{\beta^{-}}{\stackrel{5 d}{\rightarrow}}{ }_{84}^{210} \mathrm{Po} \underset{\alpha}{\stackrel{138 d}{\rightarrow}}{ }_{82}^{206} \mathrm{~Pb} \text { (stable) }
\end{aligned}
$$

In fact, with the exception of the first three nuclides, this decay chain is identical to the decay of ${ }^{242} \mathrm{Cm}$ (see Equation 3 of Reference 4). This is the most likely decay process, based on the principal branch for the decay of each nuclide ground state. For several of these decay processes, there is a competing process. Many of the alpha-decay processes also result in the emission of various energy gamma rays, and the beta-decay 
processes result in the emission of various energy beta particles and gamma rays. A very small fraction $(<1 \%)$ of the decays of ${ }^{238} \mathrm{U}$ result in spontaneous fission. ${ }^{6}$ The fraction of decays resulting in spontaneous fission is not documented, but the half-life of this process is of the order of $10^{15}$ years, or approximately one million times as long as for alpha decay, which gives an indication of this fraction.

With the exceptions of plutonium-241 ( ${ }^{241} \mathrm{Pu}$ ) (see Chapter 9), americium-241 $\left({ }^{241} \mathrm{Am}\right)$ (see Chapter 14), and ${ }^{242} \mathrm{Cm}$ (see Chapter 13), all other nuclides included in this report decay either directly to a stable nuclide or reach a stable nuclide within two decays. Therefore, this $\left({ }^{238} \mathrm{U}\right)$ decay scheme is one of the most complex included in this report.

No attempt has been made in this study to correlate the potential effects of radiation associated with the nuclide decay listed in Equation (15-1) because that would have been beyond the scope of the task. Only the effects associated with the direct decay of ${ }^{238} \mathrm{U}$ will be included. Obviously, these other nuclides will affect the behavior of uranium in a LLW site (these daughter nuclides dominate the radiological consequences) and their effects need to be considered in any comprehensive study of the behavior of uranium. The types and energies of the radiation associated with the subsequent decays are provided in the references.

The decay of ${ }^{238} \mathrm{U}$ results in the emission of alpha particles with three principal energies, 4.04 million electron volts (MeV) $-1 \%$ of decays; $4.15 \mathrm{MeV}-23 \%$ of decays; and $4.20 \mathrm{MeV}-77 \%$ of decays. ${ }^{4}$ There is electromagnetic radiation that is emitted during the decay of a ${ }^{238} \mathrm{U}$ nucleus. The $\mathrm{x}$-ray and gamma-ray energies range from 11 to 110 thousand electron volts $(\mathrm{keV})$, although the most probable energy is $16 \mathrm{keV}$. Finally, electrons may be emitted during the decay of ${ }^{238} \mathrm{U}$, with principal energies of 30 and $43 \mathrm{keV}{ }^{6}$ Again, these emissions are only from the direct decay of ${ }^{238} \mathrm{U}$ and do not include the emissions from the subsequent decay of the ground states of resultant nuclides, as shown in Equation (15-1).

Since a released electron is often emitted with an energy less than its theoretical maximum, an antineutrino particle is simultaneously emitted and this particle carries off the energy difference between the released electron and the total energy given off by the associated decay process. Consequently, electrons are emitted with a continuous energy spectrum ranging from zero to the maximum energy. Since neutrinos and antineutrinos rarely interact with matter, they are not considered radiologically important. Therefore, the antineutrino particle is usually not shown in the overall decay equation.

As stated above, approximately $77 \%$ of the decays of ${ }^{238} \mathrm{U}$ result in the emission of an alpha particle with an energy of $4.20 \mathrm{MeV}$. The range of these alpha particles is approximately $2.6 \mathrm{~cm}$ in air. Thus, even a small distance removed from a ${ }^{238} \mathrm{U}$ source would provide sufficient shielding from the alpha radiation. The $43-\mathrm{keV}$ electron that can be emitted during the decay would have a range of $3.0 \mathrm{mg} / \mathrm{cm}^{2}$ (to obtain the linear range in a given material, divide this value by the density of the material).

In addition to alpha and electron particle radiation, the decay of ${ }^{238} \mathrm{U}$ can also result in $\mathrm{x}$-ray and gamma-ray emission, with a maximum listed energy of $110 \mathrm{keV}$. The probability that the decay of a ${ }^{238} \mathrm{U}$ nucleus would result in the emission of a $110-\mathrm{keV}$ gamma ray is approximately $0.02 \%$, which is small but still finite. Table 15-1 lists the half-value layers (the thickness of a given material that would result in the reduction of a stream of $110-\mathrm{keV}$ gamma rays by one-half) for a photon of this energy in several common materials. The values in this table were derived using data in Tables 5.1 and 5.4 of Reference 7.

Table 15-2 lists the radiotoxicity of several important radionuclides and Table 15-3 compares the electron emission energy associated with ${ }^{238} \mathrm{U}$ decay together with the maximum and average electron energies associated with electron emitters. ${ }^{238} \mathrm{U}$ is listed with other nuclides that have "High Toxicity" in Table 15-2.

a. Private communication between J. P. Adams (INEL) and D. F. Harmon (INEL), August 8, 1995. 
This designation is based on Table I in Reference 8. The basis is not given for listing this nuclide with the others in this classification, although the definition of toxicity is stated. It is assumed to be principally due to the emission of relatively high-energy alpha particles since neither the gamma rays nor electron emissions would be considered high energy. Another possible reason for this designation is the presence of one or more of the decay daughters. The most energetic (and most prevalent) alpha particle energy of $4.2 \mathrm{MeV}$ is less than the maximum alpha particle energies for the other nuclides in this classification (4.78 MeV for neptunium-237 [ [37 $\mathrm{Np}$ ]; $4.85 \mathrm{MeV}$ for ${ }^{241} \mathrm{Pu} ; 5.49 \mathrm{MeV}$ for ${ }^{241} \mathrm{Am}$; and $6.12 \mathrm{MeV}$ for ${ }^{242} \mathrm{Cm}$ ). The specific activity of ${ }^{238} \mathrm{U}$ is $3.39 \times 10^{-7} \mathrm{Ci} / \mathrm{g}^{5}$

Table 15-1. Half-value layers for the $110-\mathrm{keV}$ gamma ray emitted from the decay of a ${ }^{238} \mathrm{U}$ nucleus. ${ }^{\mathrm{a}}$

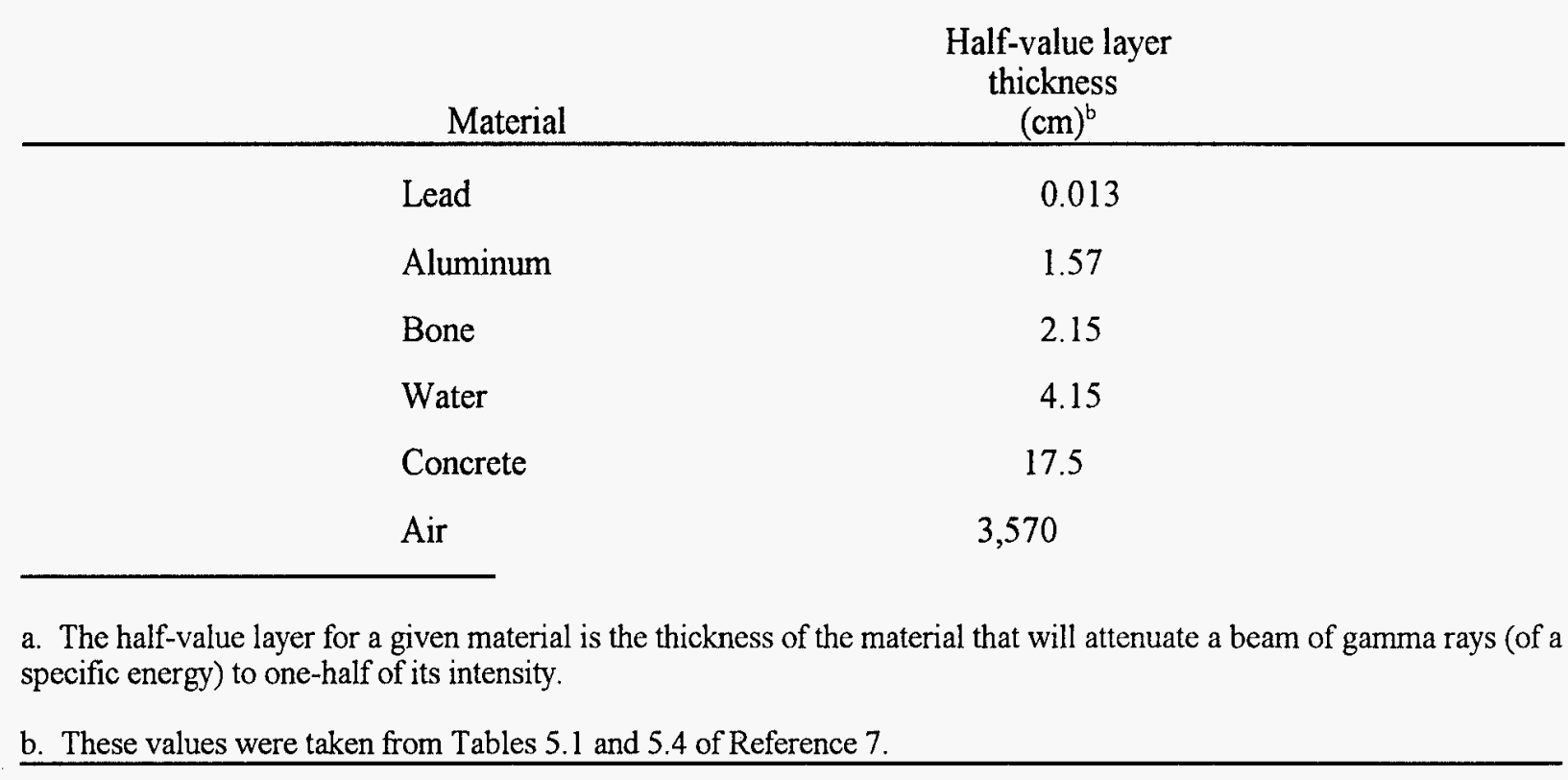

Table 15-2. Comparison of the radiotoxicity of several important radionuclides.

\begin{tabular}{lll}
\hline \multicolumn{1}{c}{ Radiotoxicity } & \multicolumn{1}{c}{ Group } & \multicolumn{1}{c}{ Nuclides } \\
\hline High toxicity & & ${ }^{237} \mathrm{~Np},{ }^{242} \mathrm{Cm},{ }^{241} \mathrm{Am},{ }^{238} \mathrm{U}$ \\
Medium toxicity & Upper subgroup A & ${ }^{129} \mathrm{I},{ }^{60} \mathrm{Co},{ }^{137} \mathrm{Cs}$ \\
Medium toxicity & Lower subgroup B & ${ }^{63} \mathrm{Ni},{ }^{99} \mathrm{Tc},{ }^{59} \mathrm{Ni},{ }^{14} \mathrm{C}$ \\
Low toxicity & & ${ }^{3} \mathrm{H},{ }^{99 \mathrm{~m}} \mathrm{Tc}$ \\
\hline
\end{tabular}

a. The definition of radiotoxicity, as stated in the reference, is "...the ability of the nuclide to produce injury, by virtue of its emitted radiations, when incorporated in a body." 
Table 15-3. Average and maximum kinetic energies of electrons released during decay of several important radionuclides. (Information compiled from data presented in References 6,9,9, 10, and 11.)

\begin{tabular}{lcc}
\hline & \multicolumn{2}{c}{ Released electron energy } \\
\cline { 2 - 3 } Radionuclide & $\begin{array}{r}\text { Average energy } \\
(\mathrm{keV})\end{array}$ & $\begin{array}{c}\text { Maximum energy } \\
(\mathrm{keV})\end{array}$ \\
\hline Nickel-59 $\left({ }^{59} \mathrm{Ni}\right)$ & $4.1^{\mathrm{b}}$ & $\sim 7.7$ \\
Tritium $\left({ }^{3} \mathrm{H}\right)$ & 5.7 & 19.0 \\
Nickel-63 $\left({ }^{63} \mathrm{Ni}\right)$ & 17.1 & 67.0 \\
Curium-242 $\left({ }^{242} \mathrm{Cm}\right)$ & $39^{\mathrm{c}}$ & - \\
Iodine-129 $\left({ }^{129} \mathrm{I}\right)$ & 40.0 & 150.0 \\
Uranium-238 $\left({ }^{238} \mathrm{U}\right)$ & $43^{\mathrm{c}}$ & - \\
Carbon-14 $\left({ }^{14} \mathrm{C}\right)$ & 49.0 & 156.0 \\
Technetium-99 $\left({ }^{99} \mathrm{Tc}\right)$ & 85.0 & 293.0 \\
Niobium-94 $\left({ }^{94} \mathrm{Nb}\right)$ & 156.0 & 500.0 \\
Cesium-137 $\left({ }^{137} \mathrm{Cs}\right)$ & 195.0 & $1,176.0$ \\
Cobalt-60 $\left({ }^{60} \mathrm{Co}\right)$ & 94.0 & $1,480.0$ \\
\hline & & \\
a. $1,000 \mathrm{keV}=1 \mathrm{MeV}$ & & \\
b. The data for ${ }^{59} \mathrm{Ni}$ represent Auger electrons and not electrons emitted from the nucleus. \\
c. The electron energies for ${ }^{242} \mathrm{Cm}$ and ${ }^{238} \mathrm{U}$ represent the highest energy major emission electron group and may not \\
represent either the average or maximum energy.
\end{tabular}

\section{Chemical and Physical Characteristics}

Uranium is a member of the actinide series of the periodic table, which includes actinium, thorium, protactinium, neptunium, plutonium, americium, curium, berkelium, californium, einsteinium, fermium, mendelevium, nobelium, and lawrencium. This series lies between radium and rutherfordium and is chemically similar to the lanthanide series, which is the group of elements between barium and hafnium. In both cases, the series consists of elements whose inner electron shell of 14 " $\mathrm{f}$ " electrons is being filled. In the case of the actinides, the $5 \mathrm{f}$ shell is being filled, and in the case of the lanthanides, the $4 \mathrm{f}$ shell is being filled. This results in two series, each of whose members are chemically similar to a member of the other series. For the case of uranium, it is chemically similar to neodymium. Although the members of the actinide and lanthanide series are chemically very similar, there are significant differences. One difference is that the members of the actinide series are much more prone to complex formation whereas most compounds formed with members of the lanthanide series are ionic in nature. ${ }^{12}$

Uranium has one of the highest densities of all metals and has three crystalline structures in the solid phase. It forms a wide range of intermetallic compounds (e.g., with manganese, nickel, and tin). It is chemically reactive and combines directly with most of the elements in the periodic table. In air, the surface is rapidly converted to a yellow and subsequently a black nonprotective film. Powdered uranium metal is frequently pyrophoric, that is, if it is finely divided (e.g., as a powder), it can be ignited and sustain combustion. 
The chemistry of uranium has been widely studied. In fact, it may be the best known of all metal chemistries. For example, metallic uranium reacts rapidly, and reversibly, with hydrogen isotopes to form a stable black powder, uranium hydride $\left(\mathrm{UH}_{3}\right)$. This reaction can be easily reversed simply by elevating the temperature of the powder. This characteristic has been extensively exploited in the nuclear industry by using uranium (principally depleted uranium) as a storage medium for hydrogen isotopes, such as tritium. Whenever the tritium needs to be available, the uranium bed is heated up and the tritium evolves. These beds can be cycled multiple times, making uranium an ideal storage medium.

The uranium-oxygen system is one of the most complex oxide systems known. This is because uranium can exist in many oxidation states. One of the most common oxides is $\mathrm{UO}_{2}$, which is used extensively in nuclear fuel. Another common oxide is $\mathrm{U}_{3} \mathrm{O}_{8}$. In all, there are six stoichiometric oxides of uranium, $\mathrm{UO}_{2}, \mathrm{U}_{4} \mathrm{O}_{9}, \mathrm{U}_{3} \mathrm{O}_{7}, \mathrm{U}_{2} \mathrm{O}_{5}, \mathrm{U}_{3} \mathrm{O}_{8}$, and $\mathrm{UO}_{3}{ }^{13}$ In addition, the uranium oxide can deviate from stoichiometry (for example, additional oxygen atoms can be added to $\mathrm{UO}_{2}$ without affecting notable structural changes in the oxide-extending the phase from $\mathrm{UO}_{2}$ to $\mathrm{UO}_{2.25}$ ).

Uranium also chemically reacts with several of the halides to form compounds. Oxidation states vary from +3 (e.g., $\mathrm{UF}_{3}, \mathrm{UCl}_{3}, \mathrm{UBr}_{3}$, and $\mathrm{UI}_{3}$ ) to +6 (e.g., $\mathrm{UF}_{6}$ and $\mathrm{UCl}_{6}$ ). $\mathrm{UF}_{6}$ is a readily accessible volatile uranium compound and is used extensively in the uranium enrichment process, wherein ${ }^{235} \mathrm{U}$ is separated from ${ }^{238} \mathrm{U}$ by a series of membrane filter units.

Uranium also forms oxyhalides and many other binary compounds. For example, uranium forms stable compounds with boron, carbon, silicon, nitrogen, phosphorus, tin, selenium, and sulfur. It also can form uranyl salts.

Uranium metal can be melted by any of several different techniques. However, because uranium is very reactive when heated in air, melting must be done either under a protective inert atmosphere or in a vacuum. ${ }^{14}$ Uranium and its alloys are considered difficult to machine and almost all machining of uranium results in some sparking or burning because of its pyrophoricity. Problems associated with machining are due to a combination of characteristics, including toughness, stringiness, abrasiveness, galling, and work hardening.

Health and safety considerations must be carefully considered when using uranium because of its high toxicity and pyrophoricity. The main hazard to health occurs where finely divided particles can become airborne and inhaled. For this reason, vents and fume hoods should be used, or the workers should use respirator equipment to avoid inhalation. Additionally, special clothing and footwear should be used to minimize spread of contamination.

Uranium is the heaviest naturally occurring element that exists in recoverable amounts, averaging about 4 ppm in the earth's crust. ${ }^{11}$ The majority of leaching processes for processing of uranium ore involves leaching the crushed and ground ore with sulfuric acid. This means that uranium tailings are often acidic.

There are several types of uranium ore. These are named after some distinguishing feature, such as the host rock, mineralizing process, or structural and stratigraphic setting. They include quartz-pebble conglomerate, unconformity-related vein, disseminated, contact, classical vein, sandstone, volcanogenic, and surface deposits. They are widely distributed through the earth's crust, and economical mining of uranium has taken place in Australia, North America, South America, Asia, Europe, and Africa.

Table 15-4 summarizes some of the important chemical and physical characteristics of this element. 
Table 15-4. Chemical and physical characteristics of uranium (from References 12,15 , and 16).

Physical property (units)

Uranium data

\begin{tabular}{ll} 
Melting point $(\mathrm{K})^{\mathrm{a}}$ & 2,123 \\
Boiling point $(\mathrm{K})$ & 4,091 \\
Heat of fusion $(\mathrm{kJ} / \mathrm{mole})$ & 19.7 \\
Heat of vaporization $(\mathrm{kJ} / \mathrm{mole})$ & 446.4 \\
Heat of sublimation @ $0 \mathrm{~K}(\mathrm{~kJ} / \mathrm{mole})$ & 487.9 \\
Heat capacity @ $298 \mathrm{~K}(\mathrm{~kJ} / \mathrm{mole})$ & 27.7 \\
Thermal conductivity @ $343 \mathrm{~K}(\mathrm{~J} / \mathrm{cm} \bullet \mathrm{s})$ & 0.29 \\
Electrical conductivity $(\Omega \cdot \mathrm{cm})^{-4}$ & $2-4 \times 10^{4}$ \\
Density ( $\left.\mathrm{g} / \mathrm{cm}^{3}\right)$ & 19 \\
Crystal form & Alpha-orthorhombic \\
& Beta-complex tetragonal \\
\hline a. Zero Kelvin equals $-273.15^{\circ} \mathrm{C},-459.67^{\circ} \mathrm{F}$. & \\
b. The transition temperatures between crystalline phases are $941 \mathrm{~K}$ for alpha to beta and 1,048 K for beta to gamma.
\end{tabular}

\section{Uranium-238 Production}

${ }^{238} \mathrm{U}$ is not only produced by humans; it exists as a naturally-occurring nuclide. This nuclide comprises more than $99 \%$ of all existing natural uranium and makes up approximately $4 \mathrm{ppm}$ of the earth's crust. For use in nuclear reactors, uranium (enriched to a higher concentration of ${ }^{235} \mathrm{U}$ ) is typically formed into $\mathrm{UO}_{2}$ pellets, though in some reactors metallic uranium is used (often alloyed with another metal such as aluminum).

Economically minable ores (defined as containing at least $500 \mathrm{ppm}$ uranium) are available, though not abundant. " Deposits occur in nearly every major rock type. The majority of uranium ore processing techniques involve leaching with sulfuric acid. This means that uranium tailings typically are acidic in $\mathrm{pH}$, which affects the solubility of uranium in groundwater and soil.

Between the years of 1948 and 1982, the production of uranium in the free world totaled about 828,000 tons of $\mathrm{U}_{3} \mathrm{O}_{8}$. Of this, $42 \%$ was mined in the United States, $22 \%$ in Canada, and $15 \%$ in South Africa. The total known resources in the free world (defined as reasonably assured resources available using economic mining techniques) total 1.68 million tons of $\mathrm{U}_{3} \mathrm{O}_{8}$ in $1983 .{ }^{11}$ Estimates for the total uranium content of the earth's crust, to a depth of $25 \mathrm{~km}$ is calculated to be $4.5 \times 10^{17} \mathrm{~kg}\left(5.0 \times 10^{14}\right.$ tons $)$ and in the oceans, $4.5 \times 10^{13} \mathrm{~kg}\left(5.0 \times 10^{10}\right.$ tons $){ }^{1}$ 


\section{Waste and Disposal Data on Uranium-238}

This section discusses the types of activities that generate ${ }^{238} \mathrm{U} L L W$, waste types and forms that contain ${ }^{238} \mathrm{U}$, and disposal data on ${ }^{238} \mathrm{U}$.

\section{Nuclear Reactors}

Much of the uranium that is used in commercial applications is used to produce nuclear fuel. A typical ${ }^{235} \mathrm{U}$ enrichment for commercial reactors is approximately $3 \%$ (i.e., $3 \%$ of the uranium in a nuclear fuel rod is ${ }^{235} \mathrm{U}$, the rest being ${ }^{238} \mathrm{U}$ ). Since it is the "fissile" ${ }^{235} \mathrm{U}$ that is "burned" up in the fission reaction, most of the ${ }^{238} \mathrm{U}$ remains when the fuel rods are taken out of the reactor and sent to storage. This ${ }^{238} \mathrm{U}$ is mixed with highly radioactive fission products and activation products that result from the fissioning process. The presence of these other species means that this ${ }^{238} \mathrm{U}$ cannot be disposed of as LLW without extensively reprocessing the fuel to remove the fission and activation products. As a consequence, this source of ${ }^{238} \mathrm{U}$ does not end up in LLW streams. However, the manufacture of these enriched fuel elements results in the production of depleted uranium (uranium with less than the usual mass of ${ }^{235} \mathrm{U}$ ). For each kilogram of uranium enriched to $3 \%{ }^{235} \mathrm{U}, 5-6 \mathrm{~kg}$ of depleted uranium are produced, which contain between 0.2 and $0.3 \%$ ${ }^{235} \mathrm{U}$. This is a major source of ${ }^{238} \mathrm{U}$ for nonnuclear applications, discussed below.

\section{Medical, Academic Institutions, and Commercial Uranium-238 Waste}

There are no known medical uses for ${ }^{238} \mathrm{U}$, either for diagnosis or treatment of diseases (this was confirmed by a communication with personnel at the American College of Radiologists). ${ }^{b}$

There are, however, several commercial and military uses for this nuclide. These arise due to its high density, abundance, relatively low cost, and pyrophoricity. There are four principal nonnuclear uses of depleted uranium: radiation shielding; counterweights in airplanes, helicopters, and missiles; armor (for example, on tanks); and armor-piercing projectiles for military ordinance. ${ }^{12}$

Shipping containers made of depleted uranium are used as spent fuel casks for transporting highly radioactive spent fuel elements from commercial reactors to disposal sites. These casks are heavy (up to several metric tons) and have to withstand and dissipate the heat generated by the decaying fission products. These casks are usually clad with stainless steel to minimize corrosion and contamination. Other containers are used to ship radioactive isotopes for medical and industrial applications. These are much smaller and lighter. In these applications, uranium can be used as shielding instead of lead (which is much more bulky due to its smaller density) or tungsten (which is harder and more expensive to fabricate). In fact, uranium can be used as both the shielding and structural material, greatly reducing the size and improving the mobility of these containers. Additionally, depleted uranium is extensively used to house and shield industrial radioactive sources such as iridium-192, cobalt-60, and cesium-137. In these applications, the shielding can either contain an aperture to collimate a beam of gamma rays or be used as a container out of which the source is removed for irradiation purposes.

Depleted uranium is used as counterweights in airplanes, missiles, and helicopters to maintain the center of gravity when these devices are moved. These counterweights need to be small and shaped to fit in spaces where they will not be in the way of the normal payload. Depleted uranium is ideal because it is dense

b. Private communication between C. Sperry, American College of Radiologists, and J. P. Adams Idaho National Engineering Laboratory, May 15, 1995. 
is dense (minimizing the size) and can be machined into various shapes to fit in unusual spaces. As an example, counterweights of $1,500 \mathrm{~kg}$ depleted uranium are used in all Boeing 747 airplanes.

The largest single use of depleted uranium is kinetic-energy projectiles for the military. Again, the high density of this element provides excellent penetrability, and this, with its pyrophoricity, ease of fabrication, abundant availability, and low cost, make this material ideal for this application. Each of the three military services (Army, Air Force, and Navy) has at least one specific weapons platform that uses a depleted uranium projectile.

Other uses for deleted uranium include sinker bars for inserting instruments into oil wells, special high-performance gyroscope rotors, flywheels for large inertial energy-storage devices, vibration damping bars, and tritium storage beds.

Calibrated sealed sources of ${ }^{238} \mathrm{U}$ are available in a variety of strengths. Reference 17 lists several, primarily European, suppliers of radioactive sources including Czechoslovakian and English sources of ${ }^{238} \mathrm{U}$. The Czechoslovakian sources range from $8.3 \times 10^{-5}$ to $3.3 \times 10^{-3} \mu \mathrm{Ci}$ sources with aluminum backing. The English sources range from $10^{-3}$ to $10^{5} \mu \mathrm{Ci}$ with either thin foil or copper backing. Both of these suppliers indicate the use of these sources for alpha particles. The U.S. Department of Energy (DOE) is also a supplier of calibrated ${ }^{238} \mathrm{U}$ sources, with isotopic enrichment $>99.9 \%$ and ${ }^{235} \mathrm{U}$ content less than $500 \mathrm{ppm} .{ }^{18}$ The source strength varies according to order and the price depends on the ${ }^{235} \mathrm{U}$ contamination level.

\section{Disposal Data on Uranium-238}

${ }^{238} \mathrm{U}$ has been deposited in the three LLW sites in Richland, Washington; Barnwell, South Carolina; and Beatty, Nevada over a period of several years. The Manifest Information Management System Database ${ }^{c}$ provided information concerning this nuclide's activity, sources, and waste types deposited at these sites. Figure 15-1 shows the total annual ${ }^{238} \mathrm{U}$ activity deposited in the three sites for each year between 1986 and 1995 . Over $65 \%$ of the total activity for this nuclide was deposited during four years, 1986-1989.

Figure 15-2 shows the activity of ${ }^{238} \mathrm{U}$ deposited in these three sites as a function of waste source. Industrial sources account for nearly $96 \%$ of the total deposited in these three sites. An additional $4 \%$ came from utilities and government sources and the rest from the other sources. The definition of disposal categories given in Figure 15-2 is as follows: academic - sources associated with university laboratories; government - sources associated with the government, such as military hospitals; industry sources associated with manufacturing, other than utilities; medical - sources associated with hospitals and medical laboratories, excluding pharmaceutical manufacturing; utility - sources generated by nuclear utilities and stored onsite or sent to one of the three disposal sites. Waste treatment facilities are included in the utility category.

Figure 15-3 shows the activity of ${ }^{238} \mathrm{U}$ deposited in the Richland and Beatty sites as a function of waste type. The waste disposal manifests for the Barnwell site did not break down the waste by type, which is unfortunate since more than $90 \%$ of this nuclide has been stored at this site. As shown in this figure, more than $94 \%$ of this nuclide was in the form of dry solids. The waste types illustrated in Figure 15-3 are from nuclear reactors, academic institutions, and medical facilities.

c. Information provided through the DOE waste management system maintained by the National Low-Level Waste Management Program, Idaho National Engineering Laboratory (INEL). 


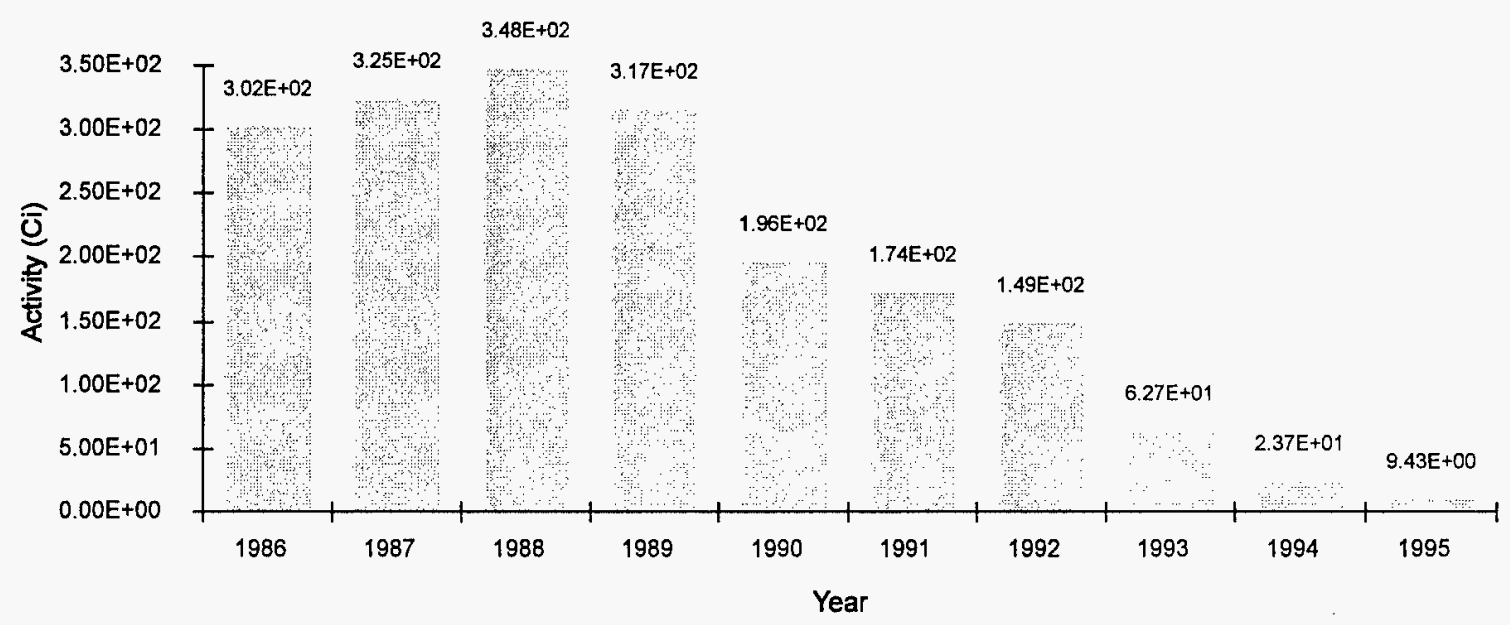

Figure 15-1. ${ }^{238} \mathrm{U}$ activity deposited at the Richland, Beatty, and Barnwell sites by year (log scale).

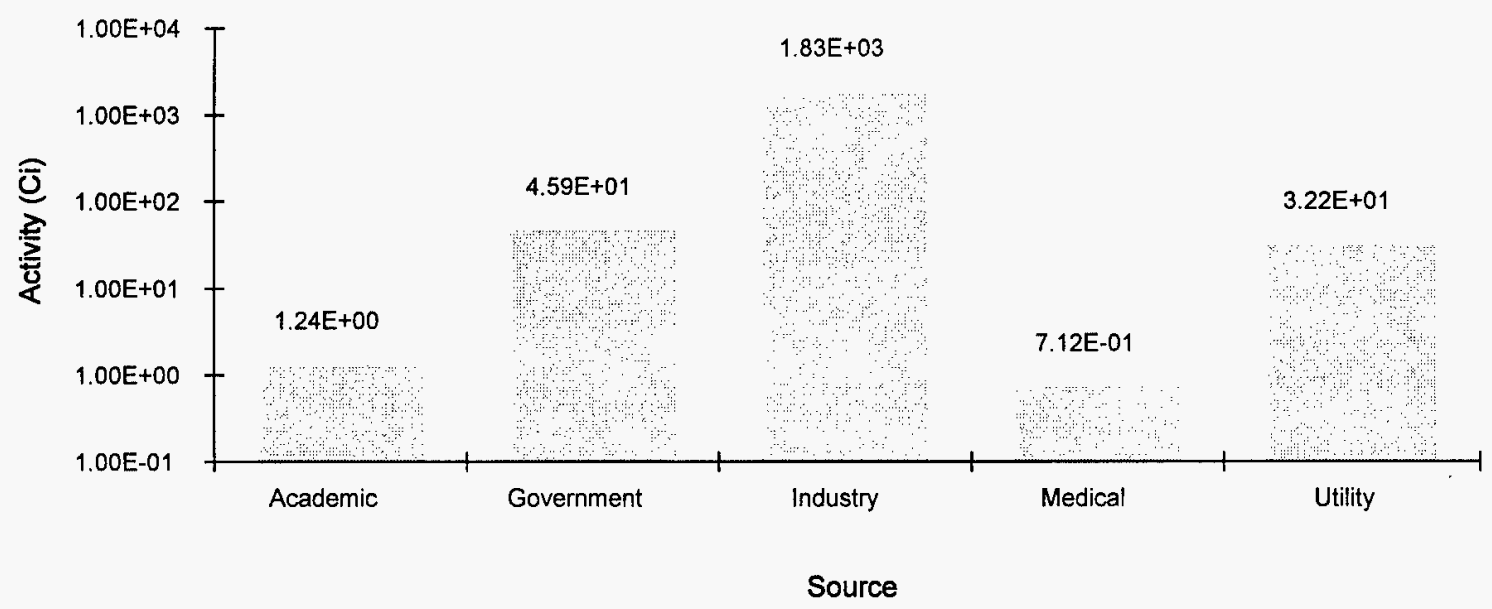

Figure 15-2. ${ }^{238} \mathrm{U}$ activity deposited at the Richland, Beatty, and Barnwell sites by source (log scale). 


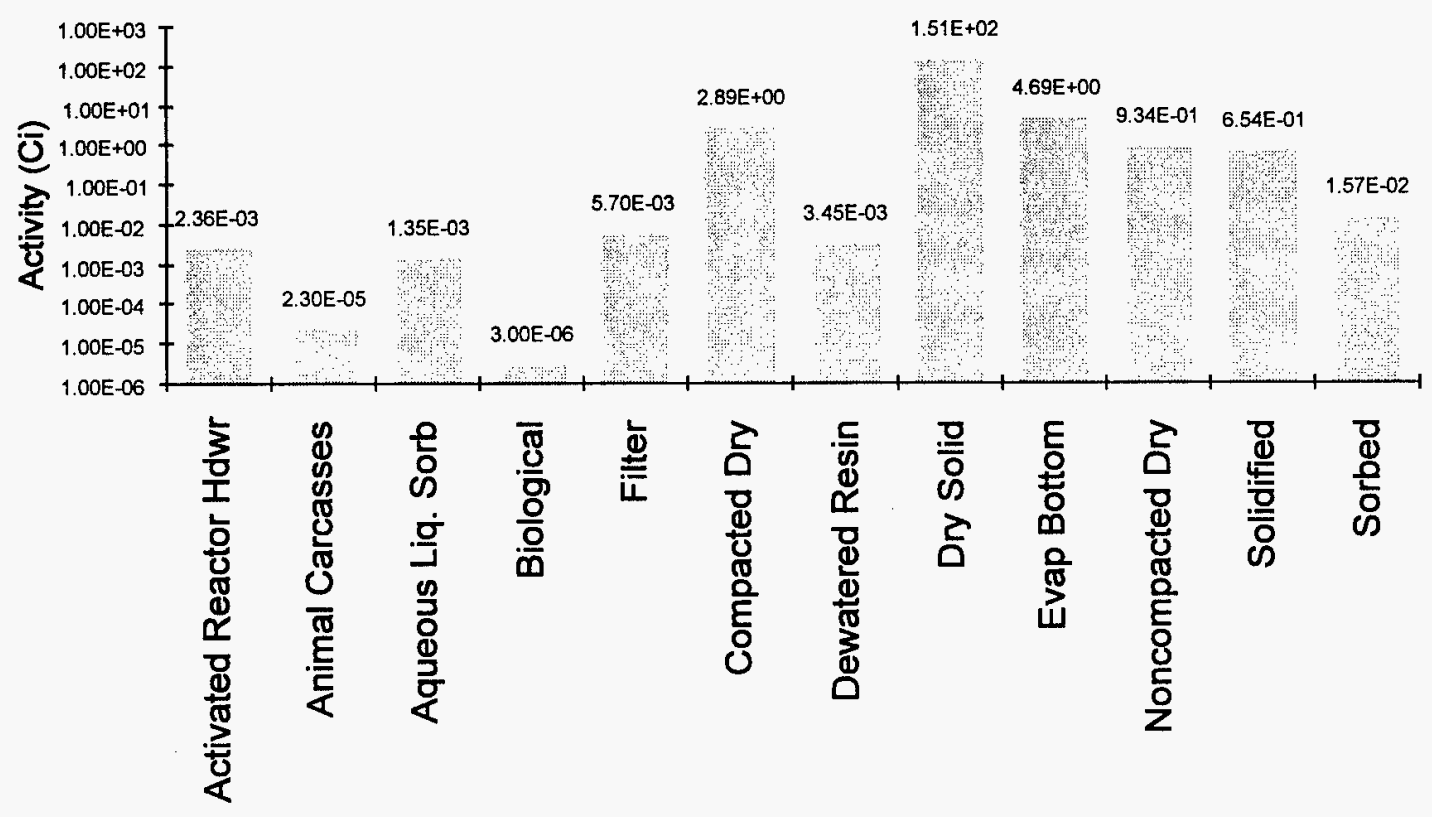

Waste Type

Figure 15-3. ${ }^{238} \mathrm{U}$ activity deposited at the Richland and Beatty sites by waste type (log scale).

\section{Behavior of Uranium-238 in the Environment}

\section{Uranium-238 in Soils}

Understanding the behavior of radioactive materials, such as ${ }^{238} \mathrm{U}$, in the soil is important in assessing the possibility of transport of these radionuclides through the biosphere. It is important to understand the interactions between radionuclides and various media along the path to the biosphere, whether disposal is in deep or shallow rock caverns or in shallow overburden facilities.

Four parameters were reported to be essential in accurately predicting soil concentrations from either contaminated groundwater or irrigation water. ${ }^{19}$ The four parameters, in order of decreasing importance, are (a) soil retention, (b) annual precipitation, (c) soil texture, and (d) depth to the water table. The soil retention parameter represents the solid/liquid partition coefficient and is denoted by the symbol $\mathrm{K}_{d}$. $\mathrm{K}_{\mathrm{d}}$ is defined by $\mathrm{K}_{\mathrm{d}}=\mathrm{C}_{\mathrm{s}} / \mathrm{C}_{\mathrm{l}}$, where $\mathrm{C}_{\mathrm{s}}$ is the uranium concentration in the soil ( $\mu \mathrm{g}[\mathrm{U}] / \mathrm{gram}$ of soil) and $\mathrm{C}_{1}$ is the uranium concentration in the groundwater $\left(\mu \mathrm{g}[\mathrm{U}] / \mathrm{mL}\right.$ of liquid). Therefore, the units of $\mathrm{K}_{\mathrm{d}}$ are $\mathrm{mL} / \mathrm{g}$ (i.e., $\mathrm{mL}$ of water per gram of soil). This empirical model combines all soil retention mechanisms into a simple linear partition relation between the soil and surrounding groundwater. This model assumes that the uranium concentrations in groundwater and soil are in equilibrium with each other. Using this definition for $\mathrm{K}_{\mathrm{d}}$, it follows that the larger the value (i.e., the higher the radionuclide concentration in the soil relative to that in the groundwater) the slower the migration of the radionuclide relative to groundwater flow. Therefore, $K_{d}$ can be thought of as a measure of the amount of "fixing" or holdup in the soil.

Typically, $K_{d}$ is measured under laboratory conditions, using samples that are relatively homogenous, and where it can be ensured that equilibrium conditions are met. Applying these values to specific soils in the field can be difficult because actual soils are generally inhomogeneous and there are uncertainties as to how long it takes for the uranium concentrations in the soil and groundwater $\left(\mathrm{C}_{\mathrm{s}}\right.$ and $\left.\mathrm{C}_{1}\right)$ to reach equilibrium with each other. Therefore, one must be careful to ensure that soil samples used in laboratory studies are as 
closely representative of the field as possible. Even though the soil samples do not precisely match conditions in the field, $\mathrm{K}_{\mathrm{d}}$ values from laboratory studies can be used in computer models that extrapolate data from laboratory experiments and field studies. In addition, some experiments are conducted using intact field samples to validate the laboratory $\mathrm{K}_{d}$ values and to study the effects associated with soil inhomogeneity.

Reference 20 lists ranges of $K_{d}$ values for various elements in soils and clays. For uranium, this range is from 11 to $4,400 \mathrm{~mL} / \mathrm{g}$, which is a large range. Although no explanation is given for this large range, one possibility is the range of soil $\mathrm{pH}$ since it is known that the solubility of uranium is strongly dependent on this parameter. This reference also lists native soil concentration ranges for several elements. The typical concentration range for uranium is 0.9 to $9.0 \mathrm{ppm}$ and the extreme range is up to $250 \mathrm{ppm}$.

A study was made of the ${ }^{238} U$ content in soils in Venezuela and adjacent islands by scientists of the Instituto Venezolano de Investigaciones Cientificas. ${ }^{21}$ This study was conducted to determine the cumulative fallout from nuclear weapons tests and nuclear accidents as well as the natural radioactivity from primordial radionuclides. For the case of ${ }^{238} \mathrm{U}$, the manmade and primordial sources could not be differentiated. Samples were taken from a large number of different locations and at several depths in order to obtain the best information on the distribution of these nuclides. The ${ }^{238} \mathrm{U}$ concentrations ranged from less than 1 to $64 \mathrm{~Bq} / \mathrm{kg}(1.7 \mathrm{nCi} / \mathrm{kg})$ of soil with a mean concentration of $27 \pm 16 \mathrm{~Bq} / \mathrm{kg}(0.73 \pm 0.43 \mathrm{nCi} / \mathrm{kg})$. This mean translated to $2 \mathrm{ppm}$ of uranium. Concentrations showed a strong dependence on altitude and proximity to the sea. Values for high altitudes and large $(<1 \mathrm{~km})$ distances from the sea were about one-quarter of those for low altitudes and closer distances from the sea, probably due to different ratios of sand and clay minerals in the soils. In general, the external gamma ray dose due to these nuclides (excepting ${ }^{137} \mathrm{Cs}$ ) was comparable to that due to cosmic radiation.

A similar study was performed by scientists of the Okayama Prefectural Institute for Environmental Science and Public Health in Japan. ${ }^{22}$ Samples representing four weathering conditions were taken in the vicinity of Kamisaibara village near Okayama, Japan. Samples were taken of river bed soil, paddy field soil, field soil, and uncropped soil. The mean activity concentration of ${ }^{238} \mathrm{U}$ ranged from 0.028 to $0.041 \mathrm{~Bq} / \mathrm{g}$ $(0.76$ to $1.1 \mathrm{pCi} / \mathrm{g})$. The concentrations in river bed soil and field soil were similar, approximately $0.028 \mathrm{~Bq} / \mathrm{g}(0.76 \mathrm{pCi} / \mathrm{g})$ but the concentrations in paddy field soil and in uncropped soil were significantly higher, approximately $0.04 \mathrm{~Bq} / \mathrm{g}(1.1 \mathrm{pCi} / \mathrm{g})$. Although a type of phosphatic manure (containing high concentrations of uranium) is used as fertilizer, it is unclear how this affected the soil concentrations.

Phosphate ores contain concentrations of uranium that are significantly higher than average soil concentrations. Since phosphate slag is sometimes used as road bed material, scientists from the University of Idaho decided to measure uranium concentrations on and near some of these roads. ${ }^{23}$ Soil samples were taken at three depths (up to $15 \mathrm{~cm}$ ) and five distances from the roadbeds (up to $12 \mathrm{~m}$ ) at 12 different locations and the distribution was mapped. Surface samples averaged from 3.5 to $9 \mathrm{ppm}$, depending on distance from the road (higher concentrations were from samples taken near the road and lower concentrations, from samples taken further away). There was little difference between $0-10 \mathrm{~cm}$ depth and 10-15 depth samples, with concentrations ranging from 3.6 to $6.8 \mathrm{ppm}$, depending on the distance from the road.

Scientists from the Institute of Hygiene and Public Health, Bucharest, Romania, measured the concentrations of uranium in soil samples from areas close to and far from high natural uranium concentrations. ${ }^{24}$ The measured average concentrations of uranium were $386 \mathrm{ppm}$ and $62 \mathrm{ppm}$ for the close and far away locations, respectively. This study was conducted to determine the uptake into the food chain and, ultimately, into the human population. 
Members of the Radiology and Radiation Biology Department at Colorado State University measured uranium concentrations in soil samples and sediment from a tailings pond near a uranium mine and mill as part of a study of the uptake into the food chain. ${ }^{25}$ The uranium mine and mill operation that was studied is located in the southeastern plains of Wyoming at an elevation of $2,200 \mathrm{~m}$. This is a semiarid environment with about $25 \mathrm{~cm}$ annual precipitation that is dominated by grasses, forbs, and sagebrush. The uranium ore is approximately $100 \mathrm{~m}$ below the surface and mining operations have been conducted since 1969 . Soil concentrations of ${ }^{238} \mathrm{U}$ in samples taken several meters downwind from the tailings ranged from 200 to $363 \mathrm{mBq} / \mathrm{g}$ ( 5.4 to $9.8 \mathrm{nCi} / \mathrm{g})$. The sediment had a mean uranium concentration of $0.4 \mathrm{~Bq} / \mathrm{g}(11 \mathrm{pCi} / \mathrm{g})$ and a $\mathrm{K}_{\mathrm{d}}$ of $1.0(\mathrm{~Bq} / \mathrm{g}) /(\mathrm{Bq} / \mathrm{mL})$. The relatively low value for $\mathrm{K}_{\mathrm{d}}$ is believed to be a function of the high water solubility of the uranium compound (probably a sulfate due to the acid leaching process). The $\mathrm{pH}$ values ranged from 2 to 5 , indicating the presence of residual sulfuric acid from the leaching process.

In summary, ${ }^{238} \mathrm{U}$, as the overwhelming isotope of uranium, is naturally present in soils with concentrations in the few parts per million range. In addition, this nuclide can be present due to human activities. In the presence of acidic soil conditions (for example, in uranium tailings), uranium is very soluble in water and is not readily adsorbed in the soil.

\section{Uranium-238 in Water}

The natural concentration of uranium in groundwater is listed in Reference 10,18 , along with natural concentrations of several other elements and compounds. The natural concentration of uranium ranges from 0.1 to 40 parts per billion (ppb).

The migration of ${ }^{238} \mathrm{U}$ in the groundwater of sandstone aquifers was studied by scientists in Germany. ${ }^{26}$ Based on their study, the retardation factor (defined in the reference) was measured to be $8.6 \times 10^{6}$ and the removal rate was measured to be $1.3 \times 10^{-3} \mathrm{yr}^{-1}$ for a Triassic sandstone aquifer in the German Democratic Republic.

The concentration of ${ }^{238} \mathrm{U}$ in the water and suspended sediments of the Miami River (near the Mound Laboratory in Ohio) were measured in a study conducted by scientists of the Argonne National Laboratory. ${ }^{27}$ The average concentration of ${ }^{238} \mathrm{U}$ in the river water was $0.59 \mathrm{pCi} / \mathrm{L}$, which is approximately six times the average concentration of this nuclide in Lake Michigan. The distribution coefficient of this nuclide between the suspended solids and the surrounding water was 1,800 .

A study was made of the activity of certain actinides and beta emitters in the process water used in the Loviisa VVER-440-design nuclear power plant in Finland. ${ }^{28}$ The process waters and the ion-exchange resins used for purification of the process waters were sampled and analyzed for ${ }^{238} \mathrm{U}$ concentration. The coolant and ion-exchange resin samples from the primary circuit represent the normal operation state and a fuel leakage situation. ${ }^{238} \mathrm{U}$ was found in several of the anion and cation exchange resins, both from the column and in the waste tanks. This nuclide was also found in primary coolant samples, both in plants with and without known fuel failures. The concentrations of this nuclide in ion-exchange resin samples were all $<8 \mathrm{kBq} / \mathrm{m}^{3}\left(<0.22 \mu \mathrm{Ci} / \mathrm{m}^{3}\right)$. Though this nuclide was measured in coolant samples, the concentrations were small, resulting in large statistical uncertainties.

An environmental study was made of the radionuclides in the effluent from the Argonne National Laboratory (ANL) that was discharged into streams in the vicinity. ${ }^{29}$ The concentration of ${ }^{238} \mathrm{U}$ in the Sawmill Creek ranged from 0.5 to $2.0 \mu \mathrm{Ci} / \mathrm{mL}$, with an average concentration of $1.1 \mu \mathrm{Ci} / \mathrm{mL}$. The concentration of ${ }^{238} \mathrm{U}$ in the Des Plaines River ranged from 0.5 to $2.0 \mu \mathrm{Ci} / \mathrm{mL}$, with an average concentration of $1.3 \mu \mathrm{Ci} / \mathrm{mL}$. The concentrations of this nuclide in domestic wells at the ANL were also measured and ranged from 0.05 to $0.14 \times 10^{-9} \mu \mathrm{Ci} / \mathrm{mL}$. This study contains a great deal of additional information on this 
nuclide plus many other nuclides included in the ANL measurement plan. Based on the measured activities of ${ }^{238} \mathrm{U}$, as well as the activities of numerous other radioactive nuclides at the ANL, it was determined that the maximum dose to any member of the public did not exceed $0.1 \mathrm{mrem} / \mathrm{yr}$, or $0.02 \%$ of the $500 \mathrm{mrem} / \mathrm{yr}$ standard.

The effects of an uranium mining facility on the concentration of uranium in the aquatic food chain were studied by scientists of the Jozef Stefan Institute of the E. Kardelj University in Yugoslavia ${ }^{30}$ In this study, surface waters, river and stream sediments, and biological samples were taken from several sampling points in the vicinity of the uranium mine at Zirovski and the Nuclear Power Plant at Krsko, both in Slovenia. The concentrations of ${ }^{238} \mathrm{U}$ ranged from 0.11 to $12.5 \mathrm{mg} / \mathrm{m}^{3}$ and in the corresponding sediment, from 2.04 to $9.83 \mathrm{mg} / \mathrm{kg}$. Accumulation factors ranged from 540 to 30,000 for the same set of samples.

Reference 22 also included measurements of the concentrations of uranium in groundwaters near and far from locations of high uranium concentrations. The average uranium concentrations were 166 and $6.7 \mu \mathrm{g} / \mathrm{L}$ for the near and far away locations, respectively.

The water concentrations used in the Reference 23 study were measured to be $0.5 \mathrm{~Bq} / \mathrm{mL}(0.1 \mathrm{pCi} / \mathrm{mL})$. As stated earlier, this resulted in a partitioning between soil and water with a $\mathrm{K}_{\mathrm{d}}=1.0$.

A researcher at the Pacific Northwest National Laboratory conducted a study into the waterborne release of uranium during the enrichment process at the Oak Ridge (Tennessee), Paducah (Kentucky), and Portsmouth (Ohio) facilities. ${ }^{31}$ The reported water releases ranged from $12-26 \mathrm{GBq}(0.32-0.70 \mathrm{Ci})$ from Oak Ridge, $1.5-25 \mathrm{GBq}(0.041-0.68 \mathrm{Ci})$ from Paducah, and 11-29 GBq (-.30-0.78 Ci) for Portsmouth The time frame for these releases was from 1982 to 1986 .

Researchers at the DOE Environmental Measurements Laboratory conducted a study into the daily intake of various radioactive nuclides (including ${ }^{238} \mathrm{U}$ ) in New York. ${ }^{32}$ The reason for this study was that, although it was recognized that uptake of naturally occurring radionuclides represents a major source of radiation exposure to humans, fundamental information was lacking concerning the chronic intake of these radionuclides by humans. Therefore, this study included measurements of the concentration of ${ }^{238} \mathrm{U}$ in city tap water. Typical concentrations ranged from $0.67-1.1 \mathrm{mBq} / \mathrm{L}(18-30 \mathrm{fCi} / \mathrm{L})$.

In summary, uranium is naturally present in groundwater with concentrations in the parts per billion range. Concentrations may be much larger near uranium processing facilities, such as mines and fuel reprocessing plants. Concentrations near such facilities can be in the microcurie per millimeter range.

\section{Uranium-238 in Plants}

Scientists at the Oak Ridge National Laboratory measured the accumulation of various actinides, including ${ }^{238} \mathrm{U}$, by plants in a contaminated fresh-water pond. ${ }^{33}$ This particular pond, Pond 3513 , was used for receiving LLW for a period of 30 years, ending in $1976 .{ }^{238} \mathrm{U}$ was measured in grass that grew on the shore of the pond. It was determined that of the four elements studied (with multiple radioactive isotopes for some of the elements), uranium resulted in the highest relative uptake.

Reference 22 included measurements of the concentration of uranium in vegetation growing in locations both near to and far from areas of high uranium backgrounds. The vegetation used in this study was referred to as "fodder vegetation," presumedly plants used to feed livestock, and the samples were first turned into ash prior to measuring the uranium content. The average concentrations of uranium were 78 and $9 \mathrm{ppm}$ for the plant material for samples taken near to and far away from the areas of high uranium background, respectively. 
Reference 23 concluded their study with measurements of the plant uptake from contaminated soils. The vegetation collected and measured in this study were mixed grasses, mixed forbs, and big sagebrush. The uranium concentrations ranged from $5.6-407 \mathrm{mBq} / \mathrm{g}(0.15-11 \mathrm{pCi} / \mathrm{g})$, depending on location. This compared to a value of $4.4 \mathrm{mBq} / \mathrm{g}(0.12 \mathrm{pCi} / \mathrm{g})$ for a background sample. The concentration ratio (ratio of vegetation concentration to soil concentration of uranium) ranged from 0.04 to 0.8 , with no apparent correlation between soil concentration and concentration ratio.

Scientists from the Pacific Northwest Laboratory conducted a survey of vegetation along the stretch of the Columbia River near the DOE's Hanford Site. ${ }^{34}$ The shoreline vegetation at this location consists of a narrow zone of broad-leafed deciduous trees (e.g., the mulberry, which provides food for mule deer as well as other mammals) and shrubs (e.g., willows) intermingled with perennial grasses (e.g., reed canary grass, which provides food for wild Canada geese) and forbs. These plants, which provide indirect food for humans via wild animals, remain green despite the dry, desert-like environment in the summer because of their access to the river. This analysis did not result in unusually high levels of ${ }^{238} \mathrm{U}$. The highest concentrations of uranium in vegetation were found in onions, and even there, there were no significant differences in concentrations between those onions located near the Hanford Site and those harvested upstream of the site. Measured concentrations were of the order of picocuries per gram dry weight.

Researchers at the Environmental Measurements Laboratory of the DOE conducted a study into the daily intake of various radioactive nuclides (including ${ }^{238} \mathrm{U}$ ) in New York. ${ }^{32}$ Therefore, in addition to water concentrations, this study also included measurements of the amount of ${ }^{238} \mathrm{U}$ ingested by a typical New Yorker in various food products. The amounts of ${ }^{238} \mathrm{U}$ ranged from $9 \mathrm{mBq} / \mathrm{yr}(0.2 \mathrm{pCi} / \mathrm{yr})$ for rice to $1,935 \mathrm{mBq} / \mathrm{yr}(52 \mathrm{pCi} / \mathrm{yr})$ for shellfish.

In summary, uranium is taken up into plants relatively easily. Typical uranium concentrations in plants are in the picocurie per gram range. Concentration ratios, the ratio of uranium concentration in a plant to the concentration in the surrounding soil, are generally less than 1.0.

\section{Uranium-238 in Air}

From a biological hazard standpoint, one of the most important pathways for actinides to contaminate humans is inhalation. For this reason, it is important to understand how uranium can become suspended in air where it can be inhaled. Reference 23 included a study of the possibility that radioactive dust particles could be abraded from road surfaces (constructed using phosphate slag, which contains relatively high concentrations of uranium) and become suspended in air as aerosols. To do this, aerosols were collected at several sites by pumping air through filters and differentiating between aerosol sizes. Based on the belief that the critical aerosol size for retention in the lungs was 0.01 to $5.0 \mu \mathrm{m}$, this was the aerosol size the authors concentrated on in their study. They determined that the concentration of ${ }^{238} U$ in aerosols of this size was less than $0.03 \mu \mathrm{g} / \mathrm{m}^{3}$ of air. The authors concluded that this was not sufficient to cause serious concern about the use of phosphate slag in road construction.

Researchers at the Pacific Northwest Laboratory also conducted a study into the airborne release of uranium during the enrichment process at the Oak Ridge, Paducah, and Portsmouth facilities. ${ }^{31}$ The reported atmospheric releases ranged from $<0.07-0.37 \mathrm{GBq}(4-10 \mathrm{mCi})$ from Oak Ridge, $0.07-4.8 \mathrm{GBq}$ $(2-130 \mathrm{mCi})$ from Paducah, and $1.4-3.3 \mathrm{GBq}(38-89 \mathrm{mCi})$ for Portsmouth. The time frame for these releases was from 1982 to 1986.

Researchers at the Environmental Measurements Laboratory of the DOE conducted a study into the daily intake of various radioactive nuclides (including ${ }^{238} \mathrm{U}$ ) in New York. ${ }^{32}$ Therefore, in addition to water 
and food concentrations (discussed earlier), this study also included measurements of the amount of ${ }^{238} \mathrm{U}$ in New York air. The mean concentration in the air was $0.94 \mu \mathrm{Bq} / \mathrm{m}^{3}\left(0.03 \mathrm{fCi} / \mathrm{m}^{3}\right)$.

A similar study was performed by scientists at the Okayama Prefectural Institute for Environmental Science and Public Health for the area north of the city of Okayama. ${ }^{35}$ Specifically, these scientists assumed that a principal source of uranium-laden aerosols is soil erosion caused by wind. To maintain scientific integrity, they maintained, as closely as possible, similar sampling conditions between sampling times, including rainfall, snowfall, wind speed, and direction. Typical activity concentrations for ${ }^{238} \mathrm{U}$ ranged from $0.5-9.3 \mu \mathrm{Bq} / \mathrm{m}^{3}\left(0.01-0.3 \mathrm{fCi} / \mathrm{m}^{3}\right)$ with a geometric mean of $2.2 \mu \mathrm{Bq} / \mathrm{m}^{3}\left(0.06 \mathrm{fCi} / \mathrm{m}^{3}\right)$.

In summary, inhalation of ${ }^{238} U$ is one of the most important pathways of exposure to this nuclide. Uranium can be suspended in air either due to leakage of volatile uranium (e.g., UF 6 ) or by weathering of uranium tailings and wind-driven suspension. Examples of the latter mechanism can result in air concentrations of the order of microbecquerel per cubic meter.

\section{Behavior of Uranium-238 in the Human Body and in Animals}

This section summarizes several studies of the behavior of ${ }^{238} \mathrm{U}$ in the human body and in animals. Since ${ }^{238} \mathrm{U}$ is principally an alpha emitter, the human hazard from this nuclide is dominated by internal dose when the nuclide is either ingested or inhaled. Both exposure pathways are important in understanding the hazard this nuclide presents to humans. This nuclide can become airborne either by atmospheric release (e.g., from an enrichment facility if a leak in the volatile $\mathrm{UF}_{6}$ line were to occur) or by weathering and resuspension due to wind (e.g., at a uranium tailings site). Ingestion can occur when plants take up the nuclide from contaminated soil and then are themselves either directly ingested by humans or first ingested by animals, which are in turn eaten by humans. A number of factors may influence the pathway to humans, including chemical form of the nuclide, particle size distribution (for the case of aerosols), and water and/or plant concentration effects. Where the specific studies included a discussion of these effects, they are also summarized.

Scientists at the Institute of Biophysics, Ministry of Public Health in Moscow, Russia, conducted a study into the effects of various chelating agents on the removal of various radionuclides that had been ingested by dogs and rats. ${ }^{36}$ This work was performed to determine how effective these agents are in reducing the dose due to these nuclides on the human body. A number of various agents were studied, all related to polyaminepolyalkylphosphonic acids, as possible substitutes for other agents that, while successful in removing the radionuclides, are harmful to animals in general and the kidneys in particular. All of the compounds were successful in reducing uranium from the contaminated animals, reducing the skeleton burden by $50-84 \%$ and the kidney burden by $82-95 \%$, compared to a control group.

The study, documented in Reference 32, was performed to determine the extent to which radioactive contamination in a radioactive waste settling basin could enter the food chain. Both invertebrates (dragonfly nymphs, water bugs, and snails) and vertebrates (goldfish, catfish, and tadpoles) were included in this study. In addition, rats that populate the shoreline were also trapped and studied. This study concluded that the overall comparative uptake of actinides by these animals indicated that uranium is the most easily absorbed actinide.

A similar study was performed for the area near a uranium mine in Slovenia. ${ }^{30}$ In this study, the uptake of uranium (that contaminated surface waters) into fish food and fish was measured. The uranium concentrations in the fish varied from $1.07-42.9 \mu \mathrm{g} / \mathrm{kg}$, depending on the location relative to the mine. The ratio of uranium concentration in the fish $(\mu \mathrm{g} / \mathrm{kg})$ to that in the surrounding water $\left(\mathrm{mg} / \mathrm{m}^{3}\right)$ varied from $0.7-38$, with the lower ratios tending to be associated with smaller fish concentrations. 
A study of the effects of inhaling uranium dust on the pulmonary function was conducted using dogs. ${ }^{37}$ In this study, sets of young and old dogs were exposed to various lengths of time to $14 \mathrm{mg} / \mathrm{m}^{3}$ ore dust. The pulmonary function (including effective lung volume) was measured on these dogs as well as control sets of dogs (also both old and young). This study concluded that there was a significant decrease in the uniformity of ventilation in the lung as a function of exposure to uranium ore dust, although the total lung volume showed no significant effects of either age or aerosol exposure.

The ${ }^{238} \mathrm{U}$ contamination in beavers, grouse, and muskrats was studied by a researcher at the Laurentian University for the Atomic Energy Control Board in Ottawa, Canada. ${ }^{38}$ The location for the study was the Serpent River drainage basin, which is near a uranium tailings site at Elliot Lake. Several radionuclides were included in the study, in addition to ${ }^{238} \mathrm{U}$. ${ }^{238} \mathrm{U}$ was detected in measurable amounts in the bone, muscle, and liver issues of both beavers and grouse. Concentration ratios (defined as the ration of ${ }^{238} \mathrm{U}$ concentration in an animal's diet to that in a specific tissue) were measured. This ratio exceeded unity between some vegetation items and beaver bone (concentration ratios were less than zero for other beaver tissues) at the Elliot Lake tailings site and between aspen leaves and grouse bones. All other ratios were less than 1. Estimated yearly intakes of radionuclides by people eating beaver and grouse were calculated to be below current limits established by regulating authorities in Canada.

Reference 31 cumulated the study by calculating the estimated dose to the public due to exposure to operations of the DOE's three uranium enrichment facilities. This study did not differentiate between the two principal isotopes of uranium, ${ }^{235} \mathrm{U}$ and ${ }^{238} \mathrm{U}$, in presenting the results of the dose calculation. In addition, the effects of the long-lived radionuclide ${ }^{99} \mathrm{Tc}$, which is also present in significant quantities in these facilities and which, along with the uranium isotopes, represent the major radioactive hazards due to this type of operation, are included in the dose calculations. Therefore, the doses represent upper bounds on the doses due to ${ }^{238} \mathrm{U}$ alone. The doses account for inhalation (due to airborne effluents, both gaseous or particulate) and ingestion (due to inadvertent release of radioactive effluent from maintenance and decontamination processes). The measured atmospheric and surface water releases were discussed earlier in this report. The total dose to the public due to operation of these three enrichment facilities during the years from 1982 to 1986 were (1) for the Oak Ridge, Tennessee, facility, the dose ranged from $9 \times 10^{-6}-<8 \times 10^{-5} \mathrm{man}-\mathrm{Sv}$, (2) for the Paducah, Kentucky, facility, the dose ranged from $2 \times 10^{-4}-5 \times 10^{-2}$ man-Sv, (3) and for the Portsmouth, Ohio, facility, the dose ranged from $2 \times 0^{-4}-0.1 \mathrm{man}-\mathrm{Sv}$.

The purpose of the study documented in Reference 24 was to investigate the contamination of a population in Romania due to living near an area of elevated uranium deposits. Owing to the specific local ecological processes, natural uranium is expected to be taken up into the members of a local population, which are, therefore, exposed to an increased level of natural irradiation. This was a group of non-occupationally exposed people, as contrasted with many other studies that are restricted to occupationally exposed subjects, such as uranium mine workers. Urine samples were collected from people living near an area of increased natural uranium deposits as well as a control group of people living away from this area. There were 70 people in the first group and 30 in the second group. In the exposed group, the uranium concentrations ranged from $0.8-94.5 \mu \mathrm{g} / \mathrm{L}$ with an average value of $32.5 \mu \mathrm{g} / \mathrm{L}$. For the control group, the uranium concentrations ranged from $0.8-26.2 \mu \mathrm{g} / \mathrm{L}$ with an average value of $6.7 \mu \mathrm{g} / \mathrm{L}$. Thus, the exposed group experienced significantly higher exposures to uranium than did the control group.

The principal excretion paths for ${ }^{238} \mathrm{U}$ in humans was studied by scientists at the Hines Veterans Administration Hospital in Illinois. ${ }^{39}$ Four patients in the hospital were included in the study. Their diets were strictly controlled so that an accurate uptake could be measured. The uranium ingested by these patients was of natural origin in the diet, including drinking water and milk. Although the diets for these patients was controlled during the study, prior ingestion of uranium could not be quantified. It was determined that the principal excretion path was via the intestine and that elimination via the urinary tract contributed less than 
$2 \%$ of the total excretion. The total average daily intake of ${ }^{238} \mathrm{U}$ ranged from $24-46 \mathrm{mBq} / \mathrm{d}(0.7$ to $1 \mathrm{pCi} / \mathrm{d})$ for these patients. During the study, an average of approximately $70 \%$ of the intake of ${ }^{238} \mathrm{U}$ was excreted.

The concentrations of various nuclides were measured, including ${ }^{238} \mathrm{U}$, in the bones and soft tissues of uranium miners, millers, and the general population in the state of Colorado. ${ }^{40}$ In this study, samples of lung, lymph node, liver, kidney, spleen, testis, heart, and vertebrae were collected from three uranium miners, two millers, and 15 members of the general population by autopsy and the ${ }^{238} \mathrm{U}$ concentrations were measured for each sample. Of the total body content, the skeletal burdens of this nuclide ranged from $13-79 \%$ for the miners, $9-81 \%$ for millers, and approximately $85 \%$ for the general population. In general, the skeleton accounted for $83-99 \%$ of the uranium content in all three groups. It is difficult to determine from this report if there were any other general trends, although it appeared that the heart could also concentrate this nuclide.

Researchers at the DOE Environmental Measurements Laboratory have examined bone samples from Nepal and Australia for evidence of natural uranium and fallout plutonium. ${ }^{41}$ The concentration of ${ }^{238} \mathrm{U}$ ranged from 4 to $14 \mathrm{pCi} / \mathrm{kg}$ of ash for the remains from Nepal and from 0.2 to $3.5 \mathrm{pCi} / \mathrm{kg}$ for the remains from Australia. The samples were from people who died in the 1970 s and were from people who lived up to 82 years in Nepal and 34 years in Australia. Bone ash was used because of the belief that natural uranium resides primarily in the skeleton. There was no substantial increase in natural uranium content with age, indicating that equilibrium in the body is established quickly, implying a short biological half-life. The average dose to the bone (due to alpha radiation) was $0.039 \mathrm{mrad} / \mathrm{yr}$ in Nepal and $0.009 \mathrm{mrad} / \mathrm{yr}$ in Australia

Scientists at the University of Utah's Department of Pharmacology studied the concentrations of various radionuclides in the lungs of uranium miners. ${ }^{42}$ Lung tissue samples were collected from the remains of eight miners and the ${ }^{238} \mathrm{U}$ concentrations were measured. These concentrations ranged from $0.6-11.5$ $\mathrm{Bq} / \mathrm{kg}$ (16-310 pCi $/ \mathrm{kg}$ ). The lung doses were calculated to range from 0.01 to $0.72 \mathrm{mGy} / \mathrm{yr}$ (this included the effects of ${ }^{234} \mathrm{U}$ and ${ }^{230} \mathrm{Th}$ as well as ${ }^{238} \mathrm{U}$ ).

A study was made of the inhalation of uranium due to working in an ore crushing facility. ${ }^{43}$ Both urine and fecal samples were obtained from active crushermen (men who work to crush uranium ore prior to its being processed to remove the uranium), retired crusher workers (retired at least 4 years), and control individuals who live near but who do not work at the mills. The mills studied were judged to be among the dustiest in the industry and the workers normally do not wear respirators during operations. Therefore, it was judged that these results would represent some of the highest exposures currently to be found. The urine concentrations of ${ }^{238} \mathrm{U}$ ranged from $0.2-11 \mathrm{pCi} / \mathrm{L}$ for active workers, $0.04-0.19 \mathrm{pCi} / \mathrm{L}$ for retired workers, and $0.04-0.2 \mathrm{pCi} / \mathrm{L}$ for the control group. As seen, there was little difference between the retired workers and the control group, indicating that the biological half-life of uranium in the body is fairly short. The uranium levels in the feces ranged from $2-1,930 \mathrm{pCi} / \mathrm{L}$ for active workers, from $2-73 \mathrm{pCi} / \mathrm{L}$ for retired workers, and from $5-15 \mathrm{pCi} / \mathrm{L}$ for the control group. Again, the contamination levels for the retired workers were reasonably similar to those for the control group. In addition, it is evident that the feces represents the principal removal path for this nuclide.

The dose that is received due to intake (either inhalation or ingestion) of a radionuclide is a strong function of the rate at which this nuclide either radioactively decays or is biologically removed from the body. For the case of ${ }^{238} \mathrm{U}$, the biological half-life (time for the body to biologically remove one-half of the uranium burden in the body) is 300 days for contamination of the bones, 15 days for contamination of the kidneys, and 100 days for general contamination of the body. ${ }^{25}$ This reference also lists the organs most likely to be affected by intake of various radionuclides. Per this reference, ${ }^{238} \mathrm{U}$ tends to become concentrated in the lungs and kidneys and not in the liver or bones (although another isotope of uranium, ${ }^{233} \mathrm{U}$ is concentrated in the bones). No reason was given for the apparent discrepancies (e.g., biological half-life given for bones and the fact that ${ }^{233} \mathrm{U}$ but not ${ }^{238} \mathrm{U}$, tends to concentrate in the bones). 
Reference 44 lists the organ dose that results as a result of a specific intake of ${ }^{238} U$. For exposure due to inhalation (either of a gaseous uranium compound or an aerosol), the lungs receive the largest dose, followed by the bone surface, and bone marrow-the remaining organs receive little dose. For exposure due to ingestion, the bone surface receives the largest dose, followed by the bone marrow-the remaining organs receive little dose. This reference also lists the dose rate factors for external radiation due to ${ }^{238} U$. Both for immersion in contaminated air and for ground-surface exposure, these factors are relatively small.

The annual limits on ${ }^{238} \mathrm{U}$ intake (ALI) and the derived air concentration (DAC) for ${ }^{238} \mathrm{U}$ are shown in Table 15-5. The ALI is defined as that annual intake of a radionuclide that would result in a radiation dose to a human (for calculational purposes, the characteristics of the "Reference Man" are used) equal to the allowable limit. The DAC is defined as that concentration of a radionuclide in air which, if breathed for a work-year, would result in an intake corresponding to the ALI (or, in the case of submersion, to an external exposure corresponding to the primary guide for limiting annual dose). DACs are, thus, used for limiting radionuclide intake through the breathing of, or submersion in, contaminated air. ALIs are used primarily for assessing doses due to accidental ingestion of radionuclides.

Historically, maximum permissible concentrations (MPC) in air and water have been used to determine safety guidelines for released radionuclide concentrations. Currently, the derived guidelines are presented in terms of ALIs for inhalation or ingestion and DACs for inhalation (or submersion). For a radionuclide whose derived value does not change from the old definition, the DAC is numerically equal to the MPC value in air. The information in Table 15-5 applies only to ${ }^{238} \mathrm{U}$. In the case of multiple radionuclides released in a mixture, additional guidelines outlined in the Code of Federal Regulations, Part 20 of Title $10^{45}$ must be followed.

In summary, due to its long half-life, ${ }^{238} \mathrm{U}$ is removed by the body exclusively via biological means with excretion via the gastrointestinal tract the principal removal mechanism. This nuclide can be taken up by humans by eating contaminated meat or by inhaling contaminated air. Usually, contamination levels are low. The bone surface appears to be the organ most likely to receive long-term dose, although the lungs can also receive a dose when the exposure is duc to inhalation. 
Table 15-5. Annual limits on intake (ALI) and the derived air concentrations (DAC) for ${ }^{238} \mathrm{U}$ (data obtained from Reference 46).

\begin{tabular}{llll}
\hline Radionuclide & Component & Ingestion & Inhalation $^{\mathrm{a}}$ \\
\hline${ }^{238} \mathrm{U}$ & $\mathrm{ALI}(\mathrm{Bq})$ & $5 \times 10^{5}\left(5 \times 10^{-2}\right)^{\mathrm{b}}$ & $50,000 / \mathrm{D}$ \\
& & $8 \times 10^{5}\left(5 \times 10^{-2}\right)$ & $80,000 / \mathrm{D}$ \\
& $($ bone surface $)$ & (bone surface) \\
& & $8 \times 10^{6}\left(2 \times 10^{-3}\right)$ & $30,000 / \mathrm{W}$ \\
& & $2,000 / \mathrm{Y}$ \\
& & & $40,000 / \mathrm{D}$ \\
& & & $30,000 / \mathrm{W}$ \\
& & & $20,000 / \mathrm{Y}$
\end{tabular}

a. Clearance from the lung directly to the blood stream or to the gastrointestinal tract depends on the chemical form of the radionuclide and is classified as $\mathrm{D}, \mathrm{W}$, and $\mathrm{Y}$, respectively, for clearance times of the order of days, weeks, and years. For ${ }^{238} \mathrm{U}$, the classification is $\mathrm{W}$.

b. The removal class, $f_{1}$ for each ALI is in parenthesis. A simple model of the lung was used to describe the translocation and retention of material by the body after inhalation. In this model, $25 \%$ of the inhaled activity was exhaled and $25 \%$ was deposited in the lower respiratory tract. The 50\% that was deposited in the upper respiratory tract was eventually cleared by means of mucociliary processes and swallowed. What happens then depends on whether the inhaled material was in either a soluble or insoluble chemical form. Any soluble material deposited in the lower respiratory tract is assumed to be transferred directly to the blood stream. The insoluble activity is cleared from the upper respiratory tract and then swallowed; a fraction $\left(f_{1}\right)$ enters the blood stream via the gastrointestinal tract. In the case of ${ }^{238} \mathrm{U}, \mathrm{f}_{1}=0.05$ for water-soluble inorganic compounds of uranium and 0.002 for relatively insoluble compounds such as $\mathrm{UF}_{4}, \mathrm{UO}_{2}$, and $\mathrm{U}_{3} \mathrm{O}_{8}$. Additional details of this model are described in References 46 and 47.

c. Data not available.

\section{Summary}

${ }^{238} \mathrm{U}$ is a naturally occurring, radioactive nuclide with a half-life of $4.47 \times 10^{9}$ years. This nuclide decays, by alpha particle emission, to ${ }^{234} \mathrm{Th}$. It may also spontaneously fission, creating two smaller-massed nuclides plus neutrons, although the probability of this occurring is $<1 \%$. After a combination of 14 alpha and beta decays, the stable ${ }^{206} \mathrm{~Pb}$ nuclide finally results. Moderately high-energy alpha particles, low-energy gamma rays, and low-energy beta particles are emitted when this nuclide decays. The total particle and photon spectrum is complex because of the complex decay scheme.

Because of the long half-life of ${ }^{238} \mathrm{U}$, it is not, itself, a major factor in the ability of an LLW disposal facility to meet performance objectives. The presence of the nuclide, however, can be relatively significant in assessing the long-term performance of such a site due to the quantity, radiotoxicity, and mobility of its daughter products, which include isotopes of radium and radon.

${ }^{238} \mathrm{U}$ is the most abundant isotope of uranium, comprising $>99 \%$ of all naturally occurring uranium. Another isotope of this element, ${ }^{235} \mathrm{U}$, is used widely in energy and weapons production, and ${ }^{238} \mathrm{U}$ is a byproduct of this activity. Therefore, this nuclide is equated with the term "depleted uranium." As such, this nuclide has widespread industrial and military usage, including radioactive shielding, counterweights, and nonnuclear weapons. In addition, materials containing relatively high concentrations of uranium have been 
used as roadbed material. This nuclide is also available as a radioactive sealed source, although no medical uses were identified.

Uranium is very reactive and forms compounds with many other elements, such as the halides, oxygen, and hydrogen. Its chemistry is dominated by the half-filled $5 \mathrm{f}$ electron subshell. The U-O system is one of the most complex of all oxide systems. Uranium is similar to neodymium, a lanthanide with a half-filled 4 electron subshell.

The ability of soil to adsorb ${ }^{238} \mathrm{U}$ out of the groundwater depends on a number of factors, including $\mathrm{pH}$ and the presence or absence of complexing agents. In the presence of low $\mathrm{pH}$ soil conditions (for example, in uranium tailings that were processed using sulfuric acid), uranium is very soluble and tends to remain in the groundwater rather than being adsorbed by the soil.

The principal radiological hazard associated with this nuclide is due to its relatively high-energy alpha particles. Since these alpha particles do not penetrate materials easily, external exposure to this nuclide does not pose a high risk. The principal risk is due to either inhalation or ingestion. Inhalation occurs either from release of a volatile uranium compound (such as $\mathrm{UF}_{6}$, which is used in uranium enrichment processes) or from suspension of uranium-laden aerosols (such as due to weathering of tailings or ore). Ingestion can occur when the uranium is introduced into the food chain by plant uptake. When ${ }^{238} \mathrm{U}$ is either ingested or inhaled, it is removed from the body with a biological half-life of a few hundred days, depending on which organ has become contaminated by the nuclide. This nuclide tends to concentrate in and irradiate the bones. Additionally, if inhaled, the lungs can receive a dose. 


\section{References}

1. McGraw-Hill Encyclopedia of Science and Technology, Volume 19, 6th Edition, New York: McGraw-Hill Book Company, 1987.

2. M. B. Bever, Encyclopedia of Materials Science and Engineering, Volume 7, 1986, pp. 5213.

3. J. R. Bradford, Radioisotopes in Industry, Reinhold Publishing Corporation, 1953.

4. E. Browne and R. B. Firestone, Table of Radioactive Isotopes, New York: John Wiley \& Sons, 1986, pp. 237-3.

5. D. C. Steward, Data for Radioactive Waste Management and Nuclear Applications, New York: John Wiley \& Sons, 1985.

6. C. M. Lederer, J. M. Hollander, I. Perlman, Table of Isotopes, 6th Edition, New York: John Wiley \& Sons, 1968.

7. B. Shleien and M. S. Terpilak, The Health Physics and Radiological Health Handbook, Nucleon Lectern Associates, 1984.

8. A Basic Toxicity Classification of Radionuclides, Technical Reports Series No. 15, International Atomic Energy Agency, Vienna, Austria, 1963.

9. General Electric Company, Nuclides and Isotopes, 14th Edition, 1989.

10. R. C. Weast (ed.), CRC Handbook of Chemistry and Physics, 58th Edition, Boca Raton, Florida: CRC Press, 1977.

11. Bureau of Radiological Health, Radiological Health Handbook, Revised Edition, U.S. Government Printing Office, January 1970.

12. F. A. Cotton and G. Wilkinson, Advanced Inorganic Chemistry-A Comprehensive Text, Interscience Publishers, 1962.

13. Encyclopedia of Materials Science and Engineering, Volume 7, Pergamon Press, 1986.

14. Metals Handbook, Volume 3, 9th Edition, American Society for Metals, 1980.

15. International Critical Tables of Numerical Data, Physics, Chemistry, and Technology, Volume I, 1st Edition, New York: McGraw-Hill Book Company, 1926.

16. McGraw-Hill Encyclopedia of Science and Technology, Volume 19, 6th Edition, New York: McGraw-Hill Book Company, 1987.

17. International Directory of Certified Radioactive Materials, International Atomic Energy Agency, 1975.

18. U.S. Department of Energy, Catalog of Radioactive and Stable Isotopes, April 1992. 
19. P. C. Bergamini et al., "Absorption and Distribution of ${ }^{137} \mathrm{Cs}$ by Trifolium Pratense," Health Physics, Vol. 19, October 1970, pp. 521.

20. J. Dragun, The Soil Chemistry of Hazardous Materials, Hazardous Materials Control Research Institute, 1988.

21. J. J. LaBrecque, "Distribution of ${ }^{137} \mathrm{Cs},{ }^{40} \mathrm{~K},{ }^{238} \mathrm{U}$, and ${ }^{232} \mathrm{Th}$ in Soils From Northern Venezuela," Journal of Radioanalytical and Nuclear Chemistry, Vol. 178, 1994, pp. 327-336.

22. E. Yunoki, et al., "Activity Concentration of ${ }^{226} \mathrm{Ra}$ and ${ }^{238} \mathrm{U}$ in Various Soils," Journal of Radioanalytical Nuclear Chemistry Letters, Vol. 166, No. 4, 1992, pp. 331-341.

23. C. M. Melville, et al., "Uranium Dispersion Along Roads Paved with Phosphate Slag," Bulletin of Environmental Contamination \& Toxicology, Vol. 27, No. 4, 1981, pp. 470-473.

24. N. Margocsy, et al., "The Study of the Absorption of Natural U and ${ }^{210} \mathrm{~Pb}$ Concerning a Lot of Population in Connection with the Radioactivity of the Environment in an Area with Increased Natural Background of Romania," Proceedings of the IRPA Second European Congress on Radiation Protection, Health Physics Problems of Internal Contamination, Akademiai Kiado, 1973, pp. 401.

25. S. A. Ibrahim and F. W. Whicker, "Comparative Plant Uptake and Environmental Behavior of U-Series Radionuclides at a Uranium Mine-Mill," Journal of Radioanalytical and Nuclear Chemistry, Vol. 156, 1992, pp. 253-267.

26. K. Froehlich, R. Gellermann, K. Runge, "On the Migration of Uranium Isotopes in Sandstone Aquifers," Proceedings of the Symposium on Environmental Migration of Long-Lived Radionuclides, Knoxville, TN, July 27-31, 1981, International Atomic Energy Agency, 1982, pp. 373.

27. C. W. Kennedy, G. E. Bartelt, K. A. Orlandini, "Uranium in Water and Suspended Sediments of the Great Miami River," Radiological and Environmental Research Division Annual Report, ANL-77-65, January-December 1977.

28. E. Puukko and T. Jaakkola, Actinides and Beta Emitters in the Process Water and Ion-Exchange Resin Samples from the Loviisa Nuclear Power Plant, YJT-92-22, IVO, 1992.

29. N. W. Golchert, T. L. Duffy, J. Sedlet, Environmental Monitoring at Argonne National Laboratory-Annual Report for 1984, ANL-85-17, 1985.

30. P. Stegnar and I. Kobal, "Uptake and Distribution of Radium and Uranium in the Aquatic Food Chain," Proceedings of the Symposium on Environmental Migration of Long-Lived Radionuclides, Knoxville, TN, July 27-31, 1981, pp. 364-373.

31. E. Kennedy, Jr., Potential Exposures from Uranium Enrichment, PNL-SA-15132, September 1987.

32. I. M. Fisenne, et al., "The Daily Intake of ${ }^{234,235,238} \mathrm{U},{ }^{228,230,232} \mathrm{Th}$, and ${ }^{226,228} \mathrm{Ra}$ by New York City Residents," Health Physics, Vol. 53, No. 4, October 1987, pp. 357-363.

33. C. T. Garten, Jr., J. R. Trabalaka, M. A. Bogle, "Comparative Food Chain Behavior and Distribution of Actinide Elements in and Around a Contaminated Fresh-Water Pond," Proceedings of the Symposium on Environmental Migration of Long-Lived Radionuclides, Knoxville, TN, July 27-31, 1981, pp. 299 
34. E. J. Antonio, T. M. Posto, W. H. Rickard, Jr., Radiological Survey of Shoreline Vegetation from the Hanford Reach of the Columbia River, 1990 - 1992, PNL-8797, September 1993.

35. E. Yunoki, et al., "Background Levels of ${ }^{238} \mathrm{U}$ and ${ }^{226} \mathrm{Ra}$ in Atmospheric Aerosols," Journal of Radioanalytical and Nuclear Chemistry, Vol. 189, 1995, pp. 157-164.

36. V. S. Balabukha, et al., "Polyaminepolyalkylphosphonic Acids as Effective Ligands for Binding and Eliminating Uranium and its Fission Products from the Body," Proceedings of the IRPA Second European Congress on Radiation Protection, Health Physics Problems of Internal Contamination, Akademiai Kiado, 1973, pp. 293.

37. S. M. Loscutoff, et al., "Pulmonary Function Evaluations of Dogs Exposed to Uranium Ore Dust," Pacific Northwest Laboratory Annual Report for 1979 to the DOE Assistant Secretary for Environment, PNL-3300 PT1, February 1980.

38. F. V. Clulow, Radionuclide Uptake by Beaver and Ruffed Grouse in the Serpent River Basin, INFO-0292, December 1988

39. H. Spencer, et al., "Measured Intake and Excretion Patterns of Naturally Occurring ${ }^{234} \mathrm{U}$, ${ }^{238} \mathrm{U}$, and Calcium in Humans," Radiation Research, Vol. 124, No. 1, 1990, pp. 90-95.

40. N. P. Singh, H. M. Ruth, M. E. Wrenn, "Comparative Distribution of ${ }^{238} U,{ }^{234} U$, and ${ }^{230}$ Th in Tissues of Uranium Miners, Millers, and the General Population," Radiation Protection Dosimetry, Vol. 26, No. 1, 1989, pp. 61-67.

41. I. M. Fisenne, P. M. Perry, N. Y. Chu, "Measured ${ }^{234,238} \mathrm{U}$ and Fallout ${ }^{239,}{ }^{240} \mathrm{Pu}$ in Human Bone Ash from Nepal and Australia: Skeletal Alpha Dose," Health Physics, Vol.44, Supplement 1, 1983, pp. $457-467$.

42. N. P. Singh, D. B. Bennett, M. E. Wrenn, "Concentrations of ${ }^{210} \mathrm{~Pb}$ and its States of Equilibrium with ${ }^{238} \mathrm{U},{ }^{234} \mathrm{U}$, and ${ }^{230} \mathrm{Th}$ in U Miners' Lungs," Health Physics, Vol. 51, No. 4, October 1986, pp. $501-507$.

43. D. R. Fisher, et al., "Levels of ${ }^{234} \mathrm{U},{ }^{238} \mathrm{U}$, and ${ }^{230} \mathrm{Th}$ in Excreta of Uranium Mill Crushermen," Health Physics, Vol. 45, No. 3, September 1983, pp. 617-629.

44. B. Shleien and M. S. Terpilak, Supplement I (1986) The Health Physics and Radiological Health Handbook, Nucleon Lectern Associates, Inc., 1986.

45. Code of Federal Regulations, 10 CFR 20, "Standards for Protection Against Radiation," Appendix B., Nuclear Regulatory Commission.

46. Limits for Intakes of Radionuclides by Workers, Annals of the ICRP, ICRP Publication 30, Part 1, 1979.

47. K. F. Eckerman, A. B. Wolbarst, A. C. B. Richardson, Limiting Values of Radionuclide Intake and Air Concentration and Dose Conversion Factors of Inhalation, Submersion, and Ingestion, Federal Guidance Report No. 11, Oak Ridge National Laboratory, EPA-520/1-88-020, 1988. 


\section{Bibliography}

Andersson, P. S. et al., 1995, "U-238, U-234, and Th-232 in the Baltic Sea and in River Water," Earth and Planetary Science Letters, Vol.130, p. 217.

Barisic, D., S. Lulic, A. Vertacnik, 1995, "Total Natural Gamma-Activity $\left({ }^{40} \mathrm{~K},{ }^{226} \mathrm{Ra},{ }^{228} \mathrm{Ra}\right.$, and $\left.{ }^{238} \mathrm{U}\right)$ in Soils of Istria Peninsula, Croatia," Proceedings of Radiation Protection in Neighboring Countries in Central Europe, Obergurgl/Tyrol, Austria, April 28-30, pp. 445.

Brown, J. A. and R. C. Robertson, 1986, "In Situ Determination of U-238 Concentrations in Surface Soil," Proceedings of the 19th Midyear Topical Symposium on Health Physics Considerations in Decontamination and Decommissioning, Knoxville, Tennessee, February 2, p. 299.

Bunzl, K. et al., 1994, "Transect Survey of U-238, Ra-228, Ra-226, Pb-210, Cs-137, and K-40 in an Agricultural Soil Near an Exhaust Ventilating Shaft of a Uranium-Mine," Science of the Total Environment, 149, p. 225.

Dendahl, K. H. and J. A. Brown, 1986, "Determination of U-238, Ra-226, and Th-232 by Gamma-Ray Spectrometry in Unprocessed Soil Samples," Proceedings of the 19th Midyear Topical Symposium on Health Physics Considerations in Decontamination and Decommissioning, Knoxville, Tennessee, February, p. 295.

Greeman, D. J., A. W. Rose, W. A. Jester, 1990, "Form and Behavior of Radium, Uranium, and Thorium in Central Pennsylvania Soils Derived from Dolomite," Geophysical Research Letters, 17, p. 833.

Heinrich, G. et al., 1989, "Natural and Artificial Radionuclides in Selected Styrian Soils and Plants Before and After the Reactor Accident in Chernobyl Ukrainian SSR USSR," Biochemie und Physiologie der Pflanzen, Vol. 185, p. 55.

Ibrahim, S. et al., 1982, "Concentrations and Biological Availability of ${ }^{238} \mathrm{U}$ and ${ }^{230} \mathrm{Th}$ in the Environs of a Uranium Milling Operation," Proceedings of the 5th Annual Symposium on Uranium Mill Tailings Management, Fort Collins, Colorado, December 9, p. 149.

Ishchenko, G. S. and A. S. Butnik, 1990, "Forms of Occurrence of U-238 and Th-232 in Soils of Central Asia," Soviet Soil Science, Vol. 22, p. 45.

Jain, R. K., S. K. Bose, K. K. Dwivdei, 1991, "Response of Triafol-TN Plastic Track Detectors to U-238 Ions," Pramada Journal of Physics, Vol. 37, p. 431.

Koster, H. W. et al., 1988, "Linear-Regression Models for the Natural Radioactivity (U-238, Th-232, K-40) in Dutch Soils-A Key to Anomalies," Radiation Protection Dosimetry, Vol. 24, p. 63.

Lambrechts, A., L. Foulquier, J. Garnier-Laplace, 1991, "Natural Radioactivity in the Aquatic Components of the Main French Rivers, "Proceedings of the International Symposium on the Natural Radiation Environment, Salzburg, Austria, September 22-28, p. 253.

Ludwig, K. R. et al., 1993, "234U ${ }^{238} \mathrm{U}$ as a Groundwater Tracer, SW Nevada - SE California," 10th International High-Level Radioactive Waste Management Conference, Las Vegas, Nevada, April 25-29, p. 1567. 
Mahon, D. C. and R. W. Matthews, 1983, "Uptake of Naturally Occurring Radioisotopes by Vegetation in a Region of High Radioactivity," Canadian Journal of Soil Science, Vol. 63, p. 281.

Morris, H. W. et al., 1994, "Determination of Th-234 U-238 Disequilibrium in Fresh-Water Systems," Analyst, Vol. 119, p. 2403.

Pluta, I., I. Tomza, T. Pluta, 1990, "Determination of U-238 Isotope and U-234 Isotope in Water by Liquid Scintillation Counting," Nuclear Geophysics - International Journal of Radiation Applications and Instrumentation Part E, Volume 4, p. 489.

Rayno, D. R., M. H. Momeni, C. Sabau, 1980, "Forage Uptake of Uranium Series Radionuclide in the Vicinity of the Anaconda Uranium Mill," Proceedings of the 3rd Annual Symposium on Uranium Mill Tailings Management, Fort Collins, Colorado, November, p. 13.

Schell, W. R. et al., 1988, "Recycling and Removal of Radionuclides in Forest Soil Resulting from Nuclear Accidents," Proceedings of the Cadarache International Symposium on Radioecology, Cadarache, France, March 14, p. D40.

Shiraishi, K. et al., 1992, "Daily Intakes of Thorium-232 and Uranium-238 in Japanese Males," Health Physics, Vol. 63, p. 187.

Shuktomova, I. I. et al., 1983, "Behavior of U-238, Th-232, and Ra-226 in Mountain Tundra Soils," Soviet Soil Science, Vol. 15, p. 51.

National Council on Radiation Protection and Measurements, Soil Content and Transport of Uranium-238, Bethesda, Maryland, 1984.

Tracy, B. L. and F. A. Prantl, 1985, "Radiological Impact of Coal-Fired Power Generation," Journal of Environmental Radioactivity, Vol. 2, p. 145.

Wood, R. and R. Eckart, 1991, "RESRAD Analysis of the Validity of Generic Limits on Residual ${ }^{238} \mathrm{U}$ Radioactivity in Soil," Transactions of the American Nuclear Society, 63, p. 54.

Yu, K. N., 1994, "The Concentrations of U-238 in Soil in Hong Kong," Nuclear Geophysics, Vol. 8, p. 597. 


\section{NEPTUNIUM-237}

\section{Introduction}

This chapter discusses the basic radiological, chemical, and physical characteristics of neptunium-237 $\left({ }^{237} \mathrm{~Np}\right)$ and examines how these characteristics affect the behavior of ${ }^{237} \mathrm{~Np}$ in various environmental media, such as soils, water, plants, animals, the atmosphere, and the human body. Also included are methods of production and waste and disposal data on ${ }^{237} \mathrm{~Np}$.

The presence of ${ }^{237} \mathrm{~Np}$ in a low-level radioactive waste (LLW) disposal facility can be relatively significant in assessing the long-term performance of such a site due to the quantity, radioactivity, and mobility of its daughter products, which include isotopes of radium and radon. To obtain a complete understanding of the radiological effects of this nuclide, these daughter effects would also have to be considered.

A radionuclide considered sensitive at one LLW disposal facility may not be considered sensitive at another facility. The behavior of a radionuclide at a particular LLW disposal site will depend primarily upon the radiological, chemical, and physical characteristics of the waste, and the inventory of the radionuclide. The behavior of a radionuclide also depends upon the geology, hydrology, and climate at the disposal site. This chapter reports characteristics and potential difficulties in dealing with ${ }^{237} \mathrm{~Np}$. However, since ${ }^{237} \mathrm{~Np}$ behavior and appropriate handling, storage, or disposal will vary depending on particular sites or waste form, this chapter does not attempt to discuss the extent of a difficulty or appropriate solutions. Each disposal site facility design should consider and address the specific waste content and behavior under that site's particular circumstances.

Neptunium was the first transuranium element that was produced by man. In 1940, E. M. McMillan and P. Abelson bombarded uranium with neutrons to produce ${ }^{239} \mathrm{~Np}$ according to the following reaction: ${ }^{1}$

$$
{ }^{238} U(n, \gamma){ }^{239} U \stackrel{\beta^{-}}{\rightarrow 23 \min }{ }^{239} N p .
$$

This isotope has a half-life of 2.3 days. The lighter isotope, ${ }^{237} \mathrm{~Np}$, was later produced, also by bombarding uranium with neutrons, according to the following reaction:

$$
{ }^{238} U(n, 2 n){ }^{237} U \underset{\beta}{6.75 d}{ }^{237} N p
$$

This isotope was first isolated as a pure compound, the oxide, in 1944 by L. G. Magnusson and T. J. LaChapelle. ${ }^{2}$ 
All neptunium atoms contain 93 protons $(Z=93)$ and various numbers of neutrons $(N=134$ to 149$)$ within the atom's nucleus. There are no stable isotopes of neptunium, all are radioactive. ${ }^{3}$ The half-lives of the neptunium isotopes range from 1 minute (half-life for ${ }^{227} \mathrm{~Np}$ ) to millions of years (half-life for ${ }^{237} \mathrm{~Np}$ is $2.14 \times 10^{6}$ years). Even though all isotopes of this element are radioactive, neptunium, in trace amounts, is found in nature, being produced by neutron bombardment of natural uranium (the neutrons resulting from the spontaneous fission of natural uranium). Kilogram and larger quantities of ${ }^{237} \mathrm{~Np}$ have been produced as a by-product of plutonium production in nuclear reactors. This process is the principal source of this isotope, and these quantities are used in the investigation of the chemical and physical characteristics of this isotope and element.

\section{Radiological Characteristics}

The most recent available information regarding ${ }^{237} \mathrm{~Np}$ reports a radiological half-life of $2.1 \times 10^{6}$ years. ${ }^{4}$ This nuclide is principally produced in nuclear reactor fuel rods from the bombardment of ${ }^{238} \mathrm{U}$ with neutrons. Some naturally-occurring ${ }^{237} \mathrm{~Np}$ is produced when natural uranium ore is bombarded with neutrons generated as a result of spontaneous fission. The specific activity of this nuclide is about $26 \mathrm{MBq} / \mathrm{g}(675 \mu \mathrm{Ci} / \mathrm{g}){ }^{5}$

As is the case for some nuclides discussed in this report (for example, ${ }^{238} \mathrm{U}$, Chapter 15), the decay of ${ }^{237} \mathrm{~Np}$ is very complex. The principal decay chain from ${ }^{237} \mathrm{~Np}$ to the stable nuclide thallium-205 $\left({ }^{205} \mathrm{Tl}\right)$ is: ${ }^{6}$

$$
{ }^{237} \mathrm{~Np} \underset{\alpha}{2.14 \times 10^{6} \text { years }}{ }^{233} \mathrm{~Pa}[\alpha, \beta \text { decays }] \rightarrow{ }^{205} \mathrm{Tl}
$$

The gap between protactinium-233 $\left({ }^{233} \mathrm{~Pa}\right)$ and ${ }^{205} \mathrm{Tl}$ is filled with several alpha and beta decays until the stable end state is reached. For several of the decay processes, there are competing decay processes. Many of the alpha-decay processes also result in the emission of various energy gamma-rays, and the beta-decay processes result in the emission of various energy beta particles and gamma-rays. A very small fraction (much less than $1 \%$ ) of the decays of ${ }^{237} \mathrm{~Np}$ result in spontaneous fission. ${ }^{3,6}$ The fraction of decays resulting in spontaneous fission is not documented, but the half-life of this process is of the order of $10^{18}$ years, or approximately $5 \times 10^{11}$ as long as for alpha decay, which gives an indication of this fraction.

Only the effects associated with the direct decay of ${ }^{237} \mathrm{~Np}$ are presented in this chapter, not the effects from the decay of daughter nuclides. Obviously, these other nuclides will affect the behavior of neptunium in an LLW site and their effects need to be considered in any comprehensive study of the behavior of neptunium. The types and energies of the radiation associated with the subsequent decays are provided in the references.

The decay of ${ }^{237} \mathrm{~Np}$ results in the emission of alpha particles with several possible energies. ${ }^{4}$ Of these, nine particles account for $>97 \%$ of the decays (each of the nine accounts for at least $1 \%$ of the decays), and these range in energy from 4.64 to 4.87 million electron volts (MeV). Electromagnetic radiation is also emitted during the decay of a ${ }^{237} \mathrm{~Np}$ nucleus. The $\mathrm{x}$ - and gamma-ray energies range from 11 to 280 thousand electron volts $(\mathrm{keV})$. The most probable electromagnetic radiation energies are 17 , 
29 , and $87 \mathrm{keV}$. Finally, electrons may be emitted during the decay of ${ }^{237} \mathrm{~Np}$, with energies ranging up to $280 \mathrm{keV}$. Again, these emissions are only from the direct decay of ${ }^{237} \mathrm{~Np}$ and do not include the emissions from the subsequent decay of the ground states of resultant nuclides.

Approximately $47 \%$ of the decays of ${ }^{237} \mathrm{~Np}$ result in the emission of an alpha particle with an energy of $4.79 \mathrm{MeV}^{7}$ The range of these alpha particles is approximately $3.4 \mathrm{~cm}$ in air. Thus, even a small distance removed from a ${ }^{237} \mathrm{~Np}$ source would provide sufficient shielding from the alpha radiation. Therefore, this nuclide is toxic only if either inhaled or ingested.

In addition to alpha and electron particle radiation, the decay of ${ }^{237} \mathrm{~Np}$ can also result in $\mathrm{x}$ - and gamma-ray emission, with a maximum listed "major" energy of $145 \mathrm{keV}{ }^{3,6}$ The probability that the decay of a ${ }^{237} \mathrm{~Np}$ nucleus would result in the emission of a $145-\mathrm{keV}$ gamma ray is approximately $1 \%$, which is small but still finite.

Table 16-1 lists the radiotoxicity of several important radionuclides and Table 16-2 compares the electron emission energy associated with ${ }^{237} \mathrm{~Np}$ decay together with the maximum and average electron energies associated with electron emitters. ${ }^{237} \mathrm{~Np}$ is listed with other nuclides that have high toxicity in Table 16-1. This designation is based on Table I in Reference 8. The specific basis is not given for listing any of the nuclides in this classification (i.e., the basis for each category) beyond the general definition of toxicity in the reference. The ${ }^{237} \mathrm{~Np}$ is assumed to have a high toxicity principally because of the emission of relatively high-energy alpha particles, since neither the gamma-ray nor electron emissions would be considered high-energy. Another possible reason for this designation is the presence of one or more decay daughters. The most prevalent alpha particle energy of $4.78 \mathrm{MeV}$ is less than the maximum alpha particle energies for most of the other nuclides in this classification (i.e., $4.85 \mathrm{MeV}$ for plutonium-241 [ $\left.{ }^{241} \mathrm{Pu}\right] ; 5.49 \mathrm{MeV}$ for americium-241 [ $\left.{ }^{241} \mathrm{Am}\right]$; and $6.12 \mathrm{MeV}$ for curium-242 $\left.\left[{ }^{242} \mathrm{Cm}\right]\right)$.

\section{Chemical and Physical Characteristics}

Neptunium is a member of the actinide series of the periodic table, which includes actinium, thorium, protactinium, uranium, neptunium, plutonium, americium, curium, berkelium, californium, einsteinium, fermium, mendelevium, nobelium, and lawrencium. Actinide elements generally form trivalent cations and have soluble sulfates, nitrates, halides and sulfides. Their fluorides and oxalates are usually not soluble in acid. They form binary compounds with carbon, nitrogen, silicon, and sulfur, which are of interest because they are stable at high temperatures.

The actinide series is chemically similar to the lanthanide series, which is the group of elements between barium and hafnium. Although the members of the actinide and lanthanide series are generally chemically very similar, neptunium is not as similar to its lanthanide counterpart, promethium, as the other actinides are. In addition, there are other significant differences. For example, the members of the actinide series are more prone to complex formation, whereas most compounds formed with members of the lanthanide series are ionic in nature. ${ }^{9}$ Since many of the complexes are more soluble in water than other compounds, this means that the actinides can be extracted from soils or other areas of deposit by such cleaning agents as EDTA. 
Table 16-1. Comparison of the radiotoxicity of several important radionuclides (from Table I of Reference 8). ${ }^{a}$

\begin{tabular}{lll}
\hline Radiotoxicity & \multicolumn{1}{c}{ Group } & \multicolumn{1}{c}{ Nuclides } \\
\hline High toxicity & & ${ }^{237} \mathrm{~Np},{ }^{242} \mathrm{Cm},{ }^{241} \mathrm{Am},{ }^{238} \mathrm{U}$ \\
Medium toxicity & Upper subgroup A & ${ }^{129} \mathrm{I},{ }^{60} \mathrm{Co},{ }^{137} \mathrm{Cs}$ \\
Medium toxicity & Lower subgroup B & ${ }^{63} \mathrm{Ni},{ }^{99} \mathrm{Tc},{ }^{59} \mathrm{Ni},{ }^{14} \mathrm{C}$ \\
Low toxicity & & ${ }^{3} \mathrm{H},{ }^{99 \mathrm{~m}} \mathrm{Tc}$ \\
\hline
\end{tabular}

a. The definition of radiotoxicity, as stated in the reference, is "...the ability of the nuclide to produce injury, by virtue of its emitted radiations, when incorporated in a body."

Table 16-2. Average and maximum kinetic energies of electrons released during decay of several important radionuclides. (Information compiled from References 3, 6, 7, 10, 11, and 12.)

\begin{tabular}{lcc} 
& \multicolumn{2}{c}{ Released electron energy } \\
\cline { 2 - 3 } \multicolumn{1}{c}{ Radionuclide } & $\begin{array}{c}\text { Average energy } \\
(\mathrm{keV})\end{array}$ & $\begin{array}{c}\text { Maximum energy } \\
(\mathrm{keV})\end{array}$ \\
\hline Nickel-59 $\left({ }^{59} \mathrm{Ni}\right)$ & $4.1^{\mathrm{b}}$ & -7.7 \\
Tritium $\left({ }^{3} \mathrm{H}\right)$ & 5.7 & 19 \\
Nickel-63 $\left({ }^{63 \mathrm{Ni})}\right.$ & 17.1 & 67 \\
Curium-242 $\left({ }^{242} \mathrm{Cm}\right)$ & $39^{\mathrm{c}}$ & - \\
Iodine-129 $\left({ }^{129} \mathrm{I}\right)$ & 40 & 150 \\
Uranium-238 $\left({ }^{238} \mathrm{U}\right)$ & $43^{\mathrm{c}}$ & -156 \\
Carbon-14 $\left({ }^{14} \mathrm{C}\right)$ & 49 & 293 \\
Technetium-99 $\left({ }^{99} \mathrm{Tc}\right)$ & 85 & 500 \\
Neptunium-237 $\left({ }^{237} \mathrm{~Np}\right)$ & $89^{\mathrm{c}}$ & 1176 \\
Niobium-94 $\left({ }^{94} \mathrm{Nb}\right)$ & 156 & 1480 \\
Cesium-137 $\left({ }^{137} \mathrm{Cs}\right)$ & 195 & \\
Cobalt-60 $\left({ }^{60} \mathrm{Co}\right)$ & 94 & \\
\end{tabular}


Neptunium has one of the highest densities of all metals and has three crystalline structures in the solid phase. It is silvery in appearance and is chemically very reactive. The most important oxide, from the standpoint of stability, is $\mathrm{NpO}_{2}$, though $\mathrm{Np}_{3} \mathrm{O}_{8}$ is also stable, and is similar to $\mathrm{U}_{3} \mathrm{O}_{8}$ (the most important uranium oxide) in its chemistry. Neptunium can exist in several oxide states, 3, 4, 5, and 6. Its most stable state is 5 . It forms several compounds with the halides, including $\mathrm{NpF}_{6}$, which is similar in characteristics to $\mathrm{UF}_{6}$ (uranium hexafluoride). ${ }^{9}$

Neptunium has marked metallic properties. However, its chemical activity is lower than that of plutonium and americium, two other transuranic elements. Neptunium forms stable complexes with citric and lactic acids. In aqueous salt solutions, the solubility of neptunium varies. Among the soluble compounds are nitrate, halogen (except fluoride), perchlorate, and sulfate. The poorly soluble compounds are fluoride, oxalate, hydroxide, and phosphate. ${ }^{13}$

Table 16-3 summarizes some of the important chemical and physical characteristics of this element.

\section{Neptunium-237 Production}

Trace amounts of ${ }^{237} \mathrm{~Np}$ are found in nature. These are produced from naturally occurring uranium by neutron bombardment. A determination was made of the production of various nuclides, including ${ }^{237} \mathrm{~Np}$, due to natural radiation in geological formations by researchers at the Institute of Physics and Nuclear Techniques in Krakow, Poland. ${ }^{14}$ The most important production method for this nuclide was by

Table 16-3. Chemical and physical characteristics of neptunium (from References 11, 15, and 16).

\begin{tabular}{|c|c|}
\hline $\begin{array}{c}\text { Physical property } \\
\text { (units) }\end{array}$ & Neptunium data \\
\hline Melting point $(\mathrm{K})^{\mathrm{a}}$ & 910 \\
\hline Heat capacity@298 K (kJ/mole) & 0.0296 \\
\hline Electrical resistivity $(\Omega \cdot m)$ & $1.23 \times 10^{-6}$ \\
\hline Density $\left(\mathrm{g} / \mathrm{cm}^{3}\right)$ & $\begin{array}{l}\text { Alpha-20.25 } \\
\text { Beta-19.36 } \\
\text { Gamma-18.0 }\end{array}$ \\
\hline Crystal form ${ }^{\mathrm{b}}$ & $\begin{array}{l}\text { Alpha-orthorhombic } \\
\text { Beta-tetragonal } \\
\text { Gamma-body-centered cubic }\end{array}$ \\
\hline equals $-273.15 \mathrm{C},-459.67^{\circ} \mathrm{F}$ & \\
\hline
\end{tabular}


neutron bombardment of uranium, where the neutrons resulted from the interaction of alpha particles with the surrounding materials. The expected concentrations of ${ }^{237} \mathrm{~Np}$ are of the order of a few atoms $/ \mathrm{cm}^{3}$.

However, the amounts of ${ }^{237} \mathrm{~Np}$ that occur naturally are not significant compared to manmade sources. The principal means of producing this nuclide is by neutron bombardment of ${ }^{238} \mathrm{U}$ either in nuclear fuel during normal power operations in a reactor or by irradiating a uranium source. ${ }^{3,6}$ This nuclide is available as a radioactive source from several distributors. The International Atomic Energy Agency lists this nuclide from either French or United Kingdom sources in strengths ranging from 0.001 to 20 microcuries. ${ }^{17}$ The U.S. Department of Energy (DOE) is also a source for this nuclide, offering grams of this nuclide with $>97 \%$ purity. ${ }^{18}$

\section{Waste and Disposal Data on Neptunium-237}

This section discusses the types of activities that generate ${ }^{237} \mathrm{~Np}$ LLW, waste types and forms that contain ${ }^{237} \mathrm{~Np}$, and disposal data on ${ }^{237} \mathrm{~Np}$.

\section{Nuclear Reactors}

Since ${ }^{237} \mathrm{~Np}$ is principally produced by neutron bombardment of ${ }^{238} \mathrm{U}$, an obvious source of this nuclide is in the spent fuel of nuclear power plants. For example, a typical core load at the end of useful life contains $47 \mathrm{~kg}\left(33 \mathrm{Ci}\right.$ ) of ${ }^{237} \mathrm{~Np}$ (these values are based on a calculation of a typical $100 \mathrm{MT}$, ${ }^{235} \mathrm{U}$-fueled pressurized water reactor (PWR) core with an end-of-life burnup of 33,000 MWD/MT). ${ }^{\mathrm{a}}$ However, spent fuel is currently not being processed to remove this or any other potentially valuable nuclides and it remains encased in the fuel rods. Some contamination of the reactor coolant system (RCS) pipes is possible due to the presence of "tramp" uranium (uranium that is present on the outside of fuel rods, having been deposited there during the fabrication process). After irradiation, the fission and activation products can be transported with the coolant to other parts of the RCS and deposited there. When the plant is decommissioned, some of these radioactive nuclides, including ${ }^{237} \mathrm{~Np}$, will be shipped with the piping to LLW sites for disposal. The amount of ${ }^{237} \mathrm{~Np}$ that would end up in the disposal sites is not quantified.

\section{Medical, Academic Institutions, and Commercial Neptunium-237 Waste}

Very little information was found on medical, academic, and commercial uses for ${ }^{237} \mathrm{~Np}$. In a conversation with a representative of the American College of Radiology, it was stated that there were no known medical uses for this nuclide. ${ }^{b}$ This was further substantiated by conversations with a

a. Personal communication between J. P. Adams, Idaho National Engineering Laboratory (INEL), and M. L. Carboneau (INEL) regarding an ORIGEN2 calculation for a typical PWR, November 27, 1995.

b. Personal communication between J. P. Adams (INEL) and C. Sperry (American College of Radiology) on December 10, 1995. 
representative of the Society of Nuclear Medicine ${ }^{\mathrm{c}}$ and a representative of DuPont Pharmaceuticals. ${ }^{\mathrm{d}}$ Reference 11 indicates that ${ }^{237} \mathrm{~Np}$ can be used as a component in neutron detection instruments.

As stated in the previous section, this nuclide is available, in various purities, from several sources. Gram quantities (up to 7 grams per order) of ${ }^{237} \mathrm{~Np}$, with $>97 \%$ purity, are available from the Oak Ridge National Laboratory (ORNL), as an oxide powder. The encasement of this source is not given by Reference 18. Since gram quantities at this purity level were available, it is presumed that these were used to research the chemical, physical, and radiological characteristics of this nuclide. In a conversation with ORNL, it was determined that they no longer supply the oxide powder but do have supplies of ${ }^{237} \mathrm{~Np}$ at a purity $>99.999 \%$ in the form of a ceramic wire. This wire is doubly encased in stainless steel and is used as a commercial neutron dosimeter. ${ }^{e}$ The sources available from France and the United Kingdom are ${ }^{237} \mathrm{~Np}$ dissolved in $\mathrm{HCl}$. Again, the encapsulation of the source is not discussed in Reference 17.

\section{Disposal Data on Neptunium-237}

${ }^{237} \mathrm{~Np}$ has been deposited in LLW sites in Richland, Washington; Barnwell, South Carolina; and Beatty, Nevada. Figure 16-1 shows the activity deposited in these three sites as a function of time for the years 1986-1994. Deposition of this nuclide did not occur during some years at some sites. The data for these figures, as well as for Figures 16-2 and 16-3, were obtained from the Manifest information Management System Database. ${ }^{f}$ The magnitude of the release of ${ }^{237} \mathrm{~Np}$ into the environment at the weapons facilities is not known and could be significant, compared to that which has been cataloged at these three sites. Of the activity of this nuclide deposited at these three sites, more than $85 \%$ of it was deposited in 1993.

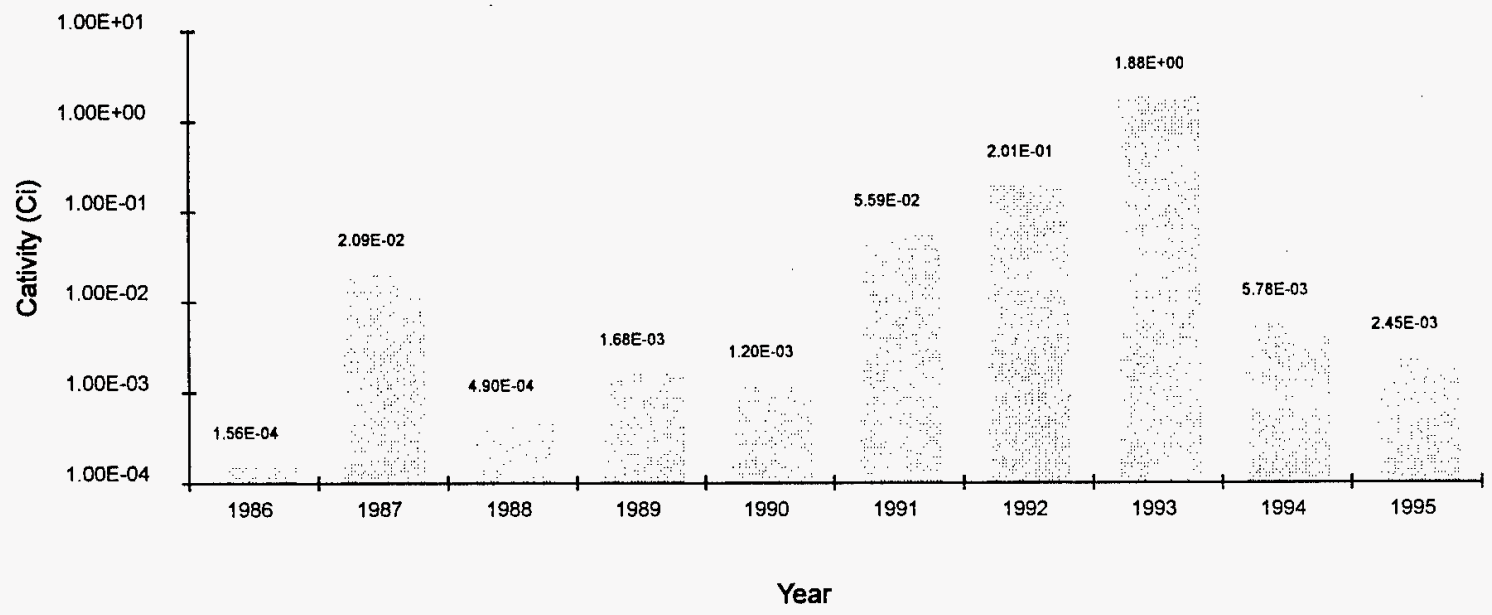

Figure 16-1. ${ }^{237} \mathrm{~Np}$ activity deposited at the Richland, Beatty, and Barnwell sites by year (log scale).

c. Personal communication between J. P. Adams (INEL) and S. Silver (SNM) on December 14, 1995.

d. Personal communication between J. P. Adams (INEL) and C. Mario (DP) on December 14, 1995.

e. Personal communication between J. P. Adams (INEL) and R. Cline (ORNL) on December 6, 1995.

f. Information provided through the DOE waste management system maintained by the National Low-Level Waste Management Program, INEL. 
Figure 16-2 shows the origins of the total depleted neptunium disposed at these three sites for the years 1986-1994. Only four generic origins are listed in this database: government-from sources associated with the government; industry -from other industrial sources; medical- sources associated with hospitals and medical laboratories, excluding pharmaceutical manufacturing; and utility-from nuclear powered electricity generating plants. Nearly all ( $>98 \%)$ of the total neptunium disposed of at these three sites is from utilities.

In addition to listing the total activity of ${ }^{237} \mathrm{~Np}$ stored at these LLW sites, the database also includes information about the form the waste is in. This specific information is only available for the Hanford and Beatty sites. There is insufficient information in the database for the Barnwell site to extract these specific data. Since more than $98 \%$ of the total deposited ${ }^{237} \mathrm{~Np}$ was deposited in the Barnwell site, the specific information regarding waste streams may not be totally accurate.

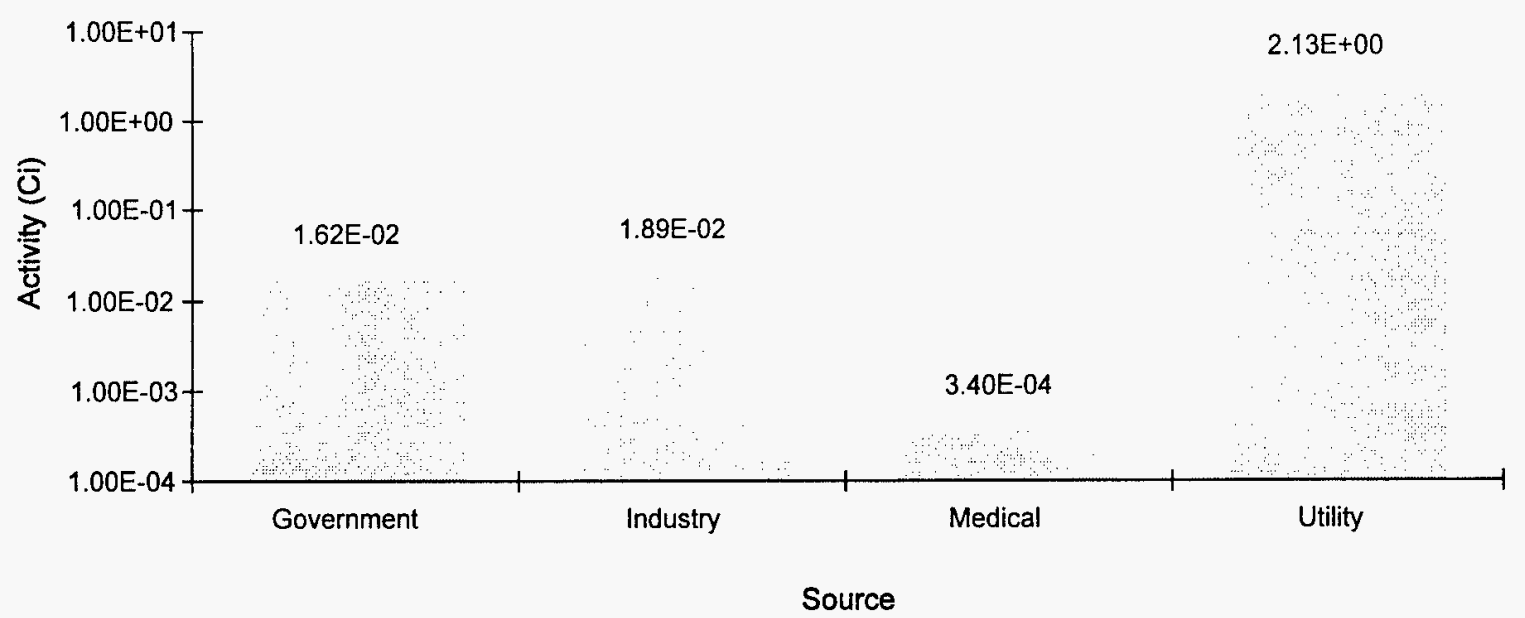

Figure 16-2. ${ }^{237} \mathrm{~Np}$ activity deposited at the Richland, Beatty, and Barnwell sites by source (log scale).

There are a total of 20 different waste streams or waste types, depending on the initial waste form (for example, reactor component) and processing prior to disposal (for example, solidified). Not every waste type is represented for each year. Rather than summarize each of these different waste types, they were grouped into a smaller number for presentation in this chapter. Figure 16-3 summarizes the total activity deposited in the Richland and Beatty sites as a function of waste type. The most prevalent waste type is dry solid waste (nearly 65\%). There are four waste types of secondary importance, activated reactor hardware, cartridge filters, dewatered resins, and non-compacted dry waste. The other waste types are of lesser importance. The interested reader is referred to Reference 19 for a more detailed discussion of these waste types. 


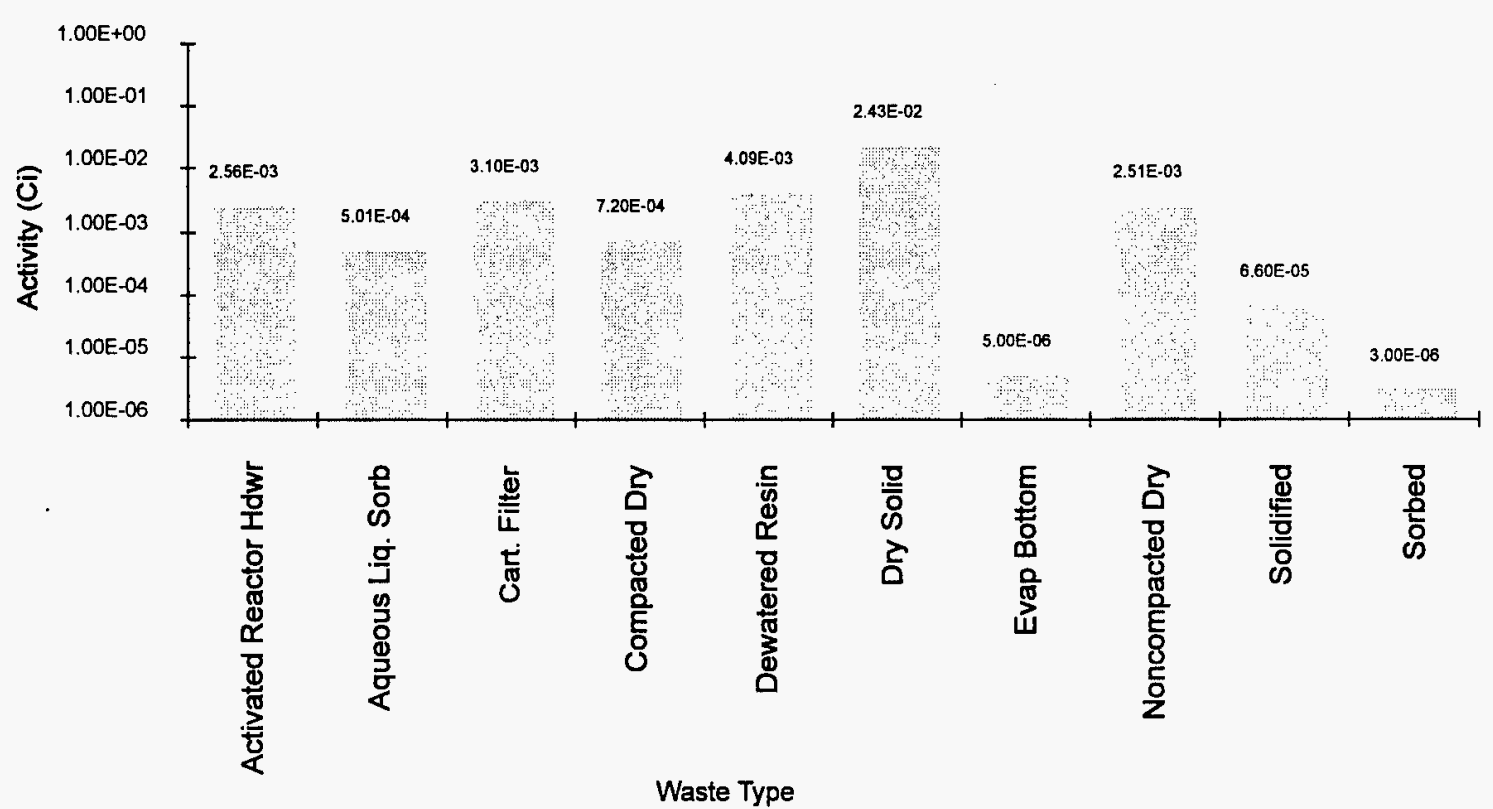

Figure $16-3 .{ }^{237} \mathrm{~Np}$ activity deposited at the Richland and Beatty sites by waste type (log scale).

\section{Behavior of Neptunium-237 in the Environment}

\section{Neptunium-237 in Soils}

Understanding the behavior of radioactive materials, such as ${ }^{237} \mathrm{~Np}$, in the soil is important in assessing the possibility of transport of these radionuclides through the biosphere. It is important to understand the interactions between radionuclides and various media along the path to the biosphere, whether disposal is in deep or shallow rock caverns or in shallow overburden facilities.

Four parameters were reported to be essential in accurately predicting radionuclide concentrations in soil from either contaminated ground water or irrigation water. ${ }^{20}$ The four parameters are: (a) soil retention, (b) annual precipitation, (c) soil texture, and (d) depth to the water table. The soil retention parameter represents the solid/liquid partition coefficient and is denoted by the symbol: $K_{d} \cdot K_{d}$ is defined by $K_{d}=C_{s} / C_{b}$, where $C_{s}$ is the neptunium concentration in the soil ( $\mu \mathrm{g}[\mathrm{Np}] / \mathrm{gram}$ of soil) and $\mathrm{C}_{1}$ is the neptunium concentration in the groundwater $(\mu \mathrm{g} \mathrm{Np}] / \mathrm{mL}$ of liquid). Therefore, the units of $\mathrm{K}_{\mathrm{d}}$ are $\mathrm{mL} / \mathrm{g}$ (i.e., $\mathrm{mL}$ of water per gram of soil). This empirical model combines all soil retention mechanisms into a simple linear partition relation between the soil and the surrounding groundwater. This model assumes that the neptunium concentrations in groundwater and soil are in equilibrium with each other. Using this definition for $\mathrm{K}_{\mathrm{d}}$, it follows that the larger the value (that is, the higher the radionuclide concentration in the soil relative to that in the groundwater), the slower the migration of the radionuclide relative to groundwater flow. Therefore, $K_{d}$ can be thought of as a measure of the amount of "fixing" or holdup in the soil.

Typically, $K_{d}$ is measured under laboratory conditions, using samples that are relatively homogenous, and where it can be assured that equilibrium conditions are met. Applying these values to specific soils in the field can be difficult because actual soils are generally inhomogeneous and there are uncertainties as to how long it takes for the neptunium concentrations in the soil and groundwater $\left(\mathrm{C}_{\mathrm{s}}\right.$ and 
$\mathrm{C}_{1}$ ) to reach equilibrium with each other. Therefore, one must be careful to ensure that soil samples used in laboratory studies are as closely representative of the field as possible. Even though the soil samples do not precisely match conditions in the field, $K_{d}$ values from laboratory studies can be used in computer models that extrapolate data from laboratory experiments and field studies. In addition, some experiments are conducted using intact field samples to validate the laboratory $\mathrm{K}_{\mathrm{d}}$ values and to study the effects associated with soil inhomogeneity.

Reference 21 lists the range of $\mathrm{K}_{\mathrm{d}}$ for ${ }^{237} \mathrm{~Np}$ as 0.2 to $929 \mathrm{~mL} / \mathrm{g}$ for various soils and clays. The mean and standard deviation of the distribution are 2.4 and $2.3 \mathrm{~mL} / \mathrm{g}$, respectively, which is fairly low for actinides.

Researchers at the Chalmers University of Technology in Goeteborg, Sweden studied the sorption behavior of neptunium in igneous rock. ${ }^{22}$ Although four types of granite were included in the overall study, only two were used specifically to measure $\mathrm{K}_{\mathrm{d}}$ for neptunium. The measured values were very similar, $0.032-0.1 \mathrm{~m}^{3} / \mathrm{kg}$, and indicate that neptunium does not appreciably adsorb onto this rock type.

Another laboratory study was performed by scientists at the Paul Sherer Institute in Switzerland. ${ }^{23}$ This was a study of the sorption of neptunium on various types of clay soils. The resultant "sorption coefficients" (assumed to be similar to the $K_{d}$ discussed above) were measured as a function of time and $\mathrm{pH}$, and ranged approximately from 20 to 1,100 (units were not given in the reference). They concluded that the only effect of $\mathrm{pH}$ on the first clay type (molasse clay) was on the time to reach equilibrium, whereas the effect of $\mathrm{pH}$ on the second type (kaolinite clay) was a dramatic increase in sorption coefficient with higher $\mathrm{pH}$ (less acidic) soil.

Scientists at the Pacific Northwest National Laboratories measured the effects of soil weathering on the sorption of ${ }^{237} \mathrm{~Np},{ }^{241} \mathrm{Am}$, and ${ }^{99} \mathrm{Tc} .{ }^{24}$ The two soils selected for this study were from eastern Washington (arid, high silt) and South Carolina (humid, high clay). In addition, the soil content of sodium and calcium was varied. The soil concentration of sodium did not significantly affect $\mathrm{K}_{\mathrm{d}}$ for neptunium, though the concentration of calcium did. Values of $K_{d}$ were in the range from 0.16 to $4 \mathrm{~mL} / \mathrm{g}$, depending on soil type and ion concentration.

Scientists at the University of California in Los Angeles measured both the sorption and extractability of several transuranic nuclides $\left({ }^{237} \mathrm{~Np},{ }^{239} \mathrm{Pu},{ }^{244} \mathrm{Cm}\right.$, and ${ }^{241} \mathrm{Am}$ ) as a function of soil $\mathrm{pH} .{ }^{25}$ Seven widely different soil types were included in the study. The values for $\mathrm{K}_{d}$ ranged from as low as 3 for low pH soils to as high as 929 for high $\mathrm{pH}$ soils (the units were not provided in the article but are believed to be $\mathrm{mL} / \mathrm{g}$, based on the units used to describe the experimental technique). Of the four transuranic nuclides studied, neptunium had the lowest values of $K_{d}$. The extractibility (a measure of the ease with which neptunium can be removed from contaminated soils) was a strong function of soil $\mathrm{pH}$, higher extractibility at low $\mathrm{pH}$ and much lower, at high $\mathrm{pH}$. Among the soils studied, the extractibility of neptunium was shown to be consistently greater than for the other nuclides included in the study. For all values of $\mathrm{pH}$, they concluded that neptunium has by far the highest mobility in mineral soils.

Scientists at Washington State University measured the diffusion of neptunium in soils (that is, movement of neptunium in the absence of mass transportation by groundwater, for example). ${ }^{26}$ These scientists concluded that, absent mass transport mechanisms, such as wind or moving water, neptunium 
would migrate only $26 \mathrm{~cm}$ per thousand years. Thus, diffusion of this element may not be a factor in migration analyses for repositories.

Several studies have been conducted to measure neptunium concentrations in soils, either as a result of world-wide fallout from atmospheric weapons testing, from the severe accident that occurred in the Chernobyl power plant, or from other sources. One of the Chernobyl-induced contamination studies is reported in Reference 27. While this reference emphasizes the measurement technique rather than the experimental results, it does include measurements of the accident-induced soil concentrations within the immediate vicinity of the reactor. The concentrations varied from 0.003 to 0.58 parts per billion (ppb) by weight, depending most strongly on distance from the damaged reactor site.

Researchers from Germany and Japan conducted a joint study of the vertical distribution of ${ }^{237} \mathrm{~Np}$ in undisturbed grasslands as a result of weapons testing fallout. ${ }^{28}$ The purpose of this investigation was to determine the observed weapons fallout of this nuclide in various layers of undisturbed grassland in Germany. More than $80 \%$ of the fallout occurred prior to 1965 , nearly 30 years prior to this study. The results of this study indicated that neptunium has a higher mobility in grassland soil than the other radionuclides included in the study, ${ }^{239,240} \mathrm{Pu},{ }^{241} \mathrm{Am}$, and ${ }^{137} \mathrm{Cs}$, though the differences were not large.

Another study of the distribution of ${ }^{237} \mathrm{~Np}$ due to fallout was conducted by scientists at the Kanazawa University in Japan. ${ }^{29}$ The authors make the point that this nuclide can be present either as a result of direct fallout or as a result of the decay of ${ }^{241} \mathrm{Am}$ and ${ }^{241} \mathrm{Pu}$. The fallout-based concentrations of ${ }^{237} \mathrm{~Np}$ were measured in several paddies in Japan. The range of concentrations was from 0.39 to 4.55 $\mathrm{mBq} / \mathrm{kg}\left(1.05\right.$ to $\left.12.3 \times 10^{-14} \mathrm{Ci} / \mathrm{kg}\right)$. The residence time for neptunium in the soil was analyzed and compared to plutonium and cesium isotopes and was found to be shorter than either of these elements.

Researchers in the United Kingdom have measured the contamination of neptunium in soils caused by discharges from the Sellafield nuclear fuel reprocessing facility. ${ }^{30}$ The maximum soil concentration of ${ }^{237} \mathrm{~Np}$ was $2.38 \mathrm{~Bq} / \mathrm{kg}\left(6.43 \times 10^{-11} \mathrm{Ci} / \mathrm{kg}\right)$, compared to $3,600 \mathrm{~Bq} / \mathrm{kg}\left(9.7 \times 10^{-8} \mathrm{Ci} / \mathrm{kg}\right)$ for ${ }^{239,240} \mathrm{Pu}$ in the same sample. Much of the measured neptunium was found at relatively great depths in the soil, implying that neptunium has a greater mobility than the other nuclides included in the study.

Scientists at the Los Alamos National Laboratory studied the effects of various naturally occurring minerals on the mobility of ${ }^{237} \mathrm{~Np} .{ }^{31}$ This study showed that the presence of even very small concentrations of iron oxides and oxyhydroxides, such as hematite and goethite, can significantly retard the migration of neptunium by sorbing this nuclide. The authors updated this study in 1993 by specifically applying it to conditions at the proposed repository at Yucca Mountain in Nevada. ${ }^{32}$ The same conclusion was reached regarding the ability of trace amounts of oxide minerals to retard the migration of neptunium. Additionally, neptunium sorption increases rapidly with increasing soil $\mathrm{pH}$ and with the presence of silicates in the Yucca Mountain soils.

The sorption and mobility information for neptunium was included in a calculation of the release of radionuclides from a proposed deep geological repository in Sweden. ${ }^{33}$ This was a calculation of the actual repository geometry, with an assumed breach of the waste containers 200 years after repository closure. Of the various radionuclides included in this study, three dominated the radioactive release at long times (greater than $10^{6}$ years), ${ }^{237} \mathrm{~Np},{ }^{242} \mathrm{Pu}$, and ${ }^{233} \mathrm{U}$. The total radioactive release is not expected to exceed $1 \mathrm{mBq} /$ year $\left(3 \times 10^{-14} \mathrm{Ci} /\right.$ year $)$ for all nuclides, including ${ }^{237} \mathrm{~Np}$. 
In summary, of all the actinides included in these various studies (both rigorous, laboratory measurements of $\mathrm{K}_{\mathrm{d}}$ and field studies of existing neptunium soil profiles), neptunium is expected to be least likely to be adsorbed in soil. Thus, absent the presence of certain soil minerals that could increase soil adsorption, neptunium is expected to be the most mobile of the actinides expected to reside in LLW sites.

\section{Neptunium-237 in Water}

The fraction of neptunium that does not adsorb onto soil particles is available to be transported with bulk groundwater. Since the diffusivity of neptunium in the absence of water is so small, dissolution by and movement with groundwater is one of the principal transport mechanisms for ${ }^{237} \mathrm{~Np}$ to be removed from a depository (another principal transport mechanism is plant uptake-discussed in the next section) and the characteristics of this nuclide in water are very important to the understanding of this transport. Some of the same mechanisms that govern the behavior of this nuclide in groundwater also influence its behavior in soil and the boundary between these two behaviors is somewhat blurred. Thus, some of the information in this section could have been placed in the previous section with equal validity.

Scientists at the Kanazawa University studied the behavior of several fallout-originated nuclides, including ${ }^{237} \mathrm{~Np}$, in a series of five lakes near the Sea of Japan. ${ }^{34}$ These lakes were chosen because of their salinity, ranging from one freshwater lake through three increasingly brackish lakes, to the fifth lake which is essentially sea water. Assumptions had to be made regarding the origin of the radionuclides, and depth profiles of the nuclides were measured. Concentrations of ${ }^{237} \mathrm{~Np}$ ranged from 1.5 to 17.2 $\mathrm{mBq} / \mathrm{kg}$ (4.1 to $\left.46 \times 10^{-14} \mathrm{Ci} / \mathrm{kg}\right)$ of sediment. Based on a comparison of concentrations between the nuclides, it was concluded that $\mathrm{Np}$ is more soluble than $\mathrm{Pu}$.

Researchers at the Lawrence Berkeley Laboratory performed a laboratory study of the solubility characteristics of neptunium, using groundwater from the Yucca Mountain, Nevada area. ${ }^{35}$ Among other parameters, the dependence of solubility on $\mathrm{pH}$ and temperature was measured for isotopes of plutonium, neptunium, and americium. The chemical form of ${ }^{237} \mathrm{~Np}$ used in this study was $\mathrm{NpO}_{2}^{+}$. There was no uniform trend of solubility with different temperatures, though there were large differences over the temperature range of 25 to $90^{\circ} \mathrm{C}$. There was, however, a fairly strong dependence on $\mathrm{pH}$-the solubility decreased with increasing $\mathrm{pH}$ over the range from 5.9 to 8.5 . Thus, the mobility of this nuclide can be decreased by increasing the alkalinity of the soil.

Another parameter that can affect the neptunium chemistry, and, hence, the mobility of this element in groundwater, is the oxidation potential. Researchers at the University of Helsinki studied the sorption potential of neptunium in groundwater under both oxidizing and reducing conditions. ${ }^{36}$ Surplus (or deficient) oxygen can cause neptunium to be in a higher (or lower) oxidation state and this can affect its behavior in water and in soils. With excess oxygen (oxidizing conditions) in the water, approximately one-half of the neptunium was sorbed onto the rock surfaces. Under oxygen-neutral (anoxic) conditions, approximately $70-80 \%$ of the dissolved neptunium was removed from the water and sorbed onto rock surfaces. For both of these cases, the dominant oxidation state was $\mathrm{Np}(\mathrm{V})$ (oxidation state of 5 ). When the conditions were changed to a reducing environment, the oxidation state was changed to $\mathrm{Np}(\mathrm{IV})$ and essentially all of the neptunium was removed through sorption onto the rocks. 
One of the disposal options being considered by researchers at the Joint Research Centre - Ispra, is deposition in geological salt domes. ${ }^{37}$ Therefore, a study was performed of the behavior of neptunium in the case that groundwater were to intrude into the salt dome and form a brine. The test included both oxidizing and slightly reducing (anoxic) conditions. The retardation factor (a measure of the delay of neptunium transport relative to the water transport velocity) was approximately 40 for the oxidizing conditions $\left(\mathrm{K}_{\mathrm{d}}=7\right)$ and 160 for anoxic conditions $\left(\mathrm{K}_{\mathrm{d}}=30\right)$.

Researchers at the Joint Research Centre - Ispra performed a laboratory study of the mobility of ${ }^{237} \mathrm{~Np}$ in soils of different origins. ${ }^{38}$ Columns of various soils were set up and contaminated with ${ }^{237} \mathrm{~Np}$. Then, synthetic groundwater was passed through the columns and the retardation factor, the ratio of the velocity of the water to that of the nuclide, was measured. There was a wide range of retardation factors measured in this series of experiments, from 39 to $>5,000$. However, in each case, the retardation factor of ${ }^{237} \mathrm{~Np}$ was much smaller than that of plutonium (plutonium retardation factors ranged from 9,000 to $60,000)$, indicating that neptunium migrates much faster than plutonium.

Finally, an overall calculation was made of the migration of ${ }^{237} \mathrm{~Np}$ within and out of the Yucca Mountain repository. In the first analysis case, it was assumed that water was dripping through cracks of a failed waste container (wet-drip case) and slowly filling a container and reacting with the spent fuel. ${ }^{39}$ In the second case, it was assumed that the container completely failed and presented no barrier to contact between groundwater and the spent fuel (wet-continuous case). The release rate of neptunium in the wet-drip case was limited by its elemental solubility. The release rate is constant with time and is proportional to the water infiltration rate. The wet-continuous case resulted in more relative release of neptunium and provides the most conservative model for this calculation. Assuming this case, the fractional release rate for ${ }^{237} \mathrm{~Np}$ is of the order of $10^{-8}$ per year.

In summary, neptunium appears to be more soluble in water than other actinides, such as plutonium, and therefore, more likely to be transported in groundwater. However, the absolute solubility of neptunium depends on several factors, including $\mathrm{pH}$ and oxidation potential. To correctly characterize neptunium transport in groundwater, these factors need to be understood.

\section{Neptunium-237 in Plants}

One of the principal mechanisms whereby neptunium can cause a radiation dose to humans is through the food chain. Plants grown on contaminated soil can take up the neptunium and when these plants are eaten, either directly by man or by animals, the neptunium enters the food chain and can eventually be ingested into man. Thus, it is important to understand the ability of plants to absorb neptunium, either directly onto the leaves and stalk or through the roots.

As part of the environmental assessment of buried wastes at the Hanford DOE site, researchers studied the ability of two native plants to absorb ${ }^{237} \mathrm{~Np}$ from contaminated soil..$^{40}$ The two plants included in this study were tumbleweed and cheatgrass, which were grown on contaminated soil for two months in a controlled environment. Shoot uptake measurements indicated that relatively large amounts of ${ }^{237} \mathrm{~Np}$ were absorbed through the roots ( $>2 \%$ of the total neptunium content in the soil), much more than the other contaminants. Uptake by cheatgrass was much less, by an order of magnitude. 
One measure of the ability of plants to absorb contaminants from the soil is the concentration ratio, or the ratio of the concentration of ${ }^{237} \mathrm{~Np}$ in the soil to that in a plant (usually based on dry weight). The smaller the ratio, the higher the uptake of a given nuclide. The concentration ratio of soybeans was measured for several radionuclides, including ${ }^{237} \mathrm{~Np}$, in a study performed by scientists at the University of California at Los Angeles and supported by the DOE. ${ }^{41,42}$ Of the four transuranic elements included in the study, neptunium, americium, curium, and plutonium, neptunium is much more easily absorbed and concentrated in soybeans than any of the others (generally several hundred times more available to the plant than plutonium and between 5 and 50 times more available than either americium or curium). The concentration ratio varied among the various soil types, as did the relative uptake of neptunium compared to the other elements. This has a direct bearing on the degree of hazard represented by neptunium relative to the other three transuranic elements. As for all these actinides, however, neptunium tends to concentrate more in the stems and leaves and less in the edible parts of the plant, such as the pods and seeds. This would reduce the amount of neptunium that is ingested since generally the pods and seeds are preferentially eaten.

The same laboratory also studied the behavior of peas grown on contaminated soils. ${ }^{43}$ As was the case with soybeans, peas tend to concentrate neptunium much more readily than plutonium, curium or americium, regardless of soil type or part of the plant being analyzed. These results are also consistent with those from a similar study conducted by scientists at PNNL. ${ }^{44}$ The concentration ratios of neptunium in the seeds $\left(10^{-3}-10^{-4}\right)$ were less than that in the leaves $\left(10^{-1}-10^{-2}\right)$ or stems $\left(10^{-2}\right)$ (the units for these values are $[\mathrm{pCi} / \mathrm{g}$ dry vegetation $] /[\mathrm{mCi} / \mathrm{Lysimeter}])$.

A third part of this study was to examine the effect of a chelating agent, DTPA, on the concentration ratio of ${ }^{237} \mathrm{~Np}$ in bush beans and barley. ${ }^{45.46}$ DTPA is used to remove various contaminants by making them more soluble in water. The study was conducted to determine whether the use of this agent also increases plant uptake of this nuclide. Without DTPA, the concentration ratio of ${ }^{237} \mathrm{~Np}$ was two orders of magnitude higher than for ${ }^{244} \mathrm{Cm}$ in both plant types. Addition of DTPA to the soil increased the ability of the plants to absorb the curium nuclide by two to three orders of magnitude but had little effect on the concentration ratio for ${ }^{237} \mathrm{~Np}$, possibly because the concentration ratio for neptunium was already relatively high.

The last study included in this section concerns the potential reforestation of an LLW burial ground at the Savannah River Site. ${ }^{47}$ If this site were to be completely abandoned in the future, the study concluded that forest vegetation will eventually return. Thus, this study was conducted to measure the ability of various types of plants to absorb transuranic radionuclides, including ${ }^{237} \mathrm{~Np}$, from the contaminated soil in the burial ground. The burial trenches are nominally 20 feet deep and are capped with four feet of clean soil, leaving a buffer zone of approximately 20 feet between the bottom of the trench and the water table in the region. Three types of trees, loblolly pine, sweetgum, and willow oak, were planted over both the contaminated area and a clean area and the uptake of the various radionuclides was measured. The researchers concluded that the tree roots will extract transuranic isotopes from the buried waste. However, the amount of radionuclide moved from the trenches to the surface is small and the level in the trees is expected to be very low. 
The uptake of neptunium into plants can be an important transport mechanism for this nuclide. This nuclide tends to be more easily taken up into plants than other nuclides, such as americium, curium, and plutonium, though the distribution within the plants is more nearly uniform than for these other elements.

\section{Neptunium-237 in Air}

Because of the long half-life of ${ }^{237} \mathrm{~Np}$, nearly all of it that has been produced by human activities still exists. Therefore, the presence of this nuclide in the environment as a result of atmospheric nuclear weapons testing, which ended in the 1970 s, and as a result of the Chernobyl reactor accident is of interest.

Scientists at the Los Alamos National Laboratory conducted a study of the production of ${ }^{237} \mathrm{~Np}$ during atmospheric weapons testing by all nations. ${ }^{48,49}$ The concentrations of this nuclide and of ${ }^{239} \mathrm{Pu}$ were measured in soil samples from Pennsylvania and Massachusetts. The resultant atom ratio of 0.7 atoms of ${ }^{237} \mathrm{~Np}$ per atom of ${ }^{239} \mathrm{Pu}$ was used, in conjunction with the total estimated production of the plutonium nuclide, to indicate that approximately three tons (nearly 3,000 kg) of ${ }^{237} \mathrm{~Np}$ were produced and dispersed into the atmosphere.

Reference 50 was a study into the relative importance of airborne effluents, compared with root uptake, on the transport of radionuclides to man. This study concluded that for the case where the plant/soil concentration ratio exceeds 0.4 or the gastrointestinal absorption fraction exceeds $10^{-4}$, the food chain pathway will be more important than inhalation (airborne) paths for particles of respirable size. Since the listed plant/soil concentration ratio for ${ }^{237} \mathrm{~Np}$ is of the order of 0.1 or less, one could conclude that under some circumstances airborne paths are potentially dominating for this nuclide.

\section{Behavior of Neptunium-237 in the Human Body and in Animals}

This section summarizes several studies of the behavior of ${ }^{237} \mathrm{~Np}$ in the human body and in animals. Since ${ }^{237} \mathrm{~Np}$ is principally an alpha emitter, the human hazard from this nuclide is dominated by internal dose when the nuclide is either ingested or inhaled. Neptunium was the first transuranic element to be investigated in an animal-the initial studies of ${ }^{239} \mathrm{~Np}$ were completed in $1943 .{ }^{51}$ Both exposure pathways are important in the understanding of the hazard this nuclide presents to man. This nuclide can become airborne by weathering and resuspension due to wind (for example, at a waste burial site). Ingestion can occur when plants take up the nuclide from contaminated soil and then are themselves either directly ingested by humans or first ingested by animals, which are in turn eaten by humans. A number of factors can influence the pathway to humans, including chemical form of the nuclide, particle size distribution (for the case of aerosols), water and plant concentration effects, etc. Where the specific studies included a discussion of these effects, they are also summarized.

When administered by injection into animals, ${ }^{237} \mathrm{~Np}$, in either nitrate or citrate form, is deposited mainly in the skeletal system (32-44\%), liver (9-16\%), and kidneys (2-6\%). However, this nuclide is only poorly absorbed from the gastrointestinal tract $(<3 \%) .{ }^{13}$ The biological effect of this nuclide depends on the amount administered. If the concentrations are very low, the biological effect is dominated by its radioactivity. If the concentrations are high, the effect is dominated by its chemical toxicity. Inhalation of this nuclide results in a relatively rapid removal from the lungs and a stable 
concentration in the bones, independent on whether the chemical form is nitrate or citrate. The removal has two effective half-lives, 15-24 days for the short-lived component and 150-170 days for the long-lived component.

French scientists studied the uptake of neptunium from sea water by some marine animals. ${ }^{52}$ Among the actinides, neptunium possesses unique physico-chemical characteristics that make it very different from uranium, plutonium, and americium and, therefore, must be studied by itself rather than trying to extrapolate its behavior from that of the other actinides. It is more closely similar to the alkali and alkaline-earth metals in its chemical behavior. There were large differences between the uptake of neptunium for the two marine animals included in this study. One of the animals tended to concentrate ${ }^{237} \mathrm{~Np}$ very readily, with concentration factors of the order of 30-40 (for the whole organism after 13 days in the contaminated sea water), whereas the factors for the other animals were of the order of 2 . This indicates that care must be taken when extrapolating data between different animal species. In both cases, the concentration factors were much lower than corresponding factors for ${ }^{239} \mathrm{Pu}$ and ${ }^{241} \mathrm{Am}$.

Scientists in Scotland measured the ability of mussels, winkles, and prawns to concentrate ${ }^{237} \mathrm{~Np}$ from sea water and food..$^{53}$ The various parts of each marine animal were examined and the distribution of this nuclide within the atimal was measured. For all three animal types, the highest concentrations were in the nonedible parts of the animals The edible parts had the lowest concentrations. This was independent of whether the neptunium was in the sea water or in the food chain.

Several studies have been conducted to determine the behavior of ${ }^{237} \mathrm{~Np}$ in terrestrial animals. Since rats are often used in studies that are extrapolated to man, scientists from the Pacific Northwest National Laboratory measured the absorption of this nuclide in the gastrointestinal tract of these animals. ${ }^{54}$ This study concentrated on the effect of iron in the diet of rats relative to the absorption and retention of this nuclide. The study showed that the lack of iron in the diet of rats results in a factor of 7 increase in the absorption of ${ }^{237} \mathrm{~Np}$, although the excretion through urine also significantly increased.

The same scientists performed a similar study of the behavior of inhaled neptunium in rats. ${ }^{55}$ Most of the inhaled dose was transferred to the gastrointestinal tract and most of the rest was in the skeletal system. The clearance half-life from the lung had three components, 1 day, 35 days, and 10,000 days (only $3 \%$ of the original dose remained in the lung after 90 days). The half-life for skeletal retention was 2,500 days.

Since the radiological half-life of ${ }^{237} \mathrm{~Np}$ is so high, the removal rate from the body is dominated by biological processes. The biological half-life is a function of both the chemical form of the nuclide and the organ from which it is being removed. Reference 56 lists the biological half-life for this nuclide, assuming it is either a chloride or a sulfate, as being 54,000 days (148 years) for the liver, 64,000 days ( 175 years) for the kidneys, 73,000 days (200 years) for bone and 39,000 days (106 years) for the total body.

Researchers at the University of California at Berkeley studied the distribution of ${ }^{237} \mathrm{~Np}$ in a monkey. ${ }^{51}$ The study of this nuclide in an adult Macaque monkey was undertaken, in part, to upgrade the biological data for this nuclide using an animal that is similar to man and to provide detailed distribution 
information that can be compared to data from other actinides. Four days after injection of the nuclide, nearly $1 / 2$ of the original amount had been excreted and most of the rest resided in the skeletal system, which is qualitatively similar to data taken using rats.

Researchers at the Argonne National Laboratory measured the effects of fasting on the absorption of ${ }^{237} \mathrm{~Np}$ through the gastrointestinal tract using adult baboons. ${ }^{57}$ In this study, the nuclide was ingested both by animals after fasting 24 hours and by animals that had recently been fed normally. The results showed that fasting animals absorbed between 5 and 50 times as much ${ }^{237} \mathrm{~Np}$ in the gastrointestinal tract as animals that were not fasting. The authors concluded that a similar effect would be present in humans and should be accounted for in dose calculations.

The final animal study included in this chapter is of the transfer of ${ }^{237} \mathrm{~Np}$ across the placenta in pregnant rats. ${ }^{58}$ This study is of interest, of course, due to the potential contamination of a pregnant woman and the concern that the fetus may also become contaminated. The study concluded that despite a relatively high degree of contamination in the female, only a very small fraction was transferred across the placenta into the fetus. The authors concluded that the placenta and fetal membranes are effective barriers to the free passage of ${ }^{237} \mathrm{~Np}$ from the mother to the fetus.

Swedish researchers have reviewed the standard parameters used to calculate dose to radiation workers and have proposed some modification relative to ${ }^{237} \mathrm{~Np} .{ }^{5}$ Based on research results stated in the study, the assumed fraction of this nuclide absorbed in the gastrointestinal tract could safely be lowered by about a factor of ten. Additionally, the study noted that neptunium acts more like calcium than plutonium in the bones and thus would be tied up in the mineral portions of the skeletal system. This means that the subsequent irradiation of the sensitive parts of the bone, the endosteal surfaces and red bone marrow, would be reduced, due to shielding, and that the resultant annual limits of intake (ALI) value for ${ }^{237} \mathrm{~Np}$ could be safely increased. This is reflected by the dose levels experienced as a result of a given inhalation of ${ }^{237} \mathrm{~Np}$-namely, that the dose to the endosteal surfaces of the bone are approximately 10 higher than the dose to the red bone marrow. ${ }^{59}$ For an ingested mass, the ratio of doses to the red bone marrow and endosteal surfaces is similar.

Researchers from the Los Alamos National Laboratory have studied the amount of human contamination resulting from the release of ${ }^{237} \mathrm{~Np}$ by atmospheric weapons testing. ${ }^{60}$ Samples were collected, at autopsy, from lung and liver tissues and analyzed for contamination by this nuclide. Additionally, ${ }^{239} \mathrm{Pu}$ measurements were made of the same tissues. The average ratio of ${ }^{237} \mathrm{~Np}$ to ${ }^{239} \mathrm{Pu}$ atoms was 0.04 . Since the atom ratio of these two nuclides in the atmospheric fallout is 0.7 , these data suggest that humans preferentially expel neptunium from the lungs, relative to plutonium. This observation is consistent with the conclusion in Reference 49 that neptunium is excreted from the body more quickly than plutonium. Additionally, the data suggest that the neptunium expelled from the lung does not concentrate in the liver. This reference additionally concludes that the concentration of ${ }^{237} \mathrm{~Np}$ in the body will be correspondingly low and that observable health effects attributable to this nuclide will be very difficult to measure.

Several studies have reported the potential radiological impact due to release of ${ }^{237} \mathrm{~Np}$ from repositories. One such study, performed by scientists in Argentina, was of release from a granite repository. ${ }^{61}$ The repository, as designed, would include transforming the waste into a glass form, 
sealing it in stainless steel containers, and placing the containers in a granite vault, several hundred meters deep. The calculated dose due to a major accident (such as a major earthquake) is of the order of $10^{-4} \mathrm{~Sv} /$ year, taking place approximately $10^{5}$ years after sealing the repository.

Plans in Finland involve the fabrication of a geological repository in hard crystalline bedrock for nuclear wastes. ${ }^{62}$ This study concluded that for long-term effects, ${ }^{237} \mathrm{~Np}$ is the dominant nuclide in high-level waste and that the only exposure route is through groundwater. Worst-case calculations indicate the dose due to this nuclide as approximating natural background radiation. Under more realistic conditions, the dose would be much lower than that due to background radiation.

The ALI and the derived air concentration (DAC) for ${ }^{237} \mathrm{~Np}$ are shown in Table 16-4. The ALI is defined as the annual intake of a radionuclide that would result in a radiation dose to a man equal to the allowable limit. (For calculational purposes, the characteristics of the "Reference Man" are used.) The DAC is defined as that concentration of a radionuclide in air which, if breathed for a work-year, would result in an intake corresponding to the ALI (or, in the case of submersion, to an external exposure corresponding to the primary guide for limiting annual dose). Thus, DACs are used for limiting radionuclide intake through the breathing of, or submersion in, contaminated air. ALIs are used primarily for assessing doses due to accidental ingestion of radionuclides.

Historically, maximum permissible concentrations (MPC) in air and water have been used to determine safety guidelines for released radionuclide concentrations. A 1985 source lists the MPC for this nuclide as $4 \times 10^{-12} \mu \mathrm{Ci} / \mathrm{mL}$ for air and $9 \times 10^{-5} \mu \mathrm{Ci} / \mathrm{mL}$ for water for the case of radiation workers and $1 \times 10^{-3} \mu \mathrm{Ci} / \mathrm{mL}$ for air and $3 \times 10^{-6} \mu \mathrm{Ci} / \mathrm{mL}$ for water for the general public. ${ }^{6}$

Currently, the derived guidelines are presented in terms of ALIs for inhalation or ingestion, and DACs for inhalation (or submersion). For a radionuclide whose derived value does not change from the old definition, the DAC is numerically equal to the MPC value in air. The information in Table 16-4 applies only to ${ }^{237} \mathrm{~Np}$. In the case of multiple radionuclides released in a mixture, additional guidelines outlined in the Code of Federal Regulations, Part 20 of Title $10^{63}$ must be followed.

In summary, due to its long half-life, ${ }^{237} \mathrm{~Np}$ is removed by the body exclusively by biological means with excretion through the GI tract the principal removal mechanism. This nuclide can be taken up by man by eating contaminated meat or by inhaling contaminated air. The bone surface appears to be the organ most likely to receive long-term dose although the lungs can also receive a dose when the exposure is due to inhalation. 
Table 16-4. Annual limits of intake (ALI) and the derived air concentrations (DAC) for ${ }^{237} \mathrm{~Np}$ (data obtained from Reference 64).

\begin{tabular}{llll}
\hline Radionuclide & Component & Ingestion & Inhalation $^{\mathrm{a}}$ \\
\hline${ }^{237} \mathrm{~Np}$ & $\mathrm{ALI}(\mathrm{Bq})$ & $2 \times 10^{4}\left(10^{-3}\right)^{\mathrm{b}}$ & $200 / \mathrm{D}$ \\
& & $5 \times 10^{4}\left(10^{-3}\right)$ & $400 / \mathrm{D}$ \\
& & $($ bone surface $)$ & (bone surface) \\
& & $-^{c}$ & $0.06 / \mathrm{D}$
\end{tabular}

a. Clearance from the lung directly to the blood stream or to the gastrointestinal (GI) tract depends upon the chemical form of the radionuclide and is classified as $\mathrm{D}, \mathrm{W}$, and $\mathrm{Y}$, respectively, for clearance times of the order of days, weeks, and years. For ${ }^{237} \mathrm{~Np}$ the classification is $\mathrm{D}$.

b. The removal class, $f_{1}$ for each ALI is in parenthesis. A simple model of the lung was used to describe the translocation and retention of material by the body after inhalation. In this model, $25 \%$ of the inhaled activity was exhaled and $25 \%$ was deposited in the lower respiratory tract. The $50 \%$ that was deposited in the upper respiratory tract was eventually cleared by means of mucociliary processes and swallowed.

What happens then depends on whether the inhaled material was in either a soluble or insoluble chemical form. Any soluble material deposited in the lower respiratory tract is assumed to be transferred directly to the blood stream. The insoluble activity is cleared from the upper respiratory tract and then swallowed; a fraction $\left(f_{t}\right)$ enters the blood stream through the GI tract. In the case of ${ }^{237} \mathrm{~Np}, f_{1}=0.001$ for all compounds, both for inhaled and ingested contamination. Additional details of this model are described in References 65 and 63.

c. Data not available.

\section{Summary}

${ }^{237} \mathrm{~Np}$ is principally a man-made nuclide, although trace amounts of it do exist in nature, caused by the irradiation of uranium ore by naturally occurring neutrons. This is the longest-lived isotope of neptunium, all of which are radioactive. This nuclide decays, by alpha particle emission, to the daughter nuclide, ${ }^{233} \mathrm{~Pa}$, also a radioactive nuclide. After several additional decays, the stable nuclide, ${ }^{205} \mathrm{Ti}$, eventually results. Moderately high-energy alpha particles, low-energy gamma rays, and low-energy electrons are emitted when this nuclide decays. The total particle and photon spectrum is complex because of the complex decay scheme.

Because of the long half-life of ${ }^{237} \mathrm{~Np}$ and its relatively low specific activity, it is not, itself, a major factor in the ability of an LLW disposal facility to meet performance objectives. The presence of the nuclide, however, can be relatively significant in assessing the long-term performance of such a site due to the quantity, radiotoxicity, and mobility of its daughter products, which include an isotope of radium.

Relatively few commercial applications of this nuclide were located. Aside from basic research applications (i.e., to determine its chemical, physical, radiological, and biological characteristics), the only commercial use found in the literature was as a neutron dosimeter. 
Neptunium, as an actinide, is very reactive and forms compounds with many other elements, such as the halides, oxygen, hydrogen, etc. Its chemistry is dominated by the half-filled 5 f electron subshell. Unlike most of the other actinides, there is no member of the lanthanide series that has a similar chemical behavior.

The ability of soil to adsorb ${ }^{237} \mathrm{~Np}$ out of the ground water depends on a number of factors, including $\mathrm{pH}$ and the type of soil. Neptunium is very soluble and tends to remain in the groundwater rather than being adsorbed by the soil. As such, it tends to migrate further in the ground with groundwater than other actinides, such as plutonium and americium.

The principal radiological hazard associated with this nuclide is due to its relatively high-energy alpha particles. Since these alpha particles do not penetrate materials easily and since the $\beta$ and $\gamma$ radiations are weak, external exposure to this nuclide does not pose a high risk. The principal risk is due to either inhalation or ingestion. Inhalation can occur as a result of suspension of neptunium-laden aerosols (such as due to weathering of burial sites). Ingestion can occur when the neptunium is introduced into the food chain by plant uptake. When ${ }^{237} \mathrm{~Np}$ is either ingested or inhaled, it is removed from the body with a biological half-life of several tens of thousands of days, depending on which organ has become contaminated by the nuclide. This nuclide tends to concentrate in and expose the bones. Additionally, if inhaled, the lungs can receive a dose. 


\section{References}

1. McGraw-Hill Encyclopedia of Science and Technology, 6th Edition, Volume 11, New York: McGraw-Hill Book Company, 1987.

2. McGraw-Hill Encyclopedia of Science and Technology, 6th Edition, Volume 18, New York: McGraw-Hill Book Company, 1987.

3. C. M. Lederer, J. M. Hollander, and I. Perlman, Table of Isotopes, 6th Edition, New York: John Wiley \& Sons, 1968.

4. E. Browne and R. B. Firestone, Table of Radioactive Isotopes, New York: John Wiley \& Sons, 1986, p. 237-3.

5. L. Johansson, Oral Intake of Radionuclides in the Population-A Review of Biological Factors of Relevance for Assessment of Absorbed Dose at Long Term Waste Storage, FOA-C40161-W4, November 1982.

6. D. C. Steward, Data for Radioactive Waste Management and Nuclear Applications, New York: John Wiley \& Sons, 1985.

7. B. Shleien and M. S. Terpilak, The Health Physics and Radiological Health Handbook, Nucleon Lectern Associates, 1984.

8. International Atomic Energy Agency, A Basic Toxicity Classification of Radionuclides, Technical Reports Series No. 15, Vienna, Austria, 1963.

9. F. A. Cotton and G. Wilkinson, Advanced Inorganic Chemistry - A Comprehensive Text, Interscience Publishers, 1962.

10. General Electric Company, Nuclides and Isotopes, 14th Edition, 1989.

11. R. C. Weast (ed.), CRC Handbook of Chemistry and Physics, 58th Edition, Boca Raton, Florida: CRC Press, 1977.

12. Bureau of Radiological Health, Radiological Health Handbook, Revised Edition, U.S. Government Printing Office, January 1970.

13. E. R. Lyubchanskiy and T. I. Levdik, Neptunium-237 Metabolism after Inhalation Thereof, AEC-TR-7457, 1972.

14. T. Florkowski, "Natural Production of Radionuclides in Geological Formations," Proceedings of the 14th European Conference in Nuclear Physics: Rare Nuclear Decays and Fundamental Processes, p. 1, Bratislava, 1990.

15. International Critical Tables of Numerical Data, Physics, Chemistry, and Technology, Volume I, 1st Edition, New York: McGraw-Hill Book Company, 1926. 
16. McGraw-Hill Encyclopedia of Science and Technology, 6th Edition, Volume 19, New York: McGraw-Hill Book Company, 1987.

17. International Directory of Certified Radioactive Materials, International Atomic Energy Agency, Vienna, 1975.

18. U.S. Department of Energy, Catalog of Radioactive and Stable Isotopes, April 1992.

19. G. W. Roles, Characteristics of Low-Level Radioactive Waste Disposed from 1987 through 1989, NUREG-1418, December 1990.

20. P. C. Bergamini et al., "Absorption and Distribution of ${ }^{137} \mathrm{Cs}$ by Trifolium Pratense," Health Physics, Volume 19, October 1970, p. 521.

21. J. Dragun, The Soil Chemistry of Hazardous Materials, Hazardous Materials Control Research Institute, Silver Spring, MD, 1988.

22. K. Andersson, B. Torstenfelt, and B. Allard, "Sorption Behavior of Long-Lived Radionuclides in . Igneous Rock," Proceedings of an International Symposium on Migration in the Terrestrial Environment of Long-Lived Radionuclides from the Nuclear Fuel Cycle, Knoxville, TN, July 27-31, $1981,1982$.

23. S. Aksoyoglu, W. Burkart, and W. Goerlich, "Sorption of Neptunium on Clays," Journal of Radioanalytical and Nuclear Chemistry, Articles, Vol. 149, 1991, pp. 119-122.

24. R. C. Routson, G. Jansen, A. V. Robinson, ${ }^{241} \mathrm{Am},{ }^{237} \mathrm{~Np}$, and ${ }^{99} \mathrm{Tc}$ Sorption on Two United States Subsoils from Differing Weathering Intensity Areas," Health Physics, Vol. 33, No. 4, 1977, pp. 311-317.

25. H. Nishita et al., "Effect of Soil Type on the Extractability of ${ }^{237} \mathrm{~Np},{ }^{239} \mathrm{Pu},{ }^{241} \mathrm{Am}$, and ${ }^{244} \mathrm{Cm}$ as a Function of pH," Soil Science, Vol. 132, No. 1, 1981, pp. 25-34.

26. J. C. Sheppard et al., Migration of Actinide Elements in Representative U.S. Soils, DOE-EV-730123,1981 .

27. V. M. Aleksandruk et al., "Luminescence Determination of Np in Soils of the Chernobyl AES 30km Zone," Soviet Radiochemistry, Vol. 33, 1991, pp. 603-605.

28. K. Bunzl et al., "Residence Times of Global Weapons Testing Fallout ${ }^{237} \mathrm{~Np}$ in a Grassland Soil Compared to ${ }^{239+240} \mathrm{Pu},{ }^{241} \mathrm{Am}$, and ${ }^{137} \mathrm{Cs}$," Health Physics, Vol. 68, No. 1, 1995, pp. 89-93.

29. M. Yamamoto et al., "Temporal Feature of Global Fallout ${ }^{237} \mathrm{~Np}$ Deposition in Paddy Field Through the Measurement of Low-Level ${ }^{237} \mathrm{~Np}$ by High Resolution ICP-MS," Radiochimica Acta, Vol. 64, 1994, pp. 217-223.

30. A. S. Hursthouse et al., "Transfer of Sellafield-Derived ${ }^{23} \mathrm{~Np}$ to and Within the Terrestrial Environment," Journal of Environmental Radioactivity, Vol. 14, No. 2, 1991, pp. 147-174.

31. I. R. Triay, A. J. Mitchell, M. A. Ott, Radionuclide Migration as a Function of Mineralogy, LAUR-91-113, 1991. 
32. I. R. Triay et al., Transport of Neptunium Through Yucca Mountain Tuffs, LA-UR-93-0071, 1993.

33. M. Lindgren and K. Skagius, SKB WP-Cave Project - Radionuclide Release from the Near-Field in a WP-Cave Repository, SKB-89-04, April 1989.

34. M. Yamamoto et al., "Fallout ${ }^{237} \mathrm{~Np}, \mathrm{Pu}$ Isotopes and ${ }^{241} \mathrm{Am}$ in Lake and Sea Sediments from the Coastal Area of the Sea of Japan," Radiochimica Acta, Vol. 51, 1990, pp. 85-95.

35. Heino Nitsche, "Solubility Studies of Transuranium Elements for Nuclear Waste Disposal: Principles and Overview," Radiochimica Acta, Vol. 52/53, 1991, pp. 3-8.

36. M. Hakanen and A. Lindberg, "Sorption of Neptunium under Oxidizing and Reducing Groundwater Conditions," Radiochimica Acta, Vol. 52/53, 1991, pp. 147-151.

37. G. Bidoglio and A. DePlano, "Neptunium Migration in Salt Brine Aquifers," Nuclear Technology, Vol. 74, No. 3, September 1986, pp. 307-316.

38. G. Bidoglio, et al., "Reaction Pathways of Pu and $\mathrm{Np}$ in Selected Natural Water Environments," Radiochimica Acta, Vol. 44/45, 1988, pp. 29-32.

39. W. W. L. Lee et al., Waste-Package Release Rates for Site Suitability Studies, LBL-30703, UC-814, April 1991.

40. K. R. Price, "The Behavior of Waste Radionuclides in Soil-Plant Systems," Pacific Northwest Laboratory Annual Report for 1972, BNWL-1750 Part 2, March 1973.

41. "Analysis of Soybean Crop Grown on Soils Contaminated with Four Transuranic Elements," Agricultural Aspects of Monitoring and Stabilization of Shallow Land-Burial Sites. Annual Report, October 1, 1978-September 30, 1979, DOE/SF/00012-T12, February 1980.

42. E. M. Romney et al., "Plant Uptake of ${ }^{237} \mathrm{~Np},{ }^{239,}{ }^{240} \mathrm{Pu},{ }^{241} \mathrm{Am}$, and ${ }^{244} \mathrm{Cm}$ from Soils Representing Major Food Production Areas of the United States," Soil Science, Vol. 132, No. 1, 1981, pp. 40-59.

43. "Analysis of Crop of Peas Grown on Soils Contaminated with Four Transuranic Elements," Agricultural Aspects of Monitoring and Stabilization of Shallow Land-Burial Sites. Annual Report, October 1, 1978-September 30, 1979, DOE/SF/00012-T12, February 1980.

44. R. G. Schreckhise et al., "Weathering and Aging of Transuranics," Pacific Northwest Laboratory Annual Report for 1977 to the DOE Assistant Secretary for Environment, Part 2, PNL-2500 (Pt. 2), February 1978.

45. "Effect of DTPA on Concentration Ratios of ${ }^{237} \mathrm{~Np}$ and ${ }^{244} \mathrm{Cm}$ in Vegetative Parts of Bush Bean and Barley," Agricultural Aspects of Monitoring and Stabilization of Shallow Land-Burial Sites. Annual Report, October 1, 1978-September 30, 1979, DOE/SF/00012-T12, February 1980.

46. E. M. Romney et al., "Effect of DTPA on Concentration Ratios of ${ }^{237} \mathrm{~Np}$ and ${ }^{244} \mathrm{Cm}$ in Vegetative Parts of Bush Bean and Barley," Soil Science, Vol. 132, No. 1, 1981, pp. 104-107.

47. C. E. Murphy Jr., and R. C. Tuckfield, Vegetation Uptake from Burial Ground Alpha Waste Trenches, WSRC-RP-89-1016, 1989. 
48. D. W. Efurd et al., Neptunium-237 Production from Atmospheric Nuclear Testing, LA-9585-MS, November 1982.

49. D. W. Efurd et al., "An Estimate of ${ }^{237} \mathrm{~Np}$ Production During Atmospheric Testing," Health Physics, Vol. 47, No. 5, 1984, pp. 786-787.

50. B. E. Vaughan, R. E. Wildung, and J. J. Fuquay, "Transport of Airborne Effluents to Man Via the Food Chain," Proceedings from a Meeting on Controlling Airborne Effluents from Fuel Cycle Plants, Sun Valley, ID, August 5, 1976.

51. P. W. Derbin, N. Jueng, and J. J. Bucher, "Initial Distribution of Neptunium-237 in a Monkey," Biology and Medicine Division Annual Report 1986, LBL-22300, April 1987.

52. P. Germain et al., "Experimental Studies of the Transfer of Neptunium from Sea Water to Sediments and Organisms (Annelids and Molluscs)," Journal of Environmental Radioactivity, Vol. 5, No. 1, 1987, pp. 37-55.

53. P. McDonald, M. S. Baxter, and S. W. Fowler, "Distribution of Radionuclides in Mussels, Winkles and Prawns. Part 2. Study of Organisms under Laboratory Conditions Using Alpha-Autoradiography," Journal of Environmental Radioactivity, Vol. 18, No. 3, 1993, pp. 203-228.

54. M. F. Sullivan and P. S. Ruemmler, "Absorption of ${ }^{233} \mathrm{U},{ }^{237} \mathrm{~Np},{ }^{238} \mathrm{Pu},{ }^{241} \mathrm{Am}$, and ${ }^{244} \mathrm{Cm}$ from the Gastrointestinal Tracts of Rats Fed an Iron-Deficient Diet," Health Physics, Vol. 54, No. 3, March 1988 , pp. 311-316.

55. M. F. Sullivan, P. S. Ruemmler, and R. L. Buschbom, "Neptunium-237 Inhalation in Rats," Health Physics, Vol. 51, No. 6, December 1986, pp. 745-753.

56. Y. Wang, Ed., Handbook of Radioactive Nuclides, The Chemical Rubber Co., Cleveland, Ohio, 1969.

57. M. H. Bhattacharyya et al., Gastrointestinal Absorption of Plutonium, Uranium and Neptunium in Fed an Fasted Adult Baboons: Application to Humans, NUREG/CR-5842, March 1992.

58. M. R. Sikov and D. D. Mahlum, "Cross-Placental Passage of Actinides in the Rat," Toxicity of Radioelements, BNWL-480.

59. B. Shleien and M. S. Terpilak, Supplement 1 (1986) The Health Physics and Radiological Health Handbook, Nucleon Lectern Associates, Inc., 1986.

60. D. W. Efurd, R. E. Perrin, and J. F. McInroy, "Neptunium-237 in Human Tissue Samples," Health Physics, Vol. 51, No. 5, November 1986, pp. 665-666.

61. E. Palacios et al., "Radiological Impact of Disposing of High Level Waste in a Granitic Repository in Argentina," Proceedings of the 7th International Congress of the International Radiation Protection Association, Sydney, Australia, April 10, 1988. 
62. R. Korhonen et al., "A Comparative Assessment of Radiological Impact Due to Nuclear Waste Disposal in Hard Crystalline Bedrock," Proceedings of Radioactive Waste Management, Volume 4, An International Conference Held by the IAEA in Seattle, WA, May 16 - 20, 1983, 1984, p. 257.

63. Code of Federal Regulations, 10 CFR 20, Chapter I (January 1, 1992), "Standards for Protection Against Radiation," Appendix B.

64. Limits for Intakes of Radionuclides by Workers, Annals of the ICRP, ICRP Publication 30, Part 1, 1979.

65. K. F. Eckerman, A. B. Wolbarst, and A. C. B. Richardson, Limiting Values of Radionuclide Intake and Air Concentration and Dose Conversion Factors of Inhalation, Submersion, and Ingestion, Federal guidance Report No. 11, Oak Ridge National Laboratory, EPA-520/1-88-020, 1988. 


\section{Bibliography}

Aarkrog, A., "Long-Lived Radionuclides Important in Marine Waste Disposal," Behavior of Long-Lived Radionuclides Associated with Deep-Sea Disposal of Radioactive Wastes, IAEA-TECDOC-368, 1986.

Amin, A., et al., Equilibrium Leach Testing of Magnox Swarf and Sludge, DOE/RW/89/048, October 1988.

Apted, M. J., et al., "Preliminary Calculations of Release Rates from Spent Fuel in a Tuff Repository," 2nd Annual American Nuclear Society (ANS) International High-level Radioactive Waste Management Conference, Las Vegas, NV, April 28-May 3, 1991.

Avogadro, A., et al., "Transport Through Deep Aquifers of Transuranic Nuclides Leached from Vitrified High-Level Wastes," Materials Research Society Annual Meeting, Boston, MA, November 26, 1979 , p. 665.

Cawse, P. A. and Turner, G. S., The Uptake of Radionuclides by Plants: A Review of Recent Literature, AERE-R9887, February 1982.

Garten, C. T. Jr., Tucker, C. S., Scott, T. G., "Plant Uptake of Neptunium-237 and Technetium-99 Under Field Conditions," Journal of Environmental Radioactivity, Volume 4, p. 91, 1986.

Guary, J. C. and Fowler, S. W., "Uptake from Water and Tissue Distribution of Neptunium-237 in Crabs, Shrimp, and Mussels," Marine Pollution Bulletin Volume 9, p. 331, 1978.

Harrison, J. D., et al., "Gastrointestinal Absorption of Transuranium Elements in Animals and the Implications for Man," 6th Congress of the International Radiation Protection Association, Berlin, F.R. Germany, May 7-12, 1984, p. 427.

Harrison, J. D., Popplewell, D. S., David, A. J., "Effect of Concentration and Chemical Form on the Gastrointestinal Absorption of Neptunium," International Journal of Radiation Biology Related Studies in Physics, Chemistry, and Medicine, Volume 46, p. 269, 1984.

Hwang, Y., et al., "Radionuclide Migration to the Aquifer Through the Porous Medium," Proceedings of the Symposium on Waste Management, Tucson, AZ, February 28-March 4, 1993.

Kirchner, G., "A New Hazard Index for the Determination of Risk Potentials of Disposed Radioactive Wastes," Journal of Environmental Radioactivity, Volume 11, p. 71, 1990.

Matthies, M., et al., "Evaluation of Radiation Exposure Due to Radioactive Releases into the Biosphere from a Salt Dome Repository," International Conference on Radioactive Waste Management, Seattle, WA, May 16, 1983.

McClellan, R. O., Casey, H. W., Bustad, L. K., "Transfer of Some Transuranic Elements to Milk," Health Physics, Volume 8, p. 689, 1962. 
McDonald, P., Baxter, M. S., Fowler, S. W., "The Uptake and Distribution of [Alpha]-Emitting Radionuclides in Marine Organisms," International Symposium on Radionuclides in the Study of Marine Processes, Norwich, UK, p. 386, 1991.

Nenot, J. C., "Metabolism and Toxicity of Neptunium," Meeting on Radionuclide Toxicity, Creteil, France, January 14, 1982, p. 18, 1983.

Norwood, W. D., Health Protection of Radiation Workers, Thomas Books, C. C. Thomas, Editor, 1975.

Pimpl, M. and Schmidt, W., "Soil-to-Plant Transfer Studies of Neptunium, Plutonium, Americium, and Curium," Cadarache International Symposium on Radioecology, Cadarache, France, March 14, 1988.

Pimpl, M., Schmidt, W., Schuettelkopf, H., "Soil/Plant Transfer of Actinides," Colloquium of the Projekt Nukleare Sicherheit (PNS) of the Kernforshungszentrum Karlsruhe, G.m.b.H, Karlsruhe, F.R. Germany, June 10, 1986, p. 549.

Prosser, S. L., Popplewell, D. S., Lloyd, N. C., "The Radiological Significance of ${ }^{237} \mathrm{~Np}$ in the Environment," Journal of Environmental Radioactivity, Volume 23, p. 123, 1994.

Ralston, L. G., et al., "The Metabolism and Gastrointestinal Absorption of Neptunium and Protactinium in Adult Baboons," Seminar on the Speciation of Fission and Activation Products in the Environment, Oxford, UK, April 16, 1985, p. 191, 1985.

Seitz, M. G. and Seliga, M., "Distribution of Alpha Activity from Neptunium on Rock Fissures," Nuclear Tracks, Volume 7, p. 155, 1983.

Sikov, M. R., Placental Transfer of the Actinides and Related Heavy Elements, PNL-SA-14209, November 1986.

Sontag, W., "Microdistribution of ${ }^{237} \mathrm{~Np}$ in the Skeleton of Female Rats," International Journal of Radiation Biology, Volume 63, p. 383, 1993.

Sullivan, M. F. and Wrenn, M. E., "Actinide Absorption from the Gastrointestinal Tract," Workshop on Measurement and Interpretation of Actinide Accumulation by Man, Snowbird, UT, October 14, 1979, p. 311, 1981.

Taylor, D. M., "Osteosarcoma Induction by Plutonium-239, Americium-241, and Neptunium-237: The Problem of Deriving Risk Estimates for Man," 7th International Congress of the International Radiation Protection Association, Sydney, Australia, p. 162, 1988.

Thorne, M. C., Editor, The Metabolism of Plutonium and Related Elements, ICRP Publication 48, Pergamon Press, 1986. 
Wirth, R. and Volf, V., "Long Term Retention of ${ }^{237} \mathrm{~Np}$ in Rats," International Journal of Radiation Biology Related Studies in Physics, Chemistry, and Medicine, Volume 46, p. 787, 1984.

Yamamoto, M., et al., "Distribution of Global Fallout ${ }^{237} \mathrm{~Np}, \mathrm{Pu}$ isotopes, and ${ }^{241} \mathrm{Am}$ in Lake and Sea Sediments," Actinides '89, Tashkent, USSR, September 24-29, 1989. 
Report Number (14) DOE $/ L \omega-238$

Publ. Date (11) $\frac{1996 / 1}{20 E / E M, X F}$
$\begin{aligned} & \text { Sponsor Code (18) } \\ & \text { UC Category (19) }\end{aligned}$ 